UNIVERSIDAD NACIONAL DE LA PLATA

FACULTAD DE HUMANIDADES Y CIENCIAS DE LA EDUCACIÓN Secretaría de Posgrado

\title{
Modelo de acumulación y hegemonía en la Argentina post-convertibilidad, 2002-2008.
}

\section{Gastón Ángel Varesi}

Tesis para optar por el grado de Doctor en Ciencias Sociales

Directora Ana G. Castellani, Universidad Nacional de Buenos Aires Codirector Aníbal O. Viguera, Universidad Nacional de La Plata

La Plata, 7 de diciembre de 2012 


\section{Índice}

Agradecimientos...........................................................

Resumen y palabras claves.................................................

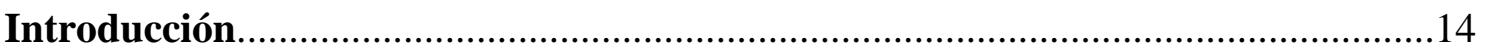

0.1. Acerca del problema de estudio............................................14

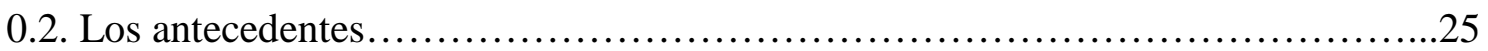

0.3. Organización de la tesis....................................................29

Capítulo 1. Modelo de acumulación y hegemonía: aportes teóricos para su

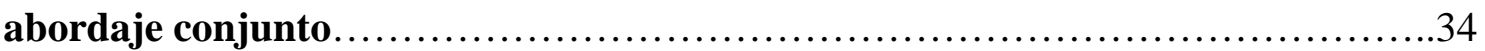

1.1. El modelo de acumulación en el centro de la estrategia analítica...................34

1.2. Una aproximación a la teoría gramsciana de la hegemonía y sus vínculos con el enfoque de análisis del modelo de acumulación....................................55

Capítulo 2. Conceptualizaciones, supuestos y estrategia metodológica.............88

2.1. Cultura política: cultura + política..........................................................89

2.2. Contradicción, antagonismo y hegemonía...................................96

2.3. La estrategia metodológica.................................................126

2.4. La dimensión epistemológica del problema..................................137

2.4.1. Acerca de los obstáculos epistemológicos.................................138 
3.1. El preludio: el 2001 como principio de crisis orgánica.... .148

3.2. El gobierno de Duhalde: contención y coerción en la fundación del modelo......170

3.2. La hegemonía kirchnerista: cultura política y proyecto de gobierno. ... 178

Capítulo 4. Las políticas fundacionales del modelo post-convertibilidad .211

4.1. Las políticas fundacionales del modelo post-convertibilidad

4.1.1. La devaluación. Origen y consecuencias del nuevo tipo de cambio competitivo .214

4.1.2. La implementación de retenciones a las exportaciones. .224

4.1.3. La pesificación asimétrica de deudas y depósitos .227

4.1.4. El "salvataje” al capital financiero. .230

4.1.5. El default: sus características, el canje y la relación con el FMI. .234

4.1.6. El congelamiento y renegociación de tarifas....

4.1.7. Inversión pública .245

Capítulo 5. Fracciones de clase y relaciones de fuerzas en la Argentina postconvertibilidad.

5.1. Fracción productivo-exportadora del capital. 255

5.2. La fracción de PyMEs. .270 
5.3. Fracción de empresas de servicios públicos

5.4. Fracción financiera del capital .284

5.5. Las clases subalternas 296

\section{Capítulo 6. El 2008 como nuevo punto de inflexión en hegemonía y acumulación.}

“Conflicto del campo” y circuito productivo sojero.

6.1. Transformaciones en el agro, en general, y en el circuito sojero, en particular....316

6.2. El impacto del cambio de modelo de acumulación sobre el sector, en general, y el circuito productivo sojero, en particular.

6.4. El conflicto agrario de 2008: hegemonía y relaciones de fuerzas.

6.4.1. Completando la dimensión estructural de las relaciones de fuerzas.... 334

6.4.2. La dimensión política de las relaciones de fuerzas y la gestación del antagonismo .343

7. Conclusiones. Neo-desarrollismo, populismo y sujetos. Entre la profundización rupturista y la restauración neoliberal. .369

8. Bibliografía 409

9. Fuentes citadas

9.1 Documentos públicos.

9.2. Leyes, resoluciones y decretos (ordenados por fecha). 438 


\section{Índice de gráficos y Tablas}

Gráfico 1. Esquema conceptual del modelo acumulación. .54

Gráfico 2. Esquema conceptual general: modelo de acumulación y hegemonía 127

Gráfico 3. Índice del Tipo de Cambio Real Multilateral dic. 2001-dic. 2007 .216

Gráfico 4. Exportaciones totales. .219

Tabla 1. Participación de la Inversión Bruta Interna Fija, el Consumo Privado, el Consumo Público y las Exportaciones en el PBI. Promedios 1993-2001 y 20022007. .220

Gráfico 5. Evolución de la Deuda Pública argentina 2001-2005. .235

Gráfico 6. Gasto primario real .237

Gráfico 7. Inversión Pública según Sector ejecutor 2003-2007. .246

Gráfico 8. Evolución del PIB en miles de millones de pesos de 1993 .249

Gráfico 9. Exportaciones argentinas según complejo exportador (año 2005). .258

Gráfico 10. Rentabilidad y resultados en porcentajes 1997-2007 .271

Gráfico 11. Exportaciones argentinas por tamaño de empresa (año 2005). .274

Gráfico 12. Promedio anual de las rentabilidades operativas de varias empresas privatizadas o vinculadas a las privatizaciones (utilidades operativas sobre ventas),

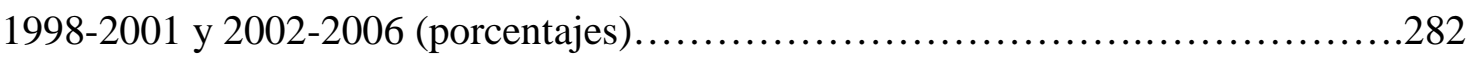

Gráfico 13. Tasa de interés real activa y pasiva 1994-2007. .290

Gráfico 14. Rentabilidad del sistema financiero 1993-2000 vs 2002-2007 .294 
Gráfico 15. Tasas de empleo, desempleo y subocupación 2002-2007

.299

Gráfico 16. Porcentaje de personas bajo las líneas de pobreza e indigencia por semestre, 2002-2007 .305

Gráfico 17. Evolución del salario real promedio y de la productividad del trabajo 19692007 .310 


\section{Agradecimientos}

El proceso de investigación que dio origen a esta tesis se remonta muchos años atrás cuando era estudiante de los últimos años de la Licenciatura de Sociología en la UNLP, por lo que un apartado de agradecimiento que abarcara a todos quienes de alguna u otra manera han aportado al desarrollo de la tesis sería interminable. Aún así es necesario agradecer a algunas personas e instituciones en particular.

Un apartado especial de agradecimiento es para mis directores, que son los que efectivamente me han enseñado todo lo que sé en materia de investigación y docencia. A Ana Castellani, mi directora, por ser una genia en todos los sentidos, por tener la combinación justa de alta exigencia y rigurosidad junto con la libertad que siempre me ha dado, alentándome a que siga mis convicciones pero con un consejo y seguimiento cercano. La verdad que soy afortunado de haber tenido una capitana como Ana, orientándome en la investigación, organizándome los tiempos, tirando siempre para adelante. Sus sugerencias, sus correcciones sin demoras, nuestras charlas en las reuniones en el IDAES, fueron un aporte indispensable. A Aníbal Viguera, a quien le debo el área de investigación, porque fue en su materia Análisis de la Sociedad Argentina donde su pasión por los temas de sociología económica creo en mí la misma pasión. El mejor docente que he tenido, que podía explicar los procesos más complejos de forma simple manteniendo plena profundidad, y que me marcó también esa pasión por la docencia. Fue tan clave su figura en todo esto que debo confesar que antes de conocerlo no me interesaban mucho ni la economía ni la docencia. Aníbal y su cátedra establecieron un parte-aguas en mi formación, en el trascurso de Análisis elegí el tema, incorporé la primera bibliografía, y un día, yo que era cuasi-mudito en el aula por aquel entonces, tuve la suerte de que Aníbal se acercara me dijera que le había gustado lo que escribía y que me incorporara a la cátedra. Así inicié esta investigación y tuve mi primera experiencia docente como adscripto, con la suerte de conocer también a mis compañeros del equipo ASA, con parte de los cuales hoy tengo el gusto de compartir el dictado del seminario de Economía Política y Sociedad en Argentina de la maestría. Y como no podía ser menor su aporte, Aníbal me dijo que me presentara al CONICET, cuando yo ni siquiera lo había pensado, todavía me quedaban muchos finales para 
recibirme, y para coronar el evento le escribió a Ana Castellani, que en ese entonces era nada menos que mi bibliografía, para que me dirigiera. Ana y Aníbal terminaron siendo lo mejor que me ocurrió en la vida académica sin cuya orientación sin dudas hubiera naufragado y esta tesis no hubiera sido posible.

También es fundamental agradecer a las instituciones que hicieron posible el desarrollo de la investigación. Principalmente al CONICET, cuyo financiamiento a través de las becas de post-grado I y II fue indispensable para poder dedicarme con exclusividad a las tareas de investigación y docencia. A la Licenciatura en Sociología de la UNLP que me dio una excelente formación de grado, y al programa de Maestría y Doctorado en Ciencias Sociales de dicha universidad a través del cual realicé mis estudios de posgrado. También al Centro Cultural de la Cooperación Floreal Gorini donde inicié la investigación como parte de la tesis de Licenciatura de grado, en el departamento de Política y Sociedad dirigido por Beatriz Rajland, quien ha estado siempre presente en mi formación, luego en una etapa posterior, en la Fundación de Investigaciones Sociales y Políticas. Debo agradecer a dicha fundación y a su dirección, por el espacio brindado y la confianza de haberme elegido como coordinador del equipo de Política económica, modelo de acumulación y estructura de clases, en el marco del proyecto trianual que teníamos con la Fundación Rosa Luxemburgo de Alemania. También tengo agradecimientos para mis compañeros del equipo de investigación con quienes hemos tenido largos y profundos debates, en particular a Juan Manuel Zanabria que me ha ayudado con gráficos y datos cuando los tiempos de entregas me acuciaban. No fue menor tampoco el aporte que representó para mí la participación en el Grupo de Trabajo sobre Economía Mundial de CLACSO, y en ese sentido agradezco a Julio Gambina por la invitación. También a Daniel Campione, a quien debo mi formación en Gramsci y con quien tuve la felicidad de compartir el dictado de un seminario gramsciano en la Facultad de Trabajo Social (UNLP). A los compañeros de Jornadas, como los de la mesa sobre Acumulación, dominación y lucha de clases de las Jornadas de Sociología de la UNLP, y las Jornadas de Estudios Sociales de la Economía de la UNSAM. Debo agradecer también a revistas como Problemas del Desarrollo de la UNAM y Cuadernos del CENDES de Venezuela por haber confiado en mí y haberme incorporado a su cartera de árbitros, lo cual fue también un aliciente para seguir esforzándome en el trabajo, sintiendo que lo que uno va escribiendo es valorado. 
Un apartado especial de agradecimientos va para los seres queridos. Por un lado, a mis compañeros de militancia, ya que la elección del tema también tiene que ver con los debates que nos dábamos para comprender los cambios que se estaban suscitando en Argentina y en América Latina, desde la convicción de que es necesario conocer la realidad para transformarla. En el fondo esta tesis no es más que eso: un intento de comprender de manera profunda la nueva etapa abierta en la Argentina desde la crisis de 2001 no por un mero acto de erudición sino para tener herramientas que permitan su transformación a favor de los trabajadores y de nuestro pueblo. También a mis compañeros de los grupos de arte, La Olla y La Vostok, por darme esa posibilidad de oxigenarme con la fotografía, la poesía, los talleres de plástica, las instalaciones, las jornadas culturales, otro insumo necesario para el alma sin el cual la tesis me hubiera terminado enloqueciendo (aún más). Por otra parte, en el largo trabajo de investigación transcurrió la vida misma, y en eso es imposible no agradecer a mis amigos, que me hicieron el aguante, acompañándome sobre todo en las coyunturas más críticas donde se hacía difícil escribir. Amigos como Chinaski, Mariano, el Chino, Araceli, Mechi, Silvia, la Flaca, Julito, Nico W., Eze, Challiol, Dieguito, entre tantos otros, fueron claves en distintos momentos y reconocerlo es un deber. Finalmente, a mi maravillosa familia, a mis viejos que me bancaron siempre en todo, que me dieron todo sin esperar nunca nada a cambio, a mi mamá Alicia, una fuente de amor inagotable, y a mi viejo Alberto, quien me hizo viajar por el mundo y me inculcó la disciplina del trabajo. A mis hermanos Nico y Seba y mis cuñadas Caro y Nay, por ser mis pares siempre presentes, tan distintos y tan unidos a la vez. Y por último, al ser más increíble de todos, mi hija Irina, la más hermosa y chiquita, que es la luz de mis ojos y la felicidad de mi vida. 


\section{Resumen}

La tesis aborda la pregunta en torno a la configuración del modelo de acumulación postconvertibilidad y los principales rasgos de construcción de hegemonía que asisten a dicho proceso, en la Argentina entre 2002 y 2008. Entendemos que un modelo de acumulación es un recorte espacio-temporal del proceso de reproducción ampliada del capital, que se observa en la identificación de relaciones sociales ligadas a tres núcleos constitutivos de políticas económicas, variables económicas y fracciones de clase, las cuales presentan tanto regularidad a lo largo del período de estudio, así como un orden de prelación que evidencia las características propias del modelo en cuestión. Asimismo abordamos la dinámica política de la política económica, conformando una mirada más integral del proceso de lucha de clases, a partir del análisis de los rasgos centrales de la construcción de hegemonía que son claves para comprender la propia gestación y desarrollo del modelo.

De este modo, abordamos sociológicamente el problema de estudio conformando un enfoque que recupera herramientas conceptuales de la perspectiva marxista, centrado en los aportes de Antonio Gramsci y Nicos Poulantzas, conjugados con desarrollos de las áreas de Sociología Económica y Sociología Política, entre otras disciplinas, en Argentina. A partir de la construcción de la definición del concepto modelo de acumulación planteamos el criterio teórico de autonomía relativa del Estado, sosteniendo como hipótesis que su ampliación a partir de la constitución de un sistema de transferencia de recursos constituye una factor clave que atraviesa tanto la consolidación del modelo como la estrategia hegemónica predominante. Partiendo del proceso de reproducción ampliada de las clases sociales damos precisiones conceptuales para la construcción de las fracciones de clase en tanto colectivo de agentes que ocupan un lugar o posición común en la estructura y que se relacionan a través de relaciones de fuerzas disímiles. Tomamos algunos aspectos centrales de la propuesta gramsciana de análisis de relaciones de fuerzas que atraviesan el corazón de nuestro problema de estudio, generando las adecuaciones necesarias para el recorte temporal y territorial en el que se encuentra nuestra investigación.

A través del análisis de un amplio espectro de indicadores económicos y sociales, así como de documentos, publicaciones en periódicos, leyes y decretos, 
desplegamos la estrategia teórico-metodológica de análisis del modelo a través de sus tres componentes: políticas económicas, variables económicas y fracciones de clase. En este camino, identificamos seis políticas fundacionales que constituyeron un punto de inflexión, quebrando las regularidades del modelo anterior y dando lugar a un conjunto de transformaciones significativas: 1) la devaluación, 2) la implementación de retenciones a la exportación, 3) la pesificación asimétrica de deudas y depósitos, 4) el “salvataje” al capital financiero, 5) el default, y 6) el congelamiento y renegociación de tarifas; a la que luego se le agrega una séptima política, ligada a la inversión pública, que sin ser fundacional comenzó a jugar un papel relevante. Este conjunto de políticas fueron dando origen a un nuevo modelo de acumulación evidenciando un conjunto de rupturas y continuidades en las variables económicas que se vincularon, asimismo, a cambios particulares en la correlación de fuerzas, definiendo un reparto diferencial de cargas y beneficios.

En este contexto emergió una fracción productivo-exportadora como principal beneficiaria del modelo post-convertibilidad, ocupando un lugar central en el mismo, ligándose también con la consecución del doble superávit, comercial y fiscal, que funcionan como pilares de sustentabilidad del modelo. Esta fracción, compuesta por distintos núcleos ligados a la extracción y procesamiento de recursos naturales así como a las terminales automotrices y segmentos de las industrias química y siderúrgica, se vio potenciada por la política de tipo de cambio, la caída del costo laboral y los altos precios de los commodities en el mercado mundial, presentando niveles de rentabilidad, ventas y crecimiento destacados en el período. Asimismo, la política cambiaria generó un marco de protección para el desarrollo de las PyMEs, impulsando la recuperación y creación de nuevas empresas de relevancia en la creación de puestos de trabajo, exhibiendo rentabilidades superiores a la década previa, al mismo tiempo que se amplió la brecha de rentabilidad respecto de las grandes empresas. Por otra parte, los conglomerados financieros vieron perjudicadas sus posiciones con la salida devaluacionista y pesificadora pero comenzaron a recuperar sus rentabilidades a partir de las transferencias gestadas en el plan de "salvataje” de 2002 y luego, con la salida del default. Finalmente las empresas de servicios públicos privatizadas aparecen como las principales “perdedoras” dentro de la clase dominante, en tanto la acción estatal regula el precio de los servicios imponiendo un esquema de precios relativos favorable a la producción de bienes transables. Las clases subalternas vieron fuertemente afectadas sus 
condiciones de vida por el impacto inflacionario de la devaluación en 2002 que licuó el salario real y llevó a niveles históricos el desempleo, la pobreza y la indigencia. A partir de 2003, con la emergencia del kirchnerismo como fuerza en ascenso hegemónico, se desplegaron un conjunto de políticas progresivas tendieron a recomponer los ingresos de las clases subalternas pero, al mismo tiempo, se incrementó su heterogeneidad y fragmentación, mostrando límites en materia de distribución funcional.

Nuestra estrategia de investigación se conjuga con la profundización del componente de políticas, indagando dos momentos que consideramos claves para su comprensión: a) el proyecto político-económico de gobierno que constituye la matriz ideológica que expresa la unidad de fines políticos y económicos y sirve de sustrato a la generación de políticas, y b) la cultura política singular en el que dicho proyecto se enmarca, que, en tanto espacio de representaciones codificadas de una fuerza política, conforma una lectura común del pasado y el futuro de plenitud a construir. En este camino, observamos la lógica hegemónica de constitución de sujetos en el campo de antagonismo, tomando los discursos presidenciales como un insumo central junto al análisis de las políticas públicas. En este sentido, analizamos las principales dinámicas de la producción de hegemonía en la Argentina post-convertibilidad, partiendo del gobierno de Duhalde para centrarnos en la fuerza política predominante en el período: el kirchnerismo. Así indagamos algunos factores de su cultura política, analizando su discurso y estrategia, realizando una aproximación a la dimensión política de las relaciones de fuerza al tiempo que caracterizamos el proyecto que inspira a las políticas constitutivas del modelo de acumulación. Asimismo, vislumbramos los factores centrales que recorren esta construcción hegemónica que, procurando suturar las distintas dimensiones de la crisis de hegemonía evidenciada en 2001, vemos atravesada por la doble lectura del populismo: como lógica política (Laclau) y como pacto populista (Rajland). En este sentido, observamos las tensiones constitutivas entre los elementos sistémicos y "heréticos” que involucran y que hacen de esta reformulación singular del peronismo una construcción ambivalente que expresa tanto una salida hegemónica para el capitalismo argentino (como dijera James) como "el hecho maldito del país burgués” (evocando a Cooke).

De este modo, manteniendo la centralidad en el análisis del modelo observamos cómo diversos factores políticos y culturales ligados al proceso de construcción de hegemonía inciden sobre el mismo, indagando la dinámica compleja que rige el proceso 
histórico a través de la articulación de las categorías de antagonismo y contradicción. El “conflicto del campo" de 2008, al tiempo que constituye un punto de inflexión que abre una nueva crisis de hegemonía, constituye un estudio de caso privilegiado para ver las principales tendencias y tensiones que se expresan en la articulación de los ejes del modelo y la construcción hegemónica. Estas tendencias y tensiones son recuperadas y generalizadas en las conclusiones a la luz del conjunto del período abordado, habilitando un debate en torno a la nominación del modelo, las potencialidades y contradicciones que alberga en su interior, el debate en torno a la "burguesía nacional” y los alcances y límites de la construcción hegemónica.

Palabras claves: modelo de acumulación, hegemonía, clases sociales, relaciones de fuerzas, política económica, antagonismo, contradicción, kirchnerismo. 


\section{Introducción}

\section{Acerca del problema de estudio}

El modelo de acumulación post-convertibilidad y la construcción de hegemonía que asistió su consolidación, tienen su origen en el contexto de crisis integral que, conteniendo una multiplicidad de factores en sus dimensiones política, ideológicocultural y económica, alcanzó su punto álgido en 2001 y marcó el colapso del modelo de la convertibilidad. Dicho modelo de acumulación, que había comenzado a configurarse a partir de las leyes de Reforma del Estado ( $\mathrm{n}^{\circ}$ 23.696) y Emergencia Económica ( $n^{\circ}$ 23.697) de 1989 alcanzando su fundación con la Ley de Convertibilidad en 1991, encarnó la forma más acabada de aplicación de las reformas neoliberales como profundización de la ofensiva del capital efectivizada a partir del golpe de Estado de 1976.

La Argentina neoliberal comenzó a constituirse con la implementación de un vasto sistema de represión y un proyecto político-económico de gobierno que buscó terminar con cualquier rasgo de “empate hegemónico” y tornar el cuadro de relaciones de fuerzas decididamente a favor de los grupos más concentrados de la clase dominante. Éstos se veían incapaces de devenir dirigentes e impulsar las transformaciones de raíz que procuraban para acondicionar drásticamente el proceso de acumulación desde los andamiajes institucionales establecidos constitucionalmente, en un contexto de gran fortalecimiento y organización de las clases subalternas. De este modo, el momento de la coerción se constituyó en un eje clave dirigido a desarticular las organizaciones de la clase trabajadora, eliminar sus expresiones armadas y disciplinar mediante el terror al conjunto de las clases subalternas de forma duradera, abriendo condiciones propicias para una profunda transformación de las bases económicas, políticas y culturales en las que se asentaba la sociedad argentina.

La convergencia entre el Estado y los sectores más concentrados del capital no sólo se hizo palpable en la represión de los trabajadores sino también en el despliegue de medidas de política económica, que tendieron a ejercer serias modificaciones en el proceso de acumulación de capital. Así, la creciente reducción arancelaria a la 
importación sumado a la liberalización financiera y al aumento de la tasa de interés, que impulsó el proceso especulación y “valorización financiera”, haciendo que por primera vez las rentabilidades más altas dejaran de estar en el sector industrial para ubicarse en el financiero. Así se fue construyendo un panorama muy dificultoso para un amplio espectro de pequeñas y medianas industrias así como para grandes empresas independientes, agentes claves en la alianza policlasista entre los trabajadores y la "burguesía nacional” ${ }^{1}$ expresada en el proyecto peronista. En este camino, un conjunto de grandes empresas de capital local y extranjero que habían iniciado un proceso de integración y/o diversificación lograron fortalecer sus posiciones en el mercado (Basualdo, 2010). En este proceso de reconfiguración de las relaciones de clase, el rol del Estado fue clave, tanto por sus políticas de cuño neoliberal, incluyendo un proceso de privatizaciones periféricas de empresas estatales, como por las relaciones de privilegio que estableció con los grupos más concentrados del capital ${ }^{2}$, a través de la conformación de ámbitos privilegiados de acumulación (Castellani, 2009). Sin embargo, estas acciones estatales eran desplegadas bajo una forma ideológica que promovía el repliegue del Estado en su rol mediación social y económica, entronizando al "mercado" como mejor distribuidor de recursos. Asimismo las políticas de liberalización financiera y endeudamiento público fueron funcionales al ciclo de “valorización financiera” (Basualdo, 2010) basada en la ganancia especulativa producto del diferencial entre la tasa de interés interna y externa que dio lugar a la tristemente célebre "bicicleta financiera", que impulsaba la fuga de capitales ${ }^{3}$. Este conjunto de políticas se asentaron en fuertes transferencias de ingresos de asalariados a capitalistas, en tanto la clase trabajadora vio cómo se depreciaba su salario real en un contexto de aumento de la productividad y de la duración de la jornada media de trabajo, en el marco represivo.

\footnotetext{
${ }^{1}$ Ver Basualdo (2010) para el análisis de las fracciones de capital que considera como constituivas de la burguesía nacional.

${ }^{2}$ Esto puede observarse en lo que Ana Castellani llamó el complejo económico estatal privado, el "conjunto de actividades desarrolladas por empresas públicas, privadas y mixtas que operan en las ramas más dinámicas de la industria, en el sector petrolero, en la construcción de obras públicas y en algunos servicios clave como la electricidad, la provisión de gas y las comunicaciones” (Castellani, 2004: 194).

${ }^{3}$ Según Azpiazu, Basualdo y Khavisse (2004) la deuda externa privada presentó un alto grado de concentración en un reducido número de operaciones (el 4,7\% de las operaciones explican el 77,3\% del valor de la deuda total contraída) generada principalmente por los grandes grupos económicos. En sucesivas operaciones la dictadura (y luego el gobierno de Alfonsín) estatizó las grandes deudas externas privadas, licuándolas y transfiriéndolas al conjunto de la sociedad.
} 
Este proceso comenzó a transformar estructuralmente la sociedad argentina, partiendo de una relativa heterogeneidad "por arriba” y homogeneidad "por abajo", en la que se sustentaba el poder de las clases subalternas, la dictadura dio pasos en una doble búsqueda: de homogeneización de los sectores dominantes y la fragmentación de las clases subalternas (Villarreal, 1985). A través de estos cambios estructurales, la dictadura ejerció un quiebre en el proceso de reproducción ampliada del capital vigente, terminando el régimen de acumulación de industrialización por sustitución de importaciones (ISI) y gestando transformaciones duraderas en el bloque histórico, a partir de la consolidación de oligopolios locales y extranjeros con creciente capacidad de decisión sobre las principales variables económicas.

En los años 80, aún con el advenimiento de la democracia y el amplio conjunto de expectativas generadas en materia política, económica y cultural, no se lograron revertir las principales dinámicas que signaban el proceso de acumulación. Tras un pequeño intento de restituir un proyecto basado en políticas progresivas teniendo al salario, al gasto público y al mercado interno como dinamizadores económicos durante la conducción económica de Grinspun, los distintos planes de política económica irían cediendo a las presiones del capital concentrado y el capital financiero ${ }^{4}$. Con un contexto internacional de crisis de la deuda ${ }^{5}$ y escasez del crédito, sumado al fortalecimiento de los organismos financieros internacionales como representantes de los acreedores externos, avanzó paulatinamente un cambio de diagnóstico que, lejos de situar las causas de la crisis económica en las transformaciones ejercidas durante la dictadura, asumía una caracterización similar a la que esta había esbozado y que por entonces promovían los propios organismos financieros. Las debilidades políticas y económicas vigentes constituyeron el marco para la apertura de un fuerte conflicto al interior de la clase dominante por la apropiación del excedente ${ }^{6}$.

Los juicios a las Juntas Militares y la condena pública al proceso dictatorial no habían alcanzado para impugnar el nuevo orden establecido por dicho proceso. Así, en

\footnotetext{
${ }^{4}$ Tanto la presión de los grupos económicos locales como del FMI en el marco de la negociación de la deuda, dieron por tierra el plan de Grinspun. A partir de la asunción de Sourrouille, con la implementación primero del Plan Austral y luego del Plan Primavera, se evidenciaría el avance ideológico de las usinas de pensamiento neoliberal, tanto sobre el diagnóstico respecto de la crisis como de las acciones estatales a aplicar.

${ }^{5}$ Debido a la entrada en moratoria de México en 1982 y el repliegue de los flujos de capitales financieros hacia las economías centrales.

${ }^{6}$ Para un análisis exhaustivo de la crisis interburguesa en los años 80 ver Ortiz y Schorr, 2006, 2006 b.
} 
las postrimerías de esa década, mediante el rol coercitivo y disciplinador sobre las clases subalternas de la crisis hiperinflacionaria (Bonnet, 2008), comenzó a constituirse un modelo de acumulación que se consolidó en los años 90 y que representó la profundización de la ofensiva del capital concentrado sobre los trabajadores a través de la aplicación de un vasto conjunto de reformas neoliberales. Éstas se fundaron sobre consensos del poder político con la clase dominante como la "flexibilización” laboral, el desarrollo de una estructura impositiva favorable al capital (con disminución de aportes patronales), la privatización de las empresas estatales ${ }^{7}$, una mayor liberalización financiera y altas tasas de interés, que impulsaron una reactualización del ciclo de "valorización financiera”, y la apertura comercial con la disminución arancelaria, manteniendo protegidos a ciertos sectores del capital concentrado (como el automotriz). El Estado mutaba sus funciones, basado en el diagnóstico de que su supuesto gigantismo empresarial y su rol de protección social se encontraban en la base de la crisis por entonces vigente. Los cambios económicos propugnados evidenciaban la formación de un esquema de precios relativos beneficiario para las empresas de servicio públicos privatizados y los conglomerados financieros. El modelo de la convertibilidad poseía cualidades que lo hacían intrínsecamente deuda-dependiente debido a que precisaba de divisas para mantener la paridad 1 peso - 1 dólar del tipo de cambio fijada por ley. Esto se vincula con que en las condiciones de escaso dinamismo de las exportaciones y apertura comercial, en el marco de la sobrevaluación de la moneda local, y un constante déficit fiscal (entre otras causas, por la privatización del sistema de jubilaciones y pensiones), se apeló incesantemente al endeudamiento público. La vulnerabilidad externa, evidenciada en el desequilibrio de la cuenta corriente, se vio agudizada por la profundización del proceso de fuga de capitales, y llegó a poner en cuestión la posibilidad de mantener el esquema cambiario fijo y convertible que actuaba como un eje articulador de aquel modelo.

El agotamiento del modelo de la convertibilidad tuvo lugar como parte de una crisis más amplia que contuvo algunos rasgos de una crisis orgánica (Gramsci),

\footnotetext{
${ }^{7}$ Las privatizaciones constituyeron una "prenda de paz” (Azpiazu y Basualdo, 2004) fundamental para saldar la crisis interburguesa por entonces vigente, ya que incorporaron en los consorcios compradores a la banca acreedora (a través de la capitalización de bonos de deuda), a los grupos económicos locales (permitiéndoles resignificar el trato preferencial que percibían del Estado a través de los ámbitos privilegiados de acumulación) y al capital extranjero (incluyendo a grandes empresas transnacionales con experiencia en el área). Además el Estado se encargó de comenzar la expulsión masiva de trabajadores de las empresas (haciéndose cargo de las indemnizaciones) y aumentar las tarifas previo a privatizarlas, generando un negocio de altísima rentabilidad con escaso o nulo riesgo empresario.
} 
exhibiendo un contexto de fuerte conflictividad social caracterizada tanto por las crecientes demandas de las clases subalternas incapaces de ser procesadas por el orden vigente como por la emergencia de importantes disputas al interior de la clase dominante. Asimismo, la crisis exhibía tanto rasgos ideológico-culturales, insinuados en la deslegitimación de algunos aspectos de la concepción del mundo imperante promovida por las usinas de pensamiento neoliberal, como también aspectos ligados a una crisis política, a partir del desgaste del bipartidismo en tanto fórmula de gestión de la gobernabilidad del período post-dictadura y la ruptura entre "representados y representantes" conllevando nuevas prácticas de organización y una masiva movilización de actores ligados a las clases subalternas. Estas dimensiones junto a la crisis económica, visualizada por la caída general de la tasa de ganancia, la recesión, el profundo deterioro de todos los indicadores socio-económicos y la disputa interburguesa articulada en torno a las distintas propuestas de salidas, dieron lugar a la gestación de un nuevo modelo de acumulación.

Nos proponemos entonces, como objetivo principal, analizar la configuración del modelo de acumulación post-convertibilidad y los principales rasgos de construcción de hegemonía que asisten a dicho proceso, en Argentina entre 2002 y 2008. Entendemos que un modelo de acumulación es un recorte espacio-temporal del proceso de reproducción ampliada del capital en el cual se observan un conjunto de relaciones sociales regulares que interactúan de modo relativamente coherente entre sí durante un período determinado; relaciones ligadas a tres núcleos constitutivos: las políticas económicas, las variables económicas y las fracciones de clases, observando sus relaciones de fuerza. A su vez, un modelo se diferencia de otro por el distinto orden de prelación de las relaciones y variables que aparecen como relevantes y características del modelo en estudio. Asimismo, sostenemos que un análisis más acabado del proceso de acumulación en nuestro período de estudio requiere del abordaje de elementos específicamente políticos y culturales. En este sentido, analizamos las principales dinámicas de la construcción de hegemonía, centrándonos en la fuerza política predominante en el período: el kirchnerismo. Para esto, indagamos algunos factores de su cultura política, su discurso y estrategia, realizando una aproximación a la dimensión política de las relaciones de fuerza al tiempo que caracterizamos el proyecto políticoeconómico de gobierno que inspira al componente de políticas constitutivo del modelo de acumulación. De este modo, manteniendo la centralidad en el análisis del modelo 
observamos cómo diversos factores políticos y culturales ligados al proceso de construcción de hegemonía inciden sobre el mismo.

Un primer aporte que nuestra tesis procura realizar es la conceptualización explícita y sistemática del modelo de acumulación, concepto que si bien es utilizado en numerosos trabajos presenta un alto grado de vaguedad y polivalencia. Proponemos una perspectiva teórico-metodológica que aborde al modelo de acumulación indagando relaciones de regularidad y prelación tanto en las variables económicas como en las políticas y las fracciones de clase, en un nivel de mayor especificidad que en el régimen de acumulación ${ }^{8}$ que lo contiene. El modelo de acumulación, como momento específico de la reproducción ampliada del capital implica siempre al mismo tiempo un proceso de reproducción ampliada de las clases sociales (Poulantzas, 1981): tanto la reproducción ampliada de los lugares que ocupan los agentes, como la reproducción y distribución de los agentes mismos en dichos lugares. Partiendo de la primacía analítica de los lugares, pensaremos desde allí a las fracciones de clase como colectivos de agentes que comparten un lugar o posición común en la estructura.

Ahora, como advierte Poulantzas (1981) las clases sociales sólo pueden abordarse tomando en cuenta la perspectiva histórica de la lucha de clases, y es por esto que analizar las fracciones de clase implica estudiar sus relaciones de fuerza, observando que este proceso de lucha de clases tiene un elemento destacado en el Estado, que sin dejar de representar de manera predominante los intereses de la clase o fracción hegemónica, reviste una autonomía relativa, en tanto asegura el interés político general del conjunto del bloque en el poder ${ }^{9}$, organizando el "equilibrio inestable de compromisos” (Gramsci) entre las distintas fracciones al tiempo que organiza esta hegemonía igualmente respecto de las clases subalternas.

Para nuestro estudio cobra importancia entonces el análisis de las políticas económicas como acción estatal porque inciden en la configuración y mantenimiento de un modelo de acumulación, en tanto el Estado cumple un rol importante en la gestión del excedente orientándolo a construir hegemonía, buscando armonizar a las fracciones

\footnotetext{
${ }^{8}$ Como explicitaremos en el capítulo 1, tomamos el concepto de régimen de acumulación de Basualdo (2007) estableciendo con el mismo relaciones de similitud y diferencia para la propia definición del concepto de modelo de acumulación, caracterizándose el primero por poseer un mayor alcance en términos de recorte temporal y espacial que el segundo.

${ }^{9}$ Como señala Poulantzas, el bloque en el poder "designa una alianza específica de las clases y fracciones de clase dominante" (1981:24).
} 
de clase en estrecha vinculación con los cambios en sus relaciones de fuerza, aspecto que leemos en la Argentina post-convertibilidad a través de la constitución de un sistema de transferencias de recursos. Los cambios en las relaciones de fuerzas los abordamos principalmente en la dimensión estructural de la propuesta gramsciana: una relación de fuerzas sociales estrechamente ligada a la estructura, objetiva, independiente de la voluntad de los hombres, analizando los grupos sociales en relación al desarrollo de las fuerzas materiales de producción, viendo la función y posición que ocupan en la producción misma. Luego complementamos dicho análisis con los principales aspectos de la dimensión política de las relaciones de fuerzas a través del análisis en término de hegemonía.

Así, entendemos que en el despliegue de la acumulación capitalista gravitan elementos de orden ideológico-cultural que inciden en la conformación de las políticas y en la dinámica conflictiva a partir de la cual se abren paso. En este sentido, tomamos elementos de la teoría de la hegemonía, centrada en la perspectiva de Antonio Gramsci e incluyendo aportes de autores posteriores. A partir del enfoque gramsciano del Príncipe moderno y los intelectuales, en su doble tarea de dirección política (incluyendo la construcción de la voluntad colectiva y la fundación estatal) y de dirección cultural (la creación y difusión de concepciones de mundo a través de la "reforma intelectual y moral”), abordamos los rasgos centrales de la construcción hegemónica, recuperando críticamente algunos aportes centrales de la teoría de Ernesto Laclau, estableciendo, en este camino, una rearticulación de las categorías de antagonismo y contradicción como clave de análisis de los procesos históricos. Sostenemos que la contradicción emerge del aspecto de negación de los polos de una unidad; es una dislocación constitutiva, expresa una potencia disruptiva que parte de la estructura, pero que se encuentra siempre sobredeterminada (Althusser 1988 [1962]) por una multiplicidad de factores superestructurales, así como por la coyuntura internacional. Acordamos con Mao TseTung (1968 [1937]) en que las contradicciones no siempre son antagónicas, sino que, como dice Laclau, necesitan un acto de resistencia, un conflicto para serlo. El antagonismo remite a una dimensión estrictamente política, que vemos a la luz de distintos elementos de la estrategia laclausiana (presentes también en el populismo como lógica hegemónica), vinculada a la articulación de demandas que, en tanto representación de faltas, permiten conformar una cadena de equivalencias, implicando el establecimiento de una frontera delimitando un adversario, en un proceso de 
conformación identitaria y emergencia de sujetos. Estas lógicas se vinculan con la promesa de plenitud que encarnan los sujetos (y que recuperaremos a la luz del análisis de Marcuse sobre la cultura) y constituye un factor clave de la construcción de hegemonía que se vincula con los proyectos de gobierno como vía de realización de dicha promesa, conteniendo la potencia del mito y avanzando como el Príncipe moderno a formar la voluntad colectiva.

También recuperamos una segunda vertiente de análisis del populismo a partir de la idea de pacto populista, conteniendo una perspectiva de análisis histórico de clases, en clave latinoamericanista. Este enfoque nos permite pensar la construcción de consensos y la armonización de los equilibrios inestables entre fracciones, articulando la noción de pacto con el sistema de transferencias de recursos. La lógica hegemónica cobra en el pacto populista una articulación clave entre elementos sistémicos y “heréticos” que generan que las fuerzas políticas que adoptan esta lógica puedan aparecer, como en el caso del peronismo, tanto como la alternativa hegemónica viable para el capitalismo argentino (James, 2006), y al mismo tiempo, según Cooke (2010 [1971]), el hecho maldito del país burgués, cuyos componentes populares no pueden dejar de ser visto con desconfianza por sectores de las clases dominantes.

Partiendo entonces de la centralidad analítica del modelo de acumulación, abordamos el plano de la hegemonía a partir de la profundización del componente de políticas del modelo, indagando dos momentos que consideramos claves para su comprensión: a) el proyecto político-económico de gobierno que constituye la matriz ideológica que expresa la unidad de fines políticos y económicos y sirve de sustrato a la generación de políticas, y b) la cultura política singular en el que dicho proyecto se enmarca, que, en tanto espacio de representaciones codificadas de una fuerza política, conforma una lectura común del pasado y el futuro de plenitud a construir.

Desde esta perspectiva, nos abocamos, por un lado, al análisis del modelo a partir de sus núcleos constitutivos, ingresando primero por un conjunto de políticas consideradas fundacionales para luego indagar las fracciones de clase y su desempeño en la Argentina post-convertibilidad. Y por otro lado, avanzamos, tras una aproximación sintética al gobierno de Duhalde, al análisis del kirchnerismo como la fuerza política hegemónica del período y como reformulación singular de la cultura política peronista. Partiendo de la crisis de 2001 como preludio ineludible para la 
comprensión de la Argentina post-convertibilidad, analizamos el gobierno de Néstor Kirchner y su estrategia de construcción hegemónica a partir de la confrontación y sutura de los principales factores constitutivos de dicha crisis. Así, abordamos el discurso del líder con el fin de delimitar el proyecto político-económico de gobierno y la concepción del mundo que encarna, la delimitación del adversario en la construcción identitaria y cómo éstos inciden en las principales políticas desplegadas con el fin de atender las demandas emergidas en la crisis. El escenario de construcción hegemónica culmina en 2008 con la apertura de una nueva crisis, teniendo como hito central el “conflicto del campo" a los comienzos de la presidencia de Cristina Fernández en relación a los rasgos del circuito productivo sojero. Dicho conflicto reviste gran relevancia, en tanto su estudio nos permite observar, en un caso concreto, las distintas aristas ligadas a la estrategia de análisis de hegemonía y acumulación que proponemos en la tesis, mostrando, a su vez, un conjunto de tensiones duraderas en las dinámicas políticas, ideológicas y económicas que caracterizan al período de estudio.

En este camino, nuestra investigación está guiada por un interrogante central: ¿Cómo se configuran el modelo de acumulación post-convertibilidad y los principales factores de la construcción de hegemonía que asisten a dicho proceso? Para dar cuenta de los rasgos del modelo de acumulación y la hegemonía precisamos abordar las siguientes preguntas complementarias ligadas al desarrollo de los objetivos específicos: ¿cuáles son y cómo se desarrollan las políticas económicas con mayor incidencia en la formación del modelo? ¿qué transformaciones y continuidades pueden observarse en las variables económicas? ¿qué cambios en las relaciones de fuerzas entre fracciones de clase se expresan en la post-convertibilidad? ¿cuáles son los principales rasgos del proyecto político-económico liderado por el oficialismo y de la cultura política en que se enmarca?

En relación al primer objetivo específico, analizamos las principales políticas económicas en distintas materias, tanto la política cambiaria, que identificamos cumpliendo un rol destacado en la conformación del modelo, así como las políticas de ingresos, con particular impacto en las clases subalternas, las políticas en torno a la deuda pública, por constituir ésta una constante de los últimos treinta años y una pesada herencia que había sido clave en el desmoronamiento del modelo anterior. Asimismo vemos la necesidad de indagar la política impositiva, que representa las cargas sobre los distintos agentes económicos nutriendo de recursos al Estado, que pone en marcha un 
complejo sistema de transferencias de recursos en pos de constituir los equilibrios inestables entre las fracciones de clase, y que da lugar a la composición general del gasto público, y a políticas particulares como las de promoción y subsidios a distintos agentes económicos. También nos proponemos dar cuenta de las políticas en materia de servicios públicos, tanto por su relevancia en términos de los precios relativos así como por el lugar destacado que habían cumplido en la década anterior las empresas privatizadas.

El segundo objetivo específico se centra en el análisis de la evolución de las variables económicas, entendiendo que se observan algunas variables que son más permeables en el corto plazo a la incidencia de la acción estatal y que denominamos de desempeño; y otras más estructurales que expresan sedimentaciones de tendencias que se fueron plasmando en las últimas décadas y sólo parecen ser modificables en un mediano o largo plazo. En este camino hacemos foco en la matriz productiva y el modo de inserción de la economía Argentina en el mercado mundial a través de su estructura exportadora y la evolución de las balanzas comercial y de pagos. Asimismo observamos la evolución del empleo, como una de las variables que presenta mayor ruptura respecto de las dinámicas previas, y abordamos la evolución del producto bruto así como de los precios y salarios preguntándonos por la distribución del ingreso en la Argentina postconvertibilidad. También consideramos el grado de concentración y extranjerización económica, que nos remiten a los rasgos de los agentes involucrados en el proceso de acumulación.

Así nos enfrentamos al tercer objetivo específico, orientado a analizar las características de las principales fracciones de clase y los cambios en las relaciones de fuerzas, indagando qué fracciones se ven favorecidas y perjudicadas en la postconvertibilidad. Esto implica tanto la formulación de los criterios teóricos del recorte de las fracciones como su construcción analítica, para dar lugar a la investigación su vínculo complejo con las políticas particulares y su desempeño global en el período 2002-2008.

El cuarto objetivo específico se orienta a analizar la construcción de hegemonía en el período, indagando los principales rasgos del proyecto político-económico de gobierno, que constituye la matriz ideológica, enmarcada en una cultura política singular, que orienta el componente de políticas del modelo de acumulación. 
Analizamos este objetivo a través del abordaje del discurso presidencial, la estrategia política oficial y la dinámica de constitución de sujetos en el campo de antagonismo.

En síntesis, la tesis aborda como central la pregunta en torno a la configuración del modelo de acumulación en la Argentina post-convertibilidad y los principales rasgos de construcción de hegemonía que asisten a dicho proceso. La existencia de un modelo de acumulación se observa, entonces, en la identificación de relaciones sociales ligadas a los tres núcleos constitutivos ${ }^{10}$, que presentan tanto regularidad a lo largo del período de estudio, así como un orden de prelación o jerarquía explicativa que evidencia las características propias del modelo en cuestión. Asimismo, indagamos la dinámica política de la política económica, pensando los rasgos de la construcción de hegemonía que son claves para comprender la propia gestación y desarrollo del modelo. Así, abordamos sociológicamente el problema de estudio conformando un enfoque que recupera herramientas conceptuales de la perspectiva marxista, centrado en los aportes de Antonio Gramsci y Nicos Poulantzas, conjugados con desarrollos específicos de las áreas de Sociología Económica, Sociología Política y otras disciplinas, en Argentina. A partir de la construcción de la definición del concepto modelo de acumulación plantearemos la noción de autonomía relativa del Estado como criterio teórico para el análisis de la acción estatal y daremos precisiones conceptuales para la construcción de la fracciones de clase en tanto colectivo de agentes que ocupan un lugar o posición común en la estructura y se relacionan a través de relaciones de fuerzas disímiles. Tomaremos algunos aspectos centrales de la propuesta gramsciana de análisis de relaciones de fuerza que atraviesan el corazón de nuestro problema de estudio, generando las adecuaciones necesarias para el recorte espacio-temporal en el que se encuentra nuestra investigación. El análisis de los tres componentes del modelo: políticas económicas, variables económicas y fracciones de clase, se conjuga con la profundización del componente de políticas, indagando los dos momentos fundamentales del proyecto político-económico de gobierno y la cultura política singular en el que dicho proyecto se enmarca, observando la lógica hegemónica de constitución de sujetos en el campo de antagonismo.

\footnotetext{
${ }^{10}$ De este modo el esquema analítico del modelo de acumulación queda conformado por el núcleo superestructural de las políticas y los dos núcleos estructurales de las variables económicas y las fracciones de clase.
} 


\section{Los antecedentes}

A partir de nuestro problema de investigación podemos confeccionar un mapa bibliográfico que nos permita clasificar las distintas producciones científicas en siete grupos de trabajos según la afinidad que los mismos presentan en relación a distintas dimensiones de nuestra investigación y según el recorte temporal de dichos estudios, de modo de poder rescatar los avances ya realizados y delimitar, al mismo tiempo, el vacío teórico al cual nuestra investigación procura aportar.

Un primer grupo está conformado por investigaciones que analizan, desde diversos enfoques, aspectos significativos de los núcleos conceptuales involucrados en el análisis del modelo de acumulación y la construcción de hegemonía. Existen trabajos de gran complejidad y alcance en esa línea, que han construido conceptos tales como “empate hegemónico” (O’Donnell, 1977, 1982; Portantiero, 1977), abordando un recorte temporal previo a las transformaciones estructurales que cobraron forma a partir del golpe de Estado de 1976. En este primer grupo se encuentra la tesis doctoral de Castellani (2009), que analiza la relación Estado-empresarios y la conformación de diversos ámbitos privilegiados de acumulación entre 1966 y 1989, desplegando un agudo análisis de clases en relación a las políticas públicas. También podemos ubicar la tesis doctoral de Basualdo (2010 [2006]) que desarrolla un destacado análisis proceso de acumulación, articulando diversos elementos vinculados a nuestro análisis del modelo, alcanzando un periodo más reciente pero sin llegar hasta la postconvertibilidad. Asimismo, el profundo trabajo de Bonnet (2008) sobre la hegemonía menemista en los años 90, desde los conceptos de estrategia de acumulación y hegemonía constituye el antecesor más directo en relación a nuestro problema de estudio. Estos trabajos constituyen antecedentes de gran relevancia teórica que remiten a periodos previos al abordado en nuestra investigación.

Un segundo núcleo de antecedentes podemos identificarlos en torno al desarrollo de investigaciones que, abordando algunas de las dimensiones significativas mencionadas en los objetivos específicos, analizan desde distintas orientaciones teóricas periodos previos en la historia argentina. Por mencionar algunos: sobre la etapa de la última dictadura (Villarreal, 1985; Schvarzer, 1996; Pucciarelli, 2004a, 2004b; Castellani, 2004), así como sobre la década del 80 (Ortiz y Schorr, 2006, 2006b; Azpiazu, Basualdo y Khavisse, 2004) y la década de los noventa (Cortés y Marshall, 
1999; Basualdo, 2000, 2003; Aronskind, 2001; Etchemendy, 2001; Gambina y Campione, 2003).

Un tercer grupo está compuesto por estudios que, ya internándose en nuestro periodo, dan cuenta de la salida de la convertibilidad y algunas de sus políticas fundacionales. Los mismos nos proveen un marco de entrada al período de estudio y abordan los principales factores socio-económicos que signaron la crisis del modelo de la convertibilidad (Castellani y Schorr, 2004; Costa, Kilicillof y Nahón, 2004; Schorr y Wainer, 2005; Rapaport, 2006; Astarita, 2007; Azpiazu y Schorr, 2008). Asimismo podemos observar la articulación de demandas y la gestación del conflicto en torno al modo de salida de la convertibilidad tratado en especificidad por Castellani y Szkolnik (2005) y su ligazón a diversos elementos que configuraron la crisis de hegemonía entonces vigente (Basualdo, 2001; Piva, 2007; Ezquenazi, 2009; Wainer, 2010). Estos trabajos, si bien generan un marco para abordar el problema de estudio, se ven acotados respecto de la perspectiva aquí desarrollada ya sea por el corte temporal o por restringirse a dimensiones específicas, ligadas a análisis principalmente económicos.

Entramos ahora en un cuarto grupo, caracterizado por abordar algunas de las dimensiones propuestas tanto en nuestro problema como en nuestro periodo de estudio. Existen trabajos que dan cuenta del perfil productivo del modelo post-convertibilidad. Por un lado, un subgrupo del mismo aborda con mayor especificidad el análisis de la industria (Schorr, 2005; Fal, Pinazo y Lizuaín, 2009; CEP, 2005, 2005b, 2008; Azpiazu y Schorr, 2010; Kulfas, 2011). Por otro lado, observamos un subgrupo que analiza los circuitos agroindustriales (Arceo y Rodríguez, 2008; Arrilaga et al, 2007; CENDA, 2008; Ciani, 2005; Rodríguez, 2005; Schvarzer y Tavosnanska, 2007). Por otra parte, encontramos trabajos sobre deuda pública y capital financiero (Becerra y Méndez, 2005; Damill, Frenkel y Rapetti, 2005; Giuliano, 2006; Golla, 2006; Katz, 2005, 2005b; Lo Vuolo y Seppi, 2008; Lucita, 2005, 2005b). También se han desarrollado análisis de políticas y agentes económicos referidos a las empresas de servicios privatizadas en la post-convertibilidad (Azpiazu y Schorr, 2003; Azpiazu, 2005; Thwaites Rey, 2003; Castellani, 2008). Finalmente, podemos identificar trabajos orientados al análisis de las consecuencias sociales (con mayor especificidad en su impacto sobre las clases subalternas) producidas por las políticas post-convertibilidad (Gambina, 2006; Graña y Kennedy, 2007; Lozano et al, 2006; Lozano, Rameri y Raffo, 2006, 2007; Lozano, 2008). Pero todos los casos previamente mencionados si bien representan avances en el 
estudio del periodo post-convertibilidad se caracterizan por la focalización exclusiva en algunas dimensiones específicas, quedando pendiente un estudio que integre los distintos núcleos conceptuales del análisis del modelo de acumulación con factores que aborden los rasgos centrales de la construcción de hegemonía.

Podemos identificar un quinto conjunto bibliográfico ligado a las distintas disputas generadas en torno a algunas de las principales políticas del modelo postconvertibilidad, articulando diversos factores político-económicos, que nos permiten pensar algunos rasgos de la articulación entre hegemonía y acumulación. Las disputas en torno a las retenciones fue extensamente trabajada en 2008 a partir del "conflicto del campo", momento que cierra nuestro periodo de estudio y constituye un punto de inflexión político-económico en tanto reabre una crisis de hegemonía y exhibe tensiones al interior del modelo de acumulación (Arceo y Rodríguez, 2008; Barsky y Dávila, 2008; CENDA 2008; Katz, 2008). Asimismo, en Cobe (2009) encontramos diversos elementos político-económicos para pensar el conflicto en torno a las políticas de pesificación asimétrica de deuda privada que derivó en un proceso de licuación de deuda favorable al gran capital y en una posterior estatización mediante la política que denominamos de "salvataje” al capital financiero. A su vez, encontramos un extenso trabajo sobre las estrategias estatales y empresariales en torno a la negociación de las tarifas de las empresas de servicios y otras disputas en relación a las empresas privatizadas durante la administración Duhalde (Azpiazu y Schorr, 2003). También distintos estudios proveen elementos para pensar las estrategias de los distintos agentes en torno al default y al canje desarrollado en 2005 (Bembi y Nemiña, 2007; Damill, Frenkel y Rapetti, 2005; Giuliano, 2006). Asimismo, debemos señalar que este conjunto de trabajos, si bien constituyen valiosos aportes, se encuentran acotados a coyunturas particulares sin alcanzar el conjunto dimensiones propuestas en nuestra investigación.

Encontramos un sexto grupo de trabajos que han abordados distintas dimensiones de la construcción de hegemonía en nuestro período de estudio. Podemos identificar un primer subgrupo mayormente enfocado en el análisis del discurso y la construcción de sentidos, y otros factores constitutivos de la cultura política kirchnerista (Slipak, 2006; Muñoz y Retamozo, 2008; Esteves, 2008; Sarlo, 2011; Guerrero Iraola, 2011). Un segundo subgrupo aparece orientado a analizar diversos aspectos de la estrategia política desplegada por el oficialismo y la conformación del campo de antagonismo (Godio, 2006; Botana, 2006; Rinesi y Vommaro, 2007; Cremonte, 2007; 
Arzadun, 2008; Malamud y De Luca, 2011; Retamozo, 2011). Estos trabajos, si bien representan avances concretos sobre diversos factores involucrados en la construcción de hegemonía entre los años 2002 y 2008, tienden a carecer de una mirada que articule dichos fenómenos con el desarrollo del modelo de acumulación, del modo en que lo proponemos en nuestra tesis.

Finalmente, encontramos un séptimo grupo de trabajos que alcanzan a constituir estudios más globales cercanos a nuestro problema, tales como CENDA (2010), Basualdo (2011) ${ }^{11}$ y Curia (2011), aunque los mismos se encuentran enfocados principalmente en el modelo de acumulación quedando pendiente un estudio que articule el análisis del modelo y su dinámica hegemónica del modo aquí propuesto.

En la perspectiva construida en el proceso de investigación, contamos con una primer aproximación desarrollada como becario del Centro Cultural de la Cooperación y en la tesis de licenciatura, donde se buscaba percibir las relaciones entre acciones estatales, clase dominante y modelo de acumulación en el período post-convertibilidad realizando un análisis comparativo con el "neoliberalismo real” en la Argentina, preguntándonos por las rupturas y continuidades (Varesi, 2008). Este proceso de investigación fue profundizado en los años siguientes comenzando a constituir el enfoque aquí propuesto a partir del abordaje de problemáticas específicas tales como la deuda pública y capital financiero (Varesi, 2008b), la inflación y la gestación de un sistema de transferencias de ingresos (Varesi, 2009a, 2010a), las acciones estatales respecto de las privatizadas (Varesi, 2009b), alcanzando lo que fuera el primer trabajo sintético que recoge las principales variables explicativas acerca del modelo de acumulación post-convertibilidad (Varesi 2009c). Asimismo, publicamos en 2011 un trabajo junto a G. Pinazo (Varesi y Pinazo, 2011) que formó parte de la publicación de la investigación trianual de la FISyP y la Fundación Rosa Luxemburgo (Alemania) sobre hegemonía y proceso de acumulación capitalista en Argentina entre 2001 y 2007. Estos trabajos fueron la base de publicaciones que fue generando el proceso de investigación de la tesis de Maestría en Ciencias Sociales titulada "La configuración del modelo post-convertibilidad: políticas económicas y fracciones de clase en Argentina, 2002-2007” (Varesi, 2012a). Asimismo, avanzamos en la profundización del análisis

\footnotetext{
${ }^{11}$ Este trabajo de Basualdo posee tres partes, la última de las cuales articula elementos del modelo de acumulación y de la construcción de hegemonía, constituyendo un ensayo valioso vinculado a nuestro problema de estudio.
} 
del circuito productivo sojero y el conflicto en torno a las retenciones (Varesi, 2010b) así como análisis político-económicos que permiten gestar una mirada sobre las principales problemáticas involucradas en nuestro problema extendiendo el período de análisis también sobre el primer gobierno de Cristina Fernández (Varesi, 2010c, 2010d). Finalmente podemos exhibir un conjunto amplio de publicaciones asentadas en el análisis de los principales factores de la construcción de hegemonía que abona este proceso. En este camino desarrollamos dos trabajos que abordan distintos elementos políticos y culturales delineando la construcción de hegemonía entre 2002 y 2007 (Varesi, 2010e, 2010f) y estudios integrales que permiten una aproximación más cabal a los desafíos cognitivos implicados en la problemática de estudio: tanto abordando las dimensiones políticas, ideológico-culturales y económicas (Varesi, 2011a, 2011b, 2012b, 2012c).

En este trayecto, la presente tesis doctoral se fue gestando sobre la base de los procesos de investigación previos que fueron articulados en tanto insumos en la profundización de un trabajo de investigación más integral a partir de los núcleos conceptuales propuestos para el análisis del modelo de acumulación y los principales factores de la construcción de hegemonía entre 2002 y 2008.

\section{Organización de la tesis}

La tesis se organiza de forma sistemática en seis capítulos seguidos de las conclusiones finales. Un primer bloque está compuesto por dos capítulos teóricos. En el primer capítulo, titulado "Modelo de acumulación y hegemonía: aportes teóricos para su abordaje conjunto”, presentamos los conceptos centrales de la tesis. En primer lugar, se plantea el enfoque propio de análisis del modelo de acumulación, que ocupa el centro de la estrategia analítica, el cual está constituido por sus tres núcleos de políticas económicas, variables económicas y fracciones de clase. Describimos el contenido y alcance de cada núcleo al tiempo que desplegamos algunos apuntes teóricos sobre el proceso de reproducción ampliada del capital, el Estado y la construcción de las clases sociales. En segundo lugar, articulamos el enfoque sobre el modelo de acumulación con la teoría gramsciana de la hegemonía, en la que exponemos el alcance general de dicha perspectiva realizando las adecuaciones pertinentes para dar respuesta al problema de investigación, al tiempo que resaltamos la importancia del análisis de relaciones de 
fuerzas. En este camino, presentamos el enfoque de Gramsci sobre el Príncipe moderno y los intelectuales, rescatando el rol de ambos en la dirección política (construcción de una voluntad colectiva y fundación de un nuevo Estado) y la dirección cultural (reforma intelectual y moral), momentos claves de toda construcción hegemónica.

El capítulo 2 aborda un conjunto de conceptos subsidiarios al enfoque central, avanzando a la explicitación tanto de los supuestos filosóficos, la perspectiva epistemológica como la estrategia metodológica. En primer lugar, partimos de la noción de proyecto político-económico de gobierno para vincularla a la de cultura política, construyendo una mirada singular que articula definiciones específicas (siguiendo a Sirinelli y Berstein) con contenidos del pensamiento gramsciano y el enfoque de Marcuse sobre la cultura afirmativa (a partir del debate cultura/civilización). Luego avanzamos sobre los supuestos filosóficos abordando las categorías de contradicción y antagonismo. En este camino, impulsamos una crítica a la crítica de Laclau sobre el marxismo, con el fin de poner en cuestión la validez de algunos de sus argumentos centrales, rescatar la relevancia de la contradicción para el análisis de las sociedades capitalistas y poder, una vez realizada dicha crítica, reapropiarnos de varios aportes significativos del pensamiento laclausiano, principalmente su estudio del antagonismo, y su relación a la construcción identitaria de sujeto. Luego presentamos la estrategia metodológica especificando las herramientas y las fuentes que fueron utilizadas para trabajar en relación a cada objetivo específico, exhibiendo las bases empíricas sobre las que se irguieron las líneas fundamentales de argumentación. Finalmente desarrollamos un apartado epistemológico en el cual, primero, se exponen los principales obstáculos (Bourdieu, Bachelard) que la investigación debió atravesar, así como las técnicas de ruptura para superarlos. Luego realizamos un conjunto de reflexiones sobre la construcción del objeto de estudio a partir de la dialéctica marxista del conocimiento expresada en los Grundrisse (Marx, 2002 [1857-61]) y tomada principalmente en clave de la lectura de Dussel (1985).

En este punto entramos en el bloque de los capítulos de análisis. El mismo se encuentra organizado a partir de criterios teóricos sistemáticos, estableciendo cortes sincrónicos según el eje de análisis prioritario y conteniendo en su interior el despliegue diacrónico. El capítulo 3 aborda los principales aspectos de la construcción de hegemonía del período, sosteniendo que para comprender dicho proceso, es necesario partir de una caracterización de la crisis de 2001 en tanto constituye un preludio 
ineludible que signa con sus rasgos al proceso histórico posterior. Abordamos la crisis de 2001 interpelándola a partir del concepto de crisis orgánica de Gramsci, distinguiendo las distintas dimensiones que la componen, analizando a su vez la articulación de demandas y el proceso de constitución de sujetos en dicho campo de antagonismo. En segundo lugar, nos centramos en la estrategia contención/coerción desplegada por el gobierno de Duhalde, observando la fragmentación propugnada sobre la cadena de demandas de 2001, la construcción de la “demanda de orden” y los rasgos centrales de su discurso en materia del proyecto político-económico de gobierno. Finalmente, analizamos la construcción de hegemonía del kirchnerismo, analizando cómo despliega su estrategia de sutura en relación a las distintas dimensiones de la crisis, al tiempo que toma y resignifica varias demandas planteadas en el antagonismo que tuvo su punto álgido en 2001, incorporándolas a la construcción de una nueva fuerza política. En este camino, indagamos la construcción del adversario en torno a las figuras deslegitimadas del neoliberalismo y la constitución identitaria del kirchnerismo, viendo cómo efectúa una reformulación de aspectos de la cultura política peronista al tiempo que plantea un proyecto de gobierno que habilite la superación de la crisis en un nuevo momento hegemónico.

En los capítulos 4 y 5 desplegamos el análisis del modelo de acumulación, elaborado también con criterio lógico-sistemático, a través de la estrategia de doble entrada ligada a las dos dimensiones, superestructural y estructural, del modelo. Así ingresamos en el cuarto capítulo, donde abordamos el momento superestructural, presentando las políticas fundacionales, es decir, aquellas que expresan rupturas suficientes como para permitirnos vislumbrar un cambio de modelo de acumulación que comienzan a darle forma a su configuración. En este camino, especificamos los contenidos y alcances de seis políticas fundacionales: 1) la devaluación, 2) la implementación de retenciones a la exportación, 3) la pesificación asimétrica de deudas y depósitos, 4) el "salvataje” al capital financiero, 5) el default, y 6) el congelamiento y renegociación de tarifas; a la que luego se le agrega una séptima política, ligada a la inversión pública, que sin ser fundacional comenzó a jugar un papel relevante. En este camino, percibimos los rasgos principales de la acción estatal y sus efectos de alteración a nivel de las "reglas de juego", desplegando una hipótesis de trabajo ligada al rol del Estado en la constitución y movilización de un sistema de transferencias de recursos ligado a la gestión estatal de parte del excedente con el fin de organizar los equilibrios 
inestables entre las fracciones de clases en el marco de nuevas relaciones de fuerzas. A lo largo del capítulo evaluamos el impacto de las políticas económicas centrales sobre las variables económicas, observando su rol en la configuración del modelo de acumulación post-convertibilidad.

En el quinto capítulo tomamos una segunda entrada analítica al modelo: abordamos la dimensión de la estructura a partir del análisis de distintas fracciones de clases, dominantes y subalternas, observando las características de su construcción teórica y sus rasgos específicos en tanto colectivo de agentes económicos que ocupan un lugar (Poulantzas) o posición (Gramsci) en la estructura. En este camino identificamos un conjunto de fracciones dominantes, tales como la fracción productivo-exportadora del capital, una fracción amplia de PyMEs, la fracción de empresas de servicios públicos (con su fuerte núcleo de privatizadas) y la fracción financiera del capital. Asimismo, abordamos el análisis de las clases subalternas, teniendo en cuenta tanto su globalidad (recuperando la definición genérica de proletariado) como su creciente fragmentación interna. En este camino, indagamos un amplio conjunto de variables e indicadores que nos permiten dar cuenta de los rasgos centrales de cada fracción y de su desempeño, así como la evolución de sus precios y rentabilidades. A su vez, analizamos el impacto que tuvieron tanto las políticas fundacionales del modelo postconvertibilidad como las políticas específicas orientadas a las distintas fracciones, estableciendo cómo se reparten las cargas y beneficios del modelo. De este modo, procuramos dar cuenta del cambio en sus relaciones de fuerzas, realizando un análisis exhaustivo de la dimensión estructural en la propuesta gramsciana. También indagamos un conjunto de variables económicas que presentan regularidad durante todo el período y que son relevantes para el análisis del modelo de acumulación, completando el nivel de la estructura.

El capítulo 6 posee un lugar destacado en la tesis. En primer lugar, está constituido por un estudio de caso: el denominado "conflicto del campo", en tanto su desarrollo constituye un punto de inflexión en términos de la construcción de hegemonía, al tiempo que nos permite vislumbrar un conjunto de tensiones propias del modelo, en la articulación analítica de las categorías de antagonismo y contradicción. En segundo lugar, es parte de un corte a nivel diacrónico, ya que el 2008 es el primer año de gestión de Cristina Fernández al frente del Poder Ejecutivo Nacional. En este capítulo analizamos, por un lado, el circuito productivo sojero, identificando agentes y 
dinámicas de acumulación que nos permite profundizar en el estudio de un núcleo interno a la fracción productivo-exportadora del capital. A su vez, vemos la articulación de las dimensiones políticas, económicas y culturales cristalizadas en el momento del “conflicto del campo”, viendo cómo los niveles estructurales y superestructurales se juegan en un caso, haciendo de la parte un todo según la máxima que Lenin resalta de la dialéctica marxista. De este modo, los ejes sistemáticos de modelo de acumulación y hegemonía se funden en un estudio concreto en el que visualizamos las tendencias y tensiones centrales en acto, habilitando un momento de la totalidad concreta explicada (Marx) que será recuperada en las conclusiones.

Llegamos así al capítulo final de la tesis. En las conclusiones realizaremos una aproximación sintética al modelo de acumulación y los rasgos centrales de la construcción de hegemonía. Para esto, recogemos los principales resultados de los capítulos anteriores, definiendo con mayor claridad las regularidades y características que presenta el modelo, destacando en ese sentido las variables fundamentales para su análisis y extrayendo las inferencias finales desprendidas del conjunto de la tesis. Estas conclusiones están atravesadas por la reflexión en torno a las relaciones entre las fracciones de clases, los alcances y limitaciones del sistema de transferencias de recursos así como las complementariedades de intereses posibles. Aparecen en escena algunos debates singulares que atraviesan transversalmente a la tesis, tales como la construcción de sujeto, la discusión sobre la “burguesía nacional”, el perfil productivo y las potencialidades de desarrollo y la Argentina en el nuevo contexto latinoamericano. Asimismo, nos proponemos elaborar una nominación adecuada para el modelo postconvertibilidad a partir de sus propios rasgos y nos preguntamos si el mismo nos permite vislumbrar el inicio de un nuevo régimen de acumulación. Finalmente reflexionaremos acerca de los componentes sistémicos y transformadores que posee la construcción de hegemonía en el kirchnerismo, su construcción identitaria de sujeto en el campo de antagonismo y las contradicciones principales a nivel del modelo, abriendo nuevos interrogantes teóricos que aporten a líneas de investigación subsiguientes. 


\section{Capítulo I}

\section{Modelo de acumulación y hegemonía: aportes teóricos para su abordaje conjunto}

Nuestro problema de estudio nos convoca al análisis del modelo de acumulación como unidad de análisis central al tiempo que indagamos los principales factores de la construcción de hegemonía. Para esto comenzaremos realizando una tarea de conceptualización del modelo de acumulación, presentando la estrategia analítica para su investigación, para luego introducirnos en la teoría gramsciana de la hegemonía con el fin de exponer su alcance general y los aportes específicos que tomaremos a los fines de la construcción y abordaje de nuestro objeto de estudio.

En este camino, nos proponemos analizar el modelo de acumulación a través de tres núcleos conceptuales constitutivos: las políticas económicas, las variables económicas y las fracciones de clase, observando el cambio en sus relaciones de fuerza. El enfoque propuesto en este trabajo parte de la necesidad de articular dichos núcleos considerando, por un lado, sus múltiples implicancias mutuas y, por otro, sus aspectos singulares. Asimismo, abordamos el análisis de los principales factores de la construcción de hegemonía ligados a la configuración y desarrollo del modelo de acumulación. En este sentido, recuperaremos la teoría gramsciana de la hegemonía con el fin de desentrañar un conjunto de dinámicas político-culturales, vinculados a la concepción del mundo, la estrategia y la fuerza política, que nos permitan comprender la gestación del proyecto político-económico de gobierno que sirve de marco para la orientación de las políticas ${ }^{12}$.

\subsection{El modelo de acumulación en el centro de la estrategia analítica}

El primer desafío presente en nuestro estudio se refiere a la ausencia de una conceptualización explícita y sistemática del concepto modelo de acumulación. Aunque

\footnotetext{
12 Debemos aclarar que el delineamiento y definición de los distintos conceptos y categorías serán estructurados en pos de dar respuesta a la pregunta en torno al modelo de acumulación en la Argentina post-convertibilidad, por lo que esta pregunta-problema posee incidencia teórico-metodológica en las construcciones analíticas y en las definiciones conceptuales que las constituyen.
} 
este concepto aparece utilizado en numerosos trabajos, su indefinición y vaguedad son notorias y constituyen parte del vacío de conocimiento que nuestra investigación procura abordar. La importancia de su uso en nuestra problemática se torna central, por lo que realizaremos una primera aproximación a la definición del concepto, mostrando su íntima relación con los tres núcleos conceptuales mencionados.

Es necesario señalar que la principal propuesta de conceptualización explícita del concepto modelo de acumulación ha sido desarrollada, en Argentina, por Susana Torrado, una importante referente en cuanto al estudio de la estructura de clases. La autora señala que dicho concepto "remite a las estrategias de acción (objetivos, proyectos y prácticas políticas) relativas a factores fundamentales que aseguran la acumulación capitalista (...) y que son dominantes en una sociedad concreta en un momento histórico determinado” (Torrado, 1992:29). Observamos que esta perspectiva contiene algunos elementos de contacto con la conceptualización que iremos construyendo, pero al mismo tiempo marcamos una diferencia fundamental: mientras que Torrado tiende a asimilar al modelo de acumulación con las “estrategias de acción”, nosotros lo distinguimos de los proyectos o prácticas políticas, aunque integramos dichos factores como un componente clave. Esto se debe a dos razones. En primer lugar, la asimilación directa entre modelo y estrategia de acción dificulta ver la relevancia que en la gestación y desarrollo del modelo poseen otros componentes, y en segundo lugar, porque entendemos que existe una tensión en "saltar" a las superestructuras sin dar cuenta de las lógicas propias de las disputas políticas, ideológicas y culturales, generando que el efecto de asimilación limite aún más el análisis del modelo. En nuestro estudio, optamos por ejercer una estrategia analítica que articula diversos factores estructurales y superestructurales, delineando su capacidad explicativa específica así como sus vínculos constitutivos. Así, entendemos que las acciones estatales son resultantes de un proceso conflictivo que se vincula tanto a las disputas entre agentes económicos y sus relaciones de fuerza a nivel estructural, como a disputas de índole específicamente política. A este orden conflictivo nos aproximaremos a través del análisis en términos de hegemonía. A su vez, estimamos conveniente establecer una diferenciación analítica al interior de las variables económicas: entendemos que dentro de las mismas algunas poseen mayor factibilidad de ser modificadas en un corto plazo (principalmente aquellas ligadas más directamente al 
rango de la política económica) y que denominaremos como variables de desempeño ${ }^{13}$, mientras que otras, que llamaremos variables económico-estructurales, exhiben más condicionantes y requieren mayores esfuerzos y períodos de tiempo para ser modificadas, ya que expresan rasgos y lógicas sedimentadas de modelos y regímenes anteriores (como por ejemplo, el perfil de especialización productivo, los grados de concentración económica, el tipo de inserción en el mercado mundial, etc. $)^{14}$. Es justamente la relevancia de las variables económico-estructurales lo que nos impide asimilar el modelo de acumulación a la acción estatal o al proyecto político que la conduce. Así las políticas constituyen no la totalidad del modelo sino un elemento central junto a otros dos: las variables económicas y las fracciones de clase ${ }^{15}$. Sin embargo, rescatamos la importancia de las estrategias de acción, y es por esto que nuestro abordaje de la hegemonía se orientará a captar los principales elementos político-culturales que conforman el proyecto político-económico de gobierno que sirve de sustrato a la generación de políticas.

Avanzando en el desarrollo de nuestro enfoque sobre el modelo de acumulación, parece importante rescatar la definición que Eduardo Basualdo fue construyendo sobre un concepto emparentado: el régimen o patrón de acumulación dominante. Para la elaboración de dicho concepto Basualdo (2010) fue tomando elementos presentes en otros trabajos de conceptualización. Así, rescata de Boyer (1989) la necesidad de pensar el conjunto de regularidades que aseguran una progresión general y relativamente coherente de la acumulación de capital, reabsorbiendo o posponiendo desequilibrios sustanciales. De Arceo (2003) toma la articulación entre estructura socio-económica y

\footnotetext{
${ }^{13}$ Estas variables de desempeño poseen un parentesco con la definición que toma la CEPAL (en Bonnefoy, 2006) de la OECD, cuando habla de indicadores de desempeño en términos de variables cuantitativas o cualitativas que permiten verificar los cambios generados por una intervención pública, relativo a lo que estaba planeado inicialmente.

${ }^{14}$ No buscamos generar una clasificación estricta de las variables en estos dos tipos, sino que, entendiendo que dicha clasificación cambia históricamente, nos interesa enfatizar la diferenciación a nivel analítico. De hecho, podemos ver cómo en determinadas condiciones marcadas por le excepcionalidad, como la articulación dramática de la estrategia política, militar y económica en la última dictadura militar (1976-1982), habilitó trasformaciones de variables económico-estructurales en un plazo relativamente breve. Aún así para nuestra investigación tomamos para el análisis de las variables desempeño al PBI (general y por sectores), Inversión bruta interna fija, inflación, tipo de cambio real, salario real promedio, balanza comercial y de pagos, e indicadores sociales más relevantes, entre otras, y como variables económico-estructurales hacemos foco en el perfil productivo, grado de concentración y extranjerización económica, distribución del ingreso e inserción internacional.

${ }^{15}$ Si bien Torrado no sostiene que las políticas sean un componente ni único ni identificable con la totalidad, sí le otorga un rango destacado de jerarquía explicativa que se expresa linealmente en la definición y nominación del modelo: por ejemplo, de la estrategia "justicialista" desplegada entre 1945 y 1955 deriva el "modelo justicialista".
} 
las luchas políticas y sociales que la van conformando y que se vinculan con el bloque de clases que deviene dominante y logra imponer condiciones de acumulación favorables a sus intereses. Asimismo, retoma de Nun (1987) la necesidad de pensar al régimen de acumulación como un proceso histórico pluridimensional, heterogéneo y atravesado por contradicciones que constituye el contexto donde operan los agentes económicos.

En este camino, Basualdo fue diseñando su propia noción sintética del régimen o patrón de acumulación: "se trata de una categoría muy abarcativa que exhibe un significativo nivel de abstracción. No obstante es necesario analizarlo porque se trata de un instrumento analítico sumamente trascendente al permitir diferenciar los distintos comportamientos económicos que se suceden en el tiempo. Esto es posible debido a que este concepto alude a la articulación de un determinado funcionamiento de las variables económicas, vinculado a una definida estructura económica, una peculiar forma de Estado y las luchas entre los bloques sociales existentes” (Basualdo, 2007:6, subrayado en el original). Notamos que en esta aproximación comienzan a aparecer elementos relevantes para nuestro problema: el Estado, al que nos aproximaremos a través del análisis de la política económica y su rol destacado en la construcción de hegemonía; las variables económicas, a las que añadimos la distinción de pensarlas en dos grupos: de desempeño y económico-estructurales; la estructura económica, formada por los lugares que definen al proceso productivo, y las relaciones que emanan de dichas posiciones estructurales en las cuales se asientan los agentes que construimos como fracciones de clase, aproximándonos a las "luchas entre bloques sociales” desde el análisis de relaciones de fuerzas.

Basualdo señala dos factores fundamentales para determinar un régimen de acumulación: "Es preciso indicar que las variables económicas para poder constatarse la existencia de un patrón de acumulación de capital deben cumplir dos requisitos: la regularidad en su evolución y la existencia de un orden de prelación entre ellas.” (Basualdo, 2007:6, subrayado en el original). La regularidad y el orden de prelación serán retomadas también como elementos cardinales para la construcción de nuestra definición del concepto de modelo de acumulación ${ }^{16}$. Esto se debe a que las variables

\footnotetext{
${ }^{16}$ Debe aclararse que nuestra definición no se ligará a un análisis etimológico del término (por ejemplo, respecto de la génesis del término “modelo”) sino a rescatar su dimensión pragmática y su proyección analítica. Esto refiere a que el concepto, aunque carente de definiciones claras y rigurosas, ha sido
} 
económicas permiten observar, a través de su regularidad, la existencia o no de un modelo de acumulación, y a través de su orden de prelación, entendido como jerarquía explicativa, las características del funcionamiento de dicho modelo. A su vez, las políticas tienen capacidad para incidir en el corto plazo en las variables económicas de desempeño, mientras que las variables económico-estructurales son modificables sólo en un mediano o largo plazo expresando lógicas sedimentadas de modelos y regímenes anteriores. Ambos grupos de variables constituyen el marco de acción de los agentes que componen las fracciones de clase, que a su vez bregan por incidir en las acciones estatales y variables con el fin de generar condiciones beneficiosas para su acumulación. De este modo, la existencia y los rasgos de un modelo de acumulación se visualizan en la presencia de regularidad y en la prelación tanto de las variables económicas como en las relaciones principales que se expresan también en las políticas y en las clases sociales, en un período y territorio determinado. Así, los tres núcleos constitutivos del modelo muestran un desarrollo relativamente estable, evidenciando ciertas reciprocidades y congruencias que lo dotan de sus características específicas.

Habiendo establecido las similitudes, debemos ahora señalar las diferencias constitutivas entre ambos conceptos. En primer lugar, debemos mencionar una diferencia de escala temporal: mientras que el concepto de régimen de acumulación abarca largos períodos (por ejemplo, podemos pensar un régimen de acumulación neoliberal en Argentina entre 1976 y (al menos) 2001), el modelo de acumulación remite a recortes temporales más breves. Esto nos lleva a una ulterior distinción: según nuestro enfoque es posible hallar distintos modelos dentro de un mismo régimen de acumulación; así tanto el modelo liberal-corporativo (en el sentido Pucciarelli, 2004b) que caracterizó a la dictadura y el modelo de la convertibilidad podrían considerarse como distintos modelos dentro del régimen de acumulación neoliberal instaurado en Argentina a partir del golpe de Estado de 1976. Si en un nivel de mayor generalidad es posible encontrar similitudes como para pensarlos como parte de un mismo régimen, en un nivel de mayor especificidad veremos diferencias en las políticas aplicadas, las variables económicas y las relaciones entre fracciones de clase. Entonces podríamos pensar el modelo de acumulación como un subperíodo particular del régimen de

utilizado en numerosos trabajos y que, pensado en relación al concepto de régimen de acumulación, estableciendo sus similitudes y diferencias, nos permitirá la elaboración de una herramienta teórica con capacidad de interpelar fenómenos singulares y relevantes no contenidos en otras expresiones conceptuales. 
acumulación. De este modo, el concepto de modelo de acumulación desciende niveles de abstracción para interpelar el proceso de acumulación de capital en un periodo más breve, donde la regularidad y el orden de prelación entre variables pueden ser observados en mayores grados de especificidad e incluso contrastados con otros modelos dentro de un mismo régimen de acumulación. Además podemos señalar una segunda diferencia: el recorte espacial. Mientras que un régimen de acumulación puede recubrir un amplio conjunto de formaciones sociales, el modelo de acumulación se acota a una sola formación social ${ }^{17}$; por ejemplo, no resulta exagerado pensar que el régimen de acumulación neoliberal llegó a expandirse, con distintos matices por el conjunto de los países de América del Sur, pero sería un absurdo sostener que en la década de los 90 todos aplicaron el modelo de la convertibilidad. Asimismo, podemos pensar momentos dentro de un régimen de acumulación en que no se pueda delimitar la existencia de un modelo, por ejemplo, por la ausencia de regularidades significativas a lo largo de un periodo determinado. Por ejemplo, podemos suponer que en el periodo presidencial de Raúl Alfonsín (1983-1989) no llegó a conformarse un modelo de acumulación específico, perviviendo las modificaciones estructurales que había infligido la política económica de la dictadura con la instauración del régimen de acumulación neoliberal y sin capacidad de mantener una regularidad significativa en el desarrollo de las políticas y las relaciones entre clases que le permitieran sostener sus planes económicos por un plazo suficiente (como ocurrió con el plan de Grispun, el Plan Austral y el Plan Primavera).

Así, el modelo de acumulación es la forma que adquiere el proceso de reproducción ampliada del capital (Marx, 2007 [1885]) en un espacio y tiempo determinado, en el cual se observan relaciones de regularidad y prelación en sus elementos estructurales y superestructurales en un nivel de mayor especificidad que en

\footnotetext{
${ }^{17}$ Según Poulantzas (1981) una formación social es una sociedad concreta en la que se articulan de forma específica distintos modos de producción. Además señala que "una sociedad concreta, una formación social implica más de dos clases, en la medida misma en que implica varios modos y formas de producción. (...) Lo que resulta exacto es que las dos clases fundamentales de toda formación social, por donde pasa la contradicción principal, son las del modo de producción dominante en esta formación: la burguesía y el proletariado en las formaciones sociales capitalistas” (Poulantzas, 1981:22, subrayado en el original). De este modo, observamos que la formación social es una sociedad concreta en un tiempo y espacio determinado donde se expresan distintos modos de producción pero lo hacen de forma jerárquica, estableciendo la existencia de un modo de producción dominante y modos de producción subordinados. Poulantzas agrega además otro elemento importante para el análisis de las formaciones sociales: la dimensión del conflicto; sostiene que las formaciones sociales son los lugares efectivos de existencia y de reproducción de los modos de producción y que "es la lucha de clases en las formaciones sociales lo que constituye el motor de la historia: el proceso histórico tiene como lugar de existencia estas formaciones sociales" (Poulantzas, 1981:22, subrayado en el original).
} 
el régimen de acumulación que lo contiene. Podemos hablar de modelo de acumulación cuando es posible identificar regularidades tanto a nivel estructural, en las variables económicas y las fracciones de clase, como en el nivel superestructural de las políticas, que definen las “reglas de juego” (evocando a Bourdieu) y marcan el campo de acción de los agentes, encuadrados estos en una relación de fuerzas particular. Asimismo, en el modelo de acumulación se manifiestan elementos sedimentados de las lógicas previas de modelos (y regímenes) de acumulación anteriores, y por esto no puede ser reducido a las políticas o a los proyectos de gobierno, al tiempo que expresa en su dinámica, como totalidad, la resultante del proceso de lucha de clases tanto en su dimensión económica como político-ideológica, enunciando una correlación de fuerzas.

Esta interrelación de los distintos núcleos conceptuales de nuestra problemática expresa aspectos específicos del proceso de reproducción ampliada del capital, un proceso en el que la "reconversión continua de plusvalor en capital se presenta como magnitud creciente del capital que ingresa al proceso de producción. Dicha magnitud, por su parte, deviene fundamento de una escala ampliada de la producción, de los métodos consiguientes para acrecentar la fuerza productiva del trabajo y acelerar la producción de plusvalor” (Marx, [1868] 2002:776, subrayado en el original).

Deteniéndonos brevemente en rastrear algunos supuestos y factores constitutivos de este proceso, recordamos que Marx señala que todo proceso de producción es al mismo tiempo un proceso de reproducción y "si la producción posee forma capitalista, otro tanto ocurrirá con la reproducción. En el primer caso, el proceso de trabajo sirve como medio para crear plusvalía; en el segundo, es un medio para reproducir o perpetuar como capital, es decir como valor que crea valor, el valor ya anticipado" (Marx, 1973:543). Este incremento del valor anticipado, este plusvalor, adquiere la forma de ganancia o renta del capital; ahora bien, la reproducción del capital puede ser distinguida según el uso que se haga de ese plusvalor en dos posibilidades: una reproducción simple del capital o una reproducción ampliada del mismo. Si en lugar de ser consumida la plusvalía, como ocurre en la reproducción simple ${ }^{18}$, al menos una parte de la renta obtenida se la emplea como un nuevo capital que se incorpora al

\footnotetext{
${ }^{18}$ La reproducción simple del capital se da cuando el capitalista emplea esa renta (plusvalor) como fondo de consumo, sin incrementar la inversión original de capital. Digamos que si la fórmula del capital es DM...P....M'-D', en la reproducción simple la D' servirá para el consumo del capitalista y para reiniciar el ciclo con una D igual al ciclo productivo anterior. En este caso hay solamente excedente, pero no podemos hablar propiamente de acumulación.
} 
anterior, se gesta la reproducción ampliada del capital. En esta reproducción del capital a escala creciente se capitaliza la plusvalía, entonces, si observamos la fórmula del capital D-M...P.... $\mathrm{M}^{\prime}-\mathrm{D}^{\prime 19}$, el nuevo ciclo se iniciará, en términos generales, con una D incrementada: $\mathrm{D}^{\prime}-\mathrm{M}^{\prime}$...P.... $\mathrm{M}^{\prime \prime}-\mathrm{D}^{\prime \prime}$, y así sucesivamente, cobrando forma de espiral. En este caso, como señala Marx, “la acumulación se resuelve, pues, en reproducción del capital en escala progresiva” (Marx, 1973:557). Aquí no se trata sólo de excedente sino que entramos en el terreno de la acumulación propiamente dicha ${ }^{20}$.

El capital es valor que se valoriza, pero para que esto tenga lugar tiene que haber un momento donde el valor original sea incrementado y entramos aquí en el corazón de la teoría del valor desarrollada por Marx. En el modelo explicativo que Marx provee, el capitalista adquiere en el mercado la fuerza de trabajo y los medios de producción, que son ellos mismos trabajo pasado, invirtiendo dinero. En el proceso de trabajo, el consumo del valor de uso de la fuerza de trabajo, junto con las materias primas y medios de trabajo, todos ellos medidos según su valor de cambio, dan lugar a un valor mayor, un plusvalor. De este modo el dinero invertido en primer lugar se ha convertido en capital. Si bien esta transformación del dinero en capital se lleva a cabo en la esfera de la circulación (a través de la compra inicial de fuerza de trabajo y medios de producción, y la venta posterior de la mercancía generada en el proceso de trabajo), la creación de plusvalor tiene su origen en una esfera distinta. Es en la esfera de la producción donde la explotación de la fuerza de trabajo produce una plusvalía, es esta mercancía especial, la fuerza de trabajo, que al ser usada (puesta a producir para realizar su valor de uso) tiene la capacidad de generar un nuevo valor, mayor a su propio valor de cambio (salario): “Al convertir el dinero en mercancías que sirven de elementos materiales de un nuevo producto, al incorporarles luego la fuerza de trabajo viva, el capitalista transforma el valor -del trabajo pasado, muerto, convertido en cosa- en capital, en valor preñado de valor” (Marx 1973:201). Pero en tanto es el capitalista quien compra la fuerza de trabajo mediante su salario como una mercancía más, y es el valor de uso de esa fuerza de trabajo la que dará origen a nuevo valor incrementado, el producto generado en el proceso del trabajo es también propiedad del capitalista y es así enajenado de su productor, el trabajador. En virtud de las relaciones de producción y,

\footnotetext{
${ }^{19} \mathrm{D}$ = Dinero; $\mathrm{M}=$ Mercancía; $\mathrm{P}=$ Producción; ' = valor incrementado.

${ }^{20}$ Cómo sintetiza Marx: “¿Qué se modifica cuando la reproducción simple es reemplazada por la reproducción en escala progresiva, por la acumulación? En el primer caso, el capitalista se devora toda la plusvalía, en tanto que en el segundo da prueba de civismo, y sólo se traga una parte, para convertir la otra en dinero" (Marx, 1973:559).
} 
específicamente, de propiedad de los medios de producción en la sociedad capitalista se gesta en esta enajenación de la nueva mercancía emergente del proceso de trabajo, siendo enajenada al mismo tiempo la plusvalía que contiene, cobrando así forma de renta del capital a partir de la cual se reproduce la clase capitalista y, en general, el conjunto de relaciones sociales que sostienen al modo de producción capitalista ${ }^{21}$.

Como señalamos, todo proceso de producción es al mismo tiempo un proceso de reproducción. De este modo podemos ver que en el proceso productivo, por un lado, “el obrero produjo (...) el fondo para su propio pago, el capital variable, antes que éste se vuelva a él en forma de salario, y sólo se lo ocupa mientras continúa reproduciéndolo” (Marx, 1973:544), es decir que el consumo productivo de su fuerza de trabajo en la producción será retribuido con un salario que garantice al trabajador (y su familia) su propia reproducción (siendo ésta histórica y culturalmente variable), pero, por otro lado y al mismo tiempo, actúa como la fuerza motriz del capital constituyendo la fuente del plusvalor y permitiendo la reproducción del capital mismo. Esta dinámica se conjuga a su vez con la condición intrínseca de competencia entre capitalistas y los procesos de concentración y centralización, generando que el proceso de acumulación se constituya en el nodo central de la expansión de la relación social capital a nivel global y hacia el interior de las distintas formaciones sociales ${ }^{22}$.

Es en el desarrollo histórico de este proceso de reproducción ampliada del capital donde se gesta la reproducción ampliada de las clases sociales (que es, a su vez, una reproducción ampliada de las relaciones sociales) (Poulantzas, 1981), y que contiene dos aspectos:

\footnotetext{
${ }^{21}$ La síntesis de este proceso se visualiza en la fórmula misma del capital: D-M...P...M $\mathbf{M}^{\prime}$-D' . Dijimos que el capitalista compra mercancías (D-M): medios de producción (trabajo pasado, muerto) y fuerza de trabajo (trabajo presente, vivo), que dentro de estas mercancías hay una que al ser usada genera un valor mayor, un plusvalor, que será incorporado a la nueva mercancía generada en el proceso productivo (M...P....M'), y que el capitalista venderá obteniendo ese plusvalor ( $\left.\mathrm{M}^{\prime}-\mathrm{D}^{\prime}\right)$ que cobra forma de renta del capital. Esta plusvalía puede ser consumida dando lugar a una reproducción simple o puede ser reintroducida en el ciclo impulsando la acumulación mediante la reproducción ampliada del capital.

${ }^{22}$ Como veremos en el capítulo siguiente, éstas son las relaciones fundantes de la contradicción entre el trabajo y el capital, así como de la existencia de relaciones contradictorias entre los capitalistas mismos, cuya condición de subsistencia también es buscar acumular por encima del resto, compitiendo con los otros agentes económicos de la clase dominante y, eventualmente absorbiéndolos, para acumular poder estructural, es decir, capacidad de decisión sobre las principales variables económicas para mejorar su rentabilidad.
} 
1. La reproducción ampliada de los lugares (o puestos) ocupados por los agentes en la división social del trabajo, que son independientes de la voluntad de tales agentes.

2. La reproducción y distribución de los agentes mismos en dichos lugares.

De este modo, identificamos una relación central en nuestro problema de estudio: el modelo de acumulación, como momento específico de la reproducción ampliada del capital en un espacio determinado, implica al mismo tiempo un proceso de reproducción ampliada de las clases sociales. Sostenemos la primacía analítica de los lugares $^{23}$ en tanto sus rasgos y desempeño nos permiten comprender características centrales del modelo de acumulación. El concepto de lugar nos sitúa en la dimensión estructural que constituye un momento clave del abordaje de nuestro objeto de estudio. Asimismo, este concepto nos permite pensar a las fracciones de clase como colectivos de agentes que comparten un lugar común, una posición (Gramsci) en la estructura, que tiene su asiento en las relaciones de producción pero a su vez las trasciende llevándonos a preguntar por su vinculación con el nivel de la superestructura ${ }^{24}$.

Como señala O’Donnell (1978), el gran diferenciador de acceso a los recursos es la clase social, entendida como posiciones en la estructura social determinada por comunes modalidades de ejercicio del trabajo y de creación y apropiación de su valor. La clase funciona como diferenciador directamente ya que por sí la posición de clase determina en gran medida la desigualdad de acceso a recursos, e indirectamente, por las

\footnotetext{
${ }^{23}$ Según Poulantzas, "el aspecto principal de la determinación de las clases es el de sus puestos, no el de los agentes que ocupan esos puestos” (1981:29).

${ }^{24}$ La teoría de los campos de Bourdieu, aunque asentada en una matriz teórica distinta, nos brinda algunos elementos pertinentes para nuestra reflexión: "La estructura del campo es un estado de relaciones de fuerzas entre agentes o las instituciones que intervienen en la lucha o (...) de la distribución del capital específico que ha sido acumulado durante luchas anteriores y que orienta las estrategias ulteriores" (Bourdieu, 1990:136). Estas luchas cobran forma a través de la acción estratégica desplegada por los distintos agentes, caracterizados por ser portadores de capital y por la posición ocupada en el campo. Estos agentes luchan por conservar o subvertir la distribución del capital específico puesto en juego en ese campo y por incidir en las reglas de juego para volverlas a su favor. Por un lado, nos alejaremos de Bourdieu y su teoría de los campos en tanto el capital aparece reducido a un poder para accionar en un campo, un poder que puede revestir distintas formas; nosotros elegimos recuperar el sentido del capital como relación social fundamental en las sociedades capitalistas, vinculada a la teoría del valor en Marx. Pero por otro lado, reconocemos que la perspectiva bourdieana contiene elementos valiosos para nuestro análisis: nos permite identificar las posiciones y, a través de sus similitudes, construir colectivos de agentes que pensados a través de su clivaje de clase conforman fracciones de clase, que están a su vez atravesadas por las relaciones de fuerza en las que se dirimen sus luchas.
} 
posibilidades diferenciales de lograr situaciones que a su vez permiten acceder al control de otros recursos de dominación ${ }^{25}$.

De esta manera, completamos teóricamente el nivel de la estructura. La estructura en tanto metáfora espacial, constituye una disposición de posiciones, de lugares, y la estructura como espacio específico de las fuerzas productivas (enmarcadas en determinadas relaciones de producción) se vincula con las características que presentan las variables económicas, que abarcan tanto las variables económicoestructurales, caracterizadas por su mayor permanencia y su rango de más largo plazo (en tanto comprenden las lógicas sedimentadas provenientes de modelos y regímenes de acumulación pasados que inciden en el presente del modelo de acumulación), así como las variables económicas de desempeño, más susceptibles de modificación en el corto plazo por la incidencia de la acción estatal, representando elementos estructurales con mayor versatilidad $^{26}$.

Ahora bien, como advierte Poulantzas, "las clases sociales no existen sino en la lucha de clases, con dimensión histórica y dinámica. La constitución de las clases, de las fracciones, de las capas, de las categorías, no puede hacerse más que tomando en cuenta esta perspectiva histórica de la lucha de clases” $(1981: 27)^{27}$. Es por esto que analizar las fracciones de clase implica estudiar sus relaciones de fuerzas, en sus componentes tanto estructurales como superestructurales. Así, este proceso de lucha de clases tiene un elemento destacado en el Estado. Según Poulantzas,

"El Estado capitalista, sin dejar de representar de manera predominante los intereses de la clase o fracción hegemónica -ésta misma variable-, reviste una autonomía relativa respecto de esta clase y fracción y respecto de las demás clases y fracciones en el poder. De una parte, porque asegura el interés político general del conjunto del bloque en el poder, al organizar el "equilibrio inestable de compromisos” (Gramsci) (...). De la otra, porque organiza esta hegemonía respecto del conjunto de la formación social, por lo tanto igualmente respecto de las clases dominadas” (1981:90).

\footnotetext{
25 En dicho trabajo, O’Donnell (1978) define a la dominación como la capacidad de imponer regularmente la voluntad sobre otros y como una relación asimétrica basada en el control diferencial de ciertos recursos: coerción física, recursos económicos, de información y el control ideológico.

${ }^{26}$ Recordamos que no pretendemos determinar una clasificación específica de qué variables económicas deben ser consideradas como de desempeño o como económico-estructurales, ya que éstas mismas son variables según el caso que se estudie, sino establecer esta distinción como orientación teórica que nos evite confundir un modelo de acumulación con los proyectos político-económicos de gobierno, que muchas veces en el discurso público o del sentido común tienden a aparecer asimilados. A lo largo del presente capítulo y del siguiente iremos realizando las anotaciones pertinentes para establecer una diferenciación analítica clara entre el modelo, las políticas y los proyectos político-económicos de gobierno.

${ }^{27}$ Como ya señalamos, este elemento también se manifiesta claramente en Bourdieu, en tanto el campo es un campo de fuerzas, de lucha.
} 
Para nuestro estudio cobra importancia entonces el análisis de las políticas económicas como acción o intervención estatal porque inciden en la configuración y mantenimiento de un modelo de acumulación reorganizando de manera singular los equilibrios inestables entre las fracciones de clase en estrecha vinculación con los cambios en sus relaciones de fuerza ${ }^{28}$. Así vemos que el abordaje del modelo de acumulación no implica sólo elementos de la estructura sino también su articulación con elementos superestructurales. Si en la reproducción ampliada del capital el elemento de partida del análisis es la generación y acumulación del excedente, estos momentos se complementan con la gestión del excedente que nos sitúa en el estudio del papel del Estado:

"la instancia política asume gran parte de este papel de gestor de una parte importante del excedente producido, en tanto en cuanto las instituciones del Estado no hacen más que reapropiarse de una parte del mismo a través, entre otros, de los impuestos, para, a continuación, administrarlo y redistribuirlo, social y territorialmente, de forma coherente con el modelo dominante en dicha sociedad” (Sánchez, 1991:71).

Abordaremos el rol de Estado en la gestión del excedente a través de su intervención en la conformación de un sistema de transferencia de recursos con el que se procura construir hegemonía, compensar y armonizar intereses entre las fracciones de clase. Es por esto que otros factores superestructurales relacionadas con la gestión del excedente a tener en cuenta son las formas de legitimación del poder en base a proyectos societarios que se juegan en la lucha por la hegemonía entre los distintos grupos y clases sociales, y esta centralidad de la lucha de clases enfatizada por Poulantzas, que atraviesa a las distintas fracciones dominantes y subalternas en la disputa también por el valor socialmente producido.

Nuevamente, si las clases no existen más que en relaciones de lucha de clases, el análisis de relaciones de fuerzas cobra importancia igualmente para emprender el

\footnotetext{
${ }^{28}$ En términos de Bourdieu, pensar el campo económico implica pensar el Estado y su influencia en el mismo, ya que "el campo económico está habitado más que cualquier otro por el Estado, que contribuye en todo momento a su existencia y persistencia, pero también a la estructura de relaciones de fuerza que lo caracteriza" (2008:25). Esta incidencia se realiza a través de las diferentes políticas coyunturales y de efectos más estructurales ejercidos por ejemplo, a través de las leyes presupuestarias, los gastos en infraestructura, las políticas en materia de transporte, energía y vivienda entre otras, "que hacen del campo burocrático un estimulador macroeconómico que contribuye a asegurar la estabilidad y la previsibilidad del campo económico" (Bourdieu, 2008:26). El Estado aparece entonces como un campo con capacidad de incidencia en otros campos, particularmente el económico, influyendo en la definición de las reglas de juego.
} 
estudio de las fracciones, para lo cual retomamos la propuesta gramsciana ${ }^{29}$. Las articulaciones de políticas económicas, variables económicas y fracciones de clase son constitutivas de este análisis. En nuestro caso, las políticas fundacionales de la postconvertibilidad fueron dando lugar a un nuevo modelo de acumulación, que presentando rupturas y continuidades respecto del modelo de los 90, tanto en términos de políticas como en las variables económicas, se vincularon a cambios particulares en la correlación de fuerzas, definiendo un reparto diferencial de cargas y beneficios, determinando que algunas fracciones se vean favorecidas por las nuevas condiciones mientras que otras fueran perjudicadas.

Estos cambios en las relaciones de fuerza serán analizados partiendo de la diferenciación que realiza Gramsci sobre los distintos momentos constitutivos de dichas relaciones. Gramsci distingue tres momentos principales, resaltando la relevancia que, a los fines del presente trabajo, reviste el primero, el momento estructural de las relaciones de fuerzas: éste refiere a "una relación de fuerzas sociales estrechamente ligada a la estructura, objetiva, independiente de la voluntad de los hombres (...). Sobre la base del grado de desarrollo de las fuerzas materiales de producción se dan los grupos sociales, cada uno de los cuales representa una función y tiene una posición determinada en la misma producción” (Gramsci, 2003:57) ${ }^{30}$. Esto implica ver las clases y fracciones en su anclaje material, en su posición específica y en su función en las relaciones de producción $^{31}$, teniendo en cuenta el desarrollo de la reproducción ampliada de dichas posiciones y de los agentes que las ocupan. En este sentido, procuraremos analizar las relaciones entre las políticas y las fracciones de clase, pensadas a partir de su posición en la estructura (o lugar según el concepto de Poulantzas), en vinculación a la configuración del modelo post-convertibilidad, cuyas cristalizaciones fueron constituyendo reglas de juego y modificaciones en las variables económicas que repercutirán asimismo sobre los diversos agentes de dichas fracciones. Por supuesto que hablar de políticas nos remite al segundo momento de las relaciones de fuerzas definido

\footnotetext{
${ }^{29}$ Realizaremos una aproximación a este componente central del pensamiento gramsciano según los tiempos de presentación de nuestra estrategia analítica en virtud del problema de estudio planteado: primero pensaremos las relaciones de fuerzas en relación al modelo, para, posteriormente, terminar de dilucidar su potencia cognitiva para el abordaje de la construcción de hegemonía.

${ }^{30}$ Como desarrollaremos más adelante, el segundo momento señalado por Gramsci refiere a la relación de fuerzas políticas mientras que el tercer momento comprende la relación de fuerzas militares.

${ }^{31}$ Incluso debemos rescatar que en su análisis del americanismo y el fordismo, Gramsci (2003) observa cómo las transformaciones del proceso productivo dan lugar a una forma de hegemonía que parte de la fábrica misma.
} 
por Gramsci, el momento de la relación de las fuerzas políticas. Como veremos más adelante, en relación a este segundo momento nos centraremos en las acciones estatales, principalmente las políticas económicas y otras que nos permitan delinear los componentes centrales de la construcción de hegemonía que asisten al desarrollo del modelo de acumulación. Estas acciones estatales son, a la vez, resultados de las interacciones y luchas que constituyen este segundo momento de las relaciones de fuerzas, y aparecen también como elementos de incidencia importante en la delimitación de las posibilidades de apropiación del excedente por parte de los distintos agentes, según sus fuerzas específicas y su posición en la estructura.

Una pregunta significativa yace ligada a los criterios de construcción de las fracciones de clase. Según Poulantzas, en El Capital de Marx parecen deducirse fracciones de clase ligadas a los ciclos del capital: del ciclo del capital productivo se derivaría la fracción productiva o industrial, del ciclo del capital mercantil, la fracción mercantil o comercial y del ciclo del capital dinero, la fracción financiera o bancaria ${ }^{32}$. Pero en El 18 Brumario de Luis Bonaparte (Marx, 2000 [1852]) las fracciones de clase son construidas en concreto a partir de la interacción con lo político: "los efectos de la instancia de lo político -las clases resultantes del conjunto de las instancias sobre las relaciones sociales- pueden producir fracciones de clase sólo en el campo de la práctica política de clase” (Poulantzas, 2001 [1968]:301).

Por un lado, partimos de la base de que el gran diferenciador para la construcción de las fracciones es su relación con el plusvalor: en este sentido aparece la importancia del capital productivo dentro de la clase dominante (Poulantzas, 1981). Nosotros rescataremos esta relevancia, tanto por su vinculación a la generación y apropiación de plusvalor, como por la jerarquía que dicha fracción adquiere en el modelo post-convertibilidad en cuanto al sostenimiento del esquema macroeconómico y a la centralidad conquistada en las relaciones de fuerzas.

Por otra parte, O’Donnell (1978b) provee criterios metodológicos para estudiar una fracción de clase. El autor señala tres planos: 1. Un plano estructural, que refiere a la posición de la fracción en el sistema productivo, que contiene dos direcciones principales: 1.1. la posición de la fracción en términos de sus relaciones económicas con

\footnotetext{
${ }^{32}$ En este caso, estaríamos en presencia de fracciones de clases construidas con base en el lugar ocupado en la estructura en vinculación con el proceso de circulación del capital.
} 
otras fracciones burguesas, con las clases subordinadas y con el aparato estatal y 1.2. una dirección "hacia adentro", que apunta a establecer su propia diferenciación estructural, su heterogeneidad interna. 2. Un plano de la organización corporativa y, finalmente, 3. el plano político-ideológico. Entre las advertencias, O’Donnell destaca que no se es clase sólo en el plano estructural, sino simultáneamente en los tres niveles.

Esto nos presenta el siguiente desafío, visible también en la perspectiva de Poulantzas: los peligros teóricos de construir las clases con base económica (aunque ambos destacan la relevancia de la posición en la producción) y cómo entrarían los elementos de otras dimensiones, principalmente los político-ideológicos. Frente a este planteo debemos señalar tres cuestiones fundamentales:

1) El caso presentado por el propio Marx y las distintas construcciones de clase realizadas ya en El Capital, ya en el 18 Brumario, nos permiten concluir que, lejos de revestir esta diferencia una contradicción o insuficiencia de la teoría, es el problema de estudio analizado el que mueve a posicionarse en la construcción teórico-metodológica de las clases ${ }^{33}$. Por el contrario, entendemos que es esta versatilidad de la teoría crítica para analizar diversos fenómenos vinculados a la lucha de clases en distintos momentos históricos y en distintos lugares lo que nos habilita a una construcción creativa de las clases sociales. En nuestra investigación, las fracciones de clase constituyen una subunidad de análisis que va a ser estudiada en función del problema en torno al modelo de acumulación, y, habiendo delimitado los componentes que el mismo contiene, enfatizamos necesaria y deliberadamente la dimensión económica a partir de la vinculación entre clase y modelo de acumulación ${ }^{34}$. Sostenemos, sin embargo, una posición alejada y crítica del economicismo ${ }^{35}$, y es por esto que emprendemos un análisis en términos de hegemonía para comprender un conjunto de factores políticoculturales que inciden en la configuración y desarrollo del modelo de acumulación y resaltamos el carácter de autonomía relativa que reviste el Estado frente a los intereses y

\footnotetext{
${ }^{33}$ Esto implica abrazar una mirada anti-esencialista y crítica de cualquier dogmatismo cerrado, en tanto lejos de ver a las clases sociales como una "realidad" univoca que sólo puede ser leída de una manera determinada, resaltamos una construcción de las clases sociales que, teniendo en cuenta las relaciones fundantes de dicha categoría, son elaboradas en vinculación con el problema de estudio y en relación al desarrollo histórico de una formación social determinada.

${ }^{34}$ En este sentido, nos emparentamos con la perspectiva analítica de Torrado (1992) en cuanto a la estructura de clases, que parte de su circunscripción a la base económica, y rescatamos las respuestas a las diversas críticas que despliega en el capítulo 1 de su trabajo.

${ }^{35}$ Es decir, planteamos una posición crítica del "imperialismo" conceptual que muchas veces se ejerce al expandir los elementos de análisis económicos acríticamente sobre un conjunto mucho más amplios de fenómenos que responden a lógicas propias, ejerciendo un efecto reduccionista.
} 
demandas inmediatas de las distintas fracciones, autonomía que siempre debe ser indagada históricamente y que puede debilitarse o reforzarse según la propia dinámica de la lucha de clases.

2) Siguiendo esta línea de razonamiento, incorporamos las políticas como elemento superestructural constitutivo, en tanto el re-ordenamiento a nivel del modelo de acumulación se gesta a partir de acciones estatales que poseen relevancia suficiente como para incidir incluso en la orientación del criterio teórico de construcción de las fracciones de clase. Esta es otra decisión teórica a través de la cual la dimensión política incide en el recorte de las clases, incluso sosteniendo explícitamente que las mismas serán delimitadas tomando como elemento central la posición estructural: encontramos en nuestro período de estudio un conjunto de políticas que modifican el proceso de acumulación de un modo tal que sus efectos deben ser tenidos en cuenta para la construcción de un colectivo de agentes en términos de clase. Esto nos lleva al tercer factor clave.

3) Parece fundamental tomar la advertencia desarrollada por Bourdieu en torno a la necesaria distinción entre las clases teóricas y las clases reales. Las fracciones de clases deben ser construidas como grupos de agentes según su homología de posición: "Sobre la base del conocimiento del espacio de las posiciones podemos recortar clases en el sentido lógico del término, es decir, conjuntos de agentes que ocupan posiciones semejantes y que, situados en condiciones semejantes y sometidas a condicionamientos semejantes, tienen todas las probabilidades de tener disposiciones e intereses semejantes y de producir, por lo tanto, prácticas y tomas de posición semejantes” (Bourdieu, 1990b:284). Esto implica no confundir las clases teóricas con clases reales (recordando que no se deben confundir las cosas de la lógica con la lógica de las cosas), y que aunque la proximidad en el espacio social predispone al acercamiento, "sólo se pasa de la clase-sobre-el-papel a la clase "real” a costa de una labor política de movilización” (Bourdieu, 1997:24).

Es por estos factores que el tipo de fracción de clase a ser construida se acerca y se distancia al mismo tiempo tanto de los criterios propuestos por O’Donnell como de las construcciones específicas que citamos en Marx. Esto se justifica en que procuramos generar un análisis del modelo de acumulación sin derivar del mismo la acción de los agentes y su configuración global en la articulación política, ideológica y cultural. 
Como señala Bourdieu, la similitud en la posición no se traduce automática ni necesariamente en acción conjunta sino que establece una tendencia, una mayor posibilidad de confluencia en la acción. Intentar la construcción de "mega-fracciones” de clase que recorran todo el espectro económico-corporativo-político de una vez y en un mismo corte puede llevar, a los fines de este estudio, a ocultar la compleja interacción que surge de los distintos componentes involucrados en el proceso de acumulación capitalista. Entonces, parece más fructífero pensar la relación con el Estado desde el criterio de autonomía relativa para ver cómo se articulan los equilibrios inestables entre las fracciones de clase en el marco de la gestación del modelo de acumulación, antes que forzar a priori la articulación de los agentes económicos, actores políticos y corporativos en macro-fracciones, construcción analítica que sobrepasa los límites de nuestro problema de investigación.

Sin embargo, vemos aquí un desafío que atraviesa al conjunto de producciones teóricas ligadas al marxismo y que también recuperaremos al volver sobre el análisis gramsciano de relaciones de fuerza: es la naturaleza de la relación entre elementos de distintas dimensiones, la relación entre factores económicos, políticos y culturales, la relación entre la estructura y las superestructuras complejas. Es por esto que, en el capítulo siguiente, dedicaremos un apartado para reflexionar sobre la naturaleza de dicha vinculación recuperando algunas ideas claves en torno a la dialéctica, el antagonismo y la contradicción.

Finalmente, debemos enfrentar un interrogante principal ligado a los criterios de clasificación de las fracciones de clase. Nuevamente, debemos recordar que éste no representa un único criterio posible sino que seleccionamos variables que resultan pertinentes en pos de dar respuesta al problema centrado en el modelo de acumulación y al proceso de construcción de hegemonía que asiste su desarrollo ${ }^{36}$.

\footnotetext{
${ }^{36}$ Decimos "que asiste", no porque esta sea la función única del proceso de construcción de hegemonía (ya que como veremos en el apartado siguiente una estrategia analítica basada en la teoría de la hegemonía habilita el abordaje de una amplia gama de fenómenos y problemas de estudio), sino porque es en nuestro propio problema de estudio centrado en el modelo de acumulación desde donde rearticulamos el análisis de construcción de hegemonía.
} 
En este sentido hemos seleccionado tres criterios de clasificación para recortar las fracciones dentro de la clase dominante ${ }^{37}$ :

1) Un primer criterio es el tamaño, que nos permite distinguir el grado de concentración económica, la capacidad de formar precios y su vinculación diferencial con la generación de empleo (y el tipo de empleo) que presentan en la post-convertibilidad, por un lado, las grandes empresas y, por otro, las pequeñas y medianas empresas (PyMEs).

2) Un segundo criterio está dado por la vinculación al mercado externo. Este criterio de corte se aplica a las grandes empresas (por su gravitación en la estructura económica en su conjunto) y se justifica por la importancia de la política de tipo de cambio internacionalmente competitivo, las drásticas modificaciones en materia de balanza comercial presenciadas en la configuración del modelo post-convertibilidad y los altos precios de los commodities existentes en el período de estudio.

3) El tercer criterio se relaciona con la inserción sectorial y la evolución de los precios relativos. Los precios expresan relaciones de fuerzas; de este modo, por ejemplo, la diferencia entre salarios (y sus distintas categorías), las canastas de precios representativas de los productores de bienes transables y las canastas de precios indicativas de los servicios parecen criterios relevantes en relación con la fundación del modelo. De hecho, destacaremos en el estudio la importancia que cobra la modificación de los precios relativos en la post-convertibilidad para dar cuenta de los nuevos rasgos tanto a nivel del modelo de acumulación como en los cambios de correlación de fuerzas.

Otro conjunto de problemas se presentan a la hora de abordar a las clases subalternas. Según Poulantzas (1985 [1973]) la clasificación de la clase obrera debería ser regida según la producción o no de plusvalor. De este modo, podemos pensar a la clase obrera como núcleo central de las clases subalternas, por su posición en la estructura. Entendemos que es en la esfera de la producción donde la explotación de la

\footnotetext{
${ }^{37}$ Si bien partimos de los agentes para la conformación de las fracciones de clase, es conveniente señalar que se tomarán como unidad de análisis para las clases dominantes a las empresas y no a los capitalistas individuales. Entendemos que ambos constituyen caminos válidos de análisis, pero a fines de nuestro problema de estudio nos parece apropiado tomar a las empresas, tanto porque en el proceso histórico muchas de las actividades que antes se encarnaban en la figura del capitalista (que era a su vez propietario como dirigente de la empresa) ahora aparecen usualmente disociadas, y la conducción económica de las empresas tiende a articularse también con las decisiones de gerentes que pueden ser o no propietarios de la misma. En este sentido, no observaremos el desempeño de los capitalistas individuales sino de las unidades económicas que son las que efectivamente dan cuenta del lugar o posición ocupada en la estructura en estrecha vinculación con el desenvolvimiento de las variables económicas. Recordemos que nuestro enfoque sostiene como criterio la primacía analítica de los lugares.
} 
fuerza de trabajo produce una plusvalía, donde el consumo productivo de la mercancía fuerza de trabajo permite generar un valor acrecentado que sobrepasa el costo de reproducción de dicha mercancía ${ }^{38}$, que es apropiado privadamente estableciendo una relación de explotación ${ }^{39}$.

Sin embargo, Poulantzas añade que los asalariados que no producen plusvalor vendrían a formar parte de una nueva pequeña burguesía, junto a la pequeña burguesía tradicional de los propietarios de pequeños establecimientos. En este punto debemos rescatar las críticas a esta clasificación realizadas por Castells (1985 [1973]) quien señala la necesidad de observar la creciente masa de asalariados que si bien no son creadores de plusvalía, sí contribuyen a la realización de la misma u otras formas de reproducción social ligadas a múltiples aparatos institucionales. Entendemos que tanto esta multitud de asalariados, así como los desocupados, si bien no son generadores

\footnotetext{
38، Conocemos ahora el modo en que se determina el valor que el poseedor de dinero le paga a quien posee esa mercancía peculiar, la fuerza de trabajo. El valor de uso que, por su parte, obtiene el primero en el intercambio, no se revelará sino en el consumo efectivo, en el proceso de consumo de la fuerza de trabajo. El poseedor de dinero compra en el mercado todas las cosas necesarias para ese proceso, como materia prima, etc., y las paga a su precio cabal. El proceso de consumo de la fuerza de trabajo es al mismo tiempo el proceso de producción de la mercancía y del plusvalor. El consumo de la fuerza de trabajo, al igual que el de cualquier otra mercancía, se efectúa fuera del mercado o de la esfera de la circulación. Abandonamos, por tanto, esa ruidosa esfera instalada en la superficie y accesible a todos los ojos, para dirigirnos, junto al poseedor de dinero y al poseedor de fuerza de trabajo, siguiéndoles los pasos, hacia la oculta sede de la producción, en cuyo dintel se lee: No admittance except on business [Prohibida la entrada salvo por negocios]. Veremos aquí no sólo cómo el capital produce, sino también cómo se produce el capital. Se hará luz, finalmente, sobre el misterio que envuelve la producción del plusvalor. La esfera de la circulación o del intercambio de mercancías, dentro de cuyos límites se efectúa la compra y la venta de la fuerza de trabajo, era, en realidad, un verdadero Edén de los derechos humanos innatos. Lo que allí imperaba era la libertad, la igualdad, la propiedad y Bentham. ¡Libertad!, porque el comprador y el vendedor de una mercancía, por ejemplo de la fuerza de trabajo, sólo están determinados por su libre voluntad. Celebran su contrato como personas libres, jurídicamente iguales. El contrato es el resultado final en el que sus voluntades confluyen en una expresión jurídica común. ¡Igualdad!, porque sólo se relacionan entre sí en cuanto poseedores de mercancías, e intercambian equivalente por equivalente. ¡Propiedad!, porque cada uno dispone sólo de lo suyo. ¡Bentham!, porque cada uno de los dos se ocupa sólo de sí mismo. El único poder que los reúne y los pone en relación es el de su egoísmo, el de su ventaja personal, el de sus intereses privados. Y precisamente porque cada uno sólo se preocupa por sí mismo y ninguno por el otro, ejecutan todos, en virtud de una armonía preestablecida de las cosas o bajo los auspicios de una providencia omniastuta, solamente la obra de su provecho recíproco, de su altruismo, de su interés colectivo. Al dejar atrás esa esfera de la circulación simple o del intercambio de mercancías, en la cual el librecambista vulgaris abreva las ideas, los conceptos y la medida con que juzga la sociedad del capital y del trabajo asalariado, se transforma en cierta medida, según parece, la fisonomía de nuestras dramatispersonce [personajes]. El otrora poseedor de dinero abre la marcha como capitalista, el poseedor de fuerza de trabajo lo sigue como su obrero; el uno, significativamente, sonríe con ínfulas y avanza impetuoso; el otro lo hace con recelo, reluctante, como el que ha llevado al mercado su propio pellejo y no puede esperar sino una cosa: que se lo curtan" (Marx, 2009: 213-214, subrayado en el original).

${ }^{39}$ Esto se debe a que es la clase capitalista quien realiza la compra de la fuerza de trabajo mediante su salario, como una mercancía más, y el valor de uso de esa fuerza que da origen a nuevo valor pertenece a dicha clase dominante, así el producto generado en el proceso del trabajo es también propiedad de los capitalistas y es enajenado de su productor, el trabajador productivo que constituye el agente fundamental e indispensable de la creación de valor.
} 
directos de plusvalor, ocupan posiciones subalternas y siguen compartiendo la característica clave del proletariado como clase: agentes desposeídos de los medios de producción que sólo tienen para vender su fuerza de trabajo.

Por otro lado, Poulantzas (2001) provee interesantes pautas para reflexionar en torno de la posición de los altos funcionarios de empresa y su clivaje de clase. Según su óptica, los altos funcionarios de las empresas deben ser entendidos como parte de la clase dominante por su ejercicio de control y gestión del proceso de explotación del trabajo. Aún cuando perciban un salario, expresan una personificación de funciones de clase dominante. En este punto se nos presenta un problema metodológico, un problema de fuentes: en las estadísticas oficiales no se distingue claramente este conjunto de agentes sino que aparecen englobados dentro de los trabajadores privados, y aunque podemos suponer que son quienes representan el núcleo de más altos ingresos dentro de los mismos, ejercen un efecto distorsivo a la hora de pensar la distribución funcional del ingreso. Aún así, vale la pena dejar constancia de dicha advertencia conceptual. Aunque será relevante establecer las distintas evoluciones salariales de las diferentes categorías laborales con el fin de observar la heterogeneidad creciente dentro de las clases subalternas así como comprender más cabalmente su lugar y características en el modelo post-convertibilidad, también conviene tener presente la subalternidad como un todo. Así, el concepto de capital como relación social en Marx es porque éste nos permite dilucidar la relación de explotación, en particular, y la subalternidad en las posiciones, en general. Como señala Olin Wright (1994) es una parte fundamental del aporte teórico del marxismo promover el análisis de clase definiendo a las mismas a partir de las relaciones de producción, tanto porque trascendiendo incluso los límites históricos del capitalismo busca construir una perspectiva que coloque a la lucha de clases como motor de la historia, como porque permite subrayar la vinculación de clase y explotación. Esto implica que más allá de la estratificación salarial y de los fenómenos de movilidad social de los agentes dentro de los puestos o lugares, analizar la estructura implica comprender la primacía de los lugares en la reproducción ampliada de las clases sociales, cuál es la evolución histórica efectiva de esas posiciones de clase y cómo éstas se articulan con la creación, apropiación y acumulación de la plusvalía en forma de capital.

Finalmente, destacamos que el recorte de fracciones elegido no agotará la totalidad de colectivos de agentes posibles, sino que serán construcciones analíticas 
creadas según su relevancia explicativa para el abordaje del modelo de acumulación y que se vinculan tanto con la acción estatal a partir de las políticas centrales que alteran las reglas de juego, así como variables económicas de desempeño y estructurales. Recordamos que la preeminencia del modelo de acumulación como unidad de análisis fundamental de la investigación es la guía a partir de la cual se articula el entramado conceptual presentado (ver Gráfico 1). Así podemos arrojar una definición sintética, sosteniendo que un modelo de acumulación es un recorte espacio-temporal del proceso de reproducción ampliada del capital en el cual se observan un conjunto de relaciones sociales regulares que interactúan de modo relativamente coherente entre sí durante un período determinado, relaciones ligadas a tres núcleos constitutivos fundamentales: las políticas económicas, las variables económicas y las fracciones de clases. A su vez un modelo se diferencia de otro por el distinto orden de prelación de las relaciones y variables que aparecen como relevantes y características del modelo de acumulación en estudio.

Gráfico 1. Esquema conceptual del modelo acumulación

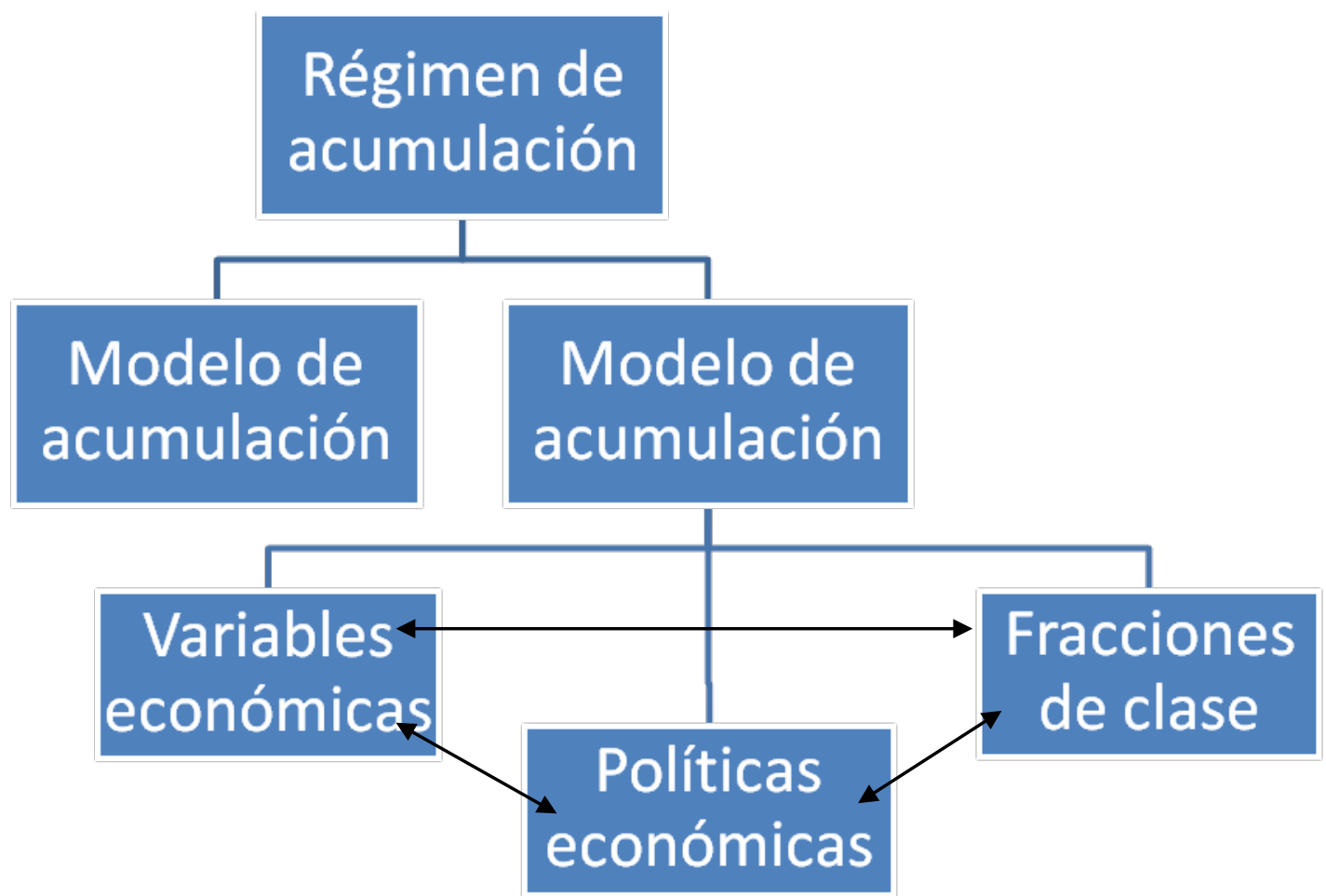


En una breve descripción del esquema sobre el modelo de acumulación, podemos observar la interacción entre sus distintos componentes. Por un lado, las variables económicas condicionan la emergencia y posibilidad de éxito de las políticas, es decir, son parte de los condicionantes que la acción estatal debe tener en cuenta, ya sea para reproducir el estado de dichas variables o para intentar su modificación. Al tiempo que las variables (sobre todo las económico-estructurales) constituyen datos previos, también la intervención estatal a través de las políticas económicas ejerce transformaciones en dichas variables (principalmente de las variables de desempeño, requiriendo plazos y esfuerzos mayores para la modificación de aquellas más estructurales). Por otra parte, las políticas marcan el campo de acción de los agentes económicos conglomerados en fracciones de clases estableciendo un conjunto de “reglas de juego”, gravando y beneficiando diferencialmente, por ejemplo, a través de las políticas tributarias y del gasto público. A su vez, las fracciones condicionan a las políticas públicas tanto a través del poder estructural de las distintas fracciones (su incidencia por ejemplo, sobre la inversión, el empleo, el manejo de divisas, etc.) así como a través de las presiones corporativas y políticas que pudieran promover. Finalmente, estas fracciones de clases se encuentran condicionadas (ya sea favorable o desfavorablemente para unas y otras) por un estado dado de la economía expresado en las variables, y deben tenerlas en cuenta para trazar sus estrategias de reproducción, al tiempo que las fracciones pueden incidir, a través de su poder estructural en las variables económicas mismas.

\subsection{Una aproximación a la teoría gramsciana de la hegemonía y sus vínculos con el enfoque de análisis del modelo de acumulación}

En un primer acercamiento al concepto de hegemonía podríamos señalar que el mismo remite (ya en su antecedente leninista ${ }^{40}$ ) a la dirección política, que en Gramsci es

\footnotetext{
${ }^{40}$ En Lenin, la hegemonía remite a la conducción política de una clase sobre las otras, para lo cual implica superar una fase gremial, corporativista, para convertirse en la dirección política del conjunto de las clases subordinadas. Usualmente se hacía referencia a la necesidad de la hegemonía del proletariado sobre el conjunto de las clases subordinadas en el marco del proceso revolucionario ruso.
} 
también dirección ideológico-cultural de un grupo social sobre otros ${ }^{41}$. La hegemonía es entonces una relación social que atraviesa distintas dimensiones: parte de una base material ligada a la posición de las clases en la estructura, y se realiza en las superestructuras, a través de una concepción del mundo que encarna la visión general y expresa los intereses del grupo dirigente, al tiempo que se plasma de formas diversas en el sentido común, en las prácticas cotidianas y, en su momento más desarrollado, en un tipo particular de Estado (Gramsci, 2003, 2008). De este modo el concepto de hegemonía provee una herramienta analítica que permite el abordaje de problemáticas de índoles diversas ligadas a la lucha de clases, siendo esta lucha el terreno de su conformación.

En primera instancia, señalamos que la construcción de hegemonía contiene un sustrato material vinculado a la estructura. Como sostiene Campione, "no hay hegemonía sin base estructural, la clase hegemónica debe ser una clase principal de la estructura de la sociedad, que pueda aparecer como la clase progresiva que realiza los intereses de toda la sociedad” (2007:75). Esto se vincula a que Gramsci (2008) concibe las sociedades en términos de bloque histórico, que se define por una relación de reciprocidad, un proceso dialéctico real, entre la estructura y las superestructuras, entendidas éstas como un conjunto complejo, contradictorio y discorde, que expresan el conjunto de las relaciones de producción, sin ser ellas un mero "resultado" sino un compuesto de distintos elementos políticos, jurídicos, ideológicos y culturales con entidad propia y, asimismo, capacidad de incidencia sobre la dimensión estructural misma. Gramsci sostiene que "la pretensión (...) de presentar exponer cada fluctuación de la política y la ideología como una expresión inmediata de la estructura, debe ser combatida teóricamente como un infantilismo primitivo, y prácticamente con el testimonio auténtico de Marx” (2008:104).

En este camino, rescata una y otra vez la cita de Marx que señala que es en el plano de la ideología en que los hombres toman conciencia de los conflictos en la estructura $^{42}$ y le da un valor gnoseológico, lo convierte en método de análisis. Gramsci

\footnotetext{
${ }^{41}$ Además, Gramsci no piensa sólo en la hegemonía de la clase trabajadora sino también para analizar cómo la dominación de la burguesía traspasa el momento de la coerción y se convierte en dirección sobre las clases subalternas.

${ }^{42}$ Este señalamiento de Gramsci acerca de la ideología como terreno de toma de conciencia sobre los conflictos en la estructura nos plantea una serie de problemáticas teóricas tanto sobre el lugar del conflicto como acerca de los conceptos de contradicción y antagonismo que serán abordados en el capítulo siguiente.
} 
(2008) critica la noción peyorativa de ideología que había arraigado en el marxismo y que identificaba a toda ideología como mera apariencia o falsa conciencia. Sostiene que este error proviene de que solía denominarse ideología tanto a una superestructura que posee correspondencia necesaria a una estructura dada, como también a meras elucubraciones arbitrarias de determinados individuos. En este sentido, el error opera al identificarse una ideología no orgánica a la estructura (o arbitraria), sostener que no son las ideologías las que modifican la estructura sino al revés, y entonces afirmar que una solución política es “ideológica”, en el sentido de ser insuficiente para modificar una estructura, y así se pasa a pensar toda ideología como pura apariencia, inútil. Gramsci distingue entre un tipo de ideologías que él llama "históricamente orgánicas", estrechamente ligadas a determinada estructura, y las separa de las ideologías “arbitrarias”, observando que las ideologías históricamente orgánicas organizan masas, forman conciencia e inciden en la lucha, mientras que las arbitrarias sólo crean movimientos individuales y polémicas. A su vez, Gramsci subraya afirmaciones de Marx que señalan que una persuasión popular tiene a menudo la misma energía que una fuerza material ${ }^{43}$.

El análisis de la hegemonía va a implicar entonces distintos momentos que Gramsci plasma en diversos escritos. En virtud de nuestro problema de estudio, procuraremos construir a hegemonía en una herramienta conceptual que nos permita profundizar la investigación del proceso de acumulación capitalista y en este sentido alumbraremos determinadas zonas de la teoría gramsciana articulando dichos elementos con nuestro enfoque en torno al modelo de acumulación. Si entendemos que el bloque histórico configura un concepto de totalidad de la teoría en tanto articulación orgánica de la estructura y las superestructuras, observaremos que el modelo de acumulación, que está conformado por distintos núcleos estructurales y superestructurales, atraviesa las dimensiones orgánicamente unidas del bloque histórico al tiempo que es una parte menor del mismo. En este sentido cobrará relevancia, en el tercer capítulo, el abordaje de la crisis de 2001 como principio de crisis orgánica, en tanto la misma implica un sacudimiento del bloque histórico, y es en ese año, que actúa de preludio de nuestro

\footnotetext{
${ }^{43}$ En este sentido, Gramsci (2008) sugiere pensar al bloque histórico teniendo en cuenta que las fuerzas materiales son su contenido y las ideologías la forma, correspondencia visible en que las fuerzas materiales no serían concebibles históricamente sin forma y las ideologías serían caprichos individuales sin la fuerza material.
} 
período de estudio, donde se termina de producir el colapso del modelo de la convertibilidad y se gestan las condiciones para la emergencia de un nuevo modelo.

En el desarrollo de la red conceptual hay un punto, previamente mencionado, que es de radical relevancia para la totalidad de nuestra investigación y que contiene en su interior algunos factores nodales que establecen tanto el vigor como las tensiones centrales del conjunto de dimensiones que procuran ser articuladas en nuestra tesis: este punto refiere al análisis de relaciones de fuerzas. Como vimos, el pensamiento gramsciano nos convoca a indagar tres momentos. Un primer momento estructural de las relaciones de fuerza ligado a la posición de los grupos sociales y a la función que cumplen en la producción. El segundo momento refiere a la relación de fuerzas políticas, que Gramsci ve vinculado al grado de homogeneidad, conciencia política colectiva y organización, y que posee distintas gradaciones: a) un grado económicocorporativo, basado en una solidaridad que se limita al grupo profesional; b) un grado más avanzado de conciencia, solidaridad y organización que se extiende a todo el grupo social, pero aún en el plano netamente económico; y c) un grado superior, estrictamente político:

\footnotetext{
"que señala el pasaje neto de la estructura a la esfera de las superestructuras complejas. Es la fase en la cual las ideologías ya existentes se transforman en "partido", se confrontan y entran en lucha, hasta que una sola de ellas, o al menos una sola combinación de ellas, tiende a prevalecer, a imponerse, a difundirse por toda el área social; determinando además de la unidad de los fines económicos y políticos, la unidad intelectual y moral, planteando todas las cuestiones en torno a las cuales hierve la lucha, no sobre un plano corporativo, sino sobre un plano "universal" y creando así la hegemonía, de un grupo social fundamental, sobre una serie de grupos subordinados. El Estado es concebido como organismo propio de un grupo, destinado a crear las condiciones favorables para la máxima expansión del mismo grupo; pero este desarrollo y esta expansión son concebidos y presentados como la fuerza motriz de una expansión universal, de un desarrollo de todas las energías "nacionales". El grupo dominante es coordinado concretamente con los intereses generales de los grupos subordinados y la vida estatal es concebida como una formación y una superación continua de equilibrios inestables (en el ámbito de la ley), entre los intereses del grupo fundamental y los de los grupos subordinados; equilibrios en donde los intereses del grupo dominante prevalecen pero hasta cierto punto, o sea, hasta el punto en que chocan con el mezquino interés económico-corporativo.” (Gramsci, 2003:57-58, el subrayado es nuestro)
}

Es este momento estrictamente político de las relaciones de fuerzas el que nos permite pensar la emergencia del kirchnerismo como fuerza política hegemónica que conforma de manera más acabada una unidad de fines políticos y económicos y una unidad ideológica que se expanden en Argentina hasta prevalecer sobre el resto. Es esta unidad la que nos permite pensar tres factores claves de nuestro problema de estudio: 
1. el proyecto político-económico de gobierno como matriz ideológica de la fuerza hegemónica que enuncia la unidad de fines políticos y económicos y, en este camino, sirve de sustrato para la generación de las políticas que inciden en el modelo de acumulación,

2. la conformación misma del kirchnerismo como cultura política, que expresa una subsuelo doctrinal en tanto lectura común del pasado y de la sociedad futura a construir, constituyendo un espacio codificado de representaciones, símbolos y valores a partir de una reformulación particular de la cultura política peronista (de la cual es parte y es tributaria), procurando imprimir esta dirección ideológico-cultural (esta “reforma intelectual y moral”), al tiempo que proyecta su estrategia de dirección política.

3. esta ideología que modela la cultura política kirchnerista será observada en su gestación tal como señala Gramsci: "planteando todas las cuestiones en torno a las cuales hierve la lucha”. Entendemos que el kirchnerismo emerge de cara a la crisis de 2001, afronta las distintas dimensiones involucradas en esta crisis, retoma varias de sus demandas y se plantea a sí mismo como momento de sutura y superación.

Consideramos que estos tres factores constituyen piezas de singular importancia y nos proponemos su análisis con el fin de comprender la hegemonía kirchnerista. Fenómeno que, como señalara Bonnet al analizar la hegemonía menemista, remite a la constitución de una nueva hegemonía política más o menos duradera, lo suficientemente sólida como para servir de marco tanto a triunfos electorales como a transformaciones profundas y perdurables (Bonnet, 2008).

Finalmente, cabe mencionar que Gramsci (2003) señala la existencia de un tercer momento de las relaciones de fuerzas, el de las fuerzas militares, que puede ser inmediatamente decisivo según las circunstancias, y que posee dos niveles: uno técnicomilitar ligado a las condiciones objetivas de las fuerzas, su tamaño, su organización, su armamento, etc. y un nivel político-militar, que refiere a la capacidad de desplegar formas de acción política que sean eficientes para disgregar "íntimamente” la eficacia militar del enemigo (por ejemplo, desmoralizándolo), o acciones de masas a lo largo de todo el territorio que lleven a diluir y dispersar buena parte de su capacidad bélica. Este momento, clave en otras épocas de la historia Argentina, no presenta hoy mayor relevancia para la investigación de nuestro problema de estudio. 
En este punto se observan tanto las vastas implicancias que una perspectiva analítica en términos de hegemonía puede abarcar, como asimismo el punto específico, la dimensión propia donde se centra dicho recorrido: la dimensión superestructural, en su grado estrictamente político, que está soldada a la realización de una concepción del mundo, a una reforma intelectual y moral que se plasma en acción, en dirección de un grupo social sobre otros.

En este sentido, Gramsci (2008) señala que la instauración y realización de una nueva hegemonía se vincula con la creación de un nuevo terreno ideológico implicando una reforma de la conciencia y de los métodos de conocimiento, realiza una nueva concepción del mundo y así introduce una nueva moral y una reforma de la filosofía. Es en este punto donde huelga una aclaración teórica relevante para la tesis en su conjunto: Gramsci está pensando en un proceso revolucionario donde se gesta un nuevo Estado a partir de la hegemonía de una clase antagónica a la previamente dominante, pero ¿qué ocurre cuándo se producen cambios al interior de las clases dominantes y en su relación con las clases subalternas, sin por ello conllevar un proceso de revolución social? Ésta es la pregunta acerca de cómo analizar las transformaciones al interior de una sociedad capitalista que cambia de modelo de acumulación sin dejar de ser capitalista, pero que sí conlleva fuertes cambios en los procesos de reproducción estructurales y superestructurales de la sociedad. Entendemos que el pensamiento gramsciano contiene igualmente una potencia palpable también en esto, visible en sus extensos análisis sobre las transformaciones de las sociedades de su tiempo, sobre la emergencia del americanismo y el fordismo, así como del fascismo, indagando cómo distintas configuraciones políticas, económicas y culturales dan lugar a cambios significativos sin alcanzar a romper la matriz de dominación de clase.

Volviendo al hilo argumentativo general de la propuesta gramsciana, se sostiene que el grupo social en ascenso hegemónico debe cobrar conciencia, organizarse en instituir una concepción de la realidad homogénea y sistemática que pueda universalizarse, es decir, ser tomada por otros grupos sociales como propia. Una nueva ideología debe contener elementos críticos del sentido común, entendido como concepción del mundo absorbida acríticamente de numerosos ambientes culturales en los cuales se desarrolla la individualidad moral del hombre medio, una concepción del mundo disgregada e incoherente (generalmente incongruente respecto de la posición social y cultural de las multitudes). La formación de un grupo social homogéneo se 
articula con la elaboración de una filosofía, desarrollada también contra el sentido común, por ser homogénea y sistemática ${ }^{44}$. Según Gramsci (2008), el nexo entre sentido común y filosofía se encuentra garantizado por la política. Esto implica que el ascenso hegemónico de un grupo social, al fundar una nueva cultura, incide en el sentido común (que Gramsci también identifica como la “filosofía” de las masas), hace que los grupos sociales subalternos participen progresivamente de su particular concepción del mundo. Pero también implica que para hacerlo ha de superar el momento de la mera dominación por coerción para alcanzar el momento hegemónico, caracterizado por el consenso. Esto es posible en tanto la dirección intelectual y moral sobre los otros grupos ejerce, a su vez, una influencia sobre sus prácticas cotidianas. Y, asimismo, un elemento indispensable de este proceso es la homogeneización de la conciencia del grupo dominante a partir de una filosofía, de un pensamiento sistemático y organizado. Como señala Portelli (1987), la política afirma la unidad ideológica del bloque histórico, ya que dota de coherencia a la multiplicidad disgregada de visiones que componen el sentido común.

Algunos de estos factores procuraremos abordar a lo largo de la tesis. Así, observamos la relevancia que posee el análisis de la ideología kirchnerista en tanto su discurso confronta con un conjunto de factores en crisis de la ideología neoliberal que habían sido puestos en jaque por el creciente proceso de conflictividad social que había atravesado la Argentina, una crisis que conllevó el avance de las disputas desde diversas organizaciones ligadas a las clases subalternas así como crecientes disrupciones y disputas al interior de las clases dominantes en torno al proyecto de salida del modelo de la convertibilidad entonces vigente. Esta ideología se constituye en proyecto de gobierno, expresando la unidad de fines políticos y económicos de la estrategia hegemónica.

Como sostuvimos, si bien una construcción de hegemonía posee anclajes estructurales, su momento específico es el momento político. En este sentido, el concepto de hegemonía debe ser entendido en relación a la estrategia política. Esta articulación es desplegada por Gramsci a partir del análisis que realiza de dos tipos de

\footnotetext{
${ }^{44}$ Como señala Portelli (1987), la filosofía es el estadio más elaborado de una concepción del mundo, el nivel donde aparecen más claramente las características de la ideología como expresión cultural de la clase fundamental.
} 
sociedades disímiles en cuanto al grado de desarrollo de la sociedad civil ${ }^{45}$ y el peso del Estado, a las que corresponderán dos estrategias revolucionarias diferentes. Denomina Oriente y Occidente a los dos tipos de sociedades: "En Oriente el Estado era todo, la sociedad civil era primitiva y gelatinosa; en Occidente, entre Estado y sociedad civil existía una justa relación y bajo el temblor del Estado se evidenciaba una robusta estructura de la sociedad civil. El Estado sólo era una trinchera avanzada, detrás de la cual existía una robusta cadena de fortalezas y casamatas” (Gramsci, 2003:83). Encontramos entonces en Oriente un Estado preponderante y un escaso desarrollo de la sociedad civil, mientras que en Occidente la sociedad civil se ha complejizado y ha desarrollado diversas instancias que resguardan al orden establecido.

A partir de esta caracterización, Gramsci piensa las distintas estrategias políticas a llevar adelante según el tipo de sociedad, para lo que utiliza una analogía entre la guerra militar, a partir de las experiencias dejadas por la Primer Guerra Mundial, y la lucha política. La estrategia a desarrollar en Oriente es la del ataque frontal, la guerra de maniobras o de movimientos, como resume Piotte: "En la guerra de movimientos, la artillería se utiliza para abrir una brecha en las defensas del enemigo, brecha que sea suficiente para hacer posible la irrupción de las tropas y conseguir un éxito estratégico importante, si no definitivo” (1973:91). Es decir, que en las sociedades con escaso desarrollo de la sociedad civil la estrategia política revolucionaria puede triunfar a partir del ataque frontal contra la clase dominante teniendo en cuenta que la destrucción del aparato estatal y de las fuerzas militares del enemigo garantizarían de modo casi concluyente el triunfo; esta sería la estrategia practicada victoriosamente en la Revolución Rusa. En una formación social sin gran desarrollo de su sociedad civil y con una vida centrada alrededor del Estado, la confrontación abierta y directa contra la dirección de ese Estado (en este caso la exterminación del zarismo y sus instituciones) sumado a la derrota de sus fuerzas militares, en un contexto de crisis signado por la guerra mundial, fue suficiente para un avance decisivo de las fuerzas revolucionarias.

Sin embargo esta estrategia es inadecuada en Occidente donde el Estado puede considerarse la trinchera más avanzada, pero la sociedad civil posee capacidad de reconstrucción del sistema hegemónico. En este caso la estrategia a aplicar es la guerra

\footnotetext{
${ }^{45}$ La sociedad civil remite a los espacios “privados” de participación voluntaria o que también podrían ser pensados como ámbitos de vida pública no estatal (en sentido estricto), tales como sindicatos, iglesias, medios de comunicación, centros de fomento, entre otros.
} 
de posiciones, que es la lucha por la hegemonía previa a la conquista del Estado, requiere de esfuerzos prolongados y de gran cantidad de recursos humanos y materiales, porque, en términos militares, la guerra de posiciones incluye tanto las trincheras, como el sistema organizativo e industrial y las fuentes de reabastecimiento. Esto debe ser traducido a la política, ya que en

\footnotetext{
"los Estados más avanzados, donde la "sociedad civil" se ha convertido en una estructura muy compleja y resistente a las "irrupciones" catastróficas del elemento económico inmediato (crisis, depresiones, etc.); las superestructuras de la sociedad civil son como el sistema de trincheras en la guerra moderna. Así como en este ocurría que un encarnizado ataque de la artillería parecía destruir todo el sistema defensivo adversario, cuando en realidad sólo había destruido la superficie exterior y en el momento del ataque y del avance los asaltantes se encontraban frente a una línea defensiva todavía eficiente, lo mismo ocurre en la política durante las grandes crisis económicas” (Gramsci, 2003:81).
}

En primer lugar, entendemos que Argentina forma parte plena del tipo de sociedad que Gramsci clasifica como Occidente, el amplio grado de desarrollo de la sociedad civil a lo largo del siglo XX es prueba sobrada de esto. Y es así cómo el análisis de la estrategia política en nuestro período de estudio debe ser visto a la luz de la "guerra de posiciones”. Esto implica una apreciación compleja de los distintos factores políticos, económicos y culturales que se articulan en la construcción de hegemonía. Si bien un análisis completo de este proceso excede los fines de nuestra tesis, nos avocaremos a vislumbrar los factores cardinales de este proceso que asisten y conforman de modo constitutivo el desarrollo del modelo de acumulación. En este sentido, debemos notar que la construcción de hegemonía como guerra de posiciones adquiere formas particulares cuando ya no es "previa” a la conquista del Estado, sino cuando se ejerce también "desde" el Estado. Esto implica vislumbrar un proceso de construcción hegemónica que combina de forma singular dinámicas provenientes tanto de la sociedad política como de la sociedad civil. En relación a nuestro problema de estudio, enfocamos el análisis de la hegemonía en la fuerza que conduce el Estado, por lo que identificaremos distintos elementos de la estrategia política desplegada por dicha fuerza política que nos permitan comprender las características del proyecto de gobierno desplegado, la unidad de fines políticos y económicos, y que en el modelo de acumulación se expresa a través del componente de las políticas.

En segundo lugar, es importante resaltar que la reflexión de Gramsci contiene una fuerte crítica al economicismo que procuramos hacer propia, sin por ello negar la importancia que posee la dimensión económica en nuestra investigación. Esta crítica se 
encuentra presente, por ejemplo, en relación al trabajo de Rosa Luxemburgo "Huelga de masas, partido y sindicato”, donde la superestructura política e ideológica aparece como mero reflejo inmediato de la estructura económica, en ese sentido se plantea que la crisis económica abre la posibilidad de asalto al poder (o sea, que la crisis económica sería un escenario propicio para el triunfo a través de la guerra de maniobras). Gramsci critica esta lectura tanto porque reduce la lucha política al contexto económico como porque se basa en una caracterización errada del tipo de sociedad y de la estrategia necesaria para el desarrollo de un proceso revolucionario. En vinculación a nuestro problema de estudio, sostenemos que la crisis de 2001 no comportó únicamente una crisis económica, y que el posterior desenvolvimiento político-económico no debe reducirse sólo a ella. Es por esto que plantearemos la hipótesis de pensar a la crisis de 2001 como un principio de crisis orgánica, para lo cual indagaremos un conjunto amplio de factores que involucra, y también sus limitaciones respecto del conjunto de elementos que Gramsci identifica en una crisis orgánica plena ${ }^{46}$.

Como ya dijimos, en contraposición a la estrategia del ataque frontal como estrategia revolucionaria a ser desarrollada en Oriente ${ }^{47}$, Gramsci entiende necesario el despliegue, en las sociedades de tipo occidental, de la estrategia de la guerra de posiciones, que como señala Buci-Glucksmann, "responde a una nueva fase histórica que exige una estrategia de largo aliento, un asedio permanente al adversario, una concentración inaudita de hegemonía que es, también, una nueva forma de hacer política” (1978:310). La guerra de posiciones es la lucha por la hegemonía, es su construcción en las sociedades complejas: así se explicita el nexo entre hegemonía y estrategia política.

La hegemonía se relaciona con el carácter dual de la acción política, que Gramsci ve en Maquiavelo, correspondiente "a la doble naturaleza del Centauro maquiavélico, de la bestia y del hombre, de la fuerza y del consenso, de la autoridad y de la hegemonía” (Gramsci, 2003:48). Podemos entender entonces que la hegemonía,

\footnotetext{
${ }^{46}$ Es en este sentido que sostenemos la caracterización de la crisis de 2001 como un "principio" de crisis orgánica, ya que muchos de sus factores se encuentran presentes, pero no como una crisis orgánica en su completitud.

${ }^{47}$ Es necesario aclarar también que Gramsci no niega la importancia de la guerra de maniobras para Occidente, pero ésta se convierte en un elemento parcial y táctico que depende de la estrategia de la guerra de posiciones; como señala Campione, Gramsci critica aquí “uno de los errores ultraizquierdistas más clásicos: el querer destruir una construcción social hegemónica por medio de la pura fuerza militar, ignorando la importancia de la lucha cultural” (Campione, 2006:35).
} 
como sintetiza Campione, es "el predominio intelectual y moral, diferente del “dominio” en el que se encarna el momento de la coerción, pero esa “dirección” tiene raíces en la base, componentes materiales junto a los “espirituales”. Es una acción con elementos tanto “materiales” como “ideales”” (2006:31). Como ya señalamos, no hay hegemonía sin base estructural, por lo que la clase hegemónica debe ser una clase principal de la estructura de la sociedad, que, asimismo, pueda aparecer como la clase progresiva que realiza los intereses de toda la sociedad. Así la clase dominante debe superar sus intereses meramente corporativos, articularlos con ciertas concesiones a otros grupos sociales para devenir en clase dirigente, en clase hegemónica. Al mismo tiempo, construye y difunde una concepción del mundo que se va constituyendo en sentido común, y de la que participan los grupos sociales subalternos, otorgando adhesión y legitimidad al orden social.

Aquí se nos plantea una tensión que mencionáramos al comienzo de este capítulo: el problema de construcción de las fracciones de clase y la relación con el Estado. Vemos en el marxismo clásico una tendencia a pensar los grandes movimientos estructurales de la historia en términos del modelo dicotómico de clases fundamentales en el capitalismo burguesía/proletariado, y ver en la fuerza política que conduce al Estado como una expresión de la burguesía, en tanto, como sostienen Marx y Engels en El Manifiesto Comunista, cuando la burguesía conquista el poder político a través de la forma de Estado representativo moderno "el Poder público viene a ser, pura y simplemente, el Consejo de administración que rige los intereses colectivos de la clase burguesa” ([1948] 1960:19). Asimismo, a la hora de analizar las dinámicas singulares de un proceso histórico situado en una sociedad contemporánea compleja debemos procurar alejarnos de toda simplificación y reduccionismo, en virtud de los diversos factores que deben ser tenidos en cuenta para abordar el problema de estudio planteado. Si bien, como señala Jessop, resulta imposible aprehender una teoría unificada sobre el Estado en Marx y Engels, ya que ellos “adoptaron diversas aproximaciones y razonamientos de acuerdo a los problemas con los que se veían periódicamente enfrentados pero no intentaron ninguna sistematización en sus diferentes formas de análisis” (1982:33), sí nos parece necesario sostener una mirada crítica sobre las lecturas meramente instrumentalistas que podrían erigirse del mismo. Como define Jessop, “el enfoque instrumentalista implica simplemente la afirmación de que el Estado no es un sujeto político independiente y soberano sino un instrumento de coerción y 
administración que puede ser usado para diversos propósitos por cualquier interés que consiga apropiarse de él” (1982:14). Sin caer en el error opuesto de pensar al Estado como independiente y soberano, es preciso desvincularse de las connotaciones ora economicistas, ora voluntaristas, que podrían alcanzarse extremando los supuestos de la visión instrumentalista ${ }^{48}$. Por ejemplo, si bien uno puede observar o imaginar períodos en nuestra historia donde los grupos más concentrados de las clases dominantes actuaron al unísono con el Estado en una ofensiva contra las clases subalternas y ver la fuerte articulación que nos permita pensar cómo determinada clase, fracción o conjunto de ellas, se vuelve hegemónica, usualmente en un contexto donde se achican los márgenes de autonomía relativa del Estado ${ }^{49}$, nos preguntamos, por otra parte, ¿qué ocurre cuando la construcción de hegemonía se realiza ampliando los márgenes de autonomía relativa? Ésta será uno de nuestros interrogantes centrales para pensar al kirchnerismo ${ }^{50}$.

Existe un segundo tipo de tensión que versa sobre la relación entre clase y hegemonía. Por un lado, construimos clases partiendo de la estructura, según su posición y función en la producción, aunque las clases rebasan la dimensión estructural y se dan en su dimensión histórica en el terreno de la lucha de clases, atravesadas por relaciones de fuerzas. Por otro lado, ubicamos la hegemonía en el momento político de las superestructuras, pero que también las rebasa y no puede ser pensada sin sus anclajes estructurales. ¿Cómo es entonces este vínculo entre clase y hegemonía?

En este punto se nos plantean dos aportes teóricos de Gramsci que son cruciales para comprender esta relación: el papel de los intelectuales y el del partido o fuerza política (Príncipe moderno); teniendo en cuenta que es el bloque histórico en tanto concepto de totalidad el centro en el cual se resuelve teóricamente dicha tensión. Esto se

\footnotetext{
${ }^{48}$ Nos referimos a los derivados economicistas de reducir al Estado a ser mero gestor inmediato de tal o cual clase o fracción, y a los derivados voluntaristas de pensar al Estado como independiente y neutral capaz de ser usado sin mayores problemas por la fuerza que lo conduzca (lo cual se encuentra, como señala Jessop, en la base de las posiciones socialdemócratas).

${ }^{49}$ Esto puede ser pensado para determinados momentos durante la última dictadura militar (aunque en este caso se haya dado una clara primacía de los elementos de coerción por sobre los hegemónicos) o en el menemismo, que logró establecer una fuerte hegemonía en base a concepciones del mundo de matriz neoliberal.

${ }^{50}$ Vale recalcar que en nuestro enfoque retomamos elementos de autores como Gramsci y Poulantzas, que Jessop incluye, a nuestro entender erróneamente, en un grupo que definiría al Estado como factor de cohesión. Decimos erróneamente, porque consideramos que lo que articula a ambos autores y aparece como su principal aporte no es el factor cohesionante del Estado (si bien este es uno de sus factores, dependiendo también de la coyuntura histórica) sino el rol del Estado ligado a la construcción de hegemonía en las sociedades complejas (el "Occidente” de Gramsci).
} 
debe a que, como señala Portelli (1987), el bloque histórico es el vínculo orgánico entre la estructura y las superestructuras y en ese camino Gramsci da una expresión concreta a este vínculo: los intelectuales, el problema de la lucha ideológica y la estrategia política. Pero no hay lucha ideológica ni política sin fuerza política, y aquí entra en escena el Príncipe moderno gramsciano. De hecho, en el pensamiento de Gramsci, Príncipe moderno e intelectuales comparten un mismo núcleo, un mismo rol orgánico: la dirección ideológico-cultural ("reforma intelectual y moral”) y la dirección política (construcción de una "voluntad colectiva") ${ }^{51}$.

El Príncipe moderno tiene origen en las lecturas que Antonio Gramsci realiza sobre El Príncipe de Maquiavelo (1995 [1513]) a la luz de las necesidades del movimiento revolucionario de su tiempo y su lugar. Podemos encontrar en el Príncipe dos cualidades esenciales que serán constitutivas de la concepción gramsciana del Príncipe moderno: se trata de un "libro viviente", un manifiesto político, "en el que ideología política y ciencia política se fundan en la forma dramática de "mito"” (Gramsci, 2003:9), y es la fuerza política que lleva adelante la tarea histórica de fundar un nuevo Estado. El Príncipe en Maquiavelo es la personificación simbólica de la voluntad colectiva que procura la concreción de un fin político para el cual deberá ser un instrumento de instrucción y convencimiento "que intenta realizar la educación política de (...) la clase revolucionaria de su tiempo, el “pueblo” y la “nación” italiana” (Gramsci, 2003:17) con el objetivo de proveer los medios para la realización de ese fin político. Así también, Gramsci avanza en la configuración del Príncipe moderno partiendo de este mismo esquema: el nuevo príncipe será un manifiesto político, un "libro viviente", ya que para Gramsci, como afirma Portantiero, "la posibilidad de transformar un pensamiento sobre la política en acción política devenía de la capacidad de construir una ideología-mito” (2000:151). Por otra parte, el Príncipe moderno, que no es un héroe individual, "sólo puede ser un organismo, un elemento de la sociedad complejo en el cual comience a concretarse una voluntad colectiva reconocida y afirmada parcialmente en la acción. Este organismo ya ha sido dado por el desarrollo histórico y es el partido político” (Gramsci, 2003:12).

\footnotetext{
${ }^{51}$ En este camino realizaremos un breve pasaje por la concepción gramsciana del Príncipe moderno para luego abordar el tema de los intelectuales, quiénes son y qué rol juegan en la construcción de hegemonía. Así observaremos el rol fundamental que afronta el Príncipe moderno construyendo hegemonía, que implica constituirse en dirección política, a través de la organización de la voluntad colectiva, y en la dirección cultural, a través de la reforma intelectual y moral, tareas todas que veremos como constitutivas también de los intelectuales.
} 
La centralidad del mito se vincula con la función de “creación de una fantasía concreta que actúa sobre un pueblo disperso y pulverizado para suscitar y organizar su voluntad colectiva” (Gramsci, 2003:10). En este sentido, el Príncipe moderno debe movilizar las pasiones, volverse pueblo en la construcción de una voluntad colectiva a partir de la articulación de los grupos sociales subalternos, dando origen a una fuerza social y política transformadora que avance en un proceso de acumulación de fuerzas hacia la creación de un nuevo Estado.

La noción de Príncipe moderno nos aporta, en sus dos acepciones, algunos elementos valiosos para reflexionar sobre nuestro problema de estudio, requiriendo a su vez de un conjunto de apreciaciones y matizaciones. La primera distancia y factor principal que debe tenerse en cuenta es que, nuevamente, Gramsci, partiendo de una perspectiva de transformación radical de la sociedad ve en la subversión de la estructura de clases un elemento nodal de la misma. Si bien compartimos esta mirada, entendemos que para el estudio de casos en los cuales se generan un cúmulo de transformaciones sin presentar las mismas un proceso revolucionario en términos clasistas, existen, como veremos en el siguiente capítulo, diversos aportes de autores posteriores, principalmente de Ernesto Laclau, que permiten avanzar en sistematizar y operacionalizar una estrategia analítica en términos de hegemonía como lógica política (especialmente por su análisis a partir de la categoría de populismo), aunque contra Laclau, sostendremos la importancia central de las clases sociales en el análisis de los procesos políticoeconómicos contemporáneos.

Según Gramsci, el carácter de libro viviente está dado por ser un manifiesto político que, sin ser un tratado sistemático, apela al mito para movilizar y organizar la voluntad colectiva de un pueblo, abordando en su análisis las problemáticas que requieren ser esclarecidas para la concreción de determinado fin político, que tanto en Gramsci como en Maquiavelo refiere a la necesidad de construcción de un nuevo Estado, así como también las formas organizativas y estrategias para su consecución. En nuestro caso, buscaremos en el discurso presidencial la piedra angular de la configuración de una ideología, componente clave de la construcción identitaria que conforma una cultura política. En el abordaje del discurso presidencial veremos la construcción de ese "nosotros" constitutivo de toda identidad que se da al tiempo que se delimita la otredad, el adversario, esbozando un campo de antagonismo. A su vez, esta construcción ideológica posee también un carácter mítico: el de proyectar una nueva 
fundación societaria que permita realizar la promesa de plenitud a partir de la confrontación del adversario y del despliegue del proyecto de gobierno, expresión de la unidad de fines políticos y económicos que conlleva toda construcción hegemónica.

Gramsci habla de libros vivientes en tanto poseen la cualidad de trascender un carácter meramente teórico para convertirse en motorizadores de la transformación social, es decir que conjugan el análisis científico con el carácter literario centrado en la idea del mito para dar forma a un proyecto político cuya realización requiere de la construcción de una voluntad colectiva. Nosotros veremos cómo el kirchnerismo en su recuperación del peronismo cumple una función mítica al establecer un imaginario que apela a una lectura del pasado como realización de la promesa de plenitud societaria, invocando la experiencia socio-política más parecida a un Príncipe moderno en términos de movilización de pasiones y de creación de una voluntad nacional y popular que contiene la historia argentina. Pero esta recuperación del peronismo originario se da de forma singular enfrentando a los adversarios del período vigente y en un contexto político-económica a nivel mundial que dista rotundamente del que sirvió de base al surgimiento del peronismo.

El Príncipe moderno, como libro viviente, en Gramsci tomaría dos cuestiones fundamentales: la voluntad colectiva y la reforma intelectual y moral. Con respecto a la voluntad colectiva, constituida en objetivo cardinal de la estrategia política, indagaría acerca las condiciones en las cuales ésta podría desarrollarse, a partir de un análisis histórico y económico de la estructura social del país y "una representación “dramática” de las tentativas realizadas a través de los siglos, para suscitar esta voluntad y las razones de sus sucesivos fracasos” (Gramsci, 2003:13). La reforma intelectual y moral refiere a una disputa respecto de la concepción del mundo así como también a una reforma cultural que vaya en dirección de elevar en este sentido a los estratos sociales más bajos a partir de un programa de reforma económica. El Príncipe moderno, debe ser quien organice y lidere estas reformas "lo cual significa crear el terreno para un desarrollo ulterior de la voluntad colectiva nacional popular hacia el cumplimiento de una forma superior y total de civilización moderna” (Gramsci, 2003:15) ${ }^{52}$. De modo

\footnotetext{
${ }^{52}$ Gramsci lleva incluso más lejos el carácter radical de la transformación social liderada por el Príncipe moderno, señalando que el Príncipe-partido comenzaría a ocupar el lugar de la religión en un proceso de laicización de la vida construyendo una nueva visión hegemónica sobre el mundo. Hay que recordar que la religión es considerada (retomando a Croce) como una concepción del mundo que deviene en norma de vida, o sea, con capacidad de incidir en las prácticas cotidianas.
} 
mucho más modesto y sistémico, observaremos cómo el kirchnerismo construye una ideología que promueve la imagen de un modelo de acumulación que, enmarcado en el modo de producción capitalista, impulsa "la industrialización con inclusión social”, una alianza entre trabajadores y empresarios productivos, y la recuperación del Estado como "mediación” 53 fundamental, invocando algunos elementos centrales del peronismo originario frente al paradigma neoliberal deslegitimado y en franca crisis hacia 2001. Y al mismo tiempo esboza un plan de reformas económicas para desarrollar este proyecto político-económico de gobierno.

El nuevo príncipe como libro viviente tendría también una parte dedicada al jacobinismo "en cuanto ejemplificación de cómo se formó y operó en concreto una voluntad colectiva que al menos en algunos aspectos fue creación ex novo, original” (Gramsci, 2003:13). Quintana señala que el espíritu que rescata Gramsci del jacobinismo, y que debe incorporar el Príncipe moderno, es el que refiere "a un partido determinado de la Revolución Francesa que concebía de determinada manera el desarrollo de la vida gala, con un programa determinado, apoyándose sobre determinadas fuerzas sociales y que llevó adelante una acción de partido y de gobierno con un método caracterizado por una extrema energía, decisión y resolución” (2000:103). Veremos cómo en el discurso de los presidentes de nuestro período de estudio aparece también una vocación fundacional, la idea de estar construyendo una nueva Argentina, en una operación hegemónica que recupera elementos culturales del pasado de los cuales se siente tributario, principalmente del peronismo, y los proyecta bajo un nuevo cariz para dar lugar a un nuevo momento histórico.

Estos temas mencionados del Príncipe moderno como libro viviente son también parte inherente a la fuerza política (partido revolucionario en $\mathrm{Gramsci}^{54}$ ), ya que es libro

\footnotetext{
53 Decimos “mediación” en el sentido de proponerse como regulador y moderador, que en el discurso cobra el lugar ficticio pero políticamente productivo de ponerse "por encima" de los conflictos de clase realizando al conjunto de las “energías nacionales”. Luego veremos el uso que da O’Donnell (1978) a la mediación, no ya entre las clases sino entre Estado y sociedad en la construcción de un referente de la acción estatal por fuera de las clases que constituyen su fractura y relación social central.

${ }^{54}$ Acerca de la concepción gramsciana del partido, es necesario recordar la activa participación política de Gramsci y mencionar el instrumento político específico al que él aportó en busca de la configuración de ese príncipe moderno: el Partido Comunista, del cual Gramsci fue su Secretario General desde 1924, en que desplaza a Bordiga, hasta un año después del encarcelamiento por el fascismo, cuando en 1927 es reemplazado por su compañero Palmiro Togliatti. Nuevamente, rescatamos las reflexiones gramscianas en torno al Príncipe moderno, no para señalar la existencia de un proceso de estas mismas características en Argentina, sino porque entendemos que la teoría que despliega contiene elementos válidos para pensar la construcción de hegemonía en procesos que, si bien no cambian el carácter de clase en la sociedad donde se insertan, sí modifican distintos factores políticos, económicos y culturales.
} 
viviente en tanto procura la transformación social, en tanto estudia las circunstancias históricas que lo rodean y busca generar, también en su apelación al mito, la instrucción acerca de las herramientas políticas y estrategias para el despliegue de dicha ideologíamito (que en Gramsci tienen un carácter revolucionario ligado al fin de construir un nuevo bloque histórico basado en las clases subalternas ${ }^{55}$ ): "En la época moderna el protagonista del nuevo príncipe no podría ser un héroe personal, sino un partido político, el determinado partido que en cada momento dado y en las diversas relaciones internas de las diferentes naciones intente crear (...) un nuevo tipo de Estado” (Gramsci, 2003:28). Si bien en Argentina no asistimos a la conformación de un "nuevo tipo de Estado” en términos de una revolución de las relaciones de clases (con traspaso dialéctico de subalternas a dominantes), sí observamos transformaciones en el Estado que se van desarrollando en virtud del cambio de signo de la intervención estatal. La misma presenta diversas rupturas y continuidades, en un proceso donde se observan alteraciones en las relaciones de fuerzas entre fracciones de clase, comenzando a esbozar un patrón de acción estatal que se distingue de aquel predominante en los últimos 30 años de historia argentina.

El Príncipe moderno se constituye en base a una doble tarea: un rol ideológicocultural que Gramsci denomina "la reforma intelectual y moral” y un rol ligado a la estrategia política, el de construcción de una voluntad colectiva. Reforma intelectual y moral en base a una tarea de crítica del orden social y las formas de dominación vigente, de construcción de concepciones de mundo alternativas y de difusión de dichas concepciones. Voluntad colectiva vinculada a la articulación de ese pueblo disperso, que superando la dimensión económico-corporativa de los reclamos alcance la dimensión estrictamente política con el fin de fundar un nuevo Estado. Esta construcción de la voluntad colectiva se vincula a su capacidad de articulación y movilización de los grupos sociales subalternos, en un proceso de “universalización”, en tanto los intereses y demandas de esta fuerza social y política puedan aparecer como portadores del bien común, como aquellos capaces de dar desarrollo a "todas" las energías nacionales. La tarea de la fuerza política es entonces la de crear y organizar una voluntad colectiva, de la cual ella misma es la expresión más activa, y emprender una reforma intelectual y moral en esa misma dirección, disputando la influencia ideológica

${ }^{55}$ En Gramsci este Príncipe-partido deberá desempeñar un rol fundamental en la construcción hegemónica de una voluntad colectiva que logre articular los reclamos subalternos y gestar una fuerza social y política capaz de fundar un nuevo Estado. 
y cultural de los otros grupos sociales y que sirva de elemento cohesionante para el despliegue de la estrategia política y la construcción de hegemonía. Aquí podemos observar la revalorización de la subjetividad en Gramsci como un elemento central de la política que conlleva necesariamente la construcción de una nueva concepción del mundo, la construcción de un sujeto-pueblo en base a una labor permanente de organización y conciencia que apela también a la pasión.

Gramsci parte de la concepción del partido político como expresión de un determinado grupo social, en este sentido "cada partido no es más que una nomenclatura de clase” (2003:32). Gramsci admite que los partidos puedan aparecer divididos en fracciones y presentarse como "partidos" diferentes y que "con mucha frecuencia el Estado Mayor intelectual del partido orgánico no pertenece a ninguna de esas fracciones pero actúa como si fuese una fuerza dirigente totalmente independiente, superior a los partidos y a veces considerada así por el público” (Gramsci, 2003:29). Este sería por ejemplo, el caso de los periódicos y la prensa informativa que, si bien pueden llamarse a sí mismos “apolíticos” o “independientes”, defienden y reproducen, en condiciones normales, los intereses fundamentales y la concepción del mundo de la clase a la que son orgánicos. Incluso vale recalcar, como lo hace Piotte (1973), que mientras las fracciones de partido, proclamadas como "partidos", se encuentran muchas veces en situación de disputas polémicas ligadas al interés inmediato de su propia organización, por ejemplo en coyunturas electorales o respecto de factores secundarios (no los fundamentales que atañen a la dominación de la clase representada), los representantes del Estado Mayor intelectual de la clase que se ubican por fuera de estas organizaciones y desligados de los intereses particulares de estas, serán más sensibles a los intereses fundamentales de la clase y a la planificación política de largo plazo ${ }^{56}$. En este sentido, la relación partido-clase no es una relación directa, de expresión de intereses como reflejo, sino una acción dinámica, compleja, relacionada a la construcción de hegemonía.

De este modo, observamos en Gramsci una doble acepción del término partido: una noción amplia donde el partido aparece como expresión del conjunto de la clase y como ideología general, superior a las distintas agrupaciones inmediatas, y una

\footnotetext{
${ }^{56}$ Cuando analicemos el cambio de escenario político surgido en 2008, observaremos cómo los principales periódicos nacionales abandonan este rol general para situarse directamente en uno de los bandos en conflicto.
} 
concepción del partido en sentido estricto, el partido como organización concreta, o sea como instrumento para la solución de un problema o grupo de problemas de la vida nacional e internacional. Nosotros nos proponemos pensar una noción intermedia, que toma parte de ambas sin desconocerlas: nos proponemos pensar la noción de fuerza política como ese lugar intermedio que se relaciona al desarrollo de las clases sociales y que materializa en organización concreta, pero que al mismo tiempo lo hace de modo difuso, más acá y más allá de los partidos particulares y en una relación no lineal con las fracciones de clases. Esta apreciación nos parece relevante para pensar una fuerza política de cuño peronista en tanto el carácter movimientista incluye en su centro al Partido Justicialista pero lo sobrepasa, y que contiene en su interior tanto componentes sistémicos como componentes “herejes” según lo denominara James (2006). Además Gramsci mismo utiliza el término de fuerzas políticas en su análisis de situaciones para pensar el paso del momento estructural al político en la construcción de hegemonía.

Al distinguir los distintos componentes que integran la fuerza política, Gramsci resalta el rol de los cuadros superiores, de los “capitanes”, que incluyen a los grandes organizadores, teóricos y estrategas, es “el elemento de cohesión principal, centralizado en el campo nacional, que transforma en potente y eficiente a un conjunto de fuerzas" (2003:33) y está dotado de capacidad de inventiva y conducción política. Gramsci considera que, si bien el partido no podría funcionar sólo con este elemento, es sin embargo el primordial ya que "un ejército existente sería destruido si le llegasen a faltar los capitanes, mientras que la existencia de un grupo de capitanes, acordes entre sí, con fines comunes, no tarda en formar un ejército aún donde no existe” (2003:33). Si bien un análisis que aborde el despliegue de los principales cuadros políticos que actuaron como organizadores, teóricos y estrategas en el campo nacional excede ampliamente los objetivos de nuestra investigación, sí incorporamos como central el rol del principal de los cuadros: el líder $^{57}$. En nuestro caso, entendemos que la figura del líder se ha encarnado, durante el período estudiado, en quienes estuvieran en la Presidencia de la Nación. Los tres presidentes, Duhalde, Kirchner y Fernández, han ocupado sucesivamente el centro de la escena política con una perspectiva fundacional palpable

\footnotetext{
${ }^{57}$ Diversas teorías que analizaron lo que en América Latina se ha dado en llamar populismo (ver por ejemplo, Mackinnon y Petrone, 1999) así como desarrollos teóricos clásicos como la teoría weberiana de la dominación carismática (Weber, 1984), han resaltado el rol dirigente y cohesionante del líder.
} 
en sus principales discursos ${ }^{58}$. Entendemos que el abordaje de sus principales discursos resulta clave para identificar los componentes centrales que involucra la formulación de una concepción de mundo que actúa de base para la conformación de un proyecto político-económico de gobierno, necesario para explicar la dirección del componente de política económica que busca imprimirse en el modelo de acumulación.

En este punto, debemos recordar que el accionar del Príncipe moderno se orienta, en materia de estrategia política para las sociedades complejas, a la propuesta de Gramsci de guerra de posiciones, que requiere un esfuerzo prolongado de construcción de hegemonía. Hegemonía que implica la construcción de concepciones de mundo alternativas a partir de una crítica del orden social imperante y que, en este sentido, se relaciona con la dirección cultural, con la reforma intelectual y moral. Hegemonía que es al mismo tiempo estrategia política para la conformación de una voluntad colectiva, que organice lo disperso y movilice las pasiones. Una voluntad colectiva que Gramsci define como nacional y popular. Nacional porque Gramsci retoma la concepción de Marx de que la revolución es nacional en su forma e internacional en su contenido, porque si bien el capitalismo es un modo de producción que se expande mundialmente, cada escenario nacional, con su propio Estado, partidos, sindicatos, tradiciones culturales, etc. constituye el ámbito concreto donde se desarrollan las luchas cotidianas configurando el marco de la acción de las distintas fuerzas. Gramsci observa la importante capacidad de interpelación de lo nacional así como el peso del Estado-nación como espacio de desarrollo de la estrategia política: frente a la derrota del proceso revolucionario desarrollado entre 1919 y 1920 del cual fue partícipe, Gramsci concluyó: “No conocíamos Italia”. Aparece entonces la imposibilidad de reducir mutuamente clase y nación, y con esta imposibilidad emerge la necesidad de comprender al conjunto de agentes y a la cultura de un pueblo. Así cobra importancia lo popular porque, si bien afirma la centralidad en la clase obrera, viendo en los productores directos de plusvalor como sujeto clave para la transformación social por ocupar el centro de las contradicciones en la relación capital/trabajo, no se limita a ésta, sino que debe articular al conjunto de grupos sociales subalternos con el fin de universalizar sus intereses y construir una nueva hegemonía que logre confrontar con la

\footnotetext{
${ }^{58}$ La centralidad de Duhalde es de carácter distinto a la de Kirchner y Fernández, ya que éste emerge, no a través del voto popular, sino por designación del Congreso en el contexto de más alta crisis y no logra constituir una fuerza política con alcances hegemónicos. Aún así, como veremos en los capítulos siguientes, hay un conjunto de políticas inauguradas en su gobierno que son fundacionales en el modelo post-convertibilidad constituyendo rasgos perennes que marcan el conjunto del período de estudio.
} 
dominante y derrotarla; así los sujetos subalternos deben conformarse en pueblo. En este sentido, Gramsci observa que es clave el rol tanto de la fuerza política como de los intelectuales, para organizar la nueva concepción del mundo, en dar homogeneidad y conciencia al grupo social de sus propios intereses y objetivos, construir la unidad de ese pueblo disperso y movilizar las pasiones para el desenvolvimiento de la estrategia política.

O’Donnell (1978) realiza, en su teoría del Estado, un interesante aporte teórico para pensar las problemáticas de pueblo y nación. El Estado en el capitalismo aparece escindido de la sociedad ${ }^{59}$ (en tanto sociedad de clases), y no puede encontrar en ésta su legitimación debido a que se encuentra fraccionada y atravesada por las relaciones de dominación y explotación. Para superar este hiato debe apelar a mediaciones que performen de fundamento ${ }^{60}$ del poder estatal, así como apelar a un referente que aparezca como beneficiario de su accionar. Por referente del Estado, el autor entiende a los sujetos y relaciones sociales a cuyo interés y reproducción el Estado sirve. Las mediaciones reengarzan la sociedad ignorando los clivajes de clase, borrando así el papel de garante y organizador de la sociedad en tanto capitalista que efectúa el Estado. Estas mediaciones son instancias generalizadoras, puestas sobre el fraccionamiento de la sociedad.

Este referente es comúnmente encarnado por la nación. La nación es el arco de solidaridades que une a un "nosotros” definido por la común pertenencia a un territorio estatal y así aparece como superior a los clivajes de clase. El Estado demarca una nación frente al “ellos” de las otras naciones. Hacia el interior, el Estado tiene la pretensión de ser el agente privilegiado que custodia, interpreta y busca los intereses generales de la nación. La nación justifica tomar decisiones en contra de los sujetos sociales con el fin de preservar el sentido homogeneizante de la nación, en una operación donde lo político tiende a esfumarse de la sociedad para quedar apropiado por el Estado-nación. Este aspecto homogeneizante niega las rasgaduras estructurales de la sociedad, pero

\footnotetext{
${ }^{59}$ O’Donnell utiliza el concepto de sociedad civil en vinculación con el uso dado por Marx, como lugar de la necesidad y de la reproducción material (distinto del uso dado por Gramsci, en tanto la sociedad civil es parte de las superestructuras).

60 O’Donnell señala "que el fundamento real del poder que ejercen las instituciones estatales les es externo: emana de las relaciones capitalistas de producción como garantía de las mismas. De la misma manera, el Estado fetichizado tiene que deber su legitimación a un fundamento que no sea la sociedad civil, por la elemental razón de que esa fetichización la ha reducido a lo privado como opacidad cotidiana fundamentalmente económica.” (1978:19)
} 
mediante una mediación menos abstracta, por ejemplo que la ciudadanía ${ }^{61}$, en tanto la nación alude a los actos concretos de las instituciones del Estado. De este modo la nación es una generalidad concreta que permite imputarle el interés general que es referente del Estado cosificado.

El pueblo o lo popular, suele presentarse como otra mediación entre Estado y sociedad, y se presenta porque la postulación indiferenciada del interés general de la nación no alcanza a tapar las evidencias de desigualdad. Esto suele generar que se pretenda que las instituciones actúen en un sentido equiparador. Los pobres, o no privilegiados, se reconocen colectivamente como tales en el pueblo. Esta mediación posee un carácter ambiguo. En primera instancia porque expresa un arco de solidaridades por encima de los clivajes de clase, en tanto abarca genéricamente a quienes se reconocen como desposeídos. Pero también, estrecha el efecto homogeneizante de la nación, en tanto el reclamo de justicia se realiza contra una parte de ella: los ricos o poderosos. La fusión de lo nacional-popular coloca fuera de este campo a dicho grupo y puede afectar los límites de la reproducción de la sociedad qua capitalista. Una segunda ambigüedad se expresa en la confrontación del discurso igualitario del Estado capitalista con las desigualdades evidentes, que abre la posibilidad de una constante reemergencia de lo popular. Lo popular no es una mediación tan abstracta como la ciudadanía ni tan indiferenciada como la nación. Sus contenidos son más concretos y menos genéricos que esta última, en tanto el arco que cubre es más estrecho que el suyo. Ambiguamente colocado entre ciudadanía y nación, por un lado, y clase, por el otro, lo popular puede ser tanto fundamento como referente de las instituciones estatales.

En relación a nuestro problema de estudio, observaremos cómo se recupera la interpelación nacional-popular en el discurso oficial, en tanto resignifica este componente clave de la cultura política peronista dotándolo de capacidad para movilizar las pasiones y constituir sujeto en el marco del antagonismo abierto en 2001. Asimismo,

\footnotetext{
${ }^{61}$ Según O’Donnell (1978) la ciudadanía es la forma en la que el Estado encuentra el fundamento de su poder en la igualdad abstracta de todos los sujetos en su territorio. El capitalismo necesita de un sujeto libre e igual ante el derecho para poder concurrir a la compra y venta de la fuerza de trabajo y la apropiación de valor. En tanto que esta igualdad formal hace que la ciudadanía sea la negación de la dominación en la sociedad. La democracia es la forma normal de organización de la sociedad capitalista en tanto la movilización de recursos de poder por el estado puede hacerse en base a un derecho conferido por todos los ciudadanos. Pero la ciudadanía es la modalidad más abstracta de mediación, y como sujeto enteramente descarnado, el ciudadano no puede aparecer como portador de intereses, como referente del Estado.
} 
visualizaremos el conjunto de tensiones expresadas por las ambigüedades de lo popular, en tanto suscitan la construcción de un sujeto que es menos que el "todos” de la nación, y que evoca un sentido reparador y movilizador de los no privilegiados avivando el componente "herético”, plebeyo, del peronismo, tensionando sus límites sistémicos.

Ahora bien, como señalamos junto al enfoque del Príncipe moderno, Gramsci desarrolla otro componente clave en cuanto a la conformación de la voluntad colectiva nacional-popular como de su dirección política y cultural: los intelectuales. ¿Pero quiénes son los intelectuales? Gramsci se pregunta si los intelectuales son un grupo autónomo o si cada grupo social tiene una categoría propia y especializada de intelectuales. Encuentra que en la historia se han dado dos modos fundamentales de formación de intelectuales. En primera instancia señala que:

\begin{abstract}
“Cada grupo social, al nacer en el terreno originario de una función esencial en el mundo de la producción económica, se crea conjunta y orgánicamente uno o más rangos de intelectuales que le dan homogeneidad y conciencia de la propia función, no sólo en el campo económico sino también en el social y en el político” (Gramsci, 2004:9)
\end{abstract}

En el capitalismo, junto con el empresario aparecen también los técnicos y especialistas que dan forma a la nueva economía, organizan la cultura, el derecho, etc ${ }^{62}$. En síntesis, con cada clase se crea y forma un grupo de intelectuales orgánicos que son fundamentales para su propio desarrollo, la conformación de una concepción del mundo acorde a sus intereses que, a su vez, le permita aparecer como el portador del "bien universal”, dando homogeneidad y conciencia al propio grupo al tiempo que avanza hacia la dirección política y cultural de los grupos subalternos.

En segundo lugar, Gramsci identifica un conjunto de intelectuales tradicionales ligados principalmente a estructuras económicas precedentes y que aparecen como portadores de una continuidad histórica no interrumpida. El ejemplo característico, que Gramsci señala, es el de los eclesiásticos, que si bien en su momento fueron intelectuales orgánicos de la aristocracia terrateniente, perviven en sociedades posteriores, incluso aunque haya desaparecido la conducción política del grupo social que le dio origen. Esta continuidad les permite forjar, a los intelectuales tradicionales,

\footnotetext{
${ }^{62}$ Gramsci también destaca la necesidad de pensar al empresario capitalista mismo como un intelectual, ya que posee capacidad dirigente y técnica, no sólo en la esfera específica de su actividad sino también en otras a ésta ligada, como la organización de masas para la producción, la gestación de articulaciones con inversores, compradores, etc. Incluso señala que una elite de los empresarios capitalistas debe tener la capacidad para organizar la sociedad en general y el Estado para crear condiciones favorables a la expansión de la propia clase y sino debe, al menos, tener la capacidad de seleccionar a los encargados (“empleados especializados”) que puedan desarrollar tales tareas (Gramsci, 2004).
} 
un espíritu de cuerpo y generar la percepción de sí mismos como autónomos del grupo social dominante. Estas dinámicas a su vez tienen implicancias superestructurales sobre otros grupos de intelectuales, como Gramsci observa en su época respecto de la filosofía idealista, que asumen para sí mismos la creencia de constituir una categoría de intelectuales independientes de los poderes establecidos (Gramsci, 2004).

Luego Gramsci se pregunta sobre la amplitud de la categoría de los intelectuales, cuál es el límite máximo que admite esta categoría. En este punto señala que el error más difundido es el de identificar a los intelectuales sólo con aquellos que desarrollan actividades específicamente intelectuales y no haber buscado esta categoría partiendo del complejo de relaciones sociales en que estas actividades se enmarcan y de los grupos sociales a los cuales se vinculan. Así llega a visualizar el límite máximo de la categoría:

\begin{abstract}
"Todos los hombres son intelectuales, podríamos decir, pero no todos los hombres tienen en la sociedad la función de intelectuales (...). Cuando se distingue entre intelectuales y no intelectuales, en realidad sólo se hace referencia a la inmediata función social de la categoría profesional de los intelectuales, es decir, se tiene en cuenta la dirección en que gravita el mayor peso de la actividad específica profesional, si en la elaboración intelectual o en el esfuerzo nervioso-muscular. Esto significa que si se puede hablar de intelectuales, no tiene sentido hablar de no-intelectuales, porque los no-intelectuales no existen. Pero la misma relación entre esfuerzo de elaboración intelectual-cerebral y esfuerzo nervioso-muscular no es siempre igual; por eso se dan diversos grados de actividad específicamente intelectual. No hay actividad humana de la que se pueda excluir toda intervención intelectual, no se puede separar el homo faber del homo sapiens. Cada hombre, considerado fuera de su profesión, despliega cierta actividad intelectual, es decir, es un "filósofo", un artista, un hombre de buen gusto, participa en una concepción del mundo, tiene una consciente línea de conducta moral, y por eso contribuye a sostener o a modificar una concepción del mundo, es decir, a suscitar nuevos modos de pensar.” (Gramsci, 2004:13)
\end{abstract}

Esta afirmación es de gran importancia a la hora de pensar la construcción de hegemonía, ya que implica que todo grupo social fundamental, independientemente de la tarea específica que realiza en el ámbito de la producción puede generar su propia categoría de intelectuales. Es por esto que Gramsci señala que todos los hombres son “filósofos”, ya que participan del lenguaje, participan del sentido común y poseen núcleos de buen sentido o sea capacidad de tomar conciencia de su lugar en la sociedad y de las contradicciones que lo atraviesan, y también porque participan de distintas variantes de religión popular, de creencias y del folklore (Gramsci, 2008). De este modo, todos son partícipes al menos de una filosofía espontánea en tanto ya en la más mínima actividad intelectual está contenida una concepción del mundo. 
Pero, si todos son, en términos amplios, intelectuales, ¿¿cuál es la implicancia y la función específica de la categoría de intelectual? ¿en qué momento esta capacidad general de los hombres de ser "filósofos" o intelectuales comienza a cumplir un rol en la construcción de hegemonía? Gramsci identifica un punto de quiebre en este sentido: se puede participar de una concepción impuesta por otro grupo social o se puede elaborar la propia concepción del mundo de manera crítica y consciente (Gramsci, 2008). El desarrollo de la crítica consciente constituye un punto de inflexión ya que permite develar la concepción del mundo que se posee, observar en ella la hegemonía construida por los grupos sociales dirigentes y generar un momento de ruptura que abra paso a la elaboración de una concepción del mundo del propio grupo social al que se pertenece. Sin este papel de la crítica no hay posibilidad de desarrollo de una hegemonía alternativa. Es por esto que la función de los intelectuales es la de impulsar una reforma intelectual y moral, en el proceso en que un nuevo tipo de sociedad se crea junto a una nueva superestructura. En nuestro enfoque, y en virtud del problema de estudio que nos convoca, indagaremos la problemática de la reforma intelectual y moral, que es la dirección ideológico-cultural, en relación a la generación y consolidación de una nueva cultura política, que contiene una concepción del mundo particular con determinados patrones doctrinales, representaciones y valores encarnados en una fuerza política, y que sirve de base a la gestación del proyecto político-económico de gobierno que da aliento a las políticas, un componente clave del modelo de acumulación.

Pero ¿qué elementos conlleva una reforma intelectual y moral? Podemos realizar una aproximación a esta problemática a través de la crítica que Gramsci realiza al Ensayo popular de Sociología de Bujarin, trabajo elaborado para la difusión masiva del marxismo en la naciente Unión Soviética, ya que en esta crítica Gramsci exhibe su concepción de la articulación intelectuales/masa en el proceso de dirección ideológicocultural que constituye un eje clave de la construcción de hegemonía. Pone como punto de partida la realización de una crítica de la filosofía del sentido común, que es, como ya señalamos, una concepción del mundo absorbida acríticamente de los distintos ambientes culturales en los cuales el individuo se va formando, una concepción del mundo disgregada, incoherente, incongruente respecto de la posición social y cultural de las multitudes. Es incongruente precisamente porque, si no hay pensamiento crítico, se participa de concepciones de mundo impuestas por otros grupos sociales, que expresan sus propios intereses. Entonces, la formación de un grupo social homogéneo 
se articula con la elaboración de una filosofía desarrollada también contra el sentido común, por ser homogénea y sistemática (Gramsci, 2008). La crítica debe partir del sentido común, romper con él y abarcar también las formas más elaboradas del pensamiento hegemónico. En este punto Gramsci critica a Bujarin por no haber discutido con lo más avanzando del pensamiento con el que confronta, sino, más bien, con sus caricaturizaciones y señala que "una ciencia obtiene la prueba de su eficacia y vitalidad cuando demuestra que sabe enfrentar a los grandes campeones de las tendencias opuestas, cuando resuelve con sus propios medios los problemas vitales que éstos han planteado, o demuestra perentoriamente que tales problemas son falsos” (Gramsci, 2008:138)

En nuestra investigación veremos, en primer lugar cómo el discurso de Kirchner incorpora la crítica de un conjunto de elementos ideológicos ligados al paradigma neoliberal en crisis, en el proceso de constitución del adversario, al tiempo que se propone como sutura y superación del mismo, como la posibilidad de recuperar la mítica promesa de plenitud a partir del desarrollo de su proyecto político-económico de gobierno. También notaremos que, en 2008, con el alineamiento de los principales grupos económicos de la comunicación con la oposición conservadora, comienza a amplificarse el debate en torno a la formación de opinión, abonando el terreno para la desnaturalización de algunos aspectos de las concepciones de mundo dominantes.

Retomando las líneas fundamentales de nuestro enfoque teórico, debemos recordar que Gramsci es particularmente duro en su crítica al trabajo de Bujarin porque entiende que el marxismo, al que suele referirse en términos de filosofía de la praxis, es la concepción del mundo fundamental tanto para el análisis crítico de las sociedades capitalistas como para su subversión superadora. Gramsci sostiene que Marx y Lenin son ambos creadores de esta concepción del mundo: Marx encarna el paso de la utopía a la ciencia, creando una concepción del mundo que fecunda una edad histórica entera y que durará hasta el fin del capitalismo; Lenin realiza el paso de la ciencia a la acción a través de la fundación de una clase dirigente y de un Estado: la Unión Soviética, la primera sociedad socialista. Ambos son claves en la conformación y desarrollo del materialismo histórico o marxismo ${ }^{63}$. Estos señalamientos implican la articulación

\footnotetext{
${ }^{63}$ Gramsci realiza una interesante analogía con el cristianismo, entendiendo que una nueva concepción del mundo precisa tanto de su creación originaria: Jesús-Marx, como de su expansión y realización práctica: San Pablo-Lenin.
} 
teórico-práctica de la construcción de concepciones de mundo, tanto en la configuración y difusión de una batalla que trascurre en el plano de las ideas y de la cultura, como de su desenvolvimiento práctico en dirección política. En una escala menor, entendemos que el kirchnerismo si bien no funda una enfoque ideológico que pueda ser simplemente considerado ex novo, ya que expresa una reformulación particular de una identidad histórica (ligada al peronismo como cultura política), sí posee cualidades que lo configuran como nueva ideología. Esto se debe a que la cultura política peronista es resignificada a la luz de un nuevo contexto histórico radicalmente diferente al que signó su formación originaria, y porque procura atraer tras de sí diversos elementos que pudieran trascender esta identidad y englobar un espectro ideológico-cultural más amplio que lo ubiquen como un hito propio en la historia política nacional. Asimismo, el rol del liderazgo es visible también en el enfoque gramsciano en tanto rescata a los líderes principales y fundacionales del movimiento comunista mundial Marx y Lenin, y posee en nuestra elección de la Presidencia de la Nación como espacio privilegiado de estudio, la virtud de juntar ambas dimensiones de la dirección política, en tanto cabeza del gobierno del Estado, y de la dirección “intelectual y moral”, con las trazas de la dirección ideológica y cultural que pueden rastrearse en los principales discursos.

A su vez, Gramsci rescata la unidad de los elementos constitutivos del marxismo, dada por el desarrollo dialéctico de las contradicciones entre hombre y materia (naturaleza, fuerzas materiales de producción). Señala que filosofía, economía y política son elementos constitutivos de una concepción del mundo, por lo que debe haber articulación, traducción entre uno y otro elemento. En la economía el centro unitario es el valor (teoría del valor-trabajo) o sea la relación entre el trabajador y las fuerzas de producción. En la filosofía, el centro es la praxis, o sea la unidad de teoría y práctica, de condiciones espirituales y condiciones materiales ${ }^{64}$. En la política, la relación entre el Estado y la sociedad civil, o sea la intervención del Estado para dar forma y conducir el ambiente social general (Gramsci, 2008). Nos interesa rescatar el espíritu de esta búsqueda teórica, por un lado, del marxismo del cual nuestro enfoque es tributario, pero también para comprender la mirada que Gramsci construye sobre el marxismo. Esto implica en nuestro estudio pensar al kirchnerismo en su articulación de

\footnotetext{
${ }^{64} \mathrm{O}$ sea relación entre la voluntad humana (superestructura) y la estructura económica (recordando la propuesta de pensar al hombre mismo como bloque histórico).
} 
elementos ideológico-culturales ${ }^{65}$, que forman la base de su cultura política que orienta la praxis desplegada, en su perfil económico, que parte de una particular visión de las relaciones entre trabajadores, Estado y empresarios ligada a un proyecto de alianza de clases, y elementos políticos, que se vinculan a las acciones estatales orientadas tanto a la gestión del excedente como aquellas más generales de importancia para la construcción de hegemonía, para la conducción del ambiente social general.

En la creación y consolidación de una concepción del mundo, la dirección política y cultural nos convoca a terminar de delinear el rol de los intelectuales y su relación con la fuerza política. Dijimos que en su versión más amplia todo hombre es intelectual aunque no todos cumplen con funciones sociales específicas de intelectual. Esto nos plantea una posibilidad relevante para la construcción de hegemonía: estas capacidades humanas implican, asimismo, que todo hombre puede convertirse en un intelectual, no en el sentido ya necesariamente de su adscripción profesional sino de su función social, esta es la clave de la posibilidad de conformación de grupos intelectuales en cada clase social:

\begin{abstract}
"El problema de la creación de un nuevo grupo intelectual consiste, por lo tanto, en elaborar críticamente la actividad que existe en cada uno en cierto grado de desarrollo; modificando su relación con el esfuerzo nervioso-muscular en un nuevo equilibrio, y logrando que el mismo esfuerzo nervioso-muscular, en tanto elemento de una actividad práctica general, que renueva constantemente el mundo físico y social, llegue a ser el fundamento de una nueva e integral concepción del mundo.” (Gramsci, 2004:13)
\end{abstract}

Gramsci piensa en un nuevo tipo de intelectual, distinto al tradicional, piensa en un genuino intelectual orgánico, con una participación activa en la vida práctica, como constructor, organizador, permanentemente persuasivo, que se constituye en “dirigente”, cuya fórmula define como: especialista + político. Es por esto que Gramsci afirma: "Que todos los miembros de un partido político deban ser considerados como intelectuales, he ahí una afirmación que puede prestarse a la burla y a la caricatura; sin embargo, si se reflexiona, nada hay más exacto” (Gramsci, 2004:20). Ahora podemos comprender más claramente el rol que Gramsci concebía para el Príncipe moderno: el partido como impulsor de una reforma intelectual y moral.

“Cómo se transforma el partido político con respecto al problema de los intelectuales? Se deben
hacer algunas distinciones: 1) para algunos grupos sociales el partido político no es más que el
modo de articular la propia categoría de intelectuales orgánicos (que se forman de ese modo y no

${ }^{65}$ Decimos elementos ideológico-culturales, ya que el kirchnerismo en particular así como el peronismo en general, no constituyen como el marxismo una filosofía, una teoría sistemática para el análisis y la transformación de la sociedad, sino una ideología que forma parte de una cultura política. 
pueden dejar de formarse, dados los caracteres generales y las condiciones de formación, de vida y de desarrollo del grupo social), directamente en el campo político y filosófico y no ya en el campo de la actividad productiva (...) 2) para todos los grupos, el partido político es justamente el mecanismo que en la sociedad civil cumple la misma función que en medida más vasta y más sintéticamente cumple el Estado en la sociedad política, es decir, procura la unión entre intelectuales orgánicos de un grupo dado, el dominante, y los intelectuales tradicionales; y el partido cumple esta función en forma dependiente de su función fundamental, que es formar sus propios componentes, elementos de un grupo social que ha surgido y se ha desarrollado como económico, hasta convertirlos en intelectuales políticos calificados, dirigentes, organizadores de toda la actividad y la función inherente al desarrollo orgánico de una sociedad integral, civil y política. Se puede decir que en su ámbito el partido político cumple su función de modo más completo y orgánico que la que el Estado cumple en un ámbito más vasto: un intelectual que entra a formar parte del partido político de un determinado grupo social, se confunde con los intelectuales orgánicos del mismo grupo, se liga estrechamente al grupo” (Gramsci, 2004:19-20)

A su vez, la actividad intelectual puede ser distinguida en grados desde el punto de vista intrínseco, grados que van desde los “administradores” y divulgadores de la riqueza intelectual ya existente, hasta el más alto grado donde se ubican los creadores de las diversas ciencias, de la filosofía, del arte, etc. En este sentido su tarea conlleva crear una nueva cultura acorde con el grupo social al que son orgánicos, lo cual implica tanto el desarrollo de descubrimientos, de innovaciones en las ciencias, el arte, etc. así como su, no menos importante, socialización en el trabajo de masas cotidiano. Además, los intelectuales orgánicos de los distintos grupos sociales que buscan establecer su hegemonía lucharán por la asimilación y la conquista “ideológica” de los intelectuales tradicionales.

A su vez, Gramsci problematiza la relación entre los intelectuales y el mundo de la producción y señala que esta no es inmediata,

\footnotetext{
"sino que es "mediata" en grado diverso en todo el tejido social y en el complejo de las superestructuras, en los que los intelectuales son los "funcionarios". Se podría medir la "organicidad" de los diversos estratos intelectuales y su conexión más o menos estrecha con un grupo social fundamental, fijando una gradación de las funciones y de las superestructuras de abajo hacia arriba (desde la base estructural hacia arriba). Por ahora se pueden fijar dos grandes planos superestructurales, el que se puede llamar de la "sociedad civil", que está formado por el conjunto de los organismos vulgarmente llamados "privados", y el de la "sociedad política o Estado"; y que corresponden a la función de "hegemonía" que el grupo dominante ejerce en toda sociedad y a la de "dominio directo" o de comando que se expresa en el Estado y en el gobierno "jurídico". Estas funciones son precisamente organizativas y conectivas. Los intelectuales son los "empleados" del grupo dominante para el ejercicio de las funciones subalternas de la hegemonía social y del gobierno político, a saber: 1) del "consenso" espontáneo que las grandes masas de la población dan a la dirección impuesta a la vida social por el grupo fundamental dominante, consenso que históricamente nace del prestigio (y por lo tanto de la confianza) que el grupo dominante deriva de su posición y de su función en el mundo de la producción; 2) del aparato de coerción estatal que asegura "legalmente" la disciplina de aquellos grupos que no "consienten" ni activa ni pasivamente, pero que el mismo está preparado para toda la sociedad en previsión de los momentos de crisis en el comando y en la dirección, casos en que no se da el consenso espontáneo” (Gramsci 2004:16)
} 
Los intelectuales entonces cumplen el rol de articulación concreta de la estructura con las superestructuras. Asentamos de este modo el enfoque subyacente con que abordaremos el rol del líder, encaramado en la conducción del Poder Ejecutivo Nacional: un intelectual orgánico destacado, un nodo que vincula en su propio rol un desempeño fundamental en la construcción de hegemonía, ya que provee las líneas ideológico-culturales para la conducción de la sociedad civil, y que es a su vez dirección de la sociedad política al situarse en el máximo cargo del Estado. Además, debemos recordar el lugar destacado que Gramsci reserva a los líderes como componente clave de la fuerza política: los “capitanes” son justamente esos intelectuales orgánicos que se ponen a la cabeza de una fuerza política, y que en el caso de los presidentes tienden a concentrar capacidad de dirección política e ideológica, por lo que sus discursos constituyen un insumo de alta relevancia para nuestro análisis.

De este modo, vemos que según Gramsci el rol principal tanto de los intelectuales como de la fuerza política (Príncipe moderno) es la construcción de hegemonía en tanto dirección política y cultural. Vimos que estas tareas parten de una crítica del sentido común dominante (cuyo grado de radicalidad dependerá del tipo de organicidad que revista y su carácter sistémico o anti-sistémico, revolucionario, reformista o reaccionario en relación al escenario de lucha de clases existente). Esto, a su vez, se relaciona con dotar al grupo social de conciencia y homogeneidad ${ }^{66}$, es decir de expresar en un proyecto la unidad de fines políticos y económicos según una concepción del mundo determinada. Es aquí donde aparece la problemática de la unidad de teoría y práctica, ambas indispensables para la construcción de hegemonía. Así, esta unidad está directamente relacionada con la creación y difusión de una concepción del mundo coherente y unitaria del grupo social, que supera el sentido común y se torna crítica. Gramsci sostiene que:

\footnotetext{
“La comprensión crítica de sí mismo se logra a través de una lucha de “hegemonías” políticas, de direcciones contrastantes, primero en el campo de la ética, luego en el de la política, para arribar finalmente a una elaboración superior de la propia concepción de la realidad. La conciencia de formar parte de una determinada fuerza hegemónica (esto es, la conciencia política) es la primera fase para una ulterior y progresiva autoconciencia, en la cual teoría y práctica se unen finalmente” (Gramsci, 2008:16)
}

\footnotetext{
${ }^{66}$ La homogeneidad refiere a que cuando la concepción del mundo no es crítica, se pertenece simultáneamente a una multiplicidad de hombres masa, por estar atravesado por un conjunto de concepciones de mundo pertenecientes a otros grupos sociales.
} 
Gramsci aclara que esto no se da mecánicamente, sino que es un largo proceso que comienza con la "distinción”, la separación instintiva del grupo y progresa hasta poseer una concepción del mundo propia. Para esto es indispensable la creación de una categoría de intelectuales, porque no hay independencia sin organización y no hay organización sin organizadores y dirigentes, “es decir, sin que el aspecto teórico del nexo teoría-práctica se distinga concretamente en una capa de personas “especializadas” en la elaboración intelectual y filosófica” (Gramsci 2008:17). De este modo observamos la relación entre fuerza política e intelectuales que expresa el movimiento de la unidad teoría-práctica ${ }^{67}$.

Si bien una visión crítica, en una perspectiva revolucionaria, implica dejar de ser dirigido por los grupos sociales dominantes que, en la sociedad de clases, poseen intereses contradictorios, potencialmente antagónicos, a los grupos subalternos, basados en la explotación del trabajo y la apropiación privada de la riqueza socialmente creada, cuando abordamos procesos de cambios que no procuran, al menos en el corto plazo, generar un proyecto alternativo al de la sociedad de clases, hay que enfocar en quiénes son construidos como adversarios y cómo se alza la crítica contra estos y su concepción del mundo.

Aparece entonces el problema de cómo identificar la teoría y la práctica, a lo que Gramsci encuentra dos caminos principales. Uno refiere a construir sobre una determinada práctica una teoría que, coincidiendo e identificándose con los elementos decisivos de la misma, acelere el proceso histórico en acto, tornando a la práctica más homogénea, coherente y eficiente, volviéndola poderosa al máximo. El otro camino implica que dada cierta posición teórica, se avanza a organizar el elemento práctico indispensable para su puesta en práctica ${ }^{68}$. En ambas posibilidades la unidad de teoría y

\footnotetext{
${ }^{67}$ En sus reflexiones sobre el proceso revolucionario, Gramsci analiza la dinámica intelectuales-masa y sostiene que el desarrollo de la capa de intelectuales debe estar ligado a un movimiento análogo de desarrollo de las masas: éste es el camino de la reforma intelectual y moral. En este trayecto advierte que la "fidelidad" de los intelectuales a las masas será puesta a prueba. También insiste en el elemento "práctica" de la unidad, las masas, que debe ir atravesando desde las fases de conciencia más ligadas a la estructura, fases, que podemos pensar en términos de los grados de conciencia y organización que Gramsci identificaba en su análisis de situaciones y relaciones de fuerza, desde las formas de conciencia económico-corporativas, a formas más abarcativas aún en el plano económico, alcanzando finalmente la conciencia política donde se desarrolla específicamente la lucha por la hegemonía.

${ }^{68}$ En este caso veremos, por ejemplo, cómo en el desarrollo de las negociaciones del gobierno de Kirchner con el FMI, la caída del acuerdo y la imposibilidad de seguir financiándolo deriva en el pago por adelantado de la deuda que sirve de base práctica para una fundamentación ideológica de largo alcance que termina por bautizar la política y convertirse en bandera cultural del oficialismo: la política de desendeudamiento para ganar soberanía.
} 
práctica es un acto crítico, consciente, por el cual la práctica se demuestra racional y necesaria, y la teoría se muestra racional y realista. Esto se ve más claramente en los momentos de transición cuando las fuerzas prácticas desatadas necesitan ser justificadas, o cuando se multiplican los programas teóricos que exigen ser justificados de manera realista y ser asimilables por los movimientos prácticos (Gramsci 2008). Veremos cómo estas dos direcciones se conjugan en nuestro período de estudio, observando cómo un conjunto de movimientos estructurales ligados al colapso del modelo de la convertibilidad y a los cambios en las relaciones de fuerzas entre fracciones de clases tienden a ser sustentados y readaptados ideológicamente, así como también determinadas orientaciones ideológicas (como el supuesto fin de una alianza estatal con el sector financiero y un nuevo pacto productivo) sientan las base para orientaciones políticas y transformaciones ulteriores ${ }^{69}$.

Así culminamos una primera delimitación del enfoque teórico del cual abordaremos nuestro problema de estudio. El centro del análisis estará enfocado en el modelo de acumulación, pensando al mismo como la forma que adquiere el proceso de reproducción ampliada del capital en un espacio y tiempo determinado en el cual se observan rasgos particulares de regularidad y prelación en las relaciones que contienen los tres núcleos constitutivos del modelo: las variables económicas, las fracciones de clase y las políticas. A su vez, entendemos que el proceso de construcción de hegemonía tiene incidencias concretas en la gestación y desarrollo del modelo de acumulación, en tanto el componente de políticas del modelo requiere legitimación y se vincula al proyecto político-económico de gobierno de la fuerza política que conduce el Estado. Dicha fuerza política como sus intelectuales orgánicos (viendo en particular el rol del líder), realizan las tareas de dirección política y cultural propias de la estrategia hegemónica: la conformación de una voluntad colectiva nacional-popular y la elaboración y despliegue de una concepción del mundo que rige la dirección cultural en tanto reforma intelectual y moral. De este modo se produce una universalización de los

\footnotetext{
${ }^{69}$ Gramsci señala que en este proceso el papel del partido político es clave, en tanto son elaboradores de concepciones del mundo al tiempo que accionan en la lucha de clases expresando en sí la unidad de teoría y práctica, involucrando en su desarrollo la dialéctica intelectuales/masa, y que todo militante es, en términos amplios, un intelectual inserto en la masa a través de su lugar de acción, buscando expandir una concepción del mundo alternativa, promoviendo la organización y la construcción de una nueva hegemonía para la transformación de la sociedad. Estas son líneas de investigación, que si bien exceden los objetivos de esta tesis que se orienta a aprehender éstas problemáticas sólo en la conducción nacional, habilitan perspectivas para estudios ulteriores.
} 
intereses particulares apareciendo como desarrollo del conjunto de las energías nacionales. Esta perspectiva permite percibir al modelo de acumulación como un producto mismo de la lucha de clases, en tanto el proceso de reproducción ampliada del capital es siempre al mismo tiempo un proceso de reproducción ampliada de las clases sociales, atravesadas estas mismas por relaciones de fuerzas.

Asimismo, para comprender de modo más cabal el enfoque teórico aquí construido, es necesario avanzar por un doble camino, por un lado, hacia la explicitación de supuestos filosóficos y epistemológicos, atravesando la incorporación de conceptos subsidiarios y teorías regionales (en relación a los pilares conceptuales de modelo de acumulación y hegemonía ya expuestos), y por otro, hacia la construcción de los referentes empíricos e indicadores que constituyen la estrategia metodológica elaborada al fin de dar respuesta a nuestro problema de estudio. 


\section{Capítulo II}

\section{Conceptualizaciones, supuestos y estrategia metodológica.}

La investigación sociológica puede ser pensada, como sostenía Alexander (1992), a través de un continuo de pensamiento científico con sus distintos momentos, un continuo que contiene tanto un momento metafísico, que avanza hacia los supuestos más generales y las orientaciones ideológicas, y que se extiende en un recorrido hacia mayores especificaciones hasta el momento empírico, donde los principales conceptos son operacionalizados a través de una estrategia metodológica con el fin de realizar observaciones e interpelar el medio fáctico ${ }^{70}$. En ese sentido, de ida y vuelta entre ambos momentos, pretendemos movernos con el fin de profundizar el enfoque teóricometodológico que constituye la tesis. Entendemos que la construcción de una perspectiva teórica requiere, por un lado, que una vez asentados los conceptos y lineamientos fundamentales, avancemos hacia el desarrollo de un entramado más amplio de conceptos que son subsidiarios de los mismos, acoplados en relación subordinada a las ideas fundamentales pero que, a su vez, permiten profundizarlas y enriquecerlas. Por otro lado, avanzaremos a explicitar un conjunto de supuestos involucrados en las concepciones teóricas, así como en los debates implicados (y necesarios) en la articulación de herramientas teóricas provenientes de distintas tradiciones de pensamiento. Una vez enriquecido el enfoque con la incorporación de las nuevas categorías y conceptos, presentaremos los lineamientos principales de la estrategia metodológica para explicitar la interpelación del momento empírico a través de nuestra red conceptual. Finalmente, desarrollaremos un conjunto de reflexiones epistemológicas que nos permitirán vislumbrar el conjunto de obstáculos y desafíos cognitivos que acarrea una investigación del tipo de la que aquí se desarrolla, así como la perspectiva involucrada en la construcción del objeto de estudio.

\footnotetext{
${ }^{70}$ Tomamos el planteo de Alexander (1992) a modo ilustrativo para alumbrar el amplio abanico de actividades que implica una investigación y cómo en el presente capítulo avanzaremos a delinear mayores especificaciones tanto hacia el momento "metafísico" como el "empírico". Asimismo, el problema del método de conocimiento será abordado en el último parágrafo a través de un conjunto de reflexiones epistemológicas sobre la construcción del objeto de estudio.
} 


\subsection{Cultura política: cultura + política}

En nuestro enfoque sobre el modelo de acumulación partimos distinguiendo los proyectos político-económicos de gobierno, de las políticas y ambos respecto del modelo, ya que la acción estatal es un componente clave pero no único del modelo, parte de una tríada teórico-metodológica que nos convida a analizar también las variables económicas y las fracciones de clase. En este camino, nos distanciamos del enfoque desarrollado por Torrado (1992), pero retomamos el énfasis que ella pone en las estrategias de acción a través de la noción de proyecto político-económico de gobierno entendido como una matriz ideológica ${ }^{71}$ que expresa la unidad de fines políticos y económicos involucrada en toda construcción de hegemonía y que sirve de sustrato a la generación de acciones estatales que inciden en el proceso de acumulación. Ahora bien, el proyecto político-económico tiene en su base una ligazón con la creación y desarrollo de una concepción del mundo, que contiene también elementos intelectuales y morales que vienen a formar parte de una cultura política singular.

Entendemos que el análisis de la concepción del mundo que se torna hegemónica en un período dado está vinculado al estudio de la cultura política que encarna la fuerza política hegemónica ${ }^{72}$. La noción de cultura política, a pesar de su polivalencia, contiene la potencialidad de articular diversas dimensiones implicadas en

\footnotetext{
${ }^{71}$ La noción de matriz ideológica tiene cierto parentesco y algunas diferencias respecto de aquella formulada por Svampa (2010). La autora sostiene que: "Por matrices político-ideológicas entendemos aquellas líneas directrices que organizan el modo de pensar la política y el poder, así como la concepción del cambio social" (Svampa, 2010:7) y encuentra cuatro matrices centrales: la indígena comunitaria, la nacional-popular, la izquierda clásica o tradicional y, de manera más reciente, la "nueva" narrativa autonomista; éstas no se encuentran nunca en estado puro, sino en diversas combinaciones. En nuestro análisis, la matriz ideológica comparte la definición general dada por Svampa en torno al entramado de directrices para pensar la política, el poder y el cambio, pero el alcance conceptual de la matriz es de menor envergadura, ya que abordamos las grandes tradiciones político-ideológicas a partir de la noción de cultura política. Pensamos a la matriz ideológica en mayores niveles de especificidad para ver cómo se gesta un entramado de ideas y directrices que constituyen el proyecto político-económico de gobierno, el cual se relaciona con la noción más general de cultura política, del modo en que desarrollaremos en el presente apartado. De este modo, existe la posibilidad de que emerjan distintos proyectos de gobierno que, si bien sean ambos tributarios de una misma cultura política, posean diferencias concretas en el modo de interpretar e intervenir en la realidad. En el capítulo siguiente, veremos un ejemplo de esto en las diferencias entre el proyecto duhaldista y el kirchnerista, que siendo ambos tributarios de la cultura política peronista evidencian distinciones (así como parecidos) a la hora de pensar e impulsar la acción estatal. Al mismo tiempo el desarrollo de una matriz ideológica genera cambios en la cultura política de la cual es tributaria pudiendo instaurar una variante particular de la misma (como veremos en el caso del kirchnerismo).

${ }^{72}$ Este planteo se emparenta con el señalamiento de Sirinelli que sostiene que "la cultura política es, a la vez, una especie de código y un conjunto de referentes formalizados en el seno de un partido o de modo más ampliamente difundido, en el seno de una familia o de una tradición política” (1993:12).
} 
nuestro problema de estudio ${ }^{73}$, en tanto el plano de las representaciones, valores y significados de la cultura, se vincula en este concepto con la dimensión de las disputas en torno a estrategias que tienen fuerte incidencia en el plano de la reproducción material, y especialmente en el diseño de las políticas públicas que conforman factores primordiales en el desarrollo de un modelo de acumulación. Habiendo introducido esta primera aproximación a la noción de cultura política, no podemos dejar de notar que la misma expresa una articulación de dos partes constitutivas: cultura y política. Como señala Sirinelli, "existe, en efecto entre lo político y lo cultural, una amplia zona de contacto y de ósmosis, que se puede legítimamente llamar cultura política” (1993:30). Pero al mismo tiempo la definición de la cultura política variará según el enfoque en que estén articulados sus dos partes constitutivas, que ya hemos comenzado a abordar en nuestra red conceptual. Habiendo avanzado con el análisis de la política a través de los aportes de Gramsci y Poulantzas, es ahora necesario detenernos brevemente en el concepto de cultura.

Si bien ya realizamos una primera delimitación del problema de la cultura en relación a la teoría gramsciana de la hegemonía, encontramos aspectos del debate civilización/cultura que puede brindarnos nuevos elementos para enriquecer nuestro enfoque $^{74}$. La discusión teórica en torno a la oposición conceptual entre cultura y civilización cobró fuerza en la Europa de entre-guerras y tuvo especial acogida en varios autores de la tradición denominada por Perry Anderson (1987) como marxismo occidental $^{75}$.

\footnotetext{
${ }^{73} \mathrm{Si}$ bien es posible encontrar en el trabajo de Almond y Verba algunas definiciones fundacionales que señalan que "El término cultura política se refiere a orientaciones específicamente políticas, posturas relativas al sistema político y sus diferentes elementos, así como actitudes con relación al rol de uno mismo dentro de dicho sistema” (1989 [1963]:12) o también que "La cultura política de una nación consiste en la particular distribución de las pautas de orientación hacia objetos políticos entre los miembros de dicha nación” (1989 [1963]:13), nos alejaremos de esta perspectiva tanto por la identificación que realiza de la cultura política como única y co-extensiva a la nación, así como por la mirada conductista que contiene. Iremos constituyendo un enfoque particular que retoma algunos aspectos planteados por Sirinelli (1993) y Berstein (1998) rearticulados en base a la matriz analítica general de la tesis que da contenido a las partes constitutivas cultura + política, profundizando el análisis de la cultura con los aportes teóricos desarrollados por Marcuse, vinculándolo con el enfoque gramsciano general.

${ }^{74}$ A lo largo de la tesis iremos recuperando algunas aristas del debate en torno a cultura y civilización tomando principalmente los aportes de Marcuse, rearticuladas con el enfoque gramsciano de hegemonía, con el fin de desplegar el entramado conceptual como marco analítico para interpelar fenómenos de la Argentina actual ligados a la emergencia del kirchnerismo como cultura política.

75 Como señala Norbert Elias (1988 [1939]), ambos conceptos no significaron lo mismo en los distintos países de occidente; en el ámbito germano-parlante la oposición entre cultura y civilización tiene sus raíces en Kant y "en los años inmediatamente anteriores a 1919 revivió la función que cumplía el
} 
Lukács presenta la oposición conceptual entre cultura y civilización en la definición misma que da de cultura: “¿qué es exactamente la Kultur? En pocas palabras: el concepto de kultur (en oposición a Zivilisation) comprende el conjunto de aptitudes y de productos dotados de valor que resultan superfluos en relación al inmediato sustento” (1973:74). Lukács construye una oposición entre vieja y nueva Kultur con el fin de realizar una crítica de la sociedad burguesa. Esta oposición, que se manifiesta con toda su fuerza entre dicha sociedad y la futura sociedad comunista, precisa de la referencia a una oposición anterior: entre la sociedad pre-capitalistas y la sociedad capitalista. En la época feudal, “La vieja Kultur era entonces la Kultur de las clases dominantes. Sólo las clases dominantes estaban en condiciones de poner al servicio de la Kultur sus aptitudes dotadas de valor, desvinculadas de toda preocupación por el sustento inmediato” (Lukács 1973:75). Con las transformaciones provenientes de la sociedad capitalista, las clases dominantes mismas se vieron empujadas al proceso productivo: la burguesía “está sometida al proceso productivo; está obligada a prestar sus propias fuerzas a la lucha por el provecho, de la misma manera en que está obligado el proletariado para mantenerse con vida” (Lukács 1973:75).

Así, la civilización, ligada al orden de la reproducción material, se expresa en el capitalismo de un modo que en éste no existiría clase que por su ubicación productiva esté llamada a la creación de la cultura. Aquí cobra sentido la oposición fundamental

concepto alemán de «cultura» (la de oponerse al de «civilización») debido a que la guerra contra Alemania se hizo en nombre de la «civilización» y debido también al hecho de que la conciencia que de sí mismos tenían los alemanes había de encontrar acomodo en la nueva situación creada con el tratado de paz" (Elias 1988:61). Si en el marco de la triunfante revolución rusa y las insurrecciones suscitadas en Europa al fin de la primer guerra mundial, esta oposición conceptual fue releída por Lukács (1973) para poner de manifiesto la crisis de la sociedad burguesa y promover la realización de una nueva cultura en la sociedad comunista, más tarde el cambio de contexto histórico marcado por la stalinización del movimiento comunista y el avance del nazismo pronto harían desaparecer las lecturas optimistas de este debate. Ya en la década de los 30 Marcuse pensó dicha oposición a través del carácter afirmativo de la cultura, observando su papel en la consolidación de la dominación en la sociedad burguesa. Más adelante, en los años 60, Adorno y Horkheimer rescataron la distinción del uso de civilización y cultura entre Francia e Inglaterra, por un lado, y Alemania por el otro, en modo similar a como ésta había sido formulada por Elias en 1939, compartiendo con este autor también los originarios alcances universalistas del concepto de civilización, y advirtiendo contra los peligros de exaltar la noción de cultura en contraposición a civilización: "Sólo un tipo de conciencia cultural que, no teniendo ya esperanzas de dar al mundo humano la forma de la libertad y de la conciencia, (...) puede llegar a esta separación rigurosa de Kultur como producto y forma del alma, y Zivilisation como exterioridad, absolutizando la primera y poniéndola contra la segunda, y abriendo con suma frecuencia las puertas de par en par al verdadero enemigo, la barbarie.” (Adorno y Horkheimer 1969:99) Por otra parte, Marcuse continuó manteniendo la distinción entre civilización y cultura en su matriz analítica, señalando que el avance de la primera sobre la segunda y su creciente asimilación consolidaron sus elementos afirmativos que "sirven para fortificar el dominio del Sistema establecido sobre el espíritu -el Sistema ha hecho asequibles al pueblo los bienes de cultura- y contribuyen a reforzar el dominio de lo que es sobre lo que puede ser y lo que debe ser" (Marcuse 1972:95-96). 
señalada por Lukács: si la civilización ha conllevado la crisis de la vieja cultura, sería la futura sociedad comunista la portadora de una nueva Kultur, en tanto la abolición del capitalismo expresaría nuevas relaciones sociales, creando las condiciones no sólo para la recuperación de la Kultur sino para su universalización, ya que ésta no se restringiría al reducido núcleo de las clases dominantes de antaño sino que se extendería a todos los miembros de la sociedad. Esto tiene estrecha vinculación con la lectura que Lukács realiza en torno a la posición de la clase trabajadora en la sociedad capitalista: ésta se ubica en el centro de la misma, como sujeto y objeto de la historia, en tanto el conocimiento de sí mismo y la realización de su conciencia abren paso a su emancipación, que a su vez implica la liberación del conjunto de las clases explotadas y el fin mismo de la explotación (Lukács, 1969).

Marcuse rescata a fines de los años 30 esta proyección emancipadora, pero ante la ausencia de un futuro promisorio, le otorga un punto de origen en tanto la vincula a la existencia de una pretensión originaria de la filosofía basada en la organización de la praxis según las verdades conocidas. También ubica el quiebre de dicha pretensión en la separación que realiza Aristóteles de lo necesario y útil respecto de lo bello, fractura que se consolidó luego con el desarrollo de la sociedad burguesa ${ }^{76}$.

Si para Lukács el desarrollo de la civilización en su fase burguesa llevaba a la negación de la cultura y a su inevitable crisis, para Marcuse la oposición entre civilización y cultura es asimilada de forma particular en la sociedad burguesa: “cuando la reproducción de la vida material se realiza bajo el imperio de la mercancía, creando la miseria de la sociedad de clases, lo bueno, lo bello y lo verdadero trascienden a esa vida” (Marcuse, 1967:47). Así, el concepto de cultura mantiene la pretensión de que lo bueno, lo bello y lo verdadero sean valores universalmente válidos y universalmente obligatorios, que “desde arriba” deben penetrar e iluminar el ámbito de lo necesario, dotando de fines al orden material de la vida. Se gesta entonces el surgimiento de la cultura afirmativa, que Marcuse define como aquella cultura que:

"pertenece a la época burguesa y que a lo largo de su propio desarrollo ha conducido a la separación del mundo anímico-espiritual, en tanto reino independiente de los valores, de la civilización, colocando a aquél por encima de ésta. Su característica fundamental es la afirmación de un mundo valioso, obligatorio para todos, que ha de ser afirmado incondicionalmente y que es

\footnotetext{
76، 'La división entre lo funcional y necesario, y lo bello y placentero, es el comienzo que deja libre el campo para el materialismo de la praxis burguesa por una parte, y por la otra, para la satisfacción de la felicidad y del espíritu en el ámbito exclusivo de la "cultura”” (Marcuse, 1967:45).
} 
eternamente superior, esencialmente diferente del mundo real de la lucha cotidiana por la existencia, pero que todo individuo "desde su interioridad”, sin modificar aquella situación fáctica, puede realizar por sí mismo” (Marcuse, 1967:50).

De este modo, a diferencia del optimismo lukacsiano ligado a la crisis de la Kultur en el capitalismo y la esperanza de una nueva Kultur emancipadora, Marcuse visualiza a una cultura particular ligada al capitalismo. Señala que la época burguesa trae consigo una nueva exigencia de felicidad, que el individuo particular es compelido a procurar haciéndose cargo él mismo del cuidado de su existencia y la satisfacción de sus necesidades. En la medida en que

\footnotetext{
"se otorgaba al individuo un ámbito mayor de aspiraciones y satisfacciones individuales -un ámbito que la creciente producción capitalista comenzó a llenar con cada vez mayor cantidad de objetos de satisfacción posible bajo la forma de mercancías- la liberación burguesa del individuo significa la posibilitación de una nueva felicidad. Pero con esto desaparece inmediatamente su validez universal ya que la igualdad abstracta de los individuos se realiza en la producción capitalista como la desigualdad concreta: sólo una pequeña parte de los hombres posee el poder de adquisición necesario como para adquirir la cantidad de mercancía indispensable para asegurar su felicidad” (Marcuse, 1967:51, el subrayado es nuestro).
}

Ahora bien, como señala Marcuse, la cultura debe hacerse cargo de la pretensión de felicidad de los individuos, pero al mismo tiempo, “en una sociedad que se reproduce mediante la competencia económica, la exigencia de que el todo social alcance una existencia más feliz es ya una rebelión” (Marcuse, 1967:53). Persisten así las tensiones propias de la oposición entre civilización y cultura, dadas por la escisión entre "cuerpo" y “alma”, “vida exterior” y “vida interior”, encontrando su correlato en la fractura propia de la sociedad capitalista operada en el carácter afirmativo de la cultura, entre ésta y el espacio de las necesidades y la reproducción material. Es precisamente en este proceso de escisión en que la cultura adquiere un carácter afirmativo, en tanto busca proponerse como ámbito de valores y aspiraciones constituidas por encima de las desigualdades concretas ligadas al orden de la reproducción material. Marcuse rastrea sin embargo una primer promesa de plenitud en el Renacimiento, como augurio de la nueva sociedad donde "el reino del alma, de la "vida interior", es el correlato de las riquezas de la vida exterior recientemente descubiertas” (Marcuse 1967:59). Pero inmediatamente sostiene que "Vista desde la plenitud de la cultura afirmativa (...) esta pretensión anímica se presenta como una promesa no cumplida” (Marcuse 1967:60, el subrayado es nuestro). Sostendremos que el mantenimiento de dicha promesa es fundamental para que la cultura afirmativa pueda cumplir su función hegemónica. 
Se promueve una búsqueda de la felicidad que, encorsetada en el individuo, capturada en el ámbito de la cultura y parcialmente saciada a través del consumo de mercancías, no ponga en tela de juicio el orden social. Sostendremos sin embargo, que para que dicha función hegemónica sea masivamente efectiva deben tenderse algunas condiciones mínimas, históricamente variables, para que el plano de la reproducción material (inicialmente, de la satisfacción de necesidades básicas y, suplementariamente, a través de la mejora de capacidad de consumo y condiciones de vida) parezca potencialmente articulable con el plano de las aspiraciones ideales. Esta mención implica traer nuevamente a escena el concepto de hegemonía desarrollada por Gramsci, cuyo aporte teórico conforma una pieza central del entramado conceptual desde el que se erige nuestra investigación y porque lo consideramos también relevante para alumbrar la relación y tensiones entre cultura y civilización en una aproximación sobre la actualidad. La hegemonía implica un predominio en el campo intelectual y moral, que se distingue del mero dominio expresado en la coerción. Este predominio moral e intelectual involucra la generación de consenso y la aceptación de la dirección política y cultural, en tanto las clases subalternas compartan las concepciones de mundo promovidas por las clases dominantes. Pensar la oposición de cultura y civilización en términos de su función hegemónica supone observar las relaciones y mecanismos a través de los cuales dicho consenso es generado, al tiempo que la universalización de una concepción del mundo particular implica que el desarrollo y realización del proyecto político-económico aparezca como una condición necesaria para la expansión de las “energías nacionales”, así la dirección política y cultural de la fuerza hegemónica se funde en un lugar mítico: la posibilidad más o menos palpable de realización de la promesa de plenitud. Esta promesa de plenitud se vincula a la existencia de un cuerpo social escindido, en tanto la contradicción de clases, propia del imperio del capital como relación social, deriva en el divorcio entre cultura y civilización; entonces la promesa es asimismo promesa de sutura de lo escindido, de una articulación perceptible entre la “vida interior" y la "vida exterior” de un pueblo. Partiremos de estas consideraciones acerca del carácter afirmativo de la cultura para reflexionar sobre la Argentina actual, recuperando una búsqueda analítica en términos de totalidad, siguiendo la concepción alternativa de cultura propuesta por el mismo Marcuse:

"Hay un concepto de cultura que para la investigación social puede ser un instrumento importante porque a través de él se expresa la vinculación del espíritu con el proceso histórico de la sociedad. Este concepto se refiere al todo de la vida social en la medida en que en él tanto el ámbito de la reproducción ideal (cultura en sentido restringido, el "mundo espiritual"), como el de la 
reproducción material (la “civilización”) constituyen una unidad histórica, diferenciable y aprehensible (Marcuse, 1967:49).

Para comprender este proceso escisión y unidad desde el plano de la construcción de hegemonía es que rescatamos una vez más la inclusión de esa noción que permite enlazar e interpelar de modo particular los campos de la cultura y la civilización: la cultura política. Porque si, por un lado, permanece cierto carácter de escisión entre el campo de la reproducción ideal y el de la reproducción material, por el imperio de la fractura clasista en la sociedad, por otro lado, la noción de cultura política nos habla del campo de su articulación de formas diversas y singulares. El punto de ligazón se encuentra en el modo en que una fuerza política propone incidir en el plano de la reproducción material para suturar lo escindido: realizar la promesa de plenitud en el despliegue de su propio proyecto. Así, recuperamos el espacio propio de la cultura política en tanto articulación de un conjunto de representaciones codificadas al interior de una fuerza política o, de modo más amplio, en una tradición política (evocando a Sirinelli, 1993), al tiempo que recuperamos algunos de los factores que identifica Berstein (1998) relacionados a la forma que cobra una identidad y los distintos componentes que contiene una visión del mundo compartida (concepción del mundo en Gramsci), atravesado tanto por el discurso como por el "subsuelo doctrinal o filosófico" en tanto lectura común del pasado y de la sociedad a construir. De este modo, una cultura política hegemónica debe resolver en su propia articulación de componentes la capacidad de interpelación con el fin de organizar y construir una voluntad colectiva nacional-popular, al tiempo que debe aparecer como portador del desarrollo de un proyecto político-económico que permita restituir y cumplimentar la promesa de plenitud.

Con el fin de generar mayores especificaciones en torno al estudio de una cultura política, parece indicativo rescatar el trabajo de clasificación que Garay Reyna (2007) realiza sobre las investigaciones de la cultura política peronista. La autora señala que los trabajos se han centrado en la observación de tres sentidos del fenómeno peronista:

1) las identidades forjadas y el debate en torno a su racionalidad/irracionalidad;

2) las prácticas de intermediación y el clientelismo político; y

3) el análisis sobre el discurso y la ideología peronistas. 
Es sobre esta tercera dimensión que basaremos nuestro análisis, observando algunos elementos centrales del discurso del líder (identificado en nuestro caso con la conducción del Poder Ejecutivo Nacional ${ }^{77}$ ), en tanto el mismo va delimitando la matriz ideológica que se inscribe en una cultura política singular pero que al mismo tiempo funda su transformación y perfil particular. Asimismo, tomaremos elementos de la primera variante mencionada por Garay Reyna, ligada a la construcción identitaria ${ }^{78}$, en tanto el kirchnerismo emerge como una reformulación particular de la identidad peronista y porque es en la operación de la estrategia política hegemónica en la cual la articulación de demandas se gesta en relación a la delimitación de un campo de antagonismo que implica la conformación de una identidad, de un "nosotros”, erigido frente al "otro" o adversario ${ }^{79}$.

En este punto, es necesario traer los aportes de Laclau que serán incorporados a nuestro entramado teórico, readaptados de modo subsidiario al enfoque gramsciano general en el que se afinca la tesis, iniciando un debate en torno a algunas categorías claves, como las de antagonismo y contradicción, que nos permite explicitar un conjunto de supuestos contenidos en nuestro enfoque general.

\subsection{Contradicción, antagonismo y hegemonía}

Nos proponemos ahora incorporar críticamente algunas herramientas teóricas proveniente del pensamiento de Laclau para el análisis de la hegemonía, observando la dinámica del antagonismo y la constitución identitaria de sujeto. Si bien con el enfoque

\footnotetext{
${ }^{77}$ Es preciso aclarar que en las fuerzas que conducen un gobierno no siempre coinciden el lugar del líder con el de la Presidencia de la Nación. Un ejemplo más que evidente de ello en nuestra historia fue la consigna destacada en 1973: “Cámpora al gobierno, Perón al poder”. Sin embargo, se da la particularidad que en nuestro período de estudio, pasado el interregno duhaldista, los presidentes elegidos por el voto popular, Néstor Kirchner y Cristina Fernández de Kirchner, encarnaron ambos el liderazgo de la fuerza política hegemónica ejerciéndolo desde el Poder Ejecutivo Nacional.

${ }^{78}$ Aunque lo haremos obviando el debate "racionalidad/irracionalidad" ya que este se encuentra ligado a las discusiones intelectuales en torno a la emergencia del peronismo, pero no reviste mayor relevancia para el análisis del kirchnerismo.

${ }^{79}$ Si bien mantenemos la categoría de antagonismo, tomamos aquí el espíritu de la propuesta de modelo adversarial de Mouffe (2007) para pensar las disputas en las sociedades democráticas, matizando las categorías de amigo/enemigo que presentan un carácter de irreductibilidad propia de la guerra (ligadas al planteo de Carl Schmitt, 1998 [1932]). En ambos casos, enemigo y adversario constituyen la otredad, el "ellos" con el cual se confronta. Asimismo, entendemos que dependiendo el desarrollo y las características propias del antagonismo en estudio, el mismo puede cobrar el rasgo de enfrentamiento radical propio de la lógica amigo/enemigo y eliminar el perfil adversarial, encontrando como punto de distinción la voluntad de eliminación del oponente.
} 
laclausiano poseemos un punto de contacto en la teoría gramsciana de la hegemonía, no podemos dejar de señalar que tanto la apreciación de la misma como la matriz teórica general tienen algunas distancias significativas, vinculadas a que el recorrido intelectual de Laclau se fue alejando del marxismo, del cual esta investigación es tributaria. En este sentido, para poder apropiarnos de algunas de sus categorías de análisis que nos permitan avanzar hacia ambos lados del continuo de pensamiento científico, debemos comenzar por la crítica de algunos de sus supuestos, poniendo en cuestión la argumentación a partir del cual abandona un conjunto de elementos centrales de la teoría marxista. En este camino problematizaremos la crítica laclausiana a la categoría de contradicción en el marxismo, para que, una vez recuperada dicha categoría, podamos rearticularla con la de antagonismo, tomando algunas apreciaciones teóricas de Laclau así como elementos de su estrategia analítica.

Uno de los pilares de la crítica que Laclau erige contra el marxismo (y que es una de las bases de su propuesta post-marxista) se relaciona con el desarrollo de su idea de antagonismo ligada a la crítica y posterior abandono de la categoría de contradicción $^{80}$. Laclau parte de una apreciación crítica de dos citas clásicas del marxismo: por un lado, la “dualidad” fuerzas productivas/relaciones de producción ${ }^{81}$, expresada en el Prólogo a la Contribución a la Crítica de la Economía Política (Marx, 1859) y, por el otro, a la afirmación del Manifiesto Comunista (Marx y Engels, 1960 [1948]) de entender la historia como historia de la lucha de clases. Sostiene que en estos textos “la estructura de las dos “contradicciones” no es idéntica” (Laclau, 1990:22). Nos detendremos en este punto, para luego abordar el tratamiento que Laclau da a la categoría misma de contradicción. Con respecto al Prólogo señala que:

\footnotetext{
"En el caso de la dualidad fuerzas productivas / relaciones de producción, se trata de una contradicción en el sentido estricto del término: la continuidad de la expansión de las fuerzas productivas más allá de un cierto punto constituye, dado un cierto sistema de relaciones de producción, una imposibilidad lógica, y esta imposibilidad se traduce, a corto o largo plazo, en el colapso mecánico del sistema” (Laclau, 1990:22-23, el subrayado es nuestro)
}

\footnotetext{
${ }^{80}$ Decimos "posterior abandono" porque en una primera etapa, Laclau mismo utilizaba la categoría de contradicción en su matriz analítica y la articulaba con la de antagonismo, por ejemplo, en sus escritos tempranos definía al pueblo como determinación objetiva, uno de los polos de la contradicción dominante a nivel de la estructura social (pueblo / bloque de poder) al tiempo que definía a las clases como polos de relaciones de producción antagónicas (Laclau, 1978).

${ }^{81}$ Si bien excede los límites de la tesis, se podría incluso problematizar el uso de "dualidad" que impone Laclau a la relación fuerzas productivas / relaciones de producción desde la perspectiva de Kohan (2003), en tanto el mismo distingue la relación dialéctica de los pares contradictorios enfrentada a la tradición filosófica del dualismo.
} 
Ya aquí encontramos una primera operación teórica de dudosa validez, en tanto realiza una lectura en clave fatalista, convoca el la idea de “colapso mecánico”, lectura que ya en ese momento no contara con ningún adepto relevante en el campo intelectual del marxismo. Al mismo tiempo no podemos dejar de notar que esta idea del colapso mecánico no aparece en el escrito de Marx (1859), sino que se sostiene que el desarrollo de las fuerzas productivas, “brindan las condiciones materiales” para la resolución del antagonismo que parte de la contradicción fuerzas productivas / relaciones de producción (donde "brindar condiciones” es una idea claramente distinta al "colapso mecánico”).

En cuanto a la crítica de las dos premisas marxistas, la del Prólogo y la del Manifiesto, Laclau enfatiza que "la dificultad reside aquí en el hecho de que si la contradicción fuerzas productivas / relaciones de producción, es una contradicción sin antagonismo, la lucha de clases es, por su parte, un antagonismo sin contradicción” (Laclau, 1990:23). La argumentación continúa realizando la siguiente lectura de ambos “tipos” de contradicciones:

\begin{abstract}
"Un punto, sin embargo está claro: cualquiera sea el tipo de articulación lógica existente entre "lucha de clases" y "contradicciones emergentes del proceso de expansión de las fuerzas productivas", es en estas donde reside, para Marx, la determinación en última instancia del cambio social (...) Pero, en ese caso, la posibilidad de integrar teóricamente las contradicciones emergentes del desarrollo de las fuerzas productivas y la lucha de clases depende de la posibilidad de reducir la segunda a momento interno en el desarrollo endógeno de la primera" (Laclau, 1990:23, el subrayado es nuestro).
\end{abstract}

Observamos aquí una segunda operación de dudosa validez, visible en la forma en que Laclau decide engarzar las dos premisas de los dos distintos textos: la reducción de la lucha de clases a un "momento interno en el desarrollo endógeno" de las fuerzas productivas, leídas estas a partir de la dualidad fuerzas productivas / relaciones de producción. Si bien efectivamente lucha de clases y fuerzas productivas poseen una relación directa, en tanto es en el terreno de la reproducción material donde las clases se gestan en relación a la producción y apropiación del valor, la lectura mecanicista que le impone Laclau a la dualidad fuerzas productivas / relaciones de producción no puede dejar de generar sino una lectura igualmente mecanicista de la lucha de clases y reducirlas a un epifenómeno ${ }^{82}$. Así, sólo puede sostenerse que la relación fuerzas

\footnotetext{
${ }^{82}$ Es visible en varios puntos de la crítica laclausiana al marxismo una tendencia a generar lecturas reduccionistas del marxismo que culminan con la "confirmación" de dicho reduccionismo como en una profecía auto-cumplida que deja el terreno despejado para la conformación de las teorías post-marxistas. Si bien muchas de las críticas realizadas forman parte, efectivamente, de las caracterizaciones menos
} 
productivas / relaciones de producción expresa una contradicción sin antagonismo si dicha relación es leída en clave fatalista-mecanicista, como “colapso" ${ }^{83}$. En este sentido, notamos que el señalamiento de que la posibilidad de integrar teóricamente las contradicciones emergentes del desarrollo de las fuerzas productivas y la lucha de clases depende de la posibilidad de reducir la segunda a momento interno en el desarrollo endógeno de las primeras puede ser criticada ampliamente por varios autores marxistas, principalmente por el mismo Gramsci. El pensador italiano ha dedicado un trabajo de largo aliento a analizar el carácter complejo y la especificidad de las superestructuras, reflexionando sobre las particularidades de la política y la cultura y su imposibilidad de reducirlo a un mero movimiento interno (y mucho menos inmediato) de la estructura.

En tercer lugar, no podemos dejar de notar que la argumentación general se erige a partir de recortar dos aseveraciones de textos de naturaleza profundamente distintas como el Prólogo a la Contribución a la Crítica de la Economía Política y el Manifiesto Comunista. Entendemos que es relevante pensar críticamente la naturaleza disímil de ambos textos, lo cual genera dificultades para la equiparación acrítica de los mismos. Precisamente porque uno es un prólogo que propone un esquema sintético para realizar una crítica de la economía política, que al mismo tiempo incluye el desarrollo de un debate, que Marx hace explícito, con el idealismo, y de ahí el énfasis en los procesos de reproducción material, el subrayado puesto en las problemáticas económico estructurales $^{84}$. Asimismo, el otro es un manifiesto, un "libro viviente" en términos gramscianos (Gramsci, 2003), una reconstrucción mítica de la historia con ánimos de motivar las pasiones en una empresa política. De este modo, Laclau equipara distintas afirmaciones de textos de distinta naturaleza, sin observar el carácter particular e

\footnotetext{
agraciadas dentro de algunas vertientes del marxismo, no podemos dejar de notar que también han sido a su vez ampliamente criticadas dentro del mismo. En este sentido, nos parece conveniente recordar la crítica que Gramsci (2008) dirigió al Ensayo de Sociología Popular de Bujarin por no haber discutido con las expresiones más avanzadas del pensamiento con el que confrontaba, sino, más bien, con sus caricaturizaciones o expresiones menos elaboradas.

${ }^{83}$ Más adelante procuraremos distinguir el enfoque y uso que daremos a las categorías de contradicción y antagonismo, pero por lo pronto podemos señalar que la forma de articulación de las dos premisas que Laclau utiliza pasa por alto que en el Prólogo Marx deja entrever que las relaciones burguesas de producción poseen una forma antagónica "que proviene de las condiciones sociales de vida de los individuos” (1959:2), es decir que parte de la contradicción a nivel de las clases sociales, de la relación social capital como unidad del par dialéctico capital/trabajo.

${ }^{84}$ Aunque por esto, claro, no haya que dejar de ejercer sobre este aspecto una mirada crítica. Además debe tenerse en cuenta, como mencionamos en el capítulo anterior, por ejemplo, que las distintas construcciones desarrolladas por Marx en torno a las clases sociales presentan variaciones según el carácter del problema abordado y el tipo de texto a través del cual se lo analiza.
} 
histórico, el vínculo relacional de dichos escritos con el contexto de emergencia y la función político-intelectual del texto.

El andamiaje argumentativo que, según Laclau, sostendría estas posiciones centrales en el marxismo, dependería “de poder mostrar que el antagonismo inherente a las relaciones de producción (el conflicto entre trabajo y capital, por ejemplo) es una contradicción; y que ese antagonismo es inherente a las relaciones de producción” (Laclau, 1990:24). Por un lado, Laclau sostiene que la relación capitalista / obrero, pudiendo ser antagónica, no es contradictoria:

\footnotetext{
"el antagonismo entre trabajo asalariado y capital es muy distinto: el hecho de que haya un antagonismo entre los dos polos de la relación -en torno a la apropiación de plusvalía, por ejemplo- no significa que la misma sea contradictoria. Antagonismo no significa necesariamente contradicción. Hay, en todo caso, una diferencia esencial entre un antagonismo considerado como no contradictorio y la contradicción hegeliana sensu stricto. En el caso de esta última, el movimiento dialéctico (y por lo tanto interno) del concepto predetermina sus formas subsiguientes, mientras que en el caso del antagonismo sin contradicción esa conexión interna está ausente. La resolución (o no resolución) del antagonismo depende enteramente de una historia factual y contingente.” (Laclau 1990:24, el subrayado es nuestro)
}

Por otra parte, se pregunta si existe una relación intrínsecamente antagónica entre trabajador y capitalista a partir del intercambio desigual que supone la extracción de plusvalía, y concluye que no, "porque es sólo si el obrero resiste esa extracción que la relación pasa a ser antagónica; y no hay nada en la categoría "vendedor de fuerza de trabajo” que sugiera que esa resistencia es una conclusión lógica” (Laclau 1990:25)

En esta argumentación desplegada por Laclau se nos presentan un conjunto de problemas cuya apreciación crítica nos permitirá, por un lado, profundizar algunos de los supuestos involucrados en nuestro enfoque y, por otro lado, reinscribir algunos de sus aportes teóricos para el abordaje de fenómenos políticos.

Ingresando en un cuarto momento crítico, notamos que Laclau habla de “contradicción hegeliana” y de movimiento interno del “concepto”, aspectos que deben ser problematizados a partir de una indagación profunda de la categoría de contradicción en el marxismo.

Entendemos que un factor central del hilo argumentativo planteado se ubica en la lectura y el uso que Laclau hace de la categoría de contradicción y su relación con el antagonismo. Laclau parte de una distinción establecida por Colleti quien a su vez retoma la distinción kantiana entre oposición real y contradicción lógica: 
"La primera coincide con el principio de contrariedad y obedece a la fórmula "A-B": cada uno de sus términos tiene su positividad propia, independiente de la relación con el otro. La segunda es la categoría de contradicción y obedece a la fórmula "A-no A": la relación de cada término con el otro agota la realidad de ambos. La contradicción tiene lugar en el campo de la proposición; sólo en un nivel lógico conceptual podemos incurrir en contradicciones" (Laclau y Mouffe, [1987] 2004:165, el subrayado es nuestro).

Este es el punto de partida de una amplia argumentación que culmina con el desecho de la categoría de contradicción y da lugar a una teoría del antagonismo desligada de la misma. Pero es en las distintas apreciaciones sobre la contradicción que hemos visto en Laclau donde se encuentra un problema central a ser desanudado. La crítica laclausiana a la contradicción en el marxismo, lejos de situarse en esta última teoría es reconducida, por un lado, a la lectura kantiana (vía Colleti) o a una lectura hegeliana pre-marxista. Emprenderemos el camino de la crítica a la crítica, con el fin de proponer una articulación propia de las categorías de antagonismo y contradicción, que enmarcará tanto la reapropiación de elementos analíticos del pensamiento laclausiano en nuestra perspectiva teórica, así como la profundización y aclaración de distintos supuestos de la misma. Para esto es necesario recrear una mirada de la contradicción en el marxismo, partiendo de los aportes de Engels, Lenin, Mao Tse-Tung y Althusser.

Lenin en su trabajo En torno a la cuestión de la dialéctica [1915] analiza la relación central que la dialéctica tiene con la categoría de contradicción, en tanto el estudio de los procesos sociales debe partir del análisis de las relaciones contradictorias, de la unidad de dos polos que se excluyen a la vez que se atraen y son mutuamente necesarios, creando dicha unidad, una identidad de los contrarios. Es en este sentido, que Lenin habla de “tendencias contradictorias”, y de la dialéctica como el camino propicio para conocer el movimiento, el desarrollo de los fenómenos sociales ${ }^{85}$ "en el sentido de la unidad de los contrarios (el desdoblamiento de la unidad en dos polos que se excluyen mutuamente y la relación entre ambos)” (Lenin, [1915] 1980:365). Así, Lenin sostiene que la dialéctica es una teoría del conocimiento y señala que deben analizarse desde esta perspectiva ya los fenómenos más sencillos ${ }^{86}$. Lenin da una definición clave de la dialéctica “como conocimiento vivo, multilateral (con el número de aspectos siempre en aumento), de innumerables matices en el modo de abordar, de

\footnotetext{
${ }^{85}$ Aunque tanto Lenin como, sobre todo, Engels ([1878] 2003), enfatizan en que este movimiento ocurre también en la naturaleza.

86 Según Lenin, dicha teoría debe enfocar en un conjunto de “cualidades: la transformación de lo particular en general, de lo casual en necesario, las transiciones, los matices, la relación mutua de los contrarios” ([1915] 1980:368).
} 
aproximarse a la realidad (con un sistema filosófico que, de cada matiz, se desarrolla en un todo)” ([1915] 1980:368). En este camino, Lenin afirma que

\begin{abstract}
"Marx, en El Capital, analiza al principio la relación más sencilla, corriente, fundamental, masiva y común, que se encuentra miles de millones de veces en la sociedad burguesa (mercantil): el intercambio de mercancías. En este fenómeno tan sencillísimo (en esta "célula" de la sociedad burguesa) el análisis descubre todas las contradicciones (es decir, el germen de todas las contradicciones) de la sociedad contemporánea. La exposición que sigue nos muestra el desarrollo (tanto el crecimiento como el movimiento) de estas contradicciones y de esta sociedad en la suma de sus partes aisladas, desde su principio hasta su fin.” ([1915] 1980:366).
\end{abstract}

Nos parece relevante tomar esta perspectiva de hacer de cada matiz un todo, de partir de fenómenos particulares con el fin de dar cuenta de un conjunto de movimientos históricos de más largo alcance; y es en este sentido que, en el último capítulo de la tesis, abordaremos el "conflicto del campo" como estudio de caso, en tanto representa una momento singular donde se funde el desarrollo de un conjunto de factores contradictorios orgánicos y coyunturales enlazados con la dinámica propia del antagonismo, exhibiendo al mismo tiempo una reapertura de una crisis de hegemonía y un cúmulo de tensiones inherentes al modelo de acumulación, permitiéndonos observar el complejo de dinámicas estructurales y superestructurales que atraviesan nuestro período de estudio en un caso particular.

Entendemos que la relación social capital, unidad compuesta por el par dialéctico capital/trabajo, constituye una relación contradictoria nodal del modo de producción capitalista implicando una disrupción permanente, una dislocación destacada, estructural, en toda sociedad capitalista en tanto la unidad de los contrarios se encuentra articulada como relación de explotación. Esta relación de explotación halla su epicentro en la teoría del valor consistente en la apropiación privada del producto del proceso colectivo de trabajo a través de la extracción de plusvalor. Por un lado, la negación actúa en las relaciones de propiedad sobre las que se funda la relación de explotación: para que haya plusvalor debe haber agentes propietarios de medios de producción y agentes negados de dicha propiedad, o sea desposeídos de medios de producción, de ahí que la relación de clase sea contradictoria. Por otro lado, la extracción de plusvalía implica la negación al trabajador del producto generado por su fuerza productiva, escindiendo su carácter colectivo en el marco de la apropiación privada. Este proceso donde ancla la contradicción entre capital y trabajo tiene expresión en la célula básica de las sociedades capitalistas: la mercancía como unidad de valor de uso y valor de cambio, que en la fuerza de trabajo expresa la propiedad 
única de esta mercancía cuyo consumo del valor de uso (trabajo) crea un valor superior a su valor de cambio (costo de reproducción de la fuerza de trabajo), siendo ésta apropiada privadamente en virtud de las relaciones de producción de la sociedad capitalista instaurando la contradicción de clase como una relación social permanente en este tipo de orden social. Éste es en el fondo la base del planteo del Prólogo a la Contribución a la Crítica de la Economía Política, la existencia de una contradicción entre un proceso de producción social, colectivo, y las relaciones de producción que involucran la apropiación privada del producto de dicho proceso involucrando relaciones de explotación y dominación. En este sentido, nos proponemos pensar la contradicción como tendencias disruptivas, como dislocación constitutiva, permanente de un orden social históricamente dado ${ }^{87}$. No se trata de un a priori, de una relación por fuera de la historia, sino de un rasgo constitutivo de un tipo de sociedad, de las formaciones sociales capitalistas, en las que deberá analizarse cómo juega la contradicción en un período particular, en relación al problema de estudio a ser analizado y, posiblemente, en relación con otro conjunto de problemáticas con especificidades propias que no deben reducirse a la contradicción de clase, tales como las étnicas o las de género, entre otras.

Habiendo realizado una primera aproximación preliminar, estamos en condiciones de señalar que la contradicción en el marxismo no responde necesariamente a la forma lógica a la que la reduce Laclau, anclada en la fórmula kantiana vía Colleti. En este camino, entendemos que no sólo la contradicción no puede reducirse simplemente a la fórmula “A- no A”, sino que posee incluso un carácter distinto del que puede emanar de dicha fórmula ${ }^{88}$. Por un lado, ciertamente nos enfrentamos a los dos

\footnotetext{
${ }^{87}$ Si bien en Lenin [1915] exclusión y antagonismo aparecen como constitutivos de la relación de contradicción, retomaremos la diferenciación que hace Mao Tse-Tung (1968 [1937]), señalando que sólo en determinados momentos la contradicción se torna en antagonismo, de este modo podemos observar contradicciones antagónicas y contradicciones no antagónicas.

${ }^{88}$ No pretendemos generar aquí una nueva fórmula lógica adecuada y reducir la contradicción a la misma, sino reflexionar sobre el carácter de las relaciones contradictorias y poner en cuestión la operación de Laclau de reducir la contradicción a la fórmula "A - no A", a partir la cual hila un conjunto de conclusiones que lo llevan al abandono de dicha categoría. Habiendo aclarado esto, me parece interesante rescatar una fórmula posible que me planteó Martín Retamozo, en la devolución crítica del borrador de este capítulo: [( $A \wedge B \wedge C)-($ noA $\wedge B \wedge D)]$. En esta definición aparece el aspecto de negación, de identidad y de diferencia que articulan los polos de una unidad. Como señalaremos a continuación, la relación A - no A es la parte de negación de toda contradicción (por ejemplo, poseedores y desposeídos de medios de producción), la B - B es la parte de identidad, el carácter común que comparten los polos de la unidad (por ejemplo, tanto trabajo como capital remiten a clases sociales mutuamente necesarias en la relación social capital) , y C - D, es la diferencia positiva propia de cada uno de los polos que excede la mera negación y que permite, por ejemplo en la relación capital - trabajo, la construcción de hegemonía propia que no se resuelve sólo en la negación (aunque esté vinculada a la misma).
} 
polos de la contradicción, donde algo del primer polo impugna al segundo (y viceversa), lo niega, lo tensa, lo excluye, lo constituye en una dislocación estructural, permanente, y en ese sentido establece una tendencia a la generación del conflicto. Es una contradicción que, como sostiene Mao Tse-tung (1968 [1937]), en determinados momentos pueden convertirse en antagónicas, o sea, dar lugar a la emergencia de un antagonismo. Pero si, por un lado, ambos polos de la contradicción de clase están mutuamente ligados y existe entre ambos una tensión constitutiva, que en el caso de la relación capital/trabajo se expresa, por ejemplo, en que la mayor apropiación del valor en tanto ganancia es inversamente proporcional a la apropiación del valor vía salario y en la posesión-desposesión de medios de producción que expresa el vínculo de negación, por otro lado, no todo se resuelve en la negación mutua. Hay algo de estos polos que, sin dejar de estar en relación de impugnación mutua, contiene una positividad propia, distinta de la mera negación: el trabajador no es sólo un nocapitalista, si así lo fuera no habría posibilidad de construcción de hegemonía, de formulación de concepciones del mundo propias con capacidad de universalizarse. Del mismo modo, las clases dominantes no se constituyen "sólo" en virtud de su carácter explotador. Ambas clases, sin dejar este anclaje estructural de mutua negación, se encuentran en una relación de contradicción que está sobredeterminada ${ }^{89}$ y, a su vez, disputan los sentidos del orden social y al orden mismo mediante estrategias hegemónicas que implican, como señala Gramsci (2003), el poder aparecer como una fuerza que desarrolla las “energías” de toda una nación. Esa misma posibilidad de no sólo construir “contra-hegemonía”, 90 es decir, de construir la negación de lo establecido (y así, la negación de la negación), sino de construir una hegemonía propia, alternativa, que no deja de lado la contradicción, sino que juega en ella a partir de una construcción propia, sin dejar esta misma de estar siempre en tensión en virtud de la negación constitutiva de ambos polos. Es por ello que entendemos que el polo del trabajo no puede reducirse sólo a "no A”, sino que sin dejar de ser parte de la negación, de estar expropiado de medios de trabajo y, por ello, depender de vender su fuerza de trabajo para poder reproducirse, es asimismo un polo con cualidades propias. Esto aparece involucrado en la misma definición marxista, ya que si bien el proletariado suele aparecer definido negativamente como no propietario de medios de producción, como

\footnotetext{
89 Como señalaremos a continuación, tomamos sobredeterminación en el sentido de Althusser (1988 [1962]).

${ }^{90}$ Que sin embargo, es un aspecto necesario en toda relación contradictoria.
} 
des-poseído, también es definido, por ejemplo, como poseedor de una mercancía particular, la fuerza de trabajo, lo cual implica un carácter particular, distinto al del capitalista como propietario de medios de producción, sin dejar por esto de estar en relación, en unidad o identidad de los polos, que incluye la posibilidad de subversión dialéctica de dicha relación (aunque esta subversión no esté garantizada de ante-mano). Esto se debe a que, como argumentaremos a continuación, la dialéctica en Marx, como señala Althusser (1988 [1962]), posee una estructura diferente a la hegeliana, implicando, entre otros aspectos, que la contradicción marxista no contiene ya la simplicidad de la contradicción hegeliana (dada en la posibilidad reducir la diversidad de un periodo histórico determinado a un principio interno simple), sino que la misma es una contradicción sobredeterminada ${ }^{91}$. De este modo,

\begin{abstract}
"la contradicción Capital-Trabajo no es jamás simple, sino que se encuentra siempre especificada por las formas y las circunstancias históricas concretas en las cuales se ejerce. Especificada por las formas de la superestructura (Estado, ideología dominante, religión, movimientos políticos organizados, etc.); especificada por la situación histórica interna y externa que la determina en función del pasado nacional mismo, por una parte (revolución burguesa realizada o "reprimida”, explotación feudal eliminada, totalmente, parcialmente o no, “costumbres” locales, tradiciones nacionales específicas, aún más, “estilo propio” de las luchas y de los comportamientos políticos, etc...), y del contexto mundial existente, por la otra (lo que allí
\end{abstract}

\footnotetext{
91 "La simplicidad de la contradicción hegeliana no es posible, en efecto, sino a partir de la simplicidad del principio interno que constituye la esencia de todo período histórico. Es debido a que es posible de derecho reducir la totalidad y la infinita diversidad de una sociedad histórica dada (Grecia, Roma, el Sacro Imperio, Inglaterra, etc...) a un principio interno simple, que esta misma simplicidad, adquirida así de derecho a la contradicción, puede reflejarse en ella. ¿Es necesario ser aún más claro? Esta reducción misma (cuya idea sacó Hegel de Montesquieu), la reducción de todos los elementos que forman la vida concreta de un mundo histórico (instituciones económicas, sociales, políticas, jurídicas, costumbres, moral, arte, religión, filosofía, y hasta los acontecimientos históricos: guerras, batallas, derrotas, etc.) a un principio de unidad interna, esta reducción misma no es en sí posible sino bajo la condición absoluta de considerar toda la vida concreta de un pueblo como la exteriorización-enajenación (EntäusserungEntfremdung) de un principio espiritual interno que no es, en definitiva, sino la forma abstracta de la conciencia de sí de ese mundo: su conciencia religiosa o filosófica, es decir, su propia ideología. Creo que se percibe bien aquí en qué sentido la "envoltura mística" afecta y contamina el "núcleo", ya que la simplicidad de la contradicción hegeliana no es sino la reflexión de la simplicidad de este principio interno de un pueblo, es decir, no de su realidad material sino de su ideología más abstracta. A ello se debe que para él no haya jamás, en el fondo, una verdadera ruptura, un fin efectivo de una historia real, ni tampoco un comienzo radical. A ello se debe también el que su filosofía de la Historia se encuentre llena de mutaciones, todas ellas uniformemente "dialécticas". No puede defender esta concepción aturdidora sino manteniéndose en la cima del Espíritu, donde poco importa que un pueblo muera, ya que ha encarnado el principio determinado de un momento de la Idea (que tiene otros a vuestro servicio), y ya que encarnándolo lo ha despojado, al mismo tiempo, a tal otro pueblo (¡aun si su relación histórica con él es muy débil!), quien, reflejándolo en su sustancia, encontrará en él la promesa de su propio principio interno, es decir, como por azar, el momento lógicamente consecutivo de la Idea, etc." Althusser, 1988:83-84, subrayado en el original). Parece interesante observar que si bien Laclau y Mouffe (2004 [1987]) rescatan la idea de sobredeterminación en Althusser, sin embargo parecen no tener en cuenta dicha lectura efectuada por el autor marxista cuando realizan la crítica a la contradicción, usualmente concretada a partir de citas a Kant y a Hegel, ya que el mismo Althusser advierte que la recuperación de la dialéctica en el marxismo no pudo efectuarse sino mediante transformaciones radicales respecto del pensamiento de sus antecesores.
} 
domina: competencia de naciones capitalistas, o "internacionalismo imperialista", o competencia en el seno del imperialismo, etc.)” (Althusser, [1962] 1988:86, subrayado en el original)

A partir de esto obtenemos dos conclusiones. Por un lado, vemos críticamente la operación cognitiva laclausiana de reducir la contradicción marxista ya al movimiento interno simple del concepto (o sea como contradicción hegeliana), ni hallamos validez tampoco, como señalamos con anterioridad, en reducir la contradicción marxista a la fórmula de la contradicción kantiana (vía Colleti). Por otro lado, podemos percibir a partir de la cita de Althusser, cómo se deshace la supuesta incompatibilidad de las premisas involucradas en la relación fuerzas productivas / relaciones de producción y en la lucha de clases, en el centro del pensamiento dialéctico mismo. Podemos afirmar que en la mercancía se expresa la contradicción entre las fuerzas productivas y las relaciones de producción, en tanto en el capitalismo emerge una mercancía particular (fuerza de trabajo) generadora de valor que, vinculada al diferencial expresado en el valor generado a través la realización del valor de uso de dicha mercancía y su valor de cambio (costo de reproducción), conlleva (en virtud de las relaciones de producción capitalistas que implican una negación de la posesión de medios de producción generando la división de clases), una apropiación privada del producto social, colectivo, instituyendo una relación de explotación y, luego, de dominación. Esto constituye la contradicción principal, la dislocación estructural que da origen a la lucha de clases, sin ser el resultado de dicha lucha un mero movimiento interno de la contradicción estructural (mucho menos con un desenlace prefijado de “colapso mecánico”), sino un proceso histórico que articula el conjunto de dimensiones del bloque histórico y se define en el terreno estrictamente político de la construcción de hegemonía, sin dejar de tener a su vez, este terreno, anclajes estructurales.

Asimismo, decíamos que entre los dos polos se da al mismo tiempo una relación de unidad necesaria y de exclusión, esta tensión constitutiva que parte de la unidad de los contrarios, está articulada, como señala Mao Tse-Tung, a partir de dos sentidos de la identidad o unidad. El primero de los cuales remite a su mutua dependencia:

\footnotetext{
"ninguno de los dos aspectos contradictorios puede existir independientemente del otro. Si falta uno de los dos contrarios, falta la condición para la existencia del otro (...) Así sucede con todos los contrarios: en virtud de determinadas condiciones, junto con oponerse el uno al otro, están interconectados, se impregnan recíprocamente, se interpenetran y dependen el uno del otro; esto es lo que se denomina identidad. Los aspectos de toda contradicción se llaman contrarios porque, en virtud de determinadas condiciones, existe entre ellos no-identidad. Pero también existe entre ellos identidad, y por eso están interconectados. A esto se refería Lenin cuando dijo que la dialéctica estudia "cómo los contrarios pueden [ . . . ] ser idénticos ". ¿Por qué pueden serlo?
} 
Porque cada uno constituye la condición para la existencia del otro. Este es el primer sentido de la identidad.” (Tse-tung, [1937] 1968:361-362, el subrayado es nuestro)

Así, los elementos contrarios están interconectados a través de una relación de unidad, de identidad, que al mismo tiempo posee un segundo carácter, en tanto está relación de identidad constituye asimismo un "puente” que habilita su dialéctica, y permite su transformación y el cambio de posición de dominados a dominantes:

\begin{abstract}
"La cuestión no se limita a la interdependencia de los contrarios; más importante aún es la transformación del uno en el otro. Esto significa que, en razón de determinadas condiciones, cada uno de los aspectos contradictorios de una cosa se transforma en su contrario cambiando su posición por la de éste. Tal es el segundo sentido de la identidad de los contrarios.

¿Por qué existe identidad aquí también? Obsérvese cómo, a través de la revolución, el proletariado se transforma de clase dominada en clase dominante, en tanto que la burguesía, hasta entonces dominante, se transforma en dominada, cambiando cada cual su posición por la que originalmente ocupaba su contrario.” (Tse-tung, [1937] 1968:362, el subrayado es nuestro)
\end{abstract}

Este segundo sentido de la identidad ${ }^{92}$ se encuentra directamente relacionado con una de las aspiraciones centrales del materialismo dialéctico: el de constituir una teoría, una genuina concepción del mundo (en el sentido gramsciano) que no sólo se limita al conocimiento de la realidad ${ }^{93}$, sino que habilita la transformación de la misma. Ésta es una máxima central de la teoría marxista, definida por Marx en la tesis XI sobre Feuerbach: "Los filósofos no han hecho más que interpretar de diversos modos el mundo, pero de lo que se trata es de transformarlo” (Marx, 1845:1) ${ }^{94}$. En este mismo sentido se expresa Lukács cuando señala que el corazón del marxismo se encuentra en su método: la dialéctica, sentenciando a continuación que "la dialéctica materialista es una dialéctica revolucionaria” (Lukács, [1923] 1969:2). Gramsci mismo evidencia que la piedra angular de su teoría de la hegemonía surge a partir del análisis de dos tipos de sociedades disímiles en cuanto al grado de desarrollo de la sociedad civil y el peso del Estado, “Oriente” y “Occidente”, y de las estrategias revolucionarias que deberían seguirse en cada una de ellas, "la guerra de movimiento" como posibilidad de un enfrentamiento frontal en determinadas condiciones críticas y la "guerra de

\footnotetext{
${ }^{92}$ Mao Tse-Tung (1968 [1937]) enfatiza la articulación de los contrarios a través de este puente que los liga al mismo tiempo que habilita su transformación, puente que llama "identidad o transformación recíproca o interpenetración”.

93 "[I] El defecto fundamental de todo el materialismo anterior -incluido el de Feuerbach- es que sólo concibe las cosas, la realidad, la sensoriedad, bajo la forma de objeto o de contemplación, pero no como actividad sensorial humana, no como práctica, no de un modo subjetivo. De aquí que el lado activo fuese desarrollado por el idealismo, por oposición al materialismo, pero sólo de un modo abstracto, ya que el idealismo, naturalmente, no conoce la actividad real, sensorial, como tal (...)” (Marx, 1845:1)

${ }^{94}$ Seguramente haya sido Lenin, quien mejor encarnó iconográficamente esta aspiración del marxismo de articulación de teoría y práctica en un sentido transformador, como Gramsci remarcaba al pensar a Marx y Lenin como las dos piezas fundamentales del marxismo en tanto concepción del mundo.
} 
posiciones”, la construcción de hegemonía de largo aliento indispensable en las sociedades complejas ${ }^{95}$.

Con respecto al señalamiento de Laclau que sostiene que la relación de contradicción sólo puede ser "interna al concepto" debemos enfatizar que ya desde dentro mismo del marxismo han sido desarrolladas lecturas que afirman que esta perspectiva hegeliana no es heredada linealmente por el marxismo, en tanto el mismo subvierte la centralidad de "la Idea” entronando a los procesos de reproducción material y la luchas de clases como lugares privilegiados de análisis del movimiento histórico: como señalara Marx (2000 [1852]), son los hombres los que hacen la historia pero en condiciones que ellos no eligieron. Nuevamente, sería un error reducir el proceso histórico a elementos lógicos simples ${ }^{96}$ (o sostener, como hace Laclau, que esto es parte ineludible del marxismo aunque siempre lo haga a través de apelaciones a Hegel o a Kant ${ }^{97}$ ), sino que como indica Tse-Tung: “Cuando decimos que, bajo determinadas condiciones, existe la identidad de los contrarios, nos referimos a contrarios reales y concretos, y consideramos que la transformación del uno en el otro es igualmente real y concreta” (1968:364). Del mismo modo se expresa Engels ([1878] 2003) cuando sostiene que la contradicción es parte constitutiva de la estructura de lo real e impulsa su movimiento, afirmación que refuta la propuesta laclausiana de que la contradicción tendría lugar sólo en el terreno lógico-conceptual de la proposición ${ }^{98}$.

Esto no implica que estos clásicos del marxismo no estén exentos de problemas teóricos, como el intento de expansión de la dialéctica a todas las formas de movimiento incluso en la naturaleza que promueve Engels, los remanentes teleológicos teñidos de inevitabilidad histórica, o la subvaloración de Tse-Tung de determinados factores político-culturales. En este último caso, observamos que Mao infravalora la potencia movilizadora y transformadora del mito, a pesar sostener que "los mejores mitos

\footnotetext{
${ }^{95}$ Tampoco Laclau rehúye de la aspiración de articulación teórico-práctica, incluso luego de abandonar la perspectiva dialéctica, títulos como "Hegemonía y estrategia socialista" o "Por qué construir un pueblo es la tarea principal de la política radical”, entre otros, son indicativos de esta preocupación.

${ }^{96}$ Nos referimos a la reducción lógica de pensar la contradicción sólo como “A - no A”.

${ }^{97}$ Por citar algún ejemplo: "La contradicción, como señaló Kant, sólo puede tener lugar entre conceptos" (Laclau, 2006:22).

${ }^{98}$ Habría que preguntarse si Laclau en esta operación de reducir la contradicción al ámbito del concepto ("La contradicción tiene lugar en el campo de la proposición; sólo en un nivel lógico conceptual podemos incurrir en contradicciones” (Laclau y Mouffe, 2004:165)) no estaría procediendo como el señor Dühring, quien sostiene que "Lo contradictorio es una categoría que no puede pertenecer más que a combinaciones de pensamientos, no a una realidad” (Engels, [1878] 2003:111), afirmación a la que Engels responde planteando justamente a la dialéctica como movimiento de lo real.
} 
poseen, como señaló Marx, "un encanto eterno"” luego desestima esta potencia sentenciando que "los mitos no se crean basándose en situaciones determinadas surgidas de contradicciones concretas y, por lo tanto, no son un reflejo científico de la realidad” (Tse-tung, 1968:365). El debate con los dogmáticos y místicos lo lleva a un materialismo que ahoga algunas especificidades y complejidades de las superestructuras, quedando limitado por una teoría del reflejo. Es con Gramsci donde el mito recobra su vigor y ocupa un lugar destacado en los procesos sociales, como vimos en el desarrollo de su teoría del Príncipe moderno, donde la centralidad del mito se vincula con la función de creación de una fantasía concreta que actúa sobre un pueblo disperso para constituir su voluntad colectiva (Gramsci, 2003) ${ }^{99}$.

También es necesario retomar las críticas de Laclau a la perspectiva teleológica que contienen diversas variantes del marxismo, impregnadas de una visión de necesariedad e inevitabilidad de la superación de los opuestos ${ }^{100}{ }^{101}$. Como ya lo dijera

\footnotetext{
${ }^{99}$ Entendemos que la introducción gramsciana del mito y el papel de las pasiones en los procesos históricos ya había implicado resquebrajar la idea que Laclau combate de una ““sociedad” como totalidad racionalmente unificada" (Laclau y Mouffe, 2004:136) que, por ejemplo, era fuertemente perceptible en los textos tempranos de Lukács en la relación entre la posición de clase y la conciencia (que derivara en el uso de la "falsa conciencia" como vía de explicación). El mito y las pasiones incorporan elementos de otro orden, que no permiten explicar el movimiento de la sociedad, ni a la sociedad misma, como un todo cerrado, racionalmente unificado de punta a punta, sino que, como se muestra en el enfoque sobre el Príncipe moderno, la conformación del mito con capacidad de movilizar las pasiones es una clave analítica para pensar la conformación misma de una voluntad colectiva nacional-popular, así como los procesos de transformación más generales.

${ }^{100}$ Por ejemplo, Mao sostiene que "en la sociedad de clases, son inevitables las revoluciones y las guerras revolucionarias y que sin ellas es imposible realizar saltos en el desarrollo social y derrocar a las clases dominantes reaccionarias, y, por lo tanto, es imposible que el pueblo conquiste el Poder. Los comunistas deben denunciar la engañosa propaganda de los reaccionarios, quienes afirman, entre otras cosas, que la revolución social es innecesaria e imposible; deben perseverar firmemente en la teoría marxista-leninista de la revolución social y ayudar al pueblo a comprender que la revolución no sólo es absolutamente necesaria, sino también enteramente posible, y que esta verdad científica ha sido confirmada ya por toda la historia de la humanidad y por el triunfo en la Unión Soviética” (Tse-tung, 1968:368, el subrayado es nuestro). En este mismo párrafo conviven tanto una idea teleológica de "inevitabilidad" pero, al mismo tiempo, aparece una matización en torno a la idea de la "posibilidad".

${ }^{101}$ Como dijimos, es necesario mantener una fuerte crítica sobre las perspectivas afincadas en la "inevitabilidad" y su optimismo en términos de la superación ineludible: en la historia las condiciones objetivas pueden transformarse y favorecer (o no) el movimiento dialéctico en un sentido superador; sin embargo, la lucha de los contrarios se dirime en el marco de relaciones de fuerzas que atraviesan un amplio conjunto de dimensiones que median, complejizan y constituyen este movimiento. Pero aun así, la dialéctica y el movimiento en torno a la contradicción sigue siendo indispensable para el análisis sociohistórico, para poder observar fisuras estructurales, constitutivas de un orden social determinado que operan como dislocaciones centrales de las cuales se presentan una tendencia permanente al conflicto (aunque el mismo no se traduzca necesaria y permanentemente en antagonismo) pero también porque permite entrever a través del análisis de la realidad concreta su posible transformación: por ejemplo, que la posibilidad de superación del modo de producción capitalista se liga a la posibilidad de resolver en el terreno histórico y contingente, en el terreno de la lucha de clases, la contradicción al interior de la relación social capital entre trabajadores y capitalistas. Es este punto el que contiene en sí el vigor de la Tesis XI sobre Feuerbach y de la concepción lukacsiana de la dialéctica materialista como dialéctica
} 
Althusser [1962], la contradicción puede ser sobredeterminada en el sentido de una inhibición histórica, de un verdadero "bloqueo" de la contradicción, o en el sentido de la ruptura revolucionaria. Entonces nada hace prever el desenlace fatalista o mecanicista de las contradicciones, sino su complejo desarrollo en una formación social particular en un período histórico dado, convocando al análisis profundo de las sobredeterminaciones que actúan y que aportan un carácter contingente, una definición histórica de las contradicciones que rompe con las miradas de necesariedad y de superación inevitable que anclaron en algunas lecturas dentro del marxismo.

En este camino, es necesario sostener una perspectiva crítica frente a las teorías del reflejo. Entendemos que dicho enfoque se vincula con el supuesto de simplificación de la estructura de clases, la cual simplificaría, a su vez, las articulaciones entre el par dialéctico estructura/superestructura. En este sentido, es necesario dar cuenta de la no corroboración de la hipótesis de simplificación de la estructura de clases (o al menos de la relevancia de contra-tendencias, dependiendo de las distintas formaciones sociales en distintos momentos de su historia) y de la constatación de la no necesariedad e inevitabilidad de resolución de las contradicciones en un sentido de superación. Esto implica erigir una crítica a los resabios teleológicos y optimistas, generados tanto por un apego lineal al modelo hegeliano o por las coyunturas históricas (previas o actuales) favorables a procesos de transformación social. Ya la máxima de Rosa Luxemburgo de "socialismo o barbarie" habilitaba la posibilidad de la barbarie como forma de resolución no teleológica de la contradicción ${ }^{102}$. También desde el análisis del Americanismo y Fordismo de Gramsci (2003) o el conjunto de estudios de la Escuela de Frankfurt evidencian, en la historia del capitalismo, la inaudita capacidad de dicho modo de producción (de la vida) para readaptarse, reformularse y persistir ${ }^{103}$.

revolucionaria. Y es, al mismo tiempo, un llamado cognitivo a rescatar la importancia del análisis de clase en la investigación en ciencias sociales.

102 Como señala Lowy, "fue la propia Rosa Luxemburgo quien (inspirándose en Engels) estableció explícitamente, por primera vez, el socialismo no como el producto "inevitable" de la necesidad histórica, sino como una posibilidad histórica objetiva. En este sentido, la consigna "socialismo o barbarie" significa que, en la historia, la suerte no está echada. La "victoria final” o la derrota del proletariado no están decididas de antemano por las "leyes de bronce” del determinismo económico, sino que dependen también de la acción consciente, de la voluntad revolucionaria de ese proletariado” (2001:1).

${ }^{103}$ El problema es que Laclau pareciera ubicar a la hipótesis de simplificación creciente de la estructura social como un supuesto que forma parte del núcleo central del programa de investigación científica (Lakatos, 1978) marxista, mientras que nosotros entendemos que se trata de una hipótesis auxiliar, que no se encuentra en el núcleo central, y que, por lo tanto, su no corroboración no implica la caída del PIC en su conjunto. Asimismo comprendemos que la caída de esta hipótesis conlleva una revisión crítica de sus consecuencias teóricas: por ejemplo, la baja de la teoría del reflejo y sus correlatos científicos (y políticos). Si bien observamos que lejos de incurrir en una creciente simplificación de las relaciones 
Entendemos que la sobredeterminación es constitutiva de la contradicción, genera que ni las modificaciones en la estructura tengan un efecto relámpago de transformación idéntica en las superestructuras, y que las formas de una nueva superestructura o distintas circunstancias nacionales o internacionales, puedan provocar "la supervivencia, es decir, la reactivación de los elementos antiguos. Esta reactivación es inconcebible en una dialéctica desprovista de sobredeterminación” (Althusser, 1988:94-95, subrayado en el original). Esto se vincula directamente con el pensamiento gramsciano de la hegemonía: en las sociedades complejas el Estado, si bien es una parte fundamental, es sólo la trinchera más avanzada detrás de la cual se encuentran otras múltiples de la sociedad civil ${ }^{104}$ con capacidad de recomponer la hegemonía y el orden previo o de marcar de forma singular al orden naciente.

En síntesis, proponemos realizar un rescate y revaloración crítica de la categoría de contradicción, para rearticularla con una visión particular del antagonismo. En primer lugar debemos identificar dos órdenes distintos:

1. La contradicción: emerge del aspecto de negación de los polos de la unidad; es una dislocación constitutiva, expresa una potencia disruptiva que parte de la estructura, pero que se encuentra siempre sobredeterminada por una multiplicidad de factores superestructurales, así como por la coyuntura internacional.

Asimismo, la contradicción nodal capital/trabajo, no se traduce inmediatamente en antagonismo, el cual requiere, como señala Laclau, de que se produzca un acto de resistencia o un conflicto. Sin embargo, Laclau sostiene que el antagonismo que podría existir entre trabajadores y capitalistas surge "por la manera en que el trabajador es constituido fuera de las relaciones de producción (el hecho que debajo de un cierto nivel de salario él/ella no puede llevar una vida digna, etc.)” (2006:31 el subrayado es nuestro), pareciendo desconocer que la idea de poder llevar una "vida digna" con su salario está implicada en el concepto marxista de costo de reproducción de la fuerza de trabajo que como afirma el propio Marx, se determina histórica y culturalmente en un momento y sociedad dados, por lo que lejos de ser un “afuera” está implicado en la

sociales generales que atraviesan al modo de producción capitalista, las mismas se han complejizado, vemos también que en este sentido se hizo indispensable el desarrollo de nuevas teorías y herramientas heurísticas que adaptaron y enriquecieron el programa de investigación científica marxista: es en este camino que el aporte de Gramsci, y su teoría de la hegemonía, constituye un momento insoslayable.

${ }^{104}$ Recordemos que la sociedad civil en Gramsci es parte de las superestructuras. 
contradicción que articula ambos polos ${ }^{105}$. Asimismo, sostenemos que los conflictos entre capital y trabajo parten de esta fisura estructural, que no es a priori sino que tiene que ver con los rasgos centrales del capitalismo como modo de producción de la vida. Esto no implica abolir el papel de la contingencia, sino rearticularla con fenómenos de carácter estructural que están, a su vez, sobredeterminados y que deben ser estudiados a la luz de un proceso histórico particular. En nuestra investigación, observaremos cómo el colapso del modelo de la convertibilidad, se vinculó tanto a la imposibilidad de continuidad de funcionamiento de un modo de organizarse la estructura como a las acciones concretas desarrolladas por el Estado y por los agentes económicos, actores políticos y corporativos. Asimismo, cuando analicemos el denominado "conflicto del campo” de 2008, veremos cómo es igualmente necesario comprender las dinámicas políticas propias del conflicto así como también el marco estructural en las que tienen lugar: sería irrisorio pensar dicho enfrentamiento sin tener en cuenta, por ejemplo, los procesos de concentración estructural que fueron gestándose en períodos previos y que dieron lugar a un triple proceso de concentración: de la tierra, del capital y de la gestión del proceso productivo, que potenció el poder estructural de los agentes involucrados, así como en la reorganización de largo plazo del proceso de trabajo se fortaleció la subsunción estructural del trabajo frente al polo del capital, y cómo estos procesos, a su vez, no lo explican todo, sino que se articulan con una dinámica particular de polarización del escenario político y de la conformación de un alineamiento opositor que fue parte clave de la ofensiva contra el oficialismo.

2. El antagonismo: remite a una dimensión estrictamente política, y que veremos a la luz de distintos elementos de la estrategia laclausiana vinculados a la articulación de demandas que, en tanto representación de faltas, permiten conformar una cadena de equivalencias, implicando el establecimiento de una frontera en un proceso de conformación identitaria y emergencia de sujetos.

En este sentido, nos proponemos realizar una re-localización de distintos elementos provenientes del pensamiento y la estrategia analítica de Laclau,

\footnotetext{
${ }^{105}$ Marx señala que "El valor de la fuerza de trabajo está formado por dos elementos, uno de los cuales es puramente físico, mientras que el otro tiene un carácter histórico o social" y agrega "en la determinación del valor del trabajo entra el nivel de vida tradicional en cada país. No se trata solamente de la vida física, sino de la satisfacción de ciertas necesidades, que brotan de las condiciones sociales en que viven y se educan los hombres. El nivel de vida inglés podría descender hasta el grado del irlandés, y el nivel de vida de un campesino alemán hasta el de un campesino livonio" (Marx, 1865:59).
} 
incorporándolos a nuestro enfoque como una teoría "regional”106. Con esto queremos señalar, que el trayecto iniciado en el debate en torno a las categorías de contradicción y antagonismo supone partir de un desacuerdo en torno a un conjunto de supuestos y valoraciones teóricas que implican que la reapropiación de los elementos teóricos laclausianos no pueda evitar sino trastocar el contenido de los mismos. Esto se debe a que, como fuimos desarrollando en nuestro enfoque, nos encontramos lejos de abonar el razonamiento que lleva de la esquematización del marxismo en clave reduccionista (reduccionismo de clase, economicismo, esencialismo, etc), que deriva en abandono de categorías marxistas centrales, la des-jerarquización de la clase social como categoría de análisis, y a la eliminación de la distinción estructura-superestructura, en pos del imperio del discurso. Es en este camino, donde la topografía del marxismo clásico es dada de baja, abrazando Laclau una nueva y única estructura donde las posiciones de sujeto son posiciones discursivas derivando, a nuestro entender, en una nueva tensión teórica que trascurre de la crítica al economicismo a un posible politicismo ${ }^{107}$, a partir de la afirmación de la primacía de la política ${ }^{108}$ y la abolición de la contradicción ${ }^{109}$. Es a partir de las distintas valoraciones y críticas que fuimos señalando que entendemos el enfoque planteado por Laclau muestra una intensa vivacidad y capacidad para el análisis político, al tiempo que presenta dificultades, por ejemplo, para el estudio del proceso de acumulación de capital y para el análisis económico en general.

\footnotetext{
${ }^{106}$ Decimos "regional” evocando a Poulantzas, en el sentido de pensar la estrategia analítica de Laclau como un aporte para pensar específicamente las lógicas políticas, pero encontrando dificultades para pensarla como una teoría general de la sociedad en su conjunto.

${ }^{107}$ No afirmamos que esto ocurra necesariamente con la teoría de Laclau, pero sí que es una tensión presente en la que puede caerse si se radicalizan de modo acrítico algunos de sus lineamientos conceptuales.

108 "Una consecuencia de nuestros análisis es que tenemos que afirmar la primacía de las políticas en la estructuración de espacios sociales” (Laclau, 2006:32)

${ }^{109}$ El carácter de la tensión que mencionamos consistiría en terminar de realizar un trayecto que implica subsumir la estructura (en términos marxistas), en las superestructuras y dentro de ella en la ideología, radicalizando la posición althusseriana de que la ideología constituye sujetos, para luego borrar estos trazos y permanecer en el imperio del sentido, del discurso como co-extensivo a toda práctica social y de una estructura única fundada a partir del mismo. Algunos autores ven realizada esta tensión en la teoría de Laclau, como, por ejemplo, Veltmeyer cuando sostiene que "Tan preocupado está Laclau por combatir el "reduccionismo clasista"-que se halla más en la mente de Laclau que en los escritos marxistas serios- y los múltiples y diversos "esencialismos" del marxismo vulgar, que él cae en la trampa del "reduccionismo discursivo": de la reducción de la realidad al concepto, transformando las cosas en palabras" (Veltmeyer, 2006:5). En el mismo sentido se expresa Rush al señalar que Laclau y Mouffe "reemplazan el supuesto esencialismo economicista de Marx y el marxismo, por lo que parece ser, como ya dije, un esencialismo "politicista y discursivista”” (Rush, 2002:s/p). También se expresan en la misma línea Boron y Cuéllar cuando sostienen que "Los pasos del tránsito de Laclau desde el estructuralismo materialista al neoestructuralismo idealista son los siguientes: a] inversión de la problemática althusseriana; b] reducción de lo económico a lo político y de lo político a lo ideológico; c] reducción de lo ideológico a lo discursivo y de la temática del sujeto a la temática de lo discursivo; y d] liquidación, a fin de cuentas, de la temática de la hegemonía en la forma que está presente en Lenin y Gramsci” (Boron y Cuéllar, 1983:10).
} 
En virtud de nuestro problema de estudio, optamos por mantener el esquema clásico estructura/superestructura, esquema que si bien no está exento de problemas, nos permite delimitar dimensiones cualitativamente distintas en términos analíticos, observando su vinculación dialéctica, trayendo a escena la idea de sobredeterminación, sin caer en una rígida oposición entre ambas ni predeterminar a priori sus articulaciones concretas sino a la luz del análisis empírico, entendiendo que, al mismo tiempo, componen una unidad compleja en el bloque histórico, categoría de totalidad gramsciana, una totalidad dinámica e histórica. Pensamos las dimensiones estructurales y superestructurales que componen la topografía marxista de lo social, enfocadas desde una mirada no esencialista sobre el nivel económico, ni una perspectiva apriorítica de las clases sociales. Esto implica restituir la relación dialéctica e histórica entre estructura y superestructura en el camino de Gramsci, observando la autonomía relativa entre ambos niveles, sus relaciones y especificidades. Además, lejos de infravalorar el análisis de las clases sociales, las vemos como elementos de significativa importancia en todo orden social capitalista, entendiendo que su construcción debe partir tanto de las relaciones inherentes a todo orden social de este tipo (relaciones de explotación, dominación, etc.), como en vinculación a la dinámica histórica, desarrollando definiciones operacionales ligadas a las coordenadas espacio-temporales abordadas y al problema de estudio. Es aquí donde encontramos una clave para pensar las distintas construcciones que aplicó Marx sobre las clases en sus distintos textos. Lejos de pensar a las clases como cristalizadas o definidas a priori, vemos que Marx en el 18 Brumario (2000 [1852]), que es un texto eminentemente político, se para desde los problemas analizados en esta dimensión para construir su recorte de las fracciones ${ }^{110}$ mientras que en un trabajo de naturaleza distinta como El Capital (2007), las clases y fracciones pueden ser apreciadas a partir de otro ángulo ${ }^{111}$.

\footnotetext{
${ }^{110}$ La construcción de fracciones tales como "fracción burguesa republicana”, "pequeña burguesía democrático-republicana” y "obreros socialdemócratas”, evidencian cómo el problema de estudio y el carácter del texto producido (en este caso un texto de claro corte de análisis político) tienen implicancias en la elaboración analítica y operacionalización de las clases (lo cual contrasta fuertemente con la acusación laclausiana de leer las clases en el marxismo en clave de reduccionismo esencialista).

${ }^{111}$ Por ejemplo, vinculadas a los distintos ciclos del capital.
} 
Habiendo realizado estas aclaraciones podemos observar la rearticulación singular de los diversos elementos teóricos laclausianos ${ }^{112}$ y su incorporación a nuestra red conceptual.

La estrategia analítica de Laclau parte de una unidad de análisis básica: la demanda social (demand), ya aparezca ésta como petición (request) o reclamo (claim). Las demandas tienen una dimensión equivalencial en tanto poseen una negatividad común: todas ellas expresan una falta, habilitando una solidaridad que permite ligarlas creando una cadena de equivalencias, al mismo tiempo que opera una lógica de la diferencia, en tanto las mismas son heterogéneas entre sí. A su vez, Laclau las clasifica según el carácter que las mismas revistan, en demandas democráticas: cuando la demanda permanece aislada; y demandas populares: demandas que, a través de su articulación equivalencial, comienzan a constituir potencialmente sujetos, implicando en la razón populista la conformación de un pueblo. Las demandas democráticas, por ende, pueden ser incorporadas en una formación hegemónica en expansión, mientras que las demandas populares representan un desafío a la formación hegemónica establecida como tal.

Comenzamos a ver cómo opera la hegemonía como lógica política en Laclau y la especificidad que contiene la lógica populista. En ambas el antagonismo ocupa un lugar central, en tanto parten de dos precondiciones:

1) la formación de una frontera interna, que en la razón populista separa al pueblo del poder

2) una articulación equivalencial de demandas que hace posible el surgimiento de sujetos políticos, del pueblo ${ }^{113}$ en la lógica populista.

La construcción de hegemonía aparece definida, en esta perspectiva, como un particular que ocupa el lugar de un universal. De este modo, observamos cómo la lógica de la diferencia y la de la equivalencia actúan en la demanda:

\footnotetext{
${ }^{112}$ Volvemos a aclarar que estos elementos teóricos no buscan aplicarse con “fidelidad” a su creador, ya que la reinscripción de los mismos en nuestro enfoque, tienden a involucrar cambios en su sentido y contenido.

113 También señala una tercera, que surge cuando la movilización alcanza un nivel más alto: la unificación de estas diversas demandas -cuya equivalencia no había ido más allá de un vago sentimiento de solidaridad- en un sistema estable de significación (Laclau, 2005).
} 
“existe la posibilidad que una diferencia, sin dejar de ser particular, asuma la representación de una totalidad inconmensurable. De esta manera su cuerpo está dividido entre lo que ella aún es y la significación más universal de la que es portadora. Esta operación por la que una particularidad asume una significación universal inconmensurable consigo misma es lo que denominamos hegemonía" (Laclau, 2005:95).

Si bien compartimos la importancia de esta definición, en tanto la construcción de hegemonía implica efectivamente la universalización de un particular, nosotros nos centramos en la perspectiva gramsciana, cuya teoría de la hegemonía posee un alcance más vasto, que involucra en su análisis las tres dimensiones de las relaciones de fuerza (estructural, política, militar, y sus distintas gradaciones) y que permite desplegar un dispositivo analítico que habilita el estudio de un amplio abanico de problemáticas, que van desde el sentido común hasta la fundación de un Estado (y que en nuestro caso adecuamos para complementar una estrategia de análisis que nos permita profundizar el estudio del modelo de acumulación). Aun así, esta aproximación laclausiana nos permite vislumbrar mejor la relación entre hegemonía y antagonismo. En la perspectiva analítica de Laclau aparecen tres dimensiones articuladas. En primer lugar, se gesta la unificación de una pluralidad de demandas en una cadena equivalencial. En segundo, se produce la constitución de una frontera interna que divide a la sociedad en dos campos. Y, finalmente, se consolida la cadena equivalencial mediante la construcción de una identidad popular que es cualitativamente algo más que la simple suma de los lazos equivalenciales (Laclau, 2005).

La producción de sujetos políticos se da entonces en estos pasos de la hegemonía como lógica política. La construcción de hegemonía implica que una demanda comience a cobrar un valor distinto, "una cierta particularidad transforma su propio cuerpo en la representación de una totalidad inconmensurable” (Laclau, 2006:26), así es como entra en escena la categoría de significante vacío. Según Laclau, su importancia está dada por la función que cumple dentro de una lógica hegemónica, nuevamente: la de ser un particular que se universaliza. Asimismo, posee una relevancia dada por su función reorganizadora y reestructuradora de los elementos que articula. Es un significante vacío en tanto “vacía” parcialmente su contenido original para poder asumir la representación del conjunto de la cadena equivalencial. Y es en este proceso a través del cual una demanda se convierte en significante vacío donde comienza a aparecer el sujeto político, en el marco de la delimitación de frontera involucrado en el antagonismo: 


\begin{abstract}
"Tenemos ahora todos los elementos necesarios para definir aquello que está involucrado en una relación antagónica. El momento del choque antagónico, que no puede ser representado directamente, puede sin embargo ser significado -positivizado, si se prefiere- mediante la producción de un significante vacío (o dos, mejor; uno a cada lado de la frontera antagónica). El campo perteneciente a la propia identidad, que no puede cerrarse alrededor de su particularidad óntica por la presencia de la fuerza antagónica, tiene que significarse por medio de una cadena de equivalencias entre sus contenidos interiores y por medio de la producción de un significante vacío sin significado, porque representa la completud imposible de la comunidad. Y lo que cada una de las fuerzas en conflicto verá al otro lado de la frontera antagónica no será una medida puramente óntica tampoco; esa medida podrá ser sólo un significado de la representación de algo diferente a sí misma: la anti-comunidad. Esta brecha entre significados ónticos de representación está impregnada de una multiplicidad de consecuencias políticas, la más importante es la esencial inestabilidad de toda cadena de equivalencias: ningún significante vacío puede controlar por completo lo que constituye los eslabones que serán parte de esa cadena” (Laclau, 2006:26)
\end{abstract}

Estas definiciones teóricas arrojan un conjunto de elementos susceptibles de ser articulados en nuestro enfoque. En primer lugar, la constitución identitaria se gesta en un campo de enfrentamiento, en la relación antagónica misma, donde "los componentes de cada polo del antagonismo no están unidos por cualquier rasgo positivo compartido (en ese caso nos ocuparíamos de una unidad puramente objetiva) sino por la oposición de todos a la fuerza con la que están confrontados” (Laclau, 2006:27). De este modo veremos la delimitación del kirchnerismo como identidad y sujeto político emergente en su conformación a través de la delimitación del adversario en sus principales contiendas; comprendiendo que las identidades de los sujetos políticos no son estables, sino que se definen en cada enfrentamiento en virtud de relaciones de fuerzas, en una vinculación dinámica con el adversario, que van implicando redefiniciones parciales de las identidades mismas.

A su vez, entendemos que el sujeto político no es reductible ni directamente asimilable al agente económico: el agente se define por su anclaje estructural, por la posición y función en la producción (y a partir de esto es que optamos por la construcción de clases con base económica), asimismo, los agentes pueden constituirse en sujeto, pero lo hacen ingresando en otra dimensión con lógicas propias. Es en vinculación a las distintas gradaciones que Gramsci distingue en el análisis de las relaciones de fuerzas políticas donde se constituyen los actores corporativos (cuando su margen de acción se limita aún a disputas económicas), y entrando ya en el grado específicamente político encontramos en su singularidad a los diversos actores políticos que, a su vez, pueden devenir en sujetos políticos, cuando participan del antagonismo y se da un salto cualitativo en la construcción de hegemonía y de voluntad colectiva amplificando la capacidad de desplegar una concepción de mundo procurando establecer un "nuevo Estado”. 
Como sostiene Retamozo, “El proceso de antagonización de la subordinación produce el recuerdo de la contingencia, revela el carácter político, tiene potencial subversivo y abre la posibilidad de un nuevo momento (re) fundante” (2009:84), y es en este sentido, que vislumbraremos cómo el proceso de antagonismo constitutivo de la crisis de hegemonía de 2001, revela ese carácter contingente del orden social, al tiempo que se articula a un conjunto de contradicciones estructurales ligadas al desempeño del modelo de acumulación por entonces vigente, da lugar a un momento re-fundante, abriendo paso a transformaciones de diverso carácter y profundidad que culminarán con la instauración de un nuevo modelo de acumulación, dando lugar, más adelante, a una nueva hegemonía, la hegemonía kirchnerista. De este modo, comenzamos a visualizar cómo serán incorporados distintos elementos del análisis laclausiano en una matriz teórica distinta, que no puede sino modificarlos en su acto mismo de incorporación ${ }^{114}$.

Laclau señala que: "Desde el punto de vista de cada una de las dos fuerzas antagónicas, su oponente no es una presencia objetiva, que completa la plenitud de la propia identidad, sino que representa, por el contrario, aquello que hace imposible alcanzar semejante plenitud” (Laclau, 2006:22). Asimismo, “la construcción del “pueblo" va a ser el intento de dar un nombre a esa plenitud ausente” (Laclau, 2005:113). Es esta promesa de plenitud que encarnan los sujetos políticos constituidos en el antagonismo que nos remite a la recuperación que proponemos del análisis de Marcuse sobre la cultura, que constituye a su vez, un factor clave de la construcción de hegemonía que se vincula con los proyectos político-económicos de gobierno, como vía de realización de dicha promesa. En este camino, no podríamos estar más de acuerdo con Retamozo cuando sostiene que "la dimensión de los proyectos políticos resulta central puesto que allí se plasma la producción de significantes aglutinantes, las promesas de plenitud inherentes a la movilización política y la elaboración del espacio mítico que permite romper con los principios de representación hegemónicos” (Retamozo, 2009:86, el subrayado en nuestro). Así vemos cómo el proyecto políticoeconómico de gobierno contiene una capacidad orientadora de la estrategia hegemónica, conformando un camino hacia la resolución imposible de la promesa con la potencia del mito, constituyendo el desenvolvimiento de estos elementos clave que vimos en el

\footnotetext{
${ }^{114} \mathrm{Si}$ bien hay un punto de referencia compartido en ambos enfoques, constituido por el pensamiento de Gramsci, la visión del mismo presenta serias distancias, lejos de ver en él, como sostiene Laclau, una ruptura con la tradición marxista anterior, nosotros no podemos dejar de notar cómo su aporte teórico es tributario tanto de Marx como de Lenin, aunque representando una renovación teórica para pensar sociedades capitalistas en creciente complejización.
} 
Príncipe moderno gramsciano ${ }^{115}$. Es necesario aclarar que no planteamos una relación directa, transparente entre el proyecto y la acción estatal, sino un marco orientador, una matriz ideológica cuya puesta en acción depende asimismo de las distintas disputas orgánicas y coyunturales y de las relaciones de fuerzas que las atraviesan.

Ahora bien, como señala Laclau, “La noción de un antagonismo constitutivo, de una frontera radical, requiere (...) un espacio fracturado” (2005:112, el subrayado es nuestro). En nuestra tarea de apropiación de algunas de sus categorías de análisis, entendemos que una vez rescatada la relevancia teórica de la categoría de contradicción, podemos pensar que las múltiples contradicciones que atraviesan a una estructura son parte de esa fractura constitutiva, de esas dislocaciones, que en el capitalismo cobran forma diversas, pero una de las cuales, la contradicción capital/trabajo, implica la emergencia de relaciones de explotación y dominación, constituyendo una falta, una plenitud ausente que puede cobrar forma hegemónica a través de la recomposición de la promesa por diversos medios (ya sea, por ejemplo, a través de la “justicia social” o directamente por la eliminación/superación de dicha contradicción), y en este sentido retomamos de modo resignificado la perspectiva laclausiana, recordando con que la construcción del pueblo es el intento de dar un nombre a esa plenitud ausente y que "Sin esta ruptura inicial de algo en el orden social (...) no hay posibilidad de antagonismo, de frontera o, en última instancia, de “pueblo”” (Laclau, 2005:113).

Llegados a este punto, podemos realizar una recuperación de la noción de cultura política trabajada al comienzo del capítulo, observando cómo se plasma en ella una articulación entre las categorías de contradicción y antagonismo. Este carácter afirmativo de la cultura emerge de la existencia de un espacio fracturado: es una escisión contradictoria dada en la separación del plano cultural respecto del orden de la reproducción material (la civilización), colocando a aquél por encima de ésta, en tanto constituye a la cultura como un reino independiente y un mandato obligatorio de felicidad para los individuos, pero en una situación de desigualdad concreta bajo el imperio de relaciones de explotación para las mayorías: una promesa de plenitud incumplida, que busca ser llenada (en la lógica sistémica) con mercancías, tarea siempre

\footnotetext{
${ }^{115}$ Además, el proyecto político-económico tiene en su base una ligazón con la creación y desarrollo de una concepción de mundo, recordando con Althusser (2003 [1970]) el rol de la interpelación ideológica en la constitución de sujetos.
} 
imposible bajo la desigualdad concreta de la sociedad de clases ${ }^{116}$. Es en esta escisión genérica entre “cultura y civilización” dada por la contradicción capital/trabajo que aparece la función hegemónica de la promesa en tanto articulación posible entre la “vida interior” y la "vida exterior”. El espacio fracturado de la contradicción se engarza así con el espacio también fracturado del antagonismo, en tanto una pieza clave de la articulación de demandas y la constitución identitaria de sujeto parte de esta misma promesa de plenitud. La resolución de esta promesa inconclusa constituye una arista fundamental de la estrategia hegemónica con el fin de movilizar las pasiones y suscitar la voluntad colectiva, dando lugar a la construcción del pueblo. La cultura política aparece así como la intersección donde el horizonte de plenitud afirmado es "traído a la tierra” articulándose con un proyecto más concreto que abre paso a una estrategia de acción. Una cultura política singular entonces se gesta en la promesa de sutura de la escisión contradictoria a partir de la resolución victoriosa en el plano de la escisión antagónica, en el triunfo del enfrentamiento del "nosotros" frente al "ellos”, de la “comunidad" frente a la "anti-comunidad”. De este modo, damos un paso para pensar la construcción del pueblo no sólo en su terreno antagónico sino también en el anclaje estructural de la contradicción.

Como habíamos introducido previamente, Laclau construye, sobre la hegemonía como lógica política, a la razón populista como una lógica particular de lo político ${ }^{117}$. Así, podemos pensar al populismo como la lógica hegemónica a través de la cual se construye un sujeto-pueblo. Laclau señala una doble acepción del pueblo, como plebs, conteniendo a los menos privilegiados, y como populus, el cuerpo de todos los ciudadanos. En tanto lógica hegemónica, la razón populista se gesta en el antagonismo: el populismo divide a la sociedad, ya que es algo menos que la totalidad de miembros de la sociedad, es un componente parcial que aspira, sin embargo a ser concebido como única totalidad legítima (Laclau 2005) ${ }^{118}$. Y en este enfrentamiento se construyen los

\footnotetext{
${ }^{116}$ De este modo, tenemos el campo escindido donde el mundo anímico-espiritual de valores de la cultura se impone universalmente "desde arriba", trascendiendo el plano de la reproducción material realizado bajo el imperio de la mercancía en la sociedad de clases, cumpliendo su carácter afirmativo desde el desgarro propio de esta estructura contradictoria.

117 "El populismo es la vía real para entender algo relativo a la constitución ontológica de lo político como tal” (Laclau, 2005:91)

${ }^{118}$ En este sentido Laclau señala que "el populismo requiere la división dicotómica de la sociedad en dos campos -uno que se presenta a sí mismo como parte que reclama ser el todo-, que esta dicotomía implica la división antagónica del campo social, y que el campo popular presupone -como condición de constitución, la construcción de una identidad global a partir de la equivalencia de una pluralidad de demandas" (Laclau, 2005:110)
} 
sujetos y sus identidades al punto que se sostiene que hay que "concebir al populismo como una de las formas de constituir la propia unidad del grupo” (Laclau, 2005:97).

En nuestro enfoque, éstas constituyen herramientas analíticas para un abordaje de los fenómenos superestructurales de constitución de los sujetos, siendo la política el campo específico de su conformación, pero que debe ser puesta en relación con la dimensión estructural que complementa el bloque histórico. En este sentido parece relevante recuperar la problemática de la construcción de un pueblo en Gramsci. El pensador italiano, sin dejar de analizar las lógicas específicamente políticas de la construcción hegemónica de un pueblo, mantiene el anclaje estructural a través del concepto de clases subalternas, de modo que un pueblo no es "cualquier" pueblo, sino precisamente un plebs, el conjunto de los subordinados envueltos en este concepto maleable que entraña la subalternidad de posiciones. Pero a su vez, no se trata de un pueblo que sea “pura” clase ${ }^{119}$, es la construcción de una voluntad colectica nacionalpopular, es decir, que está íntimamente ligado a la formación social que lo contiene y a su propia historia.

En la dinámica del antagonismo, las demandas se articulan conformando una cadena hasta alcanzar un punto donde el lazo equivalencial se cristaliza y lo que antes era mediación ahora cobra consistencia propia, “aunque el lazo estaba originalmente subordinado a las demandas, ahora reacciona sobre ellas y, mediante una inversión de la relación, comienza a comportarse como su fundamento. Sin esta operación de inversión no habría populismo” (Laclau, 2005:122). De este modo, el pueblo como parcialidad que aspira a ser concebido como totalidad, se moviliza y constituye en torno a una promesa de plenitud, la promesa de Marcuse, que en Gramsci implica la universalización de una concepción del mundo particular, la construcción de una política hegemónica que disputa el orden social en tanto la conducción política y cultural de una fuerza particular pueda aparecer como realizando el conjunto de las “energías” nacionales, o sea, como el realizador potencial de dicha promesa de plenitud.

Otro elemento clave del populismo para el abordaje de nuestro problema de estudio refiere a la centralidad del líder. En el esquema analítico de Laclau, un eslabón

\footnotetext{
${ }^{119}$ En el sentido de que las fronteras de recorte de pueblo y clase pueden no coincidir exactamente, pero entendiendo también que el pueblo no puede pensarse sin la clase (al menos en las sociedades capitalistas), como una construcción meramente discursiva so pena de caer en un nuevo reduccionismo politicista-discursivista.
} 
de la cadena equivalencial dada entre demandas heterogéneas asume la representación del conjunto de la cadena, conduce a una singularidad: "la lógica de la equivalencia conduce a una singularidad, y ésta a la identificación de la unidad del grupo con el líder” (Laclau, 2005:130). De este modo, la articulación de demandas va gestando la construcción de sujeto-pueblo y, en tanto se consolida la cadena, una demanda asume como significante vacío la representación de la cadena en su conjunto, así como la construcción identitaria va también cristalizando y se realiza en la singularidad del líder. Esta es la lógica que opera, en tanto "la unificación simbólica del grupo en torno a una individualidad (...) es inherente a la formación de un pueblo” (Laclau, 2005:130). En este sentido, el rol del líder cobra máxima relevancia para el análisis de constitución de sujeto, al tiempo que ocupa un lugar destacado en la conducción del proyecto políticoeconómico. Así, el discurso ${ }^{120}$ del líder constituye un objeto de análisis privilegiado tanto para comprender los sentidos fundantes del sujeto como los pilares del proyecto que dirige. El discurso de Néstor Kirchner y de Cristina Fernández constituirán sucesivamente un objeto de estudio a través del cual visualizaremos los rasgos principales de la constitución identitaria del sujeto político que referencian, así como las líneas fundamentales de la estrategia política y del proyecto del cuál forman parte, fundiéndose a su vez como componentes de una formulación particular de cultura política. El concepto de cultura política permite ver cómo la dimensión cultural, el orden de la construcción simbólica del sujeto y la conformación de la promesa de plenitud, encuentra en el proyecto político-económico, en tanto matriz ideológica, un puente con la dimensión política, abordada a través de la estrategia política que gesta el despliegue de la acción estatal. El lugar del líder atraviesa ambas dimensiones conteniendo en su discurso una pieza destacada de análisis en tanto conducción de proyecto, orientación de la estrategia y encarnación de la promesa ya que, como señala Laclau, el mismo reviste una "investidura radical: el hacer de un objeto la encarnación de la plenitud mítica” (2005:148). Así el líder, es el cuadro superior, intelectual

\footnotetext{
${ }^{120}$ Debe notarse que, si bien en Laclau el discurso abarca un espectro mucho más amplio de prácticas que construyen sentido, por razón de factibilidad en la resolución de nuestro problema de estudio, optamos por tomar los discursos públicos de los presidentes, en tanto líderes e intelectuales orgánicos destacados, por la relación directa que los mismos poseen con la generación de los proyectos político-económicos de gobierno que inspiran la acción estatal incidiendo sobre el proceso de acumulación.
} 
orgánico distinguido, de un sujeto que se constituye en las superestructuras complejas pero que no deja de poseer anclajes estructurales ${ }^{121}$.

En resumen, tenemos un análisis de la lógica hegemónica en su versión populista que Laclau resume en una tesis con dos componentes centrales:

“1) El surgimiento de un pueblo requiere el pasaje -vía equivalencias- de demandas aisladas, heterogéneas, a una demanda "global” que implica la formación de fronteras políticas y la construcción discursiva del poder como fuerza antagónica; 2) sin embargo, como este pasaje no se sigue de un mero análisis de las demandas heterogéneas como tales (...) debe intervenir algo cualitativamente nuevo (...) Este momento cualitativamente diferenciado es lo que hemos denominado "investidura radical" (...) la investidura pertenece necesariamente al orden del afecto.” (Laclau, 2005:142) ${ }^{122}$

Ahora bien, como señala Laclau, la polivalencia y vaguedad que acompañan a la categoría de populismo no tiene por qué ser un defecto sino tal vez una potencialidad. En este sentido, además de la perspectiva laclausiana encontramos otras que aportan también elementos valiosos para el análisis de nuestro objeto de estudio. Junto al populismo como lógica política de Laclau, visualizamos otra vertiente analítica que debe ser traída sintéticamente a colación.

Encontramos aquí la idea de pacto populista, trabajada por Rajland (2008) para el caso argentino y por Castro Gomes (1996) para el caso brasilero. En ambos casos el pacto populista es pensado como una estrategia política hegemónica de rasgos particulares analizado a partir de su anclaje de clase y en clave latinoamericana. Rajland (2008) señala que la estrategia populista se gesta en países del capitalismo periférico, basándose en un pacto caracterizado por el intento de conciliación y armonización de clases, teniendo en el Estado su gestor fundamental. Este pacto implica concesiones mutuas entre las diversas clases: tanto el abandono de los proyectos de emancipación política de la clase trabajadora con la concomitante legitimación de la sociedad capitalista, como la aceptación por parte de la burguesía de mayores niveles de intervención estatal y regulación económica, en el marco de un proyecto que articula un perfil industrializador que garantiza la reproducción de la sociedad burguesa, librándola

\footnotetext{
${ }^{121}$ Si bien Laclau señala que "el pueblo (...) no constituye ningún tipo de efecto "superestructural” de alguna lógica infraestructural subyacente sino que es el terreno primordial en la construcción de una subjetividad política" (2005:280), nosotros tomamos el terreno político como el "terreno primordial” pero si bien no es un mero "efecto", entendemos, con Gramsci, que tampoco es posible pensarlo por fuera de las condiciones materiales de emergencia, como un mero "efecto" de la política y/o el discurso, de modo que procuramos evitar caer asimismo en un reduccionismo politicista.

${ }^{122}$ Una pregunta subyacente que iremos desentrañando a lo largo de los capítulos posteriores es ¿qué ocurre cuando esa fuerza emergente del populismo ya está en el poder?
} 
de las amenazas revolucionarias aunque incluyendo la ampliación de la ciudadanía en base a la consolidación de nuevos derechos sociales para las clases subalternas. Es a la luz de esta concepción del populismo donde podremos visualizar algunas de las características del proceso de construcción de hegemonía en nuestro período de estudio: por ejemplo, observando cómo el gobierno de Kirchner impulsa un pacto caracterizado por el intento de conciliación y armonización de clases a través de un sistema de transferencia de recursos que tiene en el Estado su gestor fundamental. La intervención estatal procuró desplegar un proyecto hegemónico gestando la recuperación de un conjunto de demandas visibles en la crisis de 2001, implicando también la vuelta de las corporaciones sindicales y patronales como actores relevantes en las negociaciones, pero al tiempo que desactivaba la dimensión de amenaza al orden, gestionando el conflicto y utilizándolo como parte de la estrategia de gobernabilidad oficial.

Sin embargo, como señala Laclau respecto de la lógica populista: “cuanto más extensa sea la cadena equivalencial, más mixta será la fuerza de los vínculos que entran en su composición” (2005:101). Esta lógica hegemónica cobra en el pacto populista una articulación clave entre elementos sistémicos y "heréticos” que generan que las fuerzas políticas que adoptan esta lógica, como en el caso del peronismo, puedan aparecer tanto como la alternativa hegemónica viable para el capitalismo argentino (James, 2006), y al mismo tiempo, según Cooke (2010 [1971]), como el hecho maldito del país burgués ${ }^{123}$, cuyos componentes populares no pueden dejar de ser visto con desconfianza por sectores de las clases dominantes ${ }^{124}$.

Finalmente, procuraremos ubicar y articular estas herramientas analíticas como un aporte para pensar la dimensión estrictamente política de un estudio en términos de hegemonía, pero lo haremos abordando los distintos niveles que marca Gramsci en su análisis de relaciones de fuerzas: recalcando la existencia de una dimensión estructural (ligada al lugar de los agentes), efectuando desde allí la recuperación de la categoría contradicción, en vinculación con el análisis del antagonismo y su contribución teórica

\footnotetext{
123 "Eso explica por qué el peronismo sigue siendo el hecho maldito de la política argentina: su cohesión y empuje es el de las clases que tienden a la destrucción del statu quo” (Cooke, [1971] 2010:103-104).

${ }^{124}$ Mantenemos, por un lado, la distinción analítica entre la lógica o razón populista ya que según Laclau "por "populismo" no entendemos un tipo de movimiento -identificable con una base social especial o con una orientación ideológica-, sino una lógica política.” (Laclau, 2005:150), y el pacto populista (Rajland, 2008; Castro Gomes, 1996) que se vincula a experiencias históricas concretas de aplicación de la lógica populista en América Latina.
} 
en términos de constitución identitaria de sujeto ${ }^{125}$. Entendemos que estos dos órdenes distintos, donde afincan la contradicción y el antagonismo, no pueden reducirse simplemente uno al otro, y que su mutua implicancia y desarrollo debe determinarse históricamente: el peso de las condiciones estructurales y de los fenómenos políticos, culturales e ideológicos ligados estrictamente al antagonismo, han de ser analizados a la luz de nuestro problema de estudio. En esto fundamos también nuestro propio enfoque del modelo de acumulación como una triada de elementos estructurales y superestructurales, a su vez articulado con el análisis de la hegemonía. Esto implica resaltar que la configuración del modelo de acumulación no es sólo económica sino también política, es decir, que hay decisiones que conforman el modelo y que responden a la construcción de hegemonía, o a las propias lógicas del enfrentamiento en el desarrollo de un conflicto político particular (como veremos que ocurre en 2001 y en el “conflicto del campo”).

De este modo, efectuamos una revalorización de la esfera política, recuperando la riqueza y complejidad de las superestructuras siguiendo el ejemplo de Gramsci. Pero al mismo tiempo advertimos acerca de las tensiones que conlleva la tenue línea que separa a la "primacía de la política” del imperio asfixiante de la política leída a través de una única estructura del discurso. Esta tensión establece un puente que puede fácilmente conducir de la crítica al economicismo a un nuevo politicismo, aspecto que visualizamos, por ejemplo, en la identificación de la hegemonía como la lógica misma de la política ${ }^{126}$. Recuperamos entonces, con Gramsci, la idea de guerra de posiciones y la hegemonía como lógica fundamental pero no única de la política y su vinculación con las sociedades complejas. Asimismo, entendemos que el esquema analítico laclausiano, que parte de la demanda como unidad de análisis, la constitución de una cadena equivalencial que a través del significante vacío que permite la lógica hegemónica de presentar un particular como universal, y su vinculación a la constitución de sujetos en la delimitación de un campo de antagonismo, provee herramientas analíticas que permiten profundizar el análisis de la dimensión política. Sin embargo, rescatamos la relevancia de las dinámicas de reproducción material involucradas en la noción marxista

\footnotetext{
${ }^{125}$ Entendemos que esto no implica una acción teórica inválida, ya que podemos ver en el desarrollo mismo del pensamiento de Laclau, cómo estos instrumentos van sufriendo variaciones en sus distintos trabajos, y en vinculación con los debates teórico-políticos que atraviesa: desde su versión aún marxista (1978), a su versión del socialismo como radicalización de la democracia ([1987] 2004)), hasta la razón populista (2005).

${ }^{126}$ Lo cual no sólo quita riqueza y especificidad al análisis en términos de hegemonía, sino que dificulta ver lógicas políticas no hegemónicas.
} 
de estructura, que retomamos asimismo en el análisis gramsciano de correlación de fuerzas, que en su primer nivel valoriza justamente esta dimensión estructural. Es esta dimensión estructural que actúa de asidero de contradicciones cardinales, recurrentes a toda formación social capitalista, tal como la contradicción entre capital y trabajo, que constituye una dislocación perenne que da lugar a una tendencia al conflicto. Asimismo, encontramos dificultades de aplicar el esquema laclausiano al estudio de la dimensión económica del modelo de acumulación, ya que observamos un amplio conjunto de relaciones sociales involucradas en el proceso de reproducción ampliada del capital que no necesariamente se expresan en antagonismo y que, sin embargo, son fundamentales para la explicación de dicho proceso ${ }^{127}$. Ya que como sostenía Mao Tse-Tung, “el antagonismo constituye una forma, pero no la única, de la lucha de los contrarios” ([1937] 1968:367), al mismo tiempo que “algunas contradicciones tienen un carácter antagónico abierto, mientras que otras no. Siguiendo el desarrollo concreto de las cosas, algunas contradicciones, originalmente no antagónicas, se transforman en antagónicas, en tanto que otras, originalmente antagónicas, se transforman en no antagónicas” (1968:368).

La recuperación de la contradicción nos permite volver a destacar la relevancia del análisis de clases en las sociedades capitalistas contemporáneas ${ }^{128}$. Al mismo tiempo realizamos una recuperación analítica del pueblo, y específicamente de las lógicas de construcción del pueblo, pero entendemos que esta tarea no es sólo una construcción del ámbito del discurso ligado al significante vacío y a la demanda como unidad de análisis básica, ya que si bien valoramos la potencia de dichas herramientas para el análisis de la dimensión política, vemos la necesidad de complementarlo con el análisis de la estructura y de las contradicciones (principalmente en la relación capital/trabajo, y luego entre las distintas fracciones de la clase dominante).

\subsection{La estrategia metodológica}

El enfoque que proponemos posee el carácter de ser teórico-metodológico, es decir, que al tiempo que definimos los conceptos centrales de la investigación, su contenido

\footnotetext{
${ }^{127}$ Como en el ejemplo sobre el circuito productivo sojero.

${ }^{128}$ De este modo, sostenemos una postura crítica frente al "imperialismo conceptual” tanto del tándem política-hegemonía-populismo como del clasismo mecanicista, cuando buscan ejercer desde una única dimensión del bloque histórico la explicación del todo social.
} 
expresa el camino mismo para su abordaje. El modelo de acumulación, pensado a partir de sus tres núcleos constitutivos, así como la teoría de la hegemonía, adaptada al problema centrado en el modelo y articulada con énfasis particulares ligados a los debates teóricos de cómo ésta se construye en la Argentina post-convertibilidad, nos lleva a la elaboración del siguiente esquema conceptual (gráfico 2) a partir del cual se elabora la estrategia metodológica.

Gráfico 2. Esquema conceptual general: modelo de acumulación y hegemonía

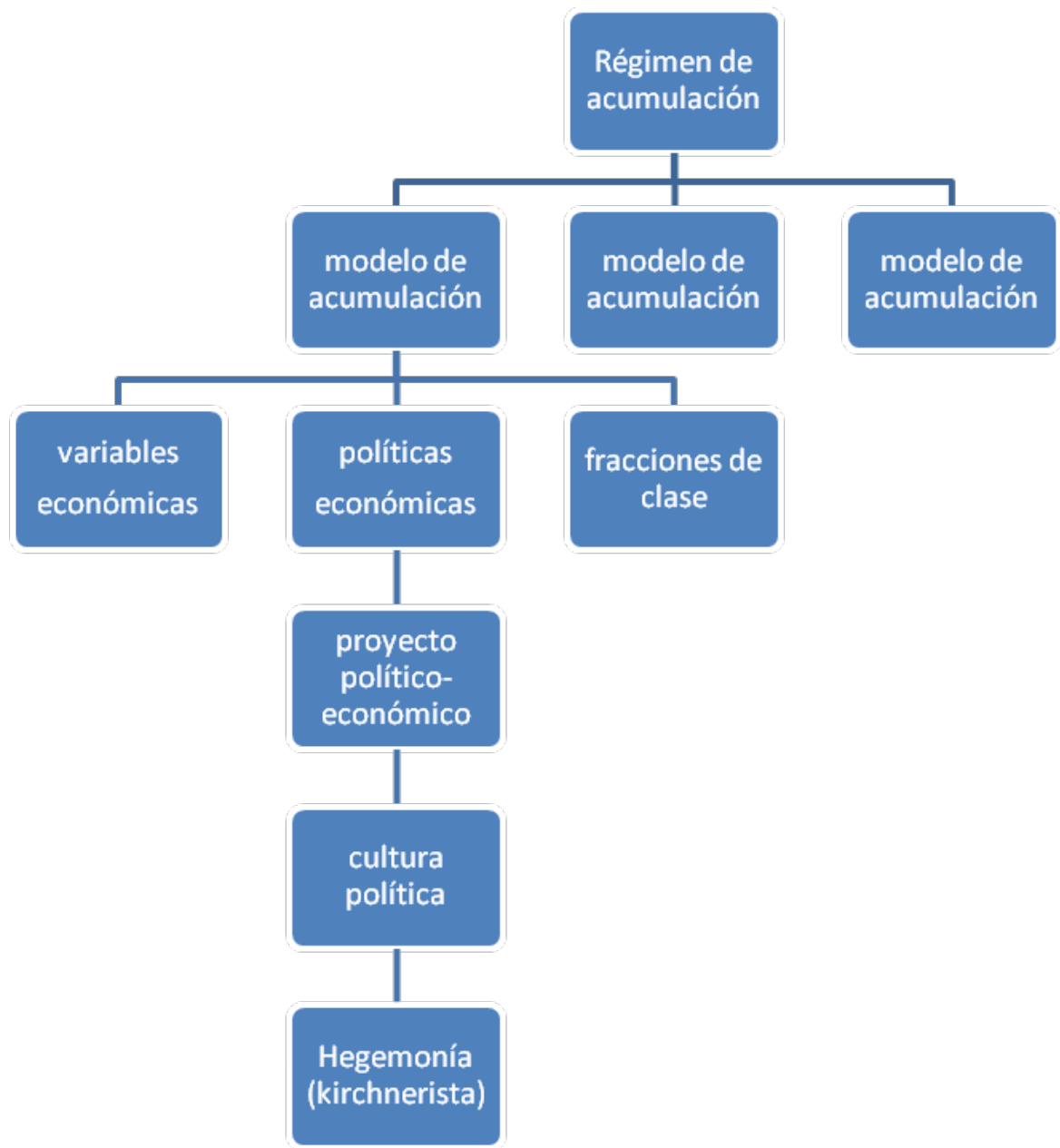

En el gráfico 2 podemos apreciar un ordenamiento conceptual que nos permite una mayor comprensión de la estrategia metodológica. En el centro de la escena tenemos al modelo de acumulación que constituye el objeto principal de nuestro problema de estudio. Según establecimos, el modelo de acumulación es un recorte 
espacio-temporal del proceso de reproducción ampliada del capital en el cual se observan un conjunto de relaciones sociales regulares que interactúan de modo relativamente coherente entre sí durante un período determinado, relaciones ligadas a tres núcleos constitutivos fundamentales que abordamos para su análisis: las políticas económicas, las variables económicas y las fracciones de clases. Por un lado, el modelo se diferencia del régimen de acumulación por poseer un alcance espacial menor, ligado a una formación social en el rango del Estado-nación, y un alcance temporal menor, pudiendo incluir un mismo régimen de acumulación varios modelos. A su vez un modelo se distingue de otro por el distinto orden de prelación de las relaciones y variables que aparecen como relevantes y características del modelo de acumulación en estudio.

Asimismo, señalamos que para avanzar en la comprensión de la construcción de hegemonía en su vinculación a la asistencia a la gestación y desarrollo del modelo, era necesario abordar el estudio del proyecto político-económico de gobierno entendido como una matriz ideológica que expresa la unidad de fines políticos y económicos involucrada en toda estrategia hegemónica que sirve de sustrato a la generación de acciones estatales que inciden en el proceso de acumulación. Efectuamos una distinción entre el componente de políticas como intervención estatal efectiva y el proyecto de gobierno como marco orientador. Ahora bien, el proyecto político-económico se encuentra enmarcado en una cultura política singular que, en tanto espacio de representaciones codificadas de una fuerza política, conforma una lectura común del pasado y el futuro de plenitud a construir.

De este modo analizaremos la hegemonía kirchnerista en nuestro periodo de estudio en tanto cultura política, que gesta una reformulación singular de la cultura política peronista (tradición en la que el kirchnerismo se inscribe), forjando su propia identidad que cobra forma en tanto constituye sujeto en la dinámica del antagonismo. En este punto recuperamos algunas herramientas analíticas del pensamiento de laclausiano, con el fin de analizar la dinámica conflictiva en la cual se forman los sujetos a partir de la articulación de un conjunto de demandas y la delimitación de una frontera que define la identidad hacia ambos lados del campo de antagonismo. En este trayecto la cadena de demandas tiende a su singularización mediante la conformación de un significante vacío que pasa a ocupar la representación del todo y en este mismo efecto se conforma la investidura radical del líder en tanto singularización y encarnación 
de la promesa de plenitud. Siguiendo a Marcuse, esa misma promesa de plenitud es promesa de unidad entre la "vida interior" y la "vida exterior", entre la cultura y la civilización, entre la reproducción espiritual y la reproducción material, escindidas en la sociedad capitalista, y performa la función hegemónica del mito, de la movilización de pasiones (evocando al Príncipe moderno gramsciano). Es en este punto donde el discurso del líder, en tanto momento de singularización y encarnación de dicha promesa, cobra relevancia para el análisis y comprensión de los pilares del proyecto de gobierno, siendo él mismo un intelectual orgánico destacado en la conducción política e ideológico-cultural de la estrategia hegemónica.

El análisis de la dimensión superestructural del modelo de acumulación, especificado en el componente de políticas y su ligazón con la construcción de hegemonía, que tiene en el grado estrictamente político de las relaciones de fuerza su terreno primordial (y de ahí la importancia de estudio del antagonismo), se articula dialécticamente a su vez con los componentes de anclaje estructural, comprendidos por las fracciones de clase y las variables económicas, dimensión de las fuerzas productivas y las relaciones de producción donde se encuentra la base material de la contradicción entre el capital y el trabajo, clave en las sociedades capitalistas.

A su vez, el desarrollo de la estrategia metodológica requiere avanzar hacia el “momento empírico" realizando un conjunto de apreciaciones acerca de cómo son construidos los datos. Para abordar empíricamente el estudio de la unidad de análisis principal: el modelo de acumulación, y las tres subunidades de análisis vinculadas: las políticas económicas, las variables económicas y las fracciones de clase, partimos de una perspectiva principalmente cuantitativa, complementada con la aplicación de técnicas cualitativas. Esta estrategia se basa principalmente en la recolección y análisis de documentos, leyes, decretos, resoluciones ministeriales e indicadores socioeconómicos, apelando también a la consulta a informantes clave como complementación. Asimismo, con el fin de analizar los principales rasgos de la construcción de hegemonía, tomamos técnicas primordialmente cualitativas, involucrando el análisis de los discursos presidenciales, documentos oficiales (producidos por distintos ministerios) y periódicos. En este camino, utilizamos diversas herramientas metodológicas en función de los requerimientos de los objetivos específicos según se señala a continuación. 
Para indagar acerca de las características generales del nuevo modelo de acumulación nos basamos en el análisis de documentos e indicadores producidos por dos tipos de fuentes distintas: por un lado, la fuente oficial del INDEC (y las producciones de indicadores desde los distintos ministerios en sus páginas web y las bases de datos del BCRA) ${ }^{129}$ y, por otro lado, otras fuentes que generan indicadores alternativos, tales como el Instituto de Estudios y Formación de la Central de Trabajadores Argentinos (IEF-CTA), el Centro de Estudios para el Desarrollo Argentina (CENDA), el Centro de Investigación y Formación de la República Argentina (CIFRA), entre otros. En ambos casos encontramos nutridas bases de datos que nos permiten percibir las principales transformaciones que se fueron dando en la configuración del modelo post-convertibilidad, tanto en lo que refiere a las variables económicas de desempeño que nos permiten observar el impacto de las políticas en el corto plazo (objetivo específico $1 .{ }^{130}$ y 2. ${ }^{131}$ ) como a las variables económico-estructurales (objetivo específico 2.) y aquellas ligadas específicamente a las fracciones de clase (objetivo específico $3 .^{132}$ ). Además resulta importante abordar ambos tipos de fuentes ya que en algunos casos difieren y discuten el criterio metodológico de construcción de indicadores, por ejemplo en lo que hace a la medición de la inflación, pobreza, indigencia y distribución del ingreso (Lozano, Rameri y Raffo, 2006) ${ }^{133}$.

En lo particular, para dar cuenta del perfil productivo del modelo realizamos una caracterización del desenvolvimiento industrial y agropecuario (centrándonos para este último sector en el circuito productivo sojero) tomando las evoluciones globales (del periodo) y anuales (en los casos pertinentes) de los siguientes indicadores que se incluyen en el objetivo específico 2.: PBI sectorial (y su relación con el PBI total),

\footnotetext{
${ }^{129}$ INDEC: Instituto Nacional de Estadística y Censos; BCRA: Banco Central de la República Argentina.

${ }^{130}$ Recordamos que el objetivo específico 1 implica analizar las principales políticas económicas en materia de: política cambiaria, políticas de ingresos, deuda pública, política impositiva, política de promoción y subsidios a agentes económicos (y composición del gasto público en general) y políticas en materia de servicios públicos.

${ }^{131}$ El objetivo específico 2 se propone analizar las transformaciones en las variables económicas. Indagando por un lado, variables de desempeño, tales como PBI (general y por sectores), Inversión bruta interna fija, inflación, tipo de cambio real, salario real promedio, balanza comercial y de pagos, e indicadores sociales más relevantes, y por otro, variables económico-estructurales haciendo foco en: perfil productivo, grado de concentración y extranjerización económica, distribución del ingreso e inserción internacional.

${ }^{132}$ El objetivo específico 3 busca analizar las características de las principales fracciones de clase y los cambios en la correlación de fuerzas, indagando qué fracciones se ven favorecidas y perjudicadas en la post-convertibilidad.

${ }^{133}$ Este debate irrumpe en 2007 en relación a la polémica en la construcción del IPC desde el INDEC y la afectación que genera para la elaboración de un amplio espectro de indicadores socio-económicos que lo utilizan como insumo.
} 
elasticidad empleo/producto, rentabilidad, costo laboral e incidencia en las exportaciones e importaciones. Estos se abordan a partir de las bases de datos provistas por INDEC, MECON, SAGPyA y $\mathrm{CEP}^{134}$ a través de sus páginas web, tomando complementariamente la construcción de datos realizados por centros de estudios y aquella exhibida en la bibliografía especializada. Un segundo conjunto de variables resultan relevantes tanto para dar cuenta del objetivo 2. como del 3., que aborda el análisis de las fracciones de clase: el origen (local/extranjero) y la propiedad (estatal/privado) del capital; el tamaño de las empresas y explotaciones agropecuarias, el grado de concentración y centralización económica. Para esto seguimos las orientaciones y criterios metodológicos propuestos por Basualdo (2007).

Asimismo, el objetivo específico 2. requiere del análisis de la inserción internacional a través de estudio de complejos exportadores y la estructura de importación de la economía, cuya composición puede ser observada en las bases de datos provistas por el INDEC y el MECON así como del estudio de la balanza de pagos, siguiendo las sugerencias de García (1998). Para el estudio de la distribución del ingreso utilizaremos principalmente series provistas por INDEC y el IEF-CTA, atendiendo a la polémica metodológica previamente mencionada.

El análisis de las transformaciones estructurales se complementa con el estudio de las acciones estatales, principalmente en materia de políticas económicas (objetivo específico 1.), desplegadas entre 2002 y 2008. Las políticas económicas al tiempo que establecen reglas de juego que inciden en el modelo de acumulación, tienden a constituir transferencias de recursos que afectan las relaciones de fuerzas entre las fracciones de clase (objetivo específico 3.). Como primer paso identificamos las políticas fundacionales de la post-convertibilidad, aquellas que expresan rasgos de ruptura suficientes como para pensar en un cambio de modelo, muchas de las cuales fueron consignadas principalmente en la Ley de Emergencia Pública y Reforma del Tipo de Cambio $\mathrm{n}^{\circ}$ 25.561. Esta ley es de destacada importancia, asimismo, para el análisis de las estrategias políticas desplegadas durante el gobierno de Duhalde (incluidas en el objetivo específico $4 .{ }^{135}$ ).

\footnotetext{
134 MECON: Ministerio de Economía y Finanzas Públicas; SAGPyA: Secretaría de Agricultura, Ganadería, Pesca y Alimentación; CEP: Centro de Estudios para la Producción.

${ }^{135}$ El objetivo específico 4 se propone analizar la construcción de hegemonía en el período, analizando cambios en la cultura política, observando el discurso presidencial y estrategia política, indagando la articulación de demandas expresadas en las políticas centrales con el fin de caracterizar el proyecto
} 
Las políticas (objetivo específico 1.), son analizadas en general, por un lado, a partir de la información desplegada por el Ministerio de Economía en sus publicaciones y documentos proporcionados por su página web, así como por la aparición de las principales políticas económicas detectadas en la publicación de diarios dispuesta en internet, buscadas por palabras clave. Damos cuenta de la formulación de las principales políticas a través del análisis de leyes, decretos y resoluciones ministeriales. En particular, indagamos acerca de las políticas de ingresos observando: evolución del salario mínimo, jubilaciones y convenios colectivos de trabajo a través de las bases de datos y documentos provistos por el Ministerio de Trabajo y el INDEC. A las series de distribución funcional del ingreso se le incorpora el análisis de las series de evolución del salario real según tipos de trabajo (privado formal, informal, estatal) provistos por las fuentes ya citadas. Estas políticas y su impacto son claves también para comprender los rasgos y desempeño de las clases subalternas en nuestro período de estudio (objetivo específico 3.).

En materia de deuda pública analizamos las bases de datos y documentos provistos por las siguientes fuentes: el BCRA y la Secretaría de Finanzas y Gerencia de Control de la Deuda Pública de la Auditoría General de la Nación. En este caso damos cuenta de la composición de la deuda pre y post-default, enfocándonos en el análisis del canje de deuda de 2005 que marca como hito las principales dinámicas en materia de deuda pública para el conjunto del período de estudio. Los indicadores que tenemos en cuenta son: relación deuda/PBI y deuda/exportaciones, deuda por residencia y deuda por moneda, evolución de la partida presupuestaria destinada al pago de deuda (su relación con el presupuesto total, las partidas de gasto social y el superávit fiscal), fuentes de financiamiento y calendario de vencimientos. Este punto tiene especial relación para dar cuenta de la fracción financiera del capital (objetivo específico 3.), a partir de la incidencia de esta fracción en la compra de bonos y títulos de deuda pública, y la relación que mantiene las tasas de interés de la deuda con la tasa de interés general de la economía, aspecto de relevancia para el análisis del modelo.

Las políticas de promoción y subsidio son importantes para dar cuenta de las transferencias de recursos hacia determinadas fracciones de clase. Éstas son abordadas a

político-económico de gobierno. Para el caso del gobierno de Duhalde, en tanto no alcanza a constituir una construcción hegemónica, nos centraremos, en primer lugar, en las políticas fundacionales y, secundariamente, en los pilares de su discurso y la estrategia de contención/coerción desplegada hacia el movimiento popular en el contexto de crisis. 
partir de las series detalladas de composición del gasto público provistas por el MECON, específicamente a través de la partida de Servicios Económicos. En esta partida se refleja también la política de subsidio referida a las empresas de servicios privatizadas, que por su relevancia en la historia reciente de Argentina debido a haber sido el núcleo de mayor rentabilidad en los 90, poseer un carácter sectorial específico (servicios públicos), por su composición fuertemente extranjerizada, y su afectación en los cambios de precios relativos, son abordadas como el componente central de la fracción de empresas de servicios públicos (objetivo específico 3.). Para analizar la relación Estado-privatizadas en la post-convertibilidad desarrollamos una tipología de acciones estatales y sus objetivos señalando rupturas y continuidades respecto del modelo de la convertibilidad, tomando como base las fuentes gubernamentales así como las publicaciones de diarios nacionales dispuestas en internet buscadas por palabras clave.

Finalmente una aproximación a la política impositiva y su relación posterior con la composición del gasto público nos permite establecer una mirada más cabal de las transferencias de recursos a partir de la acción estatal, observando cómo se distribuye el reparto diferencial de las cargas y beneficios del modelo proveyendo otro elemento para el análisis de las relaciones de fuerza (objetivo específico 3.).

De modo de completar el objetivo específico 3., donde analizamos agentes económicos vinculándolos a la estructura a través del concepto de fracción de clase, observamos la disposición de los mayores favorecidos y perjudicados del modelo, viendo quiénes mejoran o empeoran su capacidad de apropiación del valor socialmente producido, indagando de esta manera la relación entre la posición ocupada en la estructura y los cambios en la correlación de fuerza. Un insumo que es de particular importancia para complementar los factores que ya fuimos mencionando al describir la estrategia metodológica respecto de los primeros dos objetivos específicos, es la Encuesta Nacional a Grandes Empresas, ya que permite describir la composición de la cúpula empresaria, al tiempo que examinamos la composición de la fracción financiera del capital según los datos provistos por el Banco Central a través de su página web y complementamos el análisis de los grupos ligados al agro a través de los datos provistos por la SAGPyA. 
El análisis de las relaciones de fuerzas se desarrolla, en esta dimensión estructural, a partir de las acciones previamente mencionadas, implicando una articulación, por un lado, del análisis de la evolución de indicadores de rentabilidad y de de precios. Entendemos que el crecimiento desigual de los precios expresa en sí mismo relaciones de fuerzas: tomando la contrastación entre el IPC (canasta de bienes con un peso importante de no transables indicativo de la fracción de empresas de servicios) y el IPIM (canasta de bienes transables vinculada al capital productivo), la tasa de interés (relativa al capital financiero) y la evolución de las distintas categorías de salario (como indicativo del "precio" de las clases subalternas). Aquí también tenemos en cuenta el grado de concentración y centralización del capital que genera un "poder de monopolio" (Bowles y Edwards, 1985) con capacidad de fijar precios. Por otro lado, el análisis de la política económica nos permite identificar la incidencia de la acción estatal en la distribución diferencial de recursos, habilitando otra vía para el análisis de relaciones de fuerzas en tanto, como señala Poulantzas (1981), el Estado es en sí mismo una condensación de relaciones de fuerzas y la acción del Estado incide en la capacidad de apropiación del excedente por parte de los agentes económicos. De este modo, el abordaje del objetivo específico 4. se vincula estrechamente al cambio en las relaciones de fuerza en su dimensión política, ya que nos permite comprender la relación estatal a partir de la fuerza que lo conduce y analizar sus estrategias a través de las cuáles se constituye el proyecto político-económico de dicho gobierno que orienta las políticas y que tiene como marco la cultura política de la cual dicha fuerza forma parte.

Para el análisis del objetivo específico 4. acerca de la construcción de hegemonía, precisamos caracterizar un hito histórico que sirve de preludio a nuestro período de estudio: la crisis de 2001. Presentamos una caracterización sintética de la crisis de hegemonía en clave de principio de crisis orgánica, analizando las distintas dimensiones de dicha crisis y cómo las mismas marcan las estrategias hegemónicas en nuestro período de estudio.

Un segundo paso para afrontar el objetivo específico 4. implica indagar de modo sintético las principales estrategias desplegadas por el gobierno de Duhalde. Así, nos focalizaremos en el doble carácter de la estrategia desplegada: por un lado, su componente coactivo, visualizado en la criminalización y represión de la protesta social que tuvo su punto álgido en la “Masacre del Puente Pueyrredón” el 26 de junio de 2002, y por otro, su componente de contención de la protesta a través de la masificación de los 
planes sociales, principalmente el plan Jefes y Jefas de Hogar. También analizaremos la relevancia de las políticas instauradas en 2002 que consideramos fundacionales observando su condicionamiento y trascendencia en las construcciones hegemónicas posteriores, es decir, en cómo éstas generan transformaciones estructurales a nivel del modelo que signan en distinto grado el conjunto del período de estudio. Para abordar ambos aspectos analizaremos los discursos presidenciales, otras fuentes oficiales nacionales (documentos de los ministerios), la mencionada Ley de Emergencia Pública y la búsqueda en diarios nacionales, a través de palabras clave en sus sitios web. El discurso de Duhalde nos permite, a su vez, indagar los principales rasgos del diagnóstico y el proyecto político-económico de gobierno a través del cual buscaba conjurar la crisis de hegemonía. También establece en su recuperación discursiva del peronismo clásico algunos elementos duraderos en materia de cultura política y proyecto de gobierno vinculados a la relación Estado-empresarios y al lugar de la producción en el modelo de acumulación.

Como tercer momento, abordamos la construcción de hegemonía durante el kirchnerismo tomando dos caminos metodológicos. En primer lugar, analizamos el discurso presidencial de Néstor Kirchner y Cristina Fernández con el fin de identificar las características nodales del proyecto de gobierno, la unidad de fines políticos y económicos expresados en la estrategia hegemónica, vinculada asimismo a la construcción identitaria y la delimitación del adversario. Partiendo del lugar destacado del líder en la conducción política, intelectual y moral, observamos los principales aspectos de la cultura política que instituyen en tanto reformulación de la identidad peronista en clave kirchnerista, y el rol de la dinámica del antagonismo en la conformación de sujeto. Entendemos que los discursos de asunción presidencial y los de apertura de las sesiones ordinarias del Congreso de la Nación revisten gran relevancia para este análisis, en tanto parten de una caracterización del presente, postulan un diagnóstico, definen rasgos centrales del proyecto de gobierno, definen la agenda de la acción estatal y van dando cuenta, mediante balances, de su despliegue. En segundo lugar, sumamos a estos factores el análisis de las políticas (no sólo económicas) que permiten definir de forma más completa tanto el carácter del proyecto de gobierno impulsado por el oficialismo, así como los rasgos globales de la hegemonía kirchnerista. De este modo nos aproximamos a identificar los elementos centrales de la estrategia política relevantes para el análisis del modelo de acumulación y la construcción de 
hegemonía propuesto. Estas actividades son realizadas, primero, a través de su identificación según la bibliografía existente así como la consulta a expertos sobre el tema, y luego, a través del relevamiento de políticas y discursos en fuentes oficiales nacionales y en diarios de alcance nacional. La identificación de demandas y su articulación en el plan de acción oficial, conjugadas con la delimitación de los adversarios en el marco de los enfrentamientos, constituyen también elementos claves a abordar, tanto a nivel del discurso como de las políticas.

Este es el camino a través del cual delineamos una estrategia de análisis de la hegemonía que nos permite realizar una aproximación a la cultura política. Ésta contiene una dimensión ideológico-cultural vinculada a la consolidación de un subsuelo doctrinal o filosófico que constituye un código global de representaciones y valores ligados a una lectura común del pasado, que da forma al proyecto de gobierno (y así, a una lectura común del futuro a construir) y se materializa en acción, a través de las políticas, procurando la dirección sobre el conjunto de los grupos sociales. De este modo, el análisis del discurso y de la acción estatal, nos permiten indagar las relaciones fundamentales entre la cultura política, el proyecto político-económico que despliega el oficialismo, que es, a su vez, la base ideológica del componente de política económica involucrado en el análisis del modelo de acumulación, permitiéndonos una mirada más compleja sobre dicho fenómeno. En este proceso analítico realizamos un trabajo de integración de las dimensiones estructurales y superestructurales con el fin de gestar una mirada integral que articule el modelo de acumulación y la construcción de hegemonía, permitiendo, a su vez, una indagación más profunda sobre el cambio en las relaciones de fuerzas entre fracciones de clase abordando sus distintos niveles y gradaciones en el marco de la propuesta gramsciana.

Como cuarto momento, analizamos el "conflicto del campo" de 2008 como estudio de caso, porque entendemos que expresa una condensación de tensiones que nos permiten analizar el corazón del modelo de acumulación, tanto en sus rasgos expansivos como en sus aspectos críticos a nivel político, económico y cultural. Este conflicto constituye un punto de inflexión en nuestro período de estudio donde la hegemonía kirchnerista entra en crisis y abre paso a nuevas estrategias de recomposición hegemónica signadas por la lógica del antagonismo. El análisis del conflicto será realizado del siguiente modo. Lejos de presuponer a los actores involucrados, procuraremos reconstruir la dinámica política que cobró el enfrentamiento a la política 
de retenciones móviles, la articulación de demandas heterogéneas y la construcción identitaria de los sujetos antagónicos a través de distintas acciones. En primer lugar, realizaremos un relevamiento bibliográfico. En segunda instancia, recolectamos la información disponible en los diarios de alcance nacional a través de sus páginas web. Luego, avanzamos a identificar tres factores fundamentales: a) un eje de análisis se enfoca en las demandas articuladas y la constitución de sujetos en la lógica del antagonismo, siguiendo el esquema teórico laclausiano; b) dicho eje se complementa con la identificación de los actores políticos y corporativos relevantes en dichas disputas, y c) la identificación el repertorio de acción utilizado y la incidencia del mismo en la evolución de la política. Éste será el camino para generar un análisis de la dinámica política de la política económica (dada su relevancia en la configuración del modelo, su incidencia en las variables económicas y las relaciones de fuerzas entre fracciones de clase), observando elementos específicamente superestructurales para complejizar la indagación del problema centrado en el modelo de acumulación, al tiempo que vislumbraremos el rol del antagonismo en la construcción de hegemonía. Asimismo apelaremos herramientas heurísticas provistas por la teoría del análisis regional $^{136}$ (Rofman, 1999; De Jong, 1981; Bandieri, 2005; Blanco, 2006), centrándonos en el análisis del circuito productivo sojero con el fin de realizar un abordaje pormenorizado de las dinámicas de acumulación que atraviesan a dicho circuito productivo. De este modo, podremos ver la articulación de las dimensiones estructurales y superestructurales, de la contradicción y el antagonismo, de la relación entre agente y sujeto, tal como fuimos delineando en nuestro enfoque teórico, a la luz de un estudio de caso.

\subsection{La dimensión epistemológica del problema.}

Explicitados ya el enfoque teórico y la estrategia metodológica, encontramos relevante desarrollar un conjunto de reflexiones acerca de los principales desafíos epistemológicos que atraviesan nuestra investigación. En primera instancia observamos los obstáculos epistemológicos que enfrentamos en el desarrollo de la misma y las

\footnotetext{
${ }^{136}$ Este enfoque parte de recuperar nociones fundamentales de la tradición marxista para analizar las relaciones sociales en clave de las asimetrías propias de un modo de producción basado en la explotación y dominación de clase y entre los distintos agentes económicos al interior de una misma clase, observando al espacio como una dimensión constitutiva de dichas relaciones.
} 
técnicas de ruptura empleadas $\mathrm{y}$, en un segundo momento, realizamos algunas consideraciones centrales en torno a la construcción del objeto de estudio.

\subsubsection{Acerca de los obstáculos epistemológicos.}

En el desarrollo de su propuesta epistemológica, Pierre Bourdieu señala la importancia de mantener en el proceso de investigación el criterio de vigilancia epistemológica, concebido como un sistema de costumbres intelectuales vinculado a la necesidad de someter la práctica científica a una reflexión crítica, "una actitud de vigilancia que encuentre en el completo conocimiento del error y de los mecanismos que lo engendran uno de los medios para superarlos” (Bourdieu et al, 2008:18). Es a partir de este principio que Bourdieu retoma la perspectiva de Gastón Bachelard, quien sostiene "la convicción de que hay que plantear el problema del conocimiento en términos de obstáculos” (Bachelard, 1984:15, subrayado en el original), y en ese sentido plantea la noción de obstáculo epistemológico referido a las principales causas de estancamiento y retroceso en el proceso de construcción de conocimiento. Siguiendo la perspectiva de ambos autores, podemos señalar cuáles son los principales obstáculos epistemológicos que se visualizaron y confrontaron a lo largo de nuestro propio proceso de investigación.

Un primer obstáculo es el de la opinión, desarrollado por Bachelard, y relacionado al conocimiento vulgar sobre el tema a investigar. La actualidad y relevancia del tema elegido en esta investigación, su difusión en los medios masivos de comunicación y el debate público que lo impregna, se constituyen en condiciones propicias de generar constantemente este primer obstáculo. La principal implicancia del mismo en el marco de nuestra investigación consiste en el riesgo de mostrar como ya construido aquello que había que construir. La actualidad del tema genera una mayor potencialidad del conocimiento vulgar para irrumpir en el proceso de investigación sugiriendo respuestas y enfoques ligados al sentido común dominante. Para afrontar este obstáculo debemos, tal como lo indica Bachelard, trabajar conscientemente sobre el planteo del problema de investigación y sus preguntas, a partir de la convicción de que “Nada está dado. Todo se construye” (Bachelard, 1984:16). Es por esto que al momento de elaborar el proyecto de investigación apelamos a definir rigurosamente el problema y las preguntas de investigación, al tiempo que avanzamos en el proceso de análisis y 
conceptualización con el fin de apartarnos de las denominaciones cotidianas impresas en el sentido común.

Un segundo obstáculo epistemológico es el que Bourdieu llama la ilusión de la transparencia. Podemos considerar este obstáculo en el marco de nuestra investigación a partir de una doble implicancia. Por un lado, podemos pensarlo, relacionándolo con el previo (la opinión), en tanto el objeto de estudio a construir está compuesto, a su vez, de múltiples sujetos de estudio que expresan sus propias perspectivas acerca del tema a investigar y que refieren a un amplio conjunto de prenociones que incluyen también las propias del investigador. En una segunda dimensión, la ilusión de la transparencia podría filtrarse en la actividad de análisis de los discursos presidenciales y de documentos institucionales, amenazando con tomar como explicación del problema de estudio las perspectivas de los actores involucrados ${ }^{137}$, cuando son éstas las que deben ser explicadas. Bourdieu propone una técnica de ruptura para superar este obstáculo denominada principio de la no-conciencia, que establece que "las relaciones sociales no pueden reducirse a las relaciones entre subjetividades animadas de intenciones o motivaciones, porque ellas se establecen entre condiciones y posiciones sociales y tienen, al mismo tiempo, más realidad que los sujetos que relacionan” (Bourdieu et al, 2008:37). Esto implica, retomando a Durkheim, que la vida social debe explicarse no por la concepción que se hacen los que en ella participan, sino por las causas profundas que escapan a la conciencia. En este sentido, debimos mantener en alto la vigilancia epistemológica de modo de no ver una relación transparente entre la explicación de los fenómenos a ser investigados y las palabras y representaciones de los sujetos de estudio involucrados o en los documentos escritos, sino comprender dichas perspectivas a partir de las relaciones sociales que las atraviesan, en el marco de nuestro objeto de estudio; aunque el análisis de los discursos y documentos constituye al mismo tiempo una estrategia necesaria que debe ser abordada para la indagación de la dimensión ideológico-cultural de nuestro problema de estudio, siempre debe ser realizada en relación a los fenómenos estructurales con los cuales se articulan.

\footnotetext{
137 Incluso en actividades de consulta a informantes clave debe advertirse que la condición de “especialista” en un área de investigación no sustrae a dicho sujeto de un posicionamiento institucional, ideológico y político que impregna el análisis; ya que aún cuando la producción de conocimiento científico se realice buscando mantener la objetividad y rigurosidad, éstas están necesariamente vinculadas con el entramado conceptual e incluso valorativo incorporado (advertidos en el concepto de libertad valorativa de Weber).
} 
Un tercer obstáculo epistemológico a considerar es el que Bourdieu denomina como los poderes del lenguaje. Bourdieu define este obstáculo observando que "el lenguaje común que, en cuanto tal, pasa inadvertido, encierra en su vocabulario y sintaxis toda una filosofía petrificada de lo social siempre dispuesta a resurgir en palabras comunes o expresiones complejas construidas con palabras comunes que el sociólogo utiliza inevitablemente" (Bourdieu et al, 2008:41). Al abordar un problema de investigación que posee varias de sus dimensiones íntimamente vinculadas al debate de la agenda pública, y con un recorte espacio-temporal del objeto de estudio históricamente reciente o contemporáneo, quedamos mayormente expuestos frente a las distintas usinas que construyen denominaciones y definiciones, muchas veces desde el sentido común, y que pueden conducir a error las propias definiciones y conceptualizaciones que se desarrollan en la investigación. La común pertenencia de determinadas palabras como concepto científico y como denominación del conocimiento vulgar plantea un desafío epistemológico y sugiere la necesidad de aumentar la vigilancia epistemológica a la hora de definir conceptos para evitar que se filtre en la conceptualización científica una definición prefijada a partir del sentido común. En este camino, a modo de técnica de ruptura, se procura realizar la mayor explicitación de los esquemas conceptuales utilizados, diseñados en el proceso de construcción del objeto de estudio, para marcar su diferenciación con los esquemas promovidos por el conocimiento vulgar, por ejemplo, con respecto al concepto de modelo de acumulación ${ }^{138}$, afectado tanto por la masividad de uso así como por su notoria vaguedad.

Un cuarto obstáculo epistemológico relacionado a nuestra investigación es el que Bourdieu denomina la tentación del profetismo. Este obstáculo surge a partir de la opacidad en la relación que mantiene la sociología y su público, y se vincula a que

\footnotetext{
“el sociólogo está expuesto al veredicto ambiguo y ambivalente de los no especialistas que se creen autorizados a dar crédito a los análisis propuestos, siempre y cuando éstos descubran los supuestos de la sociología espontánea, pero que por eso mismo son inducidos a impugnar la validez de una ciencia que no aprueban sino en la medida en que se repita en el buen sentido" (Bourdieu et al, 2008:46).

Esto implica que las exigencias y perspectivas del auditorio pueden motivar al investigador a adoptar un punto de vista ligado al sentido común con el fin de buscar su

${ }^{138}$ En los medios de comunicación y en los discursos oficialistas es común ver múltiples apelaciones al "modelo" usado indistintamente para referirse a un modelo económico o al proyecto de gobierno, entre muchas otras acepciones.
} 
aprobación. Un problema de investigación como el nuestro, que en su proceso incluye actividades docentes tanto en la universidad como en cursos, seminarios y talleres orientados a movimientos sociales y organizaciones políticas, suele encontrar un auditorio que evalúa el análisis a partir tanto de las configuraciones más difundidas del sentido común así como del conocimiento más elaborado (por trabajo teórico o necesidad política de los sujetos), puestos en juego en el intercambio y debate que incluye la actividad docente. Si bien es sencillo renunciar a una de las dimensiones del profetismo referida a la enunciación de verdades últimas, se mantiene presente la tensión previamente señalada cuando uno está frente a un auditorio, que en general tiende a involucrarse y participar activamente en virtud de la actualidad de nuestra problemática de estudio. Aún cuando se lograra romper con las prenociones a lo largo del proceso de investigación esta tensión se reconfigurará en el momento de la comunicación: ¿cómo comunicar los resultados de una investigación científica a un auditorio no científico? Esta tensión de la comunicabilidad se profundiza en la actual investigación por la relevancia política del tema abordado; entonces al problema de comunicar se suma el problema de cómo debatir y aquí aparecen nuevos interrogantes respecto a la pretensión de convencimiento en la comunicación de una tesis frente a distintos auditorios: ¿qué correspondencia hay entre la aceptación por convención de las teorías y el convencimiento en la enunciación de las mismas?, ¿̇acaso defender una tesis no es buscar convencer de la misma?, ¿qué ocurre con esto cuando la tesis tiene relevancia en términos políticos? Comunicación y convencimiento aparecen como dos aristas del trabajo científico que hacen resurgir la tensión propia de la denominada tentación del profetismo, advirtiendo que las instancias de docencia también generan, a través del debate y el cuestionamiento, insumos que impactan en el propio proceso de investigación.

\subsubsection{Sobre la construcción del objeto de estudio.}

Una instancia fundamental en la construcción del objeto de estudio refiere a la constitución de lo que Gutiérrez Rohán denomina una estructura sintética que corresponde, siguiendo al Marx de los Grundisse (1857-61), a la construcción de una totalidad concreta “entendida como la expresión de múltiples determinaciones" (Gutiérrez Rohán, 2007:9). Se distingue entre el todo inasible e ininteligible, y la totalidad presentada como una síntesis de diversas articulaciones y facetas del fenómeno que se estudia. En este punto se anuda la dialéctica del conocimiento desarrollada por 
Marx en los Grundisse con la máxima leninista de entender a la dialéctica como conocimiento multilateral, de innumerables matices en el modo de abordar la realidad desarrollando de cada matiz, un todo. En este sentido, observamos que el proceso de construcción del objeto de estudio tiene a su vez distintos momentos que pueden ser leídos a través de la epistemología marxista.

La dialéctica expresa una aspiración a captar la totalidad (ya que, como decía Hegel, la verdad está en la totalidad) a través de la aprehensión de una realidad contradictoria en constante movimiento. El marxismo es materialismo histórico y dialéctico, en tanto expresa la relevancia epistemológica del estudio del orden material, tomando en cuenta de que "la materia de que toma su nombre el materialismo histórico no es nada más ni nada menos que la relación de unos hombres con otros y con la naturaleza (Bloch)” (Peña, [1958] 2000), retomando así las premisas de la Ideología Alemana (Marx y Engels, [1846] 1985) que parten de la acción de los hombres en sus condiciones materiales, acción que implica un modo de vida, en tanto los hombres son lo que hacen y cómo lo hacen, tomando como “primer hecho histórico” la necesidad de reproducción y la producción de medios para dicha satisfacción. Así, lo real es relacional y la totalidad es la expresión del entramado de relaciones sociales que constituyen lo real. En los Grundrisse, Marx señala que partimos de lo real concreto, el terreno de lo existente, al que nos aproximamos con una primera representación plena de la totalidad caótica ${ }^{139}$, que según Kohan (2003) se liga a una primera aproximación cognitiva de la totalidad pero atravesada por el sentido común (en los términos de Gramsci). Luego se gesta el segundo momento del acción cognitiva que consiste en la abstracción, que es un acto analítico que desagrega y separa los distintos elementos de dicha totalidad caótica, y como señala Dussel (1985:51) "separa una parte del todo y la considera como todo" realizando en este sentido este paso clave que resaltara Lenin. Una vez construidas las determinaciones abstractas desagregadas, la operación dialéctica retorna de la parte al todo, construyendo sintéticamente a partir de las determinaciones abstractas una totalidad concreta en general, transformando las representaciones y determinaciones en conceptos que se relacionan y co-determinan mutuamente al interior de dicha totalidad ${ }^{140}$, alcanzando la constitución de la estructura

\footnotetext{
${ }^{139}$ Seguimos las líneas generales establecidas por Dussel (1985).

140 "La "construcción” dialéctica obedece a un doble movimiento. Por una parte, maneja las determinaciones (claramente definidas como "conceptos", ellos mismos "construidos" en cuanto esencia pensada con determinaciones internas) y las relaciona mutuamente entre sí (producción-consumo p.ej.),
} 
sintética del objeto de estudio señalada por Gutiérrez Rohán. En este proceso comienza a desarrollarse un camino de retorno del mundo conceptual al mundo real a través de la construcción de categorías explicativas que nos permitan conquistar una totalidad concreta histórica explicada, donde "The concrete is concrete because it is the concentration of many determinations, hence unity of the diverse”"141 (Marx, [1857-61] 2002b:20), relacionándose estrechamente con la lectura althusseriana de la sobredeterminación de la contradicción:

\begin{abstract}
"Si aplicamos la definición de lo "concreto" ofrecida por Marx, no al producto de la práctica teórica, sino a una coyuntura histórica específica, sigue siendo válido que lo concreto es concreto porque es la síntesis de múltiples determinaciones. El análisis concreto de una situación concreta exigido por Lenin es, en consecuencia, el análisis de una situación en la cual se sintetizan múltiples determinaciones o, lo que es igual, el análisis de una situación sobredeterminada. Una situación histórica no es jamás el efecto de una contradicción simple o única, ni tampoco los efectos de una misma contradicción son semejantes en diversas coyunturas históricas. Así, por ejemplo, la contradicción entre capital y trabajo, contradicción fundamental en las formaciones sociales en las cuales es dominante el modo de producción capitalista, adquiere, sin embargo, una eficacia distinta en cada sociedad y en cada momento histórico, dependiendo del conjunto de las circunstancias sociales en las cuales esa contradicción opera” (Pereyra, 1977:61).
\end{abstract}

Asimismo, el pasaje de los diversos momentos metódicos conlleva un amplio conjunto de desafíos cognitivos en relación a la construcción del objeto de estudio. Por un lado, Gutiérrez Rohán señala que "no hay una teoría preexistente al objeto, lo que existe es un conjunto de conceptos y representaciones teóricas que pueden resultar útiles para construir el objeto, pero que no lo explican” (2007:10). Coincidiendo en que no existe una teoría a priori del objeto sino que ésta se construye dialécticamente en el proceso mismo de construcción del objeto de estudio, la estructura sintética nos convoca a formular una objetividad provisoria, y va atravesando un primer momento como totalidad concreta general, confrontando al objeto en sucesivas aproximaciones para dar lugar a la totalidad concreta histórica explicada.

En este camino fuimos desarrollando los conceptos y perspectivas que nos permitieron aproximarnos sucesivamente al objeto y construir esta totalidad concreta, pero debemos señalar que se presentaron diversos desafíos en la construcción del entramado teórico debido a las distintas perspectivas y alcances de los conceptos

codeterminándose mutuamente. De esta manera los “opuestos” se codefinen. En un segundo momento, se constituye sintéticamente con ellos una nueva totalidad que adquiere autonomía (es la totalidad articulada con múltiples determinaciones). Llegado a este nivel concreto lo que antes aparecía como opuesto (producción y consumo), ahora forman parte de una "unidad” que los comprende y explica” (Dussel, 1985:53).

141 "Lo concreto es lo concreto porque es la concentración de múltiples determinaciones, por lo tanto unidad de lo diverso” (traducción propia). 
seleccionados. La articulación conceptual para el abordaje de diversos fenómenos estructurales y superestructurales, necesaria para el desarrollo del objeto de estudio, que hace centro en el modelo de acumulación en relación con el proceso de construcción de hegemonía, conllevó esta tensión debido a las distintas escuelas de pensamiento que los han abordado y a los distintos alcances teóricos de los conceptos involucrados. La construcción siempre original que suscita cada objeto de estudio particular nos llama a alzar la vigilancia epistemológica para evitar "trasplantar” irreflexivamente conceptos de diversas matrices y alcances, exigiendo una configuración conceptual acorde al objeto en construcción que se fue modificando en las sucesivas confrontaciones teóricoempíricas, a los avances y articulaciones hacia ambos lados del continuo de pensamiento científico (en el sentido de Alexander, 1992). Esto incluye también la necesidad de redefinir conceptos, refinarlos, crear nuevos, según las “exigencias” del objeto mismo en el proceso de investigación. Un ejemplo de estas tensiones puede visualizarse en la incorporación de herramientas analíticas del pensamiento de Laclau en nuestro enfoque de matriz marxista ${ }^{142}$. Por un lado, entendíamos que la perspectiva laclausiana proveía insumos cognitivos relevantes para interpelar fenómenos específicos de la dimensión política, ligados a la construcción de sujeto en el marco del antagonismo, pero a su vez manteníamos una apreciación crítica de algunos de los pilares de su teoría general, principalmente en relación a la crítica que dicho autor erige contra el marxismo y los derivados teóricos que este proceso había conllevado. En este camino nos propusimos realizar una “crítica de la crítica” poniendo en cuestión el hilo argumentativo con que el que aborda el problema de la contradicción en el marxismo (y que en Laclau lleva al abandono de dicha categoría). Entendiendo como no válidos algunos momentos claves de dicha argumentación nos propusimos recuperar la contradicción, con el fin de restablecer la relevancia de la contradicción capital/trabajo y de este modo restituir, a su vez, la importancia del análisis de la estructura para rearticularla con el análisis de las superestructuras y, dentro de éstas, situar al antagonismo. Por supuesto que este proceso no trascurre dejando "ilesos" los conceptos y categorías reapropiadas, en el sentido que los mismos padecen transformaciones en el acto mismo de crítica y apropiación (como no podía dejar de ocurrir, más aún cuando se toman elementos de una teoría general para convertirlos en una teoría "regional” de lo

\footnotetext{
${ }^{142}$ Abonamos en este camino el señalamiento de Milcíades Peña ([1958] 2000) acerca de la necesidad de pensar al marxismo como marxismo abierto, abierto a recrearse y tomar diversos elementos de distintos enfoques incorporándolos para enriquecer el análisis social.
} 
político). Sin embargo, entendemos que este camino es necesario para la construcción de un objeto de estudio desde la teoría crítica, en tanto, como señala Horkheimer (2000 [1937])) la misma se constituye y expresa como conciencia de la contradicción y del carácter escindido del todo social.

Otra tensión afrontada en la construcción del objeto de estudio, que recoge también las implicancias de las técnicas de ruptura epistemológicas señaladas con anterioridad, se refiere al siguiente interrogante: ¿hasta dónde avanzar hacia la explicitación de supuestos, hasta dónde desagregar y operacionalizar los conceptos? Aparece así, junto a las problemáticas teóricas específicas, todo otro conjunto de problemas ligado a las posibilidades de la investigación concreta: los problemas de la disponibilidad horaria, del cumplimiento de plazos previstos, de la formación científica, de los recursos, etcétera, que terminan teniendo incidencia sobre las posibilidades de ampliar y profundizar el proceso de investigación tanto hacia el "momento metafísico" como hacia “el momento empírico” que menciona Alexander (1992).

También aparecen como desafíos los problemas vinculados al recorte del tiempo y espacio del propio objeto de investigación. Por un lado, se presenta la necesidad de periodización para captar la temporalidad propia del objeto, objeto que es proceso ya que se transforma durante el período de estudio y que, siendo siempre dependiente de la construcción teórica misma, debe articularse, en el ordenamiento del objeto de estudio, con la estrategia sistemática de análisis. Para nuestra tesis seguimos el espíritu de la propuesta de Marx en los Grundrisse y que refiere como señala Dussel a que "El orden de las categorías (orden del pensar teórico, que surge de la realidad pero no se confunde con la realidad) debe estar determinado por su posición sincrónica y esencial en la moderna sociedad capitalista” (1985:56). En este sentido, la organización de la tesis es regida por el orden lógico-sistemático emergido de las categorías necesarias para pensar nuestro problema de estudio, siendo el mismo prioritario sobre el corte diacrónico, incorporando a éste último de forma subsidiaria, sin desconocerlo. Así, el núcleo de análisis de la tesis parte de los rasgos principales de la construcción de hegemonía que asisten a la gestación y desarrollo del modelo de acumulación (capítulo 3), para dar lugar luego, al análisis del modelo según los conceptos principales que lo componen, delineando la “doble entrada” al mismo que definimos en el primer capítulo: a través del nivel de la superestructura, constituyendo una entrada desde las políticas (capítulo 4), y a través del nivel de la estructura, ingresando por las fracciones de clases y las variables 
económicas (capítulo 5). En el último capítulo del núcleo de análisis (capítulo 6) analizamos el "conflicto del campo" de 2008, ya que, al tiempo que constituye un punto de inflexión que abre una nueva crisis de hegemonía, representa un estudio de caso privilegiado para ver las principales tendencias y tensiones que se expresan en la articulación de los ejes del modelo y la construcción hegemónica, permitiéndonos ver en el caso el conjunto de dinámicas que constituyen la totalidad concreta histórica explicada. Estas tendencias y tensiones son recuperadas y generalizadas en las conclusiones a la luz del conjunto del período abordado, habilitando un debate en torno a la nominación del modelo, las potencialidades y contradicciones que alberga en su interior, el debate en torno a la "burguesía nacional” y la constitución de sujetos, y los alcances y límites de la construcción hegemónica.

En términos de la construcción espacial, el principal desafío enfrentado se vincula al alcance del territorio elegido: la Argentina en su extensión nacional. Junto a esta vasta unidad espacial, aparece la complejidad de su abordaje teórico, a través de las políticas nacionales y el nivel estructural de las variables económicas y las fracciones de clase también en una escala nacional, la cual se configuraría como un espacio sintético que procura abstraer las características del espacio nacional en las dimensiones que aparecen relevantes al problema de investigación, pero dando cuenta también de algunas particularidades regionales, para evitar crear una ficción de homogeneidad del espacio abordado, pero sin la posibilidad de encarar un estudio a otras escalas, por ejemplo de los impactos específicamente provinciales de las políticas nacionales, o las consecuencias que políticas provinciales pudieran tener en el modelo de acumulación. Al espacio concreto (el territorio) se agrega otro espacio, de índole eminentemente teórico-conceptual, ligado a la conceptualización de la estructura como disposición de posiciones (o lugares en términos de Poulantzas), en donde ubicamos a los agentes pensados en su vinculación a las fracciones de clase. La relación entre el espacio concreto, territorial, y el espacio conceptual de la estructura se convirtió en otro de los momentos donde procuramos agudizar la vigilancia epistemológica.

De este modo, queda desplegada la parte teórica de la tesis, habiendo abordado en el capítulo anterior los conceptos centrales en torno al modelo de acumulación y la construcción de hegemonía, y habiendo explicitado, en éste, los conceptos subsidiarios y teorías regionales, así como los supuestos filosóficos, epistemológicos y la estrategia metodológica general. Así queda constituido el entramado teórico que nos permite 
avanzar hacia una nueva sección de la tesis compuesta por los capítulos de análisis, donde veremos la aplicación del enfoque sobre el objeto de estudio. 


\section{Capítulo III}

\section{Los pilares político-culturales de la construcción hegemónica.}

Comprender la construcción de hegemonía en la Argentina post-convertibilidad implica necesariamente partir de una caracterización de la crisis de 2001. Dicha crisis de hegemonía albergó un conjunto de dimensiones que marcaron fisuras duraderas en el orden social, que las construcciones de estrategias políticas posteriores debieron asumir. Es en este camino que partiremos del análisis de la crisis de 2001 interpelándola a partir del concepto de crisis orgánica de Gramsci, analizando asimismo la articulación de demandas y el proceso de constitución de sujetos en dicho campo de antagonismo. El abordaje de las distintas dimensiones de la crisis nos permitirá, a su vez, indagar dicho proceso observando la articulación de las categorías de antagonismo y contradicción. En segundo lugar, nos centraremos en la estrategia contención/coerción desplegada por el gobierno de Duhalde, observando la fragmentación incidida sobre la cadena de demandas de 2001, la construcción de la “demanda de orden” y del discurso fundacional, a nivel del proyecto político-económico de gobierno, de inauguración de una nueva alianza estratégica del Estado con el mundo de la producción. Finalmente, analizaremos la construcción de hegemonía del kirchnerismo, indagando cómo despliega su estrategia de sutura de las distintas dimensiones de la crisis, al tiempo que toma y resignifica numerosas demandas planteadas en el antagonismo que tuvo su punto álgido en 2001. En este camino, examinaremos la incorporación de dichas demandas a la construcción de una nueva fuerza política, que construye su adversario en torno a diversas figuras deslegitimadas del neoliberalismo mientras se constituye identitariamente reformulando rasgos de la cultura política peronista, y plantea un proyecto de gobierno que le permita la derrota de dichos adversarios y la superación de la crisis en un nuevo momento hegemónico.

\subsection{El preludio: el 2001 como principio de crisis orgánica}

La construcción de hegemonía en nuestro periodo de estudio aparece signada por un preludio ineludible: la crisis del 2001, que proponemos leer como un principio de crisis 
orgánica, frente al cual las estrategias hegemónicas posteriores debieron dar respuestas, recuperando y resignificando algunas de sus demandas mientras procuraban desactivar sus componentes de impugnación al orden. Podemos entender el concepto de crisis orgánica de Antonio Gramsci como una crisis que abarca tanto la pérdida de supremacía intelectual y moral como la capacidad de los dominantes de hacer avanzar la economía ${ }^{143}$ afectando a la estructura y a la hegemonía creada, implicando un verdadero sacudimiento del bloque histórico (Gramsci, 2003; Campione, 2007). Como dijimos, el bloque histórico representa la categoría de totalidad socio-histórica en el pensamiento gramsciano, conteniendo la articulación de las dimensiones socio-económicas y éticopolíticas, de la estructura y las superestructuras ${ }^{144}$. De este modo, una crisis orgánica atraviesa un amplio conjunto de factores, tanto a nivel estructural como superestructural, constituyendo una crisis profunda de hegemonía. La hegemonía es la capacidad de dirección política e ideológico-cultural que remite a la incidencia en la construcción de concepciones de mundo e implica un proceso de universalización de intereses y valores particulares que aparecen como generales, universales, en tanto logran la adhesión y la conducción de los distintos grupos sociales. La hegemonía se expresa entonces como la dirección intelectual y moral que opera de legitimadora de la dominación económica y política, tornando esta dominación en dirección de un grupo social sobre otros: es por esto que durante las crisis de hegemonía los grupos dirigentes devienen meramente dominantes.

Consideramos que el período de conflictividad que tuvo en 2001 su momento más intenso, implicó una crisis de hegemonía generalizada que expresó distintos factores propios de una crisis orgánica que, aunque sin alcanzar su entera plenitud, se manifestó en distintas dimensiones:

o Como crisis ideológico-cultural, que aparecía insinuada en la deslegitimación de algunos aspectos de la concepción del mundo imperante y de los patrones

\footnotetext{
143 Debemos tener en cuenta que la economía argentina había entrado en recesión desde 1998 hasta el fin del modelo de la convertibilidad, conllevando una caída general de la tasa de ganancia (con excepción de algunos núcleos de la cúpula económica) así como el deterior de los indicadores sociales.

${ }^{144}$ Como vimos en el capítulo 1, Gramsci concibe a las sociedades en términos de bloque histórico, retomando una perspectiva que tiende a analizar la totalidad, y que se define por una relación de reciprocidad, un proceso dialéctico real, entre la estructura y las superestructuras, entendidas éstas como un conjunto complejo, contradictorio y discorde, que reflejan el conjunto de las relaciones de producción, sin ser ellas un mero "resultado" sino un compuesto de distintos elementos políticos, jurídicos, ideológicos y culturales con entidad propia.
} 
conductuales promovidos por las usinas de pensamiento neoliberal ${ }^{145}$. Éstos estaban relacionados al criterio de no participación pública exaltando la reclusión en la vida privada ligada, asimismo, con valores egoístas y consumistas. Además, frente al previo tipo de Estado caracterizado por su supuesto gigantismo e ineficiencia, se postulaba al mercado como mejor distribuidor de recursos, vinculado a una perspectiva individualista, donde cada uno debía procurar por sí mismo la subsistencia, conllevando ideas de "Estado mínimo”146 que identificaban la libertad de mercado como consustancial de la libertad del individuo, la consideración de que acción del Estado generaba perturbación al mercado, cuyo libre funcionamiento constituía la base del desarrollo. Las crisis de estos pilares de la concepción neoliberal se expresó en las exigencias de una mayor presencia del Estado y de cambios en las funciones del mismo, frente a la conciencia de que el "Estado mínimo" y el reino del mercado no habían derivado en un mayor bienestar social sino en una desprotección creciente de las mayorías, poniendo en riesgo hasta los derechos más básicos de trabajo, vivienda, salud y educación, largamente deteriorados. También dio aliento a distintas formas de participación popular, contrastantes con el patrón individualista de no involucramiento en la vida pública, dando lugar a múltiples experiencias de acción colectiva tales como asambleas, movilizaciones, piquetes y ollas populares, así como en el proceso de recuperación de empresas por parte de los trabajadores. Como confirma Seoane, “El proceso abierto en diciembre ha conllevado una resignificación de los mitos fundacionales que atravesaron las tres últimas décadas en el largo recorrido de instalación del neoliberalismo en Argentina” (2002:41), expresando un quiebre del disciplinamiento social, una crisis del enaltecimiento de lo privado y el individualismo egoísta y, como veremos a continuación, una crisis de la institucionalidad tal como fuera establecida con posterioridad a la dictadura. La

\footnotetext{
${ }^{145}$ Recordemos que un momento clave de la construcción de hegemonía es la conformación de una concepción del mundo que incide en el sentido común y, a través del mismo, impacta en las prácticas de la vida cotidiana.

${ }^{146}$ Ver la definición dada por Matus (2007), que señala que el "Estado mínimo” se basa en los siguientes lineamiento: 1) el mercado es consustancial a la libertad del individuo; 2) la acción del Estado perturba el buen funcionamiento del mercado; 3) el individuo usa los recursos mejor que el gobierno; 4) el déficit del presupuesto público tiende a ser proporcional al tamaño y el volumen del Estado; 5) el Estado debe interferir lo mínimo y sólo para garantizar condiciones de competencia que se aproximan a la competencia perfecta; 6) el desarrollo económico y social llega inevitablemente con la economía de mercado; 7) el espíritu y la creatividad empresarial son patrimonio de los empresarios privados y no del Estado; 8) las ideologías no hacen al progreso, sino que las ciencias lo hacen.
} 
crisis se expresa en esta dimensión hegemónica en tanto se agrietan los consensos instalados en el período anterior, deteriorando el alcance de la concepción del mundo propia del llamado “pensamiento único” neoliberal ${ }^{147}$.

o Como crisis política. La crisis política puede ser pensada en dos dimensiones, por un lado, como crisis de "la" política, en su componente institucional de representación, y por otro lado, en su componente social, como crisis de autoridad relacionada al incremento de la conflictividad que evidenció un momento álgido en la lucha de clases a nivel nacional. Referimos a "la” política como el "terreno de intercambios entre partidos políticos, de actividades legislativas y gubernamentales de elecciones y representación territorial y, en general, del tipo de actividades, prácticas y procedimientos que se desarrollan en el entramado institucional del sistema o régimen político” (Arditi, 1995:342343). En este sentido, la crisis de "la" política se produjo a partir del desgaste de legitimidad de los partidos como canales de representación y de la crisis del bipartidismo en tanto fórmula de gestión de la gobernabilidad del período postdictadura. Esta crisis política posee múltiples connotaciones afectando a la sociedad civil (Gramsci, 2003), la cual remite a los espacios “privados” de participación voluntaria y que también pueden ser pensados como ámbitos de vida pública no estatal (en sentido estricto), tales como partidos, sindicatos, iglesias, medios de comunicación, centros de fomento, entre otros. Estos son ámbitos específicos de construcción y consolidación de consensos en tanto no están vinculados directamente a mecanismos coercitivos de resguardo. La crisis de 2001 alcanzó a poner en cuestión (al menos coyunturalmente) la capacidad de los partidos tradicionales de generar consensos hegemónicos. Así, expresó un elemento clave que Gramsci identifica en los períodos de crisis orgánica: una situación de contraste manifiesto entre “representados y representantes" (2003:62). Esto se vincula, a su vez, con un aspecto de la crisis política ligado al impacto social producido por las reformas neoliberales y sus resultados en materia de desocupación, precarización laboral, pobreza e indigencia, entre otros. En este camino, la pérdida de hegemonía de los grupos sociales dominantes en la sociedad civil, la incapacidad de los mismos de seguir siendo

\footnotetext{
${ }^{147}$ Un abordaje profundo de los componentes de la ideología neoliberal y su carácter neoconservador, puede ser visto en Bonnet (2008).
} 
la conducción política a través de la generación de consensos y de concepciones de mundo compartidas, se constituyó en un espacio fértil para incremento de la protesta y la organización de los grupos subalternos. Notamos que este factor social de la crisis política caló en amplios sectores de clases subalternas, a través del impacto sufrido a causa de la flexibilización laboral, el deterioro de las condiciones de trabajo, la desocupación como realidad o amenaza, etc. y que se fue traduciendo en un proceso de conflictividad que tuvo al movimiento de desocupados, a sectores del movimiento obrero (CTA y MTA) ${ }^{148}$ y el movimiento estudiantil, como sus actores más dinámicos, a los que se sumaron luego con fuerza los sectores medios en reclamo por la devolución de sus ahorros afectados por el “corralito”" ${ }^{149}$. Se evidencia aquí otro elemento señalado por Gramsci en las crisis orgánicas: una “crisis de autoridad”. Ésta se produce cuando se desarrollan una serie de reivindicaciones que conllevan un alto grado de movilización, expresando la articulación de demandas en una cadena equivalencial que no logran ser divididas y procesadas por el orden vigente, sino que enuncian, siguiendo a Laclau, su reconversión de demandas democráticas a demandas populares. En este contexto, la crisis atravesó lo que Gramsci denomina como sociedad política, que representa el espacio del Estado (en sentido estricto ${ }^{150}$ ) involucrando las dimensiones político-jurídicas que son propias del momento de la coerción (Gramsci, 2003), mostrando la incapacidad del gobierno en su ejercicio de los aparatos del Estado para contener el conflicto creciente. Así, la crisis de autoridad llevó a hacer tambalear el alcance del momento coercitivo de la sociedad política, en tanto se masificaron los impactos de la protesta llegando a constituir una rebelión popular, que desobedeció y enfrentó el establecimiento del estado de sitio en diciembre de 2001.

o Como crisis económica, debido a que el visible agotamiento del modelo de la convertibilidad, la caída en términos generales de la tasa de ganancia y la continuidad de la recesión evidenciaron las dificultades de los grupos

\footnotetext{
${ }^{148}$ CTA = Central de los Trabajadores Argentinos; MTA = Movimiento de los Trabajadores Argentinos.

${ }^{149}$ Con ese nombre se denominó vulgarmente a la restricción a la extracción de dinero en efectivo de plazos fijos, cuentas corrientes y cajas de ahorro impuesta por el gobierno de De la Rúa con el objetivo de frenar la salida de dinero del sistema bancario, intentando evitar así una corrida bancaria y el colapso del sistema.

${ }^{150}$ Nos referimos al Estado en sentido estricto, para diferenciarlo de la concepción del Estado en sentido amplio que Gramsci también utiliza y que incorpora tanto a la sociedad política como a la sociedad civil.
} 
dominantes de hacer avanzar a la economía afectando la estructura ${ }^{151}$, expresándose "por arriba” en una fractura de intereses entre distintos sectores del capital que buscaban mejorar sus posiciones en base a dos propuestas diferentes de salida al modelo de la convertibilidad, aglutinándose en devaluacionistas y dolarizadores (Basualdo 2001; Castellani y Schorr, 2004; Castellani y Szkolnik, 2005; Schorr y Wainer, 2005). Las propuestas divergentes de salida se relacionaban con las posiciones diferentes ocupadas en la estructura así como a las estrategias de acumulación de distintas fracciones del capital. Los devaluacionistas, agrupando al capital productivo-exportador, procuraban mejorar su competitividad y capacidad de exportación, así como valorizar las ingentes masas de capitales que los agentes más concentrados mantenían fugadas en el extranjero. Otros agentes, ligados al capital financiero y las empresas privatizadas, exigían la dolarización, principalmente para mantener el valor de sus activos en dólares y garantizar la perpetuación de los beneficios de la convertibilidad de la moneda, como el envío de remesas dolarizadas al exterior. Como mostraremos, el modelo contenía en su interior un conjunto de aspectos y dinámicas que se tornaron incompatibles entre sí, manifestando la radicalización de la contradicción de dicha unidad. Asimismo, el ocaso del modelo no puede reducirse a una "implosión”, sino que su devenir se relaciona con la acción de agentes y actores, que van transformando relaciones de fuerza, modificando el escenario de lucha de clases en Argentina. Además, el deterioro de los indicadores socio-económicos con incrementos incesantes en materia de desempleo, pobreza e indigencia, generó, como señalamos previamente, condiciones para el creciente malestar de las clases subalternas que dieron lugar a la proliferación de un amplio espectro de acciones colectivas, tanto en un nivel económico-corporativo como político.

La crisis del modelo de la convertibilidad puede verse a la luz de la categoría de contradicción trabajada teóricamente en el capítulo anterior. Podemos comprender que la contradicción, lejos de situarse en un terreno exclusivamente lógico, se encuentra

\footnotetext{
${ }^{151}$ Incluso debe tenerse en cuenta que se llegó a la emisión de cuasi-monedas, bonos emitidos primero por el gobierno nacional y luego por las provincias entre 2001 y 2002, que llegaron a circular del mismo modo que la moneda de curso legal. Esto permite visualizar hasta qué punto tuvo magnitud la crisis en su dimensión económica, ya que afectó al dinero como equivalente universal, aspecto que también se vio con la proliferación de medios alternativos de intercambio de mercancías como los "clubes del trueque".
} 
(siguiendo a Engels, Lenin y Mao) en la estructura misma de la realidad, por lo que es posible la construcción analítica de conceptos de totalidad mirando en su interior contradictorio la dinámica dialéctica que impulsa el movimiento, el desarrollo de las tensiones y que, eventualmente, lleva a la negación de dicha totalidad. Si realizamos la construcción del modelo de acumulación como totalidad concreta podemos observar cuáles son las principales dinámicas contradictorias que atraviesan sus componentes y cómo se gesta su movimiento en el devenir histórico. Este enfoque nos permite explicar aspectos sustanciales del desarrollo y negación del modelo de la convertibilidad, que deben ser articulados, a su vez, con la dinámica del antagonismo: así contradicción y antagonismo constituyen dos categorías distintas pero mutuamente necesarias para la explicación de fenómenos socio-históricos complejos en los que intervienen una multiplicidad de factores de dimensiones estructurales y superestructurales (conquistando el momento de la totalidad concreta explicada).

De forma sintética, podemos observar cómo el modelo de la convertibilidad contenía en su propio interior componentes que actuaban dialécticamente en su desarrollo pero que, llegado a un determinado punto, hicieron crecientemente insostenible su continuidad, llevando a crisis a dicha unidad. Este modelo de acumulación se consolidó en los años 90 y representó la profundización de la ofensiva del capital concentrado sobre los trabajadores a través de la aplicación de un vasto conjunto de reformas neoliberales. Éstas se fundaron sobre consensos del poder político con la clase dominante como la “flexibilización” laboral, el desarrollo de una estructura impositiva favorable al capital ${ }^{152}$, la privatización de las empresas estatales, una mayor liberalización financiera y altas tasas de interés, que impulsaron una reactualización del ciclo de "valorización financiera", y la apertura comercial con la disminución arancelaria a la importaciones, manteniendo protegidos algunos sectores del capital concentrado (como el automotriz). Asimismo, evidenciaba un esquema de precios relativos beneficioso para las empresas de servicio públicos privatizados y los conglomerados financieros. El modelo de la convertibilidad poseía cualidades que lo hacían intrínsecamente deuda-dependiente ya que precisaba un flujo constante de divisas para mantener la paridad 1 peso-1 dólar del tipo de cambio fijada por ley. Esto se relacionó con que, en las condiciones de escaso dinamismo de las exportaciones y

\footnotetext{
${ }^{152}$ Las reformas a nivel tributario incluyeron una baja en los aportes patronales, aumento del IVA, eliminación de las retenciones a las exportaciones, entre otras.
} 
apertura comercial, en el marco de la sobrevaluación de la moneda local y una tendencia constante al déficit fiscal ${ }^{153}$, se apelaba incesantemente al endeudamiento público. La vulnerabilidad externa, evidenciada en el desequilibrio de la cuenta corriente, se vio agudizada por la profundización del proceso de fuga de capitales, y llegó a poner en cuestión la posibilidad de mantener el esquema cambiario fijo y convertible que actuaba como un eje articulador del modelo entonces vigente (entre otros motivos, por la incapacidad de seguir re-financiando el endeudamiento público que aceitaba el sistema).

De este modo, vemos cómo operó la dinámica contradictoria en su interior. Por un lado, las mismas prácticas de acumulación de los grupos más concentrados del capital en articulación estrecha con el Estado (que presentaba niveles mínimos de autonomía relativa) terminaron por demoler al propio modelo del cual eran beneficiarios. La reactualización del proceso de valorización financiera, en el marco de la fijación del tipo de cambio, con precios relativos desfavorables a la producción y en un esquema de privatizaciones que implicó una nueva “acumulación originaria” para el capital concentrado, tuvo como correlato la necesidad de endeudamiento público para financiar la valorización y fuga de capitales; al tiempo que la erosión de las cuentas fiscales que sustentaban este movimiento (tanto por las privatizaciones, sobre todo de las jubilaciones, como por la menor percepción de aportes tributarios del capital), generó un contexto donde la balanza de pagos comenzó a evidenciar la próxima explosión del modelo por su propia dinámica.

Este desempeño económico estaba, asimismo, íntimamente ligado al desarrollo de la lucha de clases a nivel local que comenzaba a abonar el campo del antagonismo. Así, el deterioro de los indicadores socio-económicos habilitó una fuerte conflictividad social caracterizada por las crecientes demandas de las clases subalternas que se articuló con importantes disputas al interior de la clase dominante que comenzaban a diferenciarse en torno a distintas propuestas de salida del modelo.

La ofensiva del capital sobre las clases subalternas conllevó la pérdida de conquistas históricas en materia de derechos así como el deterioro creciente de sus condiciones de vida; factores que gestaron las condiciones para la emergencia del antagonismo: las resistencias y luchas contra las políticas que daban forma al modelo

\footnotetext{
${ }^{153}$ Entre otras causas, el déficit se incrementó por la privatización del sistema de jubilaciones y pensiones, ya que el Estado debía seguir pagándolas mientras dejaba de recibir los recursos correspondientes, que luego las AFJP le prestaban a altas tasas de interés.
} 
estuvieron presentes desde la primera hora, y fueron en aumento creciente hasta plasmarse en un amplio enfrentamiento social que dio lugar a la crisis de 2001. De este modo, y con las especificidades que veremos a continuación, se fue articulando la contradicción capital/trabajo con la dinámica del antagonismo. Un segundo aspecto de esta articulación puede ser visto en la contradicción entre las distintas fracciones del capital que dieron lugar a dos proyectos de salida diferentes del modelo de la convertibilidad, ligados a las distintas posiciones (lugares) que ocupaban en la estructura, pero también según sus capacidades de encadenamiento de demandas en la lógica política de la construcción hegemónica.

La contradicción capital/trabajo posee un desempeño particular bajo el régimen neoliberal en Argentina, caracterizado por la ofensiva del capital concentrado local y extranjero sobre el conjunto de las clases subalternas, particularmente sobre los trabajadores. La inauguración de dicho régimen a partir del terrorismo de Estado y las políticas económicas que comenzaron a conformar el andamiaje del nuevo orden social, dieron lugar a un primer momento de disciplinamiento y reestructuración de las relaciones de clases que modificaron drásticamente las relaciones de fuerzas en Argentina. Un segundo momento de avanzada clave en esta misma línea fue el rol disciplinador de la hiperinflación a fines de la década de los 80 (Bonnet, 2008; Ortiz y Schorr, 2006, 2006b) y el nuevo conjunto de reformas inspiradas en el Consenso de Washington ${ }^{154}$ que ubicaron a la Argentina como alumno predilecto de los organismos financieros internacionales por la aplicación del dogma neoliberal en la conformación y desarrollo del modelo de la convertibilidad ${ }^{155}$. Pero la implementación de las reformas estructurales no se hizo sin resistencia. Como muestran Cotarelo e Iñigo Carrera (2004), ya desde 1993 empezaron a producirse levantamientos populares y numerosas acciones de protesta en diversos lugares del país, con una tendencia creciente que se radicalizó

\footnotetext{
${ }^{154}$ Según Bresser Pereira (1991) el Consenso de Washington partía de una caracterización de las crisis latinoamericanas que veía sus causas en el excesivo tamaño del Estado devenido en proteccionismo, a través de los regímenes de sustitución de importaciones, con crecientes regulaciones y desarrollos de empresas estatales acusadas de ineficaces. A esto se le sumaba el "populismo económico" definido por la incapacidad de controlar el déficit público y los reclamos salariales. Junto a este diagnóstico se pregonaban un conjunto de recetas tendientes a transformar la relación entre Estado y mercado, implicando la reducción del Estado mediante privatizaciones, control de déficit público mediante la reducción de los subsidios, a lo que se sumaba una mayor liberalización comercial y desregulación económica y la apertura irrestricta a las inversiones extranjeras directas, con firme garantía del derecho de propiedad, entre otras medidas.

${ }_{155}$ Debe notarse que la política cambiaria que da el nombre al modelo se encontraba por fuera del Consenso de Washington que bregaba por la liberalización cambiaria, pero que al mismo tiempo era percibida como la clave del fin del proceso hiperinflacionario, que sirvió de aval para el conjunto de reformas estructurales de cuño neoliberal.
} 
con la entrada en crisis del modelo de la convertibilidad. En este contexto surgieron y se desarrollaron diversos actores desde distintos espacios de la sociedad civil que, portando demandas heterogéneas, comenzaron a socavar paulatinamente el consenso neoliberal.

Un actor destacado en este proceso fue el movimiento piquetero, nombre que adquirió el movimiento de desocupados vinculado a la adopción y resignificación del "piquete" ${ }^{156}$ como principal elemento de su repertorio de lucha ${ }^{157}$. La inscripción del movimiento piquetero posee un anclaje territorial, en tanto el barrio comenzó a ser el espacio de articulación de demandas diversas que fueron luego expresadas en las medidas de lucha, pero que continuaron teniendo su centralidad en el "trabajo digno".

Siguiendo a Barbetta y Bidaseca, observamos "el desplazamiento de las posiciones de sujeto (Laclau y Mouffe, 1987) de las identidades sociales que corresponden a las categorías de pertenencia de los individuos (trabajador, desocupado) a la identidad política de “piquetero", emergente del conflicto/antagonismo que tiene como desenlace una operación subjetiva: la politización de la subjetividad, esto es, la aparición del antagonismo y la definición de un adversario, la demarcación identitaria y la construcción de una identidad precaria” (2004:69). En este punto debemos establecer una distinción de escala: si bien el conflicto genera este proceso de identificación y subjetivización, es necesario distinguir la construcción de un actor como sujeto, de la construcción de un pueblo como sujeto. Si bien las lógicas son similares, en tanto lógicas de hegemonía y antagonismo, la construcción de un sujeto-pueblo requiere de una cadena extensa que logre enlazar un espectro más amplio de demandas y con esto vaya articulando a su vez a los portadores de dichas demandas subsumiéndolos en una nueva identidad más amplia: el pueblo. Incluso debemos observar cómo mutan las identidades de los actores, portadores de demandas, cuando las demandas se articulan en la cadena y emerge un nuevo significante vacío, ya que esto suele gestar una reacción sobre los mismos portadores, ya sea uniéndolos, fragmentándolos, “reciclándolos” o

\footnotetext{
${ }^{156}$ El piquete estaba originalmente vinculado al movimiento obrero e implicaba cortar el acceso a la fábrica como medida de protesta, siendo resignificado en los años 90 como corte de calle o ruta.

${ }^{157}$ El movimiento piquetero partió de dos vertientes principales. En primer lugar, surgió en relación a los masivos despidos que implicó el proceso de achicamiento y posterior privatización de YPF, motivando levantamientos populares inicialmente en el sur-oeste y luego en el norte argentino. En segundo lugar, en el Gran Buenos Aires, con el fuerte crecimiento de la desocupación y la pobreza producto del proceso de desindustrialización y pauperización generalizada. Para un análisis completo sobre el surgimiento del movimiento piquetero ver Svampa y Pereyra (2004).
} 
incluso expulsando alguno de ellos mientras se mantiene la demanda, en el proceso de conformación de la voluntad colectiva. Algo de esto es lo que fue ocurriendo con los distintos actores que comenzaron a articularse entre sí en el ciclo ascendente de conflictividad que tuvo su momento álgido en 2001. Encadenando sus demandas hasta hacerlas inabsorbibles por el orden en crisis creciente, los actores-sujetos del conflicto comenzaron a desplazar sus posiciones de sujeto ante la conformación de un genuino antagonismo generalizado que comenzó a delimitar un adversario y parecía tener la potencialidad de gestar un sujeto-pueblo.

Ahora bien, la lógica del antagonismo en tanto dinámica política hegemónica no es ajena a las disputas en torno a las concepciones de mundo que se juegan tanto, en una menor escala, en los actores como, en una mayor escala, en las construcciones de sujeto en el antagonismo general, conteniendo siempre un componente ex novo cuando emerge una voluntad colectiva ${ }^{158}$. Según Campione y Rajland (2006), en el movimiento piquetero gravitaban dos imaginarios ${ }^{159}$ distintos en cuanto al horizonte de aspiraciones sociales que expresaban las distintas organizaciones. Un primer imaginario se fundaba en la idea del regreso a la Argentina peronista que implicaba distintos factores:

\begin{abstract}
"importante desarrollo industrial, pleno empleo, bajos índices de pobreza, alta capacidad de consumo para los parámetros sudamericanos, representación sindical eficaz en el plano económico-corporativo, políticas estatales universalistas y no focalizadas, elevada valoración social del trabajador asalariado, movilidad social ascendente relativamente accesible... El retorno a la comunidad perdida es la utopía de este sector. Se parte del supuesto de que puede volver a existir un Estado fuerte y con políticas activas, un empresariado orientado a la producción para el mercado interno; que puede reconstituirse un movimiento popular, policlasista, que logre la reconstrucción de un capitalismo nacional, compatible con un margen importante de autonomía frente al capital extranjero y los países centrales.” (Campione y Rajland, 2006:308)
\end{abstract}

\footnotetext{
${ }^{158}$ Es importante recordar que en sus análisis del Príncipe moderno, Gramsci rescataba, tomando el caso del jacobinismo, que la creación de una voluntad colectiva tiene ese componente ex novo, que es radical e irreductible a una suma de identidades pasadas, pero que al tiempo las contiene y resignifica en tanto el Príncipe moderno recupera para sí la historia de las luchas populares y se presenta como su mítica realización.

159 Siguiendo a Gómez, un imaginario, sin ser un producto acabado y pasivo, "se organiza como una compleja red de relaciones sobre la que se sostienen discursos y prácticas sociales” (2001:200), manifestándose tanto en lo simbólico como en el accionar concreto entre los sujetos en la praxis social, en tanto esta se despliega aspirando a ciertos modelos guías. En este sentido, utilizaremos el concepto de imaginario ligándolo a nuestro enfoque teórico general, ubicándose en un rango intermedio entre la concepción del mundo, siendo menos vasta que ésta, y la cultura política, siendo más vaga y difusa que ésta. Así, el imaginario expresa una consolidación (nunca acabada) de una matriz de representaciones vinculada a concepciones del mundo, que está ligada a elementos propios de una cultura política, en tanto implica una determinada apreciación del pasado histórico, de valores y aspiraciones, que incide en la praxis presente en tanto provee una proyección hacia el futuro a construir (pero que contiene menor especificidad que una cultura política particular, ya que la misma implica un mayor nivel de codificación y tiene una relación directa con la organización de fuerza política y el despliegue de un proyecto de gobierno).
} 
Como veremos a continuación, es importante comprender el alcance de esta concepción del mundo, en tanto será la base sobre la que se construirá la hegemonía post-crisis, de modo más difuso en el discurso de Duhalde y cobrando luego todo su esplendor con el kirchnerismo. Siguiendo a Campione y Rajland (2006), el segundo imaginario tenía una visión menos favorable de los años 40-60, remarcando el sometimiento de los trabajadores a las patronales, el respaldo del Estado a un modelo sindical antidemocrático y autoritario, las represiones y proscripciones que sufrían las fuerzas populares disidentes, etc. Además, procuraban nuevas formas de trabajo y relaciones comunitarias que permitieran trascender tanto los límites de aquella Argentina como del neoliberalismo vigente, ligándose a una perspectiva de izquierda heterogénea. Estas distintas visiones se vinculaban asimismo a las tradiciones políticas diversas que contenían las organizaciones piqueteras ${ }^{160}$.

Además hay que tener en cuenta, como señalan Barbetta y Bidaseca, que "hablar de movimiento piquetero no implica pensar un actor único u homogéneo, sino que se trata de un movimiento que integra otros movimientos $\mathrm{y}$ actores diversos $\mathrm{y}$ heterogéneos en su práctica y discurso que a menudo se enfrentan y toman posiciones diferentes con relación al poder, la representación y la radicalidad de la lucha” (2004:78). Pero como sostienen dichos autores, la identidad de "piquetero" no se deduce linealmente de las identidades ya constituidas (sean estas laborales, partidarias, etc.). Esto nos lleva a reflexionar nuevamente sobre la construcción identitaria de sujeto, ya que si bien entendemos que el mismo no puede ser enteramente desligado de su propia historicidad, de los rasgos y experiencias previas de quienes lo componen, hay un "plus" de identidad, un componente ex novo, gestado en el conflicto que lo hace irreductible tanto a la suma de individualidades o actores, como a ser un derivado lineal de su propio pasado. Las identidades se forman y transforman, se redefinen en la lucha: por eso la política es dinámica y para comprender sus procesos nunca alcanza con yuxtaponer una sucesión de eventos, sino que requiere del abordaje sistemático de las relaciones profundas que dicho devenir contiene. Asimismo, la constitución de sujeto

\footnotetext{
${ }^{160}$ La más grande de ellas, la Federación de Tierra Vivienda y Hábitat (FTV) estaba orgánicamente vinculada a la CTA y poseía una tradición principalmente peronista así como de cristianismo de base y de izquierda. Luego venían la Corriente Clasista y Combativa, ligada al maoísmo; los Movimientos de Trabajadores Desocupados Aníbal Verón de carácter más autonomista; el Movimiento Independiente de Jubilados y Desocupados, de izquierda; el Polo Obrero, trotskista; el Movimiento Territorial Liberación ligada al Partido Comunista: y el Movimiento Barrios de Pie, de raigambre peronista y de izquierda; entre otras. Las distintas organizaciones fueron, asimismo, generando variadas formas de articulación entre sí y de relación con el Estado.
} 
puede ser apreciada en distintas escalas que, a su vez, nos convocan a reflexionar críticamente sobre la posición topográfica de los conceptos en el enfoque teórico. El "piquetero" se constituye en actor-sujeto y contiene en su propia heterogeneidad y conformación una cadena equivalencial de diversas demandas (trabajo, vivienda, salud, etc.) al tiempo que una de ellas, el "trabajo digno" ${ }^{161}$, comienza a ocupar un lugar de significante vacío subsumiendo al conjunto de la cadena en la universalización de esta demanda, que posee, a su vez, la investidura de la promesa mítica de plenitud ${ }^{162}$. Pero por otro lado, el movimiento piquetero es un actor (en el sentido que lo definimos en el capítulo anterior), que en las distintas dimensiones de las relaciones de fuerzas gramscianas se ubica dentro del grado aún económico-corporativo, y que para volverse sujeto-pueblo precisa de articular su demanda central “trabajo digno” (con todas las que ésta subsume) con las demandas de otros portadores y disputar la fundación de un “nuevo Estado” (en el sentido de Gramsci, 2003).

El movimiento obrero sufrió fuertemente la implementación del neoliberalismo que dio lugar a su fragmentación, entre aquellos sindicatos que negociaron la aplicación de las reformas a costa del interés de sus trabajadores afianzando un modelo de “sindicalismo empresarial”163, y aquellos que resistieron y procuraron generar prácticas y estrategias alternativas. En ese camino surgió la Central de los Trabajadores Argentinos $\left(\mathrm{CTA}^{164}\right)$, como escisión de la tradicional CGT, buscando generar un modelo sindical alternativo que recuperara la democracia interna y la defensa de los intereses de la clase trabajadora. Exhibía asimismo una concepción amplia de clase, conteniendo en su interior tanto a los trabajadores ocupados como a los desocupados, a la juventud, los jubilados, etc. procurando abordar un extenso espectro de agentes subalternos; aunque en materia sindical quedó ligado principalmente a los trabajadores estatales, sin poder insertarse con mayor fuerza en los sectores industriales. A su vez, al interior de la CGT surgió el Movimiento de los Trabajadores Argentinos (MTA), conducido por Hugo Moyano, que, sin romper con la central tradicional, mostró un

\footnotetext{
${ }^{161}$ Este carácter de demanda articulante del “trabajo digno” es también señalado por Retamozo (2011) y por Campione y Rajland (2006).

${ }^{162}$ Esto se debe a que "trabajo digno" comienza a convertirse tanto en la imagen de la comunidad perdida (por ejemplo, en el imaginario de la Argentina peronista que mencionamos), pero es también sinónimo de bienestar social, educación, salud, etc.

163 El sindicalismo empresarial consistió en "transformar a sus sindicatos en unidades de negocios en donde el afiliado es más un cliente que un representado a la hora de discutir el salario y las condiciones de trabajo” (Campione y Rajland, 2006:318). Un primer trabajo que aborda el sindicalismo empresarial en Argentina de los años 90 puede en Murillo (1997).

${ }^{164}$ La CTA surge en 1992 primero con el nombre de Congreso de los Trabajadores Argentinos.
} 
carácter más combativo y movilizador diferenciándose del modelo de "sindicalismo empresarial" reinante en la CGT. Otra experiencia destacada de lucha de los trabajadores, que fue creciendo con el desarrollo de la crisis, era el movimiento de fábricas recuperadas, basado en la ocupación y puesta en funcionamiento de unidades productivas que eran cerradas por sus patrones. Este accionar contenía un fuerte contenido clasista, proyectando la posibilidad de autogestionar la producción desde los trabajadores mismos, sin necesidad de la figura del capital ${ }^{165}$. Como señala Retamozo (2011) la publicidad que obtuvo este repertorio de acción al instituir la recuperación como posibilidad, mejoró las condiciones de negociación de los trabajadores en su conjunto frente a los patrones, aun cuando no se llegaba la ocupación efectiva; asimismo también se destacan, al interior de estas experiencias, las tensiones entre la autogestión horizontal y las necesidades de hacer viable y competitiva la producción en las condiciones económicas vigentes.

En el contexto de profundización de la crisis y radicalización del conflicto se fueron articulando también las demandas de otros movimientos. El movimiento estudiantil también fue incrementando su capacidad e intensidad de acción a lo largo de los años $90^{166}$ y en 2001 fue protagonista de las luchas contra los recortes presupuestarios $^{167}$ y los planes de arancelamiento en la universidad, que motivaron masivas tomas de facultades en repudio logrando detener dicho proyecto. A esto se le sumaron el creciente avance del movimiento de Derechos Humanos, que tenía en HIJOS un actor dinámico a través de su repertorio de “escrache”, a lo que se sumaba la proliferación de movimientos contraculturales, tanto de arte y política como comunicacionales, evidenciando un fuerte componente juvenil en la masificación del conflicto que terminó derivando en la rebelión popular de diciembre. Asimismo, en el conjunto de los movimientos sociales se expresaba una mayor gravitación de distintas variantes de izquierda, tanto ligadas a los marxismos, al autonomismo y al peronismo, con crecientes niveles de impugnación al orden establecido, combinado con un fortalecimiento relativo de los partidos de izquierda y su grado de movilización, dada

\footnotetext{
${ }^{165}$ Como señalan Campione y Rajland (2006) el movimiento de fábricas recuperadas contenía posiciones heterogéneas en su interior que iban desde la toma como defensa de la fuente de trabajo hasta posturas anti-capitalistas.

${ }^{166}$ Un hito de este proceso fueron las luchas contra la Ley de Educación Superior, en 1995, cuya sanción culminó con un masivo enfrentamiento en las calles y una brutal represión policial.

${ }^{167}$ Particularmente contra el plan de ajuste que promovió López Murphy en su efímera asunción al frente del Ministerio de Economía.
} 
por su nueva inserción territorial en el movimiento piquetero, en la CTA, y su avance en el movimiento estudiantil, entre otros ${ }^{168}$.

También se incrementó la participación y organización de las capas medias. El aumento de "nuevos pobres" producto de la erosión de las condiciones laborales y niveles de vida de parte de los sectores medios, así como la indignación por los altos niveles de corrupción en la dirigencia política, encontraron un hito explosivo en la incautación de los ahorros con el "corralito” de los depósitos en el sistema financiero. La emergencia de los “caceroleros”, caracterizados por el "cacerolazo" como acción característica de su repertorio de lucha, comenzó a marcar un fuerte punto de quiebre a nivel ideológico en virtud del lugar destacado que tiene históricamente la "clase media" en el imaginario colectivo argentino ${ }^{169}$. Los caceroleros pasaron a ser un actor importante también en el desarrollo de las asambleas populares ${ }^{170}$ que marcaron un viraje en materia de participación pública resquebrajando el patrón neoliberal individualista y su visión de la política ligada a "especialistas”"171, evidenciando también la ruptura entre representantes y representados propia de una crisis orgánica. Como señala Retamozo, "La crisis de representación tuvo así en los sectores medios urbanos su cristalización organizativa en nucleamientos que asumían las formas asamblearias para la toma de decisiones, el "cacerolazo" junto a otros repertorios tradicionales y una impugnación del vínculo representativo. Las asambleas repolitizaron espacios (el barrio, las plazas, la calle) y relaciones sociales (el vecinazgo) por fuera de los canales tradicionales de participación política y la lógica estatal de la política” (2011:257). Esta experiencia de participación popular refleja tanto la crisis hegemónica en su ruptura entre representantes y representados, como las dificultades de "la” política para procesar y desactivar los componentes impugnadores de la articulación de demandas que comenzaron a aunarse en torno a una consigna preponderante: “que se vayan todos”, evidenciando la delimitación del adversario en el campo de antagonismo.

\footnotetext{
${ }^{168}$ Aunque, salvo el desempeño de Izquierda Unida (PC + MST), mantenía serias dificultades a la hora de presentar una propuesta político-electoral.

${ }^{169}$ Como ejemplo de la gravitación cultural de los sectores medios, es interesante ver las numerosas encuestas que muestran como personas de todos los segmentos sociales creen pertenecer a la "clase media”. Un ejemplo de esto puede verse en la nota de iProfesional (26/6/2011).

${ }^{170}$ Las asambleas emergieron principalmente en barrios de sectores medios en la Ciudad de Buenos Aires y el Gran Buenos Aires aunque existieron experiencias en distintas áreas del país.

${ }^{171}$ Era muy común ver en aquel entonces en los de comunicación a economistas hablando desde el lugar de "especialistas", de tecnócratas, mostrando las decisiones políticas como derivados técnicos ineludibles y ascéticos (por fuera de la disputa de proyectos e intereses que en realidad implicaban) adjudicadas a las "necesidades" de los mercados. Un interesante trabajo sobre la relación entre economistas, Estado y empresarios puede encontrarse en Heredia (2011).
} 
Pero las condiciones esta rebelión no estuvieron dadas sólo por el aumento de la conflictividad proveniente de las clases subalternas. También se asistió a un proceso de recrudecimiento de las contradicciones al interior de la clase dominante. Frente a los evidentes signos de agotamiento del modelo de la convertibilidad, la clase dominante se fue articulando en torno a dos bloques a partir del lugar que ocupaban en la estructura y sus estrategias de acumulación. Por un lado, comenzaron a aglutinarse los agentes del capital productivo, o sea, empresas de bienes transables de capital nacional y extranjero, ubicadas en sectores industriales y ligadas a la extracción y procesamiento de recursos naturales fuertemente, orientados a la exportación. Este conjunto de agentes dominantes se comenzó a plantear una salida devaluacionista procurando dos beneficios principales: 1) aumento de la competitividad para mejorar la capacidad de exportación, limitando, a su vez, la competencia externa vía importación ${ }^{172}$, y 2) la posibilidad de aumentar su patrimonio en moneda local, en tanto los agentes más concentrados mantenían abundantes divisas fugadas en el extranjero. Por otra parte, se ubicaron los agentes ligados a la fracción de empresas de servicios, con un fuerte componente de empresas de capital extranjero vinculadas a las privatizaciones, y algunas transnacionales fuertemente endeudadas en dólares en el exterior, así como el capital financiero; o sea, en su mayoría agentes del capital que produce bienes y servicios no transables. Este se agrupó en torno al proyecto dolarizador, entendido como fase superior de convertibilidad, procurando dos objetivos: 1) mantener el valor en dólares de sus activos y poder seguir remitiendo sus utilidades dolarizadas al exterior, en el caso de las empresas extranjeras, y 2) evitar el aumento de las deudas en divisas y, para el capital financiero, mantener sus activos líquidos a precio dólar, de modo de no perder competitividad internacional ${ }^{173}$.

Ambos bloques de la clase dominante perfilaron distintas estrategias discursivas y procuraron ampliar su influencia a través de la conformación de marcos de alianza que les permitieran presentar su propio interés particular como el interés general, operación clave en la construcción de hegemonía.

\footnotetext{
${ }^{172}$ Recordemos que la convertibilidad había fosilizado una sobrevaluación del peso respecto al dólar, dificultando la capacidad exportadora y abaratando los precios de los productos importados en un contexto de apertura comercial.

${ }^{173}$ Como señalamos previamente, algunos de los principales trabajos que analizan las distintas propuestas de salida de la crisis en clave de devaluacionistas y dolarizadores son Basualdo (2001), Castellani y Szkolnik (2005) y Schorr y Wainer (2005).
} 
Siguiendo a Castellani y Skolnik (2005), la estrategia dolarizadora apareció públicamente a través de los representantes políticos y otros intelectuales orgánicos a los agentes del capital concentrado con fuerte vinculación al proyecto neoliberal. Ya en el último gobierno menemista (1995-1999) se expresó a través del mismo presidente y de economistas ortodoxos planteando la dolarización como profundización más acabada de la convertibilidad y argumentando acerca de la necesidad de eliminar la incertidumbre cambiaria para atraer inversiones. Estas primeras pronunciaciones pro dolarización encontraron fuertes respuestas en los elementos que se irían conformando como el bloque devaluacionista ${ }^{174}$. Esta estrategia volvió a cobrar impulso en el año 2001, cuando, con la agudización de la crisis, sectores del gobierno de la Alianza (19992001), encabezados por el presidente De la Rúa y parte de su gabinete, comenzaron a evaluar la posibilidad de avanzar hacia la dolarización ${ }^{175}$. La estrategia dolarizadora chocó con amplios rechazos desde un variado espectro de la sociedad civil (ya sea dentro del arco devaluacionista como del espectro opositor vinculado a la CTA, los diversos movimientos sociales y partidos de izquierda) que le imposibilitaron constituir en una alianza más amplia que le permitiera aparecer como la portadora del "bien común”. Además, esta propuesta contaba con una deficiencia objetiva fundamental para realizarse fácticamente vinculada a la inmensa masa de dólares que hubieran sido necesarios para dolarizar el conjunto de la economía. En el contexto de profunda crisis política, económica y social, el desbarajuste creciente de las variables económicas, sumado al altísimo endeudamiento, hacía casi imposible adquirir las divisas necesarias para realizar el proyecto dolarizador.

Por otro lado, encontramos como uno de los principales voceros del proyecto devaluacionista a la Unión Industrial Argentina. Esta entidad empresaria aparece como representante de los intereses del gran capital productivo y apostó a construir un discurso de corte nacional e industrialista, desarrollando estrategias discursivas para hacer aparecer a este grupo social como el resurgir de una mítica "burguesía nacional” lo cual compatibilizaba con el imaginario del retorno a la Argentina peronista en su evocación a la industrialización, en una cruzada por el interés general en disputa con el

${ }^{174}$ Las críticas se centraban en los perjuicios que la dolarización efectuaría en términos de la cristalización de las tendencias negativas de la convertibilidad así como en la pérdida de soberanía económica al renunciar definitivamente al ejercicio de la política cambiaria y monetaria

${ }^{175}$ Así "la alianza pro dolarización quedó constituida por los economistas más ortodoxos (el destituido Pedro Pou y el ex ministro Roque Fernández ), algunos funcionarios de gobierno (Chrystian Colombo, Nicolás Gallo y Fernando de Santibáñez), el presidente Fernando De la Rúa y el ex presidente Menem” (Castellani y Skolnik, 2005:12). 
capital foráneo. Así comenzó a tejerse una estrategia discursiva que, en primera instancia tuvo que emerger solapada, encubierta, en tanto permaneciera el amplio consenso logrado por la convertibilidad como vencedora frente a la hiperinflación ${ }^{176}$. Esta recién apareció en público en cuanto logró sumar como aliado a un sector de la cúpula sindical de la $\mathrm{CGT}^{177}$, motivado por el imaginario del regreso a la Argentina peronista, a la alianza policlasista de la producción y el trabajo para enfrentar la crisis vigente, pasando a explicitar públicamente una posición favorable a la devaluación ${ }^{178}$.

La propuesta devaluacionista comenzó a incluir otra demanda crucial para las necesidades del capital concentrado: la pesificación de las deudas, ya que, se deba a inversiones productivas o a la simple participación en el ciclo de valorización financiera, el endeudamiento en dólares podría complicar los propios intereses de este bloque con la salida devaluacionista procurada. Castellani y Szkolnik señalan que la construcción del marco de alianza en esta estrategia, fue sumando adhesiones hasta concluir en un amplio frente pro devaluación conformado por el autodenominado Grupo Productivo ${ }^{179}$, distintas corporaciones empresarias ${ }^{180}$, algunos grupos económicos (como Techint) y varios líderes políticos del PJ y la UCR, así como la cúpula sindical de la CGT. En términos de clases, no podemos dejar de notar que a la cabeza de este bloque se encontraban agentes del capital concentrado que habían participado activamente en colaboración con la dictadura militar en el proceso de exterminio de las organizaciones de las clases subalternas, que habían hecho fortunas con la valorización financiera y habían fugado constantemente su renta, que habían apoyado la implementación de las reformas neoliberales y que habían sido fervientes promotores de

\footnotetext{
${ }^{176}$ De este modo, a partir de la crisis de 1998 y con mayor énfasis desde la devaluación del real en 1999, la UIA comenzó a reclamar medidas compensatorias para mejorar la competitividad de la producción local afectada por la sobrevaluación del peso, sin mencionar todavía abiertamente la propuesta de devaluación.

${ }^{177}$ Quienes apoyaron decididamente la salida devaluacionista fueron principalmente los encolumnados en la CGT Rebelde de Moyano, mientras que la CGT oficial permanecía dubitativa y era factible su apoyo a la opción dolarizadora.

${ }^{178}$ Así arribamos a una segunda fase de la estrategia discursiva del proyecto pro-devaluación: "de la utilización de los denominados argumentos encubiertos (propiciados especialmente por las corporaciones del capital) se pasó a una combinación de esos mismos argumentos con otros abiertamente favorables a la devaluación (exclusivamente a cargo de los sindicalistas)" (Castellani y Skolnik, 2005:16).

${ }^{179}$ Este grupo fue iniciado por la articulación de la Unión Industrial Argentina, la Cámara de la Construcción y Confederaciones Rurales Argentinas y expresó la ruptura del Grupo de los Ocho que contenía a las principales entidades patronales durante los años 90 (Sociedad Rural Argentina, Unión Industrial Argentina, Cámara Argentina de Comercio, Cámara de la Construcción, la Bolsa de Comercio, la Asociación de Bancos Privados de Capital Argentino (ADEBA) y la Asociación de Bancos de la Argentina (ABA)).

${ }^{180}$ UIA, Federación Agraria, Coninagro, Confederaciones Rurales Argentinas, la Cámara de PyMEs del sector alimenticio, Cámara Argentina de la Construcción.
} 
la caída del salario real y la flexibilización laboral, pero que, paradójicamente, lograban aparecer en esa coyuntura como la “burguesía nacional” llamada a relanzar el imaginario peronista de la industrialización, el pleno empleo y una virtuosa alianza policlasista.

Esta capacidad de articular un amplio espectro de fuerzas, de recrear un discurso con profundo arraigo en la sociedad argentina, y de pronunciarse tácticamente, primero de forma solapada, y luego, cuando el consenso de la convertibilidad comenzaba a ceder, hacerlo abiertamente, posibilitó a los agentes productivos de la clase dominante hacer aparecer sus propios intereses como la representación del bien común, un proceso de universalización hegemónica que impuso a la devaluación como la mejor e inevitable salida. Así, con la caída de De la Rúa, comenzaron a aplicarse un conjunto de políticas estructurantes dando lugar a un nuevo modelo de acumulación, que tendría un momento fundacional en el gobierno de Duhalde.

Estos son ejemplos de cómo se constituye y actúa la sobredeterminación de la contradicción en un periodo y lugar determinado, y de cómo la contradicción se vuelve antagónica evidenciando una articulación de movimientos orgánicos y coyunturales, necesarios y contingentes, expresando la dialéctica en su desempeño material. Así, vemos cómo la caída del modelo de la convertibilidad, se vinculó tanto a la incapacidad de continuidad de funcionamiento de un modo de organizarse la estructura, como a las acciones concretas desarrolladas por el Estado, los agentes y los actores. El recrudecimiento de las contradicciones tanto al interior del modelo de acumulación como unidad sintética, así como en su dimensión específica de clase, en su aspecto de contradicción interburguesa y en la relación capital/trabajo, gestaron el terreno estructural para la emergencia del antagonismo. Así la contradicción se volvió antagónica en un contexto de principio de crisis orgánica. Pero, ¿por qué nos referimos a un "principio” de crisis orgánica? ¿qué factores la tornan inconclusa?

En primer lugar identificamos un conjunto de factores constitutivos de lo que Gramsci caracteriza como crisis orgánica. La dimensión ideológico-cultural de la crisis expresó el deterioro de la concepción del mundo, que a su vez impactó tanto en la conformación del sentido común como en las prácticas mismas, habilitando la recreación de la participación en la vida pública y una mirada crítica sobre el rol del Estado en su versión neoliberal. Este aspecto se ligaba con la dimensión política de la 
crisis, en tanto erosión de la institucionalidad política para poder procesar demandas y construir consensos, llevando a un contraste manifiesto entre representado y representantes, que activó el conflicto creciente de los movimientos sociales y partidos de izquierda. A su vez, la crisis económica presentaba las dificultades del modelo de la convertibilidad para seguir en curso, motivando una fractura al interior de la clase dominante según las distintas propuestas de salida, al tiempo que el deterioro de los indicadores socio-económicos constituían el marco de un profundo malestar social que alentaba la protesta. Este conjunto de factores se fueron profundizando, evidenciado la crisis de autoridad de los poderes establecidos, hasta gestar la rebelión popular de diciembre de 2001.

Se produce así el paso de clase dirigente a clase meramente dominante, que marca Gramsci como propio de los períodos de crisis orgánica, y que puede observarse en la escalada represiva que se extendió tanto en 2001 como en 2002. Ésta tuvo sus exponentes más altos en la instauración del Estado de sitio y en la represión que cobró decenas de vidas durante los conflictos del 19 y 20 de diciembre de 2001 que culminaron con la renuncia del presidente De la Rúa, y, luego, en la "Masacre del Puente Pueyrredón”, el 26 de junio de 2002, desplegada por el gobierno de Duhalde sobre el movimiento de desocupados intentando una fallida salida represiva al creciente conflicto social, que forzó el adelanto del llamado a elecciones.

La gestación del antagonismo encadenó un conjunto de demandas populares que comenzaron a ser irreductibles con la hegemonía y el modelo de acumulación por entonces vigente: las sombras de la hegemonía menemista, ya con la deslegitimación creciente de su líder y sus intelectuales orgánicos, incapaz de ser reconvertida bajo la férula de la Alianza, y el modelo de la convertibilidad comenzando a implosionar, dividiendo a la clase dominante según distintos proyectos de salida. Sin embargo hablamos de un principio de crisis orgánica, y no de crisis orgánica en sentido pleno, ya que no se logró conformar una fuerza antagonista alternativa emergida de la subalternidad con capacidad de articular el amplio abanico de reclamos particulares en pos de una salida que lograra fundar un nuevo bloque histórico. La heterogeneidad de las demandas y de sus portadores, logró encadenamientos suficientes como para alcanzar a la delimitación provisoria del adversario ligado a la consigna que comenzó a cumplir la función de significante vacío: “que se vayan todos”. Ésta se constituyó en el significante aglutinador de las distintas demandas, cumpliendo un papel de articulador a 
partir de la negación y de la delimitación provisoria de un adversario, un "todos” que encarnaba la otredad de forma difusa, la anti-comunidad, que abarcaba a las figuras deslegitimadas del neoliberalismo, que impugnaba especialmente a la dirigencia de los partidos políticos gobernantes asociados a la corrupción como práctica política y que podía alcanzar hasta los sectores más concentrados de clase dominante (en la apreciación de los actores más radicalizados) ${ }^{181}$. De este modo el “que se vayan todos” mostraba la emergencia generalizada y disruptiva de lo político, en tanto antagonismo que alcanzó a delimitar un exterior constitutivo, un “ellos” (Mouffe, 2007). Pero, si bien bastó para golpear la hegemonía de los grupos sociales dirigentes, ahora percibidos como meramente dominantes, mostró sus limitaciones para articular de forma consistente las demandas heterogéneas de los diversos actores en un "nosotros" emergido de la subalternidad misma, impidiendo la conformación de una voluntad colectiva con permanencia en el tiempo. De este modo, no se logró articular los reclamos de los sujetos subordinados en una dimensión propositiva, en una nueva fuerza política $^{182}$. Hubo una coyuntura que parecía dar lugar a esta gestación, sintetizada en el grito popular “piquete y cacerola, la lucha es una sola”, bregando por la articulación de las demandas y sus portadores, haciendo referencia a dos de los movimientos más relevantes en la escena política. Sin embargo, con la asunción de Duhalde a cargo del Poder Ejecutivo, se desplegaron fuertes estrategias de segmentación de las demandas, en sintonía con los grandes medios masivos de comunicación que actuaban como "Estado Mayor intelectual” de la clase dominante, estigmatizando al movimiento piquetero y promoviendo la fragmentación del difuso campo popular.

El carácter inconcluso de la crisis orgánica se vincula, entonces, al carácter igualmente inconcluso del sujeto-pueblo en formación. Se dio una articulación precaria de demandas, que sin embargo lograron mutar su carácter “democrático” (en el sentido laclausiano) hasta devenir populares, dificultando su procesamiento en el marco del

\footnotetext{
${ }^{181}$ Nos referimos a la idea de "figuras deslegitimadas del neoliberalismo" para señalar que la impugnación remitía a un variable abanico, que se encarnaba en el discurso tanto en personajes concretos (Menem, Cavallo, De La Rúa, etc.) como en instituciones (como el FMI) y en políticas (el ajuste, las privatizaciones, etc.). Según Campione y Rajland (2006), el "que se vayan todos" cubrió un amplio espectro de significados vinculado al rechazo a la dirigencia política que en su versión más simplista se expresaba como antipolítica, que en un momento llegó a poner en cuestión a prácticamente todos los poderes sociales, tanto estatales como privados, aunque en general la dirigencia política aparecía en un lugar de culpabilidad mayor y con más frecuencia que el empresariado.

${ }^{182}$ Como señalan Campione y Rajland, "El Que se vayan todos tan popularizado a comienzos de 2002 no alcanzó a encarnarse en una posición más progresiva, en un programa más concreto que el rechazo global al orden existente, que en ocasiones resultaba paralizante para el propio desarrollo del movimiento" (2006:300).
} 
orden vigente. Se delimitó un adversario difuso, en el trazado del campo de antagonismo, pero sin embargo, del lado de los portadores de demandas la heterogeneidad terminó siendo más fuerte que la articulación equivalencial y las acciones del bloque dominante tendientes a profundizar la fragmentación limitaron la posibilidad de emergencia y consolidación de un sujeto-pueblo ${ }^{183}$. Así, la rebelión de 2001 no alcanzó a constituir sujeto-pueblo, y la voluntad colectiva en construcción fue vulnerable a la acción de los agentes de clase dominante y sus intelectuales orgánicos. Si bien "la insurrección de diciembre produce el fin de la hegemonía neoliberal en tanto activa la negatividad de aquellos subordinados en las distintas tramas de la dominación neoliberal” (Retamozo, 2011:257), los distintos componentes de la crisis de hegemonía no se tradujeron en dimensiones constitutivas del sujeto: identidad y proyecto.

La multiplicidad de concepciones del mundo, estrategias y rasgos particulares de los portadores de demandas involucrados en la contienda antagónica, sumado al accionar de los actores dominantes tendiente a fragmentarlos, frustraron la construcción de la voluntad colectiva que desde la subalternidad pudiera haber llevado a una crisis orgánica en sentido pleno. Así podría plantearse la tensión teórica acerca de la relación entre la articulación de demandas y la constitución de sujeto: si bien el sujeto es creación ex novo, la demanda, siendo unidad básica de este análisis, no puede dejar de ser apreciada sino en relación a sus portadores. Ya sean estos portadores considerados como agentes, por su posición estructural, o actores, en las dimensiones corporativa o política, según la instancia de inscripción en la gravitación y corte analítico que se establezca en el marco del análisis gramsciano de las relaciones de fuerza. La diversidad y multiplicidad de concepciones de mundo, de fórmulas organizativas, de caracterización de la situación concreta (en términos orgánicos y coyunturales) y de objetivos, sumado al accionar desplegado desde el bloque en el poder para fragmentación, dificultó que la cadena de equivalencias, aún precaria, pudiera consolidarse y rebotar sobre el conjunto de demandas pariendo una identidad popular común, un proyecto colectivo y, en ese camino, un sujeto-pueblo. Así, la consigna “piquete y cacerola la lucha es una sola” expresó una articulación efímera entre los distintos portadores de demandas que podría haber dado lugar a la voluntad colectiva, pero cuya fractura evidenció las limitaciones del antagonismo: el carácter inconcluso

\footnotetext{
${ }^{183}$ En el mismo sentido también se expresa Retamozo, cuando señala que: "No obstante el encuentro espacial y simbólico no se tradujo si no en una inestable subjetividad colectiva sin la estabilidad necesaria para la conformación de un sujeto político que condense los tramos de subjetividad popular” (2011:256).
} 
del sujeto-pueblo en formación, que es, asimismo, el carácter inconcluso de la crisis orgánica, circunscribiéndose a ser un principio de la misma sin revestir su forma acabada. Aun así, la crisis de 2001, como toda crisis profunda de hegemonía, reveló el carácter contingente de lo social, develó la opresión y tornó en antagónicas las contradicciones.

\subsection{El gobierno de Duhalde: contención y coerción en la fundación del modelo.}

Con la renuncia del presidente De la Rúa, la coalición gobernante (la Alianza) quedó gravemente afectada y la sucesión pasó a definirse en el otro polo del bipartidismo dominante, el Partido Justicialista (PJ). Siguiendo a Novaro, "Entre fines de diciembre de 2001 y principios de enero de 2002 el país tuvo tres presidentes peronistas, como consecuencia de la dificultad para llegar a un acuerdo dentro de esa fuerza sobre el rol y duración que debía tener el gobierno de emergencia, en función de distintas interpretaciones de la Ley de Acefalía” (2004:179). Así se sucedieron primero Ramón Puerta, quien era entonces presidente provisional del Senado y cabeza de una liga de distritos pequeños, pero no logró los apoyos necesarios de las provincias de mayor peso. Fue seguido por Adolfo Rodríguez Saá, gobernador de San Luis, quien estableció la que sería una de las políticas fundacionales de la post-convertibilidad: el default de la deuda pública, pero que intentando obviar el acuerdo de llamados a elecciones en el corto plazo fue obligado a renunciar. Así, llegó Eduardo Duhalde a la presidencia, con la condición de gobernar hasta 2003 y luego llamar a elecciones, alcanzando un acuerdo con el sector alfonsinista de la UCR, y presentándose como "presidente de transición” que convocaba a un gobierno de unidad para la "salvación nacional”.

Si bien el gobierno de Duhalde no alcanzó a constituir una fuerza hegemónica que lograra suturar el principio de crisis orgánica existente, ya que esto hubiera implicado superar el momento de la mera dominación por coerción para alcanzar el momento hegemónico caracterizado por el consenso, sí desarrolló estrategias orientadas a confrontar algunas de las aristas de las distintas dimensiones de la crisis. Esta estrategia podría sintetizarse en sus tres aspectos fundamentales:

1) En relación a la dimensión ideológico-cultural de la crisis, Duhalde, quien había sido uno de los intelectuales orgánicos de la salida devaluacionista, se convirtió 
en el primer presidente post-convertibilidad en abrazar decididamente un discurso productivista con aspiraciones fundacionales. En este camino, propuso una nueva alianza de clase liderada por el capital productivo, que incluyera a los trabajadores, apelando al imaginario peronista y buscando diferenciarse del modelo anterior que en su discurso aparecía conducido por el capital financiero.

2) Respecto de la crisis política, su gobierno impulsó una estrategia dual basada en el par contención/coerción. El componente de contención se expresó en la masificación de los planes sociales con el fin de paliar el estallido de los indicadores sociales, principalmente en materia de desocupación, pobreza e indigencia que treparon a récords históricos durante su gobierno. El componente coercitivo se evidenció en una ofensiva contra los movimientos sociales, principalmente contra el movimiento piquetero, basada en la criminalización de la protesta social y en la represión abierta. En su rol de encarnación de la “demanda de orden”, su estrategia de contención/coerción, con el sustento de los medios masivos de comunicación en la campaña de criminalización de la protesta, y el comienzo de respuestas a las demandas de los sectores medios ligadas al “corralito", terminó por materializar la fractura del “pueblo inconcluso", con el paulatino abandono de las "cacerolas" del centro del escenario del conflicto social, al tiempo que concentraba la represión sobre el movimiento piquetero.

3) En vinculación a la crisis económica, con la asunción de Duhalde se sancionó la Ley de Emergencia Pública y Reforma del Régimen Cambiario n²5561, la cual contuvo un núcleo de reformas en materia político-económica, comenzando por la devaluación de la moneda pero conteniendo también un conjunto amplio y profundo de medidas que dieron por tierra al modelo de la convertibilidad y sentaron las bases de un nuevo modelo de acumulación. De este modo, se plantearon una serie de políticas fundacionales del modelo post-convertibilidad, que analizaremos en detalle en el capítulo siguiente, en tanto representan transformaciones de largo alcance, ineludibles para una correcta caracterización de dicho modelo. También es relevante señalar que estas políticas se aplicaron con un sesgo regresivo, recayendo los costos sociales del cambio del modelo principalmente sobre las clases subalternas. 
En su discurso de asunción ante el parlamento, Duhalde define tres objetivos vinculados a la caracterización y resolución de la crisis vigente. En primer lugar, se propone reconstruir la autoridad política e institucional, atendiendo a los fenómenos que presentamos bajo el carácter de crisis de autoridad y su relación con la crisis política, tanto en términos de "la” política, promoviendo una "nueva organización institucional en la Argentina para recuperar esta república arrasada por la corrupción y el desgobierno” (Duhalde 1/1/2002), y atendiendo también al componente social devenido en conflicto masivo. Es frente a este factor que Duhalde plantea un segundo objetivo que desarrollará enfáticamente en el conjunto de sus presentaciones públicas: "garantizar la paz social”, sosteniendo que Argentina se encontraba sumida en el "caos”, al borde de la guerra civil, y que los pueblos pueden tolerar cualquier circunstancia adversa pero no la "anarquía" ${ }^{184}$. El tercer objetivo aparece vinculado directamente al cambio de modelo, como vía también de pacificación social en tanto procura resolver la problemática de la desocupación y la pobreza, con el fin de promover "la transformación productiva con equidad y propiciar un modelo sustentable fundado en la producción y en el trabajo” (Duhalde 1/1/2002).

Aparecen en escena así los pilares sobre los cuales el gobierno duhaldista basará su estrategia de pretensiones hegemónicas. De estos lineamientos, el objetivo ligado al cambio del modelo comienza a mostrar algunos rasgos que son constitutivos de la Argentina post-convertibilidad. Ya en el primer discurso como presidente exhibe un primer esbozo de crítica al neoliberalismo, planteando que hay que "romper definitivamente con el pensamiento único que ha sostenido y sostiene que no hay alternativa posible al modelo vigente” (Duhalde 1/1/2002) y planteando como horizonte la construcción de una Argentina basada en la producción ${ }^{185}$ y en este acto ejecuta una operación que también irá in crescendo durante todo nuestro período de estudio: el

\footnotetext{
184 “Tengo una primera obligación que es garantizar la paz social en la Argentina. Los países, las sociedades mejor dicho, toleran las circunstancias más adversas, vaya si lo sabemos los argentinos, lo que no toleran es la anarquía” (Duhalde, 4/1/2002). "Corremos riesgos, Argentina está -y lo he dicho muchas veces- al borde de la anarquía, y los pueblos toleran cualquier circunstancia adversa, pero la anarquía no, y es mi primera obligación como Presidente mantener la paz social en la Argentina. Que nadie se equivoque, yo no soy un presidente débil, yo soy un presidente con la autoridad que me ha dado la democracia argentina y tengo un compromiso; y ese compromiso, el primero de todos, es cuidar la paz social en la Argentina" (Duhalde, 1/2/2002).

185 "Mi compromiso a partir de hoy, es terminar con un modelo agotado que ha sumido en la desesperación a la enorme mayoría de nuestro pueblo para sentar las bases de un nuevo modelo capaz de recuperar la producción, el trabajo de los argentinos, su mercado interno y promover una más justa distribución de la riqueza” (Duhalde 1/1/2002).
} 
nuevo modelo implicaría la rehabilitación de la Argentina peronista. En este sentido sostiene:

\begin{abstract}
"pertenezco a un movimiento político que a través del presidente Juan Domingo Perón y de Eva Perón (Aplausos) fundaron la justicia social en la Argentina y levantaron las banderas de independencia económica y soberanía política. Banderas que con el tiempo, fueron asumidas por todas las fuerzas políticas de origen popular. Esas banderas han sido arriadas y tenemos hoy que preguntarnos y preguntarle a los argentinos, si verdaderamente queremos vivir en un país soberano e independiente." (Duhalde 1/1/2002).
\end{abstract}

De este modo, Duhalde recupera algunos rasgos constitutivos del frente devaluacionista del cual fuera un intelectual orgánico, y comienza a gestar una articulación perenne: caracteriza la necesidad del cambio definiendo el futuro como restitución del imaginario peronista, pero este imaginario se presenta no ya como patrimonio de un solo partido sino de todas las fuerzas progresivas, universalizado, y por eso puede ser éste la guía de un gobierno que se auto-define como "gobierno de unidad nacional” con un "programa de salvación nacional”.

En su discurso inaugural Duhalde sostiene que los dirigentes políticos de los países que progresan "hablan de la producción, hablan del trabajo, hablan de su gente. Eso es lo que no hemos hecho los argentinos. Pareciera que la clase política está desvinculada del sistema productivo; pareciera ser que somos cosas distintas” (Duhalde 1/1/2002). Este aspecto se convierte asimismo en una clave permanente del diagnóstico: la relación de la dirigencia política con el capital aparece definiendo el carácter del modelo, por eso el cambio del modelo implica un cambio de "alianza”. Es por esto que, a sólo unos días de haber asumido, realiza un discurso trascendente frente a un grupo de empresarios reunidos en la residencia de $\operatorname{Olivos}^{186}$ y a segundos de su inicio sentencia: “Ustedes, es decir la comunidad productiva, es la que debe gobernar en el país” (Duhalde, 4/1/2002). Nuevamente recupera el diagnóstico esbozado en la asunción, señala que el problema clave es que la dirigencia política se ha desvinculado del mundo de la producción ${ }^{187}$ y propone una nueva alianza para un nuevo modelo:

"Entonces vengo a decirles que debemos terminar décadas en la Argentina de una alianza que perjudicó al país, que es la alianza del poder político con el poder financiero y no con el

\footnotetext{
${ }^{186}$ El mismo Duhalde expresa la relevancia de dicha reunión diciendo: "he querido que mi primera reunión pública sea con integrantes de la comunidad productiva” (Duhalde, 4/1/2002).

${ }^{187}$ Es interesante observar que Duhalde mismo se incluye cuando habla de los errores de la dirigencia política asumiendo su responsabilidad (innegable, en tanto fuera vicepresidente del primer gobierno de Menem y luego gobernador de la provincia de Buenos Aires). Más adelante veremos la audaz operación discursiva que realiza Kirchner para despegarse de la responsabilidad del modelo anterior y de la impugnación proveniente del “que se vayan todos”.
} 
productivo. El poder financiero, las finanzas, son imprescindibles para un país -imprescindiblespero ubicadas en el lugar que corresponden. Por eso vengo a decirles que esa alianza es la que tenemos que terminar a partir de hoy en la Argentina; que quien va a gobernar dos años el país y que los que asuman nuevamente responsabilidades, sepan que Argentina decide construir una nueva alianza, que es la alianza que yo denomino, pero podemos denominarla de cualquier manera, la alianza de la comunidad productiva. No necesitamos siquiera ser muy originales en el tratamiento de estos temas, solamente saber ver lo que hacen los países que progresan." (Duhalde, 4/1/2002, el subrayado es nuestro).

Es interesante rastrear la definición de "comunidad productiva” en su discurso, en tanto marca aspectos que luego se ven plasmados en la política, ya que es una comunidad regida casi absolutamente por el polo del capital: el énfasis en el empresariado está presente en todos sus discursos; el trabajo aparece mencionado pero sólo como enteramente subsumido al capital (énfasis que veremos cambiar en el discurso de Kirchner). Más adelante, en un discurso frente a Organizaciones No Gubernamentales (ONG), da una definición más extensiva de la comunidad productiva: "la integran los trabajadores, los empresarios todos, quienes hacen circular riqueza que son los comerciantes; se suma por supuesto todo el sector de la ciencia y de la técnica que aporta al desarrollo, se fortifica ese sector con nuestros intelectuales” (Duhalde, 10/1/2002). La nueva Argentina se caracterizaría entonces por un cambio de alianza social, rompiendo la alianza de la dirigencia política con el capital financiero (como se caracteriza para los tiempos del neoliberalismo) y formulando una nueva basada en la producción, que articula a un conjunto de agentes, pero que tiene su centralidad en el empresariado productivo argentino ${ }^{188}$.

Respecto de la dimensión política de la crisis hegemónica, Duhalde perfila una estrategia de contención/coerción ligada a su caracterización de la crisis en términos de caos social ${ }^{189}$. Duhalde sostiene que su primer obligación es garantizar la paz social y afirma “Tenemos que traerle orden al país" (Duhalde, 4/1/2002). De este modo, Duhalde comienza a encarnar la “demanda de orden” (Cremonte, 2007; Rinesi y Vommaro, 2007) proveniente desde distintos sectores, primordialmente (aunque no

\footnotetext{
${ }^{188}$ Cuando se pregunta a quiénes hay que proteger, responde: “primero, empecemos por el tallercito, por ese hombre que está esforzándose, que lo persigue el municipio, que en vez de ser gestor de lo que se va a iniciar le ponen trabas; el pequeño comerciante; el pyme de todo tipo; el productor; el mediano empresario argentino, el gran empresario argentino, que si tengo que llamar para hablar con ellos seguramente no necesito este salón, los puedo atender en el living de mi casa, porque ya no nos quedan. El proceso de desnacionalización argentina ha sido tremendo, tenemos que proteger lo que nos queda y de lo que nos queda empezar a cambiar el rumbo" (Duhalde, 4/1/2002).

${ }^{189}$ Sostiene que la Argentina se encontraba al borde de una guerra civil: "hemos ido bajando escalón por escalón: recesión, depresión, estado preanárquico, caos; que lo vimos reflejado, lo escuchamos, lo vimos, lo sentimos. La gente tuvo un miedo enorme hace 20 ó 25 días cuando vio lo que podía pasar, cuando vio que un escalón más abajo es un baño de sangre en la Argentina” (Duhalde, 10/1/2002).
} 
únicamente) de la clase dominante y de algunos núcleos de las capas medias. Señala que para alcanzar dicha paz hay que garantizar a la población los derechos humanos básicos de alimentación, salud y trabajo. En este sentido, ya en su discurso de asunción manifestaba que, ante la imposibilidad de crear un millón de puestos de trabajo en el corto plazo, había que generar un plan social orientado a los jefes y jefas de hogares desocupados. Este plan se consolidó en el Programa Jefes y Jefas de Hogar Desocupados, constituyendo el primer plan de aspiraciones universalistas de la postconvertibilidad, en tanto se multiplicó rápidamente alcanzando los dos millones de beneficiarios en 2003. Ésta fue la principal herramienta de contención en un contexto de recrudecimiento de la crisis económica que presentaba una literal explosión de los indicadores sociales sumiendo a amplias porciones de la población en la desocupación, la pobreza y la indigencia. Aunque esta medida tuvo un doble efecto político, ya que si, por un lado, logró generar contención, constituyendo un paliativo frente al malestar social, por otro, los planes se convirtieron en objeto de disputa, en un logro de conquista del movimiento piquetero, proveyendo recursos materiales y simbólicos a dicho actor político.

Si bien, en los discursos, Duhalde señalaba que no era con represión que se alcanzaría la paz social, los componentes coercitivos de la estrategia estuvieron presentes desde el primer momento. Se profundizó la creciente criminalización de la protesta social $^{190}$ teniendo como principales promotores a los grandes medios masivos de comunicación actuando como “Estado Mayor intelectual” de la clase dominante ${ }^{191}$ conllevando, a su vez, una escalada represiva contra el movimiento popular. Pero debe notarse que el polo coercitivo de la estrategia política fue orientado selectivamente de modo de segmentar el lazo equivalencial de demandas que constituía el campo de antagonismo: el objetivo era fracturar la incipiente articulación visible en los momentos más álgidos de la lucha y sintetizado en la consigna “piquete y cacerola, la lucha es una

\footnotetext{
190 Para ver el crecimiento de la criminalización de la protesta social en la década de los 90: Artese (2009).

191 "La Nación esgrime la necesidad de “frenar la protesta” para conseguir la "paz social”. La protesta social es asociada a la "irracionalidad” y al "vandalismo organizado”. Actos ilícitos y “orquestados”, algunas veces por la izquierda y en otras por el PJ. A lo largo de esos convulsionados meses, en Clarín podrá observarse como los hechos de protesta se construyen en tanto que hechos de "violencia" o bien "delictivos" (en el caso de los saqueos); con el consecuente llamamiento al "orden” que de ello se desprende. En las fechas previas al estallido de diciembre pero también a la Masacre del Puente Pueyrredón, encontramos una gran cantidad de informaciones referidas a los hechos que hemos denominado de "control social” (robos, secuestros, hechos delictivos y otros que suponen una “desviación” de la norma social establecida).” (Pulleiro et al:148)
} 
sola”. En este sentido es que puede entenderse la fuerte gravitación en el discurso de Duhalde del enaltecimiento y preocupación por la "clase media":

\begin{abstract}
"El drama argentino -ustedes saben lo tremendo que es-, en el 2000, 600 mil argentinos de clase media pasaron a revistar, por perder el trabajo, por distintas razones, en la categoría de pobres, un drama tremendo, pero el año pasado superamos ese triste registro, hemos liquidado la clase media argentina. Imaginen ustedes lo que pasa con los sectores más humildes de la sociedad que saben que el que trabajó se esforzó, estudió, trabajó y le está yendo como le va. Se pierde, naturalmente, ese querer prepararse porque le parece que es imposible el progreso"(Duhalde, 2/1/2002, el subrayado es nuestro).
\end{abstract}

Este discurso evidencia la centralidad otorgada a la "clase media" argentina (ligada a su vez al impacto en el sentido común que tiene la idea de "clase media” en la sociedad argentina), mediante una doble operación. Por un lado, Duhalde define como “el drama argentino” al pasaje de núcleos de los sectores medios a la pobreza y la liquidación de la “clase media”. Pero por otro lado, aparece el enaltecimiento de la clase media como orientador social y una definición negativa de los grupos de menores ingresos de las clases subalternas, los “sectores más humildes” operando una segmentación. Nótese que la clase media parece ligada a cualidades de estudio, trabajo y esfuerzo, de los cuales los “más humildes” estarían desprovistos; y la percepción de estos últimos respecto del destino económicamente negativo de la "clase media" terminaría por liquidar aún más sus propias aspiraciones (y con esto sus potenciales virtudes de estudio, esfuerzo y trabajo que acaecerían por vía de imitación al sujeto central “clase media”).

Pero la estrategia de segmentación no fue sólo discursiva, sino que parte de la identificación de la demanda y su búsqueda de solución:

\footnotetext{
"el nuestro es un pueblo que ha sido saqueado. La clase media ha sido destruida, destruida. Ustedes habrán escuchado hablar, por ejemplo, del "corralito". Saben que son casi dos millones de personas, no de ricos, con un promedio de 30 mil pesos depositados en los bancos. En la mayoría de los casos ahorros de toda la vida, de gente que se ha esforzado, que ha trabajado, que tiene ilusiones; son decisiones tremendas y sabemos que tenemos que afrontarlas, no podemos continuar los argentinos en esta situación” (Duhalde, 2/1/2002, el subrayado es nuestro).
}

En este camino, el gobierno de Duhalde mantuvo en foco la resolución del corralito y, aun cuando no logró mantener su promesa inicial (“el que depositó dólares recibirá dólares” (Duhalde, 1/1/2002)) ya que se avanzó hacia un proceso de pesificación económica, procuró ir atendiendo esta demanda, sosteniendo su relevancia 
a nivel discursivo, buscando su paulatina solución ${ }^{192}$. La estrategia de segmentación y ruptura de la cadena operó también en el proceso de criminalización de la protesta en tanto el discurso muestra como comprensible la conflictividad de los sectores medios mientras que repele los reclamos de los desocupados en una creciente estigmatización del movimiento piquetero. La escalada represiva alcanzó tal magnitud que derivó en la Masacre del Puente Pueyrredón, el 26 de junio de 2002, desatada sobre los movimientos de desocupados que cortaban dicho puente de Avellaneda y que culminó con decenas de heridos, la primer violación por las fuerzas seguridad a un local partidario desde la dictadura ${ }^{193}$ y el asesinato de los militantes Maximiliano Kosteki y Darío Santillán. La salida represiva buscada a la crisis política vigente terminó con el adelantamiento de las elecciones por parte del gobierno de Duhalde. Aun así, la estrategia de segmentación había resultado exitosa para la clase dominante y sus intelectuales orgánicos, en tanto el fraccionamiento de la cadena había tenido lugar, limando gradualmente el componente "popular” de las demandas (en sentido laclausiano) y tornándolas nuevamente “democráticas”, o sea, procesables en el marco del nuevo orden en gestación. Éste contenía un nuevo modelo de acumulación erguido a partir de un conjunto de políticas fundacionales y que exhibía un escenario con cambios en las relaciones de fuerza entre las fracciones de clase. De este modo, se dio lugar a la fragmentación de la voluntad colectiva precaria y en construcción, a través de la fractura del lazo equivalencial y la desactivación del componente impugnador de parte de sus demandas.

El desenlace de la Masacre del Puente Pueyrredón, que constituyó una acción que llevó al límite el componente coercitivo de la estrategia duhaldista, fue el adelantamiento del llamado a elecciones. Si, por un lado, Duhalde había accedido al poder tras pactar su abstención de presentarse a las elecciones venideras, por otro lado, su control del aparato del PJ de la provincia de Buenos Aires, lo colocaba como una figura fuerte con capacidad de designar el principal candidato para dicha contienda electoral. Como señala Gálvez (2011), tras realizar una primera oferta a Reuteman, gobernador de Santa Fe, que rechazó la propuesta, apareció por primera vez una figura hasta ese entonces poco conocida a nivel nacional: Néstor Kirchner. Sin embargo,

\footnotetext{
${ }^{192}$ En primera instancia, el gobierno instauró el “corralón”, como se llamó la reprogramación de los depósitos y su pesificación a \$1,40 por dólar, luego mantuvo en su discurso presente la voluntad de solucionar la situación del “corralito-corralón”, liberando en diciembre la disponibilidad monetaria de los depósitos hasta US\$42.000 y convirtiendo el resto en plazos fijos.

${ }^{193}$ La policía derribó la puerta del local del Partido Comunista sacando violentamente a los militantes del MTL y otras fuerzas refugiadas en su interior.
} 
Duhalde no tenía el poder suficiente como para que el PJ presentara un solo candidato, ni tampoco para garantizar una interna, derivando en que el partido autorizara la presentación de tres candidatos: Rodríguez Saá, Kirchner y Menem. Asimismo, del desgastado radicalismo, que llevó a Terragno como candidato oficial, se desprendieron tanto Elisa Carrió como Ricardo López Murphy. El bipartidismo que expresaba la fórmula de gobernabilidad post-dictadura se presentaba fragmentado en seis candidatos. Las elecciones de abril de 2003 culminaron con Menem en el primer lugar, con un 24,3\% de los votos, y Kirchner en segundo, con un 22\%. Así, "las alternativas que quedaron fueron, por un lado Menem, quien representaba la profundización de las políticas neoliberales de la década del 90; y, por el otro, Kirchner como representante de un modelo nuevo, no muy claro aún pero que implicaba por lo menos un moderación de aquellas políticas, tal como la gestión de Duhalde había demostrado” (Gálvez, 2011:s/p). Frente a la inminente derrota que sufriría en las urnas el menemismo, Menem decidió no participar del ballotage. De esta manera, Kirchner accedió a la presidencia con una doble debilidad de origen: saliendo segundo con apenas el $22 \%$ de los votos a su favor y siendo tutelado por Duhalde, quien le legaba varios de sus ministros incluyendo al de economía, Roberto Lavagna.

\subsection{La hegemonía kirchnerista: cultura política y proyecto de gobierno.}

Como planteamos en el primer capítulo, Gramsci otorga a la ideología un valor gnoseológico, una vía de acceso privilegiada para la comprensión de los procesos hegemónicos en tanto los mismos contienen en su seno la conformación y expansión de una concepción del mundo realizada en la conducción político-económica de una sociedad. La doble dimensión constitutiva de dichos procesos se juega (tanto en el príncipe/fuerza política como en su componente de intelectualidad orgánica) en la conformación de la voluntad colectiva y en la dirección ideológico-cultural. En este trayecto reconocemos la relevancia cognitiva del concepto de cultura política, en tanto ligazón explicativo de los vínculos que atraviesan y articulan los planos de la disputa ideológica y el orden de la reproducción material, conteniendo un factor clave en el discurso como por el "subsuelo doctrinal o filosófico" en tanto lectura común del pasado y de la sociedad a construir, permitiéndonos ver la matriz ideológica que compone el proyecto político-económico de gobierno. 
Es en este trayecto que identificamos la posibilidad de desagregar el componente de políticas del modelo de acumulación, primero hacia la dilucidación del proyecto político-económico de gobierno de la fuerza hegemónica (del kirchnerismo en nuestro caso) que enuncia la unidad de fines políticos y económicos, y que justamente sirve de sustrato para la implementación de las políticas que inciden en el modelo de acumulación. Asimismo, entendemos que un paso subsiguiente para comprender el proyecto implica analizar la conformación del kirchnerismo como cultura política, en tanto se instituye a partir de una reformulación particular de la cultura política peronista (en cuya tradición se inscribe), definiendo el carácter de la dirección ideológico-cultural que se proyecta junto a su estrategia de dirección política, cobrando forma en la dinámica del antagonismo. Nos preguntamos entonces: ¿cuáles son los factores principales sobre los que se funda la hegemonía kirchnerista?

En primer lugar, la concepción del mundo que modela la cultura política kirchnerista debe ser observada en su gestación, en el sentido de Gramsci, “planteando todas las cuestiones en torno a las cuales hierve la lucha”. Así, el kirchnerismo emerge de cara a la crisis de 2001, afronta las distintas dimensiones involucradas en esta crisis y se plantea a sí mismo como momento de sutura y superación. Son los factores constitutivos de esta crisis que nos permiten proponer la hipótesis de que existen tres elementos fundamentales del kirchnerismo como cultura política:

- la construcción del neoliberalismo como adversario en el discurso.

- la recuperación del Estado como mediación ${ }^{194}$, con un rol destacado en el proceso de “armonización” de intereses.

- la restitución de la promesa de articulación de la vida interior y exterior del pueblo a partir de la recomposición de las condiciones de vida de las clases subalternas.

Estos tres elementos atraviesan las distintas dimensiones de la crisis, y nos permiten ver la relevancia del concepto de cultura política y su relación con el proyecto

\footnotetext{
${ }^{194}$ Entendemos que hay mediaciones de distinto tipo. Por un lado, el Estado como mediación se vincula a las transformaciones históricas del rol del Estado, en que la incorporación de la subalternidad a la vida política y la inclusión elementos de la misma en la coalición gobernante, implicaban una ampliación de la autonomía relativa estatal y su interlocución mediadora y articuladora con las corporaciones sindicales y patronales. En este sentido, el Estado como mediación implica la apariencia de que el Estado estuviera parándose (de modo siempre imposible) por fuera de la lucha de clases, como en un arbitraje que se sugiere imparcial sobre las partes en pugna, en búsqueda del "bien común".
} 
político-económico de gobierno: estos ejes que hacen a la construcción identitaria poseen un bagaje histórico que habilita la recomposición hegemónica, la recuperación y reformulación del peronismo en la cultura política kirchnerista, que va conformando su identidad de cara al antagonismo abierto en 2001 en tanto plantea a dicha fuerza política emergente y a su proyecto de gobierno como momentos de sutura.

Dijimos que en 2001 el campo de antagonismo no termina de conformarse en su completitud, debido a la ausencia de conformación de un sujeto estable articulado desde la subalternidad, de una voluntad colectiva con capacidad de proyectar la formación de un nuevo Estado desde los oprimidos, y que por eso es "principio" de crisis orgánica, sin llegar a revestir su estado acabado. No alcanzan a producirse enteramente sujetos definidos a ambos lados, pero el espacio está efectivamente fracturado y permite la delimitación provisoria de un adversario, que aparecía impugnado, enfrentado en el “que se vayan todos”; pero, de este lado, lo que había era una cadena amplia, más o menos amorfa, que combinaba actores políticos, corporativos y agentes económicos de forma particular en tanto se articulaban en acciones y demandas pero sin cristalizar la cadena en un sujeto-pueblo. Entendemos que es recién con el kirchnerismo que se conforma y estabiliza una cadena, se singulariza en el líder y se comienza gradualmente a construir una voluntad colectiva a partir de la recuperación de varias demandas candentes de 2001, pero este proceso se hace centralmente desde el Estado. Nos preguntamos nuevamente ¿qué ocurre cuando el populismo como lógica política se opera desde el Estado? ¿cuál es el otro-poder que enfrenta esta voluntad? Así se va a transcurrir de un "nosotros" fragmentario que poseía un fuerte componente de organizaciones de izquierda y movimientos sociales heterogéneos, a un "nosotros" nacional-popular en que el kirchnerismo reformula la histórica identidad peronista ${ }^{195}$. Ahora bien, como las identidades no son estables, también la identidad del kirchnerismo mismo fue mutando al ritmo de contradicciones y antagonismos.

El plano del discurso presidencial nos provee una dimensión que nos permite captar el vínculo entre el gobierno y la crisis de 2001, en tanto éste la asume como desafío y se propone como momento resolutorio de la misma. De este modo el gobierno

\footnotetext{
${ }^{195}$ La construcción de identidad posee comúnmente la referencia a anclajes históricos basados en las grandes tradiciones políticas, las cuales fueron constituidas ellas mismas a través de múltiples antagonismos. Pensar una cultura política actual que apela a ser tributaria de una cultura política con identidad histórica implica ver cómo se recuperan y resignifican sus elementos a la luz de los antagonismos presentes, al tiempo que éstos le imprimen su carácter ex novo.
} 
confronta los avatares de la crisis ideológico-cultural, incorporando a su discurso una parte considerable de las demandas expresadas durante la crisis y se propone como momento de clausura en tanto se plantea como su superación dando respuesta (en distintos grados) a dichas demandas, en un doble movimiento que procura comenzar a saldar también aspectos de la crisis política. La construcción del adversario, es un primer factor clave para entender el proceso de sutura. El campo de antagonismo demarcado en 2001 había implicado en su dimensión ideológico-cultural un amplio y vago espectro de figuras ligadas al neoliberalismo como responsables de la crisis a ser enfrentados. La construcción de la otredad en la estrategia de esta fuerza, que se gesta desde el Estado, va a estar entonces delimitada por diversos componentes de aquel pasado impugnado en 2001. Para ver esto nos preguntamos ahora: ¿cómo es constituido este adversario al interior del discurso kirchnerista? y ¿cómo se relaciona con el rol del Estado y la restitución de la promesa de plenitud?

$\mathrm{Si}$, como señala Marcuse, en la filosofía burguesa "todo individuo se encuentra en relación inmediata consigo mismo: sin mediación terrenal o celestial” (Marcuse, 1967:55), esta afirmación, para el caso argentino, cobró mayores fuerzas junto a las transformaciones estructurales ligadas al proceso de instauración del neoliberalismo. En términos generales, podemos decir que en la Argentina del régimen de industrialización por sustitución de importaciones previo al golpe de Estado de 1976, si bien ya burguesa y secularizada, las luchas de las clases subalternas y las condiciones de acumulación a nivel local y global habían dado origen a un Estado como mediación. Como señala Novaro, desde los primeros gobiernos de Perón "los sectores populares vivieron incorporados mayoritariamente a una cultura política que tenía por motivo central cohesionante y por actor principal al Estado” (1997:4). El Estado como mediación se encuentra entonces vinculado a las transformaciones del rol del Estado, ya que la incorporación de la subalternidad a la vida política, incluyendo elementos de la misma en la coalición gobernante, implicaba la ampliación hegemónica de la autonomía relativa estatal, y su interlocución mediadora y articuladora con las corporaciones sindicales y patronales. En contraposición, el neoliberalismo se presentó discursivamente como la capacidad de abolir las colectividades supuestamente opresivas de ese antiguo régimen, enquistadas en el Estado y los sindicatos, para "liberar" y devolver la iniciativa al individuo; aunque con el más claro objetivo de desarticular colectivos con algún tipo de capacidad de resistencia, fragmentar a las 
clases subalternas y dejar a sus individuos librados a la ofensiva del capital. El hecho de que fuera un líder del peronismo, como Menem, quien impulsara de forma más acabada las políticas neoliberales, no podía dejar de tener efectos profundos en dicha cultura política. Según Novaro,

\begin{abstract}
"La orientación pro mercado de las reformas iniciadas en 1989 aprovechó, y en parte estimuló, una redefinición muy profunda de ciertos patrones culturales tradicionales: la suerte de cada individuo o familia se estaba convirtiendo en un asunto de orden privado, dejaba de estar vinculada a un proyecto inclusivo e integrador y a una responsabilidad pública. (...) Lo que logró Menem fue abrir la cultura peronista a su influencia, y desactivar, de este modo, no pocas de las reivindicaciones tradicionales de los sectores populares identificados con el peronismo (1997:10).
\end{abstract}

El peronismo clásico u originario ${ }^{196}$, con su ampliación de la ciudadanía y la conquista de numerosos derechos sociales y políticos para las clases subalternas, había logrado performar la promesa de plenitud (con distintos grados de materialización), de articulación de la "vida interior" con la "vida exterior”, ya que, aunque sin romper las relaciones de explotación capitalista y de mercantilización de la vida, el peronismo transformó mediante reformas progresivas "la vida exterior" de las clases subalternas, al tiempo que las dotó de una "vida interior” con las que se identificaran masivamente: el peronismo como cultura política. En un contexto mundial y local profundamente distintos, es el kirchnerismo el que procura cumplir la función de restituir la promesa, fracturada durante el auge neoliberal, y aunque ésta no sea cumplida en su completitud (ya que no promueve transformaciones sociales de raíz que habiliten la abolición/superación de la contradicción estructural de clase), intenta recomponerla como aspiración ideal efectiva.

Kirchner se consagra presidente luego de que Menem, habiendo ocupado el primer lugar, desistiera de enfrentarlo en el ballotage. Este enfrentamiento inicial y la debilidad de origen de su presidencia son factores relevantes en lo que fue la

\footnotetext{
${ }^{196}$ Nos referimos al peronismo clásico u originario para remitir al proceso de conformación del peronismo como cultura política en Argentina, que tuvo su preludio entre 1943 y 1945, y se constituyó y afirmó en los dos períodos presidenciales entre 1946 y 1955. La referencia se realiza principalmente a comprender al peronismo clásico en tanto síntesis mítica de dicho proceso y que contiene distintos componentes vinculados a las importantes conquistas sociales del período y a la consecución de niveles elevados de bienestar para las clases subalternas. Si bien la literatura académica tiende a utilizar el término "clásico" para referirse a este período, utilizaremos también el de originario, ya que entendemos que existe una disputa hegemónica de sentido por las fuerzas que, siendo tributarias del peronismo, buscan plantarse como herederas legítimas de dicha cultura política, detentando ser los "verdaderos" intérpretes y seguidores de la raíz de dicho movimiento, de su sentido primigenio y constitutivo. Para el caso del kirchnerismo esto es cardinal, ya que, como toda cultura política, se funda en una lectura del pasado, el cual es apropiado en clave presente para alumbrar, con su resignificación, el camino a seguir hacia el futuro; más aún cuando la apelación al imaginario del "retorno a la Argentina peronista" adquiere un lugar importante en la interpelación a un amplio espectro de actores.
} 
construcción de la cultura política. En este contexto, aparece el primer elemento: Kirchner construye en su discurso un adversario, un "ellos", que refiere al neoliberalismo, en términos amplios, abarcando un conjunto de actores y políticas que tuvieron su punto álgido en los años 90:

"No puede ser el norte de ninguna sociedad la convivencia con la miseria, la marginalidad, la exclusión y la inequidad a que ha dado lugar la aplicación del pensamiento único y el señoreo del pensamiento neoliberal que caracterizó la economía mundial y la propia en el último decenio” (Kirchner, 11/12/2003) ${ }^{197198}$.

Además opuso en su discurso la recta gestión frente a la corrupción y la impunidad, ambas relacionadas con dichos actores y políticas. En este camino, el kirchnerismo se fue proponiendo como una propuesta resolutoria particular de la crisis hegemónica que eclosionara hacia 2001, en tanto discute con las figuras deslegitimadas frente a los cuales se alzaron los reclamos en aquel entonces. Kirchner propone al proyecto que lidera como momento de ruptura frente al neoliberalismo, y en su discurso recopila las diversas aristas que caracterizaron aquel principio de crisis orgánica. El 2001 es concebido como un "estallido cívico (...) un reclamo ciudadano que le demandó a la democracia un proyecto de país” (Kirchner, 10/7/2003) ${ }^{199}$, y el kirchnerismo aparece como la fuerza en construcción designada para trazar e impulsar dicho proyecto. De modo sintético, Kirchner plantea: “Queremos suturar las terribles heridas que produjeron las políticas erradas aplicadas en el pasado” (Kirchner, 1/3/2005, el subrayado es nuestro) $)^{200}$.

Muestra de esto es, entre otros, el discurso dado en la Cumbre de las Américas

\footnotetext{
197 Este discurso fue pronunciado en el 79 Aniversario de la Cámara Argentina de Comercio, lo cual muestra como parte del proyecto de gobierno la voluntad de cambiar la relación Estado-empresarios, alejada del signo neoliberal que la constituyera previamente.

198 También, en su discurso de asunción señaló: "En la década de los 90, la exigencia sumó la necesidad de la obtención de avances en materia económica, en particular, en materia de control de la inflación. La medida del éxito de esa política, la daba las ganancias de los grupos más concentrados de la economía, la ausencia de corridas bursátiles y la magnitud de las inversiones especulativas sin que importara la consolidación de la pobreza y la condena a millones de argentinos a la exclusión social, la fragmentación nacional y el enorme e interminable endeudamiento externo” (Kirchner, 25/5/2003).

${ }^{199}$ Este discurso, enunciado en el $149^{\circ}$ Aniversario de la Bolsa de Comercio de Buenos Aires, conforma junto a otros expresados frente al empresariado, un primer momento de expresión pública frente a los agentes dominantes del proyecto de gobierno, donde se establece el diagnóstico de la situación vigente y comienzan a delinearse los principales aspectos del proyecto de gobierno en construcción.

${ }^{200}$ Este discurso fue enunciado en la apertura de las $123^{\circ}$ Sesiones del Congreso. Dentro de los discursos oficiales es interesante rescatar el rol que cumplen tanto el discurso de asunción presidencial como los de apertura de las sesiones legislativas, en tanto permiten ver la continuidad entre diagnóstico y plan de acción que configuran aspectos cardinales de la construcción del proyecto político-económico de gobierno.
} 
en Mar del Plata (2005) donde se enterró el proyecto del ALCA ${ }^{201}$ y dio una muestra clara de priorizar el proceso de integración latinoamericana por sobre las "relaciones carnales” que habían caracterizado la sumisión del Estado argentino frente a los intereses norteamericanos ${ }^{202}$. En aquel discurso Kirchner sostuvo que la crisis argentina de 2001, entendida como la peor crisis económica y social de su historia ${ }^{203}$, ejemplificaba el fracaso del neoliberalismo y la conveniencia de seguir un camino propio, ajeno a las recetas de los organismos internacionales. También señalaba al FMI como co-responsable de la debacle argentina ${ }^{204}$. Este es otro de los momentos rupturistas del discurso de Kirchner que generó amplia adhesión popular: el presidente, que llamaba a construir "lo nuevo", se plantaba a denunciar "lo viejo", habiendo ya usufructuado todo lo que significaba la derrota de su rival, Menem, uno de los principales símbolos encarnados del paradigma neoliberal, desafiando además los planes geopolíticos de la principal potencia mundial y denunciando el rol de los organismos financieros internacionales. Así, ya en el discurso de asunción de Kirchner a la presidencia, presentaba a su gobierno como "lo nuevo" que permite la clausura y superación de “lo viejo”:

"El 27 de abril, las ciudadanas y los ciudadanos de nuestra patria, en ejercicio de la soberanía popular, se decidieron por el avance decidido hacia lo nuevo, dar vuelta una página de la historia (...) Por mandato popular, por comprensión histórica y por decisión política, ésta es la oportunidad de la transformación, del cambio cultural y moral que demanda la hora. Cambio es

${ }^{201}$ El ALCA (Área de Libre Comercio de las Américas) fue el tratado impulsado por Estados Unidos para crear una zona continental de libre comercio favorable a la reproducción ampliada de sus empresas transnacionales (expandiendo el NAFTA, Tratado de Libre Comercio de América del Norte entre Estados Unidos, México y Canadá). Este proyecto fue rechazado por los gobiernos de Venezuela, Brasil y Argentina, en la IV Cumbre de las Américas de 2005 en Mar del Plata.

${ }^{202}$ A principios de aquel año, Kirchner planteaba: "Este tiempo de la historia continental y mundial está signado por el cambio a favor de los pueblos, y el pueblo argentino es el principal protagonista de los cambios que estamos produciendo" (Kirchner, 1/3/2005).

${ }^{203}$ Esto aparece en distintos discursos, como en el de apertura de las $123^{\circ}$ Sesiones del Congreso, donde Kirchner sostuvo que "venimos de la más profunda crisis escalando peldaño a peldaño, lo que ha sido y es el calvario de Argentina. Superando con esfuerzo lo que constituyó la peor crisis de nuestra historia" (Kirchner, 1/3/2005). En el mismo sentido se expresó al año siguiente en la apertura de las $124^{\circ}$ Sesiones del Congreso: "vamos de a poco superando con esfuerzo lo que constituyó la peor crisis de nuestra historia; vamos escalando peldaño a peldaño lo que ha sido y todavía es el calvario de la Argentina. Venimos del infierno intentando todavía salir de él” (Kirchner, 1/3/2006).

204 “En la obtención de esos consensos para avanzar en el diseño que las nuevas políticas exigen, no puede estar ausente la discusión respecto de si aquéllas habrán de responder a recetas únicas con pretensión de universales, válidas para todo tiempo, para todo país, para todo lugar. Esa uniformidad que pretendía lo que dio en llamarse el "Consenso de Washington" existe evidencia empírica respecto del fracaso de esas teorías (...) Nos hacemos cargo como país de haber adoptado esas políticas, pero reclamamos que aquellos organismos internacionales, que al imponerlas, contribuyeron, alentaron y favorecieron el crecimiento de la deuda, también asuman su cuota de responsabilidad (...) Es entonces la experiencia regional y no la teoría de las burocracias de los organismos financieros multilaterales, la que demuestra que lo aconsejable es dejar que, en un marco de racionalidad, cada país pueda elegir su mejor camino para el desarrollo con inclusión social” (Kirchner, 4/11/2005) 
el nombre del futuro" (Kirchner, 25/5/2003) ${ }^{205}$.

En tanto Kirchner se plantea a sí mismo como "lo nuevo”, convoca la figura del outsider, invoca el modelo de la llegada, desarrollado por Sigal y Verón (2004) ${ }^{206}$, posibilitado también por el desconocimiento relativo en otras partes del país de sus gestiones en la provincia de Santa $\mathrm{Cruz}^{207}$, que permitió a Kirchner aparecer como la principal figura del recambio. Lo nuevo emerge desde la exigencia de cambio, se evidencia una fuerte vocación fundacional en la proclama de dar vuelta una página de la historia al reclamo de 2001, como Kirchner mismo identificaba en su discurso.

Además Kirchner añade otro elemento fuerte del discurso peronista original proclamando que viene a trabajar por los argentinos, diciendo en la jura del gabinete: "Yo y quienes me acompañan seremos sus servidores, trabajaremos con mucho esfuerzo y, para terminar, les quiero decir qué es lo que sentimos que somos: hombres comunes con responsabilidades muy importantes” (Kirchner, 25/5/2003b). Kirchner se presenta entonces como lo nuevo opuesto a las viejas prácticas corruptas y a las políticas neoliberales que devastaron el nivel de vida del pueblo resquebrajando la promesa, y esto nuevo responde a la "llamada" del pueblo perjudicado para encarnar el elemento reparador a partir de una vocación de servicio desinteresada. Esta estrategia discursiva contiene dos consecuencias: por un lado, la desactivación de la impugnación del "que se vayan todos” y, por el otro, la rearticulación de varias demandas establecidas en la cadena de 2001 y su complementación con otras que dan lugar a la kirchnerismo como cultura política que avanza en la construcción hegemónica de sujeto.

Estos elementos del discurso fueron resquebrajando la impugnación generalizada, anclada en el “que se vayan todos”, que caracterizó el ánimo político del momento álgido de la crisis, y fueron generando un desdoblamiento de su contenido, de modo de apartar al gobierno de la negación implicada en dicha consigna. Muñoz y Retamozo (2008), aportan interesantes claves para pensar esta desactivación, destacando una serie de operaciones discursivas que parten del reconocimiento de la crisis, la identificación del pueblo como entidad dañada, pero al mismo tiempo como

\footnotetext{
${ }^{205}$ Esto mismo volvía a sostener al abrir las $125^{\circ}$ Sesiones del Congreso, en su último año al frente de la Presidencia de la Nación: "Por mandato popular, por comprensión histórica y por decisión política, el nombre de nuestro futuro es el cambio: Argentina protagoniza una profunda transformación, es hora del cambio cultural y moral” (Kirchner, 1/3/2007).

${ }^{206}$ Un desarrollo más completo de esta idea puede encontrarse en Slipak (2006).

${ }^{207}$ Kirchner provenía de largas experiencias en el Poder Ejecutivo, primero como intendente de Río Gallegos desde 1987 a 1991 y desde entonces como gobernador de Santa Cruz.
} 
fuente de soberanía de la que emerge el presidente y su gobierno como parte de ese sujeto e intérpretes de sus intereses. Al tiempo que se construye al Estado como instancia reparadora del pueblo dañado, retomando símbolos del peronismo original, se identifica al enemigo con los actores del neoliberalismo y se desata así su asociación con el conjunto de la clase política, mientras que simultáneamente se apropia del enemigo construido por los distintos movimientos populares. Se visualiza así con mayor claridad la función del segundo elemento: el Estado como mediación, una mediación reparadora. Este rol ya aparecía manifiestamente en el discurso de asunción de Kirchner: "Es el Estado el que debe actuar como el gran reparador de las desigualdades sociales” (Kirchner, 25/05/2003).

Si la ideología neoliberal proponía "liberar” al individuo de las mediaciones y veía al "mercado" como ámbito de realización de su libertad, en contraposición, el kirchnerismo emerge como un grito por la restitución de las mediaciones vulneradas: la vuelta del Estado (o mejor dicho, de algunos de sus roles perdidos o mutados) tiene una presencia destacada en su discurso:

\footnotetext{
"Se trata, entonces, de hacer nacer una Argentina con progreso social, donde los hijos puedan aspirar a vivir mejor que su padres, sobre la base de su esfuerzo, capacidad y trabajo. Para eso es preciso promover políticas activas que permitan el desarrollo y el crecimiento económico del país, la generación de nuevos puestos de trabajo y la mejor y más justa distribución del ingreso. Como se comprenderá el Estado cobra en eso un papel principal, en que la presencia o la ausencia del Estado constituye toda una actitud política." (Kirchner, 25/5/2003 el subrayado es nuestro)
}

Pero si el Estado constituye la mediación fundamental, también está acompañado por la vuelta de otras colectividades mediadoras como los sindicatos y las corporaciones patronales, en tanto desde el gobierno se los reconoce como entidades válidas de representación y negociación sectorial. Esta recuperación de elementos propios de la cultura política del peronismo originario tuvo su correlato en políticas tales como el impulso masivo a los convenios colectivos de trabajo y la convocatoria al “Consejo Nacional del Empleo, la Productividad y el Salario Mínimo Vital y Móvil”, entre otras.

La dimensión ideológico-cultural de la crisis de hegemonía que Kirchner busca conjurar, contenía la negación de la idea de movilidad social ascendente, que se había ido arraigando desde el peronismo clásico y que luego había comenzado a ser puesta en jaque a partir de 1976. El neoliberalismo fue oxidando la función social de la movilidad 
social ascendente, y esto fue clave en la fractura de la promesa: el menemismo había terminado de ahogar la cultura política peronista con su mística esperanzadora y había llenado, a través de su signo neoliberal, la “vida interior” del pueblo con una ideología individualista y consumista, un consumismo que ante el deterioro social creciente se fue convirtiendo en una aspiración absolutamente inalcanzable para las mayorías populares, ampliando la brecha al punto de eliminar la función hegemónica de la promesa. Como mostraremos en los capítulos posteriores, el kirchnerismo recompone esta brecha a través de sus políticas, enmarcadas en el proceso de configuración del modelo postconvertibilidad iniciado en 2002. Así cobra un sentido particular la articulación en el discurso presidencial de las nociones de "Estado", "progreso social” y "bienestar común”. El mítico peronismo originario es recuperado como posibilidad de extensión material de la "felicidad” (en el sentido de Marcuse): acerca el ideal, lo hace "arañable” por los individuos. El kirchnerismo cumple el papel de resurrección de esta aproximación, de que el plano de lo real y lo ideal parezcan efectivamente articulables para más amplios sectores de la población. En este sentido es que el kirchnerismo se opone a la cultura menemista-neoliberal que alejaba cada vez más para cada vez mayores espectros de las clases subalternas la posibilidad del bienestar y la movilidad social; Kirchner construye en su discurso a los distintos factores de esta cultura en crisis como antagonista, y esta acción ya constituye un paso para allanar el camino hacia la restitución de la promesa.

Es en este sentido que toda promesa de plenitud se encuentra ligada a un proyecto político-económico de gobierno, en tanto conforma una matriz ideológica que consigna las tareas que permitirían transitar del momento de crisis a la sutura. $\mathrm{Y}$ a su vez, el proyecto se encuentra enmarcado en una cultura política singular que se expresa en el discurso como subsuelo doctrinal, realizando una particular lectura y recuperación del pasado y una proyección, un delineamiento, del futuro a construir.

Así, en el discurso en el Parlamento el día de su asunción presidencial, Kirchner llama a construir un "capitalismo nacional” que permita la movilidad social ascendente, volviendo a la senda del desarrollo con inclusión social: “En nuestro proyecto ubicamos en un lugar central la idea de reconstruir un capitalismo nacional que genere las alternativas que permitan reinstalar la movilidad social ascendente” (Kirchner, 
$25 / 5 / 2003$, el subrayado es nuestro) ${ }^{208}$. Para esto, sostiene que se deben implementar políticas activas para el crecimiento económico, la generación de puestos de trabajo y una más justa distribución de la riqueza, recuperando el Estado un rol central ${ }^{209}$. Podemos observar un discurso que capta varios aspectos de la crisis de hegemonía: propone dar fin a la crisis económica a través del proyecto de “capitalismo nacional”, atendiendo a las consecuencias de dicha crisis en materia de desempleo, pobreza, etc., abordando así demandas inabsorbibles en el orden previo que dieron origen a la crisis política, resolviéndolas e incorporándolas a la propia cadena equivalencial; además plantea una respuesta a la crisis ideológico-cultural, rechazando la idea de Estado mínimo a favor de la exigencia de “más” Estado, que remite a la necesidad de cambiar la forma de intervención estatal ${ }^{210}$, y que en el largo plazo se va a ir constituyendo en una revalorización de la política como vía privilegiada de cambio de las sociedades, alejada de la perspectiva tecnocrática de la política de cuño neoliberal. La visión que se le imprime al Estado desde el discurso presidencial se vincula directamente con la ampliación de la autonomía relativa:

\begin{abstract}
"necesitamos un Estado inteligente que establezca los límites precisos dentro de los cuales se desenvuelva la economía. Allí donde el mercado no es capaz de guardar equilibrio el Estado debe estar presente (...) El Estado en representación del bien común debe ser quien arbitre en las relaciones sociales y económicas (...) Un Estado que no se instituya para favorecer a uno $u$ otro sector de nuestra economía, pues de ese modo se tergiversa y corrompe” (Kirchner, 10/7/2003, el subrayado es nuestro).
\end{abstract}

El kirchnerismo plantea la recuperación de la capacidad mediadora y reguladora del Estado en el marco del proyecto de “capitalismo nacional”, expresándose como la vía para la expansión de todas las “energías” nacionales (en el sentido de Gramsci) y la concreción del “bien común”. Siempre identificando al neoliberalismo como adversario, Kirchner delinea un proyecto que atienda a reparar los “desequilibrios” por este generado:

\footnotetext{
${ }^{208}$ Además, en un discurso frente a la Cámara Argentina de Comercio, Kirchner ligó los cambios a nivel del proyecto de gobierno para suscitar la movilidad social ascendente directamente con el cambio de visión del mundo: "Si queremos construir un capitalismo moderno, que genere las alternativas que permitan instalar la movilidad social ascendente, tenemos que enfrentar el desafío de crear los nuevos paradigmas, mirar con ojos nuevos los viejos problemas y dotarnos de esperanzas nuevas, aún cuando debamos usar el material de hierros viejos que tengamos a nuestra mano” (Kirchner, 11/12/2003).

${ }^{209}$ Como se verá a continuación, tanto el discurso de asunción presidencial (Kirchner, 25/5/2003) como el dado en el $149^{\circ}$ Aniversario de la Bolsa de Comercio (Kirchner, 10/7/2003) constituyen momentos claves para comprender los rasgos del proyecto político-económico de gobierno, evidenciando también la concepción de Estado que involucra.

${ }^{210}$ Un análisis de las transformaciones al interior del Estado durante el kirchnerismo, que retoma, a su vez, a la crisis de 2001 como punto de referencia, puede verse en Bonnet y Piva (2010).
} 


\begin{abstract}
“Queremos recuperar los valores de la solidaridad y la justicia social que nos permitan cambiar nuestra realidad actual para avanzar hacia la construcción de una sociedad más equilibrada, más madura y más justa. (Aplausos). Sabemos que el mercado organiza económicamente, pero no articula socialmente, debemos hacer que el Estado ponga igualdad allí donde el mercado excluye y abandona” (Kirchner, 25/5/2003).
\end{abstract}

La acción reparadora del Estado se liga a su vez con la alianza de clases que contiene el proyecto político-económico de gobierno, el cual constituye el sustrato estructural del capitalismo a ser construido. Este proyecto de capitalismo "normal"211, “serio" y "nacional” continúa los andamios discursivos establecidos por Duhalde cuando enunciaba la necesidad de un cambio de alianza estratégica, que abandonara la centralidad del capital financiero con el fin de basarse en la articulación de empresarios productivos y trabajadores. En este sentido se expresa Kirchner, justamente en un aniversario de la Bolsa de Comercio, sosteniendo que se orientará a “fijar los pilares de un nuevo país en que los valores de la producción y el trabajo destierren para siempre los vicios del oportunismo y la especulación” (Kirchner, 10/7/2003). Pero en términos de las clases sociales que componen la alianza a consolidarse en el proyecto de gobierno kirchnerista cambian los énfasis en relación al discurso de Duhalde, tanto respecto del capital productivo como de los trabajadores. Se mantiene la centralidad de la "burguesía nacional”, el empresariado productivo, aunque se lo comienza a ver como un actor que no está plenamente constituido sino que debe ser apuntalado, orientado desde el Estado: "necesitamos recrear un empresariado con decisión nacional, comprometido con la realidad social y económica de nuestra patria y absolutamente decidido a aceptar el desafío de la competencia” (Kirchner, 10/7/2003, el subrayado es nuestro). Es este acto de recreación, que Cristina Fernández identifica, sobre el final del período, como característico del peronismo clásico, cuando “ante la ausencia un gran empresariado nacional, de una gran burguesía nacional, el Estado fue a sustituir esa carencia, esa ausencia para el modelo de acumulación de aquellos años” (Fernández, 30/5/2007). El Estado ya no debe sustituir la ausencia de este actor, sino orientarlo desde las políticas entendiendo que, para superar la crisis de 2001, era necesario "apuntar a un modelo de producción en definitiva y no a un modelo de servicios como se había venido dando en el país” (Fernández, 30/5/2007). Así, el componente de políticas del modelo de acumulación se enmarca en el proyecto político-económico de gobierno que le sirve de matriz y exhibe un factor central en la ampliación de la autonomía relativa, explicitado en el discurso de Kirchner: “Quiero dejar absolutamente claro también que no

\footnotetext{
211 "Debemos asegurar la existencia de un país normal, sin sobresaltos, con el sector público y el sector privado cada uno en sus respectivos roles” (Kirchner, 25/5/2003).
} 
dejaremos que sean los sectores de interés quienes fijen nuestra agenda o el supuesto proyecto económico que ellos desean arreglado a la sola solución de sus problemas” (Kirchner, 10/7/2003) ${ }^{212}$.

Asimismo, comienza a cobrar mayor peso el lugar de los trabajadores, componente clave del pueblo como entidad dañada por el neoliberalismo que debe ser recompuesta en el marco del proyecto kirchnerista. Kirchner señala que en 2001 se expresó “un reclamo ciudadano que le demandó a la democracia un proyecto de país que contenga a todos los argentinos, un modelo político y económico que regenere la calidad institucional de la República, que termine con el abuso, la concentración y la pobreza, que ponga en marcha la producción y recupere el trabajo como única forma de desarrollo digno en la sociedad moderna" (Kirchner, 10/7/2003, el subrayado es nuestro). En este camino, el Estado, en tanto mediación reparadora, debe proteger a los más vulnerables: a los trabajadores. Los trabajadores alcanzan una mayor gravitación en el discurso oficial, así Kirchner, en un encuentro con la militancia, afirma: "tenemos que construir la Argentina donde el obrero vuelva a ser el respeto central de nuestras acciones" (Kirchner, 11/3/2004, el subrayado es nuestro). La protección de los trabajadores se ubica en el rol reparador del Estado respecto del pueblo como sujeto dañado, es un papel equiparador frente a la unilateralidad del poder establecida en tiempos de neoliberalismo ${ }^{213}$. Así, el kirchnerismo asume explícitamente en el discurso del líder el rol reparador del Estado frente al pueblo dañado: “Sabemos que discutimos intereses económicos y sabemos de qué lado estamos. Esta vez, el pueblo argentino tendrá en el gobierno el primer defensor de sus intereses" (Kirchner, 1/3/2005, el subrayado es nuestro) ${ }^{214}$. En este camino, el proyecto kirchnerista impulsaría un nuevo modelo, definido como "un modelo argentino con crecimiento e inclusión, a partir de la creación de trabajo digno, un modelo en que el pueblo argentino resulte el principal actor y beneficiario” (Kirchner, 1/3/2007). De este modo, sostiene la necesidad de proteger a trabajadores, industrias y productores, integrantes de la nueva alianza

\footnotetext{
${ }^{212}$ La tesis de la ampliación de la autonomía relativa como pieza clave para pensar tanto las políticas como el proceso más general de construcción de hegemonía es planteada, en este capítulo, en el plano del discurso su lugar en la dimensión ideológico-cultural, y, en los capítulos siguientes, será contrastada con el desarrollo efectivo de las políticas económicas.

213 “A la Constitución hay que leerla completa. La seguridad jurídica debe ser para todos, no solamente para los que tienen poder o dinero” (Kirchner, 25/5/2003).

${ }^{214}$ Como señalamos antes, es importante prestar atención a los discursos que, como éste, abren las sesiones parlamentarias, ya que hacen balance partiendo del diagnóstico y despliegan la agenda procurando el desarrollo, en acciones concretas, del proyecto político-económico de gobierno.
} 
policlasista, con políticas activas para promover el desarrollo y el crecimiento económico, generando nuevos puestos de trabajo y una distribución del ingreso más justa, en una estrategia donde el Estado cumple un rol central que, en algunos aspectos, va a contramano de la concepción del mundo neoliberal: “el Estado se incorporará urgentemente como sujeto económico activo” (Kirchner, 25/5/2003).

En este punto recuperamos el análisis de O’Donnell (1978), que aborda las mediaciones desde un ángulo distinto, no ya en la presunción de un Estado mediando entre las partes de la comunidad en pugna, sino en el reengarce del Estado mismo con la sociedad, vínculo fracturado por las relaciones de dominación y explotación que la atraviesan, y que busca ser rearticulado ignorando los clivajes de clase, borrando así el papel de garante y organizador de la sociedad en tanto capitalista que efectúa el Estado. El tipo de mediaciones que O’Donnell construye teóricamente remiten tanto al referente de la acción estatal como a su fundamento, y son instancias aglomeradoras, puestas sobre el fraccionamiento de la sociedad que permiten fundamentar el poder estatal. Es la restitución de lo nacional-popular, donde podemos ver las claves perennes del período: la nación como referente homogeneizante y general y el pueblo o lo popular, que suele presentarse como otra mediación entre el Estado y sociedad de clases, que emerge porque la postulación indiferenciada del interés general de la nación no alcanza a tapar las evidencias de desigualdad en la sociedad burguesa. Es frente al estallido de desigualdad y el deterioro en términos históricos de las condiciones de vida de las clases subalternas que trajo aparejado el neoliberalismo, que el Estado kirchnerista sostiene que las instituciones deben actuar en un sentido equiparador, y al mismo tiempo, la recuperación de lo nacional-popular como referente y fundamento de la acción estatal habilita la vinculación de la acción reparadora con un proyecto que expresa (en términos gramscianos) una unidad de fines políticos y económicos que impulsarían al máximo desarrollo al conjunto de las “energías” nacionales.

Así se va gestando un doble movimiento que parte de la identificación del adversario enmarcado en los actores y políticas del neoliberalismo y que, como toda construcción identitaria emergida en un campo de antagonismo, provee claves para expresar el proyecto del "nosotros” en construcción. Es un "nosotros” llamado a suturar las grietas producidas por la "anti-comunidad" en tanto se provee los rasgos de la nueva comunidad propia enmarcada en la perspectiva de la cultura política que va configurando la propia fuerza en ascenso hegemónico: “ya vimos adónde llegó la 
Argentina con la ortodoxia, el fundamentalismo de mercado y el discurso uniforme. Debemos salir del pensamiento único para consolidar la marcha hacia la construcción de un proyecto estratégico” (Kirchner, 10/7/2003). Así se instituye la doble lectura del populismo: a) como lógica política, es un populismo que conforma un otro-poder, identificando a su adversario en torno al neoliberalismo, pero cuyo centro de acción parte, a su vez del Estado mismo, porque dicho Estado es constituido como emanación de la voluntad popular para reparar al propio pueblo dañado, y b) como pacto populista, en una vasta estrategia de conciliación de clases a través de la ampliación de la autonomía relativa del Estado, gestando una nueva alianza estratégica tripartita entre el Estado, los trabajadores y la "burguesía nacional”.

En este camino, el proyecto político-económico de gobierno comenzó a ser definido por algunos rasgos básicos que aparecen explicitados en el discurso:

"El objetivo básico de la política económica será el de asegurar un crecimiento estable, que permita una expansión de la actividad y del empleo constante. (...) El resultado debe ser la duplicación de la riqueza cada quince años, y una distribución tal que asegure una mayor distribución del ingreso y, muy especialmente, que fortalezca nuestra clase media y que saque de la pobreza extrema a todos los compatriotas” (Kirchner, 25/5/2003, el subrayado es nuestro).

Son estos componentes básicos que comenzarán a delinear el proyecto de capitalismo nacional centrado en el crecimiento del producto y empleo que promueve una restitución de la promesa en tanto apunta a confrontar las consecuencias más dramáticas de la crisis y mejorar la distribución del ingreso. Para lograrlo aparece, ya desde el discurso de asunción, la percepción de lo que vamos a denominar como los dos pilares de estabilidad del modelo, el superávit fiscal y el superávit comercial, cuya función clave será explicitada en los capítulos siguientes:

\footnotetext{
"Hay que dotar a la República Argentina de buena administración, gobernabilidad, estabilidad con inclusión y progreso social y competitividad. Con equilibrio fiscal, la ausencia de rigidez cambiaria, el mantenimiento de un sistema de flotación con política macroeconómica de largo plazo determinada en función del ciclo de crecimiento, el mantenimiento del superávit primario y la continuidad del superávit externo nos harán crecer en función directa de la recuperación del consumo, de la inversión y de las exportaciones.” (Kirchner, 25/5/2003)
}

El proyecto de gobierno también va a contener otros elementos claves tales como la integración latinoamericana, priorizando la inserción comercial en el $\operatorname{MERCOSUR}^{215}$ al tiempo que busca ampliar su composición; a contraposición de la

\footnotetext{
215 "Nuestro país debe estar abierto al mundo, pero abierto al mundo de una manera realista, dispuesto a competir en el marco de políticas de preferencia regional y fundamentalmente a través del MERCOSUR,
} 
década previa, se propone terminar con las políticas de ajuste e impulsar la recuperación de los ingresos de los trabajadores para aumentar el consumo y así dinamizar el crecimiento $^{216}$; retomar la obra pública como política de Estado ${ }^{217}$; resolver el default de la deuda pública ${ }^{218}$ y modificar la estructura impositiva ${ }^{219}$. También refuerza la necesidad de crecimiento del producto, la inversión, el superávit primario, la recaudación y el empleo, así como el descenso de la tasa de interés para permitir una reconversión productiva, renegociar los contratos de las empresas de servicios públicos privatizadas y procurar un cambio profundo en las estructuras financieras y productivas (Kirchner, 10/7/2003) $^{220}$, evidenciando la estrategia estatal de sostener los cambios en las relaciones de fuerzas entre fracciones de clases emergidos con la caída del modelo de la convertibilidad. Así, el proyecto de gobierno delimita en un conjunto de puntos (del cual aquí mencionamos los más relevantes) que conforman la matriz ideológica que orienta las políticas económicas: son el camino a seguir para la conquista del "bienestar común”, del "progreso social”, de la promesa mítica de plenitud a través del cual una fuerza política (en este caso el kirchnerismo) procura generar consensos al tiempo que incide en su propia configuración identitaria, y atraviesa desde las definiciones estratégicas generales (como “capitalismo nacional”), el tipo de alianza de clases (Estado-trabajadores-empresarios), hasta inspirar las políticas específicas a desarrollar.

Pero, debemos recordar, junto a Muñoz y Retamozo, que “para generar el

(aplausos), y de políticas cambiarias flexibles acordes a nuestras productividades relativas y a las circunstancias del contexto internacional” (Kirchner, 25/5/2003).

${ }^{216}$ “ $\mathrm{Al}$ contrario del modelo de ajuste permanente, el consumo interno estará en el centro de nuestra estrategia de expansión. Precisamente para cumplir con esta idea de consumo en permanente expansión, la capacidad de compra de nuestra población deberá crecer progresivamente por efecto de salarios, por el número de personas trabajando y por el número de horas trabajadas” (Kirchner, 25/5/2003).

217 "Tenemos que volver a planificar y ejecutar obra pública en la Argentina, para desmentir con hechos el discurso único del neoliberalismo que las estigmatizó como gasto público improductivo" (Kirchner, 25/5/2003).

${ }^{218}$ En este caso, Kirchner afirmaba "No se puede recurrir al ajuste ni incrementar el endeudamiento. No se puede volver a pagar deuda a costa del hambre y la exclusión de los argentinos", pero advertía: "No somos el proyecto del default" (Kirchner, 25/5/2003).

219 "Produciremos cambios en el sistema impositivo para tornarlo progresivo" (Kirchner, 25/5/2003). Este componente del proyecto figura entre las principales deudas en nuestro período de estudio y encontró una fuerte resistencia desde los agentes económicos, sobre todo en 2008 ante el intento de modificación del régimen de retenciones a la exportación.

${ }^{220}$ En la apertura de las $124^{\circ}$ Sesiones del Congreso en 2006, Kirchner recupera los principales puntos del proyecto sobre los cuales se ha avanzado, dando "inicio a una nueva etapa de funcionamiento de la economía del país. Disciplina fiscal, reducción de la carga de la deuda, prudencia monetaria, superávit externo, crecimiento de las reservas, vigoroso crecimiento y diversificación de las exportaciones, aumento de la inversión productiva, reversión de la fuga de capitales, creación de millones de puestos de trabajo genuinos, recuperación del poder adquisitivo de los salarios, reducción de la pobreza y la indigencia, inicio de la reversión del deterioro en la distribución del ingreso, son solo algunos de los rasgos característicos que señalan el comienzo de esta nueva etapa” (Kirchner, 1/3/2006). 
consentimiento de la población, los gobiernos deben traer al presente pequeños retazos de la promesa futura” (2008:143). En este camino, y como parte de la estrategia resolutoria de la crisis de hegemonía abierta en 2001, el gobierno de Kirchner logró recuperar y rearticular algunas demandas de las clases subalternas que habían cobrado fuerza en el proceso previo de conflictividad, y dar cauce a distintos niveles de resolución, incorporándolas resignificadas en una nueva cadena que comenzó a ser constitutiva de su propia identidad. Algunas acciones destacadas refieren a su política de Derechos Humanos, el descabezamiento de la cúpula militar, los cambios en la Corte Suprema de Justicia, los discursos críticos frente al FMI, y su acercamiento a gobiernos populares de América Latina. Estas medidas, entre otras, produjeron amplias adhesiones, incluyendo personalidades y organizaciones previamente opositoras, y comenzaron a constituir puntos de sutura de la crisis.

El posicionamiento en materia de Derechos Humanos tiene una gráfica relevancia tanto en relación a la delimitación del adversario como en torno a la rearticulación de demandas de los movimientos sociales. Ya en la asunción presidencial Kirchner se situó como parte de la generación que enfrentó a la dictadura: “Formo parte de una generación diezmada, castigada con dolorosas ausencias; me sumé a las luchas políticas creyendo en valores y convicciones a las que no pienso dejar en la puerta de entrada de la Casa Rosada” (Kirchner, 25/5/2003). Éste fue el punto de partida para el despliegue de una política que rearticuló aspectos centrales de las demandas históricas de movimiento de DD.HH. y produjo acciones de alta trascendencia como el apoyo a la anulación de las leyes de Obediencia Debida y Punto Final ${ }^{221}$, el retiro de los cuadros de los dictadores y la transformación de la $\mathrm{ESMA}^{222}$ en un museo para la memoria.

\begin{abstract}
"Yo no vengo en nombre de ningún partido, vengo como compañero y también como Presidente de la Nación Argentina y de todos los argentinos (...) seguimos luchando como podemos, con las armas que tenemos, soportando los apretujones y los aprietes que nos puedan hacer. Pero no nos van a quebrar, compañeros y compañeras. Aquella bandera y aquel corazón que alumbramos de una Argentina con todos y para todos, va a ser nuestra guía y también la bandera de la justicia y de la lucha contra la impunidad. Dejaremos todo para lograr un país más equitativo, con inclusión social, luchando contra la desocupación, la injusticia y todo lo que nos dejó en su última etapa esta lamentable década del '90 como epílogo de las cosas que nos tocaron vivir" (Kirchner, 24/03/2004, el subrayado es nuestro).
\end{abstract}

Kirchner aparece en su discurso como un compañero más, que no ha claudicado

\footnotetext{
${ }^{221}$ Esta había sido una iniciativa presentada numerosas veces por diputados de izquierda que encontró recepción en el gobierno de Kirchner y formó parte de una vasta política de Estado en materia de DD.HH. ${ }^{222}$ La ESMA, Escuela de Mecánica de la Armada, fue uno de los principales centros clandestinos de detención durante la última dictadura militar.
} 
en la lucha de su juventud setentista por un mundo mejor, repudia el genocidio junto con las reformas neoliberales en un movimiento similar al manifestado por los actores políticos y sociales beligerantes del 2001: “la década del 90 como epílogo” marca el signo de relación entre la violencia dictatorial y el neoliberalismo como proyecto societario, y permite delimitar una otredad a ser confrontada en la lógica populista, aun cuando la misma sea desplegada desde el seno del Estado mismo ${ }^{223}$. Ese otro-Estado, otra-cultura, otro-proyecto, es "lo viejo" que tiene acta de nacimiento en el genocidio de los años 70 y que cristalizó como forma más acabada en los años 90 de la mano de un líder a quien el kirchnerismo acababa de derrotar (o forzar su retiro) en las elecciones de 2003. La reacción neoliberal es el "ellos", la anti-comunidad que signó el pasado quebrando la promesa, constituyendo los peores años de la historia argentina: pero también es un peligro presente... un adversario que está en pie y que amenaza con volver a instaurarse, formando parte de un relato que cobrará todo su esplendor durante el gobierno de Cristina Fernández.

De esta manera, la política de DD.HH. se convierte en una constante que habilita la crítica al neoliberalismo y acarrea una reivindicación de la militancia como medio de transformación social. Debe notarse que esta reivindicación parte de una lectura del pasado que si bien realza la lucha política, aparece limada, en principio, de sus orientaciones anticapitalistas (fuertemente presente, en la década de los 70, en el ala izquierda del peronismo). Se gesta una crítica que avanza a impugnar al neoliberalismo pero que se limita al marco del proyecto de capitalismo “serio”, “normal”, “nacional” con la propuesta de articulación de la burguesía productiva con los trabajadores. En este movimiento importantes sectores del movimiento de DD.HH. pasaron a alinearse con el gobierno, tales como Madres y Abuelas de Plaza de Mayo, constituyendo uno de varios ejemplos de demandas encadenadas en que las pequeñas batallas por la hegemonía van definiendo el campo más general de antagonismo al tiempo que van configurando la identidad de la fuerza emergente, habilitando la sutura de la dimensión política de la crisis.

\footnotetext{
${ }^{223}$ Comenzamos a ver en este punto cómo funciona la dialéctica identitaria en el antagonismo de la constitución del “nosotros” en base a la delimitación del “ellos”. El trazado del adversario que articula las políticas y actores ligados al neoliberalismo, desde la dictadura en adelante, y cómo se contrapone al “nosotros” kirchnerista y su proyecto de pretensión nacional, puede verse en el discurso del líder en la apertura de las sesiones del Congreso: “Tenemos que dar los pasos que nos permitan dejar atrás un país del que se adueñaron los intereses y proliferaran los genocidas, ladrones y corruptos, para ser una Nación que sobre la base de un proyecto nacional reinstale la movilidad ascendente” (Kirchner, 1/3/2005).
} 
Un factor relevante a tener en cuenta en la construcción de hegemonía en nuestro periodo de estudio, es que el kirchnerismo recupera y explota los sentidos de lo nacional-popular (Retamozo, 2011). Entendemos que esto se vincula, en primer lugar, a la resignificación del peronismo que el kirchnerismo realiza en su configuración identitaria, en tanto confronta con las figuras deslegitimadas del neoliberalismo que había sido llevado a su esplendor con el liderazgo del propio PJ en los tiempos de Menem. Y, al mismo tiempo, con la productividad política de interpelar un imaginario arraigado en una parte de los movimientos sociales movilizados en 2001: la idea del regreso a la Argentina peronista. Ambos aspectos del mismo fenómeno permiten pergeñar una impresión de la propia identidad en construcción, que facilita la articulación y encadenamiento de demandas, en el restablecimiento mítico de la promesa de plenitud. Esta acción performa una característica clave que Gramsci ve en el Príncipe moderno: la capacidad de volver a narrar la historia nacional de la construcción de la voluntad colectiva incorporando los intentos pasados (tanto el mito del regreso a la Argentina peronista como el del kirchnerismo en tanto recuperación de la juventud setentista diezmada por la dictadura neoliberal) e inscribir el surgimiento del "nosotros" kirchnerista, del Príncipe/fuerza política, como legítimo heredero que viene a terminar de construir de forma novedosa ese legado restituyendo y avanzando hacia la realización de la promesa.

Esta estrategia se liga a su vez con la posibilidad de superar la crisis de hegemonía abierta, suturando sus dimensiones al tiempo que recuperando $\mathrm{y}$ reinscribiendo varias de sus demandas en la nueva cadena que se singulariza en el líder. Si Duhalde había cumplido un rol de segmentación de las demandas y los portadores del sujeto popular inacabado de 2001 mediante la lógica contención/represión que rompió el lazo entre "piquetes y cacerolas”; Kirchner viene a rearticular y resignificar varias de las demandas en la construcción de una nueva cadena hegemónica. Para esto apela a un doble movimiento: a) de incorporación de demandas y portadores a la fuerza oficialista, que culminará, como observa Retamozo, en la inscripción a la fuerza kirchnerista de movimientos sociales que, en su mayoría, "son capaces de acción colectiva pero no asumen la lógica de la protesta y sus movilizaciones se enmarcan bajo las directrices del gobierno nacional” (2011:261); y b) de marginación de los movimientos opositores, que “por izquierda” procuraban radicalizar los elementos impugnadores al orden global evidenciados en 2001 y enfrentaban el proceso de recomposición de la hegemonía y la 
gobernabilidad desplegado por el kirchnerismo.

A los actores del movimiento de DDHH ya mencionados, se suma una creciente incidencia de la estrategia oficial sobre el movimiento obrero. El MTA, constituido desde el año 2000 en CGT "Rebelde”, va a ir avanzando con el apoyo del gobierno nacional hasta la reunificación y conquista de la CGT en su conjunto en 2004. Además, comienza a realizar acercamientos a sectores de la CTA vinculados a la tradición nacional-popular. Otro tanto ocurre con las organizaciones de raigambre nacionalpopular en el movimiento piquetero (FTV, el Movimiento Evita, Barrios de Pie (que luego sale de la coalición oficialista), entre otros). Este trayecto se gesta también en la táctica de división del movimiento piquetero entre piqueteros “duros” y "blandos”, procurando deslegitimar a los primeros y abriendo espacios de diálogo, otorgando recursos estatales e incluso espacios de gobierno a los segundos. A su vez, el incremento sustancial del empleo que, en discurso y en políticas concretas, adquiere una creciente centralidad en el proyecto de gobierno kirchnerista, va a ir socavando las bases materiales de sustento del movimiento piquetero, a través de la resolución parcial pero creciente de la demanda por trabajo, al tiempo que refuerza la relevancia del movimiento obrero en el escenario político-social. Asimismo, la creciente resolución de la devolución de depósitos terminó de desactivar el énfasis conflictivo de lo que quedaba del movimiento cacerolero, que había comenzado a ser desarticulado durante el gobierno de Duhalde. Éstos conformaron un conjunto de pasos certeros de la fuerza oficialista para desactivar los componentes impugnadores que la dimensión política de la crisis mantenía en ciernes. Asimismo, si durante el gobierno de Duhalde el elemento coercitivo se impuso ampliamente por sobre los mecanismos consensuales, la administración Kirchner instaló el principio de no represión a la protesta social como política de Estado, contrastando también con los años neoliberales. Esto evidenció la fuerte apuesta de incorporación de demandas a la cadena equivalencial que iba articulando y nutriendo de legitimidad a la fuerza hegemónica en formación, al tiempo que no podía dejar de tener impactos sobre la identidad misma de dicha fuerza.

A su vez, encarando la crisis de "la" política, la estrategia hegemónica tuvo un capítulo importante en el armado político. El kirchnerismo, marcado por su debilidad de origen, procuró construir fuerza propia: el Frente para la Victoria que, jugando desde dentro y desde fuera del Partido Justicialista, realizó un despliegue que articulaba la construcción de la transversalidad, abriendo espacios a sectores progresistas y de 
izquierda, mientras procuraba acumular fuerzas para la progresiva conquista de las lealtades y la estructura del PJ. Esta contienda por la conducción del aparato tuvo en su disputa con Duhalde, quien originalmente lo había apadrinado para las elecciones presidenciales, un momento fundamental, en el que el kirchnerismo terminó imponiéndose en el marco de las elecciones del 2005 con el triunfo de Cristina Fernández de Kirchner sobre Hilda González de Duhalde por el senado en la provincia de Buenos Aires. El kirchnerismo quedó, luego de estas elecciones con mayoría en las dos cámaras legislativas y con legitimidad suficiente como para cambiar al ministro de economía Roberto Lavagna que representaba el principal legado de Duhalde en su gobierno, reemplazándolo por Felisa Micelli con el fin de afirmar la propia comandancia del presidente sobre las políticas económicas. Según Rudnik (2012) las elecciones de 2005 constituyeron un punto de inflexión en el armado político, en tanto marcó el declive de la experiencia transversal y la priorización de la conquista del PJ, intervenido judicialmente por la virtual acefalia en que había quedado por el enfrentamiento entre kirchneristas y anti-kirchneristas en su interior. Este proceso culminó con el triunfo de Kirchner como presidente de dicho partido resuelto judicialmente en 2008, en un trayecto donde la acumulación incluyó la incorporación de políticos previamente ligados a la derecha (como aquellos provenientes de la UCD) y una alianza con los intendentes conservadores del conurbano bonaerense.

Hacia el arco de la transversalidad, el gobierno de Kirchner había inaugurado una política de acercamiento a distintos actores del campo popular con políticas activas. El nivel de éxito de esta estrategia se expresó en la incorporación a la gestión oficial de organizaciones populares y de izquierda, con distinto grado de posicionamiento crítico al gobierno, y la creciente marginación de las organizaciones de similar perfil político que quedaron en la oposición. De este modo, el gobierno logró mitigar el impacto de la crisis política dotando con elementos novedosos al proceso de construcción hegemónica en marcha. Avanzada la reconquista del PJ, comenzó a cobrar forma una nueva táctica de armado político: la concertación, a través de la cual se buscaba incorporar a la fuerza kirchnerista a sectores de otros partidos tradicionales, principalmente del radicalismo y el socialismo que, estando en crisis con sus propias orgánicas, mostraban un creciente acercamiento al proyecto oficial. Este recorrido fue teniendo impactos en términos del escenario político nacional: entendemos que el gobierno planteó una estrategia que reconfiguraba el bipartidismo erosionado en dos nuevos polos, de centro-izquierda y 
centro-derecha ${ }^{224}$. Así, el oficialismo procuró encarnar el primer polo, en una coalición donde el PJ fue adquiriendo centralidad, junto a la táctica de transversalidad y la táctica de concertación, atrayendo nuevas fuerzas aliadas con el fin ampliar su legitimidad y consolidar su acumulación de fuerza política, marginando a la izquierda opositora y confrontando con espacios de una nueva derecha electoral que tenía en Mauricio Macri $^{225}$ a su principal referente y una variante más heterogénea que se nucleaba en torno a Elisa Carrió ${ }^{226}$.

De este modo, el gobierno asumió plenamente el desafío abierto en materia de crisis de "la” política, que señalábamos al comienzo, buscando recomponer el vínculo entre “representados y representantes", reformulando el desgastado par PJ-UCR característico de las décadas del 80 y 90 para dar lugar a un esquema que rearticulaba fuerzas y actores de manera singular. Así, la estrategia kirchnerista contuvo en su interior dos tácticas articuladas para suturar la crisis política, la de la transversalidad y la concertación, teniendo un rol fundamental, en la primera, la incorporación de demandas y parte de sus portadores a la nueva cadena equivalencial constituida en el kirchnerismo y, en la segunda, la reconquista y aumento de la gravitación del PJ y la alianza con sectores de otros partidos tradicionales en la concertación, que terminó con su cristalización en la fórmula Cristina Fernández-Julio Cobos $^{227}$ en 2007.

Finalmente se nos plantea la necesidad de conceptualizar adecuadamente este proceso de guerra de posiciones que fuimos analizando a lo largo del capítulo. Primero, es importante destacar, por la particularidad misma de esta fuerza ligada a la doble lectura del populismo que realizamos (como lógica política y como pacto populista), cómo se articulan los elementos normalizadores y conflictivos en este proceso de construcción hegemónica. En segundo lugar, precisamos enfrentar un conjunto de debates en torno a la dinámica de constitución de la voluntad colectiva en el marco del campo de antagonismo del cual emerge, en simultáneo, la fuerza hegemónica, al ser coconstitutiva del Príncipe moderno.

\footnotetext{
${ }^{224}$ Este esquema no es una reproducción del europeo en tanto es atravesado por las lógicas particulares de las tradiciones políticas argentinas que tienen en el peronismo un actor fundamental.

${ }^{225}$ Empresario del grupo SOCMA (Sociedad Macri) y Jefe de gobierno de la Ciudad de Buenos Aires desde 2007 por el PRO.

${ }^{226}$ Líder del ARI y la Coalición Cívica, producto de una fractura de la UCR.

${ }^{227}$ Gobernador radical de Mendoza cercano por aquel entonces al kirchnerismo, con el cual rompería en 2008 durante el "conflicto del campo".
} 
En relación a la hegemonía kirchnerista, destacamos una tensión central que durante nuestro período de estudio se dio, como acertadamente señalan tanto Cremonte (2007) como Rinesi y Vommaro (2007), entre el orden y el conflicto: entre el espíritu y demandas propias de la conflictividad que marcó al 2001, y el espíritu y demanda de normalización que terminó primando en 2002, y la conjugación de elementos de ambos en las acciones desplegadas por el gobierno de Kirchner. Esta afirmación nos habilitan a pensar al kirchnerismo como una construcción ambivalente: como proyecto de normalización política y económica ${ }^{228}$, pero que cobra forma conflictivamente articulándose con un discurso que constituye sus propios antagonistas y abre juego a los componentes heréticos del peronismo.

Previamente señalamos que al inicio del gobierno de Kirchner persistían los contenidos centrales de la crisis hegemónica. Ya en 2002, con la solución de la movilidad de fondos afectados por el "corralito" (en diciembre) y con la masiva ofensiva mediática de estigmatización sobre el movimiento piquetero y la feroz represión desatada por el gobierno de Duhalde, la articulación de “piquetes y cacerolas” se fue desmembrando, buena parte de los sectores medios se fueron retirando del conflicto para sumarse al reclamo por “orden” y “seguridad”, que más adelante tuvo en las multitudinarias marchas de Blumberg ${ }^{229}$ un hito de sesgo conservador. Así podemos ubicar la “demanda de orden”, demanda que pareciera paradójica contrastada con la evolución de los indicadores sociales: de hecho, en 2002 el salario real alcanza su piso histórico, los niveles de pobreza, indigencia y desocupación literalmente explotan. Pero resulta difícil también pensar que la "clase media” podría haber constituido sola, en sí misma, el sujeto que expresaba el reclamo al orden. Si así era presentado a nivel de los medios masivos de comunicación, debemos tener en cuenta que las políticas fundacionales del modelo de acumulación post-convertibilidad, instituidas principalmente a partir de la Ley de Emergencia Pública y Reforma del Régimen Cambiario $\mathrm{n}^{\circ} 25561$ del 6 de enero de 2002, ya habían dado el paso fundamental para el establecimiento del orden. Dichas políticas habían comenzado a configurar el nuevo modelo vinculado a los cambios en las relaciones de fuerzas, sobre todo al interior de la

\footnotetext{
${ }^{228}$ Aunque esto se dio en condiciones particulares marcadas por el cambio en las relaciones de fuerzas entre las distintas fracciones de clase y la conformación de un nuevo modelo de acumulación.

${ }^{229}$ Estas marchas, desarrolladas entre 2004 y 2006, fueron convocadas a través de los medios masivos de comunicación por Juan Carlos Blumberg cuyo hijo había sido asesinado en un secuestro, dando aliento al reclamo de seguridad, a través de un discurso claramente conservador, que estigmatizaba a los sectores populares (incluso legitimando el "gatillo fácil") y conllevaba propuestas de incremento de los atributos de la autoridad policial para enfrentar al delito.
} 
clase dominante, derivados de las disputas interburguesas que acompañaron el fin del modelo de la convertibilidad. Es también en este contexto donde re-emerge el Estado, en acto, en políticas, como un actor preponderante en la gestión del excedente económico a través de la constitución de un complejo sistema de transferencia de recursos tendiente a compensar a las distintas fracciones de clase al tiempo que se las confronta para la aceptación del nuevo modelo. Así, las políticas comenzaron a constituir y movilizar múltiples mecanismos de transferencia que procuraron saldar la crisis hegemónica, dando lugar a una nueva armonía inestable que requirió sustantivos insumos políticos, en tanto el Estado como mediación se convirtió en un actor clave. El gobierno de Kirchner va a continuar profundizando el sistema de transferencia de recursos, dándole un sesgo más progresivo en tanto asume al Estado como mediación reparadora, al tiempo que le permite incrementar los niveles de autonomía relativa ${ }^{230}$.

Pero es en este mismo proceso de armonización en base a la constitución de un sistema de transferencias de recursos donde se encarna también la dimensión del conflicto, ya que grava a distintos agentes para redistribuir hacia otros. El Estado, como actor clave de este proceso de normalización, lejos de constituirse en un actor pasivo que libra el desarrollo del proceso de acumulación de capital a la mera iniciativa privada, es parte fundamental de su gestión. Y además, la dimensión del conflicto aparece presente en el modo en que son desplegadas las políticas que constituyen este proceso. El kirchnerismo recuperó, al igual que el peronismo originario, las calles y las plazas como ámbito de disputa política en las estrategias oficialistas, comenzando a despertar en sus discursos evocaciones al espíritu combativo de los años 70, incorporando a distintos dirigentes sociales protagonistas del conflicto de 2001 a funciones gubernamentales, planteando desafíos a sus adversarios que denunciaba públicamente, movilizando toda su fuerza política en cada batalla ${ }^{231}$. Se agitan así las connotaciones heréticas que el peronismo había sabido poseer en tiempos pasados, incluso dentro de sus filas, algunos sectores más radicalizados impulsan la

\footnotetext{
${ }^{230} \mathrm{El}$ aumento de autonomía relativa no fue total, ya que, como señala Castellani (2010) se observan continuidades en la relación Estado-empresarios a partir de la conformación de nuevos ámbitos privilegiados de acumulación ligados principalmente a los planes de obra pública, las promociones industriales, los subsidios, entre otros.

${ }^{231}$ Esto transcurrió tanto en el enfrentamiento público que tuvo con miembros de la Corte Suprema ligados a la "mayoría automática" menemista (ver para este caso el discurso de Kirchner del 5/6/2003), como incluso en la confrontación con petroleras transnacionales por el aumento del combustible que culminó en un bloqueo de las organizaciones populares ligadas al gobierno a las estaciones de servicio ligadas a dichas empresas.
} 
identificación del gobierno como parte de un movimiento latinoamericano para avanzar hacia transformaciones emancipatorias, teniendo como hito el "No al Alca” de 2005.

Es en este sentido, que acordamos con el señalamiento realizado tanto por Cremonte (2007) como por Rinesi y Vommaro (2007) respecto de que Kirchner combina conflicto y orden, acercándose en esto al estilo de conducción política del líder originario del peronismo. Tanto en la reformulación que el kirchnerismo realiza de la cultura política peronista como en las acciones estatales concretas que promueve, la tensión orden y conflicto se articula en un sentido particular: "el conflicto, en Kirchner, funciona como productor de orden” (Cremonte 2007:400). Y es en la combinación de la recuperación de varios de los reclamos de 2001 y de las demandas de orden de 2002, imbricados complejamente en el discurso y en las políticas, en donde busca operarse la sutura de la crisis de hegemonía.

Podemos observar cómo el kirchnerismo, sin procurar una transformación radical del orden (en sentido de clase), avanza a recomponer la promesa de plenitud, de articulación de la "vida interior” y “exterior” del pueblo (como señalara Marcuse), en tanto son reconstituidas las condiciones básicas de vida para millones de argentinos que recuperan su empleo y ven mejorados, en distinta medida, sus ingresos. En este sentido, sostenemos que el kirchnerismo juega un rol que repone el horizonte de la promesa, al tiempo que su componente normalizador, en el marco del proyecto de capitalismo “serio" o "nacional” que promueve, no puede sino reincorporar al pueblo a la cultura afirmativa y su aspecto igualmente normalizador. Esto se debe a que el proyecto no propone una superación/abolición de las escisiones propias de las sociedad capitalista, tanto entre “cultura y civilización” como las específicas de la sociedad fracturada en clases que convocan los intentos de reengarce a través de diversas mediaciones (dentro de las cuales destacan la relación Estado-pueblo-nación). Este mismo componente normalizador abriga dicho carácter afirmativo de la cultural, como recuerda Marcuse, donde cultura significa un mundo más noble: un mundo al que no se ha de llegar mediante la transformación del orden material de la vida subvirtiendo las relaciones de clase, sino mediante algo que acontece en el estado interno del hombre ${ }^{232}$ y que en la sociedad burguesa tiende a verse inundado por la primacía de la mercancía como vía de

\footnotetext{
${ }^{232}$ Marcuse señala que en la cultura afirmativa "La humanidad se transforma en un estado interno del hombre: la libertad, la bondad, la belleza, se convierten en cualidades del alma (...). De una situación de este tipo ha de fluir un actuar que no está dirigido ante el orden impuesto” (1967:56).
} 
satisfacción (y de ahí la relación entre la restitución de la promesa y la recuperación del empleo y el consumo como vía de inclusión social). Así la recomposición de la promesa en el marco de proyecto reformista pero sistémico, constituyendo un avance en las condiciones materiales de existencia para las clases subalternas, expresa en simultáneo la posibilidad de construcción de un pueblo que no tienda a actuar contra el orden.

Pero, ¿qué pueblo es construido en el discurso de Kirchner? Y aquí podemos nuevamente observar cómo es retomada una noción de pueblo prefigurada en el proyecto político-económico de gobierno y que se despliega en términos similares a los que caracterizaron a la cultura política del peronismo originario: es un pueblo articulado a partir de la alianza entre trabajadores y empresarios nacionales que en Kirchner aparecen unidos en su propuesta de “capitalismo nacional”. Por un lado, entendemos que la voluntad colectiva en construcción remite a la acepción de populus, ya que sobrepasa tanto el plebs de los agredidos como a los anclajes de clase de la subalternidad y se entrelaza con sectores de la clase dominante, en tanto ciudadanos ${ }^{233}$ claves del orden a consolidar. Es justamente la resultante del populismo como pacto entre trabajadores y "burguesía nacional” que convierte al pueblo en populus, ya que toma a los ciudadanos más allá de la clase a la que pertenezcan, empresarios y trabajadores son igualmente parte de ese pueblo en construcción, limitando la potencia herética y subversiva del plebs. Lo nacional-popular implica una tensión generalizante en la nación que procura ampliar al pueblo a un espectro más amplio, a un populus, que apela a un sentido equiparador de las desigualdades que afectan al plebs y lo constituyen en tanto tal. De este modo, el pueblo como plebs convoca al Estado como mediación reparadora, pero limitada a la construcción de un pueblo como populus y la nación como referente generalizante de la acción estatal.

Asimismo, es tal vez en este punto donde la construcción discursiva del pueblo cumple un papel primordialmente ideológico que contrasta con el orden de la reproducción material, volviendo a plantear la pregunta por la burguesía nacional que atravesará implícitamente los capítulos siguientes y será explicitada en las conclusiones. Creemos que allí se ponen de manifiesto algunas limitaciones de las teorías de la hegemonía que focalizan en exceso el imperio del discurso sin dar cuenta de los sustratos materiales de los agentes y actores implicados en dichas construcciones. Esto

\footnotetext{
${ }^{233}$ Debemos tener en cuenta que, como señala O’Donnell (1978), la ciudadanía tiende a ser el referente por excelencia de la acción estatal en las sociedades capitalistas.
} 
puede verse tanto en la referencia al empresariado que encarnaría la burguesía nacional como en la construcción del pueblo.

Según Poulantzas, "se entiende por burguesía nacional la fracción autóctona de la burguesía que, a partir de determinado tipo y grado de contradicciones con el capital imperialista extranjero, ocupa, en la estructura ideológica y política, un lugar relativamente autónomo, y presenta así una unidad propia” (1981:67). En la historia argentina, la burguesía nacional fue una fracción clave del régimen de acumulación basado en la industrialización por sustitución de importaciones. Comprendía a agentes del capital productivo, que en Basualdo (2010) abarcaba un amplio espectro de pequeñas y medianas industrias junto a grandes empresas locales independientes. Lo que hacía clave a esta fracción era el lugar o posición estructural que ocupaba, ya que en un régimen de acumulación cuyo eje central estaba en la producción industrial orientada al mercado interno, el desarrollo de esta burguesía era compatible con una alta participación en el ingreso por parte de los trabajadores y con el pleno empleo, ya que el salario era un componente fundamental como consumo en el mercado interno para la realización del capital. Aquí hallamos el anclaje estructural que habilitaba la potencia política de los proyectos nacionales y populares, como el peronismo, en tanto procuraban articular desde el Estado una alianza de clases basada en la burguesía nacional y la clase trabajadora (compatible, a su vez, con los intereses del gran capital industrial aunque sin ser una expresión directa de éste ${ }^{234}$ ). A partir del golpe de Estado de 1976 y la instauración del régimen de acumulación neoliberal, las transformaciones estructurales implementadas no sólo ejercieron un deterioro sobre las condiciones materiales de las clases subalternas (sin dudas, la principal perjudicada) sino que también erosionó las bases estructurales en las que se asentaba la burguesía nacional y, de conjunto, sobre las cuales se erigía la alianza policlasista en el peronismo. En los capítulos siguientes analizaremos el proceso de rupturas y continuidades que dan cuenta de la emergencia de un nuevo modelo de acumulación, observando cómo se conforma la clase dominante e indagando acerca de la posibilidad en torno a la re-emergencia de la burguesía nacional, en un contexto global profundamente distinto al que caracterizaba los años de la ISI.

\footnotetext{
${ }^{234}$ Según Basualdo, la orientación económica del tercer gobierno de Perón procuraba "que el Estado fuera el impulsor y garante de una asociación entre el capital extranjero y la fracción dinámica de la burguesía nacional que condujera el proceso de industrialización, pero reconociendo la necesidad de implementar una redistribución del ingreso hacia los asalariados” (2010:109).
} 
Con respecto al pueblo, debemos tomar también algunas precauciones analíticas. Si bien en la construcción de sujeto-pueblo hay creación ex novo, y el discurso (sea el discurso político en su especificidad o el discurso como práctica con sentido en general) posee un lugar destacado en dicho proceso, hay asimismo articulación de actores y agentes preexistentes con historias y anclajes estructurales particulares, que inciden a la vez ponen coto a las construcciones discursivas particulares, requiriendo nuevamente de la articulación de las categorías de antagonismo y contradicción para poder realizar un análisis adecuado. En este sentido pensamos al pueblo no sólo como una construcción discursiva sino también en sus anclajes estructurales específicos, viendo tanto la articulación de demandas que da lugar a la conformación del campo de antagonismo, como también las relaciones estructurales y las posiciones concretas ocupadas por los portadores de dichas demandas. Por ello, es necesario cruzar la dimensión discursiva del sujeto-pueblo con las posiciones de dominación o subalternidad. Si bien el pueblo no puede reducirse a la clase y expresa un concepto diferente, el pueblo construido en una sociedad de clases tampoco puede desprenderse enteramente de la referencia a las mismas.

Hasta aquí la guerra de posiciones en el kirchnerismo nos muestra al conflicto como productor de orden en una dimensión normalizadora que pareciera primar sobre los componentes heréticos. Sin embargo, la construcción de la cadena equivalencial que promueve en su conducción política y cultural nos lleva a una revalorización del aspecto rupturista contenido en la lógica hegemónica desplegada, abriendo la discusión en torno a la idea de cooptación y el concepto gramciano de revolución pasiva.

Entendemos que el rol de las políticas públicas y la interpelación ideológicocultural desplegada por la fuerza en ascenso hegemónico permiten dar cuenta del aspecto de incorporación de la estrategia oficial, de la articulación de la cadena de demandas, y el fortalecimiento del rol de dirección política y cultural, prescindiendo de la idea de cooptación ${ }^{235}$, abordando el debate más amplio en torno a la lectura del proceso en clave del concepto gramsciano de revolución pasiva. Según Campione (2007), Gramsci concibe dos vías alternativas para las transformaciones radicales: la revolución en sentido clásico, impulsada fundamentalmente desde abajo, y la revolución pasiva, orientada desde arriba. Si bien ambos procesos presentan cambios profundos, la

${ }^{235}$ Para citar un trabajo importante que utiliza esta noción: Campione y Rajland (2006). 
revolución pasiva se liga a la dialéctica entre "lo nuevo” y "lo viejo”, que Gramsci retoma de Marx en cuanto señala que un sistema social no termina de caer hasta que se hayan desarrollado en su interior todas sus posibilidades y que puede subsistir introduciendo un conjunto de "novedades" en las que las clases dominantes impulsan transformaciones expropiando la iniciativa a las clases subalternas. En este sentido podemos leer la conclusión a la que arriban Bergel y Fornillo, señalando que luego de la crisis de 2001, "la iniciativa ha pasado de los movimientos sociales a una nueva elite política gobernante comandada por el presidente Néstor Kirchner” (2006:1). Claro que este planteo involucra la pregunta por la relación que adoptan los intelectuales orgánicos en procesos de ampliación de la autonomía relativa del Estado, aquí encontramos una clave del análisis de Gramsci sobre el proceso de reunificación italiana que nos sirve para pensar nuestro problema: "no es que un grupo social sea el dirigente de otros grupos, sino que el Estado (...) sea el "dirigente” del grupo que debería ser dirigente” (Gramsci citado en Campione 2007:93). Esto nos permite comprender algunos rasgos duraderos del kirchnerismo (en particular, y del peronismo clásico en general) relacionado a los agentes en la estructura de clase: la percepción de una burguesía nacional incompleta o desviada de sus tareas nacionales que requiere de la orientación del Estado para performar su papel "histórico” en el pacto populista. Otra característica de la revolución pasiva que vemos presente es la ausencia de una iniciativa popular unitaria: el sujeto-pueblo inconcluso de 2001, que impidió la completitud de la crisis orgánica en desarrollo.

Sin embargo, hay elementos de la revolución pasiva que deben ser puestos en cuestión para el análisis de nuestro caso. Como señala Kohan, “mediante la revolución pasiva los segmentos políticamente más lúcidos de la clase dominante y dirigente intentan meterse “en el bolsillo” (la expresión es de Gramsci) a sus adversarios y opositores políticos incorporando parte de sus reclamos, pero despojados de toda radicalidad y todo peligro revolucionario” (2006:1). Si bien efectivamente la estrategia hegemónica kirchnerista incorpora parte de las demandas subalternas y despoja su sentido impugnador del orden, la idea de “meterse en el bolsillo" a los adversarios se liga a la idea de cooptación, en la que un actor pierde su autonomía a cambio de recursos económicos o políticos. Ahora bien, entendemos que el kirchnerismo no puede ser reducido a una maniobra de “meterse en el bolsillo” a los movimientos sociales, en tanto observamos que hay un plus que no se explica por esa lógica. Ciertamente hay 
incorporación de reclamos orientados a desactivar el perfil anti-sistémico involucrado en muchas de las demandas de 2001 así como en parte de sus portadores, sin embargo es la propia rearticulación en los tres planos de la ideología, la política y la economía (dimensiones constitutivas de la crisis de 2001) que nos permiten observar la gestación de un proyecto político-económico de gobierno de más largo aliento que posee capacidad de interpelación a los actores involucrados y viabiliza la articulación de demandas en una nueva cadena de equivalencias mediante la desactivación del "que se vayan todos”. El problema de la idea de cooptación es que desubjetiviza, niega la capacidad de decisión de los actores “cooptados” impidiendo ver la lógica y motivos de la articulación, los componentes mismos de la interpelación. Es a través del abordaje del proyecto político-económico de gobierno y de la cultura política singular que pudimos alumbrar algunos aspectos claves de esta dinámica: tanto la interpelación al imaginario nacional-popular presente en amplios sectores de las clases subalternas, como las políticas sociales y de ingreso orientadas hacia dichas clases permiten pensar la incorporación de distintas organizaciones populares al kirchnerismo sin necesidad de visualizarlo como mera cooptación.

Esto nos deja en pie un segundo planteo crítico sobre la posibilidad de aprehender totalmente el proceso que analizamos desde el concepto de revolución pasiva. Gramsci señala que “sólo la tesis desarrolla todas sus posibilidades de lucha, hasta acaparar a los llamados representantes de la antítesis: justamente en ello consiste la revolución pasiva o revolución-restauración” (Gramsci, 2003:86). Hay una pregunta que subyace a la caracterización de la crisis de hegemonía de 2001 que se relaciona directamente con esta afirmación gramsciana ¿qué es lo que estaba en juego en 2001 ? ¿era la sociedad capitalista en sí y la posibilidad de abrir paso a un proceso emancipador? ¿o era la crisis de un régimen capitalista particular: el neoliberalismo? Porque depende de cómo respondamos esta pregunta el modo en que podremos identificar la “tesis” y la “antítesis”. Si lo que estaba en juego era la sociedad burguesa en tanto tal, entonces podríamos caracterizar al kirchnerismo sin más como revolución pasiva. Pero para esto deberíamos haber dado cuenta de la existencia de una sujetopueblo constituido en la lucha con proyecto anti-capitalista y, si bien había actores portadores de proyectos con dicho carácter, la conclusión a la que llegamos fue la no existencia de un "nosotros” consolidado desde la subalternidad y por eso definimos el proceso como principio de crisis orgánica sin alcanzar su plenitud. Por ende, en primer 
lugar, no había “empate hegemónico” del cual el kirchnerismo pudiera dar cabida a lecturas en torno al bonapartismo o cesarismo. Pero en segundo lugar, si lo que estaba en juego era el régimen neoliberal, no podemos dejar de notar que el proyecto que encarna el kirchnerismo contiene en su fundación misma algunos elementos de negación del neoliberalismo, si bien lima efectivamente las aristas anti-sistémicas más inmediatas recuperando la "demanda de orden", la incorporación de las demandas emergidas de la crisis de 2001 integran elementos inestables desde el punto de vista de la lucha de clases en tanto comprenden reivindicaciones de largo arraigo popular que no puede sino imprimir ese tono popular, herético a la cadena misma. Por eso es relevante pensar al kirchnerismo en clave de la doble lectura del populismo, como lógica hegemónica y como pacto populista, viendo la articulación inestable entre un proyecto que en su raigambre peronista encarna tanto la salida hegemónica para el capitalismo argentino (a lo James) como al hecho maldito del país burgués (a lo Cooke), en tanto la cadena está imantada de la lógica del conflicto con que la vio nacer. A su vez, es este el punto que nos permite acercarnos, a un interrogante central propuesto por Godio (2006), quien analiza al kirchnerismo en clave de revolución “desde arriba”, y plantea la pregunta abierta de si este proyecto puede convertirse en una revolución “desde abajo”, que en nuestra lectura podría estar motivado por el componente herético que visualizamos como constitutivo del kirchnerismo.

Este componente herético no sólo aparece en la lógica del conflicto a través del cual se abren paso las políticas públicas en el escenario nacional sino que es parte del posicionamiento gubernamental en materia de política exterior, caracterizada como señalan Moreira y Barbosa, por "sumarse a la ola de gobiernos de una nueva izquierda que cubría el continente” (2010:196), ubicándose como parte de un movimiento latinoamericano contra el neoliberalismo (por más que, como veremos en los próximos capítulos, se encuentran múltiples continuidades del mismo a nivel del modelo de acumulación). Por eso no puede hablarse sólo de cooptación ni de revolución pasiva en todo su esplendor, porque la sobredeterminación de las contradicciones que alberga el movimiento más general de la sociedad de clases está enmarcada (y justamente sobredeterminada) por un escenario internacional que va a ser de crisis del neoliberalismo ( $\mathrm{y}$ por esto antitético) y de transformación progresiva a nivel latinoamericano. Nos situamos en un contexto donde un conjunto de formaciones sociales son conducidas por bloques populares que adelantan proyecciones hacia un 
horizonte socialista, que puede visualizarse en experiencias como la de Venezuela, Bolivia, y luego Ecuador (junto a la histórica resistencia de Cuba) y de las cuales Argentina, junto con otros países (como Brasil y Uruguay) representan versiones más moderadas (en términos de la relación capital/trabajo). Es el conjunto de gobiernos que componen este abanico de experiencias que fueron impulsores de este proceso que contuvo un primer desafío antiimperialista en el No al ALCA en 2005, al que se le sumaron otros pasos tales como la incorporación de Venezuela como Estado Asociado al Mercosur ${ }^{236}$, la firma del Banco del Sur en el último día del gobierno de Néstor Kirchner $^{237}$ y la histórica firma del tratado base para la formación de UNASUR, ya bajo el gobierno de Cristina Fernández, en 2008.

El kirchnerismo gesta desde el Estado una recuperación y primacía de la política que contrasta con la subordinación al imperio directo del gran capital (en nombre de las necesidades del "mercado") y a los mandatos de los organismos financieros internacionales ${ }^{238}$. Esta reivindicación de la política es un factor clave en la ampliación de la autonomía relativa del Estado y, al mismo tiempo, constituye un elemento de la cultura política que, enlazado con la recuperación del pasado setentista, reaviva el componente herético. Sin embargo, la función del conflicto como productor de orden y la limitación de éste a un horizonte sistémico en el proyecto de capitalismo "serio" imprime una tensión perdurable entre estos dos componentes que marcan la cultura política de esta fuerza fundada en el pacto populista: el componente sistémico y el herético permanecen en un “tire y afloje”, articulándose e imponiéndose alternativamente, motivando en este movimiento la pregunta sobre la posibilidad de que la revolución “desde arriba” (parcial e incompleta) pueda devenir en una revolución “desde abajo”. Sólo de este modo la cultura política emanada de la fuerza-Príncipe podría romper la escisión constitutiva de la cultura afirmativa y sus límites normalizadores; proceso que dependería en última instancia de mayores márgenes de

\footnotetext{
${ }^{236}$ Y luego, en 2012, el ingreso de Venezuela como miembro pleno al MERCOSUR.

${ }^{237} \mathrm{Y}$ asimismo es necesario señalar que no todo fue ruptura en el escenario internacional, que esta estrategia de priorizar el MERCOSUR no se encuentra en contradicción con las estrategias de acumulación de las empresas transnacionales (ya que el Mercosur se encontraba ya en primer lugar en materia de términos de intercambio, mientras que el NAFTA se encuentra en último lugar, después de la Unión Europea y el bloque asiático). Además, el gobierno continuó disputando con los bloques más poderosos (NAFTA y UE) desde la exigencia de más apertura comercial, criticando las medidas proteccionistas de los mismos. También la aprobación de leyes “antiterroristas” exigidas por los EEUU y el mantenimiento de tropas en Haití señalaron eventos de respuesta efectiva a exigencias del gobierno de los EEUU.

${ }^{238}$ En un sentido similar también se expresan Moreira y Barbosa (2010).
} 
autonomía de las clases subalternas en la formación de la voluntad colectiva constituyendo un sujeto-pueblo que pase de a la conducción del pacto populista y a su supresión superadora. 


\section{Capítulo IV}

\section{Las políticas fundacionales del modelo post-convertibilidad.}

El modelo de acumulación iniciado en 2002 tiene su origen en el contexto de crisis integral que marcó el fin del modelo de la convertibilidad (1989-2001), el cual encarnó la forma más acabada de aplicación de las reformas neoliberales como profundización de la ofensiva del capital efectivizada a partir del golpe de Estado de 1976. Ante los crecientes signos de agotamiento del modelo de la convertibilidad y el deterioro de la hegemonía entonces imperante, se fue generando una fractura de intereses entre distintas fracciones del capital que buscaban mejorar su capacidad de apropiación del valor socialmente producidos en base a dos propuestas divergentes de salida ${ }^{239}$. Como vimos, dichas propuestas se relacionaban con las diferentes posiciones ocupadas en la estructura y con las estrategias de acumulación de las distintas fracciones del capital. Unos procuraban la devaluación, aglutinando al gran capital productivo en general, y dentro del mismo particularmente a aquellos orientados a la exportación, buscando mejorar su competitividad y capacidad de inserción en el mercado mundial, así como valorizar las ingentes masas de capitales que los grandes agentes económicos locales mantenían fugadas en el extranjero. Por otra parte, el capital financiero y las empresas de servicios privatizadas, exigían la dolarización, principalmente para mantener el valor de sus activos en dólares y garantizar la perpetuación de los beneficios de la convertibilidad de la moneda, como el envío de remesas dolarizadas al exterior y la existencia del seguro de tipo de cambio que la convertibilidad implicaba.

La capacidad de la propuesta devaluacionista de construcción de alianzas más amplias (Castellani y Szkolnik, 2005) y las limitaciones objetivas del proyecto dolarizador por las restricciones para conseguir las divisas necesarias en un contexto de crisis integral, sumado al desenvolvimiento efectivo de las variables económicas afectadas por la vulnerabilidad externa, favorecieron a la salida devaluacionista. Esta salida marcó el inicio de un nuevo modelo que expresó diversas continuidades y rupturas con el anterior, rearticulando agentes y políticas de manera singular.

\footnotetext{
${ }^{239}$ Algunos trabajos referentes de esta idea son: Basualdo, 2001; Castellani y Szkolnik, 2005; Schorr y Wainer, 2005.
} 
Ingresamos de este modo al bloque de dos capítulos de análisis específico del modelo de acumulación desplegado a través de la estrategia de doble entrada: el momento superestructural y el momento estructural. En cuanto al recorte temporal abordado en el bloque, nos concentraremos en el período 2002-2007, en tanto entendemos que el mismo constituye el período de configuración del modelo postconvertibilidad, siendo el año 2008 un nuevo punto de inflexión en términos políticos y económicos, que será abordado en el capítulo 6, y que marca el comienzo de una nueva etapa, tanto a nivel del modelo como de la construcción de hegemonía. ${ }^{240}$

En el presente capítulo nos proponemos abordar el modelo de acumulación desarrollando una primera aproximación a través de su dimensión superestructural: las políticas económicas. Esta entrada analítica nos permite exponer cómo la acción estatal instaura, a través de un conjunto de políticas fundacionales, un momento de ruptura que marca el comienzo de un nuevo modelo de acumulación. En este sentido, caracterizaremos las políticas, principalmente las fundacionales así como otras que aparecen como centrales para la configuración del modelo, y percibiremos su impacto en las variables económicas ${ }^{241}$.

\subsection{Las políticas fundacionales del modelo post-convertibilidad}

La salida devaluacionista se articuló con un conjunto más amplio de políticas que fueron claves en la gestación del modelo post-convertibilidad en tanto instauraron nuevas reglas de juego delimitando variaciones en el campo de acción de los agentes económicos, los cuales se relacionaron conflictivamente con las mismas y entre sí, en la disputa del excedente económico ${ }^{242}$.

\footnotetext{
${ }^{240}$ Otro motivo para efectuar este corte es que hasta 2007 está asegurada la confiabilidad de los índices oficiales, puesta luego en discusión la construcción del Índice de Precios al Consumidor, y todos los otros indicadores elaborados en base a éste.

${ }^{241}$ Veremos el impacto de las políticas principalmente sobre las variables económicas de desempeño, es decir, aquellas más vinculadas al corto plazo de la acción estatal y que permiten evaluar su resultado.

${ }^{242}$ Damos inicio al abordaje del modelo de acumulación a través de las políticas como primer paso para el desarrollo de la propuesta metodológica para su análisis. Si bien, en este capítulo, no se pretende agotar la presentación de las mismas (ya que por una necesidad expositiva algunas políticas específicas serán introducidas en el análisis de las fracciones de clase), abordaremos aquellas que marcan el origen del nuevo modelo de acumulación.
} 
En este camino, el modelo post-convertibilidad comenzó a configurarse a partir de seis políticas fundacionales ${ }^{243}$ :

1) la devaluación

2) la implementación de retenciones a las exportaciones

3) la pesificación asimétrica de deudas y depósitos

4) el "salvataje” al capital financiero

5) el default

6) el congelamiento y renegociación de tarifas.

Teniendo en cuenta que el default ya había sido establecido el 23 de diciembre de 2001, las restantes cinco políticas fundacionales fueron perfiladas a partir de la Ley de Emergencia Pública y Reforma del Régimen Cambiario $n^{\circ} 25.561^{244}$ promulgada el 6 de enero de 2002. Un análisis de esta ley parece necesario para aportar a la comprensión del actual modelo de acumulación debido al profundo alcance de las políticas en ella consignadas. La ley declara en su artículo $1^{\circ}$ "la emergencia pública en materia social, económica, administrativa, financiera y cambiaria” (Ley n²5561, art. 1) delegando amplios atributos al poder ejecutivo con los fines explícitos de:

1. Proceder al reordenamiento del sistema financiero, bancario y del mercado de cambios.

2. Reactivar el funcionamiento de la economía y mejorar el nivel de empleo y de distribución de ingresos, con acento en un programa de desarrollo de las economías regionales.

3. Crear condiciones para el crecimiento económico sustentable y compatible con la reestructuración de la deuda pública.

4. Reglar la reestructuración de las obligaciones, en curso de ejecución, afectadas por el nuevo régimen cambiario.

\footnotetext{
${ }^{243}$ Estas políticas aparecen presentadas, no por un orden cronológico sino por un orden lógico con el fin de estructurar la exposición de sus impactos.

${ }^{244}$ De ahora en adelante nos referiremos a esta ley como Ley de Emergencia Pública.
} 


\subsubsection{La devaluación. Origen y consecuencias del nuevo tipo de cambio competitivo.}

La devaluación, consignada en el artículo $2^{\circ}$ de la Ley de Emergencia Pública, generó un tipo de cambio internacionalmente competitivo que dio lugar a la dinamización de las exportaciones y, a través de su gravamen mediante retenciones y el aumento general de la recaudación tributaria, permitió la recomposición de las cuentas públicas. La recuperación económica trajo aparejado un aumento de la producción manufacturera, impulsada por la dinámica exportadora y un fenómeno incipiente de sustitución de importaciones producto de la protección que generó la modificación del tipo de cambio al aumentar el costo de los productos importados. Por otra parte, el efecto inflacionario ligado a la devaluación redujo sustancialmente el salario real, y junto al congelamiento relativo de las tarifas de servicios, los elevados precios de los commodities y el nuevo tipo de cambio, permitieron a los agentes productivo-exportadores generar elevados márgenes de ganancia y recuperar niveles de actividad económica. Los gobiernos postconvertibilidad han desarrollado una política activa para mantener el tipo de cambio competitivo y alentar esta vía de expansión económica que tiene un elemento destacado en el crecimiento de las exportaciones ${ }^{245}$.

Esta acción estatal iniciada por el gobierno de Duhalde contó como principal beneficiarios a los agentes articulados en el "frente devaluacionista", liderado por el capital productivo-exportador junto con sectores de las corporaciones empresariales y sindicales, y de los partidos tradicionales. Así, en 2002 la Presidencia procuró orientar las políticas instaurando un nuevo modelo acorde con el polo del capital de la “comunidad productiva”.

\footnotetext{
${ }^{245}$ Un camino de abordaje de las modificaciones en el tipo de cambio puede realizarse a través del Tipo de Cambio Real Multilateral (TCRM). Como señala el Banco Central de la República Argentina (BCRA, 2005) el TCRM es el precio relativo de los bienes y servicios de una economía con respecto a los de un grupo de países con los cuales se realizan transacciones comerciales. Si bien comúnmente se observa la variación nominal del tipo de cambio respecto del dólar y la variación real de tipo de cambio real respecto de la moneda e inflación estadounidense, estos indicadores explican sólo una pequeña parte de los cambios en la competitividad de la economía argentina, ya que el comercio con Estados Unidos representa un porcentaje relativamente bajo del comercio total de Argentina (el 17.6\% en 2004). Por este motivo el BCRA resalta que los cambios del valor del peso contra las monedas de los restantes socios comerciales y sus respectivas inflaciones deben ser tenidos en cuenta para evaluar la competitividad de la economía Argentina. De este modo, el TCRM "es una herramienta útil para observar cómo las fluctuaciones del valor del peso en relación con las monedas de nuestros socios comerciales y la evolución de los respectivos niveles de precios influyen sobre la estructura de la demanda interna, sobre la estructura de la producción, sobre el patrón de comercio internacional y sobre la competitividad de nuestra economía” (BCRA, 2005:2).
} 
Los últimos años del modelo de la convertibilidad habían evidenciado un periodo de apreciación cambiaria que abarcó desde agosto de 1996 hasta diciembre de 2001, explicada por la apreciación de la divisa norteamericana, y por lo tanto del peso (anclado al dólar mediante la ley de convertibilidad), y la devaluación del Real brasileño en enero de 1999, aunque compensados parcialmente por la deflación experimentada por la economía argentina (3\%). Como sostiene el BCRA, “esta combinación de apreciación real del peso y deflación tuvo efectos muy negativos en el nivel de actividad y de empleo en Argentina, sobre todo a partir del tercer trimestre de 1998” (BCRA, 2005:7).

Con la devaluación tuvo lugar una evolución radicalmente diferente del tipo de cambio real. Al derogar la convertibilidad de la moneda que conllevaba un tipo de cambio fijo, el Estado recuperó la capacidad de influir en el tipo de cambio a través de la política cambiaria y monetaria. La post-convertibilidad se inició a través de la Ley de Emergencia Pública con un régimen de flotación cambiaria. “El mantenimiento del tipo de cambio es clave, porque de eso depende el comportamiento de las exportaciones y, como consecuencia, la disponibilidad de divisas y los ingresos fiscales (por las retenciones a las exportaciones); por ende el superávit fiscal” (Cibils, 2006:5-6); al mismo tiempo se acumulan reservas para el desarrollo de políticas anticíclicas en contextos de dificultad de acceso al crédito internacional. 


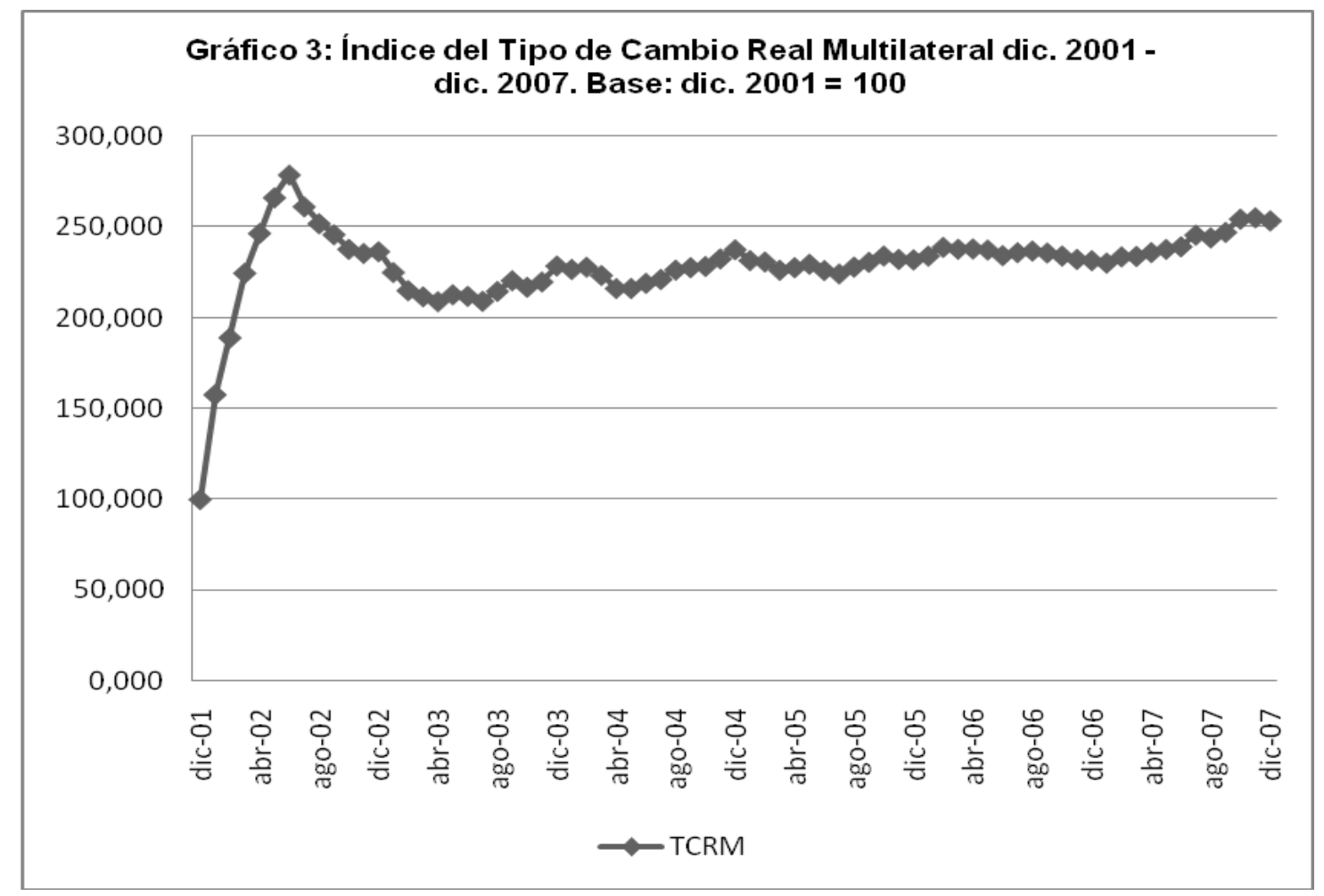

Elaboración propia en base a datos del BCRA

Según la evolución del Tipo de Cambio Real Multilateral (TCRM) es posible distinguir tres períodos:

A) Un periodo de depreciación que se extiende desde la devaluación en enero de 2002 hasta junio de 2002, mes que representa el punto más elevado para el conjunto de periodos entre 2002-2007. En dicho mes el índice trepa hasta acercarse a 279, representando un aumento del 179\% respecto de diciembre de 2001 (tomado como fecha base =100). Este desarrollo se explica por la entrada en el régimen de libre flotación de la moneda y las expectativas devaluacionistas sobre la misma. Como señala Rapetti, en un primer momento,

"se dispuso la creación de un mercado oficial para ciertas operaciones de comercio internacional y financieras ${ }^{246}$ a una paridad fija de 1,40 pesos por dólar, y un mercado de libre flotación para el resto de las operaciones. Poco después, la conducción del FMI hizo saber al gobierno que no iniciaría ninguna negociación hasta tanto no se unificara y liberalizara el mercado de cambios. El gobierno rápidamente cedió ante la presión multilateral. Una vez que se decidió dejar flotar al

\footnotetext{
246 En lo sustancial, abarcaba a las exportaciones de bienes y servicios (de liquidación obligatoria), importaciones de bienes de capital, insumos intermedios y materias primas consideradas prioritarias por el gobierno y el pago de un pequeño conjunto de servicios reales, financieros y transferencias
} 
dólar, el valor de la divisa subió abruptamente, alcanzando niveles cercanos a los 4 pesos, en un ambiente de difundidas expectativas de depreciación de la moneda local” (2005:6).

Para evitar el desarrollo de una corrida cambiaria, el Estado impulsó medidas con el objetivo de aminorar la fuga de depósitos, ya afectados por las restricciones al retiro de depósitos conocidas como “corralito” y la reprogramación forzada de los vencimientos de los depósitos y su pesificación (“corralón”247), culminando en un decreto de prohibición por 120 días de devolución de depósitos por amparos judiciales.

B) A partir de julio de 2002 se inicia un segundo periodo caracterizado por la apreciación cambiaria que se extiende hasta abril de 2003, mes que presenta el índice más bajo del periodo post-devaluación en su conjunto llegando a 209. El principal factor explicativo se encuentra en el comienzo de una decidida política de control y gestión del tipo de cambio a partir de la intervención estatal, procurando la estabilización de un nuevo tipo de cambio internacionalmente competitivo que al mismo tiempo desalentaron las especulaciones y corridas contra el peso. La acción estatal fue desplegada desde el Banco Central, que intervino en el mercado cambiario a través de la compra y venta de divisas. Esta estrategia de política cambiaria fue fortalecida a partir de la decisión de obligar a los exportadores a liquidar en el BCRA las exportaciones superiores a un millón de dólares (límite que fue variando) habilitando una mayor acumulación de reservas y amplificando la capacidad estatal de intervención en el mercado cambiario (Frenkel y Rapetti, 2007). Asimismo, Frenkel y Rapetti señalan que el fuerte incremento en las tasas de interés dotó de relevancia a los activos financieros locales que aumentaron su atractivo como sustituto del dólar ${ }^{248}$. En segundo lugar, debemos tomar en cuenta que el incremento de la inflación tuvo efectos erosivos sobre el tipo de cambio ${ }^{249}$. En este contexto, la tendencia a la apreciación cambiaria evidenciada en este periodo ayudó a contener la expectativa devaluacionista, reforzando la capacidad de la política cambiaria de ejercer una función de regulación del tipo de cambio frente a la amenaza de corridas especulativas con el peso.

\footnotetext{
${ }^{247}$ El “corralón” estableció un cronograma para la reprogramación de los vencimientos de los depósitos a través de la Resolución 06/2002 del Ministerio de Economía que reglamentaba la directiva dispuesta en el decreto 71/2002 del 9 de enero de 2002, el cual implicaba la pesificación de los depósitos a \$1,40 por dólar.

248 "En julio de 2002, la tasa de los depósitos a plazo fijo alcanzó 76\%, y la de las Lebac a 14 días alcanzó el 115\%" (Frenkel y Rapetti, 2007:8).

${ }^{249}$ Si bien fue en los primeros nueve meses de 2002 cuando se produjo el pico máximo del proceso inflacionario, la continuidad, luego más moderada, del aumento de precios influyó también en sentido de la apreciación cambiaria.
} 
C) Un tercer periodo se extiende desde mayo de 2003 hasta diciembre de 2007 (correspondiente a la presidencia de Kirchner), exhibiendo una mayor estabilidad cambiaria tendiente a la depreciación aunque con desarrollo irregular. Desde mayo de 2003 hasta mayo de 2004 se abre un sub-periodo de leve depreciación caracterizado por su evolución irregular, de modo de mostrar oscilaciones constantes de apreciación y depreciación cambiaria que pueden percibirse prácticamente de modo mensual. En el total del sub-periodo se parte de un número índice de 212 en mayo 2003 a 216 en mayo 2004. A partir de entonces, observamos un nuevo sub-periodo de depreciación pero de rasgos más constantes, que parte de junio de 2004 (219) a diciembre de 2007 (acercándose a 254), presentando un incremento del 38\% entre el último mes del subperiodo anterior y el último mes de la serie. Este sub-periodo evidencia el desarrollo de una política activa que procura mantener el tipo de cambio internacionalmente competitivo orientado a expandir la capacidad exportadora. Junto a la intervención en el mercado cambiario para regular la evolución del tipo de cambio, el Banco Central desplegó distintos instrumentos de esterilización (como la emisión de letras y notas, encajes, cancelación de redescuentos, entre otros) con el fin de cumplir con las metas monetarias fijadas en su planificación. Por otra parte, si bien la inflación (que no puede ser explicada, en nuestro período de estudio, por la emisión monetaria en tanto la misma tiende a acompañar el crecimiento económico) vuelve después de más de una década a convertirse en una constante de la economía argentina, ésta logra ser moderada respecto de los primeros meses del modelo post-convertibilidad, permitiendo también un mayor control sobre el desenvolvimiento del tipo de cambio real.

El escenario desarrollado a partir de la salida devaluacionista, nos confronta con una política de tipo de cambio que cobra prelación, jerarquía explicativa, sobre un amplio espectro de fenómenos relevantes en el modelo de acumulación. Esta política expresa una ruptura en materia de acción estatal en relación a los años 90 a la vez que mantiene regularidad a lo largo de todo el período 2002-2007, confirmando su importancia destacada para el análisis de la Argentina post-convertibilidad. En este sentido, podemos señalar dos impactos fundamentales:

- Mejora de las condiciones de comercio exterior y comienzo de una era superavitaria de la balanza comercial 
- Origen de un proceso inflacionario que generó una fuerte caída del salario real y del costo laboral

Con respecto al impacto de la política cambiaria sobre el comercio exterior, los distintos gobiernos post-convertibilidad han desarrollado una política activa para mantener el tipo de cambio competitivo y alentar esta vía de recuperación económica a partir del crecimiento de las exportaciones, favoreciendo como estrategia de acumulación la inserción exportadora en el mercado mundial. El crecimiento de las exportaciones ha alcanzado un 121\% durante el período 2002-2007, participando de un fenómeno de carácter regional ${ }^{250}$. Además, como se observa en el siguiente gráfico, la salida exportadora abierta en la post-convertibilidad reviste una mayor intensidad y duración en el crecimiento de las exportaciones que las fases expansivas anteriores.

\section{Gráfico 4:}

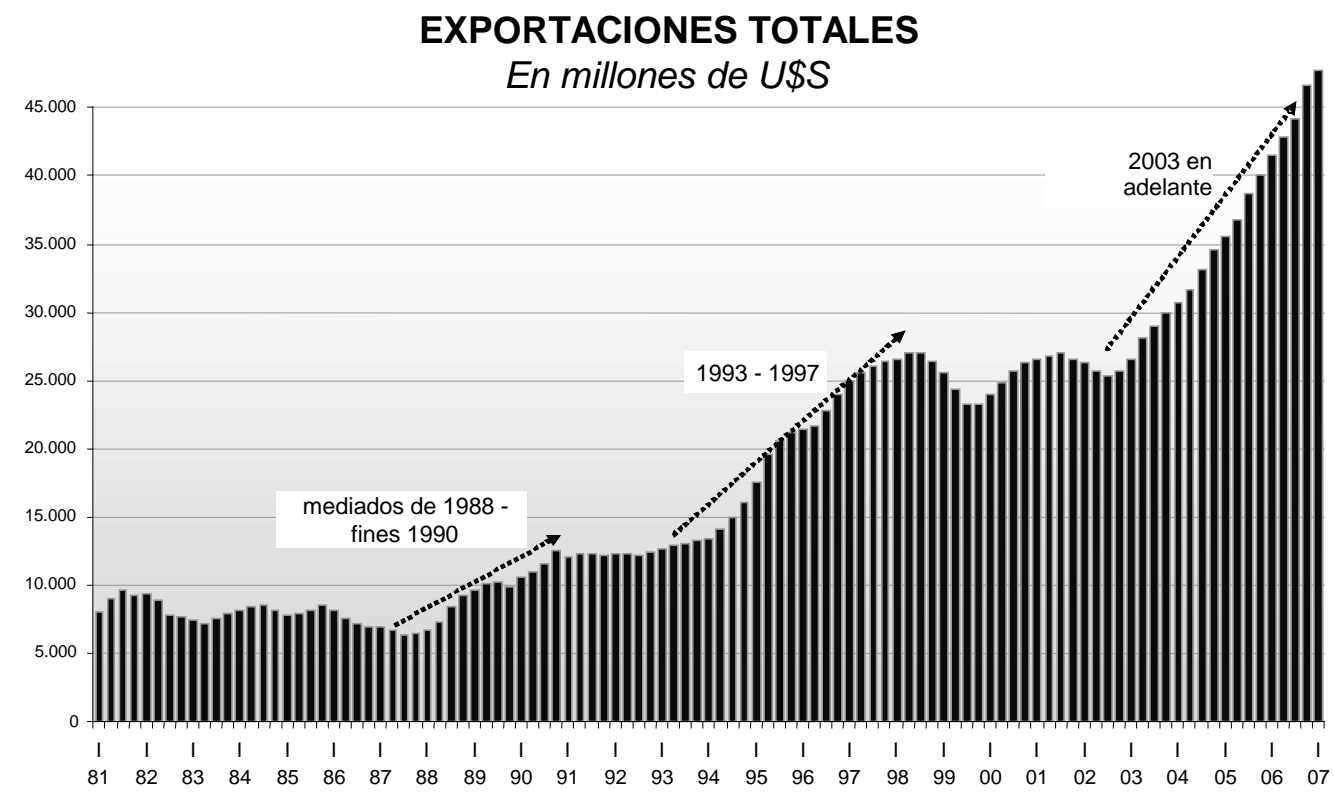

Fuente: Ministerio de Economía. “Argentina Indicadores económicos” Mayo 2007

El peso de las exportaciones como elemento dinamizador en la realización del capital puede observarse en el comportamiento de los distintos componentes de la

\footnotetext{
${ }^{250}$ Aunque Argentina está lejos de encabezar la dinámica exportadora regional, resaltamos este fenómeno como una clave fundamental para comprender cambios en el modelo de acumulación con particular énfasis en las relaciones de fuerzas entre fracciones de clase y en la consecución del doble superávit, fiscal y comercial, que actúan como pilares de estabilidad del modelo.
} 
demanda agregada en relación al PBI. Como muestra la Tabla 1, en la comparación de la gravitación de las exportaciones entre 1993-2001 versus 2002-2007, el único componente que aumenta su participación porcentual en el producto son las exportaciones, incrementándose en 4 puntos porcentuales, mientras que el que exhibe una mayor retracción es el consumo privado, con -3,3 puntos porcentuales ${ }^{251}$.

Tabla 1. Participación de la Inversión Bruta Interna Fija, el Consumo Privado, el Consumo Público y las Exportaciones en el PBI. Promedios 1993-2001 y 2002-2007.

\begin{tabular}{|lrrrr|}
\hline & & & & \\
\hline
\end{tabular}

Elaboración propia en base a datos INDEC

En este camino, las exportaciones comenzaron a cumplir una función clave en la configuración del modelo post-convertibilidad, ya que el impulso que cobraron permitió alcanzar un considerable superávit comercial que junto al superávit fiscal, favorecido vía retenciones a los productos exportados, constituyen los dos pilares de estabilidad del modelo ${ }^{252}$. Estos dos pilares se vinculan tanto a la entrada de divisas e incremento de las Reservas Internacionales que permitieron al Banco Central ejecutar la política de tipo de cambio competitivo, como a que la reinstauración de las retenciones permitieron fortalecer la recaudación de fondos públicos a partir de los cuales el Estado ha venido desplegando diversos mecanismos de transferencia de recursos con el fin de organizar y compensar los distintos intereses en pugna entre las fracciones de clase bajo el marco del nuevo modelo de acumulación.

\footnotetext{
${ }^{251}$ En un sentido similar se expresa un informe de la Fundación de Investigaciones Sociales y Políticas, sosteniendo que la importancia que posee la evolución de las exportaciones puede observarse en que, desde 2002 a 2007, "su participación en el PBI aumentó un 37.6\%, mientras que la participación del consumo privado y público cayó alrededor de un 7\%” (FISyP, 2009:4).

${ }^{252}$ Entre 2003 y 2007 la Argentina presentó un superávit comercial anual promedio del 7,6\% en relación al PBI, y en materia de superávit fiscal primario dicho valor es ubicó en el 3,3\%, marcando un desempeño contrastante con el período precedente.
} 
En este sentido, rescatamos la relevancia conceptual de la autonomía relativa del Estado frente a las fracciones de clase, que refiere a que el Estado capitalista, sin dejar de representar de manera predominante los intereses de la clase o fracción hegemónica asegura el interés político general del conjunto del bloque en el poder, y procura la construcción de hegemonía respecto del conjunto de la formación social, tanto de las fracciones dominantes como subalternas (Poulantzas, 1981). Este posicionamiento teórico será desplegado a través de la tesis de la constitución de un sistema de transferencias de recursos, que busca organizar el equilibrio inestable de compromisos entre las fracciones de clase en el marco de las nuevas relaciones de fuerzas, involucrando una ampliación creciente de los márgenes de autonomía relativa del Estado.

En cuanto a la inflación, la salida devaluacionista implicó un proceso de aumento de precios que es necesario desentrañar para comprender el modelo de acumulación post-convertibilidad. La inflación se convirtió en una variable económica que, si bien muestra variaciones de intensidad en el periodo de estudio, vuelve a constituir una presencia regular y cuya prelación, en términos de jerarquía explicativa, se observa en la relevancia que la misma presenta para el abordaje de un amplio conjunto de fenómenos económico-sociales, ligado a los cambios en los precios relativos y a las relaciones de fuerzas que esta disímil evolución de los precios evidencian, en tanto representan diferentes capacidades de apropiación del valor socialmente creado.

Para este análisis tomaremos la conceptualización sobre inflación desarrollada por Diamand en los años 70 para pensar dicho fenómeno en el marco del régimen de acumulación basado en la industrialización por sustitución de importaciones (ISI), reelaborando algunos de sus contenidos para interpelar el proceso inflacionario en la Argentina post 2001. Podemos pensar este proceso en clave de lo que Diamand denomina inflación cambiaria, un tipo de inflación que "nace a raíz del estrangulamiento en la provisión de divisas, de un desequilibrio consecuente entre la oferta y la demanda en el mercado cambiario y de la devaluación que esta induce." (Diamand, 1973:116, énfasis en el original). Esta inflación se origina en una devaluación obligada a la que caracteriza como una devaluación por déficits externos causados por la divergencia permanente entre exportaciones e importaciones, que surge de las propiedades de la estructura productiva y que es independiente de una inflación 
previa (Diamand, 1973). La devaluación obligada por estrangulamiento, evidenciado en el desempeño de la balanza de pagos, acuciada por la fuga de capitales sobre el fin del modelo de la convertibilidad, actúa a través de lo que Diamand denomina el efectoingreso: provoca una recesión, una caída de las actividades del país y un consecuente descenso de las importaciones. El fenómeno recesivo se produce a través del aumento de precios que ocasiona la devaluación. Este efecto-ingreso, se encuentra constatado en la abrupta caída del PBI en 10,9\% en el año 2002 originada en combinación con fuertes incrementos tanto en el IPC $^{253}$ (41\%) como en el IPIM $^{254}$ (118\%). Sin embargo, al producirse la devaluación no en un período de auge económico sino de recesión dio lugar hacia 2003 a una nueva fase expansiva a través de la recuperación de la tasa de ganancia empresaria relacionada con el nuevo tipo de cambio competitivo, la disminución del costo laboral, el aumento de la productividad y los elevados precios internacionales de los commodities, favorables a las exportaciones argentinas.

La inflación cambiaria se expresa a través de dos efectos característicos: el efecto-propagación y el efecto-arrastre. Según Diamand, el efecto-propagación se vincula a que en el proceso de devaluación obligada el tipo de cambio determina los costos en moneda nacional de los insumos importados, los combustibles y bienes de capital incidiendo directamente sobre los costos industriales, influencia que en mayor o menor medida se transmite a los precios y que acarrearía en cadena el alza de los servicios. Para pensar la post-convertibilidad, debemos señalar que este efectopropagación ya no se vincula a la dinámica sustitutiva característica del régimen de acumulación basado en la ISI sino a que la creciente extranjerización y concentración económica profundizada en los años 90 fue regida por actores empresariales transnacionales que tendieron a dejar de adquirir insumos en el mercado interno para comprarlos a empresas de sus propios consorcios en el exterior, en el marco de una apertura comercial pronunciada. De este modo, la devaluación conllevó, junto al aumento de precios de los insumos importados y su impacto en los costos de producción y los precios de bienes finales, un efecto periférico de sustitución de importaciones relacionado a la barrera de protección que generó el nuevo tipo de cambio, que fue gravitando cerca de los 3\$ por 1US\$. Por otra parte, la propagación de la inflación a los servicios fue moderada a partir de las acciones estatales desplegadas en el marco de la

\footnotetext{
253 Índice de Precios al Consumidor. Indicador utilizado para medir oficialmente la inflación.

254 Índice de Precios Internos al por Mayor.
} 
Ley de Emergencia Pública, donde se dictaminó el congelamiento de tarifas y se dispusieron recursos legales para que el Estado evaluara y negociara con las empresas de servicios privatizadas dichos aumentos. La limitación del efecto-propagación hacia los servicios gestó un cambio relevante en los precios relativos, favorable a la producción de bienes transables. Esto puede ser constatado en la comparación de los índices IPC e IPIM, en tanto el primero incluye una canasta de bienes y servicios, su incremento de 98,7\% entre diciembre de 2001 y de 2006, presenta una elevada brecha con el IPIM, que incluye precios al por mayor sólo de bienes transables, y ha aumentado, en el mismo periodo, un 194,2\%. Asimismo, en el año clave de la devaluación, 2002, al interior del aumento de 41\% del IPC “se registraron comportamientos disímiles entre los correspondientes a los bienes (67\%) y los servicios (14,8\%)” (Azpiazu y Schorr, 2010:228).

En segundo lugar, encontramos el efecto-arrastre de la devaluación. Este se vincula a que, como señala Diamand, las ventas para el mercado interno no se realizan a precios menores que los que se podrían obtener exportando la producción. Por esta causa, el tipo de cambio determina casi directamente el precio interno de los productos exportables. Así, al ocurrir la devaluación, sube el precio de los bienes exportables en el mercado local. Este efecto es fundamental para comprender el proceso inflacionario en el período post-convertibilidad por diversos motivos. En primer lugar, debemos observar cómo se compone la principal oferta exportadora, observando que el 52\% de las ventas al exterior está protagonizado por la suma de manufacturas de origen agropecuario y productos primarios, bienes de naturaleza dual (Tolón, 2005), que al ser al mismo tiempo productos de exportación y de consumo masivo de la población incrementa el nivel de inflación, afectando particularmente las condiciones de vida de las clases subalternas. Si bien la inflación expresa un aumento generalizado de precios, este incremento se da de forma dispar, expresando cambios en la correlación de fuerzas $^{255}$. El fuerte incremento de los índices de precios se dio en un contexto de alta desocupación y congelamiento relativo de los salarios. De este modo, como señalan Costa, Kicillof y Nahón, "la inflación registrada (del 45\%) bastó para reducir los

\footnotetext{
${ }^{255} \mathrm{Si}$ bien remarcamos el incremente de precio de los bienes transables en su conjunto, es posible visualizar variaciones en su interior que se vinculan tanto al cambio en las relaciones de fuerza como al efecto-arrastre de la salida devaluacionista en su ligazón a los precios internacionales. En este sentido, encontramos, por ejemplo, que "si bien los precios mayoristas industriales registraron una importante alza desde la salida de la convertibilidad (172,0\% entre 2001 y 2007), ésta se ubicó por debajo de la correspondiente al conjunto de los productos primarios (278,8\%), los agropecuarios (223,2\%), los ganaderos (220,6\%) y los de petróleo crudo y el gas natural (391,3\%)” (Azpiazu y Schorr, 2010:231).
} 
ingresos reales de los trabajadores en un tercio en el período 2001-2003” (2004:83). Este brote inflacionario licuó el salario real con claros impactos sobre el costo laboral real en la industria manufacturera que, según el Ministerio de Trabajo, fue en el primer trimestre de 2003 un 61,7\% inferior al de $1993^{256}$. Si bien debemos tener en cuenta que los salarios reales se han ido recuperando a partir de 2003 (principalmente los privados registrados en los sectores más dinámicos de la industria), estos aumentos lejos están de generar un estrangulamiento de la ganancia empresaria, en contextos de incremento de la productividad. Sin embargo, a medida que acercándose a 2007 los salarios reales aumentaron y se acercaron a los promedios de 2001, entendemos que el efecto-arrastre de la inflación cambiaria, decisivo en la evolución de precios al principio del periodo, iría siendo luego superado en énfasis por la puja distributiva, evidenciando la voluntad del empresariado de mantener sus altos márgenes de ganancia en tanto procuran que sus precios evolucionen por encima del salario nominal.

Finalmente, debemos remarcar que el efecto-arrastre posee otro alcance teórico relevante ya que nos convoca también a pensar el papel de las retenciones, otra política fundacional de la post-convertibilidad de destacadas implicancias político-económicas.

\subsubsection{La implementación de retenciones a las exportaciones}

La implementación de retenciones, por un lado, procura limitar el impacto inflacionario del efecto-arrastre, morigerando el precio neto que consiguen los exportadores, intentando "desacoplar” precios externos e internos; y por otro lado, buscan gravar las rentas y ganancias extraordinarias, en tanto estos sectores no sólo se ven beneficiados por la renta diferencial (Marx, 2006) producto de la fertilidad pampeana y la abundancia de recursos naturales sino también por los altísimos precios internacionales que los commodities exhibieron durante todo el periodo.

Otro factor clave que debe ser atendido para comprender el alcance de las retenciones es el tipo de cambio. Si bien las retenciones habían sido eliminadas o reducidas significativamente en los años 90, la paridad cambiaria establecida en durante la convertibilidad fijó un tipo de cambio real apreciado desfavorable a las exportaciones locales que implicaban transferencias de recursos que afectaban a los agentes

\footnotetext{
${ }^{256}$ Datos tomados de Ministerio de Trabajo, empleo y seguridad social (2004).
} 
productivo-exportadores. La devaluación que instauró un tipo de cambio internacionalmente competitivo funcionó como un multiplicador de las rentas ${ }^{257} \mathrm{y}$ ganancias obtenidas por dichos agentes en moneda local, tanto por la relación peso/divisa como por el abaratamiento de los costos laborales y de insumos en el mercado interno. Asimismo, como señalan Rodríguez y Arceo (2006), las nuevas condiciones generadas por la devaluación promovieron un significativo incremento del precio de la tierra implicando una elevación de las ganancias patrimoniales. En este marco la reaparición de las retenciones no representaron un mayor perjuicio para los agentes gravados por las mismas, sino una limitación de la percepción de rentas y ganancias extraordinarias habilitadas por el nuevo tipo de cambio y el favorable contexto internacional; limitación que implica a su vez una participación del Estado en dichos recursos fortaleciendo las cuentas fiscales. En este sentido, debe notarse que en el caso de las retenciones agrícolas, las mismas procuran limitar también el incremento del precio de la tierra que tiene impacto directo sobre el conjunto de la producción de alimentos.

Las retenciones han afectado distintamente a los productos exportados. En el caso del petróleo, cuyo precio aumentó de US\$32 en 2002 a US\$90 en 2007 por barril, las retenciones pasaron del 20\% en 2002, al 25\% en 2004, llegando a 45\% en 2007 , estableciendo a final de ese año un ingreso tope para las petroleras de US\$45 por barril. El caso de las mineras, las empresas instaladas en Argentina previo al 2002 gozaron durante todo nuestro periodo de estudio de la exención de las retenciones amparadas en una ley menemista, que recién se dejó sin efecto en diciembre de 2007. El resto de las mineras pagaban tan sólo entre el 5\% y el 10\% según el mineral explotado, al tiempo que usufructuaban múltiples beneficios tributarios y devoluciones impositivas, por lo que podría afirmarse que los minerales en Argentina se extraen de forma casi "gratuita”. Este marco se agrava si observamos que los precios de los productos minerales han aumentado un 482,10\% (IPIM, dic. 2001- abril 2007) generando ganancias extraordinarias para las empresas del sector. Finalmente, las retenciones agropecuarias afectaron de modo diferente según el producto: para el caso de la soja las retenciones, entre 2002 y 2007 fueron del 27,5\%, mientras el precio del grano rondó los US\$ 160 por tonelada promedio. Estas retenciones aumentaron en noviembre de 2007 al 35\%

${ }^{257}$ Como señalan Rodríguez y Arceo, "La devaluación de la moneda en el año 2002 provocó una modificación sustancial de la magnitud de la renta agraria apropiada por los productores, que se quintuplicó con respecto a los valores registrados en los años noventa" (2006:6, el subrayado es nuestro). 
cuando su valor superó los US\$240. A fines de 2007, las retenciones para trigo, girasol, y maíz fueron del 28\%, 32\% y 25\% respectivamente. En todos los casos, las retenciones fueron menores para los productos agropecuarios industrializados, impulsando el desarrollo de las cadenas productivas a éstos ligados y promoviendo así un mayor valor agregado. La carne y los lácteos partieron con una retención del 5\% aumentando hasta alcanzar entre el $10 \%$ y el $15 \%$ en 2005 . A pesar de las retenciones aplicadas sobre los productos agropecuarios, el rubro de alimentos y bebidas del IPC presentó un aumento del 135,2\% entre 2001 y 2007 con un fuerte impacto negativo sobre el nivel de vida de las clases subalternas.

Nuevamente debemos resaltar que la aplicación de retenciones a las exportaciones constituyeron una medida fundamental en la articulación de los dos pilares de estabilidad del modelo, ya que permiten atraer recursos y divisas provenientes del superávit comercial para promover la consecución del superávit fiscal, el cual se alimenta también del conjunto del proceso de crecimiento económico iniciado a partir de 2003. Como veremos a lo largo del trabajo, las retenciones representan una arista del sistema de transferencias de recursos clave en la gestión estatal del excedente económico ya que, por un lado capta fondos de un sector de la fracción predominante en la post-convertibilidad, la fracción productivo-exportadora, para redirigirlos de forma compensatoria hacia otras fracciones, por ejemplo, al capital financiero a través del pago de deuda, a las empresas de servicios privatizadas a partir de subsidios y a las clases subalternas a través de políticas de ingresos. Al mismo tiempo actúa en beneficio de las clases subalternas, en tanto busca moderar la inflación que corroe el salario real de los trabajadores. También debe notarse que los alimentos poseen una fuerte gravitación en el consumo de los trabajadores, lo cual tiende a incrementar el costo de reproducción de la mercancía fuerza de trabajo, afectando la estructura de costos de los agentes económicos ligados a la producción industrial.

Para sintetizar podemos concluir que las retenciones actúan en los siguientes sentidos fundamentales:

- Limita el efecto-arrastre de la inflación al desacoplar precios internos y externos. 
- La aplicación de menores tributos a los productos elaborados con respecto a los primarios promueve la generación de mayor valor agregado local previo a la exportación.

- Grava ganancias y rentas extraordinarias de agentes favorecidos por el nuevo tipo de cambio y los altos precios internacionales de los commodities.

- Limita el incremento del precio de la tierra y su impacto sobre la producción de alimentos.

- Fortalece las cuentas fiscales, permitiendo transferir luego recursos hacia otros agentes y fracciones ubicados en distintos sectores de la economía.

\subsubsection{La pesificación asimétrica de deudas y depósitos.}

La pesificación asimétrica fue el mecanismo implementado durante el gobierno de Duhalde para resolver la problemática de las deudas y depósitos ligados al sistema financiero local, en el contexto post-devaluación, que culminaría en un masivo proceso de licuación de las deudas del capital. El régimen cambiario del modelo de los 90 al tiempo que fijaba el tipo de cambio, fue conllevando una creciente dolarización de la economía, expresada en que el sistema financiero tenía los depósitos y créditos dolarizados al 70 y $80 \%$ respectivamente. En el proceso de agotamiento del modelo de la convertibilidad, el aumento de la fuga de capitales provocó un fuerte drenaje de recursos que amenazaba con desestabilizar el sistema financiero local. Frente a este escenario el gobierno de la Alianza (1999-2001) dispuso diversas medidas entre la que se destacó la restricción de retiro de recursos del sistema bancario conocido como “corralito”. El gobierno de Duhalde debió enfrentar la resolución de dicha medida, que se había convertido en uno de los principales focos de protesta desde las capas medias, cuya desactivación aparecía como un objetivo destacado en su estrategia de segmentación de las demandas. A pesar de declarar públicamente que su gobierno garantizaría la devolución de los depósitos en su moneda original, la ausencia de respaldo en divisas de los mismos fue gestando un panorama cruzado por fuertes disputas en torno a la resolución de dicha controversia. En este contexto emergió la política de pesificación asimétrica, como parte constitutiva del origen mismo del 
modelo de acumulación post-convertibilidad, incidiendo en el cambio de relaciones fuerzas entre fracciones de clase.

La pesificación asimétrica implicó que los bancos debieran devolver los depósitos en dólares a \$1,40 por cada US\$1, mientras que, como se determinó a partir de la Ley de Emergencia Pública en su artículo $6^{\circ}$, los deudores con la banca local vieron pesificadas sus deudas en dólares a \$1 por US\$1.

En dicho artículo, la Ley habilitó al Poder Ejecutivo Nacional a disponer medidas tendientes a disminuir el impacto producido por la modificación del régimen cambiario a los agentes endeudados en divisas extranjeras con el sistema financiero local. Pero las medidas desplegadas para ese fin fueron variando sustancialmente según el espectro de agentes considerados e incluidos para ser compensados y el modo en que esta compensación se realizaría. La política de pesificación asimétrica contuvo dos momentos principales que evidencian el avance de los agentes económicos concentrados en influir sobre las acciones estatales desplegadas. En un primer momento, la Ley fijó el siguiente espectro de compensación:

\footnotetext{
“El Poder Ejecutivo nacional reestructurará las deudas con el sector financiero, estableciendo la relación de cambio UN PESO (\$1) = UN DOLAR (US\$ 1), sólo en deudas con el sistema financiero cuyo importe en origen no fuese superior a DOLARES CIEN MIL (US\$ 100.000) con relación

a) Créditos hipotecarios destinados a la adquisición de vivienda; b) A la construcción, refacción y/o ampliación de vivienda; c) Créditos personales; d) Créditos prendarios para la adquisición de automotores; y e) A los de créditos de personas físicas o jurídicas que cumplan con los requisitos de micro, pequeña y mediana empresa (MIPyME). $\mathbf{O}$ hasta a esa suma cuando fuere mayor en los casos del inciso a) si el crédito fue aplicado a la adquisición de la vivienda única y familiar y en el caso del inciso e)” (Ley $n^{0} 25.561$, art.6, énfasis en el original).
}

Así, la política de pesificación, que implicaba un alivio en las cargas de las obligaciones en moneda extranjera respecto de la banca local, estuvo orientada inicialmente a las capas medias y a los agentes económicos ligados a la fracción de pequeñas y medianas empresas.

Sin embargo, el fuerte lobby empresarial de los agentes ligados al capital concentrado logró forzar al gobierno a derogar el techo impuesto inicialmente para la pesificación de deudas. Eliminado el límite de los US\$100.000, la política de pesificación asimétrica se convirtió en un mecanismo de licuación masiva de las deudas del gran capital productivo, quien ya había incluido esta demanda desde la conformación del "frente devaluacionista", y de las privatizadas con la banca local. Se 
abrió así un segundo momento en el desarrollo de esta acción estatal gestado en dos pasos. Luego de pasar por una primera formulación de la pesificación asimétrica orientada a capas medias y agentes subordinados del capital, el primer paso hacia la licuación masiva de deuda se constituyó a partir de una resolución que dio habilitación para que las deudas superiores a US\$ 100.000, sin techo de monto, fueran fijadas a 1,40\$ por 1US\$. Sin embargo, la continuidad de las presiones gestaron un nuevo paso, que cobró forma a través del decreto 214/02 en febrero de 2002, en el cual se consolidó de forma definitiva el segundo momento de la pesificación asimétrica.

El decreto 214/02 estableció en su primer artículo la pesificación de todas las obligaciones en monedas extranjeras. En su artículo 2 ratificó la conversión y devolución de todos los depósitos en dólares u otras monedas extranjeras existentes en el sistema financiero, en pesos a razón de \$1,40 por cada dólar (o su equivalente en otra moneda extranjera) aclarando que la entidad financiera cumpliría con su obligación devolviendo pesos a la relación indicada. Una opción alternativa, fijada en el artículo 9, era la posibilidad de recibir bonos en dólares hasta $30.000 \mathrm{US} \$^{258}$.

Instituido de este modo el criterio definitivo de devolución de los depósitos, el segundo momento de la pesificación asimétrica como licuación masiva de deudas del gran capital quedó establecido en su tercer artículo:

\footnotetext{
“Art. $3^{\circ}$ - Todas las deudas en DOLARES ESTADOUNIDENSES u otras monedas extranjeras con el sistema financiero, cualquiera fuere su monto o naturaleza, serán convertidas a PESOS a razón de UN PESO por cada DOLAR ESTADOUNIDENSE o su equivalente en otra moneda extranjera. El deudor cumplirá con su obligación devolviendo PESOS a la relación indicada” (Decreto 214/02 art.3) ${ }^{259}$.
}

De este modo, una política que inicialmente orientó una compensación a agentes subordinados en las relaciones de fuerzas se convirtió en un mecanismo de transferencia de recursos hacia el gran capital. Fueron privilegiadas por dicha acción estatal, tanto la fracción productivo-exportadora, que había capitaneado el frente por la salida devaluacionista y cuyos agentes locales más concentrados mantenían ingentes masas de

\footnotetext{
258 “Art. 9 - Dispónese la emisión de un Bono en DOLARES ESTADOUNIDENSES, con cargo a los fondos del Tesoro Nacional, por el que podrán optar los depositantes en el sistema financiero, a los que se refiere el Artículo $2^{\circ}$ del presente, en sustitución de la devolución de sus depósitos. Dicha sustitución alcanzará hasta la suma tope de DOLARES ESTADOUNIDENSES TREINTA MIL (U\$S 30.000) por titular y por entidad financiera. Las entidades financieras obligadas con los depositantes que opten por la entrega de tales Bonos, deberán transferir al Estado Nacional activos suficientes para atender su pago" Decreto 214/02.

${ }^{259}$ También se estableció la indexación de depósitos y deudas al coeficiente CER, vinculado al índice de inflación.
} 
divisas fugadas en el exterior (valorizadas en términos locales por el nuevo régimen cambiario), como numerosas empresas privatizadas de la fracción de servicios públicos. Eran agentes que por su peso en la estructura tenían, en términos generales, capacidad de haber afrontado dichas obligaciones. En este punto, la pesificación asimétrica se volvió una política que reforzó la concentración y fortaleció a la fracción productivoexportadora dominante en el escenario post-convertibilidad, mientras que compensó a las empresas de servicios privatizadas, al punto que un núcleo de éstas licuaron deudas por montos equivalentes, en general, a las ganancias obtenidas en el año $2000^{260}$. Al mismo tiempo, entre fines de 2002 y principio de 2003, el gobierno de Duhalde resolvió la apertura del “corralón”, avanzando a resolver la demanda vinculada a los depósitos de los sectores medios ${ }^{261}$. Así, en el trascurso de la política de pesificación asimétrica, terminó de realizar la estrategia de segmentación de demandas atendiendo a la "clase media”, que ocupaba un lugar importante en su discurso, y logró satisfacer los reclamos del capital productivo-exportador, transfiriéndole cuantiosos recursos.

De este modo, la pesificación asimétrica de deuda implicaba:

- una licuación de deuda privada con la banca local, evidenciando el poder de presión de los grandes agentes económicos sobre el Estado a través de la modificación del abanico de agentes abarcados por esa política.

- ponía en debate quién asumiría el costo de dichas transferencias de recursos, si recaería sobre el capital financiero o si era socializada sobre las clases subalternas a través de su estatización.

\subsubsection{El "salvataje" al capital financiero}

La pesificación asimétrica en su formulación final amenazaba con desestabilizar al sistema financiero local $\mathrm{y}$, en este sentido, se gestaban presiones desde los distintos agentes del sector para evitar las cargas que suponía la política de pesificación

\footnotetext{
${ }^{260}$ Sobre el impacto de la pesificación asimétrica en las privatizadas ver Azpiazu y Schorr (2003).

${ }^{261}$ En diciembre de 2002, Duhalde comenzó a destrabar el “corralón” llegando en marzo de 2003 a la apertura del mismo para los depósitos originales de hasta u\$s30.000 (o \$42.000), canjeados por su equivalente a $\$ 1,40$ + CER y la diferencia cambiaria con el dólar libre sería cubierta por el Estado con la opción de un bono voluntario, el Boden 2013, para los depositantes que acepten este mecanismo. Por otra parte, los depósitos entre $\$ 42.000$ y $\$ 100.000$ se convertirán en plazos fijos de 90 días y los superiores a \$100.000, a 120 días, al cabo de los cuales estarían totalmente disponibles (Infobae 30/3/2003).
} 
asimétrica de deudas y depósitos. Mientras que la fracción financiera del capital se había sumado, en términos generales, a la propuesta dolarizadora de salida de la convertibilidad con el fin de mantener sus activos en divisas y ganar competitividad internacional, el decreto 214/02 fijó en su artículo 10 que las entidades financieras debían depositar en el Banco Central todos los billetes en dólares u otras monedas extranjeras que tuvieran como disponibilidades, las que serían convertidas a pesos con la equivalencia establecida por el artículo 2 de dicho decreto. También establecía que todos los saldos existentes en dólares u otra divisa en el BCRA a favor de cada entidad financiera serían convertidos en idéntica relación. Esto parecía consolidar el papel de subordinación de la fracción financiera en el marco del naciente modelo de acumulación.

Sin embargo, el mismo decreto ratificó la perspectiva ya enunciada en la Ley de Emergencia Pública:

“Art. $7^{\circ}$ — Dispónese la emisión de un Bono con cargo a los fondos del Tesoro Nacional para solventar el desequilibrio en el sistema financiero, resultante de la diferencia de cambio establecida en el artículo $3^{\circ}$ del presente Decreto” (Decreto 214/02, art.7).

De este modo, el Estado no sólo se hizo cargo de los costos de compensación a los agentes provenientes de capas medias ligadas a las clases subalternas y de la fracción de pequeñas y medianas empresas, sino que asumió la compensación a la fracción financiera del capital proveniente de la licuación masiva de de deuda de los agentes más concentrados de la clase dominante. En este punto podemos observar cómo la política de pesificación asimétrica se tornó en un mecanismo de licuación y estatización de deuda privada. Este mecanismo cobró estatus de ley en diciembre de 2003, mediante la Ley ${ }^{0}$ 25.820, que en su segundo artículo dispuso la eliminación del segundo párrafo del artículo $6^{\circ}$ de la Ley n ${ }^{\circ} 25.561$ donde estaban consignados tanto el techo máximo de la pesificación asimétrica como los sujetos que abarcaba en primera instancia.

En este contexto el gobierno dispone el plan de "salvataje” al capital financiero, que ya aparecía previsto en la Ley de Emergencia Pública, que en el mismo artículo $6^{\circ}$ definía: "El Poder Ejecutivo nacional podrá establecer medidas compensatorias que eviten desequilibrios en las entidades financieras comprendidas y emergentes del impacto producido por las medidas autorizadas en el párrafo precedente, las que podrán incluir la emisión de títulos del Gobierno nacional en moneda extranjera garantizados” 
(Ley $\mathrm{n}^{\circ}$ 25561, art. 6). En dicha ley también figuraba la indicación de establecer retenciones a los hidrocarburos con el fin de financiar las compensaciones. Sin embargo, este mecanismo sería rezagado por la presión ejercida por las petroleras y el Estado fue asumiendo el costo de las medidas devaluacionistas y pesificadoras, políticas cardinales en la fundación del modelo de acumulación post-convertibilidad. De este modo, se buscó generar una compensación de una fracción afectada por el modo de salida de la convertibilidad, transfiriendo recursos a través de endeudamiento público, en el marco de las nuevas relaciones de fuerzas entre las fracciones de clase.

Como señala Cobe, en la Ley de Emergencia Pública "quedó establecido el criterio de estatizar las pérdidas del sector financiero derivadas de las medidas para el tratamiento de las obligaciones pactadas en dólares. En definitiva, ello implicaba que la sociedad en su conjunto debería asumir una porción significativa de las pérdidas de ese sector proveniente de la caída del régimen de convertibilidad del cual fue uno de los principales beneficiarios” (2009:59). También es necesario aclarar que en una formación social que posee un sistema tributario fuertemente regresivo como es el de Argentina, el peso de la financiación de estas políticas terminó recayendo con mayor énfasis sobre las clases subalternas.

En este camino, el "salvataje” al capital financiero cobró forma a partir de operaciones de diverso tipo destinadas a compensar a la fracción financiera del capital por las implicancias de la salida devaluacionista y la pesificación asimétrica, y que fueron cubiertas con la emisión de nueva deuda pública por un monto total de US\$ 14.386 millones, constituyendo el 51\% de la deuda pública post-default. Este monto de endeudamiento se explicó por la emisión US\$ 5.900 millones de compensaciones por la pesificación asimétrica, unos US\$ 2.400 millones en "bonos cobertura" con arreglo al impacto generado por la devaluación, US\$ 6.086 millones en bonos para canjear por los depósitos reprogramados ${ }^{262}$. Por otra parte, el Estado nacional apuntaló el sistema financiero absorbiendo las deudas que los Estados provinciales mantenían con los bancos involucrando recursos por US\$ 9.679 millones. De este modo, el Estado nacional movilizó unos US\$24.065 millones en diversas operaciones destinadas a recomponer el sistema financiero, ya sea como transferencia directa hacia el capital

${ }^{262}$ Ver Damill, Frenkel y Rapetti (2005). 
financiero, asumiendo o no los bancos obligaciones con el Estado, o de forma indirecta, asumiendo los pasivos de los Estados provinciales con los bancos ${ }^{263}$.

Podemos señalar que la articulación de las políticas de pesificación asimétrica y “salvataje” al capital financiero involucraron transferencias de recursos en las siguientes direcciones: del capital financiero al capital productivo y las privatizadas vía pesificación asimétrica, y del conjunto de la sociedad hacia el capital financiero vía compensaciones estatales a través de mayor endeudamiento público. Como señala Cobe,

\begin{abstract}
"estas medidas produjeron una significativa redistribución regresiva del ingreso, al habilitar ingentes transferencias a favor del capital concentrado interno. En particular, beneficiaron a los grandes grupos económicos locales y conglomerados extranjeros con una inserción en actividades vinculadas a la exportación y sustanciales activos en el extranjero, que lograron licuar sus deudas en dólares contra el sistema financiero local. A la vez, favorecieron a las privatizadas con este tipo de deudas y coadyuvaron a la banca en términos patrimoniales al asumir el Estado una porción de los pasivos de las entidades” (Cobe, 2009:95).
\end{abstract}

Estos mecanismos de transferencia, desplegados por el gobierno de Duhalde (a quien definimos como un intelectual orgánico de los grupos dominantes aglomerados en la salida devaluacionista), representan acciones estatales que, por un lado convalidan el predominio de la fracción productivo-exportadora del capital a través de la licuación de sus pasivos con el sistema financiero local, al mismo tiempo que instituyen medidas compensatorias hacia el núcleo de empresas de servicios privatizadas y la fracción financiera del capital que, desfavorecidas por la salida devaluacionista, son objetos de políticas que buscan organizar el equilibrio inestable de compromisos promoviendo un nuevo momento de convergencia al interior de la clase dominante que aporte a suturar la crisis de hegemonía evidenciada sobre el fin de la convertibilidad.

\footnotetext{
263 “Otra medida "asimétrica” afectó también el patrimonio de los bancos. El gobierno fijó diferentes mecanismos de ajuste por inflación de los depósitos y créditos pesificados. Se resolvió que los depósitos se ajustaran por un índice que sigue la evolución de los precios al consumidor (CER) y que los préstamos bancarios lo hicieran de acuerdo a otro que refleja el comportamiento de los salarios medios (CVS). Como la inflación minorista fue superior al aumento nominal de los salarios, los pasivos pesificados de los bancos crecieron a un mayor ritmo que los activos. El Congreso sancionó en octubre de 2003 una ley en la que se facultaba al Poder Ejecutivo a compensar a las entidades financieras por la "indexación asimétrica” con la emisión de títulos (BODEN 2013) por hasta \$ 2.800 millones. Hasta el momento el gobierno no ha concretado la emisión” (Damill, Frenkel y Rapetti, 2005:34). Según Cobe (2009) esta compensación finalmente sólo fue de 90 millones de pesos.
} 


\subsubsection{El default: sus características, el canje y la relación con el FMI.}

El 23 de diciembre de 2001 el presidente Rodríguez Saá declaró la suspensión de pagos de la deuda pública, excluyendo los referidos a organismos financieros internacionales y otros préstamos garantizados ${ }^{264}$. El default fue mantenido por la posterior administración de Duhalde y aparecía como uno de los principales desafíos que heredaba el gobierno de Kirchner. El análisis de la deuda pública, implica indagar acciones estatales que tuvieron un alto impacto en la configuración del modelo en general y en las relaciones de clases en particular, en tanto una parte considerable de los bonos en default estaban en manos de los conglomerados financieros. Por ello, es un aspecto relevante para pensar la situación del capital financiero, que se había visto perjudicado con la salida devaluacionista y pesificadora y que había comenzado a ser compensado en el gobierno de Duhalde a través de la emisión de nueva deuda implicada en la política de “salvataje”.

Debemos recordar que en el tercer objetivo especificado dentro del artículo $1^{\circ}$ de la Ley de Emergencia Pública se proponía “Crear condiciones para el crecimiento económico sustentable y compatible con la reestructuración de la deuda pública”. En este camino, la salida del default ${ }^{265}$ comenzó a debatirse a partir de la propuesta oficial realizada por el ministro de economía Roberto Lavagna en la asamblea anual del FMI (2003) en Dubai, Emiratos Árabes Unidos, proponiendo una quita del 75\% sobre el valor nominal de los bonos, dando inicio a las negociaciones que concluyeron con el canje de deuda de $2005^{266}$.

Del total de los US\$ 81.800 millones que entraron en default en 2001 el canje fue aceptado en un 76,15\%, de modo que US\$ 62.300 millones fueron cambiados por los nuevos títulos elegibles. Finalizado el canje, estos US\$ 62.300 millones se redujeron a US\$ 35.300 millones, representando una quita del 43,4\%. Un factor a tener en cuenta es que si bien la magnitud de la deuda disminuyó, su monto total se mantuvo en niveles

\footnotetext{
${ }^{264}$ Es por esto que del total de los US\$ 178.000 millones a los que la deuda había alcanzado al momento de comenzar el canje en 2003, unos US\$ 79.000 nunca se dejaron de pagar.

${ }^{265} \mathrm{El}$ análisis detallado del enfoque expresado sobre deuda pública puede verse en Varesi (2008b).

${ }^{266}$ Como veremos en el capítulo siguiente cuando analicemos la fracción financiera del capital, los distintos tipos de bonos propuestos para la salida del default tuvieron distintas implicancias en los agentes económicos, así como también lo tuvo el criterio de no distinguir entre grande y pequeños tenedores de bonos.
} 
similares a los que poseía al momento del default, o mayor aún si se toma en cuenta la porción no ingresada a canje:

\section{Gráfico 5: Evolución de la Deuda Pública argentina 2001-2005*}

en miles de millones de dólares

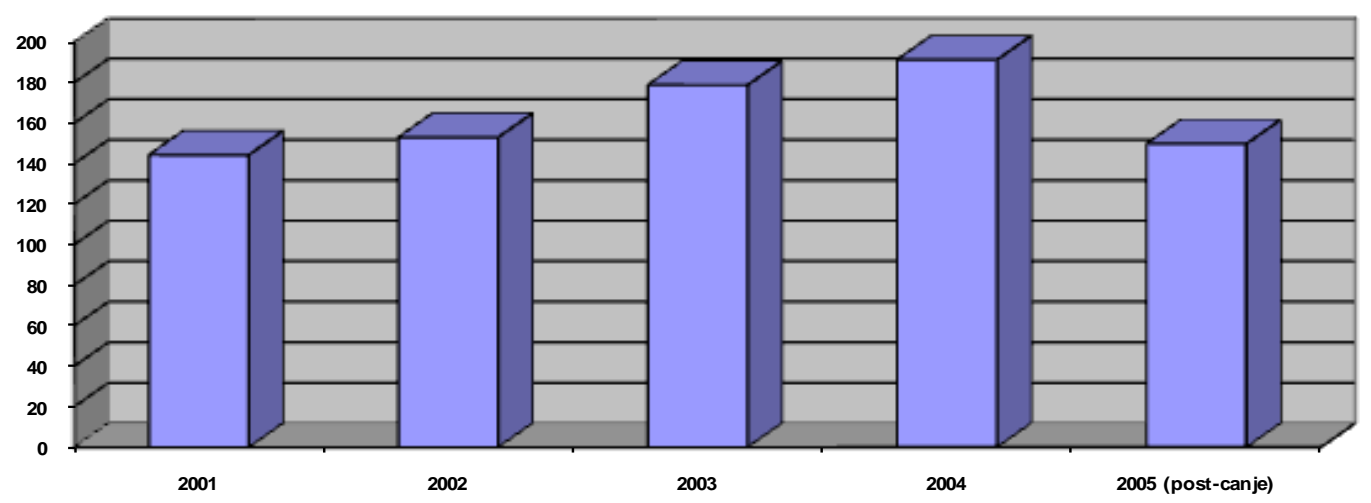

*2005: incluye deuda no ingresada al canje

Elaboración propia en base a datos Lucita, 2005.

El canje concluyó con la incorporación de dos componentes dinámicos que merecen ser destacados. Uno de los elementos más novedosos del canje y del endeudamiento posterior es el cambio de moneda: finalizado el canje el $41 \%$ de los bonos de deuda pública estaban en Pesos + CER. Esto significa un mayor peso de la deuda pesificada e indexada a la inflación, que año a año se acercó a los dos dígitos: se calcula que por cada punto de inflación los pagos por deuda aumentan en aproximadamente $\$ 1.800$ millones $^{267268}$. La indexación de deuda a la inflación debe ser entendida como una medida que garantiza al capital financiero no verse mayormente perjudicado en la correlación de fuerzas respecto del capital productivo-exportador, principal beneficiario del ciclo inflacionario y la salida devaluacionista y pesificadora. Este mecanismo compensatorio puede ser vislumbrado también en el segundo

\footnotetext{
${ }^{267}$ Consideramos que éste es el principal motivo por el cual el gobierno de Kirchner (y luego el de Cristina Fernández) mantuvo desde 2007 intervenido al INDEC con el fin de manipular a la baja el índice de inflación buscando, entre otras cuestiones, limitar el impacto de la deuda sobre las cuentas públicas. Esto tiene consecuencias también en la construcción de los indicadores sociales.

${ }^{268}$ Esto ha implicado aumentos en los pagos de aproximadamente US\$ 5.000 millones anuales en 2006 y 2007.
} 
componente dinámico que emergió del canje, las Unidades Ligadas al $\mathrm{PBI}^{269}$, cupones que, en las condiciones de crecimiento económico de los años posteriores al canje fueron arrojando rentas que se multiplicaron año tras año. Así, el Estado debió pagar en materia de las Unidades Ligadas al PBI \$1.242 millones adicionales de deuda en 2006, monto que se duplicó en 2007, alcanzando los \$2.450 millones.

Las opciones adoptadas para la resolución del default construyeron un nuevo escenario. Los vencimientos de los tres títulos elegibles permitieron "patear" hacia adelante la amortización del capital de la deuda ingresada en canje entre unos 30 y 40 años. También el peso de la deuda sobre PBI disminuyó significativamente, pasando de representar el 127\% del PBI en 2004 al 74\% en 2005, cayendo al 56\% en 2007, valor que aún se encontraba por encima del $54 \%$ en 2001, previo al default ${ }^{270}$. También la relación deuda pública externa sobre reservas internacionales mejoró de forma sustancial: del pico más alto de 2002 en 823\% se redujo al 135\% en 2007. Otra mejoría considerable se observa en la relación deuda pública externa/exportaciones, de $281 \%$ en 2004, cayó con el canje a 131\% en 2005 terminando en 94\% en 2007.

Aún con la importante quita del canje y la mejora de las variables previamente mencionadas, quedó un pesado calendario de pagos que conllevaba vencimientos anuales de capital e intereses que variaban entre los US\$ 10 y 20 mil millones para los años subsiguientes. Asimismo, la magnitud del endeudamiento siguió siendo tal que ya en 2007, sólo dos años después de realizado el canje, el Estado pudo afrontar con los recursos del superávit fiscal solamente el $40 \%$ de los pagos, debiendo profundizar el endeudamiento con el sólo fin de pagar deuda. Esto nos suscita una doble evaluación:

A) Por un lado, el canje no rompió la continuidad del ciclo de endeudamiento en términos absolutos. El stock de deuda pública ha aumentado año a año; sin contar el monto no ingresado al canje, la deuda crece de US\$ 128.600 millones en 2005 a US\$ 136.700 millones en 2006, llegando a US\$ 144.700 millones en 2007. La clave explicativa se encuentra en que la resolución del default, si bien representó un alivio del

\footnotetext{
${ }^{269}$ Son cupones que otorgan dinero sólo si se cumplen determinadas condiciones: si el PBI real crece más del 3\% y si supera al PBI "base". Este PBI base se construye a partir del PBI de 2004, al que se le adiciona año a año un crecimiento de aproximadamente el $3 \%$. Si estas pautas se cumplen, entonces el tenedor del cupón recibe un monto de pago del 5\% del excedente del PBI a precios corrientes (excedente que expresa la diferencia de crecimiento entre el PBI y el PBI "base") dividido por el tipo de cambio, con un tope máximo de 0,48 según la moneda vinculada al cupón.

${ }^{270}$ Datos tomados de Secretaría de Finanzas, 2007.
} 
peso de la deuda sobre los indicadores macroeconómicos, no logró romper el “círculo vicioso" del endeudamiento público. La estrategia de desendeudamiento tuvo por resultado aplazar vencimientos de capital, pero impuso una pesada carga de desembolsos. Si consideramos la magnitud de la quita argentina en la resolución del default como un caso histórico y que el gobierno de Kirchner sostuvo puntillosamente los criterios de superávit fiscal destinado a deuda, es difícil pensar bajo qué circunstancias un país deudor podría dejar de serlo. Esto puede verse en que el gasto primario real en la post-convertibilidad, aunque se fue incrementando desde 2004 (mostrando la política de inversión pública y aumento del gasto desplegada por el kirchnerismo ${ }^{271}$ ), se mantuvo en promedio por debajo del de los últimos años del modelo de la convertibilidad, privilegiando la derivación de recursos al pago de deuda.

\section{Gráfico 6: Gasto primario real*}

Deflactado 0,5 IPC y 0,5 IPIM - Acumulado enero-septiembre

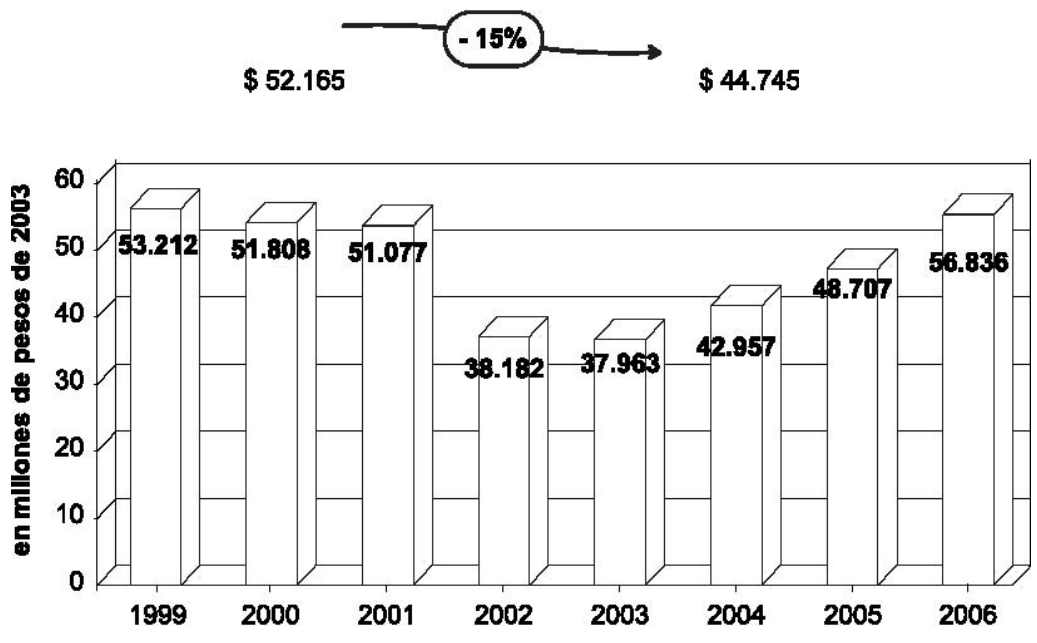

* Excluye transferencias automáticas a las provincias por coparticipación, ya que dicho concepto no representa un gasto del sector público nacional.

Fuente: Ministerio de Economía (2007)

Como señala el CENDA, “comparado con el quinquenio anterior a la crisis de 2001 (excluyendo este último año), durante el período 2002-2006 el gasto total

\footnotetext{
${ }^{271}$ Es a partir del gobierno de Cristina Fernández que esta tendencia se profundiza, mostrando un mayor énfasis en el incremento del gasto público como dinamizador económico.
} 
ejecutado por el sector público fue en promedio un 5,1\% menor como proporción del PIB, y un 17,3\% más chico en términos absolutos si se toman los valores a pesos constantes. Asimismo, en 2006 el gasto público como porcentaje del producto era todavía un 10\% más bajo que en 2001” (CENDA, 2007:21) ${ }^{272}$.

De este modo, tanto por la quita histórica del canje como por los estrictos criterios de superávit destinados a deuda, se hace evidente que la función a nivel global de la deuda no implica que esta sea finalmente pagada, sino que el endeudamiento es un circuito en sí de transferencia de ingresos. Esta transferencia de recursos, dada la estructura tributaria regresiva de Argentina, genera traspasos de las clases subalternas al capital financiero y se complementa con el mecanismo de la dependencia, en tanto los Estados deudores terminan priorizando el pago de deuda por encima de las necesidades de las clases subalternas, condicionando las políticas económicas ${ }^{273}$. Esto puede observarse en que, como señala Lucita, los recursos fiscales que se han destinado a deuda, en los primeros años de la post-convertibilidad, superan a la suma de las partidas presupuestarias de Salud, Educación, Vivienda y Agua potable, es decir el gasto social que define la calidad de vida de los sectores populares, así “por cada peso que se utiliza para pagar la deuda, sólo 0,75 centavos para servicios esenciales para la comunidad” (Lucita, 2005b:1).

B) Por otra parte, la deuda en la post-convertibilidad posee un papel distinto al que tenía en los años 90, ya que deja de ser el eje articulador del proceso de valorización financiera y fuga de capitales, característico del modelo de la convertibilidad. Esto puede observarse en las mejoras de los índices relativos a PBI y exportaciones, en vinculación con la notable mejora de las cuentas fiscales, que hacen que la deuda postcanje no constituya una amenaza de corto plazo a la continuidad y regularidad del modelo post-convertibilidad. Asimismo, permite visualizar un cambio en las relaciones de fuerzas, en detrimento, en términos relativos, del capital financiero, confirmando una mayor centralidad de los agentes productivos en el nuevo modelo de acumulación.

\footnotetext{
${ }^{272}$ En el capítulo siguiente veremos los cambios en la composición del gasto público y qué agentes y fracciones de clase aparecen como beneficiarios del mismo.

${ }^{273}$ La deuda pública externa ha sido históricamente un mecanismo de sujeción que las potencias centrales y la banca transnacional ejercen sobre las formaciones sociales periféricas. También está vinculada a las políticas que, de modo extorsivo, buscan imponer los organismos financieros internacionales a cambio de créditos para que las economías con dificultades de pago puedan seguir afrontando sus deudas.
} 
El análisis de la deuda nos abre paso para analizar una acción estatal que, sin ser fundacional, debe ser considerada como una política central del modelo postconvertibilidad: la cancelación de la deuda con el FMI, que se ligó a la suspensión del acuerdo firmado con dicho organismo y permitió ampliar márgenes de libertad para el desarrollo de las políticas económicas.

Según Chomsky la rigurosa adhesión al FMI que había tenido Argentina en los 90 fue una de las claves principales que llevó al país a un verdadero “desastre económico” (Chomsky, 2007). En este mismo sentido se orientaron numerosos discursos del presidente Kirchner, cuyo gobierno desplegó una doble estrategia: en primer lugar, mantuvo una mayor firmeza en la negociación de las exigencias en materia de políticas que el FMI pedía para la aprobación de la revisión del tratado por entonces vigente, que había sido suscrito por la administración Duhalde, y en segundo lugar, culminó las negociaciones con la suspensión del dicho acuerdo y el pago por adelantado de la deuda total con el Fondo.

El gobierno de Kirchner adoptó una postura de mayor intransigencia frente al FMI, en tanto no aceptó aplicar parte de las acciones estatales que este organismo reclamaba con el fin de aprobar la revisión del acuerdo en vigencia. El FMI presionaba principalmente por un aumento tarifario como vía de compensación a las empresas privatizadas por los efectos de la salida devaluacionista, y también exigía mejores condiciones para el canje de la deuda en default. El gobierno, amparado por el coyuntural aval del gobierno de los Estados Unidos y el crecimiento económico que experimentaba la economía nacional, tuvo mayor margen para disputar las exigencias del Fondo, optando finalmente por dejar virtualmente suspendido el acuerdo vigente. Asimismo, el propio FMI venía promoviendo que sus principales deudores cancelaran pagos con el fin de reducir sus riesgos financieros. Esto se debe a que el FMI tenía el 80\% de sus préstamos colocados en sólo 5 países, que en caso de entrar en cesación de pago con dicho organismo le hubieran producido un gran problema económico (AIPE, 2005). Esta estrategia puede visualizarse en tanto que tres de los principales cuatro deudores del FMI, Argentina, Brasil y Rusia, estaban efectivamente avanzado en el pago de sus deudas con este organismo. 
La recuperación económica y el aumento de la recaudación pública permitieron al gobierno prescindir de los desembolsos del FMI, pero el fin del acuerdo implicaba no poder seguir refinanciando la deuda con dicho organismo. Según Bembi y Nemiña,

\begin{abstract}
"la progresiva cancelación de los créditos pendientes con el Fondo nunca había sido planteada por el gobierno como un fin en sí mismo, sino que, en realidad, era el resultado de la suspensión unilateral del acuerdo vigente, lo que obligaba a nuestro país a continuar cancelando sus créditos con el organismo sin recibir sus desembolsos. Esto implicaba que, lógicamente, el stock de deuda con dicho organismo comenzaría a reducirse de manera más acelerada” (2007:87-88) ${ }^{274}$.
\end{abstract}

Así, el gobierno de Kirchner fue construyendo una perspectiva que oficialmente sería denominada como política de "desendeudamiento", cancelando por adelantado el total de su deuda de US\$ 9.810 millones con el FMI, utilizando para esto el 35\% de las Reservas Internacionales del Banco Central ${ }^{275}$. Si por un lado, el gobierno de Kirchner se convirtió en el que más deuda pagó a los organismos financieros internacionales en la historia argentina, por el otro, el fin del tratado con el Fondo (el cual era señalado en el discurso oficial como co-responsable de la crisis argentina) marcó un punto de inflexión en las posibilidades de conquistar mayores márgenes de libertad para la acción estatal. Debe recordarse que durante la década de los 90 el FMI había orientado la política económica a través de sus directivas exigidas para la aprobación de préstamos y procuraban seguir incidiendo en las acciones estatales mediante el mantenimiento de los acuerdos y las “evaluaciones” que el organismo realizaba para su sostenimiento. Estos nuevos márgenes de autonomía relativa del Estado nacional tuvieron implicancias explícitas en el corto plazo sobre las relaciones de fuerzas: las exigencias del fondo promovían políticas orientadas a favorecer claramente a las fracciones del capital financiero y de las empresas de servicios públicos (con su núcleo primordial de privatizadas), lo cual hubiera trastocado la correlación de fuerzas post-convertibilidad favorable al capital productivo-exportador en el marco de un nuevo esquema de precios relativos y el nuevo contexto macro-económico.

\footnotetext{
${ }^{274}$ Los autores señalan además que "la consecuencia de la suspensión del acuerdo era resignificada pocos meses después como un pilar central de la política económica nacional, por lo que un resultado colateral de una decisión se convertía en el objetivo central de la misma: lograr mayor autonomía en la definición de las políticas estatales en materia económica” (Bembi y Nemiña, 2007:88).

${ }^{275}$ Aunque debe señalarse que esto no significó una reducción neta de la deuda sino un cambio de acreedor, ya que el Estado entregó al Banco Central bonos por la misma cantidad. Claro que el endeudamiento intra sector público posee un carácter sustancialmente distinto de aquel sostenido con agentes externos al mismo, y más aún con el FMI, en virtud de los condicionamientos que dicho organismo impone en materia político-económica.
} 
En este punto puede visualizarse cómo en la política de canje de deuda y en el pago adelantado al FMI gravitaron los distintos componentes del proyecto políticoeconómico de gobierno, en tanto la importante quita alcanzada y el fin de la relación de dependencia directa con el FMI habilitaron la posibilidad de sostener un mayor énfasis en la producción en bienes transables y limitar los cuantiosos recursos destinados a deuda liberándolos para efectuar las distintas transferencias claves en la construcción de hegemonía durante la post-convertibilidad. El distanciamiento de los mandatos del FMI es entonces una condición de posibilidad de sostener el nuevo cuadro de relaciones de fuerzas en la Argentina post-convertibilidad (en virtud de las presiones del fondo para derivar recursos al capital financiero y a las empresas de servicios públicos privatizadas) y expresa un incremento en la autonomía relativa del Estado, ampliando su capacidad de juego sobre la gestión del parte del excedente económico.

\subsubsection{El congelamiento y renegociación de tarifas}

De las seis políticas fundacionales, la devaluación, la pesificación asimétrica y el congelamiento y renegociación de tarifas tuvieron impactos destacados respecto de las privatizadas, un núcleo clave en la fracciones de empresas de servicios públicos que vieron desfavorecidas su capacidad de apropiación del excedente económico con el fin de la convertibilidad. Como señalamos, estas acciones estatales cobraron forma inicialmente a partir de la Ley de Emergencia Pública ${ }^{\circ}$ 25.561. En el artículo $8^{\circ}$ se dejaron sin efecto las cláusulas indexatorias de tarifas a índices de precios de otros países, que habían beneficiado a las privatizadas durante el modelo de la Convertibilidad, y se desdolarizaron las tarifas, pesificándolas en relación 1\$ por 1US\$. También se habilitó, en el artículo $13^{\circ}$, al gobierno a regular transitoriamente los precios de insumos, bienes y servicios críticos, a fin de proteger los derechos de los usuarios y consumidores, de la eventual distorsión de los mercados o de acciones de naturaleza monopólica u oligopólica ${ }^{276}$. Por un lado, las privatizadas, que presentaban un origen de capital predominante extranjero, se vieron afectadas por la devaluación tanto por la disminución de las utilidades en divisas como por el encarecimiento de los insumos que adquirían a través de empresas ligadas a sus holdings. Por otro lado, fueron beneficiadas por la pesificación asimétrica de deudas.

\footnotetext{
${ }^{276}$ Una ampliación de este abordaje puede ser leída en Varesi (2009b).
} 
Como sostienen Azpiazu y Schorr (2003) la Ley de Emergencia Pública establecía un marco propicio para una reconfiguración profunda de las relaciones entre las empresas de servicios públicos privatizadas y el Estado posibilitando la revisión integral de los contratos y de las contravenciones acumuladas de los años precedentes. Por ejemplo, permitía revisar el conjunto de ajustes tarifarios de dudosa legalidad desarrollados durante el modelo de la convertibilidad que les garantizaron a las privatizadas ganancias extraordinarias en contexto de nulo riesgo empresario, y también impulsar una investigación por las inversiones incumplidas. Sin embargo, rápidamente comenzó a notarse que las discusiones Estado-privatizadas se limitarían a las negociaciones tarifarias, creándose una Comisión de Renegociación para asistir al Ministerio de Economía en dicha tarea. Durante la administración Duhalde las renegociaciones avanzaron lentamente, con presiones tanto de gobiernos extranjeros como del FMI, pero mediada por la intervención del poder judicial que invalidaba los intentos de aumentos que pretendían contrariar la Ley de Emergencia Pública. Esto nos permite pensar esta acción estatal en toda su dimensión, ya que trascendió la iniciativa a nivel del Poder Ejecutivo comprendiendo en su estrategia a otras instituciones estatales que permitían mostrar una voluntad política condescendiente con las presiones realizadas por las potencias extranjeras y los organismos financieros internacionales, pero que contaba con el resguardo de la Ley de Emergencia Pública y la posibilidad de anulación por parte del poder judicial de los aumentos tarifarios que la vulneraban. Como concluyen Azpiazu y Schorr, el gobierno de Duhalde desplegó una estrategia de renegociación dual:

\footnotetext{
“* la de aquellas actividades en las cuales el gobierno implementó un conjunto de medidas fuertemente cuestionables en términos procedimentales y, más aún, legales, pero que resultaron plenamente funcionales al proceso de acumulación y reproducción del capital de las compañías prestatarias: vías fluviales por peaje, servicios aeroportuarios, correo postal, terminales del puerto de Buenos Aires, transporte ferroviario de pasajeros y puente Rosario-Victoria; y

* la de aquellos sectores en los que, a pesar de que las firmas que se desenvuelven en los mismos no lograron que se concediera buena parte de los desmedidos reclamos que presentaron al inicio del proceso de renegociación, la estrategia gubernamental consistió en focalizar prácticamente toda la "revisión contractual" en cuánto tendrías que incrementarse las tarifas, abandonando los distintos criterios establecidos de manera taxativa por la Ley de Emergencia (como, entre otros, las inversiones efectivamente realizadas, el grado de cumplimiento de los contratos originales, los niveles de rentabilidad empresaria, el impacto de los cuadros tarifarios sobre la distribución del ingreso y la competitividad de la economía, y la calidad de los servicios prestados), en dilatar todo lo posible aun esa acotada negociación tarifaria y, en síntesis, en dejar todo lo posible aun la renegociación global de los contratos -e incluso, la tarifaria en las áreas más sensibles socialmente- como una pesada herencia para la próxima administración gubernamental elegida por el voto popular" (2003: 267-268)
} 
Durante el gobierno de Kirchner se desplegó una estrategia heterogénea consistente en tres acciones estatales diferenciadas: renegociación, reestatización y creación empresarial. Esta estrategia fue desplegada persiguiendo tres objetivos: 1) desmantelar los procesos judiciales que muchas privatizadas llevaban adelante en el CIADI $^{277}$, que a inicios del 2005 implicaban juicios por US\$ 17.000 millones; 2) mantener el nuevo esquema de precios relativos favorable a la producción de bienes transables, evitando un "tarifazo" que aumentara la inflación; y 3) aumentar la influencia del Estado en determinadas áreas.

En este capítulo nos centraremos en las renegociaciones, dejando para el siguiente las otras aristas de la estrategia estatal, ya que nos permitirán una mayor comprensión de la fracción de empresas de servicios públicos y el cambio en la correlación de fuerzas. El gobierno continuó utilizando la Ley de Emergencia Pública como herramienta fundamental. Ésta, en el artículo $9^{\circ}$, autorizaba al poder ejecutivo a renegociar los contratos de prestación de servicios públicos tomando los siguientes criterios: “1) el impacto de las tarifas en la competitividad de la economía y en la distribución de los ingresos; 2) la calidad de los servicios y los planes de inversión, cuando ellos estuviesen previstos contractualmente; 3) el interés de los usuarios y la accesibilidad de los servicios; 4) la seguridad de los sistemas comprendidos; y 5) la rentabilidad de las empresas” (Ley n²5561, art.9).

En los casos en que se llevaron a cabo las renegociaciones que pusieron fin al congelamiento tarifario, éstas culminaron en aumentos entre el 15 y el 30\%, (por ej. Edesur, Edenor, Gas Natural Ban, entre otros) muchos de los cuales se dirigieron principalmente a los grandes consumidores, evitando el "tarifazo" directo sobre las clases subalternas y buscando redireccionarlo hacia los agentes productores de bienes transables, principales beneficiarios del nuevo esquema de precios relativos, pero impactando igualmente en la población por la transferencia parcial del aumento de los costos a los precios que efectúan los agentes empresariales. Si bien en todos los casos los acuerdos implicaron el retiro de las demandas del CIADI, no se les exigieron a las privatizadas las inversiones previamente incumplidas. Un ejemplo de esto es la negociación con la empresa Gas Natural BAN, a quien se le avaló un aumento del 27\%

\footnotetext{
277 Centro Internacional de Arreglo de Diferencias relativas a Inversiones. Tribunal ligado al Banco Mundial.
} 
para los medianos y grandes usuarios y un $17 \%$ para las casas de familia ${ }^{278}$. Esta negociación se llevó a cabo a partir del retiro de la demanda judicial de la Gas Natural BAN en la CIADI. Otras negociaciones que culminaron en aumento tarifario fueron las de las autopistas del acceso Norte y Oeste, que presentaron un incremento del 15\% que comenzó a cobrarse en abril del 2006.

Una importante renegociación fue la llevada a cabo en el sector energético, que comenzó con los regímenes de “premios y castigos” implicando aumentos según la cantidad de consumo de energía y que continuó con la negociación de contratos y tarifas. En las negociaciones con Edenor y Edesur, el gobierno fue avanzando, logrando el retiro de las demandas judiciales en el CIADI y otorgando aumentos de tarifas a los medianos y grandes usuarios implicaron una mejora en los ingresos de las distribuidoras del orden del 28\%. Además del ajuste para los clientes no residenciales, los nuevos contratos contenían dos nuevas vías de actualización tarifaria ${ }^{279}$. La renegociación con Edelap incluyó el retiro por parte de la empresa de una causa judicial contra el Estado argentino por US\$1.000 millones y el permiso para efectuar un 15\% de aumento tarifario $^{280}$. Es de importancia remarcar que una de las principales problemáticas que el gobierno ha tenido que enfrentar es la crisis energética que, por falta de inversiones y por el crecimiento que presentó la economía, puso al sistema energético al límite de sus capacidades en momentos de intenso aumento de la demanda. En este contexto el gobierno comenzó a desplegar una fuerte política de subsidios y transferencias superiores a los 9.000 millones de pesos al sector energético privado.

Otros agentes que se han convertido en beneficiario de los subsidios estatales han sido aquellos ligados al sistema de transporte público, principalmente los ferrocarriles concesionados. Esta política de subsidios puede ser apreciada en el aumento de la partida presupuestaria de servicios económicos "que en términos reales prácticamente se quintuplicó entre 2002 y 2005” (CENDA, 2007:27).

Los gobiernos post-convertibilidad, si bien han asumido una postura de mayor firmeza frente a las empresas de servicios privatizadas en la negociación de tarifas que

\footnotetext{
${ }^{278}$ Clarín 18/9/2006.

${ }^{279}$ Por un lado, cada seis el ENRE (Ente Nacional Regulador de Electricidad) verificará los costos operativos y si aumentan un 5\%, determinará el ajuste correspondiente. Y por otro lado, las empresas podrá solicitar una revisión "extraordinaria" cada vez que sus costos se eleven más del 10\% (Clarín 26/12/2006).

${ }^{280}$ El Día 18/1/2005.
} 
los gobiernos anteriores, no han propuesto un plan integral de recuperación de los recursos estratégicos. Como veremos en el capítulo siguiente, en el modelo postconvertibilidad las privatizadas ocupan una posición subordinada respecto de la ocupada en los años 90. Si bien en el modelo actual las empresas de servicios públicos privatizadas (a diferencia de las privatizadas de la fracción productivo-exportadora como Repsol-YPF) han perdido posiciones al interior de la cúpula empresaria, se ha desplegado una política de subsidios que representa un mecanismo de transferencia de recursos de carácter compensatorio, con montos que alcanzaron, por ejemplo, los \$6.700 millones anuales para el sector transporte y más de \$9.230 millones al sector energético, en 2007, procurando armonizar las relaciones entre fracciones de clases en el marco de las nuevas relaciones de fuerzas, que confirmaban, con el nuevo esquema de precios relativos, y una mejor capacidad de apropiación del excedente económico por parte de los grandes agentes productores de bienes transables ligados a la exportación.

\subsubsection{Inversión pública.}

Una acción estatal destacada dentro del modelo post-convertibilidad ha sido el incremento de la inversión pública principalmente orientada a la conformación de grandes planes de obra pública. Como sostiene el Ministerio de Economía (2008), la inversión pública consiste en el adelanto de recursos que se materializan principalmente en la incorporación al proceso productivo de activos especializados, y que viabilizan incrementos sistemáticos de productividad, al tiempo que integra la demanda de corto plazo, como un componente autónomo (o sea no dependiente del ingreso corriente de los individuos). A su vez, debe considerarse que la ejecución de proyectos de inversión pública requiere de períodos de tiempo considerables, por lo cual precisan de una política constante de modo de no comprometer el desarrollo de los mismos. Esta acción estatal si bien no constituye una política fundacional del modelo, se fue conformando desde 2003 en una constante de alta relevancia por los crecientes recursos involucrados. Por este motivo puede ser considerada como una política central en la configuración del modelo de acumulación que impulsa un acondicionamiento del proceso de reproducción ampliada del capital y que, a su vez, remite al rol destacado que juega el Estado como articulador del proyecto político-económico de gobierno del kirchnerismo, tanto como 
articulador del pacto populista, como distribuidor diferencial de recursos gestionando parte del excedente económico.

La inversión pública total se compone de las inversiones ejecutadas tanto por el Sector Público Nacional, el Sector Privado mediante transferencias de capital de la Nación, y las ejecutadas por el Sector Público Provincial. Mientras la inversión pública había alcanzado el piso mínimo histórico en 2002, la misma comenzó a recobrar creciente dinamismo desde 2003 mostrando una expansión del 539\% al año 2007. Debe notarse que el financiamiento hasta 2006 fue desarrollado ampliamente con recursos del Sector Público Nacional, año en que llegó a aportar aproximadamente la mitad de los fondos de inversión totales ejecutados por las provincias. Sin embargo en 2007 se revirtió esta situación, y las provincias aportaron cerca de dos tercios de la inversión ejecutada por ellas mismas, evidenciando la recuperación económica fiscal de los Estados provinciales y su mayor capacidad de desarrollar inversiones en línea con la tendencia observada a nivel nacional.

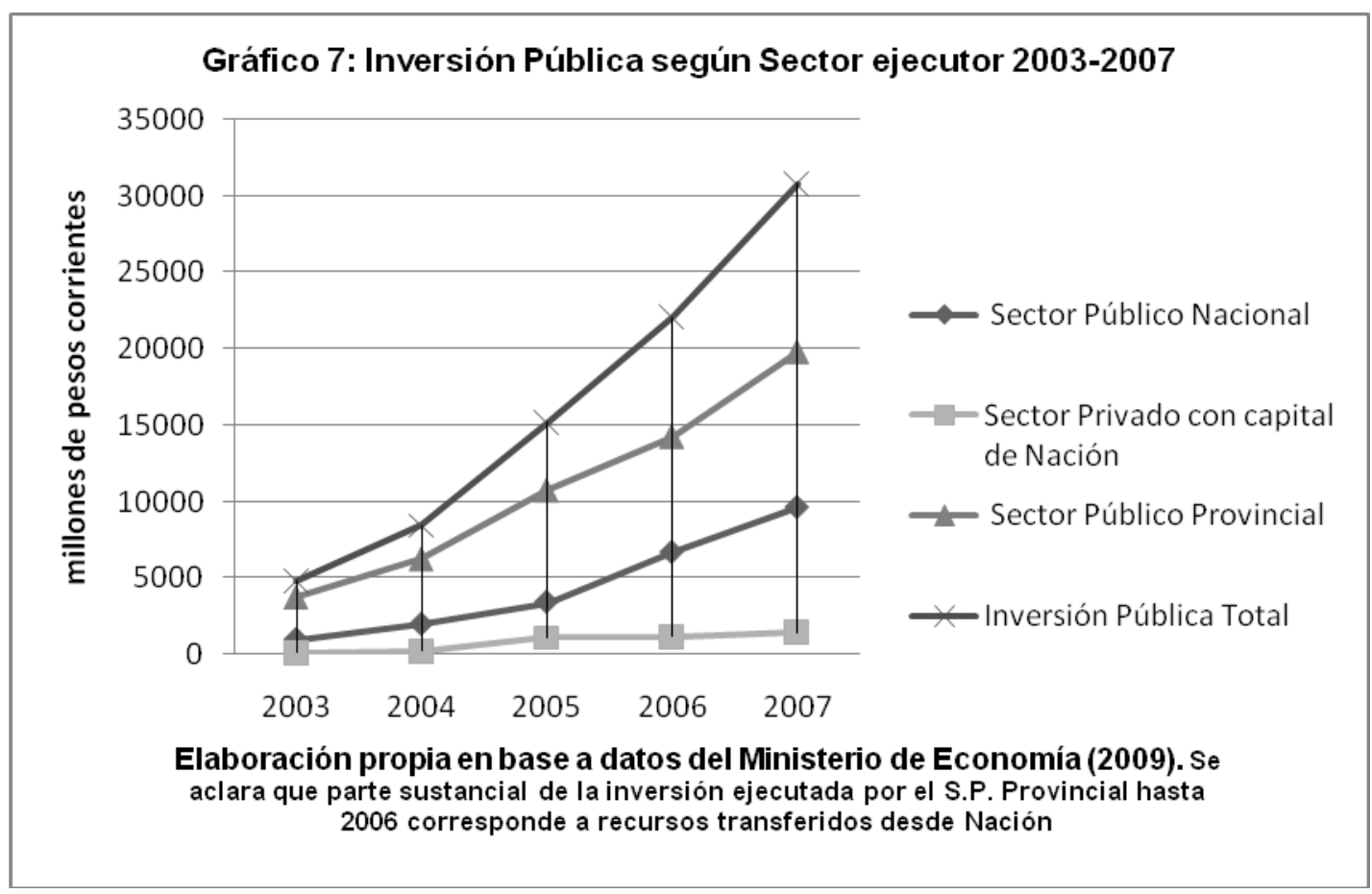

La inversión pública nos permite visualizar algunos componentes novedosos que comenzaron a conformarse en rasgos significativos de esta acción estatal. Por un lado, 
los fondos presupuestarios nacionales y provinciales destinados a inversión pública (o sea aquellos que excluyen las inversiones realizadas por las empresas públicas, universidades y fondos fiduciarios, entre otros) cobraron creciente relevancia por su tendencia a explicar mayores porcentajes de la Inversión Bruta Interna Fija (IBIF), partiendo de representar sólo el 6,4\% de la misma en 2002 y terminando en 2007 por explicar 10,7\% de la misma. En este camino, puede observarse que la inversión pública total en la post-convertibilidad, como componente de la IBIF, haya crecido a mayor ritmo en el periodo 2003-2007 que la inversión privada, evidenciando su prelación creciente en el modelo de acumulación.

A su vez, la inversión presupuestaria muestra su componente más dinámico en las Inversiones Reales Directas (IRD), es decir los proyectos de inversión pública ejecutados directamente por el gobierno nacional, que presentaron un aumento, en valores corrientes, del 734\% entre 2003 y $2007^{281}$. La IRD tuvo dos instancias de gestión principales: la Dirección Nacional de Vialidad, que administró el 56,3\% de los fondos administrados y el Ministerio de Planificación, con el 9,4\% (año 2007). Si, por un lado, más de la mitad de la IRD se orientó a distintos proyectos viales, los fondos manejados por el Ministerio de Planificación se concentraron en tres programas de infraestructura: Programa de Desarrollo Integrador del Norte Grande, Formulación y Ejecución de Políticas de Transporte Automotor y Ferroviario y, por último, Formulación y Conducción de Políticas Portuarias ${ }^{282}$. Asimismo, las transferencias de capital hacia las provincias tuvieron un destino principal en la construcción de viviendas y desarrollo urbano (40\%), mientras que las transferencias de capital hacia el sector privado se orientaron preferentemente, aunque con distintos porcentajes según el año, al sector energético.

Por otra parte, un componente que marca una clara ruptura con el modelo de los años 90 es la reaparición de la inversión pública por parte de empresas estatales. La misma fue cobrando relevancia con las reestatizaciones de empresas de servicios previamente privatizadas y la creación de nuevas empresas estatales durante el gobierno de Kirchner. En este proceso se observa un superlativo aumento porcentual del 1832\%,

\footnotetext{
${ }^{281}$ De $\$ 800$ millones en 2003 a $\$ 6673$ en 2007. Datos tomados de Ministerio de Economía (2009).

${ }^{282}$ Especificaciones de inversión pública del 2006 tomados de "Plan Nacional de Inversiones Públicas 2006-2008. Resumen Ejecutivo” del Ministerio de Economía (2006). En 2007 se incrementaron los fondos para proyectos portuarios.
} 
pasando de tan sólo \$59 millones invertidos por las empresas estatales en 2003 a los \$1140 millones en 2007.

Estos distintos elementos nos permiten visualizar cómo desde el Estado nacional se lidera la inversión constituyendo una acción estatal de creciente peso, convirtiéndose en una variable económica regular del modelo de acumulación post-convertibilidad. Asimismo, vemos que comienza a ocupar un lugar importante en el orden de prelación como componente de crecimiento destacado al interior de la IBIF. La IBIF a su vez presentó un crecimiento destacado entre 2002 y 2007 del 206\%, siendo una de las claves del proceso de crecimiento económico. En este camino, la inversión pública debe ser considerada como una intervención tendiente a sostener e impulsar el proceso de crecimiento económico que comenzó a experimentar Argentina desde 2003, acondicionando el proceso de reproducción ampliada del capital.

De este modo, concluimos un primer abordaje del modelo de acumulación a través de sus componentes superestructurales, realizando la presentación de las seis políticas fundacionales, a la que añadimos la política de inversión pública como una política central a tener en cuenta para la comprensión de nuestro objeto de estudio ${ }^{283}$. Este conjunto de acciones estatales muestran su relevancia al instaurar momentos de ruptura que nos permiten vislumbrar el fin de un modelo y el inicio de otro, que se sostiene posteriormente con la regularidad establecida en las variables, al tiempo que se configura el modelo de acumulación, convocando al análisis prioritario de un espectro determinado de variables que evidencian su prelación en términos explicativos.

Las políticas fundacionales que instauran el modelo de acumulación postconvertibilidad generan un primer momento de contracción de la actividad económica que expresa por un lado el contenido regresivo de la salida devaluacionistainflacionaria con su negativo impacto sobre las condiciones de vida de las clases subalternas y las masivas transferencias hacia el capital a través de la política de pesificación asimétrica de deudas y depósitos. Al tiempo que la depresión del salario real y las transformaciones en las “reglas de juego" establecidas por la acción estatal, en un contexto internacional favorable, dio impulso a un nuevo ciclo de expansión

\footnotetext{
${ }^{283}$ Ciertamente podrían añadirse otras políticas como centrales, que cobraron forma posteriormente a las identificadas como fundacionales, éste es el caso de las políticas de ingreso, que por razones expositivas dejaremos para el capítulo siguiente.
} 
económica que logró sostenerse también a partir de dos pilares de estabilidad: el superávit comercial y el superávit fiscal.

Gráfico 8: Evolución del PIB en miles de millones de pesos de 1993

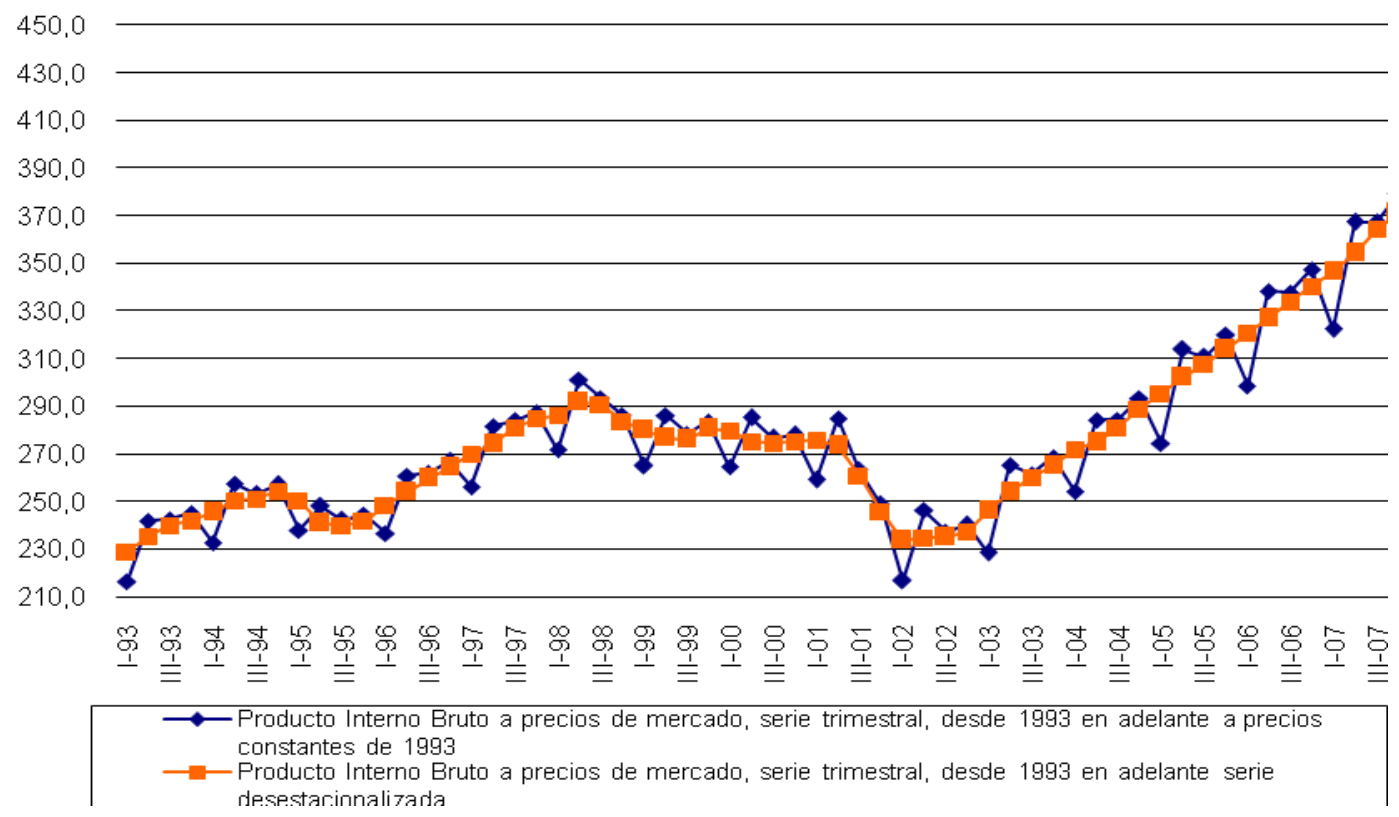

Elaboración propia en base a INDEC

Debemos tener en cuenta que la acción estatal expresó una mayor autonomía relativa del Estado capitalista para el reordenamiento y acondicionamiento del proceso de acumulación. Autonomía que implica y se visualiza en la elevación de la acción estatal por sobre los intereses inmediatos, económico-corporativo, de las fracciones y agentes particulares del capital con el fin de suturar el proceso de crisis que signó el fin del modelo anterior, y que definimos como un principio de crisis orgánica. Pero es relativa, en tanto el conjunto de acciones estatales analizadas no tienden a una ruptura que subvierte el bloque de poder a favor de las clases subalternas, sino que, como veremos a continuación, expresa un cambio en las relaciones de fuerzas entre las distintas fracciones de clase en el marco del mantenimiento de la relación social fundamental: el predominio del capital como núcleo central de la formación social, o lo que es lo mismo, la relación social capital como eje fundamental de la articulación de la sociedad. Es en esta articulación de mayor autonomía relativa y del predominio del capital en proceso de acumulación, donde se despliega el proyecto político-económico recuperando al Estado como mediación activa, interviniendo, como veremos, en la 
recuperación de condiciones laborales y niveles de vida de las clases subalternas con el fin de conformar el pacto populista.

Ya en el desarrollo de las políticas fundacionales del modelo postconvertibilidad podemos observar la conformación de un sistema de transferencias de recursos a través del cual el Estado gestiona parte del excedente económico y busca estabilizar las relaciones de clases procurando constituir un equilibrio de compromisos, siempre inestable, entre las distintas fracciones en el nuevo cuadro de correlación de fuerzas con el fin de afirmar un nuevo momento hegemónico. El carácter fundacional de dichas políticas se expresa en el momento de ruptura que ejerce a nivel del proceso de acumulación y en el rasgo perenne que imprime a la evolución de las variables económicas en vinculación a los cambios en las relaciones de fuerzas.

Asimismo, debemos notar el diferente énfasis y sesgo político entre las políticas desarrolladas en 2002 y aquellas desplegadas desde la asunción del kirchnerismo. Si por un lado, establecimos al 2002 como año inaugural, clave para la conformación del modelo y en el cual tienen origen la mayor parte de las políticas fundacionales que dotaron de rasgos duraderos al modelo de acumulación, no podemos dejar de notar el sesgo político regresivo de dicho comienzo. Este sesgo regresivo se vincula al fuerte predominio del polo capital en el proyecto de gobierno perfilado por el gobierno de Duhalde y se expresa en la tendencia a descargar el costo de salida de la crisis y el cambio de modelo (con sus transferencias de recursos) sobre las clases subalternas, incrementando las condiciones de explotación en un año que evidenció la licuación del salario real y un profundo deterioro de sus condiciones de vida. Es entonces esta apropiación privada de plusvalía extraordinaria la que sienta las bases del nuevo modelo de acumulación, impulsa al alza la rentabilidad empresaria convocando la inversión privada. También vemos que el capital productivo (dirigente de la "comunidad productiva” en el discurso duhaldista) posee centralidad en relación a las políticas y las transferencias de recursos que lo benefician. Este proceso comenzó a cobrar un perfil político distinto desde 2003, si bien se mantuvieron las bases estructurales del modelo, el énfasis por la disminución del desempleo y las políticas de ingreso que veremos en el capítulo siguiente, habilitaron una fuerte recuperación del consumo interno y un desarrollo destacado de la inversión pública. Estos factores nos muestran la faz progresiva del modelo post-convertibilidad en el desarrollo de proyecto político- 
económico kirchnerista que fue cobrando forma en el despliegue de su propia ambivalencia, entre los componentes sistémicos y sus componentes heréticos. 


\section{Capítulo V}

\section{Fracciones de clase y relaciones de fuerzas en la Argentina post- convertibilidad}

El modelo de acumulación expresa un recorte espacio-temporal del proceso de reproducción ampliada del capital que implica el análisis de dos dimensiones: una dimensión superestructural, ligada a las políticas económicas, y una dimensión estructural, vinculada a las fracciones de clase y a las variables económicas. Habiendo realizado una primera incursión analítica a través de las políticas fundacionales del modelo post-convertibilidad, nos proponemos abordar ahora el modelo de acumulación haciendo énfasis en su dimensión estructural ${ }^{284}$.

Como señala Poulantzas (1981) la reproducción ampliada del capital es a su vez una reproducción ampliada de las clases sociales: implicando, por un lado, la reproducción de los lugares (Poulantzas) o posiciones (Gramsci) y, por otro lado, la reproducción y distribución de los agentes mismos en dichos lugares. En este sentido, entendemos que el nivel de la estructura expresa tanto una metáfora espacial, en términos de disposición de posiciones, de lugares, como el conjunto de variables económicas, principalmente las variables económico-estructurales, que exhiben las lógicas sedimentadas de modelos y regímenes anteriores y que son modificables en un plazo mayor que las variables económicas de desempeño, las cuales son más permeables a las alteraciones promovidas por la acción estatal.

Emerge así la pregunta por la construcción analítica de las clases. En primer lugar, señalamos la importancia, destacada por Olin Wright (1994), del análisis de clase para expresar una relación fundamental de las sociedades capitalista: la relación de explotación, y en este sentido se dispone un corte entre agentes dominantes y subalternos en torno a la generación y apropiación del plusvalor. Manteniendo el foco en el modelo de acumulación, podemos partir de la homología de posición de los agentes en la producción para construir colectivos en términos de fracciones. En este

\footnotetext{
${ }^{284}$ Esto no implica dejar de apuntar apropiadamente las distintas acciones estatales que tienen incidencias específicas en la explicación del desarrollo de los núcleos estructurales.
} 
camino, definimos tres criterios de clasificación para recortar las fracciones de clase. Un primer criterio ligado al tamaño, para distinguir su peso estructural, el grado de concentración económica, la capacidad de formar precios y su vinculación diferencial con la generación de empleo que presentan en la post-convertibilidad, por un lado, las grandes empresas y, por otro, las pequeñas y medianas empresas (PyMEs). Un segundo criterio está dado por la vinculación al mercado externo, que se aplica a las grandes empresas (por su gravitación en la estructura económica en su conjunto y su capacidad exportadora) y se justifica además para pensar nuestro periodo de estudio por la importancia de la política cambiaria, las variaciones favorables en los precios de los commodities y las significativas modificaciones en materia de balanza comercial. El tercer criterio se relaciona con la inserción sectorial y la evolución de los precios relativos. Como sostuvimos, los precios expresan relaciones de fuerzas; de este modo, por ejemplo, la diferencia entre salarios (y sus distintas categorías), las canastas de precios representativas de los productores de bienes transables y las canastas de precios indicativas de los servicios parecen criterios relevantes para analizar la evolución disímil de los agentes en relación con la fundación del modelo y su disímil capacidad de apropiación del excedente económico.

Estos tres criterios nos llevaron a distinguir las siguientes fracciones dentro de la clase dominante ${ }^{285}$ :

1) Una fracción productivo-exportadora: grandes empresas productoras de bienes transables caracterizadas por su inserción en el mercado externo, que se encuentra principalmente ligada al agro, la industria y la extracción y procesamiento de recursos naturales (como petróleo y minería).

2) Una fracción amplia de PyMEs: empresas de bienes y servicios principalmente orientadas al mercado interno (para consumo o bienes intermedios), caracterizadas por su tamaño, baja productividad y su relevancia en la generación de puestos de trabajo, aunque con bajos salarios y altos niveles de informalidad.

3) Una fracción de empresas de servicios públicos compuesta principalmente por empresas privatizadas, a las que se sumarían las nuevas empresas estatales producto de

\footnotetext{
${ }^{285}$ Profundizaremos en el análisis en la clase dominante por considerar que los cambios en las relaciones de fuerzas en su interior son fundamentales para comprender las transformaciones en el modelo de acumulación.
} 
una estrategia estatal heterogénea. Este núcleo se explica tanto a partir de la importancia que poseían las privatizadas en el modelo de acumulación anterior como "prenda de paz” interburguesa (Azpiazu y Basualdo, 2004), como por la relevancia explicativa que, en el modelo post-convertibilidad, poseen la modificación de precios relativos y las nuevas acciones estatales respecto de esta fracción.

4) La fracción financiera: vinculada a la importancia de los conglomerados financieros, tanto a nivel estructural como fracción no productiva ligada al interés, como en relación a las políticas en torno a la deuda pública y la tasa de interés. Esta fracción se compone principalmente de conglomerados financieros privados, públicos y cooperativos, que abarcan un amplio espectro de entidades financieras, como $\mathrm{AFJP}^{286}$, Compañías de Seguros y Fondo Común de Inversión, encabezada por un banco (Golla, 2006).

A lo hora de abordar las clases subalternas retomamos las críticas desarrolladas por Castells (1985 [1973]) a Poulantzas, sosteniendo la necesidad de no limitar el corte a la producción directa de plusvalor, sino observar también la creciente masa de asalariados que si bien no son creadores directos de plusvalía, sí contribuyen a la realización de la misma u otras formas de reproducción social ligadas a múltiples aparatos institucionales, entendiendo que tanto estos asalariados, así como los trabajadores desocupados, representan posiciones subalternas y siguen compartiendo la característica clave del proletariado como clase de ser agentes desposeídos de los medios de producción que sólo tienen para vender su fuerza de trabajo. Si bien es relevante analizar la heterogeneidad de las clases subalternas, observando las distintas evoluciones salariales de las diferentes categorías laborales así como comprender más cabalmente su lugar y características en el modelo post-convertibilidad, también creemos necesario tener presente la subalternidad como un todo, resaltando nuevamente el concepto de capital como relación social en Marx, en tanto nos permite dilucidar la relación de explotación. Esto remite a que, más allá de la estratificación salarial y de los fenómenos de movilidad social de los agentes dentro de los puestos o lugares, analizar la estructura implica comprender la primacía de los lugares en la reproducción ampliada de las clases sociales, cuál es la evolución histórica efectiva de esas posiciones de clase y cómo éstas se articulan con la creación, apropiación y acumulación de la plusvalía en forma de capital.

\footnotetext{
${ }^{286}$ Administradoras de Fondos de Jubilaciones y Pensiones, que existieron desde la privatización del sistema público de reparto en 1993 hasta su reestatización en diciembre de 2008.
} 
Asimismo, destacamos que el recorte de fracciones realizado no agota la totalidad de colectivos de agentes posibles, sino que son construcciones analíticas, clases lógicas, creadas según su relevancia explicativa para el abordaje del modelo de acumulación y que se vinculan tanto con las políticas económicas que alteran las reglas de juego, así como a las variables económicas de desempeño y estructurales. En este camino, analizaremos las fracciones abriéndonos paso desde las mismas a la investigación de las variables económicas, visualizando también las acciones estatales específicas que las afectan.

Finalmente, debemos recordar que las clases se encuentran atravesadas por relaciones de fuerzas. La entrada de abordaje desde el momento estructural del modelo de acumulación que compone el actual capítulo, nos permitirá complementar aquellas modificaciones en la correlación de fuerzas en su dimensión política ya visualizable en el análisis de los factores centrales de la construcción de hegemonía y en los rasgos de las políticas fundacionales previamente analizadas, con lo que Gramsci (2003) marca como una dimensión estructural de las relaciones de fuerzas, ligadas a condiciones objetivas e independiente de la voluntad de los agentes, en estrecha relación con la posición (lugar) y función que las fracciones desarrollan a nivel de la producción. Consideramos que elementos tales como la concentración económica, la variación en los precios relativos y los indicadores de rentabilidad constituyen factores a tener en cuenta para la caracterización de los cambios en las relaciones de fuerzas entre las distintas fracciones de clase, en estrecha vinculación con otros aspectos del modelo que recorren desde sus características más estructurales como el perfil productivo o la estructura exportadora hasta cualidades mayormente ligada a la acción estatal, tales como la estructura tributaria y el gasto público, permitiéndonos percibir distintos mecanismos de transferencias de recursos así como la distribución de cargas y beneficios entre los agentes económicos.

\subsection{Fracción productivo-exportadora del capital ${ }^{287}$}

Nos proponemos pensar una fracción productiva-exportadora compuesta por grandes agentes económicos ligados principalmente a la producción agropecuaria, industrial, minera y petrolera, o sea una fracción productora de bienes transables orientados a la

\footnotetext{
${ }^{287}$ Se dedicará un mayor espacio al análisis de esta fracción de clase por considerársela clave para la comprensión del modelo de acumulación pos-convertibilidad, así como por constituir su principal beneficiaria.
} 
exportación que surgió, en términos globales, como la principal beneficiaria de la configuración del modelo post-convertibilidad y también del proceso inflacionario en tanto sus precios presentaron aumentos por encima de aquellos exhibidos por el resto de las fracciones dominantes y subalternas. El análisis de esta fracción nos convoca al abordaje, tanto de su cualidad productiva (y su relación con el perfil productivo del modelo) como de su cualidad exportadora (visualizando la estructura exportadora argentina). De este modo, delinearemos algunos rasgos generales del modelo de acumulación vinculados a esta fracción del capital, para luego poder delimitarla con mayor precisión en sí misma, en su posición estructural.

El inicio de la fase expansiva del ciclo económico se dio con un aumento de la producción de bienes transables en general, relacionado con la dinámica exportadora promovida por el nuevo tipo de cambio e incluyó también un fenómeno incipiente de sustitución de importaciones, habilitando el resurgimiento de algunas ramas que habían sido afectadas por las reformas de los 90 y la recesión, tales como la textil, la metalmecánica, entre otras (Schorr, 2005). Esta expansión de la producción puede verse en la recuperación de la capacidad ociosa instalada, así como en el incremento continuo, desde 2003, de la inversión en relación al PBI. Si la fase expansiva del ciclo económico 2003-2007 arrojó un crecimiento promedio del PBI de 8,8\% anual, la industria creció, en el mismo período, por encima de dicho crecimiento: “la industria argentina creció a un promedio anual del 10,3\% en términos del Índice de Volumen Físico (IVF) (...) Cabe destacar que el proceso de crecimiento industrial 2003-2007 ha exhibido una recuperación más pronunciada que la registrada en la salida de las cuatro recesiones precedentes” (CEP, 2008:14-15). El crecimiento del producto industrial y del PBI en su conjunto, ha tenido un impacto positivo en la reducción de la desocupación que, según el INDEC, pasó del 23,3\% en su punto más alto en mayo de 2002, a 7,2\% en su momento más bajo en el IV trimestre de 2007, dando sustento material a la construcción de hegemonía a partir del proyecto político-económico de gobierno basado en el “crecimiento” e industrialización con inclusión social.

Si, como señalan Féliz y Pérez (2004), el salario real refleja el poder de compra que reciben los trabajadores como remuneración, constituyendo la expresión en valores de uso del valor de la fuerza de trabajo ligada a su costo de reproducción, y la productividad expresa el valor de la producción creada por los trabajadores en un tiempo determinado, la diferencia entre la evolución del salario real y la productividad 
del trabajo evidencia la formación de plusvalor apropiado en forma de ganancia por el capital. Así, el crecimiento del empleo y de la producción se conjugó, por un lado, con un aumento en la productividad laboral potenciado por la intensificación del proceso de trabajo y las inversiones en innovación tecnológica, y por otra parte, con una baja del costo laboral provocada por el descenso del salario real, que alcanzó un piso histórico en 2002 por el desarrollo del proceso inflacionario. Estos factores articulados con la explotación intensiva de los recursos naturales, los precios internacionales favorables y el nuevo tipo de cambio competitivo permitieron a los agentes productivo-exportadores generar elevados márgenes de ganancia y recuperar niveles de actividad económica.

En este camino, parece necesario destacar que "si por un lado la devaluación creó las condiciones en el ámbito de los procesos de valorización para la generación potencial de mayores niveles de rentabilidad, a su vez lo hizo en la esfera de la circulación, para articular una nueva forma de realización. A partir de ese momento, la salida exportadora (el superávit externo) debía convertirse en el elemento dinámico más importante en la realización del excedente” (Féliz y Pérez, 2007:329-330, el subrayado es nuestro). Esto nos permite complejizar la perspectiva que comenzamos a delinear mediante el análisis de la política cambiaria y la variación de la participación de los componentes de la demanda agregada en el PBI, así como entender la función central que comenzó a ocupar la fracción productivo-exportadora del capital en el modelo post-convertibilidad, al situarse en un lugar que empezó a constituir un eje clave en el proceso de acumulación. Es por esto que, como sostuvimos, los gobiernos de la post-convertibilidad han desarrollado una política activa para mantener el tipo de cambio competitivo promoviendo el crecimiento de las exportaciones del $121 \%$ entre 2002 у 2007.

Las principales actividades que componen la estructura exportadora se encuentran en el complejo de oleaginosas, explicado casi totalmente por la producción sojera, que participa del $23,3 \%$ del valor total exportado $\left(2005^{288}\right)$. Si al complejo ${ }^{289}$ de las oleaginosas le sumamos el cerealero, el de origen bovino y el frutihortícola, el conjunto de estas actividades primarias y productoras de manufacturas de bajo valor agregado representan el $41,7 \%$ del valor total exportado. El segundo complejo

${ }^{288}$ Tomamos el año 2005 ya que es un año intermedio de la serie en el cual las políticas fundacionales ya habían sido aplicadas y constituye el primer año de normalización completa de la actividad económica después del canje de deuda.

${ }^{289}$ Tomamos los complejos exportadores según la clasificación realizada por el INDEC. 
exportador es el petrolero-petroquímico con un 19,1\% de las exportaciones. La industria automotriz continúa con una fuerte presencia representando el 8,6\% de las exportaciones. Otro complejo de relevancia es el siderúrgico con un 4,2\% de las exportaciones. Las exportaciones mineras, si bien no presentan una gran relevancia sobre el total exportado, han crecido fuertemente en la post-convertibilidad ${ }^{290}$, presentando un aumento del 241\% entre 2003 y 2008 (Subsecretaría de Comercio Internacional, 2010).

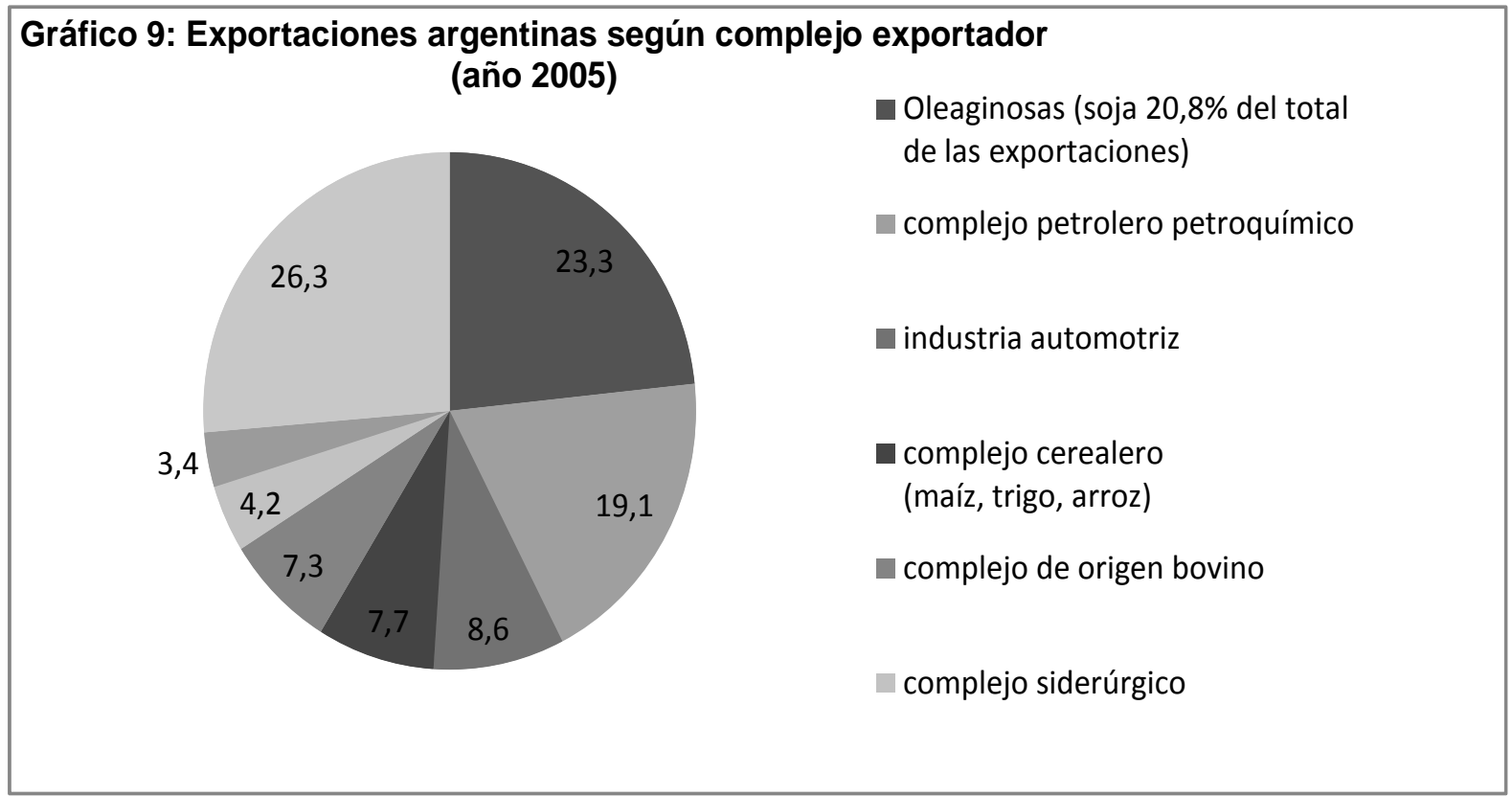

Elaboración propia en base a datos INDEC publicados por Informe Industrial $\mathrm{n}^{\circ} 208$

Las exportaciones constituyen un núcleo dinámico en el modelo de acumulación post-convertibilidad ya que, como mencionamos previamente, desde 2002 a 2007 constituyó un factor fundamental en el crecimiento económico constituyendo una vía clave de realización del capital. Podemos observar que la composición de la estructura exportadora se basa principalmente en la explotación de los recursos naturales, marcando, en su perfil, una fuerte continuidad con el modelo anterior: el mantenimiento de la reestructuración regresiva en la matriz productiva ${ }^{291}$ (Azpiazu y Schorr, 2010).

\footnotetext{
290 También debe observarse que los precios de los productos mineros consignados en el IPIM muestran los principales aumentos de la post-convertibilidad.

291 En este sentido, Azpiazu y Schorr señalan que durante la post-convertibilidad se profundizaron en el sector manufacturero "algunos de los rasgos de una estructura de especialización de escaso dinamismo a escala mundial (agroindustrias y commodities fabriles), con acotados efectos locales en términos de
} 
De este modo, la Argentina continúa siendo, en términos generales, exportadora de productos primarios y de manufacturas con escaso valor agregado, a lo que se suma la industria terminal automotriz y algunos segmentos de la industria química y la siderúrgica $^{292}$. La exportación de manufacturas de origen industrial, si bien no logran (durante nuestro recorte temporal) modificar sustancialmente la composición de la estructura exportadora, sí muestran un mayor dinamismo, cuya tendencia se manifestará más claramente en años posteriores ${ }^{293}$.

Esta aproximación al modelo a través de los complejos exportadores también nos permite comenzar a identificar los principales grupos de agentes que componen a la fracción productivo-exportadora.

En primer lugar, encontramos agentes ligados a la industria automotriz. Estos agentes fueron beneficiarios de las políticas de promoción y protección a dicho sector que continuaron desde la década de los 90 y, a partir de la devaluación, han exhibido un comportamiento crecientemente dinámico llevando a niveles de récord histórico la producción de automóviles marcado por una fuerte orientación exportadora. Esto se observa en el significativo aumento en las ventas al mercado externo del complejo automotriz "que pasó de exportar 1.700 millones de dólares en 2002 a más de 5.000 millones de dólares en el 2007” (CENDA, 2008b:23). Asimismo, debe observarse que las principales actividades de este complejo están vinculadas al ensamble de los automotores y no a la producción de partes de alto valor agregado, mostrando niveles notablemente bajos de inversión en investigación y desarrollo. Esto se debe a las transformaciones producidas en el sector automotriz e involucran tanto a las dinámicas

empleo y encadenamientos virtuosos hacia crecientes estadios en materia de productividad agregada. Se trata, en su mayoría, de manufacturas que se caracterizan por poseer estructuras de oferta oligopólica y en las que los salarios desempeñan un papel mucho más asociado a su condición de costo empresario que de factor dinamizador de la demanda interna” (2010:235-236).

${ }^{292}$ Esta continuidad puede observarse también en la escasa variación en los capítulos de exportación argentina. Esto se evidencia en que los primeros 6 capítulos exportadores son exactamente los mismos en el tanto en el periodo 1993-2001 (cuando explicaban en promedio el 51,5\% del total exportado) como en 2002-2007 (con una participación en las exportaciones que llegó al 55.3\% promedio). Estos son (por orden de importancia en la post-convertibilidad): 27 Combustibles minerales, aceites minerales y productos de su destilación; materias bituminosas; ceras minerales; 23 Residuos y desperdicios de las industrias alimentarias; alimentos preparados para animales; 15 Grasas y aceites animales o vegetales; productos de su desdoblamiento; grasas alimenticias elaboradas; ceras de origen animal o vegetal; 10 Cereales; 87 Vehículos automóviles, tractores, ciclos y demás vehículos terrestres, sus partes y accesorios; 12 Semillas y frutos oleaginosos; semillas y frutos diversos; plantas industriales o medicinales; paja y forrajes.

${ }^{293}$ Si bien las exportaciones de MOI abarcaban en 2007 un 31\% (dos puntos porcentuales menos que en 1998) vs $34 \%$ de las MOA, el dinamismo de las exportaciones industriales va a llevar a cambiar esta relación en 2011, alcanzando las MOI un 35\% vs un 33\% de las MOA. 
de producción como a los agentes involucrados. Como señalan Santarcángelo y Pinazo (2009), si durante los tiempos de ISI se podía percibir una complementariedad entre el desempeño de las transnacionales que dirigían la producción y las empresas locales que funcionaban como proveedoras de insumos, en la actualidad las transnacionales que dirigen el segmento automotriz guardan poca relación con el empresariado local y el empleo asalariado, ya que su producción y la provisión de insumos están ligados principalmente al mercado externo. En este sentido, observamos que la industria automotriz ha llegado a explicar el 30\% del nuevo valor creado en el sector industrial y su producción se orienta en un $60 \%$ a la exportación, presentando un $63 \%$ de uso de piezas y accesorios importados, sin generar mayores eslabonamientos al interior del entramado productivo local (Fal, Pinazo y Lizuaín, 2009). El creciente peso de los importados ha implicado que, a pesar de la creciente capacidad exportadora, el complejo automotriz continúe con un saldo comercial fuertemente deficitario, constituyendo a este sector más en un demandante de divisas que en un generador de las mismas. O sea, que si bien un amplio conjunto de empresas se vinculan al circuito productivo de esta actividad, la misma aparece centrada en las terminales automotrices orientadas a la exportación y presenta serias limitaciones para sustituir importaciones dada la disociación entre el desempeño de las terminales y la industria autopartista, sector que es "especialmente relevante en términos de empleo; de hecho, constituye durante los últimos 20 años alrededor del 55\% del total de la rama (las terminales han pasado del 31\% el 15\% entre 1996 y 2004 (...))” (Santarcángelo y Pinazo, 2009:54), pero que ha ido perdiendo participación frente al fuerte peso de los insumos importados. Otro factor relevante para pensar la distribución de recursos al interior del sector automotriz es la participación decreciente del trabajo asalariado:

\footnotetext{
"si a fines de la segunda etapa del desarrollo sustitutivo, el costo laboral total representaba alrededor del $20 \%$ de las ventas de automóviles, hoy ese valor ha descendido al $5 \%$, en un contexto donde el personal ocupado es casi una tercera parte menor. (...) además la participación del personal asalariado en el negocio ha descendido a su piso histórico en 2007 ubicándose por debajo del 10\% del valor agregado" (Santarcángelo y Pinazo, 2009:59)
}

Si en 1974 la industria automotriz empleaba a unas 57 mil personas, en 2006 sólo empleaba a 19 mil, exhibiendo unos 4 mil puestos menos que en $1996^{294}$. Esta menor absorción de empleo, en el contexto de aumento récord de la producción observado en la post-convertibilidad, se relaciona con una mejora en la productividad física del 70,4\% entre 2002 y 2006, lo cual “indica que el sector ha sido capaz de crecer

\footnotetext{
${ }^{294}$ Datos tomados de CENDA (2008b).
} 
sostenidamente a partir de la devaluación sobre la base de la reorganización del proceso productivo y del aprovechamiento de escalas y equipamiento, sin necesidad de incrementar a la par su plantilla laboral” (CENDA 2008b:25)

Dentro de la fracción productivo-exportadora del capital podemos encontrar también a un grupo de grandes empresas ligadas a la explotación de los hidrocarburos. El mercado hidrocarburífero comenzó a ser desregulado desde el comienzo del modelo de la convertibilidad, avanzando también en un proceso privatizador y extranjerizador que llegó a su punto más alto con la venta de la petrolera estatal YPF a Repsol. Los hidrocarburos en Argentina se encuentran oligopolizados en tanto las tres primeras empresas del sector, Repsol, Panamerican y Total concentraban el 61\% de la extracción de petróleo y el 75\% de la de gas y poseían una legislación favorable que les permite enviar hasta un 70\% de las remesas obtenidas al exterior. Si bien durante la postconvertibilidad se fue incrementando la participación de capitales nacionales en el mercado hidrocarburífero, esto no ha implicado una reversión de las principales cualidades que lo caracterizan: la falta de inversión y la explotación no sustentable del recurso. Esto puede verse en la estrategia de la principal empresa del sector, Repsol, que mostró un agotamiento creciente de las reservas de petróleo y gas, las cuales entre 1999 y 2007, cayeron el 45\% y el 63\% respectivamente, producto de la falta de exploración de nuevos pozos y yacimientos. Así, Repsol se concentró en expoliar los recursos ${ }^{295}$ maximizando sus utilidades, que alcanzaron un récord de más de US\$1.800.000 en 2005 (Mansilla, 2008) ${ }^{296}$. Estas estrategias predatorias de los recursos hidrocarburíferos llevaron en una genuina crisis energética local con dificultades para mantener el suministro durante las fases de alto crecimiento económico.

Esta situación de pérdida de la soberanía energética se vio reforzada en 2007 por la denominada “Ley Corta” que, reglamentando una disposición de la reforma constitucional de 1994, terminó de pautar la provincialización de las reservas, implicando que las empresas dejaran de negociar con el Estado Nacional, y lo hicieran directamente con los Estados Provinciales, en una relación de fuerzas mucho más

\footnotetext{
${ }^{295}$ El trabajo de Mansilla (2008) muestra como sólo en 2003 y 2006 Repsol tuvo una tasa de reposición positiva de barriles de petróleo (del 19\% y el $49 \%$ respectivamente) mientras que los años restante fue negativa condenando a la desaparición del recurso en el corto plazo.

${ }^{296}$ También debe observarse que mientras Repsol obtiene de Argentina el 50\% de sus utilidades a nivel mundial, sólo destina al país el 20\% de sus inversiones.
} 
favorable para estos agentes económicos, conllevando masivas licitaciones y prórrogas sin exigencia de inversiones adecuadas (Mansilla, 2008).

Por otra parte, la imposición de retenciones a las exportaciones petroleras y otras regulaciones, permitieron moderar los precios locales de las naftas, exhibiendo aumentos menores en relación a los países limítrofes, aspecto beneficiario para seguir impulsando el crecimiento de la economía en general, aunque sin limitar las rentas y ganancias extraordinarias que se apropian estos agentes en el marco de los precios récords que alcanzó el petróleo durante nuestro periodo de estudio.

Otro núcleo que debe ser destacado refiere a los agentes ligados a la minería, actividad que creció un 20.000\% entre 1997, año en que se reglamentó el Código Minero, y 2007. El código minero instituyó un marco legal ampliamente favorable a las grandes empresas transnacionales frente a las locales, garantizando al conjunto del sector amplios beneficios impositivos. Como señalan Gambina et al,

\begin{abstract}
"La regalía pagada al fisco por las mineras apenas alcanza al 3\% del valor del mineral en boca de pozo. Sin embargo el monto que efectivamente pagan las empresas es de $1,2 \%$ a $1,5 \%$ porque se toma el valor de boca de mina y se le deben deducir una serie de gastos del proyecto. Quizá lo más grave está dado por el hecho de que la base de imposición de estos porcentajes es hecha en función de una declaración jurada de la empresa de cuánto ha producido sin ningún control estatal. Agravado el tema debido a los reintegros por exportación y la no obligación por liquidar las divisas producto de la exportación” (2009:2)
\end{abstract}

Esta actividad tuvo un gran impulso en nuestro período de estudio, ya que en 2007 arribaron inversiones provenientes de veintitrés países, destinadas a actividades de exploración, desarrollo de proyectos y producción de minerales por más de \$5.600 millones, implicando un crecimiento acumulado de $748 \%$ con respecto a $2003^{297}$.

De los principales 200 proyectos que se encontraban en distintas fases de desarrollo sobre el fin de nuestro periodo de estudio, el 92,5\% estaban vinculados a empresas de origen extranjero, partiendo de la participación de un 60\% ligado a empresas canadienses (dentro de las que se destaca la Barrick Gold), y sólo un 7,5\% a capitales argentinos. Nos referimos a una actividad extractiva que se orienta casi exclusivamente a la exportación y que posee cualidades altamente contaminantes ${ }^{298}$. Estas prácticas perjudiciales para el medio ambiente están ligadas a la obtención de una

\footnotetext{
${ }^{297}$ Datos provistos por Subsecretaría de Comercio Internacional (2010).

298 Según Gambina et al (2009), son muchos los casos como el de Bajo la Alumbrera en Catamarca donde el Estado provincial le otorgó un permiso a la compañía minera para extraer 4 millones de litros de agua por hora en una zona desértica, agua que se vuelve inservible e irrecuperable para cualquier otro uso.
} 
máxima rentabilidad de las empresas mineras, ya que se utilizan metodologías altamente contaminantes con el fin de una mayor recuperación de los minerales extraídos. Para tener una dimensión de los recursos involucrados, podemos observar que sólo los principales 8 proyectos mineros alcanzan los US\$ 218.000 millones, montos mayores que la mismísima deuda pública argentina, que son extraídos de modo prácticamente gratuitos del país, y derivados al exterior. Además, se observa el agravante de que (hasta 2012) se les permitía dejar el $100 \%$ de las divisas fuera del país ${ }^{299}$.

Un cuarto núcleo que puede ser destacado dentro de la fracción productivoexportadora del capital nos remite a los agentes ligados a los diversos circuitos agroindustriales en Argentina, dentro del cual sobresale el circuito productivo sojero ${ }^{300}$ por la creciente relevancia que el mismo ha ido cobrando en la producción agraria y en la matriz productiva en general. La producción agrícola en general y sojera en particular se ha ido intensificando con el desarrollo de la denominada "revolución verde”, que se plasmó de modo significativo en la década de los 90, y que consta de diversos elementos: la proliferación del uso de semillas genéticamente modificadas (GM), la implementación extendida de la siembra directa, la masificación de los agroquímicos y el cambio de la escala de producción que conllevan ${ }^{301}$. La aplicación del "paquete tecnológico”, si bien representa una disminución en los costos y aumentos constantes en los rendimientos, requiere de una elevada inversión de capital que amplía la escala necesaria para su aplicación rentable. Esta ampliación de escala se vincula, como veremos en capítulo 6, con otros procesos que se han ido profundizando: la concentración de la propiedad de la tierra, del capital y de la gestión del proceso productivo. Estos fenómenos han provocado un proceso de agriculturización ligado tanto a la expansión de la frontera agraria como al crecimiento de la agricultura a ritmos muy superiores a los de la ganadería que fue perdiendo espacios volcándose a formas de producción más intensivas. Asimismo, la soja pasó de representar el tercer cultivo en la campaña 1996/97, alcanzando el primer lugar en 1998/99, para superar la

\footnotetext{
${ }^{299}$ Asimismo, no existían disposiciones que indicaran un tratamiento diferenciado para la mega-minería, debido a que la Ley de Actualización Minera de 1995 derogó el régimen para minería de gran escala del Código de Minería (Subsecretaría de Comercio Internacional, 2010).

${ }^{300}$ Como analizaremos en especificidad en el capítulo 6, el concepto de circuito productivo nos convoca a observar una serie de encadenamientos tales como la obtención de la materia prima, los procesos manufactureros, la comercialización y el financiamiento.

${ }^{301}$ Asimismo, la implementación del doble cultivo implicó que se pudieron realizar dos cosechas anuales, lo que significó duplicar la superficie utilizada del suelo y elevar fuertemente los ingresos de los productores agropecuarios (Barsky y Dávila, 2008).
} 
cuadruplicación de su producción en diez años, creciendo a ritmos marcadamente más elevados que los otros cultivos.

Como dijimos, las actividades del circuito productivo sojero tienen un alto impacto en la estructura exportadora argentina en tanto el complejo soja llegó a explicar, por sí solo, el 24,3\% de las exportaciones totales del país en 2007. Es importante para comprender el desempeño del circuito tener en cuenta que aproximadamente el 95\% de la producción sojera se orienta a la exportación. Esto nos señala una línea de actividad central constituida por la dinámica producciónexportación, confirmando la adecuación de pensar al circuito sojero y sus agentes dentro de la fracción productivo-exportadora del capital. Si bien podemos ubicar a los principales agentes de este circuito en el tramo final de la cadena, ligados a la industrialización y exportación de los productos, la perspectiva implicada en el concepto de circuito productivo nos permite ver cómo el conjunto de la cadena se beneficia de las condiciones comunes que el modelo post-convertibilidad y su orientación exportadora provee para un amplio espectro de los agentes involucrados.

El circuito sojero culmina en su eslabón de elaboración industrial seguido de exportación. Las plantas aceiteras, que con su creciente desarrollo constituyen uno de los principales polos industriales del país, aparecen como los agentes encargados de la molienda y refinado de la soja, convertida en harina y aceite, así como de su exportación, los cuales presentan fuertes proceso de concentración incluyendo la presencia de las principales empresas refinadoras a nivel mundial ${ }^{302}$. Pero esta dinámica envuelve un conjunto más amplios de agentes que incluyen poderosas empresas agropecuarias (como Los Grobo y El Tejar) y la conformación de pools de siembra. También se articulan a lo largo de este circuito un amplio conjunto de actividades y agentes: proveedores de insumos, productores de maquinaria, acopiadores y el conjunto de productores, contratistas y rentistas. Todos ellos se han visto beneficiados por la política de tipo de cambio competitivo, la regulación de las tarifas de servicios públicos y del precio de los combustibles, la pesificación asimétrica con su licuación y estatización de las deudas, así como por el contexto de altos precios de los commodities, al tiempo que son gravados por la política de retenciones.

\footnotetext{
${ }^{302}$ El creciente poderío de estos agentes se ha desarrollado a tal punto que los mismos tienden a integrar varias actividades de la cadena como transporte, la propiedad de los puertos, entre otras.
} 
Los fertilizantes y agroquímicos, junto con la petroquímica, constituyen subsectores de la industria química que tienen relevancia en la estructura exportadora Argentina. En la post-convertibilidad la industria química comenzó a mostrar una dinámica crecientemente exportadora respecto de los años precedentes, pasando de exportar unos US\$ 1.349 mil millones en 2002 a US\$ 2.917 mil millones en 2007, aunque en términos sectoriales exhibe un saldo comercial deficitario (US\$-3879 mil millones). Debe notarse también que el sector de sustancias y productos químicos es, en importancia, el segundo sector de la industria argentina en su conjunto, después de la producción de alimentos y bebidas.

Para completar el cuadro de los principales agentes productivo-exportadores debemos mencionar a la industria siderúrgica. El inicio del modelo post-convertibilidad tuvo un efecto muy favorable sobre las rentabilidades de las principales empresas del sector $^{303}$. Siguiendo a Amadeo (2003), podemos señalar que el mismo se encuentra concentrado en pocas empresas de gran envergadura tales como Acindar y Siderar (Ternium - grupo Techint), abocados a la producción primaria y la elaboración de algunos productos determinados, como es el caso de chapas, hojalata, flejes planos laminados en caliente y en frío, mientras que Tenaris Siderca aglomera toda la producción de tubos sin costura. Asimismo, la producción de aluminio en Argentina se encuentra casi en su totalidad concentrada en una sola empresa, Aluar. Tanto Tenaris Siderca, del grupo Techint, como Aluar poseen una fuerte dinámica exportadora ya que destinan aproximadamente el 70\% y 85\% de su producción total al mercado externo, respectivamente. Por otra parte, Acindar es el mayor productor local de lo que se denomina productos largos, orientados principalmente al sector automotriz, la industria metalmecánica y a la construcción. Siderar se especializa en la producción de laminados en frío y en caliente, proveyendo de insumos a la industria automotriz, a la construcción y al agro. De este modo, observamos agentes económicos traccionados por la dinámica exportadora, ya sea ubicando directamente sus productos en el mercado externo o como proveedor de insumos a otros agentes producto-exportadores como las automotrices, participando de su circuito productivo. También se vieron beneficiadas por la reactivación y crecimiento económico global en la post-convertibilidad afianzando su peso en el mercado interno.

${ }^{303} \mathrm{Al}$ respecto ver Azpiazu, Basualdo y Kulfas (2005). 
A la fuerte concentración de estos agentes, visible en la característica oligopólica del mercado como, se le suma su creciente extranjerización, evidenciada, por ejemplo, en que en 2006 Acindar termina de perder toda participación de capitales locales pasando a ser controlada en su totalidad por capitales foráneos.

De los rasgos de la estructura exportadora y la fracción productivo-exportadora del capital podemos extraer varias conclusiones. En primer lugar, el perfil productivoexportador que cobró el modelo post-convertibilidad y la relevancia de la fracción que expresaron este dinamismo, posee claras implicancias en el desarrollo de un nuevo proceso inflacionario, como fue descripto en el capítulo anterior, debido a que las ventas para el mercado interno se realizan a precios que gravitan cerca de los que se podrían obtener exportando la producción, por lo que el tipo de cambio determina casi directamente el precio interno de los productos exportables. Asimismo la fuerte composición de agro-alimentos que posee la estructura exportadora argentina ha tenido serios efectos en el incremento de precios que van en detrimento directo de las condiciones de vida de las clases subalternas. Si entendemos que los precios expresan relaciones de fuerzas y su variación desigual se relaciona a la disímil capacidad de apropiación del valor socialmente creado, podemos observar que esta dimensión inflacionaria fortalece, en términos generales, la capacidad de acumulación de la fracción productiva-exportadora en tanto los precios de dicha fracción evolucionan por encima de los precios exhibidos por las restantes fracciones de clase. Sin embargo, el proceso inflacionario posee al mismo tiempo un efecto contradictorio, al deteriorar el tipo de cambio real, un elemento clave en la ecuación macroeconómica en la que esta fracción sustenta su poder.

Asimismo el mantenimiento de una estructura productiva desequilibrada ${ }^{304}$ (Diamand, 1972) con un sector primario internacionalmente competitivo, al que se le suman algunos núcleos industriales dinámicos de grandes empresas, muchos de los cuales procesan recursos naturales orientados al mercado externo, y que se diferencian de un tejido industrial de baja productividad, implicando que un tipo de cambio real alto

\footnotetext{
${ }^{304}$ Diamand (1972:1) se refiere a una estructura productiva desequilibrada sosteniendo que "Se trata de una estructura productiva compuesta de dos sectores de niveles de precios diferentes: el sector primario agropecuario en nuestro caso -, que trabaja a precios internacionales, y el sector industrial, que trabaja a un nivel de costos y precios considerablemente superior al internacional”. En este punto debemos señalar que la evolución posterior de la industria argentina ha mostrado la conformación de núcleos industriales dinámicos ligados precisamente al procesamiento de recursos del sector primario, como en el caso de las agroindustrias y otras grandes industrias de alta productividad, como las terminales automotrices.
} 
genere ganancias y rentas extraordinarias en relación al resto de los agentes económicos. Es en este contexto que deben entenderse las retenciones, ya que por un lado procuran amortiguar, al menos parcialmente, el impacto inflacionario “desacoplando” precios externos e internos; y por otro lado, buscan gravar las rentas y ganancias extraordinarias, en tanto gran parte de estos agentes económicos se ven beneficiados por los altísimos precios internacionales de sus productos. De este modo, cobra mayor visibilidad la comprensión de las retenciones como un mecanismo de transferencia de recursos, que el Estado aplica sobre agentes que emergen como principales beneficiarios de la post-convertibilidad, tanto para estabilizar las cuentas públicas y contener la presión inflacionaria que deteriora el salario real y el tipo de cambio real, como para redistribuir luego este ingreso hacia otras fracciones de clase. Si bien las retenciones cumplen mediante estas dinámicas un factor compensatorio que promueve la convergencia de las distintas fracciones del capital, también se fueron constituyendo en un factor diferenciador entre los agentes afectados y los beneficiados, incluso al interior de la fracción productivo-exportadora.

A su vez, se afianza una dualidad estructural en el sector manufacturero implicando que el reducido núcleo de 100 empresas líderes ligadas al procesamiento de recursos básicos (integrantes de la fracción productivo-exportadora del capital) exhiban una balanza comercial positiva en unos US\$15.810 millones, mientras que el resto es altamente deficitario (US\$-16.529 millones) (Azpiazu y Schorr, 2010). Esto denota el poder estructural de este conjunto de agentes a partir de la posesión de divisas y su creciente concentración en base al aprovechamiento del bajo costo laboral y las ventajas comparativas naturales.

En segundo lugar, otro aspecto de la fracción productivo-exportadora que es importante destacar en tanto posee implicancias en el conjunto del modelo y en las relaciones de fuerzas, es su grado de concentración. La concentración económica implica que un pequeño grupo de grandes empresas predominen en las distintas ramas de la economía, teniendo una incidencia fundamental en la producción de valor de dicha rama. Este predominio genera un poder de monopolio que reside en la posibilidad de una o pocas empresas de excluir al resto de la competencia y desarrollar acciones efectivas sobre los factores determinantes de la tasa de beneficio, principalmente sobre el precio (Bowles y Edwards, 1985). De este modo, la concentración económica tiene también serias implicancias en el desarrollo del proceso inflacionario en tanto produce 
grandes formadores de precios con una importante capacidad de imponer aumentos por fuera de los mecanismos de mercado competitivo.

Esta concentración puede verse claramente en la fracción productivoexportadora, ya que por un lado, sólo las primeras 50 empresas aumentaron su participación en las exportaciones totales, pasando de explicar el 36,2\% en 1993, en una tendencia creciente que alcanzó el 54,9\% en 2007 (año en que explicaron el 80,5\% de las exportaciones de las 200 primera firmas) ${ }^{305306}$. Por otra parte, el peso de esta fracción se observa en que las principales empresas exportadoras en Argentina (RepsolYPF, Bunge Argentina, Cargill, Aceitera Gral. Deheza, etc.) constituyen, al mismo tiempo, las principales empresas de la estructura económica en su conjunto. La concentración es un rasgo estructural que se profundizó sobre todo al inicio del modelo post-convertibilidad, al mismo tiempo que se da un proceso de “concentración dentro de la concentración”, en tanto las primeras diez empresas de la cúpula crecieron y acumularon a ritmos muy superiores al resto (Lozano, Rameri y Raffo, 2007b).

La concentración es también una característica fundamental del crecimiento del poder estructural de los agentes productores agropecuarios y agroindustriales de la fracción productivo-exportadora. Como veremos en detalle en capítulo siguiente, las transformaciones en los circuitos agroindustriales (en el circuito productivo sojero en particular) dieron lugar un triple proceso de concentración: de la tierra, del capital y de la organización y gestión del proceso productivo mediante grandes empresas agropecuarias-financieras y los pools de siembra.

El conjunto de factores mencionados confluyen en que esta fracción tiende a presentar niveles de rentabilidad y ventas superiores al resto de las fracciones de clase. Tanto el sector agropecuario como la industria manufacturera alcanzaron ganancias muy superiores a las que percibían durante los años 90. Como señala el CENDA, en el sector agropecuario esto puede ser confirmado mediante la comparación del margen bruto por hectárea en 2007 con el de los años previos, por ejemplo "en el caso de la soja, el margen actual (\$/Ha. 671) es 295\% mayor al del 2001 (\$/Ha. 170) y 49\% superior al de 1997 (\$/Ha. 450), el mejor año de los noventa” (CENDA, 2007b:9), mientras que la rentabilidad fabril se mantuvo en sus récords históricos, un 28\% por encima de 1997.

\footnotetext{
${ }^{305}$ Datos tomados de Azpiazu et al (2011).

${ }^{306}$ Esta dinámica también puede verse en que, como señala Basualdo, la cúpula empresaria "genera el 74\% de las exportaciones totales en 2008” (2011:174).
} 
Asimismo, en materia de ventas observamos que los agentes productivo-exportadores fueron consolidando sus posiciones líderes en el mercado, llegando a que en 2007, nueve de las diez principales empresas correspondan a dicha fracción, ubicándose respectivamente: Tenaris, Repsol-YPF, Ternium, Cargill, Grupo Petrobras, Louis Dreyfus, la excepción de Telecom Argentina, Bunge Argentina, Volkswagen Argentina y Aceitera General Deheza ${ }^{307}$.

Los rasgos de concentración y extranjerización de los agentes de esta fracción sumado a su orientación exportadora, los constituye en agentes sustancialmente distintos a la "burguesía nacional" apelada recurrentemente tanto en los discursos oficiales como de las corporaciones patronales, ya que lejos de ver en el salario un factor fundamental (como consumo en el mercado interno) para la realización del capital, encuentra en él un costo que busca ser reducido para ganar rentabilidad; en tanto una de las claves de la competitividad internacional y ganancias empresarias en la postconvertibilidad se halla en que, en un contexto de aumento de la productividad laboral, la limitada evolución del salario real generó una reducción del costo laboral: salarios bajos en pesos que son aún mucho más bajos en dólares.

Podemos concluir que el crecimiento, la concentración y el lugar ocupado por este conjunto de agentes, nos permiten pensar en la configuración de una fracción productiva-exportadora del capital como núcleo dinámico del modelo postconvertibilidad. Esta fracción es la principal beneficiaria de la variación de precios relativos involucrados en el proceso inflacionario, en tanto sus precios presentan aumentos por sobre los precios exhibidos por el resto de las fracciones dominantes y subalternas: en este sentido la inflación se constituye en sí misma en un mecanismo de transferencia de recursos.

Finalmente, parece relevante señalar que el fortalecimiento de esta fracción tiene vinculación directa con las transformaciones gestadas en el modelo de acumulación, ya que el dinamismo que cobró la orientación exportadora ha permitido alcanzar un considerable superávit comercial que junto al superávit fiscal, favorecido vía retenciones a las exportaciones, configuraron los dos pilares de estabilidad del modelo.

${ }^{307}$ Datos tomado del ranking de la Revista Mercado, junio 2008. 


\subsection{La fracción de PyMEs}

Pensar una fracción de Pequeñas y Medianas Empresas ${ }^{308}$ implica observar una doble relación social: agentes que son parte de la clase dominante en la relación capital/trabajo a través de la explotación y apropiación de plusvalía, pero que, por otro lado, constituyen agentes subordinados al interior de la clase dominante, a partir del menor poder estructural que establece su tamaño y escala de producción. Asimismo, la relevancia de esta fracción en la economía argentina se evidencia en que sus agentes explican cerca del 50\% del PBI y cerca del 75\% del empleo asalariado (Sevares, 2010).

En términos generales podemos sostener que las PyMEs se vieron beneficiadas por las transformaciones suscitadas en la conformación del modelo post-convertibilidad. Tras atravesar la fuerte contracción económica producida en 2002, año de inicio del modelo, la protección brindada por el nuevo tipo de cambio, la alteración de los precios relativos, tanto por la contención de las tarifas como principalmente por la caída del costo laboral, sumado a los beneficios brindados por la pesificación asimétrica de deudas ya desde su primer versión, permitieron a las PyMEs obtener importantes márgenes de rentabilidad, promoviendo la expansión de su actividad económica. Como confirma Kulfas, "el margen de rentabilidad sobre ventas de las PyMEs pasó del 2,42 por ciento en el período 1997-1999 al 7,6 por ciento entre los años 2003 y 2007, es decir el triple que en el anterior período de crecimiento (en el medio, en el trienio 2000-2002 la tasa de rentabilidad fue negativa en 4,07 por ciento). Un aspecto destacable es que pareciera haberse establecido un nuevo nivel de rentabilidad que se mantuvo relativamente estable a lo largo del quinquenio 2003-2007” (2011:38). Sin embargo, notamos también la posición subordinada al interior de la clase dominante, corroborando la importancia de establecer un corte a partir del tamaño, ya que si bien las PyMEs amplían su nivel de rentabilidad respecto de períodos previos, observamos que esto se da en un proceso de crecimiento de conjunto de las rentabilidades empresarias que en su disímil evolución dieron como resultado la ampliación de la

\footnotetext{
308 La construcción de una fracción de PyMEs se relaciona directamente con el criterio de corte establecido a partir del tamaño. El tamaño de una empresa tiende a expresar en sí una relación de fuerzas, ya que establece el grado de gravitación, poder de negociación y de decisión sobre las variables económicas, habilitando condiciones más favorables a aquellos agentes de mayor tamaño, relacionados, a su vez, con los procesos de concentración y centralización. En virtud de estas consideraciones, el corte establecido a partir del tamaño parece prioritario para la delimitación de esta fracción por sobre las diferencias sectoriales.
} 
brecha con respecto a las grandes empresas. Esto se evidencia en que las ganancias de las PyMEs equivalieron al 3,49\% del PBI mientras que las de las grandes empresas fueron igual al 9,43\% del PBI, por lo que en la fase expansiva de la post-convertibilidad la brecha se amplió al triple, relación que en el período 1997-1999 era del doble (Kulfas, 2011).

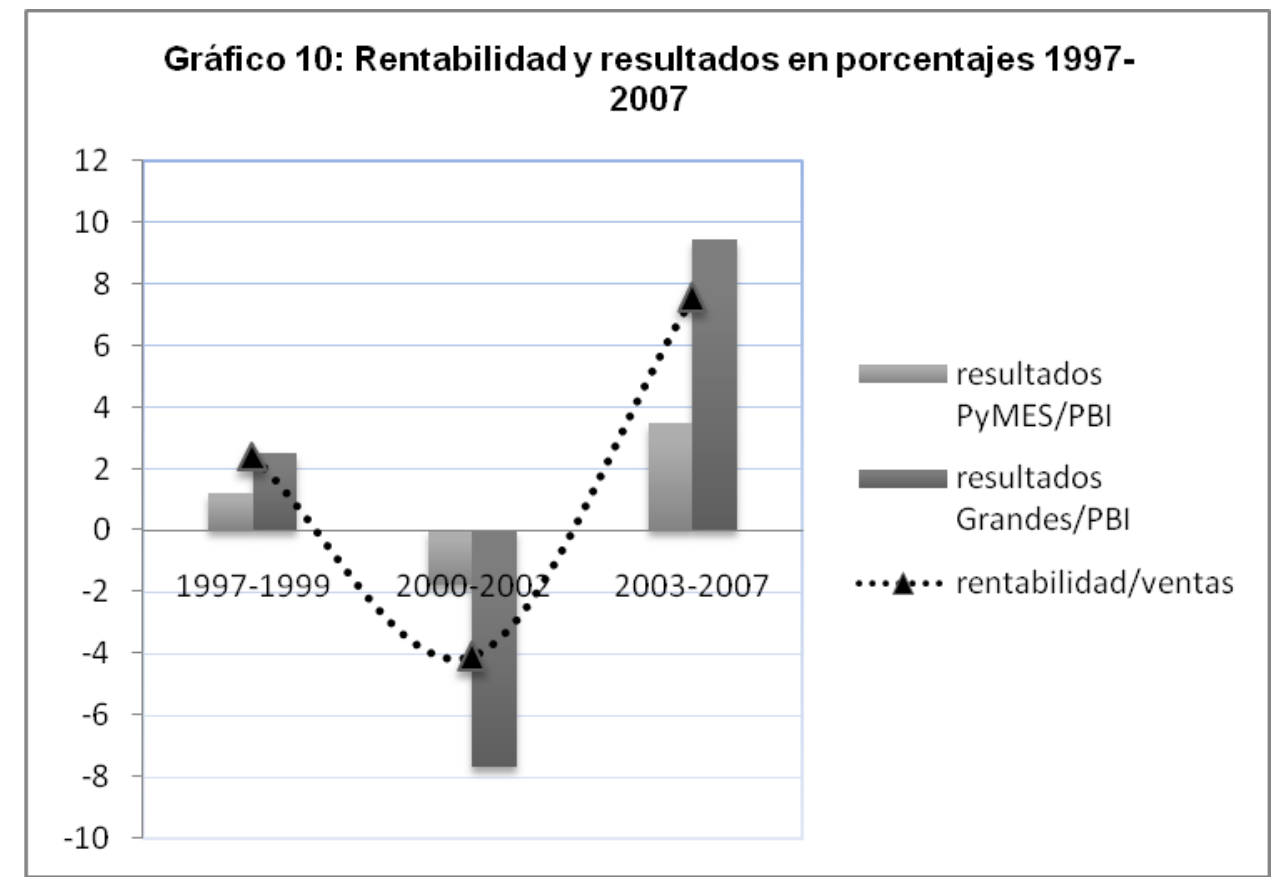

Elaboración propia en base a Kulfas, 2011

Podemos observar que las transformaciones producidas en el modelo de acumulación nos enfrentan, por un lado, a un cambio en las relaciones de fuerzas que favorece a las grandes empresas en detrimento de la fracción de PyMEs, pero que sin embargo se da en un contexto de mejora global de los indicadores que presenta esta fracción. Las nuevas condiciones establecidas a nivel del modelo de acumulación habilitaron la creación de 87.000 nuevas empresas en términos netos entre 2003 y 2006, que permitió recuperar las 47.000 que se habían perdido entre 1999 y 2002, y con un margen adicional de unas 40.000 nuevas empresas, exhibiendo una clara diversificación sectorial liderada el crecimiento de la actividad del software, la fabricación de máquinas de oficina, las manufacturas de cuero y la industria de indumentaria (Kulfas, 2009). 
También se observa un incremento de la dinámica inversora de estos agentes. Como sostiene Kulfas (2011) la proporción de PyMEs que realizó inversiones pasó de poco más del 10\% entre 2001 y 2002, acercándose al 20\% entre 2003 y 2004 y superando el 25\% entre 2005 y 2006; con la particularidad de que sólo menos de un tercio de las PyMEs que realizaron inversiones lo hicieron a través de financiamiento bancario. Esto muestra la relevancia del incremento de la rentabilidad de estos agentes empresarios como base para el autofinanciamiento de las inversiones. Asimismo, notamos que la inversión en el sector industrial de las PyMEs fue importante, ya que el 48\% de las mismas realizó inversiones entre 2003 y 2006, teniendo como principal destino la incorporación de maquinaria (un 43,5\% del total) y, luego, la modernización o actualización de los procesos productivos (19,3\% del total) (Kulfas, 2009).

Las inversiones fueron incentivadas, a su vez, desde el Estado a través de algunas herramientas políticas. Este es el caso del Programa de Bonificación de Tasas (PBT) que otorga un subsidio sobre la tasa de interés a los créditos otorgados por entidades financieras, con una bonificación que va desde los 3 a los 8 puntos porcentuales anuales o hasta el $50 \%$ de la tasa, variación que busca favorecer la inversión en regiones que presentan menor desarrollo (Kulfas, 2011). En el periodo 2003-2007 esta política involucró un monto de \$1.763 millones con más de 15 mil empresas beneficiarias, que orientaron sus inversiones principalmente a financiar capital de trabajo, distribuyéndose principalmente hacia los sectores de comercio e industria. En 2007 apareció una segunda herramienta orientada a mejorar las condiciones para la inversión, el Programa Global de Crédito, que desarrolló a través del Banco Interamericano de Desarrollo con el fin de facilitar a las PyMEs el acceso a créditos de largo plazo, casi inexistentes en el mercado financiero local. Como consigna Kulfas (2009), en 2007 se entregaron más de 3.300 créditos por un monto total de $\$ 1.190$ millones, con un plazo promedio de cinco años y montos promedio de medio millón por préstamo, orientándose principalmente al sector agropecuario y agroindustrial (el 44\% de las financiaciones).

Un elemento a mencionar es el desarrollo de un sector de las PyMEs ligadas a la exportación. La relación entre los agentes de la fracción PyMEs y las exportaciones puede leerse desde dos dimensiones: por un lado, en términos cualitativos según el tipo de mercancía exportada, y por otro, en términos de cantidades según la evolución de la capacidad exportadora en relación al conjunto de la estructura exportadora. En primer 
lugar, se observa que el tipo de mercancía exportada por las PyMEs presentan un mayor grado de incorporación de valor agregado, debido a que el precio medio en US\$ de su producción por tonelada casi triplica el de las grandes empresas, y poseen una fuerte producción relativa de manufacturas de origen industrial (del 77\% de su composición en la pequeñas y micro empresas a un 52\% en las medianas) (CEP, 2005). En segundo lugar, observamos que, al igual que el conjunto de agentes productores de bienes transables, la devaluación y el nuevo contexto macroeconómico han mejorado la capacidad exportadora de las PyMEs, que incrementaron sus ventas al exterior durante todo el período de crecimiento post-convertibilidad. En este camino las PyMEs han pasado de exportar aproximadamente 2.250 millones de dólares corrientes en 2002 a unos 4000 millones en 2007. Además, según la encuesta a PyMEs exportadoras desarrolladas por el CEDEX (2007), la mayor parte de éstas, un 74,55\% de las empresas encuestadas, son exportadores de manufacturas de origen industrial. Este desempeño es relevante en tanto las PyMEs, en términos de cantidad, representan el 70\% del total de empresas exportadoras.

Sin embargo, algunos indicadores vuelven a exhibir un aumento de la brecha, antes señalada, entre los agentes de la fracción de PyMEs y las grandes empresas. Notamos una disímil evolución de la variación del crecimiento interanual de las exportaciones, ya que las PyMEs aumentan este desempeño hasta 2004, en que alcanza un 20\%, pero luego comienza a decaer hasta el 10\% en 2007. Esta evolución contrasta con el desempeño de las grandes empresas que sólo en 2004 exhiben un indicador inferior al de las PyMEs, pero que en los años restantes muestran un desempeño superior llegando a 2007 con un 20\% de variación interanual del crecimiento de las exportaciones. En segundo lugar, a pesar del buen desempeño mostrado por las PyMEs en materia de exportación, las mismas mantienen poco peso en la estructura exportadora en su conjunto. La profundización del proceso de concentración económica desarrollado durante los primeros años del modelo post-convertibilidad (2002-2005), derivó en que el núcleo reducido de las grandes empresas realizara ventas al exterior que representan valores superiores al 89\% del total de las exportaciones realizadas. 


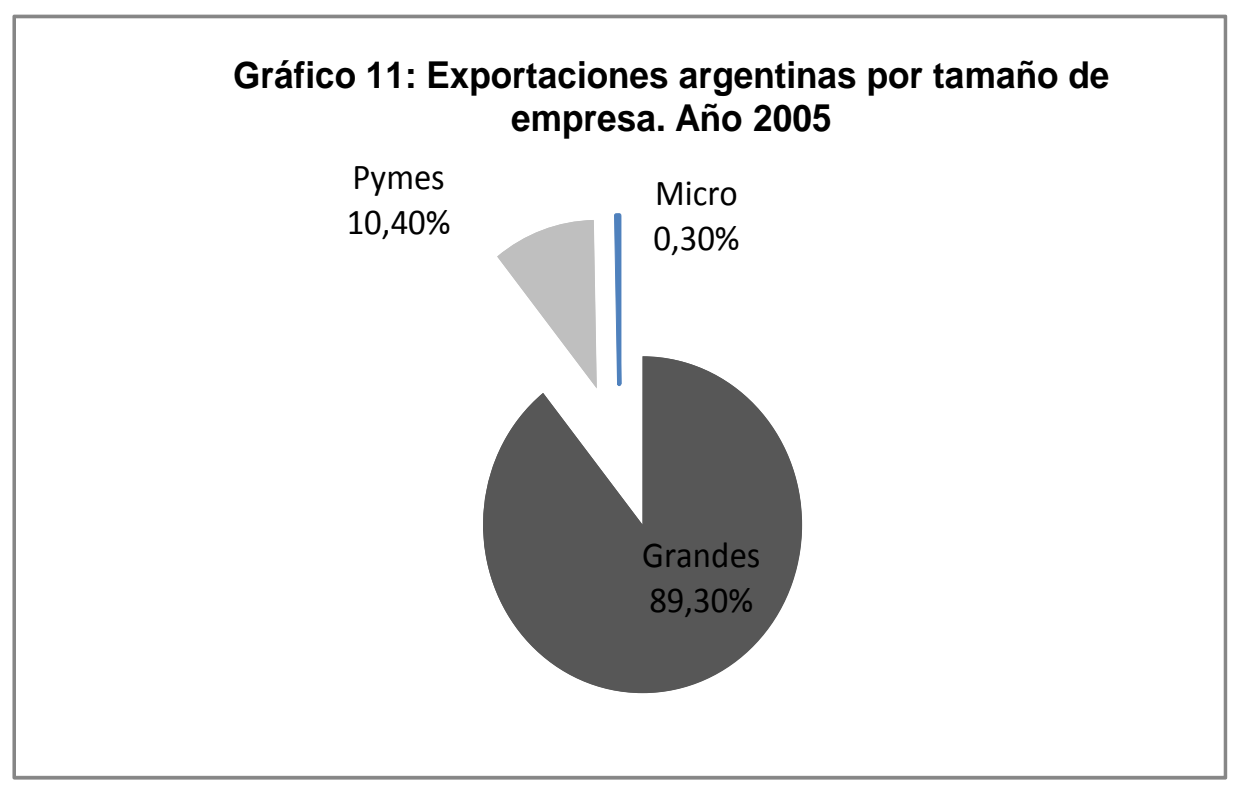

Elaboración propia en base a datos INDEC, 2007

Observamos entonces que el perfil productivo-exportador que fue cobrando el modelo de acumulación impactó también en esta fracción, favoreciendo el desarrollo de la producción de bienes transables y la inserción en el mercado mundial. Sin lograr revertir la brecha respecto de las grandes empresas, ésta se amplía mostrando variaciones en la correlación de fuerzas a nivel estructural desfavorables para los agentes de la fracción de PyMEs pero en un contexto macroeconómico y de crecimiento general del producto que lejos de asfixiar el desarrollo de estos agentes, lo impulsa.

Finalmente encontramos un elemento clave involucrado en el desempeño de la fracción de PyMEs que impacta en el modelo de acumulación y que se vincula directamente con la relación capital/trabajo: el empleo, tanto en términos cuantitativos como en términos cualitativos. Las PyMEs poseen un peso destacado en términos cuantitativos, como señala Kulfas,

\footnotetext{
“a comienzos de 2007 las micro, pequeñas y medianas empresas de la Argentina empleaban a poco más de seis millones de personas, de las cuales el $40 \%$ eran empleados registrados. Los empleos generados por las PyMEs explican en Argentina el 73,6 por ciento del empleo asalariado (incluyendo patrones y excluyendo empleo doméstico). Si consideramos exclusivamente el empleo privado, las PyMEs representan el 50,3 por ciento, y si incluimos la totalidad de los puestos de trabajo de la economía, el 41,6 por ciento corresponde a estas empresas” (2011:52)
}

En este sentido, si bien el perfil productivo del modelo habilitó la recuperación del empleo, no fueron principalmente los agentes concentrados de la fracción 
productivo-exportadora quienes motivaron dicho fenómeno. Si el descenso de la desocupación se sostuvo a partir del avance de la construcción y la industria, el 85\% del nuevo empleo industrial fue generado por PyMEs. Pero adentrándonos en la dimensión cualitativa del empleo, debemos notar que este sector empresario posee un situación que “en relación a la antigüedad de los equipos existentes de producción, los bajos niveles de inversión, el escaso financiamiento y la baja escala de producción, establecen niveles de productividad inferiores al de sus competidores, llevando, necesariamente, a que el salario se convierta en su principal variable de ajuste” (Fal, Pinazo y Lizuaín, 2009:7879). Esto se observa en que las PyMEs pagaron salarios para el I trimestre de 2007 un $48 \%$ inferior al de las grandes empresas. Además, se observa una alta tasa de informalidad laboral, con más del 60\% de los empleos no registrados en el conjunto de las PyMEs. Como contraparte de este fenómeno, las empresas más grandes del conjunto de la economía, si bien en términos cuantitativos no son los agentes fundamentales de la reducción del desempleo, en términos cualitativos tienden a otorgar mejores salarios con una mayor tasa de formalidad.

Podemos concluir que la relación capital/trabajo se expresa en los agentes de la fracción de PyMEs en esta doble dimensionalidad, jugando, por un lado, un papel importante en la recuperación del empleo en términos cuantitativos, pero, por otro, encontrando la clave de su rentabilidad en el aumento de las condiciones de explotación a través de los bajos salarios y la alta informalidad que caracterizan la calidad del empleo que proveen. A su vez, este incremento en la rentabilidad empresaria y las nuevas condiciones establecidas en el modelo de acumulación habilitaron un contexto de creación de nuevas empresas, de impulso a la inversión y a las exportaciones. Si bien esta dinámica contrasta con el desempeño de las PyMEs en períodos anteriores, al mismo tiempo no logra comenzar a revertir la brecha que las distancia de las grandes empresas, la cual se amplía por la multiplicación de la rentabilidad de estas últimas en relación a las primeras.

\subsection{Fracción de empresas de servicios públicos}

Esta fracción se compone de un amplio espectro de empresas de servicios en distintas áreas tales como telefonía, concesionarios viales, servicios de agua potable y 
saneamiento, hidrovías, terminales portuarias, servicios aeroportuarios, transporte público y proveedores de servicios de gas y electricidad. El análisis de esta fracción requiere realizar una breve reseña del proceso de privatización que despojó al Estado del manejo de la mayor parte de los servicios y del control de algunos recursos estratégicos, como los hidrocarburos. Es por esto que esta fracción contiene en sí un importante núcleo de empresas privatizadas, que se habían constituido en agentes predominantes en el modelo de acumulación de la convertibilidad.

Las privatizaciones de las empresas públicas, con posibilidades de rentabilidades extraordinarias y nulo riesgo empresario, fueron el principal incentivo para fundar un momento de convergencia al interior de la clase dominante ${ }^{309}$, conformaron una "prenda de paz” (Azpiazu y Basualdo, 2004) para sellar la crisis interburguesa evidenciada en el periodo hiper-inflacionario acontecido hacia fines de la década de los 80. También permitió debilitar a las clases subalternas limitando su presencia y capacidad de veto en las estructuras estatales. Las privatizaciones dotaron a un conjunto de agentes del capital concentrado local y extranjero ${ }^{310}$ de un poder fundamental en la determinación de los precios relativos para el conjunto de la economía argentina. Estos factores, sumados a la casi inexistencia de regulación pública y protección a los usuarios, generaron inmensas rentas de privilegio (ampliamente por encima del resto de las fracciones del capital) en condiciones de mercado cautivo.

La acción estatal jugó decididamente a favor de las principales fracciones de la clase dominante, al punto que el Estado mismo se encargó de aplicar fuertes aumentos tarifarios y expulsión masiva de mano de obra de las empresas públicas previo a su traspaso al capital privado con el fin de incrementar el "atractivo" de este negocio. Estos aumentos en las tarifas, que perjudicaron principalmente al conjunto de las clases subalternas, afectó la estructura de costos de los agentes productores de bienes

\footnotetext{
${ }^{309}$ El proceso de privatizaciones se produjo principalmente a partir de la sanción de la Ley de Reforma del Estado n²3.696 de 1989 (aunque ya se registraban experiencias de privatizaciones de sectores marginales de las empresas del Estado durante el gobierno militar y el radical). Las características propias de este proceso, como la permeabilidad al lobbying empresario y el establecimiento de patrimonios mínimos elevados que llevaron a la presentación de pocos oferentes en las licitaciones, promovieron una fuerte concentración y centralización del capital y su reforzamiento en condiciones monopólicas u oligopólicas. ${ }^{310}$ Así como a los acreedores externos, posibilitados de capitalizar su deuda pagando con títulos de la misma.
} 
transables, que, sumado a la sobrevaluación del peso y la apertura económica, profundizaron el sesgo desindustrializador del modelo de los $90^{311}$.

Las superganancias de las privatizadas fueron aseguradas también por una cláusula de indexación de las tarifas según la inflación de Estados Unidos, pese a la expresa prohibición de la misma por la Ley de Convertibilidad n 23.928. También se recurrió constantemente a la renegociación de los contratos originales, en beneficio siempre de las empresas, como en los casos de exenciones en el pago del canon o modificaciones en los programas de inversiones. A su vez, a partir de 1995, la creciente venta de acciones por parte del capital local con el fin de realizar ganancias patrimoniales, habilitadas a partir de la subvaluación original de los activos privatizados y de las condiciones de alta rentabilidad, profundizó la extranjerización de esta fracción (Basualdo, 2003)

La caída del modelo de la convertibilidad y el surgimiento de un nuevo modelo de acumulación modificaron fuertemente el escenario para esta fracción de clase. Como señalamos en el capítulo anterior, de las políticas fundacionales, la devaluación, la pesificación asimétrica y el congelamiento y re-discusión de tarifas tuvieron impactos destacados respecto de las empresas de servicios privatizadas. La Ley de Emergencia Pública $\mathrm{n}^{\circ} 25.561$ en su artículo $\mathrm{n}^{\circ}$ 8, dejaba sin efecto las cláusulas indexatorias presentes en los contratos y desdolarizaba las tarifas. También habilitaba al gobierno para renegociar los contratos de las privatizadas y regular, transitoriamente, los precios de insumos, bienes y servicios críticos, a fin de proteger los derechos de los usuarios y consumidores de la eventual distorsión de los mercados o de acciones de naturaleza monopólica u oligopólica. Mientras fueron afectadas por la devaluación, por su composición accionaria principalmente de origen extranjera, disminuyendo las utilidades en divisas y encareciendo los insumos que adquirían a través de empresas en el exterior ligadas a sus holdings; por otra parte fueron beneficiadas por la pesificación asimétrica de deudas: "Entre los 50 mayores deudores privados que a comienzos de 2002 vieron licuados sus pasivos con el sistema financiero local (...) quedaron incluidas 25 empresas privatizadas que por ese medio obtuvieron un beneficio -del orden de los

\footnotetext{
${ }^{311}$ A esto se le suma la tendencia de las privatizadas a comprar sus insumos a empresas vinculadas a sus propios consorcios, especialmente a través de importación, generando el desmantelamiento de numerosas unidades productivas que eran tradicionalmente proveedores de las empresas públicas.
} 
2000 millones de dólares- prácticamente equivalentes a las ganancias obtenidas por las mismas en el año 2000” (Azpiazu y Schorr, 2003:77).

Durante la administración Duhalde las acciones estatales se limitaron a las renegociaciones tarifarias que avanzaron lentamente, con presiones tanto de gobiernos extranjeros como del FMI, pero mediadas por la intervención del poder judicial que invalidaba los intentos de aumentos que pretendían vulnerar la Ley de Emergencia Pública. Según Azpiazu (2005) se visualizaron dos estrategias: por un lado, las empresas utilizaron su poder de lobbying bajo amenaza de abandonar el país, declararse en default o en convocatoria de acreedores, de recurrir a tribunales internacionales en el marco de los Tratados Bilaterales para la Promoción y Protección de Inversiones Extranjeras $^{312}$ firmados por Argentina, de reducir inversiones o despedir masivamente trabajadores, con el fin de reclamar medidas favorables a ellas. Por otro lado, el gobierno de Duhalde desplegó una estrategia dual, ya que, en un conjunto de actividades donde gravitaban de modo importante capitales locales y que no tenían un fuerte impacto directo sobre los sectores de menores recursos, aplicó medidas legalmente cuestionables funcionales con el proceso de acumulación de capital de las empresas, como en los casos de vías fluviales dolarizando tarifas y otorgando subsidios, servicios aeroportuarios con dolarización de tarifas, correos postales con fuertes aumentos, terminales del puerto de Buenos Aires con tarifas dolarizadas, y asistencia financiera para el puente Rosario-Victoria. Pero en las actividades que las tarifas tenían una mayor relevancia sobre el nivel de vida de las clases subalternas (sobre todo en servicios públicos sensibles como agua y saneamiento, transporte ferroviario, peajes viales, teléfonos, gas, electricidad), el gobierno buscó dilatar las renegociaciones y dejarlas para el futuro gobierno que lo siguiera.

Esta compleja situación fue heredada por el gobierno de Kirchner, que, como anticipamos en el capítulo anterior, desplegó una estrategia heterogénea respecto de los servicios públicos consistente en tres acciones estatales diferenciadas: renegociación, reestatización y creación empresarial. Esta estrategia fue desplegada persiguiendo tres objetivos principales: 1) desmantelar los procesos judiciales que muchas privatizadas

312 Como señala Azpiazu, los TBI refieren a "un acuerdo entre Estados, sujeto al derecho público internacional, por el que los inversores de cualquiera de los países signatarios pueden recurrir a tribunales internacionales para la resolución de diferendos o controversias con el Estado receptor de sus capitales. En suma: la equiparación entre un inversor privado y un país soberano. (...) se busca la sustitución de las viejas invasiones imperialistas en defensa de los intereses de sus empresas por un instrumento que, en principio resultaría menos cruento aunque de resultados potencialmente equiparables” (2005:45). 
llevaban adelante en el CIADI; 2) mantener el nuevo esquema de precios relativos favorables a la producción de bienes transables, evitando un "tarifazo" que afectara la recuperación económica y el nivel de inflación; y 3) aumentar la influencia del Estado en determinadas áreas.

Ya hemos tratado la estrategia de renegociación en el capítulo anterior, en tanto constituye una política fundacional del modelo post-convertibilidad. Como síntesis, podemos señalar que en general se trató de evitar un aumento tarifario que impactara directamente sobre los sectores de menos recursos de las clases subalternas y que, si bien, en todos los casos el acuerdo implicó el retiro de las demandas del CIADI, no se exigieron a las privatizadas las inversiones previamente incumplidas. En este sentido, la política de renegociación desplegada quedó fuertemente centrada en el control de las tarifas con el fin de mantener el nuevo esquema de precios relativos.

Por otro lado, la política de reestatización de las empresas privatizadas -que se efectuó mediante la rescisión del contrato y la asunción de dichas actividades por parte del Estado- marca una arista de una estrategia novedosa. En primera instancia, debemos señalar que estas empresas estatales se crean como sociedades anónimas consignadas bajo la ley $n^{0} 19.550$ que regula y tipifica las sociedades comerciales. Esto quiere decir que escapan a las regulaciones tradicionales de las empresas estatales, tales como la Ley sobre Contrataciones, la Ley de Contabilidad de Empresas Públicas, y la Ley de Administración Pública.

Este es el caso del Correo que fue reestatizado en 2003, pasando a ser controlado por el Ministerio de Planificación, luego de que se le rescindiera el contrato a la Sociedad Macri (SOCMA) debido a una millonaria deuda en concepto de canon ${ }^{313}$. Esta reestatización se manifestó en efecto como un ejemplo exitoso que ayudó a desmitificar uno de los consensos de los 90, respecto de la supuesta incapacidad del Estado de gestionar los servicios, ya que a tres años de realizada, la administración pública había logrado mantener las tarifas minoristas congeladas, no generó déficit ni utilizó dinero proveniente de subsidios y obtuvo una ganancia aproximada de \$18 millones en el $2006^{314}$.

\footnotetext{
${ }^{313}$ Para un análisis de este caso ver Castellani (2008).

314 Crónica, 18/11/2006.
} 
Otro caso particular de reestatización es el de Aguas Argentinas, contrato rescindido al grupo Suez por el fuerte deterioro del recurso y la voluntad del concesionario de retirarse, que dio origen a AySA (Aguas y Saneamientos Argentinos). AySA se convirtió en una empresa cuya composición accionaria se dividió en un 90\% para el Ministerio de Planificación y el 10\% restante quedó en manos de los empleados a través de un Programa de Participación Accionaria. Otro caso similar ha sido la anulación del contrato a la empresa francesa Thales Espectrum, que tenía a su cargo el control del espacio radioeléctrico argentino. La reestatización del espacio radioeléctrico puede ser explicada principalmente por el objetivo del Estado de recuperar influencias en ciertas áreas claves así como por las deudas en materia de canon. Un caso de reestatización parcial podemos encontrarlo en Aeropuertos Argentina 2000, donde el gobierno adquirió el $40 \%$ del paquete accionario constituyendo una sociedad mixta. Por otro lado, en el caso del Ferrocarril San Martín, podemos ver otro caso mixto en que la empresa es administrada por el Estado y su gestión técnica queda en manos de una Unidad de Gestión Operativa (UGOFE) a cargo de un grupo de empresas privadas.

Las reestatizaciones aparecen como una novedad respecto de las políticas aplicadas en los años noventa donde primaron el discurso y las políticas privatistas. Sin embargo, durante nuestro período de estudio, se avanzó sólo sobre servicios cuya gestión privada había sido evidentemente escandalosa, ya sea por deterioros graves en la prestación del servicio o por incumplimientos en el pago del canon al Estado. En este sentido, no pareció desarrollarse una planificación política más integral que procurara volver a la gestión estatal los principales servicios y recursos estratégicos.

La tercera variante de la estrategia heterogénea es la creación empresarial. Esta opción implica la creación de una empresa estatal, como sociedad anónima regida por la ley $\mathrm{n}^{\circ} 19.550$, sin quitar las concesiones hechas en el área. Este es el caso de ENARSA (Energía Argentina S.A), creada como parte de la política energética del gobierno para incidir en esta área clave, cuya composición accionaria preveía incluir un 35\% de participación de capital privado. A pesar de las similitudes con las experiencias señaladas en el punto anterior (se crea una empresa comercial donde el Estado es el principal accionario), ENARSA representa ciertos aspectos de continuidad con las políticas de los años 90. Esto se debe a que ENARSA abre las puertas al gran capital a explotar “conjuntamente" las riquezas de la cuenca marítima, el último reducto de reserva petrolera sin concesionar. Así, ENARSA impulsó la formación de consorcios 
para la exploración y explotación de la cuenca marítima, donde tenía participación minoritaria y por esto, escasa capacidad de decisión. Además ENARSA ofrecía importantes beneficios impositivos ${ }^{315}$ para promover la explotación y exploración, tarea incumplida por las privadas del sector que habían generado un verdadero saqueo del recurso desde su privatización. Sin realizar un reclamo soberano sobre los hidrocarburos $^{316}$, el gobierno permitió a las petroleras remitir al exterior el 70\% de las divisas entrantes por exportaciones, aunque ha establecido retenciones y controles de precios sobre los combustibles. Por otra parte, cabe destacar que ENARSA permitió recuperar una incidencia estatal en el área energética y buscaba convertirse, en articulación con las petroleras estatales latinoamericanas, en una herramienta de integración regional.

El nuevo contexto brindado por el modelo de acumulación post-convertibilidad nos enfrenta con que la fracción de empresas de servicios públicos aparece subordinada en el nuevo estado de fuerzas al interior de la clase dominante. Esto no implica la ausencia de ganancias, sino una menor capacidad de apropiación del valor socialmente creado con respecto a las condiciones previas constituidas durante el modelo de los años 90. Como se observa en el siguiente cuadro, la mayor parte de las empresas privatizadas muestran una rentabilidad positiva, aunque en términos generales son menores al promedio obtenido entre 1998 y 2001.

\footnotetext{
315 Según Ortiz y Schorr las empresas que se asocien con ENARSA "podrán obtener la devolución anticipada del Impuesto al Valor Agregado, la amortización del Impuesto a las Ganancias y la exención del Impuesto a la Ganancia Mínima Presunta sobre la totalidad de los gastos e inversiones realizadas en la etapa de exploración y las concretadas en el período de explotación de los recursos. También se exime del pago de los derechos de importación y todo otro derecho por la introducción de bienes de capital necesarios para la ejecución de las actividades de exploración y explotación” (2009:22).

${ }^{316}$ Esto cambió con la nacionalización del 51\% de la participación accionaria de YPF en 2012.
} 
Gráfico 12: Promedio anual de las rentabilidades operativas de varias empresas privatizadas o vinculadas a las privatizaciones (utilidades operativas sobre ventas), 1998-2001 y 2002-2006 (porcentajes)

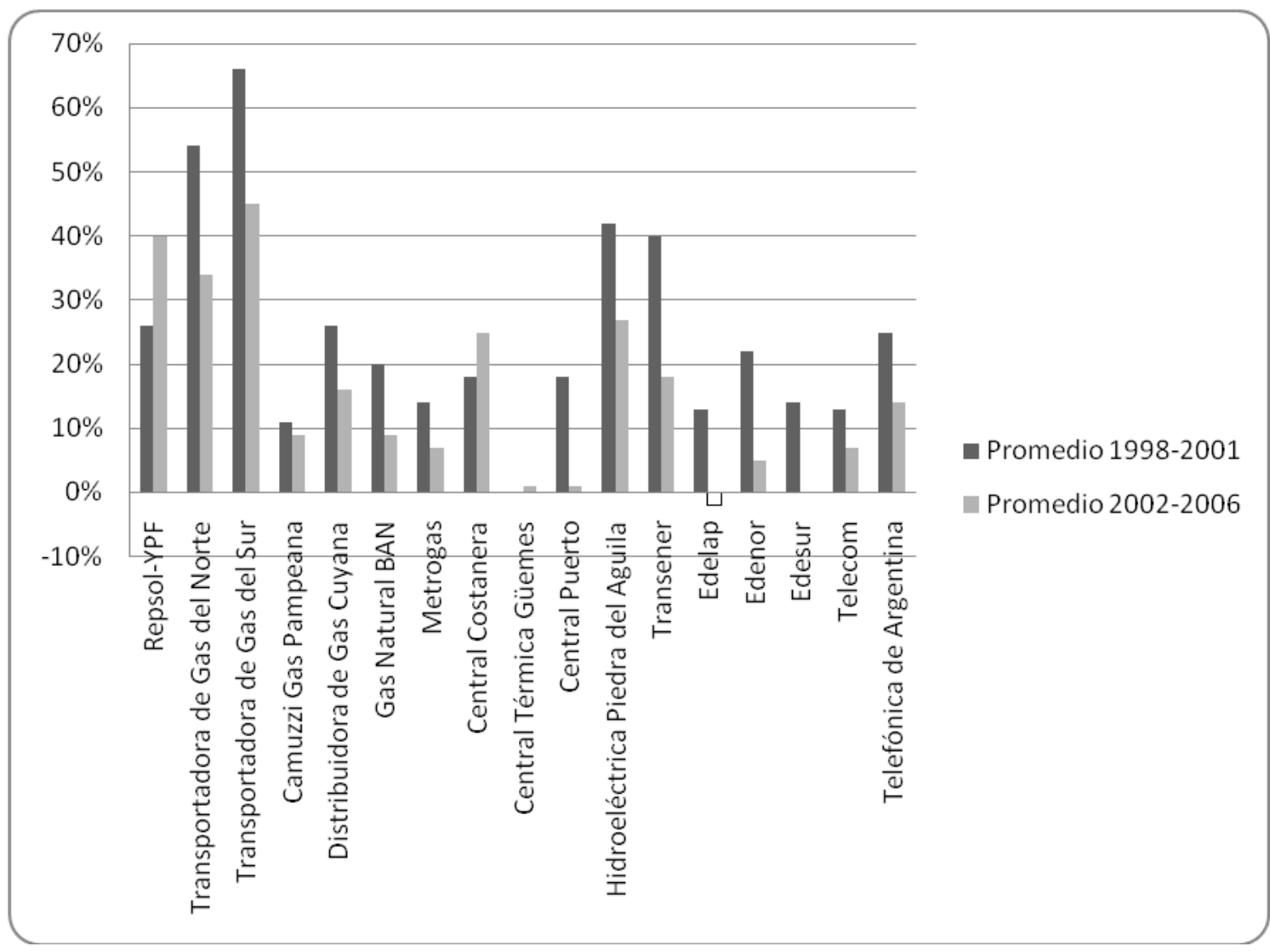

Elaboración propia en base a Ortiz, Ricardo y Martín Schorr (2007)

Como conclusión podemos señalar que las privatizadas han sido afectadas por las políticas inaugurales de la post-convertibilidad: perjudicadas por la devaluación y el congelamiento tarifario, pero beneficiadas por la pesificación asimétrica que implicó licuación y estatización de un monto importante de deudas. En este contexto, emergieron estrategias desde los gobiernos de nuestro periodo de estudio que presentan continuidades y rupturas respecto de la política netamente privatista de los años 90 . El Estado obtiene un mayor grado de incidencia en los servicios utilizando herramientas legales para fortalecer su posición en la renegociación de tarifas, aunque sin alcanzar a realizar (hasta 2008) un replanteamiento integral de los recursos naturales y servicios fundamentales ${ }^{317}$. En este sentido, se mantuvo el amplio grado de extranjerización y concentración económica en los servicios y se recompone parcialmente su rentabilidad

\footnotetext{
${ }^{317}$ El proceso de reestatización comenzó a marcar una constante que se profundizó en los años posteriores a nuestro recorte temporal. En este camino fueron estatizadas varias empresas como Aerolíneas Argentinas, llegando a una acción estatal de alcance estructural con la estatización del 51\% de YPF.
} 
sin exigir las inversiones no realizadas. Apareció, como ruptura en materia de acción estatal, la reestatización y aunque, se realizó por fuera de las figuras legales correspondientes a empresas estatales ${ }^{318}$, comenzó a constituir un factor constante como intervención estatal sobre el desarrollo del modelo de acumulación. Se creó una empresa en el sector de los hidrocarburos, pero sin capacidad, en esta etapa, de contrarrestar y reformular las dinámicas predatorias ejercidas por los agentes económicos en dicho sector.

Los gobiernos en nuestro período de estudio, al tiempo que asumieron una postura de mayor firmeza que los anteriores frente a las empresas de servicios privatizadas, se cuidaron de no desarrollar una prédica nacionalista respecto de los recursos naturales, ni de reactivar la antinomia “estatal/privado” (Svampa, 2006). Así, las privatizadas ocuparon una posición subordinada en relación a las super-ganancias que acaparaban en los años 90, cuando representando sólo el 13\% de las empresas de la cúpula empresaria, explicaban aproximadamente el 57\% de las ganancias totales de la misma $^{319}$. Como indicador del cambio en las relaciones de fuerzas, sostenidas por la acción estatal, podemos ver que la evolución del precio de los servicios fue menor que la de los bienes transables. Esto puede constatarse en la disímil evolución de los índices de precios IPC e IPIM: mientras que el IPC incluye una canasta de bienes y servicios, su incremento de 98,7\% entre diciembre de 2001 y de 2006 presenta una elevada brecha con respecto al IPIM, que incluye precios al por mayor sólo de bienes transables, y ha aumentado, en el mismo periodo, un $194,2 \%{ }^{320}$. Esto marca una clara diferenciación en la capacidad de acumulación entre las empresas privatizadas productoras de bienes transables (como Repsol ex-YPF y Siderar ex-Somisa ligadas a la fracción productivoexportadora) y las empresas de servicios privatizadas que componen la fracción estudiada en el presente apartado.

Pero si bien en el modelo post-convertibilidad las empresas de servicios públicos privatizadas han perdido posiciones al interior de la cúpula empresaria (aunque algunas, como Telecom, siguieron entre los primeros diez puestos), el gobierno de Kirchner ha desplegado una política de subsidios compensatorios. Esta política de subsidios, que se

\footnotetext{
${ }^{318}$ Algunas críticas realizadas a este proceso sostenían que se crean empresas con escaso control estatal, dotando de cierto poder discrecional al Ministerio de Planificación.

${ }^{319}$ Datos tomados de Azpiazu y Basualdo, 2004.

${ }^{320}$ Además, como vimos en el capítulo anterior, en 2002, año clave de la devaluación, al interior del aumento de $41 \%$ del IPC los bienes aumentaron un 67\%, mientras que los servicios sólo lo hicieron en un 14,8\% (Azpiazu y Schorr, 2010).
} 
multiplicaron año a año, constituyó un mecanismo de transferencia de recursos que procuró beneficiar la acumulación de los agentes de la fracción de servicios públicos al tiempo que evitó un impacto directo sobre los sectores más vulnerables de las clases subalternas y buscó mantener un esquema de precios relativos favorable a la producción de bienes transables.

Asimismo, debe observarse que, una vez pasado lo más agudo de la contracción económica al inicio de la post-convertibilidad, la mayor parte de las empresas de servicios mostraron resultados operativos positivos (incluso durante el congelamiento tarifario). Aunque muchas de ellas presentaron déficits financieros, producto de las prácticas de endeudamiento en el exterior que habían desarrollado en la década de los 90 mientras obtenían máximas ganancias extraordinarias con nulo riesgo empresario. Éste pasó a constituir el principal problema para estas empresas tras la devaluación.

\subsection{Fracción financiera del capital}

La fracción financiera del capital se encuentra vinculada a la relevancia de los conglomerados financieros, tanto a nivel estructural como fracción no productiva que se apropia del valor a través del interés y la provisión de servicios, como en relación a las políticas en torno a la deuda pública y de regulación de la tasa de interés. Una perspectiva a tener en cuenta acerca de las características y el peso de la fracción financiera del capital es su creciente conglomeración, fenómeno que Golla identifica “con empresas o sociedades que desarrollaban originalmente su actividad en un determinado segmento del mercado financiero y que, posteriormente, incursionan en otros segmentos de los servicios, diferenciados (aunque a veces complementarios) de su motivación original” (2006:14). Es decir, los conglomerados financieros abarcan un amplio espectro de entidades financieras, encabezados por un banco, tienden a incluir a las AFJP, Compañías de Seguros y Fondo Común de Inversión.

Según Golla, el sistema financiero argentino presenta un 80,5\% de sus fondos en poder de conglomerados de distintos tipos (privados, estatales y cooperativos). Los conglomerados financieros en Argentina tienen un importante grado de extranjerización: del conjunto de conglomerados financieros, un 59,9\% es capital de 
origen extranjero, en tanto que sólo el $10,9 \%$ es de capital privado nacional ${ }^{321}$. Si bien existe una fuerte presencia del sector público en el sistema financiero (conglomerados nucleados en torno al Banco Nación y al Banco de la Provincia de Buenos Aires), los mayores cuatro conglomerados privados (20\% del total) representan más del 50\% de los fondos manejados por el total de conglomerados (\$131.111 millones). Esta cifra da cuenta de una de las características propias de las fracciones del capital en la Argentina: su alto grado de concentración.

Los principales cuatro conglomerados financieros privados, por orden de importancia eran:

1) Conglomerado nucleado en torno al BBVA Banco Francés, comprendía a Consolidar AFJP, BBVA Seguros Generales, Consolidar ART, VIDA y Retiro (compañías de seguros), y el fondo común de inversión Francés Administradora de Inversiones;

2) Conglomerado nucleado alrededor del Banco Santander Río, incluía el 69,4\% de Orígenes AFJP, las compañías de seguros Río Seguros Generales, Internacional Vida (59,2\%), Orígenes Retiro (59,2\%), y el fondo común de inversión Santander Investment.

3) Conglomerado nucleado en torno al Citibank, contenía a Siembra AFJP, las compañías de seguros Siembra Retiro y Siembra Vida, y el fondo común de inversión Citicorp Inversora.

4) Conglomerado nucleado en torno al HSBC Bank Argentina, abarcaba Máxima AFJP, las compañías de seguros HSBC Buenos Aires, HSBC NY Life retiro y HSBC NY Life Vida, y el fondo común de inversión HSBC Administradora de Inversiones. $^{322}$

Otro aspecto general de la fracción financiera del capital a señalar es que, como indica Boron: "Mientras la prosperidad del viejo capital industrial de la época fordista tenía como una de sus principales condiciones la existencia de un alto tenor de consumo de masas, las requeridas por el capital financiero se encuentran totalmente disociadas

\footnotetext{
${ }^{321}$ Como mostraremos luego, si bien se mantiene un importante grado de extranjerización, un factor destacado de la post-convertibilidad es que la misma muestra una tendencia a la disminución.

${ }^{322}$ Datos a diciembre de 2004 obtenidos de Golla (2006).
} 
del bienestar colectivo o de los consumos populares; de ahí su carácter parasitario y predatorio" (Boron, 2001). Esto es constatado por el autor con la estimación de que cerca del 95\% del capital dinerario que se moviliza en los circuitos financieros internacionales es de carácter especulativo.

En los años 90 la fracción financiera del capital ocupó un lugar destacado en el modelo de acumulación, en tanto las altas tasas de interés interna y la convertibilidad de moneda establecida por ley generaban que las grandes corporaciones de distintas fracciones buscaran incrementar la apropiación de valor destinando parte de su excedente a la denominada "valorización financiera”323 (Basualdo, 2010). A partir de 1994 se profundizó en Argentina el proceso de extranjerización de la fracción financiera del capital, articulándose con un fuerte sesgo concentrador. Como confirma Cobe (2009), entre 1994 y 1999 la cantidad de entidades bancarias se redujo de 168 a 92 y los cinco mayores bancos pasaron de controlar el 37\% a 45\% de los depósitos bancarios, al tiempo que la cantidad de bancos extranjeros varió de 31 a 38, pasando a controlar del 17\% al $47 \%$ de los depósitos. En la crisis del modelo de la convertibilidad, los principales agentes del capital financiero se encolumnaron detrás de la propuesta dolarizadora con el fin de cristalizar los privilegios que dicho modelo les garantizaba.

Definida la salida devaluacionista, los agentes del capital financiero fueron afectados de diversas formas por el conjunto de políticas fundacionales del modelo post-convertibilidad. La combinación de devaluación y pesificación asimétrica de deudas y depósitos incidió fuertemente en la fracción financiera del capital, evidenciando cambios en las relaciones de fuerzas. La posible absorción de la diferencia establecida en la pesificación asimétrica parecía dejar al conjunto del sistema financiero al borde del colapso. En este contexto, el gobierno de Duhalde comenzó a desplegar la política de "salvataje" al capital financiero que implicó la emisión de nueva deuda pública por un monto total de US\$ 14.386 millones, a lo que se sumaron otros US\$ 9.679 millones con los que el Estado nacional apuntaló el sistema financiero absorbiendo las deudas que los Estados provinciales mantenían con los bancos. Así, el Estado Nacional movilizó unos US\$ 24.065 millones en diversas operaciones destinadas a recomponer el sistema financiero, ya sea como transferencia directa hacia el capital

\footnotetext{
${ }^{323}$ Retomamos aquí la idea de Basualdo, remitiéndonos a la "valorización financiera”, no en términos de creación de valor (ya que el capital financiero no crea valor) sino en relación a la dinámica de apropiación de valor de relevancia (aunque con distintos énfasis) entre 1976 y 2001.
} 
financiero, asumiendo o no los bancos obligaciones con el Estado, o de forma indirecta, asumiendo los pasivos de los Estados provinciales con los bancos. Asimismo, los conglomerados financieros son importantes agentes del endeudamiento público (por ejemplo, las AFJP tenían casi el 20\% de la deuda, y ocupaban con bonos cerca del 50\% de sus carteras) ${ }^{324}$ a los que se suman los organismos financieros internacionales y los Estados nacionales, prestamistas y deudores. Los conglomerados financieros eran poseedores de una parte significativa de la deuda en default.

Habiendo analizado en el capítulo anterior el default y el canje con que se le dio resolución, podemos destacar ahora algunas claves de este proceso que nos permiten analizar la relación entre deuda pública y capital financiero. Como ya dijimos, del total de los US\$ 81.800 millones que entraron en default en 2001 el canje fue aceptado en un $76,15 \%$, equivalente a US\$ 62.300 millones que canjeados se redujeron a US\$ 35.300 millones, representando una quita del $43,4 \%$. Se presentaron tres nuevos bonos para el canje: el discount ${ }^{325}$, de mayor quita y con capitalización de intereses; el cuasipar $^{326}$ orientado especialmente a las AFJP y grandes tenedores de bonos; y el par ${ }^{327}$, sin quita ni capitalización y con menores intereses. En la composición de los bonos se observan dos factores importantes: largos plazos de vencimiento para su amortización final y distintas variantes de quita en combinación con los intereses y los montos mínimos de ingreso que definió quiénes podían adquirirlos y quiénes no. Además, debemos recordar que no se hizo distinción entre grandes y pequeños tenedores de bonos, sino que, en general, el establecimiento de montos mínimos benefició a los más grandes.

\footnotetext{
${ }^{324}$ Otro factor que evidencia el peso de los conglomerados financieros en el proceso de endeudamiento público se observa en el canje de títulos realizado en diciembre de 2001 por más de 42 mil millones de dólares en préstamos garantizados que luego no entraron en default y en cuya operación participaron bancos con un 31\%, AFJP con el $41 \%$ y particulares sólo con el $28 \%$.

325 El bono discount conllevaba una quita del 66,3\%, rindiendo un interés fijo creciente, con capitalización en los primeros diez años. Presentó títulos en monedas euro, dólar, yen y pesos + CER. No exigió un monto mínimo para su adquisición. Finalizado el canje, fue emitido por un monto de capital de US\$ 11.900 millones. Vence el 31 de diciembre de 2033.

${ }^{326}$ El bono cuasi-par presentó una quita del 30,1\%. Bono sólo en pesos + CER. Este bono es importante porque estuvo orientado principalmente a las AFJP y otros grandes tenedores de bonos, ya que poseía un monto mínimo para canje de US\$350.000. Ofrecía una tasa fija del 3,31\% con capitalización en los primeros diez años, y fue emitido por un total de US\$ 8.300 millones. Vence el 31 de diciembre de 2045.

${ }^{327}$ El bono par no presentó quita alguna. Ofrecido en monedas euro, dólar, yen y peso + CER. Con tasas crecientes que tendrían un promedio de 3,46\%, sin capitalización. Durante las primeras tres semanas de canje sólo se permitió el acceso de US\$ 50.000 por tenedor, abriéndose, en la última semana, el saldo restante disponible. Fue emitido por US\$15.000 millones. Vence el 31 de diciembre de 2038.
} 
También debemos recoger algunos componentes claves señalados en el capítulo anterior:

- Más del 40\% de la deuda post-canje se encontró en pesos pero indexada al CER, coeficiente que expresa la inflación.

- Las Unidades Ligadas al PBI, cupones indexados al crecimiento, constituyeron otro elemento que aumentó los desembolsos por deuda.

Estos componentes indexatorios de la deuda, tanto la parte en pesos + CER como los cupones de PBI, representan elementos dinámicos que impulsan el alza del endeudamiento público, incrementando de forma variable las transferencias de recursos que dichos empréstitos representan. A esto se suma la capitalización de intereses que presentan tanto el bono discount como el cuasi-par durante los primeros diez años, que tienen como efecto aumentar el stock de la deuda (en unos US\$ 1.000 millones anuales $^{328}$ ). Los mecanismos indexatorios a crecimiento e inflación nos convocan a pensar la configuración del sistema de transferencias de recursos que procuró gestar un nuevo momento de convergencia al interior de la clase dominante, superando, al menos momentáneamente, las disrupciones que había conllevado la salida del modelo de la convertibilidad, pero en un nuevo marco de relaciones de fuerzas. Así, se busca ligar una parte de los recursos de deuda al desempeño de las restantes fracciones del capital, a través del crecimiento del producto y los precios ${ }^{329}$.

Sin embargo, entendemos que se produce un cambio cualitativo en la función ocupada por la deuda en el modelo de acumulación, que hace directamente a las relaciones de fuerza vinculadas a la fracción financiera del capital. Mientras que en los años 90 el amplio proceso de endeudamiento público cumplía el papel de sustentar la convertibilidad de la moneda, en estrecha relación con el proceso de endeudamiento externo privado, la valorización financiera de recursos y la fuga de capitales, ahora la deuda sigue siendo un mecanismo de transferencia y dependencia pero no ocupa ya un lugar central en la dinámica de acumulación del conjunto de los grandes capitales.

\footnotetext{
${ }^{328}$ Para ver en detalle los distintos elementos que pesan sobre el aumento de stock de deuda ver Castiñeira (2008).

329 También nos permite pensar, como veremos en el próximo capítulo, a las retenciones como una herramienta de armonización de las relaciones al interior de la clase dominante, en tanto el Estado aplica un impuesto sobre la fracción más dinámica del capital (productivo-exportador), que irá a engrosar el superávit fiscal primario que derivará, entre otras cosas, al pago de la deuda.
} 
Además, sin tipo de cambio fijo y con la economía pesificada (a diferencia del modelo anterior, que en 2001 tenía el 70\% de los depósitos del sistema bancario y los créditos el $80 \%$ nominados en dólares ${ }^{330}$ ), el conjunto de modificaciones estructurales cambiaron el rol jugado por la fracción financiera del capital, estableciendo nuevas condiciones que al principio del período de estudio afectó su rentabilidad más allá de las compensaciones recibidas.

En este camino, el canje dio por resultado una importante disminución del peso de la deuda sobre PBI y sobre exportaciones: de representar el 166\% del PBI en 2002, esta se redujo al 56\% en 2007, mientras que la relación deuda pública externa/exportaciones pasó del 301\% en 2002 al 94\% en 2007. También se produjo una disminución del endeudamiento público externo, incrementando los empréstitos con agentes internos y con el mismo Estado (principalmente con el ANSES y el BCRA), ya que el indicador de deuda pública según residencia exhibe que la deuda externa pública pasó del 57\% en 2002 al 43\% en 2007. Otro factor destacado, en este sentido, es el cambio de moneda de la deuda, en tanto la deuda en moneda extranjera abarcaba el 79\% en 2002 y disminuyó hasta el 53\% en 2007. Asimismo, algunos elementos nos convidan a reflexionar acerca de la vigencia de la deuda pública argentina. Tras el canje quedó un exigente calendario de pagos y el stock de deuda continuó aumentando año a año sin lograr romper el “círculo vicioso” del endeudamiento público, de tener que continuar endeudándose con el sólo fin de pagar deuda. Aún con una política de maximizar esfuerzos fiscales para pagar deuda, ya en 2007 el Estado cubrió con el superávit destinado a deuda sólo un poco más de un tercio de los pagos, siendo el resto cubierto por endeudamiento intra-sector público y colocación de nueva deuda. Esto marca la pauta fundamental de la actualidad de la deuda pública, en tanto que, a solo dos años del canje, el Estado se veía obligado a contraer más deuda de la que podía pagar, profundizando el “círculo vicioso” de endeudamiento.

Este contexto genera a su vez un alza en los rendimientos de los bonos: a fines de 2007 los nuevos bonos en dólares garantizaban en promedio una tasa de interés cercana al $12 \%$ anual en dólares, dos veces y media la tasa de interés internacional, mientras los títulos en pesos + CER arrojaron un rendimiento aproximado del 20\%. Esto aparece como una tensión perdurable ya que, por un lado, amenaza con dar un nuevo

${ }^{330}$ Datos tomados de Cobe (2009). 
aire a la valorización financiera en tanto representa un negocio financiero a tasas sumamente elevadas respecto de los estándares internacionales, y, por otro, pone un piso mínimo de tasa de interés sumamente elevado para la emisión de nuevos bonos por parte del Estado para seguir financiando el círculo vicioso del endeudamiento. El cambio de deuda externa por interna también incrementa el impacto del endeudamiento sobre la tasa de interés local, con incidencia en las actividades productivas. Estas tensiones aparecen moderadas por dos factores, la movilidad del tipo de cambio que establece un contexto radicalmente distinto al de la convertibilidad, pero también por otro elemento fundamental para el análisis de la fracción financiera del capital: la tasa de interés. El perfil productivo del modelo y la limitación al atractivo de inversión especulativa en busca de valorización financiera están vinculados por la evolución de la tasa de interés real, es decir la relación entre la tasa de interés nominal, como "precio" de la fracción financiera del capital, y el índice de precios establecido para la inflación. En este sentido, podemos observar que, en contrapunto a lo sucedido en los años 90, la tasa de interés real tendió a ser negativa en la mayor parte del período 2002-2007.

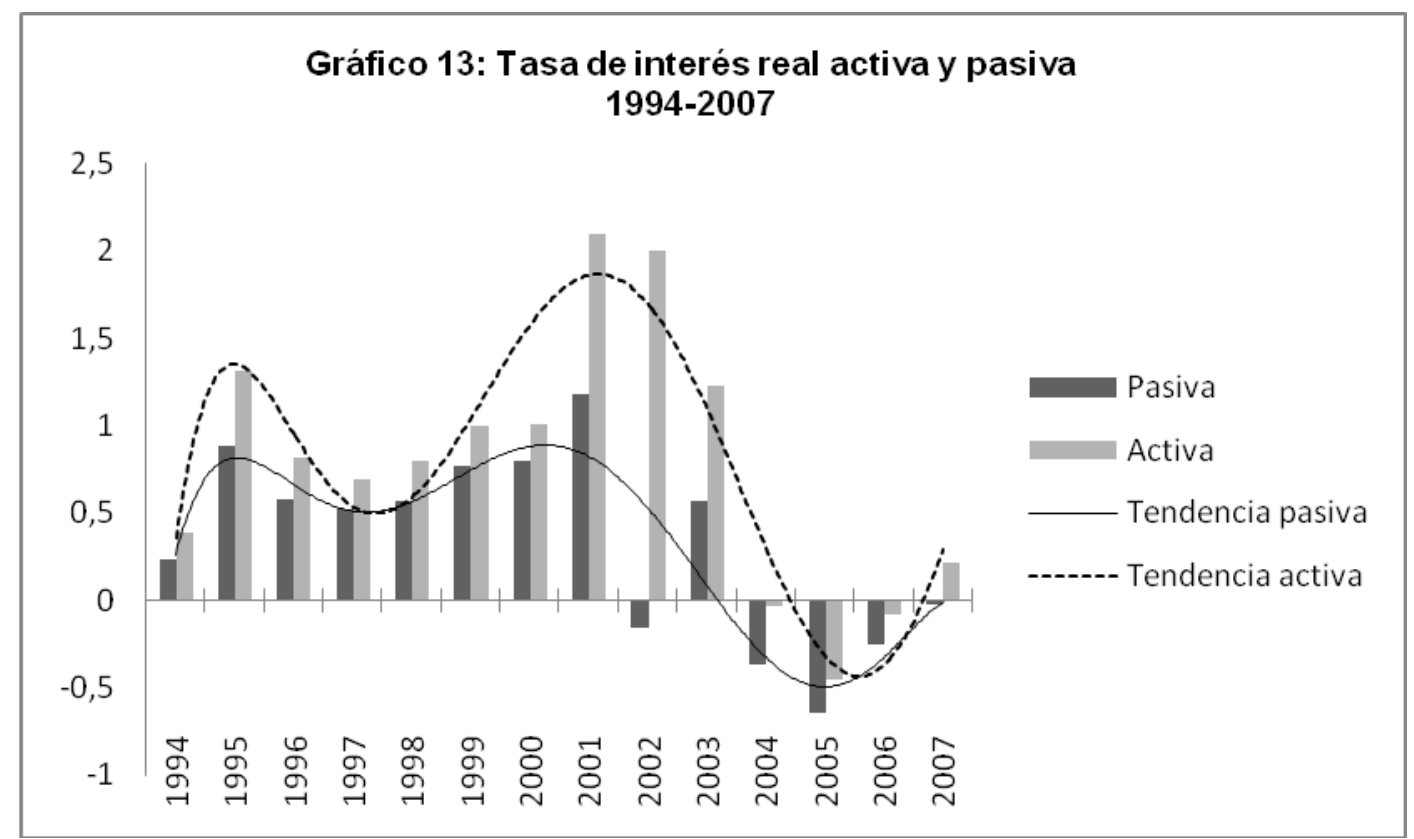

*Tasa activa: promedio aritmético de las tasas de interés fijadas para operaciones de crédito a empresas de primera línea.

Elaboración propia en base a datos CEPAL 
Esto no implica necesariamente una crisis de rentabilidad para los agentes de esta fracción, ya que si bien mencionamos la posibilidad de pensar la tasa de interés como "precio" de la fracción, es por la relevancia de ésta en términos de precios relativos que hacen a las relaciones de clases según su vinculación a nivel del modelo de acumulación. Para poder analizar este lugar ocupado por la fracción financiera así como terminar de definir los rasgos propios de dicha fracción en nuestro período de estudio y observar su desempeño, debemos tomar tres variables fundamentales: concentración, extranjerización y rentabilidad.

En primer lugar, encontramos la profundización de una tendencia presente en el modelo de acumulación de los años 90: el incremento de la concentración económica en la fracción financiera del capital. Esto puede ser observado, por un lado, a partir del acaparamiento a nivel de depósitos y activos por los principales agentes de la fracción. En este sentido, vemos que “mientras que en el año 2000, los cinco mayores bancos contaban con el 52 por ciento de los depósitos en el sistema (y el 46 por ciento de los activos), en 2007 lograron captar el 55 por ciento de los depósitos (y el 50 por ciento de los activos)" (Cobe 2009:114). De este modo, notamos que los cinco bancos de mayor peso en la economía argentina, siendo los mismos tres bancos privados (dos extranjeros y uno de capital nacional) y dos bancos públicos, incrementaron aún más su gravitación sobre el conjunto de la fracción. Otro indicador que corrobora el aumento de la concentración se vincula a la cantidad de bancos:

\footnotetext{
“entre 2000 y 2002 la cantidad de bancos se redujo de 89 a 78; disminución que continuó en los años posteriores y que se produjo sobre todo a través de fusiones y absorciones. Esta caída se explica mayormente por la reducción de la cantidad de bancos extranjeros que pasaron, entre 2000 y 2002, de 39 a 29, y en 2007 a 21 (...). Los extranjeros que se retiraban de la plaza local en su mayoría controlaban bancos locales de pequeño y mediano porte” (Cobe 2009:111)
}

En este sentido, observamos cómo se entrelazan las variables de concentración y extranjerización en el periodo 2002-2007: se profundiza la concentración, pero en un modo que expresa una ruptura con las tendencias de los años 90, es decir, con una merma en la extranjerización de la fracción. Nuevamente, podemos observar como indicador de este proceso la participación de los bancos según origen del capital sobre depósitos y activos. En este camino, "advertimos un cambio en la participación en el mercado de los distintos grupos de bancos, en particular los privados. En el caso de los depósitos del sector privado no financiero, entre 2001 y 2007, la banca extranjera redujo su participación en la captación de los mismos del 56 al 38 por ciento y la banca privada 
nacional logró llevarla del 15 al 32 por ciento, a partir de adquirir las entidades de sus pares extranjeros” (Cobe, 2009:112). Tendencia que se confirma en la caída de la participación de la banca extranjera en el total de activos del sistema, en el período 2002-2007, del 54\% al 28\%.

Así, observamos cómo se transforman los agentes de la fracción financiera del capital, cuyos rasgos presentan un incremento en la concentración al tiempo que una baja en la extranjerización, cobrando mayor relevancia los agentes privados de capital nacional.

A la hora de indagar su desempeño, observamos que la rentabilidad de los agentes de la fracción financiera exhibe un primer momento de fuerte caída seguida de un proceso de recomposición. Según Cobe, “entre 2002 y 2003, el sector bancario registró importantes pérdidas. Durante 2004 se produjo una recuperación de la rentabilidad del sector, que se afianzó en 2005, dando comienzo a un patrón de resultados positivos, en un contexto de crecimiento general de la economía” (2009:115).

En este mismo camino, Sevares (2010) observa la recuperación de la rentabilidad bancaria a través de los indicadores ROA y ROE. El indicador ROA, Rendimiento sobre activos (Return On Assets), mide la rentabilidad del negocio en su conjunto, en tanto el ROE, Rendimiento sobre capital (Return On Equity), mide la rentabilidad sobre el patrimonio. Según Sevares, ambos indicadores de rendimiento tienen signo negativo en el período de crisis de 2001-2002, pero luego se recuperan y, a partir de 2005, tienen valores superiores a los del último quinquenio de la convertibilidad.

Esta misma tendencia de pérdida y recuperación de rentabilidad también es observada por Wainer quien sostiene que:

\footnotetext{
"tras la salida de la convertibilidad los grandes bancos sufrieron una más profunda y duradera caída en sus niveles rentabilidad, ya que la misma recién volvió a ser positiva en $2005^{331}$. La crisis del sistema financiero local, el abandono de la paridad cambiaria, la pesificación asimétrica (...) y los cambios en los precios relativos hicieron que los bancos pasaran de ser unos de los principales beneficiarios de la política económica de los años noventa a unos de los más perjudicados. De todos modos cabe desatacar que a partir de 2006 el nivel de rentabilidad de los grandes bancos superó al promedio de las grandes empresas no financieras, dando cuenta así de una recuperación tardía pero muy importante.” (2011:117)
}

\footnotetext{
${ }^{331}$ Para calcular la rentabilidad de las grandes entidades financieras se tuvo en cuenta la relación entre los resultados y los ingresos (ingresos financieros e ingresos por servicios).
} 
Pero entonces ¿qué significa el incremento de la rentabilidad de los grandes bancos? ¿representa una vuelta a la “valorización financiera”? Para responder esta pregunta debemos por un lado indagar los componentes de la rentabilidad de los agentes de la fracción financiera y traer, a modo de conclusión, distintos elementos que fuimos analizando a lo largo del estudio de esta fracción que nos permitan ponerla en relación con el todo, en términos del modelo de acumulación.

En primer lugar, debemos adentrarnos en desagregar los componentes que integran la rentabilidad bancaria. En este camino, tomaremos el análisis minucioso desarrollado por Sevares (2010), en su abordaje a través del Margen Financiero, el cual está formado por los resultados por intereses, por títulos y por otros rubros, principalmente servicios. Sevares determina que tanto los resultados por intereses como por servicios presentan una fuerte caída en contextos de la crisis de los años 2001-2002, pero que luego comienzan a recuperarse aunque sin llegar, hasta 2007, a los niveles exhibidos durante los años 90. Por otro lado, los resultados por títulos se presentan todos por encima de los obtenidos en los años 90.

Esta descomposición analítica de la rentabilidad bancaria nos permite observar elementos que hacen al modelo de acumulación en su conjunto. El hecho de la obtención de altos resultados positivos por títulos nos marca que los bancos obtienen su principal fuente de ganancia por la simple tenencia de títulos valores, como inversores financieros, en forma puramente rentística (Sevares, 2010). Esto se encuentra en relación con papel clave de los agentes financieros con el proceso de endeudamiento público que fuimos describiendo. Es aquí donde reaparece la relevancia del cambio de rol de la deuda pública en el modelo post-convertibilidad, una deuda que si bien mantiene su actualidad con incrementos de stock y un pesado calendario de pagos, ya no cumple cabalmente el papel característico de los años 90 de financiar el proceso de “valorización financiera” y fuga de capitales en relación directa con un proceso de quiebre de las cuentas públicas. Esto se liga, a su vez, con la variación en los precios relativos, que pone en vinculación a la fracción financiera del capital con las otras fracciones de clase, y que muestra un descenso en la tasa de interés real, aspecto que se observa en que los resultados por intereses no ocupan el lugar principal de la rentabilidad bancaria. Esto se confirma observando, en el gráfico 14, que mientras en el período 1993-2000 el Margen Financiero fue de 6,9\%, explicado en su mayor parte por 
el resultado por intereses, que fue del 4,9\%, en cambio en el período 2002-2007, el Margen Financiero fue de 4,5\% y los resultados por intereses fueron tan sólo del 0,7\%.

Gráfico 14: Rentabilidad del sistema financiero 1993-2000 vs 2002-2007.

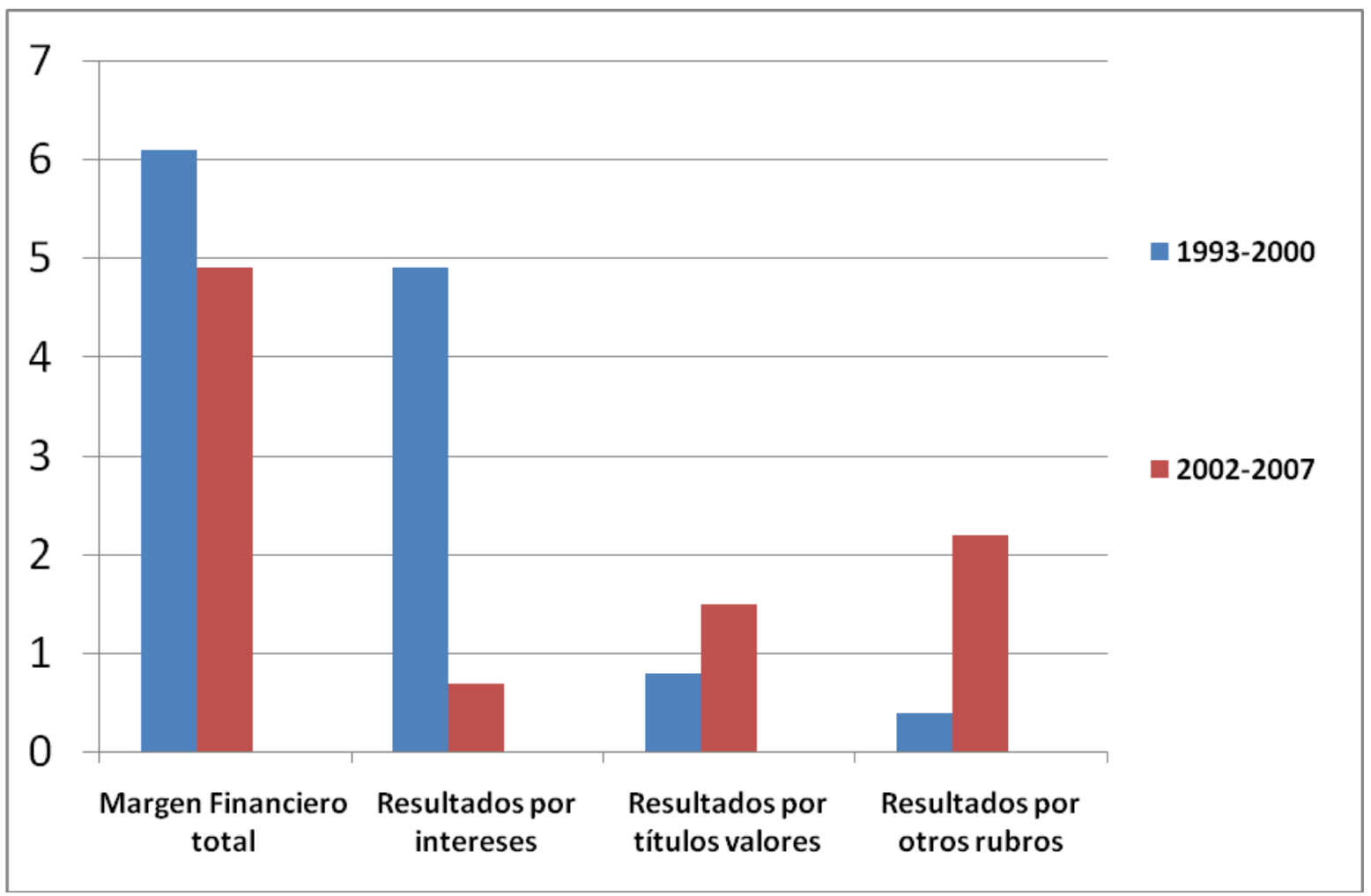

Elaboración propia en base a datos de Sevares, 2010

Entonces ¿es posible pensar a la fracción financiera del capital como una fracción subordinada al interior de la clase dominante en relación al modelo anterior? Si bien la rentabilidad bancaria vuelve a ser elevada luego de la crisis que inauguró la postconvertibilidad, entendemos que el análisis de relaciones de fuerza en vinculación al modelo de acumulación no se define únicamente por la rentabilidad, sino por el lugar ocupado y por las características de ese lugar en relación al conjunto. En los años 90 el capital financiero expresaba un eje de articulación a través del cual se derivaba también parte del excedente de las grandes empresas en el proceso de valorización financiera, en cambio, en la post-convertibilidad el eje articulador lo expresa el capital productivoexportador, ocupando el centro del modelo de acumulación, motorizando un proceso de 
crecimiento económico y encabezando, a su vez, un proceso de cambio en los precios relativos favorables al mismo. Si bien la fracción de PyMEs posee una alta relevancia en término de la generación de empleo, la vinculación entre estos agentes y la banca privada es muy débil, ya que el mantenimiento de la desregulación del sector financiero y de la Ley de Entidades Financieras ( ${ }^{\circ}$ 21.526) de $1977^{332}$ no favorecen su articulación. Asimismo, incluso el proceso de merma de la extranjerización tanto en el capital financiero como (en menor medida) de las privatizadas, se explica, según Cobe (2009) por una reorientación de la inversión extranjera hacia los sectores productivoexportadores. En este punto se comprende el rol de la tasa de interés real, ya que la tasa de interés, que sigue siendo demasiado alta para la fracción de PyMEs, tendió a quedar por debajo de los incrementos de precios que favorecen a los grandes agentes productivo-exportadores, en un contexto de aumento de los precios internacionales de los commodities y el nuevo diseño macroeconómico.

Finalmente, debemos remarcar una política que afectó a los agentes de la fracción financiera del capital: la reestatización de las AFJP, realizada en diciembre de 2008, con la promulgación de la Ley n² 26.425. Con esta acción, el Estado transfirió fondos acumulados por \$97 mil millones y comenzó a recibir aportes anuales calculados entre \$12 y 15 mil millones. Uno de los objetivos de esta medida respondió a fortalecer las cuentas fiscales, tanto para aprovisionar recursos para hacer frente a la crisis mundial que comenzaba a mostrar sus primeros efectos en la economía nacional como para poder afrontar los pagos de la deuda pública que para el año siguiente aumentaban a US\$ 20.000 millones, teniendo en cuenta que las AFJP eran importantes acreedores del Estado, ya que más del 50\% de sus fondos estaban invertidos en bonos de la deuda pública. En este camino, los conglomerados financieros fueron expropiados de un millonario negocio que habían usufructuado desde la ola de privatizaciones de los años 90 y recuperados para la gestión estatal, aunque esto no significó una embate drástico para la rentabilidad de los agentes financieros, que se encontraba ya en franca recuperación y ascenso.

\footnotetext{
${ }^{332}$ Entendemos que el sostenimiento de esta ley representa una de las principales trabas para modificar el lugar y la función cumplidas por el capital financiero en la Argentina y cualquier proyecto que pretenda transformar radicalmente esta situación deberá avanzar en un nuevo entendimiento entre los agentes financieros y el resto de los agentes económicos, poniéndolos al servicio de la producción y de las necesidades populares.
} 


\subsection{Las clases subalternas}

Abordar el análisis de las clases subalternas implica pensar un conjunto de agentes que se caracterizan por una posición subordinada en el proceso de acumulación, que en primera instancia no se apropian directamente de plusvalor, es decir, no rigen una relación de explotación: remite al término genérico de proletariado, en tanto aglomera agentes que, viéndose desprovistos de medios de producción, sólo tienen para vender su fuerza de trabajo. La subalternidad señala esta no-dominación, es un carácter amplio y difuso, cuyo principal componente es el conjunto de trabajadores asalariados productivos, genuinos generadores de valor por estar incluidos directa y materialmente en la relación de explotación que constituye el centro de las relaciones sociales en el capitalismo, la relación capital/trabajo.

Es en este sentido que retomamos de Poulantzas (1985 [1973]) la relevancia de la clase obrera en la producción de plusvalor, participando directamente de la relación de explotación ${ }^{333}$ y constituyendo el núcleo central, por su posición en la estructura, de las clases subalternas. Sin embargo, nos distanciamos de Poulantzas cuando sostiene que los asalariados que no producen plusvalor vendrían a formar parte de una nueva pequeña burguesía, junto a la pequeña burguesía tradicional de los propietarios de pequeños establecimientos. En este punto recogemos las críticas realizadas por Castells (1985 [1973]) quien señala la necesidad de observar la creciente masa de asalariados que si bien no son creadores de plusvalía, sí contribuyen a la realización de la misma u otras formas de reproducción social ligadas a múltiples aparatos institucionales. Entendemos que tanto esta multitud de asalariados como los desocupados e incluso parte de los trabajadores por cuenta propia, si bien no son generadores directos de plusvalor, representan posiciones subordinadas y forman parte de las clases subalternas. En síntesis, pensar en términos de clases subalternas, implica identificar agentes en las relaciones de producción que incluyen a los generadores directos de plusvalor pero que

\footnotetext{
${ }^{333}$ Como dijimos previamente, nos proponemos recuperar el concepto de capital como relación social en Marx porque nos permite dilucidar la relación de explotación, en particular, y la subalternidad en las posiciones, en general. Como señala Olin Wright (1994) es una parte fundamental del aporte teórico del marxismo promover el análisis de clase definiendo las mismas a partir de las relaciones de producción, tanto porque busca construir una perspectiva que coloque a la lucha de clases como motor de la historia, como porque permite subrayar la vinculación entre clase y explotación. Esto implica que, más allá de la estratificación salarial y de los fenómenos de movilidad social de los agentes dentro de los puestos o lugares, analizar la estructura implica comprender la primacía de los lugares en la reproducción ampliada de las clases sociales, cuál es la evolución histórica efectiva de esas posiciones de clase y cómo éstas se articulan con la creación, apropiación y acumulación de la plusvalía en forma de capital.
} 
los exceden, acaparando un conjunto de trabajadores que intervienen de forma subordinada en distintas instancias del proceso de acumulación.

La constitución del modelo post-convertibilidad ha tenido diversos efectos sobre las clases subalternas en los que se articulan de forma compleja fenómenos estructurales con la incidencia de las acciones estatales específicas.

En primer lugar, debemos remarcar que el inicio mismo en que se gestó el modelo de acumulación vigente se basó en un deterioro de carácter histórico de las condiciones de vida de las clases subalternas. La salida devaluacionista, definida por el gobierno de Duhalde, dio lugar a una contracción del producto que en 2002 alcanzó el 10,9\%, combinado con un estallido de los índices de desocupación que trepó al 23,3\%\%, subocupación 19,9\%, pobreza e indigencia al 57,5\% y 27,5\% respectivamente. A su vez, la inflación desatada al comienzo del modelo (del 45\%) bastó para reducir los ingresos reales de los trabajadores en un tercio entre 2001 y 2003 (Costa, Kicillof y Nahón, 2004). En este sentido, observamos que la base sobre la que se asentó la posterior fase expansiva del proceso de acumulación fue la contracción de las clases subalternas en la participación del valor creado, motivando una extracción extraordinaria de plusvalía que estableció, en conjunto con las políticas fundacionales que estaban teniendo lugar, un elevado margen de rentabilidad para los agentes capitalistas. Como vimos en el capítulo 3, en 2002, frente al pico de deterioro de las condiciones de vida de las clases subalternas y los niveles crecientes de conflictividad social, el gobierno de Duhalde desarrolló una estrategia de contención/coerción consistente, por un lado, en la masificación de los planes sociales y por el otro en una ofensiva de represión y criminalización de la protesta social.

Por un lado, se puso en juego el plan social de mayor alcance hasta ese momento: el Programa Jefes y Jefas de Hogar Desocupados con el fin de contener el conflicto y limitar las consecuencias que la crisis económica estaba teniendo sobre las clases subalternas. Este plan se masificó rápidamente alcanzando los dos millones de beneficiarios en 2003. También es necesario destacar su impacto macroeconómico, ligado a la mayor propensión marginal a consumir de los agentes de menores ingresos. Como señalan Pérez et al, 
propensión marginal a consumir de quienes lo perciben) en consumo de bienes y servicios finales, lo cual tiene un efecto multiplicador positivo sobre el total demandado. Un estudio de la Secretaría de Empleo de la Nación estima dicho multiplicador en 2,57 (o sea que por cada peso que se destina al consumo de estos sectores a partir de la transferencia se genera un aumento del PIB de 2,57). De esta manera, con un valor anualizado de 3700 millones de pesos se obtendría un aumento del PIB de 9990 millones y teniendo en cuenta que de ese incremento se cobraría un $21 \%$ de IVA, la recuperación impositiva sería equivalente a un 50\% del costo total del programa (considerando que existen artículos que tributan menos IVA y algún nivel de evasión)”. (2006:304)

Durante 2002, el plan fue financiado, por un lado, con recursos presupuestarios y, por otro, mayoritariamente con recursos provenientes de las retenciones a las exportaciones, mostrando un mecanismo de transferencia que, captando recursos de los agentes beneficiados por la salida devaluacionista, se destinó a mitigar levemente las graves condiciones en que se vieron sumidas las clases subalternas ${ }^{334}$. Asimismo, Pérez et al (2006) recuerdan que esta transferencia de recursos fue limitada si se la vincula con las realizadas hacia otras fracciones de clase, como al caudal de $\$ 80.000$ millones derivados a la fracción financiera del capital en la política de "salvataje” que prosiguió a la pesificación asimétrica de deudas y depósitos. Además, el monto quedó fijo en \$150, por lo que, en el contexto inflacionario, fue perdiendo gradualmente su valor real.

Por otra parte, se asistió a una escalada, tanto desde los medios masivos de comunicación como desde fuentes estatales, a criminalizar la protesta social incrementada durante el 2002, procurando debilitar las articulaciones al interior de las clases subalternas, visibles hacia fines de 2001, entre las capas medias, los trabajadores ocupados y los desocupados, de gran protagonismo en esos años. La criminalización de la protesta estuvo acompañada por un aumento de la violencia represiva que tuvo su punto álgido en la “Masacre del Puente Pueyrredón” que constituyó el intento de aplacar el conflicto por vía represiva, pero cuyo masivo repudio llevó a Duhalde a adelantar el llamado a elecciones.

El comienzo de la fase expansiva del modelo de acumulación postconvertibilidad, visible desde 2003, trajo un conjunto de cambios y continuidades en los que se articularon factores estructurales y el resultado de las políticas.

En primer lugar, el perfil productivo del modelo, revitalizado a partir de los cambios en los precios relativos y el nuevo tipo de cambio, permitió la disminución de la desocupación, que inició un descenso continuo desde el punto más agudo en que

${ }^{334}$ Ya en 2003 el financiamiento provino de un préstamo del Banco Mundial. 
trepó al 23,3\% en 2002 al 7,2\% en su mejor momento en 2007. Otro tanto ocurrió con la subocupación, que descendió de los 19,9\% en 2002 al 9,1\% en 2007.

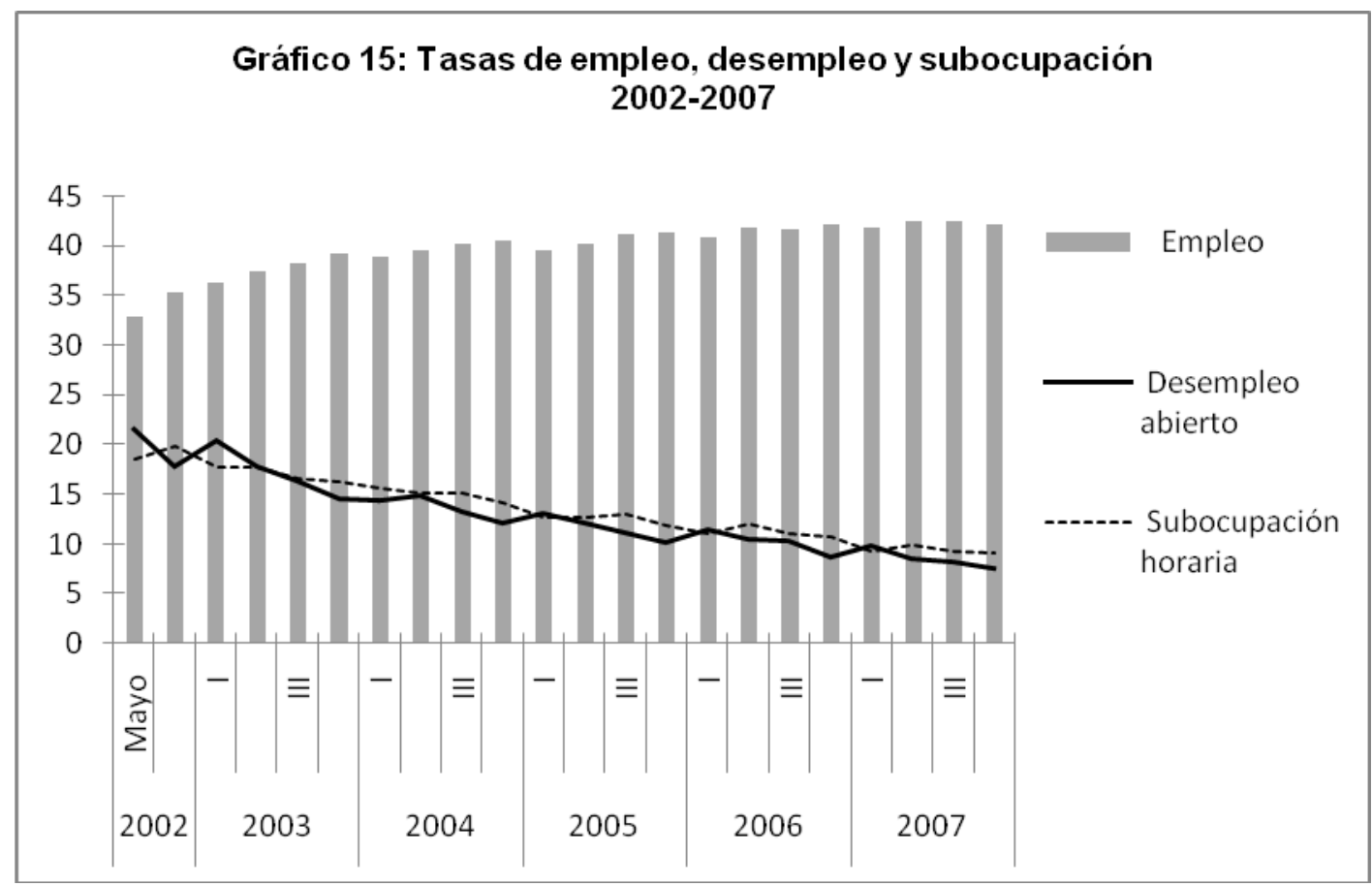

Elaboración propia en base a datos CEPAL

La caída de la tasa de desempleo fue explicada por la creación de 4.200 .000 puestos de trabajo entre 2002 y 2008, impulsada especialmente por la industria manufacturera, la construcción y algunos rubros del sector servicios. En este sentido, acordamos con el CENDA (2010), cuando expresa que el alto crecimiento del empleo en relación al producto se debió principalmente a tres procesos: la recuperación de la capacidad ociosa instalada, la abrupta caída del costo laboral tras la devaluación y la recuperación de los sectores trabajo-intensivo en virtud de la nueva estructura de precios relativos.

La fuerte creación de empleos industriales marca un punto de quiebre respecto de las dinámicas características del modelo previo de acumulación, presentando una tasa anual media de creación de empleos industriales del 5,8\% entre 2003 y 2008, 
contrastante con el -4,2\% del período 1991-2001 ${ }^{335}$. Esta tendencia también puede observarse en los disímiles niveles de elasticidad empleo-producto ${ }^{336}$ : mientras que en la fase expansiva desarrollada entre 1995-1998 fue de 0,131, la misma se elevó al 0,737 en el período 2002-2007 (Marticorena, 2010).

De este modo, el modelo post-convertibilidad logró revertir la tendencia previa al aumento de la desocupación, conformando así una vía de mejora de las condiciones de vida de las clases subalternas. Con el descenso de la desocupación también se fue gestando el descenso de los planes de desempleo, tendiendo a ser suplantados tanto por el empleo conseguido como por distintos planes de empleo y capacitación.

Por otra parte, el trabajo no registrado comienza a aparecer como otro rasgo duradero que afecta a las clases subalternas. Si bien el mismo comienza un proceso de descenso desde el punto más alto alcanzado, del 48,6\% en 2004, llegando a 36,5\% en 2008, éste se encuentra aún bastante por encima del promedio de la década de los 90, ubicado en $32,6 \%$.

En segundo lugar, observamos que, a partir del gobierno de Kirchner, se han desplegado un conjunto de acciones estatales tendientes, por un lado, a apuntalar los ingresos mínimos de las clases subalternas y, por otro, a aumentar de forma más significativa los salarios reales en los sectores más dinámicos de la economía. Esta estrategia se basó en cuatro mecanismos fundamentales: a) aumento del salario mínimo, b) impulso a los acuerdos y convenios colectivos de trabajo, c) aumento y extensión de las jubilaciones mínimas y d) acuerdos de precios para limitar la inflación.

a) El salario mínimo, luego de una década de estar congelado, comenzó a constituir nuevamente una herramienta para orientar los ingresos mínimos de las clases subalternas en el conjunto de la economía. Esta política cobró forma primero a través de aumentos por decreto y, rápidamente, a partir de la convocatoria al “Consejo Nacional del Empleo, la Productividad y el Salario Mínimo Vital y Móvil”, en la que comparecieron entidades empresarias, obreras y representantes gubernamentales, revitalizando las mediaciones corporativas como instancia

\footnotetext{
${ }^{335}$ Datos tomados de Tavosnanska y Herrera, quienes remarcan "la firme tendencia a la generación de empleo exhibida por la industria local entre 2003 y 2008, que vino a quebrar un impactante recorrido de expulsión neta de trabajadores industriales que llevaba unos 25 años” (2009:155).

${ }^{336}$ Se toma en cuenta a los asalariados no-jerárquicos del sector industrial.
} 
clave de disputas por mejoras en las condiciones de vida de los trabajadores, ligado a la estrategia de construcción del pacto populista. En este trayecto el salario mínimo fue llegando a \$450 en 2004, a \$510 en 2005, a \$630 en el 2006, alcanzando los $\$ 980$ a fines de 2007, superando así su duplicación en sólo tres años. Debe tenerse en cuenta que esta medida alcanza directamente sólo a los trabajadores privados registrados y a los dependientes del sector público nacional, pero también funciona de regulador de los “pisos” de ingresos para el conjunto de las clases subalternas.

b) El gobierno ha impulsado los acuerdos y convenios colectivos de trabajo. Estos son un mecanismo de mediación en la puja distributiva que había perdido peso durante el proceso de instauración del neoliberalismo. Para el análisis de los mismos debemos tomar dos factores: uno cualitativo ligado al ámbito de debate y alcance de las negociaciones colectivas y otro, cuantitativo, vinculado a su magnitud. En términos cualitativos, debemos tener en cuenta que la Ley de Ordenamiento Laboral $n^{\circ} 25.877$ que sustituyó a la previa ley laboral (la $n^{\circ}$ 25.250, promulgada en el año 2000 con probada compra de votos a legisladores) introdujo modificaciones, favoreciendo las negociaciones en un ámbito mayor en relación a la fuerte preeminencia de las negociaciones limitadas al ámbito de la empresa. Si bien las negociaciones por actividad mostraron mayor relevancia que la tendencia evidenciada en los años 90, no se logró revertir totalmente este fenómeno ${ }^{337}$. Asimismo, las negociaciones quedaron limitadas principalmente a discusiones salariales, dejando de lado en general, otras reivindicaciones ligadas a las condiciones laborales. En términos cuantitativos se visualizan mayores grados de ruptura. Los convenios colectivos se multiplicaron desde la asunción de Kirchner a la presidencia y representan un factor novedoso que ha permitido a sus beneficiarios importantes recuperaciones de salario real, teniendo relación directa con el despliegue del proyecto de gobierno y la construcción de hegemonía. En relación al alcance, los convenios colectivos pasaron de involucrar de 3 millones a comienzos de 2002, a superar los 4,5 millones de trabajadores del sector privado en 2007. Con respecto a la cantidad de acuerdos y

\footnotetext{
337 Según los datos de Marticorena (2010) en el período 1995-1999 los convenios colectivos se desarrollaron a nivel empresa en un 76,6\% y a nivel actividad en un 23,4\%, esta relación cambia a partir de 2004, con la Ley 25.877, llevando las negociaciones aproximadamente al 67\% a nivel empresa y al $33 \%$ a nivel actividad, aunque se mantiene la fuerte preeminencia de las negociaciones en el ámbito menor de la empresa por sobre el de la actividad.
} 
convenios homologados, ya en 2004 alcanzaron los 349, duplicando el promedio de los 10 años anteriores y representando el nivel de negociación más alto desde comienzos de la década de los 90, y centrándose en la industria manufacturera. Esta tendencia se iría amplificando hasta superar los 1000 convenios y acuerdos colectivos en 2007, evidenciando que constituye un rasgo perenne de las relaciones capital/trabajadores en el modelo post-convertibilidad.

c) Con respecto a las jubilaciones, se observan dos acciones importantes: el aumento de los haberes jubilatorios y la extensión de las jubilaciones a sectores que se encontraban desprovistos de la misma. Por un lado, al inicio del gobierno de Kirchner las jubilaciones mínimas se encontraban en \$200 mensuales. A través de varios aumentos alcanzaron en agosto de 2007 los \$596. A pesar de estos incrementos, la jubilación mínima quedó muy por debajo de la línea de pobreza, establecida por los organismos oficiales en \$ 923 (julio 2007). Además, se motivó una masificación de las jubilaciones mínimas de modo de ampliarlas hacia un conjunto de agentes de las clases subalternas que se encontraban por fuera del sistema jubilatorio. En este camino, el gobierno dispuso dos planes: el de Prestación Anticipada por Desempleo, dirigido a personas desempleadas con los años de aporte necesarios pero con menor edad de la requerida, y el Programa de Inclusión Previsional, orientada hacia quienes poseían la edad necesaria para jubilarse pero no tenían los años de aporte requeridos, completándose los mismos con una moratoria que se descontaría del haber (Mira y Kiper, 2009). Estas acciones estatales dieron como resultado, hasta 2007, la extensión de la jubilación mínima a aproximadamente a 1.800 .000 personas que se encontraban por fuera del régimen, iniciando un proceso tendiente a la universalización de la incorporación al sistema jubilatorio. Este proceso se profundizó con la reestatización en 2008 del sistema de jubilaciones y pensiones y la sanción de la Ley $\mathrm{n}^{\circ} 26.417$ de movilidad jubilatoria, que establece dos incrementos anuales a partir de un índice conformado según la variación de los recursos previsionales recaudados y la evolución del índice general de salarios.

d) El gobierno impulsó acuerdos de precios con los principales productores y comercializadores para intentar contener la inflación, que acumuló cifras cercanas al $10 \%$ promedio anual. Las retenciones a las exportaciones actuaron también en el mismo sentido. El gobierno negoció la adjudicación de subsidios a 
agentes del capital concentrado para limitar el aumento de precios, comprometiendo a mantener la estabilidad del precio de determinados productos. En algunos casos de productos que eran a la vez de exportación y de consumo masivo de la población los subsidios equivalieron a la brecha entre el precio de exportación y el precio interno de dichos productos (Mira y Kiper, 2009). Aún así ya en 2007 volvió a desatarse una fuerte presión inflacionaria ligada a la puja distributiva.

A estos mecanismos claves, se le han sumado un amplio conjunto de acciones estatales tendientes a mejorar los ingresos y condiciones de vida de las clases subalternas, mostrando un punto de inflexión en el año 2003, relacionado al papel más relevante que tienen los trabajadores en el proyecto de gobierno kirchnerista y su estrategia hegemónica global. Otras de las políticas hacia las clases subalternas consistieron en aumentos salariales de suma fija otorgados por decreto que luego se incorporaron al básico, aumentos constantes en las asignaciones familiares, suspensión de los despidos sin causa justa, modificación de la ley de quiebras $n^{\circ} 26.086$ devolviendo a la justicia laboral la competencia en los reclamos de los trabajadores contra las empresas en concurso de acreedores o quebradas, limitación de las facultades de los patrones para modificar las condiciones de trabajo a partir de la ley $\mathrm{n}^{\circ} 26.088$, comienzo de la reforma previsional habilitando la posibilidad de pasarse de las AFJP al ANSES, entre otras (CENDA, 2007c).

Por otra parte, el mantenimiento de una estructura tributaria regresiva, basada principalmente en el Impuesto al Valor Agregado (el IVA explica cerca de un tercio de la recaudación tributaria) que recae sobre el consumidor final y posee mayor peso sobre los ingresos de los sectores que menos recursos perciben, marca límites de la acción estatal en este período para transformar las condiciones de vida de los agentes subalternos. Además, más allá de los aumentos al mínimo no imponible del Impuesto a las Ganancias, debido a su falta de actualización tendió a afectar a sectores crecientes de trabajadores $^{338}$.

\footnotetext{
${ }^{338}$ Se puede señalar que la gravitación de un impuesto de ganancias sobre los trabajadores refuerza la regresividad de la estructura tributaria y constituye una paradoja en sí mismo, en tanto los trabajadores, por definición, no perciben ganancias sino salarios, ingresos de naturaleza profundamente distintas en virtud de la relación de clase que los atraviesa.
} 
A la hora de evaluar el impacto de las políticas debemos tener en cuenta también un conjunto de factores estructurales que dan forma al modelo de acumulación y que nos permiten comprender más cabalmente el lugar que ocupan las clases subalternas en la post-convertibilidad. En este camino, observamos que las diversas políticas laborales y de ingresos aplicadas han tenido un efecto positivo, pero limitado en términos generales, y dispar en términos particulares.

El efecto positivo se destaca en el aumento de los ingresos reales y mejora de los indicadores sociales respecto del momento de su aplicación, elevando sobre todo los “pisos” de ingresos como resultado de las políticas en materia de salario mínimo, jubilaciones mínimas y caída del desempleo. Esto se ve claramente en el fuerte descenso de la pobreza, que había alcanzado picos históricos al inicio del modelo postconvertibilidad llegando en octubre de 2002 al 57,5\% de la población comenzó un continuo descenso hasta el 26,9\% en el segundo semestre de $2006^{339}$. La misma tendencia a la baja se encuentra aún más acentuada en materia de indigencia, que pasó del 27,5\% al 8,7\% en el mismo periodo, reduciéndose cerca de un 70\%.

\footnotetext{
${ }^{339}$ Tomamos el segundo semestre de 2006 como último dato certero, ya que en 2007 el gobierno intervino el INDEC manipulando deliberadamente la construcción del IPC con su impacto en los indicadores socioeconómico, como la Canasta Básica de Alimentos que se utiliza para medir la indigencia y la Canasta Básica Total usada para la medición de la pobreza (estos impactos pueden ser vistos en detalles en CENDA, 2008c).
} 


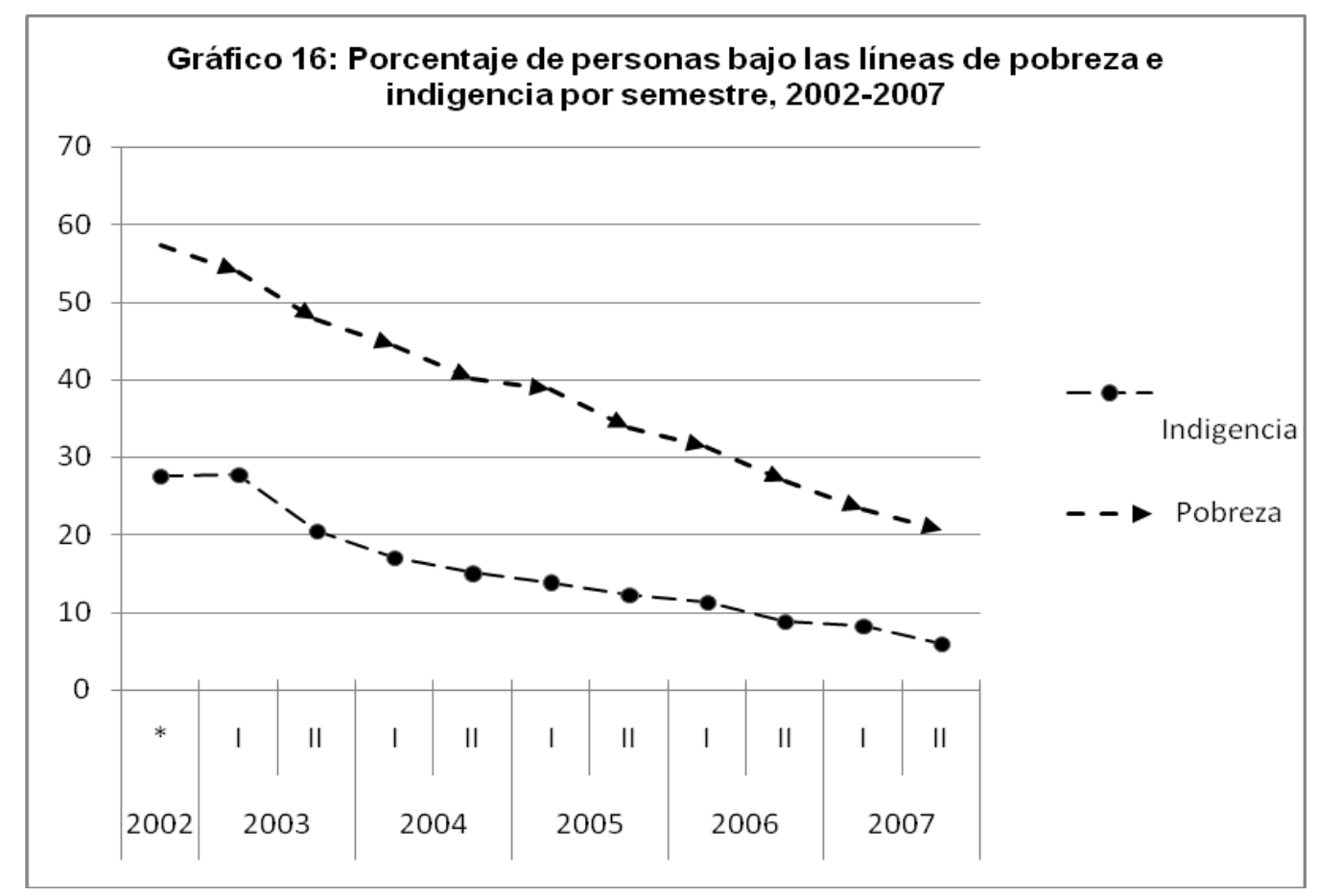

*Para 2002 tomamos octubre.

Elaboración propia en base a datos EPH - INDEC

Un elemento interesante a tener en cuenta es el análisis de las tendencia de largo plazo en materia de pobreza realizado por el CENDA (2008d). Éste sostiene que, desde la década del 80, pasados los picos de crisis que elevan fuertemente el índice de pobreza, en los escenarios post-crisis si bien el nivel de pobreza desciende producto de la estabilización económica, el nuevo piso fue siempre superior al que estaba vigente previamente. En la post-convertibilidad por primera vez, la caída sostenida implicó que el nivel de pobreza perforara el piso de partida previo al alza generada por la crisis. Asimismo, se señala que por primera vez desde 1980 los niveles de pobreza e indigencia exhiben cinco años seguidos de reducción. Sin embargo, no se ha logrado mejorar los niveles existentes al comienzo de la década de los 90, con un nivel de pobreza del 17\% (1993) y de indigencia del 3,7\% (1994). También mejoraron los índices de desigualdad, ya que en 2002 la crisis social desatada en el marco de la salida devaluacionista-inflacionaria de la convertibilidad llevó a que el 10\% de la población más rica percibiera 80 veces más recursos que el 10\% más pobre, relación que se redujo alcanzando en 2006 a ser de 1 a 31. La reducción de la desigualdad puede observarse también en el coeficiente Gini que pasó del 0,537 en 2003 al 0,485 en 2006. Así, desde 
2003 en adelante se constata una recomposición de la participación de los asalariados en el ingreso que si bien varía según las estimaciones, en todas es significativa.

En segundo lugar encontramos que las políticas han tenido un efecto limitado en términos generales. El mismo se relaciona a que, si bien el conjunto de indicadores sociales mejoran respecto del cataclismo de 2002, la participación de los asalariados en la distribución funcional del ingreso es en 2006 (41,3\%) aún inferior a la del 2001 (42,1\%), presentando también disminución en la participación del ingreso mixto (cuenta propistas + patrones de PyMEs) que baja del 16,2\% al 13,6\%, conllevando en total un aumento del excedente bruto de explotación del 41,8\% (2001) al 45,1\% (2006) ${ }^{340}$. Esto no sólo parece mostrar un "techo" que no modifica significativamente la distribución respecto de los momentos finales del modelo de la convertibilidad sino que, como sostiene Basualdo, “el capital está en mejores condiciones que antes debido a que se apropió a través de sus ganancias de una porción mayor del valor agregado generado anualmente, registrándose una participación creciente del mismo en el ingreso” (2008:34). A medida que la recomposición de los salarios fue avanzando los agentes dominantes fueron desplegando distintas estrategias para mantener holgados márgenes de ganancia, entre los que Basualdo destaca el impacto que tiene la inflación sobre la distribución del ingreso y sostiene que "el régimen inflacionario impulsado por los sectores dominantes durante los últimos años tiene como uno de sus principales objetivos impedir el ascenso de la participación de los asalariados” (2011:169). Asimismo existen otros factores que enmarcan la disputa distributiva que deben ser tenidos en cuenta.

En este punto parece propicio reflexionar sobre la relación entre la ganancia empresaria, el salario y la productividad. El salario real está vinculado al valor de cambio de la mercancía fuerza de trabajo, es decir, su costo de reproducción, en tanto expresa la capacidad de adquisición de mercancías para reproducir tanto al trabajador como a su familia, asegurando la persistencia del proletariado como clase y de la fuerza de trabajo. A su vez, la productividad del trabajo refleja la creación de valor a través del uso de fuerza de trabajo en un tiempo determinado; la realización del valor de uso de la misma implica un consumo productivo de la fuerza de trabajo que genera un valor que sobrepasa el costo de reproducción de dicha mercancía y que es el origen de la

\footnotetext{
${ }^{340}$ Datos tomados de Lozano (2008).
} 
plusvalía, apropiada por la clase dominante en forma de ganancia luego de saldar los costos del proceso productivo ${ }^{341}$. La distribución funcional del ingreso es entonces una relación que exhibe quién se apropia del valor socialmente creado, expresando una contradicción perenne en la estructura de clases que da origen a la disputa por la apropiación del excedente económico.

Graña y Kennedy (2007) analizan la distribución funcional a través de la relación entre el Costo Laboral Unitario Horario (CLUH) que expresa cuál es para el empresario el peso del salario en cada unidad de mercancía producida ${ }^{342}$, y la productividad horaria, es decir, cuánto rinde el obrero en términos de producción, teniendo el primero una relación directa y el segundo una relación inversa sobre la participación asalariada. Los autores señalan que el CLUH se contrae violentamente en 2002-2003 por el incremento de precios y la no indexación salarial (proceso que impactó, como señalamos, en una contracción mayor al 30\% del salario real). A partir de 2004, el crecimiento de los salarios por encima de los precios, implicó un proceso de recuperación del CLUH. Por su parte, la productividad venía arrastrando un proceso de descenso desde la crisis anterior de 1998 que se detuvo en 2004, exhibiendo una reducción del 11\% en dicho periodo. Esta reducción se explica en 2002 por el desplome del nivel de actividad y las horas trabajadas, tanto por la disminución del nivel de empleo como de la jornada, comenzándose luego a revertir con el crecimiento del producto y mostrando en 2005-2006 un incremento del 15\% de la productividad. Graña y Kennedy concluyen que “para el 2001-2006 la caída de la participación asalariada se explica por la confluencia de ambos factores: incremento de la productividad del $7 \%$ y caída del CLUH del 12\%” (2007:13). Esta reducción de la participación asalariada en el ingreso tiene como contrapartida el incremento del superávit de explotación que, en las mediciones de estos autores, se incrementa 4,1 puntos porcentuales entre 2001 y 2006. Asimismo, es interesante rescatar la vinculación que hacen de este proceso a los distintos agentes económicos según su tamaño, el deterioro de la participación asalariada se explica por evoluciones marcadamente diferentes de sus variables determinantes, mientras que en las grandes empresas se explica por aumentos de la

\footnotetext{
${ }^{341}$ Esta ganancia puede ser consumida improductivamente por los agentes de la clase dominante o puede ser reinvertida dando lugar a la reproducción ampliada del capital, a la acumulación.

${ }^{342}$ El CLUH expresa la relación entre la evolución del salario nominal y el índice de precios que enfrenta el empresario (Índice de Precios Implícitos, IPI) y, en este sentido, es distinto del salario real que vincula el salario nominal al IPC.
} 
productividad no transferidos a salarios, en las PyMEs la caída encuentra principalmente su razón en el deterioro del costo laboral.

De este modo, vemos factores de carácter más estructural que están signando la relación capital/trabajo y que se remontan a la existencia de una estructura productiva desequilibrada donde un núcleo de grandes empresas de alta productividad con capacidad de inserción en el mercado externo ${ }^{343}$, que pueden otorgar mayores aumentos salariales (aunque los mismos sigan fuertemente depreciados en términos de divisas, otorgando competitividad internacional) pero que proporcionalmente generan menos absorción de mano de obra, frente a una amplia fracción de PyMEs que son fundamentales en la generación de empleo, pero cuya condición de existencia son los bajos salarios en términos de costo laboral. Este es un nudo clave para observar las dinámicas y contradicciones que atraviesa el proceso de acumulación en la postconvertibilidad, y que se vincula también, como veremos, con la creciente heterogeneización de las clases subalternas.

Es en este contexto que, continuando con el análisis de las consecuencias que tuvieron las distintas medidas distributivas, observamos que las mismas han tenido un impacto dispar en lo particular, ya que, dentro de los asalariados puede percibirse una fractura en dos sentidos:

1) por un lado, pueden observarse evoluciones diferentes entre las distintas categorías laborales: los salarios reales de los trabajadores registrados del sector privado muestran en 2007 una mejora del 6\% respecto del año 2001; los trabajadores no registrados exhiben pérdidas del 13,3\% respecto de 2001, y los trabajadores estatales obtuvieron en 2007 un salario real un 21,7\% por debajo de $2001^{344}$. De este modo, observamos la profundización de los rasgos de heterogeneidad en las clases subalternas según las distintas categorías laborales como una característica que perdura y se acrecienta desde la instauración del neoliberalismo en Argentina. Puede notarse también una relación entre los niveles récords de la tasa de empleo y los bajos salarios de una parte de las

\footnotetext{
${ }^{343}$ También con distintos grados de relación a la extracción y procesamiento de recursos naturales, y en este sentido conectado con la apropiación de renta.

${ }^{344}$ Datos tomados de Lozano (2008).
} 
clases subalternas, ya que muchas veces impulsa a que más de un miembro de la familia deba buscar trabajo para salir de la pobreza ${ }^{345}$.

2) por otro lado, puede visualizarse una fuerte diferenciación salarial en la estructura de ingresos de los trabajadores formales mismos donde "el 11,9\% de ellos concentran el $32,5 \%$ de la masa salarial total, mientras el 61,1\% de los trabajadores formales perciben el 30,6\% de la misma” (Lozano, 2008:9). Esto podría estar señalando una diferenciación clave: la distinción entre agentes gerentes del proceso productivo que, si bien perciben salario y no son propietarios de los medios de producción, expresan una personificación del capital en tanto ejercen la función de control del proceso de trabajo. Recuperamos aquí el señalamiento de Poulantzas (2001) en torno de la posición de los altos funcionarios de empresa y su clivaje de clase. Según su óptica, los altos funcionarios de las empresas deben ser entendidos como parte de la clase dominante por su ejercicio de control y gestión del proceso de explotación del trabajo, por lo que, aún cuando perciban un salario, expresan una personificación de funciones de clase dominante. También se puede incluir en este renglón a los intelectuales orgánicos (Gramsci, 2004) a las clases dominantes que ocupan altos cargos en el Estado ${ }^{346}$.

Es importante tener en cuenta que estas comparaciones se realizan contrastando el año 2001, último año del modelo de la Convertibilidad que acarreaba el deterioro propio del ciclo recesivo inaugurado en 1998, con el 2007, quinto año de crecimiento consecutivo a tasas sumamente elevadas, expresando la fase expansiva del ciclo económico. Esto constata la perdurabilidad del carácter regresivo de la distribución del ingreso en el modelo post-convertibilidad en tanto el auge de la fase expansiva del ciclo económico (2007) muestra niveles distributivos y algunas variables socio-económicas

\footnotetext{
${ }^{345}$ Agradezco este señalamiento a Germán Pinazo. Esto se relaciona también con los "trabajadores pobres por ingresos" que mencionan Azpiazu y Schorr (2010).

${ }^{346}$ Esto no quiere decir que todos aquellos que ocupan altos cargos en el Estado sean efectivamente intelectuales orgánicos de las clases dominantes, ya que éstos constituyen una categoría que debe ser definida en el análisis de situaciones concretas en la dimensión específicamente política de las relaciones de fuerzas. Cabría preguntarse ulteriormente acerca de la tensión entre los lugares y quiénes los ocupan en un análisis profundo de las superestructuras complejas para definir si en este caso también observamos la primacía de los lugares o si la toma de posición y la orientación política de la fuerza en conducción del Estado puede determinar que dichos agentes posean un carácter de clase distinto al de las fracciones predominantes en la estructura. Esta es una pregunta por la relación entre estructura y las superestructuras, implicando una ruptura explícita con cualquier teoría del reflejo en la relación, y al mismo tiempo es una pregunta por los procesos de transformación social. Por ejemplo, parece razonable sostener que la Revolución Bolivariana de Venezuela expresa una fuerza estrechamente vinculada a las clases subalternas en conducción del poder político gestando un proceso de transformación social radical, y sin embargo, aun presentando sustanciosos avances en la correlación de fuerzas, estas clases siguen siendo asimismo subalternas hasta el momento.
} 
cercanas al último año del ciclo recesivo del modelo anterior (2001); como confirmamos previamente, la depresión del 2002 representa el inicio del modelo actual y es parte fundamental de su constitución, ya que establece características a nivel de la acumulación de capital que se mantienen firmes a pesar del conjunto de acciones estatales favorables a las clases subalternas inauguradas desde 2003.

Gráfico 17: Evolución del salario real promedio y de la productividad del trabajo 1969$2007(1976=100)$

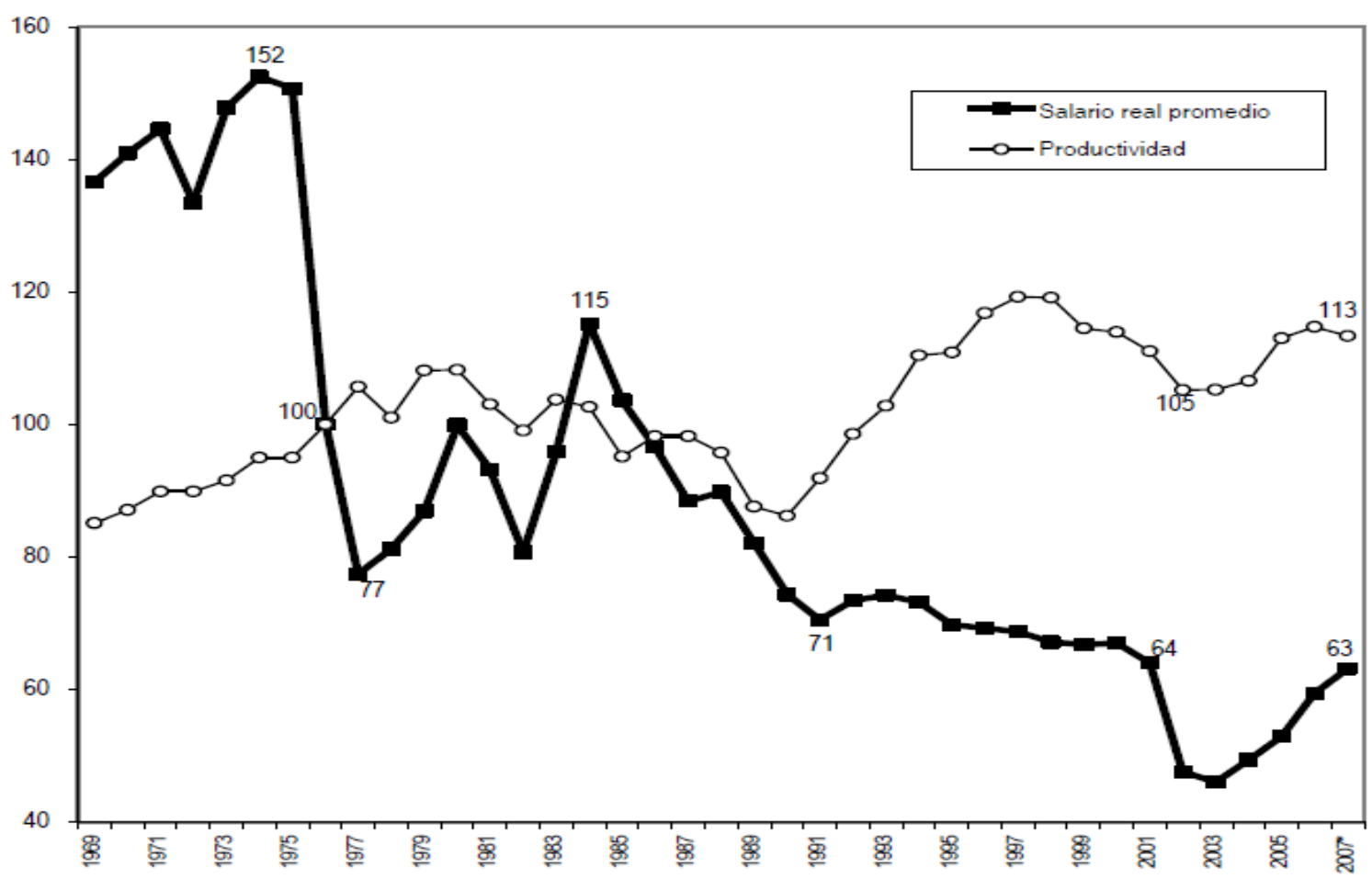

*todos los valores son anuales, salvo 2007 que comprenden el primer semestre

Gráfico realizado por Basualdo (2008)

El gráfico 15, nos confronta con una doble situación. Por un lado, muestra un cambio de tendencia: por primera vez desde 1984 se realiza la mayor recuperación sostenida del salario real. Pero si bien los salarios reales se han recuperado a partir de 2003, debemos notar, por otro lado, que estos aumentos no son lo suficientemente altos como para ejercer una modificación profunda del cuadro de distribución del ingreso ya que, en contextos de incremento de la productividad laboral, asistimos a una caída del 
costo laboral que beneficia al empresariado, en tanto el trabajo es más "barato”, aún más si se toma su precio en dólares, constituyendo una de las claves de la competitividad internacional y las ganancias empresarias. Entendemos que un limitante estructural del crecimiento salarial en el actual modelo se encuentra en que, por un lado, el perfil exportador del gran capital productivo tiende a ubicar el salario principalmente como un costo y no como un elemento fundamental de demanda para la realización del capital, y por el otro, las PyMEs, mayormente involucradas con el desarrollo del mercado interno pero en general de baja productividad, encuentran en los bajos salarios su condición de subsistencia. Estas parecen ser los principales componentes contradictorios y las limitantes estructurales del modelo post-convertibilidad, que ponen coto a las políticas de ingresos desplegadas desde 2003 con el fin de mejorar las condiciones de vida de las clases subalternas. Éstas han logrado sobre todo mejorar los “pisos” de ingresos de los agentes subalternos, pero se enfrentan a serios límites para superar los “techos” de distribución en relación a los años 90. Este fenómeno también se hace palpable en que, una vez alcanzado el salario real niveles similares al 2001, volvió a desatarse una fuerte presión inflacionaria explicada ahora por la reanudación de la puja distributiva, ya que los agentes del capital procuran trasladar a precios los aumentos salariales con el fin de preservar sus ganancias.

Asimismo, notamos que el actual modelo por su perfil productivo, por un lado tiende a aumentar los niveles de empleo expresando una clara ruptura frente a las tendencias de los año 90, pero la estrategia de acumulación orientada al mercado externo y el tipo de exportaciones ligadas a la explotación de recursos naturales y a productos vinculados a las necesidades elementales de la población (como los alimentos) genera una constante tensión entre la realización de las ganancias del capital concentrado y el mantenimiento de las aún críticas condiciones de vida de las clases subalternas. Es así como se conforman los rasgos específicos que dan sustrato material a la contradicción capital/trabajo bajo el modelo de acumulación post-convertibilidad y que establecen el terreno disruptivo que cultiva potencialmente el antagonismo y pone en tensión al proyecto político-económico kirchnerista con su componente de pacto populista. Si bien algunas acciones estatales presentan novedades respecto del modelo de los años 90, en tanto tienden a apuntalar el salario mínimo y aumentar el salario real 
principalmente de los trabajadores formales privados ${ }^{347}$ (que incrementan la demanda y permitieron reactivar el mercado interno), no han logrado postular una redistribución del ingreso favorable a la clase trabajadora en su conjunto, que si bien mejora desde 2003, comienza a exhibir límites y tensiones ya en 2007. También el mantenimiento de altos índices de trabajo no registrado y la baja tasa de sindicalización (en términos históricos) constituyen factores que debilitan el poder de negociación y disputa de los agentes subalternos. Aun así, las políticas activas han mejorado las condiciones de vida de las clases subalternas mostrando fuertes tendencias a la reducción de la pobreza y la indigencia, e incluso de la desigualdad, conformando este complejo escenario que presenta tanto rupturas como continuidades.

347 También es necesario señalar que los principales aumentos han estado ligados a sindicatos que se encuentran principalmente enrolados en la CGT, un aliado importante del oficialismo. Mientras que la CTA continuó sin conquistar la personería gremial, conduciendo sindicatos principalmente vinculados al Estado cuyos ingresos han estado, en términos globales, por debajo de los del año 2001. 


\section{Capítulo VI}

\section{El 2008 como nuevo punto de inflexión en hegemonía y acumulación. “Conflicto del campo" y circuito productivo sojero.}

El año 2008 establece un nuevo punto de quiebre que expresa la reapertura de una crisis de hegemonía al tiempo que exhibe un conjunto de tensiones a nivel del modelo de acumulación. De modo de poder apreciar el todo en la parte, abordamos el análisis del “conflicto del campo" y del circuito productivo sojero, que constituye su sustrato estructural, realizando un estudio de caso que habilita la profundización de un conjunto de rasgos presentes en el problema en torno al modelo de acumulación y a la construcción de hegemonía. Pondremos en juego, a su vez, la articulación de las categorías de antagonismo y contradicción, con el fin de vislumbrar en el caso particular una serie de tendencias y tensiones que son claves en el conjunto del período y cuya entrada en crisis marca un punto de inflexión a nivel de nuestro problema de estudio.

En este camino, indagamos el circuito productivo sojero argentino identificando agentes económicos, dinámicas productivas e impactos territoriales y su relación con las políticas fundacionales del modelo de acumulación post-convertibilidad. Abordaremos esta problemática incorporando aportes teóricos específicos del enfoque de análisis regional, una perspectiva que por sus características ${ }^{348}$ propias posee un alto grado de complementariedad con nuestra propia matriz teórica permitiéndonos profundizar en el estudio de caso. La relevancia de esta tarea nos convoca también a saldar otro vacío de conocimiento: el circuito productivo sojero no ha sido suficientemente analizado en tanto circuito productivo regional ${ }^{349}$. Esto se debe a que dicho concepto nos remite al enfoque de análisis regional, el cual se ha constituido a partir de una crítica a las

\footnotetext{
${ }^{348}$ Este enfoque retoma elementos del marxismo y los articula con desarrollos específicos de diversas disciplinas tales como Geografía, Historia y Economía, involucrando, en nuestra investigación, una mirada desde la Sociología.

${ }^{349}$ La bibliografía exhibe, por un lado, trabajos que abordan las transformaciones técnicas y tecnológicas del agro, en general y de la producción de soja en particular (Díaz Ronner, 2003; Reboratti, 2006; Arrilaga et al, 2007; Pengue, 2007; Basualdo, 2008b; Bisang, 2008). Por otra parte, se destacan trabajos sobre la producción sojera que promueven una mirada holística abordando sus diversas dimensiones (Schvarzer y Tavosnanska, 2007; Barsky y Dávila, 2008; Joensen y Semino, 2004; Katz, 2008; Giarraca et al, 2008) así como trabajos sobre aspectos específicos de la misma (Weskamp, 2006; Llovera, 2006; Ingaramo, 2006; Garbers, 2007). Asimismo, el debate sobre la relación entre el agro y el empleo ha ocupado un lugar importante (Llach et al, 2004; Rodríguez, 2005; CENDA, 2008) así como el análisis de la renta y la rentabilidad (Ingaramo, 2004; Rodríguez y Arceo, 2006; Arceo y Rodríguez, 2009). Sin embargo, no existe un abordaje de este momento específico de nuestro problema a partir del concepto de circuito productivo regional.
} 
investigaciones que buscan explicar las dinámicas socio-económicas a nivel nacional a partir de Buenos Aires: este factor ha llevado, como tendencia, a restringir los estudios del enfoque regional a experiencias productivas de las denominadas "economías regionales” usualmente ubicadas en zonas extrapampeanas (de Jong, 1995; Rofman, 1999; Bandieri, 2005; Blanco, 2006). Como señala Bandieri, el enfoque de análisis regional comenzó a cobrar forma a partir de la crítica a la noción tradicional de región, que contenía un concepto de región que

\begin{abstract}
"no escapaba fácilmente de los límites políticos provinciales o, a los sumo, intentaba reflejar macro-regiones geográficas, entendidas como tales a partir de denominaciones de uso común. Esta definición apriorística del objeto de estudio reflejaba no otra cosa que la enorme influencia de la geografía tradicional y su concepto de región como objeto de estudio en sí mismo” (2005:93).
\end{abstract}

Desde una crítica sistemática a dicha perspectiva comenzó a configurarse un enfoque alternativo donde "la región comenzó a entenderse como una construcción humana, siendo el hombre y su cultura quienes actuaban sobre el espacio y lo modificaban” (Bandieri, 2005:97). La región es pensada así como una construcción que, lejos de ser percibida como un recorte arbitrario, conlleva una "idea de totalidad que implica aprehender y comprender los fenómenos globales involucrados en una región” (Bandieri 2005:98). Si la región no remite a una delimitación apriorística sino que posee una íntima relación con la construcción del objeto de estudio, entonces podemos acordar con de Jong que "la región comienza y termina donde comienza y termina su explicación” (1981:29).

Para realizar el análisis propuesto tomaremos el concepto de circuito productivo regional desarrollado por Alejandro Rofman: "El circuito productivo abarca un conjunto de unidades de producción, distribución y consumo que operan intervinculadas entre sí a partir de una actividad común a todas ellas” (1999:35). El concepto de circuito productivo nos convoca a observar una serie de encadenamientos tales como la obtención de la materia prima, los procesos manufactureros, la comercialización y el financiamiento ${ }^{350}$. Por otra parte, es de suma relevancia recordar que:

"La dinámica del circuito no es sólo generada internamente, sino que proviene de la dinámica
general de funcionamiento del sistema económico-social tanto a nivel nacional como
internacional. Esto significa que la comprensión del funcionamiento del circuito debe incluir las

${ }^{350}$ Reconociendo que la dimensión espacial en Rofman (1984) se encuentra profundizada a partir del concepto de subsistema espacial, dentro del cual se inscribe el circuito productivo, nosotros nos centraremos en este último, en tanto hacemos énfasis en las relaciones económicas y de poder que involucra, ligadas a nuestro problema de estudio. 
condiciones generales de desenvolvimiento del sistema productivo pues sería imposible pensar en la dinámica cómo cada agente económico y social se inscribe en el circuito aislándolo del contexto global” (Rofman, 1999:40).

Es por esto que el análisis del circuito sojero tiene estrecha relación con el modelo post-convertibilidad dentro del cual se desenvuelve, viendo su relación con las políticas, las variables económicas, y los cambios de correlación de fuerzas que fueron afectando a la estructura de clases, habilitando un debate también sobre el papel de las retenciones, la inflación y el poder estructural emergente de los procesos de concentración económica.

El estudio del circuito productivo está atravesado transversalmente por los aspectos metodológicos sugeridos por Rofman (1999) que consisten en:

- Reconocer el nivel de predominio de determinadas formas técnicas de producción que son centrales al circuito y que utilizan los diferentes agentes económicos en los eslabones que conforman el encadenamiento respectivo.

- Identificar los modos de producción dominantes a que están sometidos los procesos sociales que caracterizan el circuito, atendiendo a los cambios en el proceso de trabajo.

- Detectar las actividades dominantes que actúan como eje central del circuito y alrededor de las cuales se articula todo el proceso de determinación de precios y modalidades de acumulación.

Para esto debemos dar cuenta de las transformaciones centrales en las técnicas de producción ligadas a la denominada "revolución verde”, observando sus impactos económicos, sociales y territoriales en el proceso productivo. A continuación, observaremos la especificidad que tuvo para el circuito sojero el pasaje del modelo de la convertibilidad al modelo post-convertibilidad, indagando el impacto de las principales políticas que fueron configurándolo, con el fin de generar el marco desde el cual comprender la relevancia y características de las actividades dominantes del circuito productivo sojero en el período 2002-2008 ${ }^{351}$, para centrarnos luego en sus agentes y las disímiles capacidades de acumulación de los mismos. En un momento posterior, articularemos el análisis del modelo de acumulación con el análisis de las principales

351 Un primer abordaje que realizamos del circuito productivo sojero puede encontrarse en Varesi (2010b). 
dinámicas de la construcción de hegemonía que se expresaron en el conflicto agrario de 2008. Observaremos la ligazón de las diversas dimensiones que componen el problema general de la tesis en este caso que marca un nuevo hito, cuya comprensión es clave para dar tanto una visión global del periodo de estudio como para atender a la particularidad de este parte-aguas que marca un primer momento de crisis en la hegemonía kirchnerista.

\title{
6.1. Transformaciones en el agro, en general, y en el circuito sojero, en particular.
}

Argentina ha asistido a una profunda transformación de su producción agropecuaria y, en particular, de su circuito sojero. Sintéticamente podemos señalar que la denominada “revolución verde”, que se plasma de modo significativo en la década de los 90, consta de diversos elementos: la proliferación del uso de semillas genéticamente modificadas (GM), la implementación extendida de la siembra directa, la masificación de los agroquímicos y el cambio de la escala de producción que conlleva su articulación.

En primer lugar, este proceso implicó un alto grado de desarrollo biotecnológico en la producción de semillas GM. En Argentina la utilización de la soja $\mathrm{RR}^{352}$ resistente al glifosato mostró un veloz avance, alcanzando a representar más del 95\% del total de semillas de soja utilizadas ${ }^{353}$.

En segundo lugar, aparece la masificación de la siembra directa. Ésta reduce los costos al prescindir de labranza, y, según Reboratti,

\begin{abstract}
“al no remover el suelo más de lo estrictamente necesario, se mantiene la humedad del subsuelo, no se afecta a los microorganismos activos en los procesos de degradación biológica y se mantiene la estructura radicular, evitando los procesos de erosión hídrica y eólica. Esto significa que los restos de la cosecha anterior quedan en el suelo, lo que es muy positivo desde el punto de vista de retorno de nutrientes al suelo y la contención de la erosión. En contrapartida, las pestes y malezas se difunden muy rápidamente, lo que obliga al uso masivo de biocidas” (2003:178).
\end{abstract}

Esto se encuentra en relación directa con otra de las innovaciones de la “revolución verde”: la masificación de agroquímicos, como el glifosato, que articula el

\footnotetext{
${ }^{352}$ Llamada así por ser compatible y resistente al herbicida Roundup Ready, producido por Monsanto, cuyo principio activo es el glifosato.

${ }^{353}$ Como señalan Gras y Hernández, con el fin de desarrollar su estrategia comercial para la inserción de las semillas transgénicas, "las semilleras ofrecieron, a quienes aún podín hacer pie en el sistema, un modo de financiación del paquete que permitía diferir su pago al momento de levantar la cosecha” (2009:8).
} 
uso de semillas GM resistentes al mismo y la posibilidad de extender la siembra directa como técnica de producción ${ }^{354}$. Por otra parte, se extiende el uso de fertilizantes para evitar la creciente erosión del suelo, aunque en cantidades insuficientes para detener el proceso de deterioro general.

Asimismo, encontramos la implementación del doble cultivo de soja y trigo, que permite incrementar la producción agrícola al mismo tiempo que la rotación de cultivo aminora el deterioro del suelo. Como señalan Barsky y Dávila, “al combinarse la soja como segundo cultivo después de la adopción de variedades de ciclo corto del trigo, se pudieron realizar dos cosechas anuales, lo que en términos prácticos significó duplicar la superficie utilizada del suelo y elevar fuertemente los ingresos de los productores agropecuarios” (2008:180). Estas transformaciones también estuvieron acompañadas de la utilización de nueva maquinaria especializada y la diversificación de los sistemas de ensilado, con variedades más flexibles y baratas (Reboratti, 2003).

Los cambios técnicos han conllevado modificaciones en los procesos de trabajo que nos permiten definir el modo de producción dominante en los circuitos agrícolas: estamos en presencia de la constitución de un modo de producción capitalista con altos índices de desarrollo técnico y tecnológico que genera profundas transformaciones en las dinámicas específicas del circuito productivo sojero ${ }^{355}$. La aplicación del "paquete tecnológico”, si bien representa una disminución en los costos y aumentos constantes en los rendimientos, requiere de una elevada inversión de capital que amplía la escala necesaria para su aplicación. Esta ampliación de escala se articula, a su vez, con distintos procesos de concentración presentes en las últimas décadas y que se han ido profundizando. La concentración de la propiedad de la tierra puede percibirse en la desaparición de 87.688 establecimientos productivos agropecuarios (un 21\% del total) entre 1988 y 2002, con un incremento de superficie media de cada establecimiento en aproximadamente 25\% (de 470 a 590 hectáreas promedio) (Arrilaga et al, 2007).

\footnotetext{
${ }^{354}$ Subyacen dos problemas relevantes a la aplicación del glifosato. Por un lado, el impacto que tiene sobre la fumigación con dicho biocida sobre la salud de las poblaciones, y por otro, que las malezas se tornan crecientemente resistente al mismo, requiriendo aplicaciones crecientes del glifosato multiplicando sus implicancias sanitarias.

${ }^{355}$ Como sostienen Gras y Hernández, en este proceso se fueron desarrollando diversas instituciones de carácter "técnico", como la Asociación Argentina de Consorcios Regionales de Experimentación Agrícola (AACREA) y la Asociación Argentina de Productores en Siembra Directa (AAPRESID), que fueron afirmándose como referentes del empresariado agrario. "El centro del trabajo de estas entidades ha sido principalmente la "empresa agropecuaria" antes que la defensa de intereses corporativos. Desde ese eje, fueron promotores de muchos de los cambios tecnológicos más importantes de las últimas décadas" (2009:12).
} 
Respecto del tamaño de las explotaciones, como señalan Gras y Hernández (2009), la disminución alcanzó su mayor expresión (26\%) entre las unidades de hasta 200 Ha, mientras que las explotaciones de más de $1000 \mathrm{Ha}$ aumentaron en su importancia relativa (en 2.3 punto porcentuales), principalmente las del tramo de 1.000 a 2.500 hectáreas (8,5\%). Asimismo, si bien las explotaciones de mayor tamaño (más de 10.000 Ha) disminuyeron en cantidad (-4,5\%), las mismas controlaban mayores superficies: “así, en 2002 este estrato que conformaba la cúpula del sector agrario representaba el 0.9\% del total de explotaciones y controlaba casi el 36\% de la tierra” (Gras y Hernández, 2009:8). Por otra parte, como veremos más adelante, el capital fue concentrándose, separándose parcialmente de la tenencia de la tierra, con la consolidación de la figura del contratista. Además, el conjunto de factores productivos se fue articulando con una creciente concentración de la organización y gestión del proceso productivo a través de nuevas estrategias como la de los pools de siembra y la emergencia de grandes empresas financiero-agropecuarias.

Estos fenómenos han profundizado el proceso de agriculturización ligado tanto al crecimiento de la agricultura a ritmos muy superiores a los de la ganadería como a la expansión de la frontera agraria. La superficie sembrada creció un 15\% entre los censos agropecuarios de 1988 y 2002 y fue incrementándose en los años posteriores. Esta expansión conlleva fuertes impactos territoriales en tanto promueve la producción agrícola, en general, y sojera, en particular, en tierras lejanas a la “zona núcleo” ${ }^{356}$ de mayor rendimiento, lo cual puede observarse en que mientras la pampa húmeda aumentaba en un 85\% el área sembrada de soja entre la campaña 1997/1998 y la de 2004/2005, el NOA (noroeste argentino) lo hacía en un 220\% y el NEA (noreste argentino) en un $417 \%{ }^{357}$. El aumento sustancial del área sembrada ha acarreado preocupación por su impacto ecológico ligado al proceso de desmonte que afectó a más de 500 mil hectáreas (Ha) entre 1998 y 2002 en Chaco, Salta y Santiago del Estero. Este proceso también fue implicando conflictos vinculados a la expulsión del campesinado originario situado en dichas tierras.

De este modo si la región debe ser pensada a partir de las dinámicas de la actividad del circuito estudiado, podemos observar que las transformaciones estructurales del agro argentino produjeron una ampliación de la región vinculada a la

\footnotetext{
${ }^{356}$ Incluye norte de Buenos Aires, centro y sur de Santa Fe, sudeste de Córdoba y sudoeste de Entre Ríos.

${ }^{357}$ Datos de la SAGPyA presentados por Ciani (2005).
} 
expansión territorial del circuito productivo sojero. Como resultado, la soja pasó de representar el tercer cultivo en la campaña 1996/97 a alcanzar rápidamente el primer lugar en 1998/99 y superar la cuadruplicación de su producción en diez años, creciendo a ritmos marcadamente más elevados que los otros cultivos así como en relación a la producción ganadera, que fue perdiendo espacios volcándose a formas de producción más intensivas.

\subsection{El impacto del cambio de modelo de acumulación sobre el sector, en general, y el circuito productivo sojero, en particular.}

El modelo de la convertibilidad tuvo un triple impacto sobre el circuito productivo sojero: a) dio impulso a las transformaciones estructurales de corte neoliberal modificando el escenario político-económico general y, en particular, la relación entre el Estado y los agentes económicos; b) afianzó las dinámicas productivas gestadas en el marco de la "revolución verde” con la aplicación del paquete tecnológico y c) generó una limitación relativa de la rentabilidad de los agentes involucrados a través de la apreciación cambiaria.

En primer lugar, observamos el impacto de la reforma estructural del Estado y su relación con los agentes económicos, tendiente a una creciente desregulación y liberalización del proceso productivo. Como confirman Gras y Hernández:

\footnotetext{
"las medidas neoliberales significaron el retraimiento del Estado en sus funciones reguladoras (eliminación de entes de control como la Junta Nacional de Granos, de Carnes, Dirección Nacional del Azúcar, Instituto Nacional de la Yerba Mate, entre otros) y el afianzamiento en su rol de garante del libre juego del mercado. Concomitantemente, se dejaron de lado políticas proteccionistas y redistributivas, se eliminaron casi todos los impuestos a las exportaciones, se privatizaron las empresas de servicios y se desmantelaron institutos públicos de apoyo técnico al agro, siendo el Instituto Nacional de Tecnología Agropecuaria (INTA) un caso emblemático" (2009:6)
}

Como señalan los autores, la desregulación derivó en una fuerte apertura económica de los mercados de bienes y servicios, lo que en el sector agropecuario se tradujo, por un lado, en la transnacionalización del mercado de insumos y, por el otro, en una importante presencia del capital financiero a través de los pools de siembra y de los fondos de inversión directa, quienes tomaron a la actividad agrícola como un espacio de especulación de alto rendimiento (alcanzando hasta un $30 \%$ de retorno anual). Este proceso de mayor gravitación del capital financiero privado se produjo junto con la retracción del Estado del sistema bancario, con la consecuente desaparición de los 
llamados créditos blandos, sumamente importantes para los medianos y pequeños agricultores (Gras y Hernández, 2009).

En segundo lugar, en 1996 se autorizó legalmente, con la firma de la resolución 167/96 por parte del Secretario de Agricultura, Pesca y Alimentación, la producción y comercialización de las semillas GM, habilitando la proliferación de la soja RR, una pieza clave de las transformaciones señaladas, por su articulación con el glifosato y la siembra directa. La apertura comercial implicó el descenso de los aranceles a la importación de agroquímicos y maquinarias, ampliando la capacidad de acceso a insumos y bienes de capital, facilitando la aplicación del paquete tecnológico. Este punto de inflexión puede constatarse en que si la superficie sembrada con soja había tardado casi cuarenta años en alcanzar las 8.000.000 de Ha hasta la campaña de 1995/96, en menos de una década, específicamente desde la campaña de 1996/1997 hasta la de 2005/2006 se aproximaría a los 16.000.000 de Ha, duplicando la superficie sembrada. En este trayecto la soja transgénica pasó de representar el 5,5\% de la producción sojera total al 98,4\% en la campaña 2006/07. A esto también debe añadirse que la aplicación del paquete tecnológico mejoró el rendimiento, que pasó de promediar los 2 kilos por Ha, para comenzar a variar, en términos generales, entre los 2,5 y los 3 kilos promedio por Ha.

En tercer lugar, la sobrevaluación del peso respecto del dólar cristalizada en la paridad cambiaria fijada por ley a \$1- US\$1, generaba restricciones relativas a la rentabilidad de las actividades del circuito, que se profundizaban por el esquema de precios relativos vigente, favorable a las empresas de servicios privatizadas ${ }^{358}$. Además, se evidenciaban limitaciones a la capacidad exportadora, debido, entre otros motivos, a que la sobrevaluación cambiaria restaba competitividad internacional a este cultivo orientado principalmente a la exportación y con escasa salida para el consumo interno. En este contexto, los agentes del agro compartían similitudes estructurales con gran parte del resto de los sectores productores de bienes transables, afectados además por la apertura económica y las transformaciones estructurales promovidas a través del modelo más acabado del neoliberalismo en Argentina. Si bien los principales grupos

\footnotetext{
${ }^{358}$ Según los cálculos de Rodríguez y Arceo "una parte significativa de la renta agraria no fue apropiada por los productores agropecuarios, que sólo percibieron 12.879 millones de pesos de una masa total estimada en 77.209 millones de pesos. Por lo tanto, como consecuencia de la sobrevaluación cambiaria durante la vigencia de la convertibilidad los productores agropecuarios transfirieron la suma de 64.330 millones de pesos del año 2004” (2006:13).
} 
económicos locales participaron del proceso de concentración y centralización del capital beneficiándose de las reformas neoliberales, cuando este modelo comenzó a mostrar signos de agotamiento, gran parte de los sectores productores de bienes transables, tanto los agentes económicos con intereses en el agro como en la industria, comenzaron a impulsar la salida devaluacionista de la convertibilidad.

El desarrollo de las políticas fundacionales del modelo de acumulación postconvertibilidad marcó las dinámicas socio-económicas generales a nivel nacional y constituyó un nuevo punto de inflexión en el desarrollo del agro, en términos amplios, y particularmente en el circuito sojero. Como vimos, la devaluación generó un tipo de cambio internacionalmente competitivo favoreciendo a los agentes ligados a la exportación. Asimismo, la pesificación asimétrica de deudas y depósitos promovió transferencias de recursos desde el capital financiero a los agentes productivos que luego fueron cubiertas con compensaciones estatales a los bancos a través de la política de "salvataje" al capital financiero. También, la regulación de tarifas de servicios y los combustibles constituyó una política favorable al desarrollo del circuito productivo sojero. En este contexto,

\footnotetext{
“la gran devaluación del año 2002 y la pesificación de los créditos a los deudores bancarios representaron una gran transferencia de recursos al sector agropecuario. Los altos precios internacionales de los cereales, las oleaginosas y los productos ganaderos, y los costos internos depreciados por la devaluación, determinaron una ecuación económica extremadamente favorable para los productores, a pesar de la implantación de retenciones” (Barsky y Dávila, 2007:161).
}

Esto se dio en un contexto mundial altamente propicio donde el consumo mundial de soja y sus subproductos se había ido incrementando en los últimos años. En esto incidió un factor que debe ser destacado: la multiplicación del consumo en China. Como señalan Schvarzer y Tavosnanska “el consumo de esa nación era de 12,3 millones de toneladas a comienzos de la década del 90, pero llegó al 2002 con 26 millones y el año siguiente dio un nuevo salto hasta superar los 43 millones, de modo que se convirtió en el primer consumidor mundial de soja y su demanda ya representa el $20 \%$ de la cosecha mundial” (2007:5). También se encuentran entre los grandes consumidores mundiales EEUU, Brasil (que son al mismo tiempo los principales productores mundiales de soja), India y la Unión Europea. Este incremento de la demanda de productos sojeros en el mercado mundial resultó un importante estímulo al circuito productivo sojero en el contexto auspicioso a las exportaciones locales provisto por las 
políticas y condiciones generales establecidas en el marco del modelo de acumulación post-convertibilidad.

\subsection{Circuito sojero: agentes económicos y relaciones de fuerza.}

Pensamos a los principales agentes del circuito sojero formando parte de la amplia fracción productivo-exportadora del capital que surge como principal beneficiaria del modelo post-convertibilidad. En este camino, precisamos volver de lo general a lo particular, del modelo de acumulación en términos macro al circuito sojero ${ }^{359}$, hasta desagregarlo en sus encadenamientos y agentes, para comprender más cabalmente los lugares ocupados por éstos en la estructura e indagar la tercera dimensión metodológica sugerida por Rofman acerca de las actividades centrales, el proceso de determinación de precio y las modalidades de acumulación. Este conjunto de elementos de análisis nos permitirá una aproximación a la dimensión estructural de las relaciones de fuerzas y a las lógicas productivas que componen el sustrato estructural del conflicto agrario de 2008.

Como sostuvimos, las actividades del circuito productivo sojero tienen un alto impacto en la estructura exportadora argentina en tanto el complejo soja llegó a explicar el 24,3\% de las exportaciones totales en 2007. Teniendo en cuenta que aproximadamente el 95\% de la producción sojera se orienta a la exportación, mientras que sólo el 5\% se dirige al consumo interno, vemos que la línea de actividad central está constituida por la dinámica producción-exportación; de ahí que pensemos al circuito sojero y a sus agentes dentro de la fracción productivo-exportadora del capital. En tanto el $80 \%$ de la producción del circuito sojero se exporta en forma industrializada como aceite o harina de soja, comenzaremos a indagar la cadena desde la producción de insumos hasta las grandes aceiteras y exportadoras, pasando también por las lógicas de organización de la producción.

Un primer núcleo de agentes se articula en torno a la producción de insumos, semillas, fertilizantes y herbicidas, por un lado, y productores de maquinaria agrícola y

\footnotetext{
${ }^{359}$ Hasta el momento hemos dado cuenta de las transformaciones técnicas y tecnológicas que actuaron cambiando el proceso de producción del circuito sojero, para luego articularlo con las dinámicas del modelo de acumulación, desde la convertibilidad a la era post-convertibilidad, analizando el marco nacional e internacional que atraviesan la historia reciente del circuito productivo de soja.
} 
bienes de capital, por el otro. Dentro del primer grupo, la empresa Monsanto surge como un agente económico fundamental por ser el principal productor de dos de los elementos simbióticos del desarrollo sojero: las semillas transgénicas, soja RR, así como el herbicida al cual esta es resistente: el glifosato. Como señalan Schvarzer y Tavosnanska,

\begin{abstract}
“en un primer momento, Monsanto logró mantener el monopolio de su oferta en el mercado local pero pronto esta comenzó a verse amenazada por dos factores concurrentes. En primer lugar, la soja OGM puede ser reproducida por los productores y ello permitió que estos se lanzaran, primero, a generar su propia semilla y luego a venderla a otros a través de la llamada "bolsa blanca" (semillas sin marca). Monsanto protesta contra estas actividades pero el hecho es que, por diversas razones hay un vacío legal en el patentamiento de las semillas que permite este desarrollo aunque no sea aceptado por esa empresa” (2007:41).
\end{abstract}

Estos autores también señalan que el control de Monsanto sobre el glifosato se ha ido erosionando debido al ingreso de nuevos oferentes. Si bien se ha limitado el carácter monopólico que presentaba inicialmente la provisión de insumos, estos mantienen un perfil concentrado, encontrando una válvula de escape en la reproducción local y la venta de la "bolsa blanca", aunque debe recordarse que Monsanto sigue ejerciendo presión internacional para efectivizar el patentamiento. Aún así, subsiste un factor relevante ligado a la concentración de la producción de innovaciones científicas:

\footnotetext{
"el flujo innovativo en los nuevos desarrollos tecnológicos proviene de las grandes empresas transnacionales que dominan la mayor parte de la producción y el comercio de insumos claves como las semillas y agroquímicos. Dado que el desarrollo genético y los paquetes tecnológicos modernos son costosos, en tanto implican mayor capital para la producción, éstos están en manos de los centros de investigación y de las grandes empresas transnacionales de los países industrializados. El mercado de los transgénicos evidencia esta marcada privatización en las actividades de investigación y generación de las nuevas tecnologías para el sector agropecuario" (Díaz Ronner, 2003:4).
}

Otro grupo dentro de este núcleo está constituido por los productores de maquinaria agrícola. El crecimiento de la producción agrícola a partir del paquete tecnológico, la masificación de la siembra directa y la adopción de la agricultura de precisión impulsaron la necesidad de sembradoras, pulverizadoras, fertilizadoras y cosechadoras, entre otras máquinas. En Argentina existen unas 650 empresas de maquinaria agrícola que se concentran territorialmente en las principales provincias sojera, particularmente en Santa Fe, donde se ubica el 47\% de las mismas. Estos agentes también han aumentado crecientemente su producción para el mercado interno así como su capacidad exportadora. Esto generó una recomposición de la producción de maquinaria en Argentina de sembradoras, pulverizadoras, acoplados y fertilizadoras pero también implicó un incremento significativo de las importaciones, en tanto se calcula que un $80 \%$ de los tractores y un $70 \%$ de las cosechadoras son importados. 
Un segundo núcleo de agentes que componen la cadena refieren a los productores, contratistas y rentistas. Los productores comprenden a aquellos agentes que al tiempo que son propietarios de la tierra también la trabajan, mientras que los rentistas son los propietarios del suelo que alquilan su tierra para ser trabajada por otro, recibiendo por esto una renta en dinero o especias. La relación entre estos dos actores puede ser evaluada, por un lado, a través de las variaciones a nivel escala y, por otro lado, a partir del régimen de tenencia de las explotaciones agropecuarias. En el primer caso fuimos señalando que las innovaciones técnicas y tecnológicas promovieron un aumento de escala para la producción sojera: esto implicó alteraciones en las actividades de los pequeños productores, que para hacer rentable su inversión debían enfrentar un costoso paquete de insumos y maquinarias de nueva tecnología. Barsky y Dávila observan variaciones en el régimen de tenencia y las dinámicas de producción que fundamentan esta perspectiva: ellos señalan que en el período intercensal 1988-2002 puede observarse "una importante caída a nivel nacional de las unidades con propiedad privada en forma exclusiva y un importante crecimiento de las unidades en arrendamiento. Igualmente, un gran crecimiento de las unidades que combinan propiedad con tierras arrendadas” (2008:80). Este fenómeno indicaría, según los autores, que los pequeños y medianos productores ceden la gestión de sus unidades a otros agentes, como los propietarios agrarios de mayor capacidad económica, los contratistas, entre otros.

Aquí debemos señalar que el agro argentino presenta un creciente desdoblamiento entre aquellos que lograron capitalizarse y adquirir maquinaria y aquellos que se convirtieron en rentista. Por un lado, muchos de aquellos que lograron una acumulación de capital para acceder a la maquinaria se transformaron en contratistas, un agente económico que realiza tareas de siembra, cosecha y fumigación, y que abarca una serie de variaciones en su desempeño: trabajando el campo de terceros, ya sea por dinero o especias, por un monto fijo o variable según producción, siendo o no propietario él mismo de explotación agropecuaria. Se calcula que un $70 \%$ de los granos en Argentina son cosechados por contratistas. Por otro lado, ante el constante aumento del precio de la tierra, que pasó entre 2002 y 2007 de 2.692 a 8.700 dólares por Ha en la zona maicera pampeana, arrastró al alza el precio de los alquileres, por lo que muchos productores han optado por convertirse en rentistas obteniendo una 
renta entre 400 y 500 dólares por $\mathrm{Ha}^{360}$. Pero este fenómeno también se encuentra ligado al proceso de concentración del capital y de la gestión y organización del proceso productivo que vino marcando recientemente la estructura agraria en Argentina: "Los actuales procesos implican procesos de concentración en los que no se trata de aumentar la extensión de los campos propios sino de incrementar la cantidad de explotaciones que son arrendadas y unificadas bajo una misma dirección organizativa” (Barsky y Dávila, 2008:101).

En este camino emergen nuevas modalidades de organización y gestión del proceso productivo, cuyo formato más conocido es el pool de siembra. El pool de siembra, antes que un agente económico, es una dinámica de organización y gestión que articula distintos agentes del circuito productivo. Según el INTA, un pool de siembra “es cualquiera de las combinaciones posibles por las que el cultivo se lleva adelante. Una forma frecuente es la combinación del dueño de la tierra, un contratista y un ingeniero agrónomo, que convienen una producción aportando cada uno sus recursos (tierra, labores e insumos respectivamente) y se reparten utilidades de acuerdo a su participación”361. Es decir, que el pool de siembra representa una modalidad de articulación de diversos eslabones del circuito productivo sojero, pudiendo recorrer desde la compra de insumos hasta la exportación. Esta modalidad se abre paso a partir de la constitución de fideicomisos o diversas variantes de fondos de inversión y puede implicar desde la articulación de pequeños productores con el objetivo de aumentar la escala y disminuir costos, hasta la configuración de gigantescas organizaciones permanentes caracterizadas por este modo de organización.

Pensado de esta manera, el pool de siembra tiene una doble implicancia en su articulación con las transformaciones generales que atraviesan al circuito sojero. En primer lugar, el pool de siembra comporta un serio cambio en la relación entre territorio y producción: lejos de procurar la compra de tierra, el pool instituye una relación flexible con la misma arrendando explotaciones en diversas zonas con el fin de diversificar riesgos. Esta dinámica habilita serias implicancias territoriales y ecológicas: en tanto que la tierra no es trabajada por su propietario, tienden a expandirse modos de uso focalizados en la ganancia a corto plazo que deterioran la fertilidad de la misma. Ya

\footnotetext{
${ }^{360}$ Según Barsky y Dávila "el dueño de 100 hectáreas que decide arrendar a estos precios podría obtener entre US\$ 40.800 y 51.000” (2008:171).

${ }^{361}$ Definición dada por el INTA (Instituto Nacional de Tecnología Agropecuaria) a través de su página web: http://anterior.inta.gov.ar/extension/finan/tool/pool.htm
} 
mencionamos previamente el impacto negativo que tiene la expansión de la frontera agrícola a través de la deforestación y el desmonte en el norte del país, a esto se suma el deterioro de los suelo por la disminución de nutrientes agravada por la tendencia al monocultivo de soja, que no logra ser compensada por la aplicación de fertilizantes, habilitando un proceso de desertificación. En segundo lugar, paralelo al proceso de concentración del capital, aparece la concentración de la gestión y organización productiva y se vincula de un modo particular con la tenencia de la tierra, ya concentrada estructuralmente. El pool de siembra permite atraer capitales de otros agentes económicos no necesariamente vinculados previamente con el circuito, en calidad de inversión financiera. El aumento de escala y la articulación concentradora de recursos aumentan su capacidad de negociación y habilitan la baja de costos.

En este camino, han surgido poderosas empresas agropecuarias basadas en el usufructo de una modalidad similar al pool de siembra, en tanto mantienen la lógica de articular los diversos factores productivos ganando escala, concentrando gestión y conllevando consecuencias similares a nivel territorial, pero que en vez de estar fundados en un fondo de inversión o confluencia de agentes, actúan a través de grandes redes de contratos pergeñados desde la empresa misma. Dentro de estas grandes empresas financiero-agropecuarias "los casos más conocidos son Los Grobo y El Tejar que administran alrededor de 150.000 hectáreas cada uno, de las cuales sólo un $10 \%$ es actualmente de su propiedad. La lógica es no invertir en tierras, arrendando, ni en capital maquinaria, utilizando contratistas” (Barsky y Dávila, 2008:98). Según Godio y Robles, la principal diferencia entre las nuevas empresas agrícolas y los pools de siembra es que las primeras "se organizaron siguiendo la lógica de la tercerización típica de la empresa toyotista, algo que en el campo argentino generó un nuevo fenómeno histórico: la del pequeño y mediano propietario rural volviéndose arrendadores (rentista), así como la eventual desaparición del pequeño arrendatario. Es la gran empresa la que se volvió arrendataria, ocupando un lugar históricamente relacionado con el pequeño productor” (2008:155). Otra distinción clave se refiere a los plazos de las operaciones, mientras los pools procuran por lo general obtener una alta rentabilidad financiera en el corto plazo pudiendo disolverse tras la cosecha y venta de la producción, las grandes empresas poseen un carácter más estable en su actividad.

Otro momento de la cadena productiva sojera es el acopio. El acopio se basa en actividades de almacenamiento, que se articulan también con el secado de granos, la 
provisión de insumos y la comercialización. Según Llovera, si tenemos en cuenta tanto a los acopiadores particulares como a los cooperativos, para el sector granario en general, “en la actualidad, más del 70\% de los insumos llega al productor vía acopio. Con su manejo profesional optimiza la circulación de los granos en espacio y tiempo (transporte y almacenamiento). El 80\% de los productores utiliza el servicio de transporte a planta brindado por el acopio, con lo que se asegura un fluir ordenado y de calidad homogénea de los granos a los centros de industrialización y exportación” (2006:46).

Los agentes del acopio (y a través de estos, el circuito sojero en general) se han visto beneficiados por distintas políticas en la post-convertibilidad. En relación a las tareas de secado (para la cual se utiliza tanto gas natural como gas licuado de petróleo y gas oil) y de transporte, fueron favorecidos por la limitación del aumento tarifario y por las retenciones al petróleo y otras regulaciones que han limitado la evolución del precio de los derivados del petróleo, en comparación con los países limítrofes. De este modo, se incrementó la competitividad de estos agentes económicos.

El acopio particular y el cooperativo presentan una capacidad de almacenaje de aproximadamente el 70\% y el 30\% respectivamente. Además, los agentes ligados al acopio cumplen, en el caso de la soja que destina un $80 \%$ de su producción a su elaboración industrial, un importante papel en la intermediación y negociación comercial: "La presencia y participación de las cooperativas y acopiadores en los mercados a través de sus corredores, atenúa los efectos de una demanda concentrada frente a una oferta de producción muy atomizada” (Llovera, 2006:47).

El circuito sojero culmina en su eslabón de elaboración industrial seguido de exportación. Las plantas aceiteras, que con su creciente desarrollo constituyen uno de los principales polos industriales del país, aparecen como los agentes encargados de la molienda y refinado de la soja, convertida en harina y aceite, así como de su exportación. Un primer aspecto a señalar es la fuerte concentración de estos agentes económicos, ya que seis empresas controlan más del $80 \%$ de la capacidad total de refinado: "tres de esas empresas son filiales de multinacionales (Bunge, Cargill y Dreyfus) y tres son de capital local (Molinos, Vicentín y General Deheza)” (Schvarzer y Tavosnanska, 2007:44). El creciente poderío de estos agentes se ha desarrollado a tal punto que los mismos tienden a integrar varias actividades de la cadena contando 
muchas veces tanto con capacidad de transporte propia así como con la propiedad de los puertos a través de los cuales exportan más del $90 \%$ de la soja industrializada. Por otra parte, la orientación exportadora de estas industrias promueve su concentración territorial en torno a los puertos; de este modo, la provincia de Santa Fe explica el 80\% de la capacidad de molienda nacional total. La industria aceitera fue expandiéndose durante toda la post-convertibilidad, ya que diversos factores tales como la avanzada tecnología de procesamiento y las cortas distancias desde las zonas de producción hasta los centros de molienda y exportación constituyen las principales claves de la competitividad internacional de estos agentes económicos.

Estas características del circuito productivo sojero han convertido a Argentina en el principal exportador mundial de aceite y harina de soja y el tercer exportador de granos, constituyendo al circuito sojero en la principal cadena agroexportadora en ingresos por exportaciones del país. Esta cadena culmina en la exportación donde China emerge como el principal receptor de la soja en grano y aceite, mientras que la Unión Europea aparece como principal receptora de harina de soja ${ }^{362}$. El peso de la dinámica productivo-exportadora que caracteriza al modo de producción del circuito sojero puede observarse también en sus implicancias de concentración territorial: “desde la producción, las instalaciones de almacenaje y las oficinas que ejecutan los procesos de comercialización, están concentradas en un radio de 500/600 Km. cuyo epicentro natural es la ciudad de Rosario. El complejo industrial y las instalaciones de embarques, están distribuidas a $80 \mathrm{Km}$. al Norte y a $80 \mathrm{Km}$. al sur de la misma” (Weskamp, 2006:50).

Con respecto al proceso de formación de precios y la expresión de relaciones de fuerzas a través del mismo debemos mencionar algunos factores. En primer lugar, a pesar del peso de la economía argentina en la producción sojera mundial, el precio de la soja es definido a través de la Bolsa de Chicago, a partir del cual gravita el precio en el mercado local. Según Schvarzer y Tavosnanska (2007), los precios pagados al productor dependen del precio internacional, corregido teóricamente teniendo en cuenta el flete hasta el Golfo de México (principal puerto exportador mundial), del tipo de cambio y de la existencia o no de retenciones. Por otro lado, los costos del productor dependen de un amplio conjunto de variables, entre las que estos autores mencionan: la

\footnotetext{
${ }^{362}$ China recibió el 64\% de las exportaciones argentinas de poroto de soja, el 34\% de las de aceite y la UE receptó el 57\% de las exportaciones de harina de soja. Datos SAGPyA, presentados por Ciani (2005).
} 
distancia del campo cosechado al puerto, la dimensión absoluta de la explotación y su capacidad de negociar los costos de comercialización, la productividad de los equipos utilizados en toda la actividad, la fertilidad del suelo y el uso de fertilizantes y, finalmente, el uso o no de silos en chacra y el precio de la semilla. Debemos tener en cuenta que "los costos dejan un beneficio bruto que en la práctica argentina puede ser captado por el productor propietario o bien éste reparte con un contratista que posee la maquinaria necesaria, trabaja el campo, y paga al dueño un alquiler. En ese caso el contratista obtiene, en términos clásicos, la ganancia "industrial” (correspondiente a su inversión en maquinaria, personal y capital de trabajo) mientras que el propietario percibe exclusivamente la "renta” de la tierra generada por sus condiciones específicas (ubicación, fertilidad, etc.)” (Schvarzer y Tavosnanska 2007:37). Finalmente, estos autores extraen las siguientes conclusiones acerca de cómo se distribuye el ingreso en la cadena:

\footnotetext{
"Del ingreso bruto, alrededor de la mitad se utiliza para cubrir los costos de producción y distribución. Esta parte es captada por los productores de insumos, los intermediarios, los transportistas, etc. El resto es ingreso del productor, o se divide entre arrendatario y dueño de la tierra, en caso de que quien controle la producción no sea al mismo tiempo propietario. En la cadena parte se "derrama" aguas abajo mientras que el resto es apropiado por los actores con suficiente poder de mercado como para captar parte de la renta. En esta línea se encuentran propietarios de grandes extensiones de tierras, productores que controlan mediante el arrendamiento parte importante de la producción, las grandes empresas aceiteras -entre las cuales hay tres multinacionales- y productores de insumos en sectores concentrados” (2007:5859).
}

A estas conclusiones alcanzadas por Schvarzer y Tavosnanska debemos añadirles otros factores importantes. Por un lado, dentro del primer núcleo de agentes, se destaca el poder de Monsanto en la producción de insumos, impulsando litigios internacionales para recuperar poder monopólico a través del patentamiento, y también el crecimiento de los agentes fabricantes de maquinaria agrícola, marcados también por la dinámica productivo-exportadora. En segundo lugar, el papel de almacenaje e intermediación de los acopios, tanto particulares como cooperativos. Por otra parte, emerge como lógica fundamental del circuito un triple proceso de concentración: a) los procesos de concentración estructural de la tierra, donde sólo el 4,2\% de las explotaciones agropecuarias (que poseen más de $2500 \mathrm{Ha}$ ) poseen el 62,8\% de las Ha totales, con la mencionada desaparición del 21\% de las explotaciones agropecuarias en el periodo inter-censal 1988-2002, con un incremento de superficie media de cada establecimiento de aproximadamente un 25\%. b) El proceso de concentración del capital presente tanto en el desdoblamiento creciente entre propietarios (devenidos en 
rentistas) y contratistas (propietarios de tierra o no) donde se calcula que el $40 \%$ de la superficie agrícola es trabajada mediante esta dinámica cosechando cerca del $70 \%$ de los granos del país, a la que se suma la concentración del capital en los eslabones finales del circuito productivo sojero en tanto sólo seis empresas controlan el $80 \%$ de la industrialización de la soja, dentro de las cuales pueden identificarse tres de capital extranjero (Bunge, Cargill y Dreyfus) que concentran el $42 \%$ de la capacidad de molienda instalada en los tres principales productores sojeros mundiales: EEUU, Brasil y Argentina. c) Finalmente, el circuito presenta creciente concentración de la organización y gestión del proceso productivo mediante la consolidación de grandes empresas agropecuarias-financieras y la expansión de los pools de siembra.

Para terminar el análisis de los agentes del circuito productivo sojero y vincularlo a la indagación acerca de la estructura de clase, emerge la pregunta por los trabajadores. Esta pregunta nos acerca a un problema que presenta una doble dimensión: por un lado, la capacidad de generación de empleo de este circuito y, por otro, las características propias del trabajo involucrado.

En torno a la generación de empleo, se da un importante debate donde, sintéticamente, confrontan dos perspectivas antagónicas acerca del impacto laboral de las actividades del agro en general y cuyas conclusiones centrales se trasladan al circuito sojero. Algunos autores sostienen que el sector agropecuario es el generador, directo e indirecto, de más de un tercio del empleo total del país, mientras que otros remarcan su escasa participación en el mismo, a partir de la comparación de la evolución del empleo en relación al crecimiento de la producción agropecuaria.

El primer núcleo de autores, entre los que podemos señalar a Barsky y Dávila (2008), se basan en las conclusiones desarrolladas por Llach, Harriague y O'Connor (2004) quienes afirman que las cadenas agroindustriales genera el 35,6\% de los empleos totales en Argentina. Sin embargo, esta conclusión que sustenta la mirada del “campo” (productos primarios y manufacturados en sus diversos encadenamientos) como principal motor del desarrollo nacional ha sido demostrada como inválida a partir de la rigurosa crítica metodológica realizada por Rodríguez (2005) quien evidencia una multiplicidad de falencias en la construcción de los datos ${ }^{363}$. Rodríguez sostiene que el

\footnotetext{
363 "Los autores tenían por objetivo demostrar que las cadenas agroindustriales inciden en forma muy significativa en la creación de empleo. Para ello debieron recurrir a cierto tratamiento especial del tema:
} 
sistema agroalimentario ampliado, que incluye las producciones primarias agropecuarias y pesquera, las etapas de industrialización y terciarias (comercio mayorista y minorista, transporte de todo tipo), abarca el 18,1\% de los puestos de trabajo de toda la economía.

La refutación de las conclusiones obtenidas por el trabajo de Llach et al (2004) ha debilitado la validez de las afirmaciones de todo el espectro de autores que fundamentaba sus posiciones en base a este trabajo. Así, se fortalece la posición antagónica que sustenta una mirada crítica con respecto a la capacidad de generación de empleo del sector agropecuario. De hecho, debemos destacar que entre 2002 y 2007, el producto de la actividad agropecuaria creció un 32,48\% pero la cantidad de puestos de trabajo se incrementó tan sólo en un 4,12\%, mostrando una elasticidad empleo-producto de 0,12. Esto contrasta fuertemente con el desempeño de la economía argentina en su conjunto, que en dicho periodo incrementó su producto en un 52,69\% y exhibió una creación de puestos de trabajo del 28,77\%, presentando una elasticidad empleoproducto de 0,54. Si bien las actividades agropecuarias implican una diversidad de dinámicas productivas y agentes, el CENDA (2008) señala como principal causa de la escasa generación de empleo del sector a la implementación del paquete tecnológico vinculado a la producción de soja. Podemos observar entonces que las transformaciones técnicas del proceso de trabajo han acarreado un cambio profundo en la composición orgánica del capital a lo largo del circuito productivo sojero masificando la participación del capital constante y reduciendo la gravitación de la fuerza de trabajo (capital variable). En este sentido, los cambios en la producción que han afectado la cadena disminuyeron su capacidad de generación de empleo. Esta afirmación puede ser constatada en los datos provistos por la SAGPyA:

\footnotetext{
"La demanda de mano de obra en la cadena oleaginosa en los tres eslabones básicos de la misma (producción, acondicionamiento y destino industrial o exportación) deriva de una actividad granaria extensiva. En el caso particular de los oleaginosos, en Argentina debemos incluir una significativa participación de la industria interna, ya que alrededor del $80 \%$ de la producción se destina a la molienda interna. Sin embargo, debemos tener en cuenta que la industria aceitera no
}

incluyeron el empleo directo, pero también ciertos empleos indirectos que corresponden a otros complejos, sin señalar esta cuestión a los lectores. Calcularon un porcentaje, que consideran su resultado más importante, pero en realidad dicho valor no es sobre el 100\%, sino sobre un valor mayor, por el doble conteo entre complejos agroindustriales y no agroindustriales. Adicionalmente, la doble contabilización se hace mayor cuando se adicionan los puestos de trabajo generados por la oferta con los generados por la demanda. Por último incrementan artificialmente la estimación de los puestos de trabajo en más de un $20 \%$ con la justificación de que la inflación - variación de precios relativos mediante- es un motor del incremento de empleos” (Rodríguez, 2005:13-14). 
se caracteriza por ser intensiva en mano de obra, siendo relativamente bajo el valor agregado de la misma y alta la incidencia de la materia prima en el valor industrial” (2006:38).

La segunda dimensión que refiere al trabajo en el circuito productivo sojero puede ser apreciada en las características propias del empleo involucrado. Esta dimensión nos permite comprender de un modo más acabado las relaciones entre los agentes económicos en vinculación a sus clivajes de clase. Por un lado, un núcleo de trabajadores crecientemente relevante en la producción agrícola son los empleados por los contratistas. En un estudio sobre la provincia de Buenos Aires, podemos observar que la cantidad de empleados transitorios y permanentes, aunque representa una incidencia minúscula sobre el empleo provincial, se ha incrementado desde unos 9.000 en 2001/02 a cerca de 18.000 en 2005/06 (Garbers, 2007). La existencia de formas de pago a porcentaje y de trabajo familiar involucrado podrían tender a generar entrelazamientos de intereses con los agentes empresarios del circuito sojero incrementando la subordinación a los mismos.

Por otro lado, como señala Katz, "Los asalariados del campo padecen un régimen laboral impuesto hace tres décadas por la dictadura que impide la vigencia de las ocho horas, desconoce la entrega de ropa de trabajo y el otorgamiento de extras por escolaridad. Por esta razón en el campo rige una elevada tasa de informalidad laboral (63\%) y remuneraciones que apenas alcanzan al 60\% del promedio urbano” (Katz, 2008:4). Además, la informalidad preponderante en el empleo rural "es coherente con un modelo de relaciones laborales clientelar-paternalista, ya que es la ausencia de derechos que caracteriza al trabajo informal la que conforma una relación de sumisión y fidelidad personal del trabajador frente al empleador, de cuya buena voluntad depende enteramente la vida del trabajador, la de su familia y su futuro" (Godio y Robles, 2008:163). En un marco legislativo ${ }^{364}$ que provee menores derechos a los trabajadores rurales en relación a los restantes sectores de la economía, con un elevadísimo nivel de informalidad y las remuneraciones más bajas del país, los trabajadores rurales no cuentan entre los beneficiarios del auge productivo-exportador que revisten las principales actividades del agro. De hecho, la retracción del salario de los trabajadores rurales en dólares desde la devaluación frente al fuerte incremento de rentabilidad de los agentes propietarios implica que "la transferencia de ingresos mediante ese proceso, de

${ }^{364}$ El 27 de diciembre de 2011 fue se promulgó la Ley n ${ }^{\circ} 26.727$ que establece una nueva legislación referente a los trabajadores rurales, derogando el anterior "Régimen Nacional del Trabajo Agrario" de la Ley $\mathrm{n}^{\circ} 22.248$ y sus modificatorias, vigente desde 1980. La misma establece un conjunto de regulaciones que procuran saldar las principales problemáticas que afectan a los trabajadores del sector. 
los trabajadores a los propietarios y arrendatarios rurales, puede ser estimada en unos 2.000 millones de dólares anuales” (Godio y Robles, 2008:164).

Estos rasgos del trabajo rural se agravan cuando los complementamos con la contraparte de la relación de clase en términos de participación en el ingreso socialmente producido: según el CENDA, tomando el caso de Pergamino, en la zona núcleo, sólo el 3,0\% del valor agregado se destinaba al pago de salarios directos (2004), por lo que las ganancias y rentas acaparaban el 97,0\% y aún si se incluyeran como parte de las remuneraciones los posibles gastos salariales en estructura, en el caso de la producción de soja, ese porcentaje estaría entre el 6,0\% y el 8,8\%, según los rendimientos obtenidos con el cultivo. Observando que se trata de un valor significativamente menor que el que se obtiene en el resto de la economía, se concluye que el agropecuario se caracteriza por ser uno de los sectores donde los asalariados tienen menor participación sobre el producto generado (CENDA, 2008).

Las dos dimensiones del trabajo en el circuito productivo sojero, tanto la capacidad de generación de empleo como las características del trabajo involucrado, nos convocan a reflexionar sobre el carácter de clase del proceso de transformación que se fue gestando al interior del circuito. El circuito sojero emerge como un circuito altamente dinámico tanto por los cambios técnicos y tecnológicos como por la expansión de la actividad y por su rentabilidad, que se muestra superior al resto de las actividades agropecuarias, marginándolas en términos relativos, pero los agentes económicos que rigen este proceso contienen dos rasgos con claras implicancias en las relaciones de clase: son agentes propietarios (de bienes de capital o de tierra) y con un perfil concentrado. En este marco el papel del trabajo asalariado encuentra condiciones de clara subordinación expresada en su diminuta participación en las riquezas socialmente producidas y arrastrando condiciones laborales inferiores a las padecidas por los trabajadores del resto de la economía ${ }^{365}$. El circuito productivo sojero se constituye entonces como un circuito regido por agentes económicos capitalistas (desde los contratistas propietarios de los bienes de capital, hasta las mega-empresas proveedoras de insumos, aceiteras, exportadoras, etc.) y propietarios rentistas (desde los pequeños, que al no poder alcanzar la escala suficiente terminan alquilando su campo,

\footnotetext{
${ }^{365}$ Estas distintas claves que caracterizan la subsunción del trabajo frente al capital en el agro argentino son fundamentales para comprender el desempeño del "conflicto de campo", tanto la masividad que adquieren las movilizaciones como las dificultades de diferenciación al interior del polo "campo".
} 
hasta los grandes terratenientes) articulados por una creciente dinámica de tipo pool de siembra, que abre el juego al capital financiero y a grandes empresas que utilizan este formato dinámico de organización concentrada de la producción.

\subsection{El conflicto agrario de 2008: hegemonía y relaciones de fuerzas}

\subsubsection{Completando la dimensión estructural de las relaciones de fuerzas.}

El conflicto agrario de 2008 establece un punto de inflexión, un hito en la historia argentina reciente que precisa ser abordado en su complejidad ya que, por un lado, expresa un conjunto de tensiones políticas y económicas a nivel del modelo y del proyecto político-económico de gobierno y, por otro lado, genera modificaciones en el escenario de lucha de clases en Argentina que tendrán consecuencias duraderas, dejando su marca en todo el período que le sigue.

Para comprender el “conflicto del campo” parece necesario realizar un recorrido guiado por la propuesta gramsciana de análisis de relaciones de fuerzas aplicada a este caso concreto. En el apartado anterior comenzamos a establecer los principales rasgos que conforman las relaciones de fuerzas a nivel estructural en vinculación a los circuitos agroindustriales, en general, y al sojero, en particular. En este camino, seguiremos apuntando algunas precisiones de carácter estructural para luego abordar la dimensión política de las relaciones de fuerzas en sus distintas gradaciones: del carácter económico de la disputa hasta la dimensión estrictamente política donde el conflicto se convierte en guerra de posiciones, en una genuina batalla por la hegemonía.

En primer lugar, observamos que la configuración del modelo de acumulación post-convertibilidad benefició el desarrollo del circuito productivo sojero. Este modelo, en el marco más general de las transformaciones del agro previamente señaladas y el favorable contexto internacional, impulsó un crecimiento de la producción de soja en un 78\% desde la última campaña de la convertibilidad, 2000/01, hasta la campaña de 2007/08. Como vimos, esto se debió a distintos factores constitutivos del modelo. La devaluación dotó de mayor competitividad a la producción agropecuaria impulsando su dinámica exportadora, en este camino la exportación de soja (en granos y productos elaborados) pasó de representar el 17,7\% en 2001 hasta alcanzar el 24,4\% en 2007 del 
total exportado en Argentina; este crecimiento puede ser visualizado también en su incremento absoluto en tanto en dicho periodo la exportación de soja pasó de 4.701 a 13.602 millones de dólares. Por otro lado, la pesificación asimétrica les permitió salvar sus propiedades a los deudores hipotecarios, pero también al conjunto más amplio de agentes endeudados con la banca local, inyectando capital en el sector. Esta deuda fue luego "socializada” y estatizada a través del plan de "salvataje” al capital financiero con la emisión de deuda pública. Además, estos mismos sectores se vieron favorecidos por las políticas de regulación de las tarifas de servicios públicos, marcando claros cambios en las relaciones de fuerzas en tanto se afectaba a agentes del sector con mayor capacidad de acumulación durante la convertibilidad en beneficio de los productores de bienes transables. También el control del precio interno de los combustibles, en un contexto de aumento de precios a nivel mundial, favoreció la contención del costo de transporte de los productos y de la producción, al ser el gasoil un insumo fundamental para la cosecha.

En el capítulo 5 analizamos cómo la fracción productivo-exportadora se convirtió en la principal beneficiaria de la configuración del modelo postconvertibilidad. Tomamos esta fracción en sentido amplio, ya que el dinamismo que había cobrado la orientación exportadora permitió alcanzar un considerable superávit comercial que junto al superávit fiscal, favorecido vía retenciones a las exportaciones, constituyeron los dos pilares de estabilidad del modelo. Así, el esquema de estabilidad del modelo basado en los dos superávits (comercial y fiscal) se alimentaba a través de un canal que se fue convirtiendo en el centro del conflicto entre los agentes económicos afectados y el gobierno y, al mismo tiempo, en un motor de disidencia y diferenciación al interior de la fracción productivo-exportadora, entre los agentes de las cadenas agroindustriales y los restantes. Es por este motivo que el debate en torno a las retenciones fue cobrando creciente centralidad. Las relaciones entre retenciones, inflación y ganancias constituyen un aspecto central de la dimensión estructural del análisis de relaciones de fuerzas que atraviesan el conflicto agrario de 2008.

El gobierno ha desplegado distintas acciones, como las retenciones, con el fin de participar de las ganancias extraordinarias de los circuitos exportadores más beneficiados por el tipo de cambio competitivo y el aumento de los precios internacionales, buscando limitar sus consecuencias inflacionarias y redireccionar recursos a otras fracciones de clase. Con respecto al impacto inflacionario, debemos 
recordar la tendencia del empresariado a realizar las ventas de los productos exportables para el mercado interno a precios que gravitan cerca de los que se podrían obtener exportando la producción, por lo que el tipo de cambio determina casi directamente el precio interno de dichos productos. El fuerte componente agroalimentario de la estructura exportadora argentina presenta la tensión de que los principales productos de exportación son al mismo tiempo de consumo masivo de la población, afectando específicamente las condiciones de vida de las clases subalternas y el costo de reproducción de la fuerza de trabajo (devenido en costo laboral para los agentes empresarios de la industria y los servicios). Aparece entonces una tensión contradictoria entre la tendencia a la realización de la máxima ganancia a través de la exportación de agroalimentos y la necesidad de proveer alimentos baratos en el mercado interno ${ }^{366}$. Además, la dimensión inflacionaria conlleva también un efecto contradictorio al deteriorar el tipo de cambio real, factor clave en la dinámica exportadora.

Si bien la soja no es un producto de consumo masivo de la población, su crecimiento por sobre los otros cultivos, la producción de carne y lácteos tiende a incrementar los precios vía limitación de la oferta o, al menos, restringiendo una reducción potencial de precios por incremento de la oferta ${ }^{367}$. Esto debe ser considerado, en determinados casos, en términos relativos, ya que la producción de algunos cultivos también continuó aumentando por la expansión de la frontera agrícola y los mejores rendimientos por Ha ligados a la aplicación del paquete tecnológico, pero en otros casos, ha tenido un efecto directo en la disminución de cultivos. De cualquier forma, en términos porcentuales, el cultivo de soja creció muy por encima del resto quitándoles participación relativa. Esta afirmación se encuentra verificada observando la última década de campañas previa al conflicto: mientras en la campaña 1996/97, el trigo aparecía como el principal cultivo con una producción de 15.913.600 toneladas, el maíz se ubicaba segundo con 15.536 .820 tn, la soja aparecía como el tercer cultivo con 11.004.890 tn, en la campaña 2006/07 la soja había trepado al primer puesto con 47.460.936 tn, presentando un asombroso aumento del 331\%, mientras que el maíz se ubicó segundo con 21.755.364 tn y el trigo, tercero con 14.550.450 tn, mostrando una evolución marcadamente menor para el maíz del 40\% y una disminución del trigo, un cultivo de gran importancia para el consumo interno, en más de un $8 \%$. Vale la pena

\footnotetext{
${ }^{366}$ Un planteo similar puede encontrarse en Godio y Robles (2008).

${ }^{367}$ Aspecto que, en el caso de los cultivos, varía también según la incidencia de dichas producciones en la conformación del precio internacional.
} 
señalar que en ese mismo periodo el cultivo de otra oleaginosa, el girasol, contrajo su producción un 33\%.

Asimismo, el auge sojero ha conllevado notables incrementos en la renta de la tierra, elevando el precio de la misma e incrementando por esta vía los costos del conjunto de los productos agropecuarios. Como señalan Godio y Robles, hay una relación directa entre el aumento del precio de la soja y su impacto en el aumento del precio de la tierra ${ }^{368}$ y de éste con el incremento del precio de los alimentos: "uno de los efectos de las retenciones son, efectivamente, limitar el aumento del precio de la tierra (al limitar la rentabilidad y la dolarización del precio)” (2008:173). El incremento del precio de la tierra se vincula, a su vez, al aumento de la renta diferencial I (Marx, 2006 [1894]) la cual no sólo es favorecida por la fertilidad propia de la denominada "zona núcleo” y su ubicación privilegiada dentro del circuito, sino que se ha incrementado en términos generales a partir del proceso de expansión de la frontera agraria argentina hacia tierras menos fértiles y peores ubicadas, aumentando, a través de esta mayor desigualdad, el precio y las rentas de las tierras más fértiles.

Es en este contexto que deben entenderse las retenciones ya que, por un lado procuran amortiguar, al menos parcialmente, el impacto inflacionario, morigerando el precio neto que consiguen los exportadores, intentando “desacoplar" precios externos e internos; y por otro lado, buscan gravar las ganancias y rentas extraordinarias relacionadas a los altísimos precios internacionales de sus productos y al tipo de cambio competitivo. Las retenciones han afectado distintamente a los productos exportados. En el caso de las retenciones agrícolas, éstas afectaron de modo diferente según el producto. Presentado menores porcentajes para los productos elaborados, las retenciones a los granos se ubicaron a fines de 2007 en 28\%, 32\% y 25\% respectivamente para trigo, girasol, y maíz. Para el caso de la soja las retenciones, entre 2002 y 2007 fueron del 27,5\%, mientras el precio del grano rondó los US\$ 160 por tonelada (tn). Estas retenciones aumentaron, cuando su valor superó los US\$240 ${ }^{369}$, en noviembre de 2007 al 35\%. En marzo de 2008 el precio alcanzó los US\$ 590 por tn, amenazando con generar un conjunto de desestabilizaciones económicas tanto en

\footnotetext{
${ }^{368}$ Según Godio y Robles el alza vertiginosa del precio de la tierra, de un 380\% entre 2003 y 2007, es consecuencia del aumento de su rentabilidad, por ende: "el aumento del precio de la soja, aumenta la rentabilidad de la tierra y por lo tanto aumenta su precio" (2008:173), y este incremento en el precio de la tierra va a impactar después en el aumento de precios de los alimentos en general.

${ }^{369}$ Recordamos que a pesar de las retenciones aplicadas sobre los productos agropecuarios, el rubro de alimentos y bebidas del IPC presentó un aumento del 135,2\% entre 2001 y 2007.
} 
materia de precios como en materia cambiaria, y fue en este contexto que el gobierno lanzó las retenciones móviles, que ligaban dicho tributo a la evolución del precio internacional, llevándolas en ese momento al $44 \%{ }^{370}$. Este hecho constituyó el inicio de la escalada confrontativa entre los agentes del agro, encabezados por las corporaciones agrarias, y el gobierno recientemente electo de Cristina Fernández de Kirchner.

Para analizar el “conflicto del campo”, es necesario vislumbrar la articulación entre diversos factores ligados al modelo de acumulación y a la construcción de hegemonía, pasando del análisis de la dimensión estructural de las relaciones de fuerzas a la dimensión política de las mismas. Iniciaremos este camino planteando una afirmación que, en el contexto de enfrentamiento entre las patronales agropecuarias y el gobierno, pudiera parecer paradójica: es posible pensar a las retenciones, que gravan a un sector de la fracción más dinámica del capital, como una herramienta que ha procurado, además de incrementar la recaudación fiscal, aportar armonización de las relaciones al interior de la clase dominante. Pero si las retenciones pueden ser consideradas como parte de un conjunto de acciones estatales tendientes a restablecer la paz interburguesa perturbada en el contexto de salida de la convertibilidad, algunos de los factores del circuito productivo sojero que venimos analizando pueden servir de base para la explicación de la irrupción del conflicto. ¿Por qué un grupo de agentes que emergieron entre los principales beneficiarios del modelo post-convertibilidad se rebelaron contra un gobierno que encarnaba el proyecto que fue dando forma a la Argentina post-convertibilidad? ¿Estaba amenazada la subsistencia de dichos agentes por el nuevo esquema de retenciones? Analicemos esta doble dinámica de la armonía y el conflicto.

La hipótesis de la armonización se encuentra sustentada en dos factores principales. En primer lugar, en que el Estado aplica un impuesto sobre el capital productivo-exportador que irá a engrosar el superávit fiscal primario que se destinará a transferencias de recursos hacia las distintas fracciones de clase. Algunos autores, sostienen que se ha derivado principalmente al pago de deuda pública ${ }^{371}$, que sumados

\footnotetext{
${ }^{370}$ Las retenciones para productos de soja elaborados siempre fueron menores, con el objetivo de promover la industrialización del producto. También fueron incrementadas las retenciones al petróleo que beneficiaría al sector agropecuario en tanto contiene los precios de los combustibles utilizados tanto para el transporte como para el secado de los granos.

${ }^{371}$ Por ejemplo, según Lozano, “en conjunto para el período 2002 - 2005 los pagos netos de deuda ascendieron a \$57.338,6 millones; mientras el superávit primario fue de \$45.659,1 millones. Es decir los
} 
al "salvataje" ya mencionado durante el gobierno de Duhalde y los mecanismos indexatorios a crecimiento e inflación de buena parte de la deuda post-default, se orientaron a dirigir recursos al capital financiero. Por otra parte, el gasto público en subsidios se orientó tanto al crecimiento de las PyMEs como, sobre todo, a compensar a las empresas de servicios privatizadas, cuyas ganancias quedaron limitadas con respecto a las obtenidas durante el modelo de la convertibilidad por la regulación de las tarifas. De este modo se genera una distribución "por arriba” del ingreso, que apuntala las posiciones del capital financiero, da aire a la fracción de PyMEs y compensa parcialmente a la fracción de empresas de servicios con su núcleo de privatizadas. Así podemos pensar las retenciones como una acción estatal que procura gestar, a través del sistema de transferencia de recursos, un nuevo momento de convergencia, una nueva armonía al interior de la clase dominante, superando, al menos momentáneamente, las disrupciones que había conllevado la salida del modelo de la convertibilidad. A esto debe sumarse el incremento del gasto social y el desarrollo de las políticas públicas orientadas a mejorar las condiciones de vida de las clases subalternas que constituyen un componente clave de la construcción de hegemonía en la Argentina postconvertibilidad y que nos permite completar el cuadro de armonización.

Es en este punto donde comenzamos a comprender la dinámica del conflicto: un Estado activo que instituye un sistema de transferencia de recursos pero que, al hacerlo, queda expuesto frente a los agentes que afecta con sus políticas. A esto debemos añadir otros factores relevantes. En primera instancia, podemos señalar que los procesos de concentración en el agro incrementaron el poder de presión de los agentes vinculados al circuito sojero. El mantenimiento de la concentración de la tierra en pocas manos, la concentración del capital, tanto en manos de contratistas como de poderosas empresas de insumos y agroindustriales, junto a la concentración de la organización y gestión del proceso productivo articulado crecientemente bajo el formato pool de siembra con incorporación del capital financiero o a través de mega-empresas, se constituyeron en factores de poder estructural. Este fortalecimiento de los agentes ligados al circuito sojero estuvo alimentado también por las ganancias extraordinarias que fue adquiriendo este sector debido al incremento de la demanda externa y al aumento de los precios de la soja, en particular, y de los principales cultivos, en general. De este modo, no es la 
“crisis” de los agentes involucrados que los llevó a la protesta sino su fortalecimiento en el marco de un cambio en las relaciones de fuerzas en la estructura de clases en Argentina.

En segunda instancia, debemos atender a las relaciones capital/trabajo y recalcar que este es un circuito productivo de clara predominancia empresarial, en el sentido del importante grado de subordinación del trabajo que contiene. Es por este motivo que, lejos de encarnar una "rebelión popular” ${ }^{372}$, el conflicto fue cobrando forma de una ofensiva patronal que incluyó un amplio repertorio de acción, tales como cortes de ruta, paro de comercialización, desabastecimiento, cacerolazos, entre otros. Esto no implica que en su desarrollo no haya arrastrado a distintos agentes económicos y sociales con motivaciones diversas, desde el interés económico hasta cruces particulares con debates históricos del tipo federalismo/centralismo, peronismo/anti-peronismo, entre otros. Sino que se relaciona a que el modo de producción dominante en el circuito sojero es un modo capitalista altamente desarrollado en su incorporación de nuevas técnicas y tecnologías. El proceso de transformación de los circuitos agroindustriales no sólo cambió las lógicas y alcances de la producción sojera sino que modificó el carácter de los agentes económicos y las relaciones de clase, tanto a su interior como en vinculación con las otras fracciones y agentes de la clase dominante. Es a partir de esta dinámica singular del agro en general y del circuito sojero en particular, que la fracción productivo-exportadora comienza a manifestar distinciones de intereses en su interior respecto de otros núcleos de agentes que la componían, como los industriales ajenos a los circuitos del agro. Es esta acumulación de fuerzas la que permitió a los agentes económicos del circuito sojero confrontar de forma abierta contra un gobierno representativo del modelo post-convertibilidad.

Es en este sentido que el "conflicto del campo" emerge como una limitante al proyecto armonizador de los intereses del capital bajo el formato post-convertibilidad. El pacto populista comienza a mostrar deficiencias para contener en su seno a grupos del capital relevantes, en tanto un núcleo de agentes con capacidad de acumulación creciente buscaba apropiarse de las ganancias extraordinarias que el mismo modelo había facilitado y que se magnificaban con la coyuntura de altísimos precios

\footnotetext{
${ }^{372}$ Principalmente porque no se plantearon reclamos propios de los trabajadores o que implicaran una distribución progresiva al interior del sector, sino que el conflicto fue dominado en forma exclusiva por el debate en torno a las retenciones y la defensa de la ganancia y renta de los propietarios.
} 
internacionales. El circuito sojero, lejos de estar amenazado por potenciales pérdidas económicas salió al conflicto en el momento en que percibía las más altas ganancias:

\begin{abstract}
"un establecimiento de 150 hectáreas en la región pampeana trabajada por su propietario, en octubre [2008] esperaba un margen bruto de 434 dólares por hectárea, y a la cosecha obtuvo 681 dólares por hectárea incluyendo compensaciones. (...) Asimismo, la renta obtenida por el propietario también es mayor en todos los casos respecto a la expectativa, tanto por la valorización de la tierra como por el ingreso por arrendamiento. El propietario de un campo de 2.000 hectáreas en la zona núcleo esperaba una renta de $\$ 5.195 .040$ y realmente obtuvo \$15.193.280” (Barsky y Dávila, 2008:173-174).
\end{abstract}

Esta perspectiva también es corroborada por Arceo y Rodríguez, quienes indican que la rentabilidad agropecuaria “en 2007 se ubicó un 72 por ciento por encima de la registrada durante la vigencia del plan de convertibilidad (...). En este contexto, la elevación de las alícuotas de exportación no sólo no genera una reducción de los márgenes de rentabilidad con respecto a los registrados en la campaña 2006/07 sino que, más aún, involucra un alza del 43 por ciento de mantenerse los precios vigentes” $(2008: 17)^{373}$. Sin embargo, según los datos provistos por estos autores, si entre 2007 y 2008, con la implementación de las retenciones móviles, el margen bruto por Ha (en pesos constantes de 2007) para soja saltó en sólo un año de \$846 a \$1223, si no se aplicaban las nuevas retenciones este margen alcanzaba los \$1643. Y es en esta disputa por alcanzar la máxima ganancia posible que se articularon todos los agentes propietarios del circuito, poniendo fin a los años hegemónicos del modelo postconvertibilidad que habían logrado combinar una armonización al interior de la clase dominante con altos grados de adhesión de las clases subalternas.

De este modo, podemos observar cómo incide la dimensión estructural de las relaciones de fuerzas, con el foco realizado a nivel de las transformaciones en el modelo de acumulación e incluyendo dinámicas de más largo plazo con impacto en las variables económico-estructurales, tales como el proceso de concentración y el predominio de los propietarios en el circuito, que fueron claves en el fortalecimiento de los agentes que salieron a disputar al Estado las retenciones. Es esta dinámica la que se encontró como sustrato del denominado "conflicto del campo" donde, a pesar de multiplicar su rentabilidad, los agentes ligados al circuito sojero se lanzaron para disputar mayores

\footnotetext{
${ }^{373}$ En este mismo sentido se expresa Basualdo cuando sostiene que aún "aplicando las retenciones móviles la rentabilidad aumentaba un $45 \%$ respecto de la campaña anterior debido (...) a un acentuado incremento de los precios internacionales" (2011:152).
} 
márgenes de ganancias y rentas extraordinarias ${ }^{374}$. Podemos arriesgar que el entrecruzamiento de agentes y las dinámicas articuladas del triple proceso de concentración del circuito productivo sojero se encuentra detrás de su unificación en el conflicto, ya que éste no se expresó en un enfrentamiento entre productores y rentistas (a pesar del sustancial aumento de los alquileres de la tierra), ni en un enfrentamiento entre productores y exportadores para que absorban estos últimos el aumento de las retenciones: el conflicto se gesta entre el gobierno y los agentes vinculados al circuito en su conjunto. Esto se debe a que en el modelo post-convertibilidad el Estado queda expuesto en tanto se constituye en un actor fundamental de la distribución diferencial del ingreso en base al desarrollo de un complejo sistema de transferencias que procura compensar intereses y mantener adhesiones. Como veremos, también debe recalcarse la gran capacidad de la estrategia de los dirigentes del polo “campo" para unificar intereses diversos, incluso muchas veces contrapuestos.

Nótese que la hegemonía alcanzada hacia 2006/2007 no tambaleó por un reclamo de clases subalternas cuyos salarios reales promedio quedaron después de varios años de altas tasas de crecimiento económico, en términos generales, cercanos a los niveles de 2001; mejorando de forma constante desde la emergencia del kirchnerismo como fuerza hegemónica pero sin observar cambios significativos en la distribución funcional del ingreso en relación al final del modelo anterior. Tampoco estalló el conflicto masivo por el principal impuesto de la estructura tributaria argentina: el Impuesto al Valor Agregado, cuyo carácter regresivo afecta más a los que menos tienen, y que explica cerca de un tercio de la recaudación total. Paradójicamente, la mecha del conflicto fue encarnada por el incremento de un tributo que se ubicaba en el cuarto lugar por su recaudación (después del IVA, Ganancias y Seguridad Social), en condiciones donde los agentes que lo impulsaron, aún con el incremento previsto por las retenciones móviles, aumentaban notablemente sus beneficios tanto en términos de ganancia como de renta.

Proponemos como hipótesis que los principales factores que explican el sustrato estructural del conflicto agrario se encuentran en: a) la creciente capacidad de acumulación de dichos agentes, ligada al proceso de transformación del agro, en

${ }^{374}$ Debe notarse, asimismo, que el margen de ganancia variaba según el tamaño de los agentes, en virtud del peso de la escala de producción en el circuito productivo sojero así como por otros factores ligados a la fertilidad de la explotación agropecuaria y su ubicación respecto de los puertos, entre otros. Esto hace aún más interesante analizar cómo lograron construir una acción política unificada. 
general, y del circuito productivo sojero, en particular, que instituyó un modo de producción capitalista con un alto grado de desarrollo tecnológico; b) la interrelación de los agentes en las dinámicas productivas del circuito, junto a c) el triple proceso de concentración económica previamente señalado. Se gesta así un conflicto que tiende a poner en crisis la hegemonía post-convertibilidad basada en el proceso de armonización promovido por el Estado para conciliar los intereses de las principales fracciones de clase que, en el marco de las nuevas relaciones de fuerzas que caracterizan a la Argentina post-convertibilidad, tienen centro en el proyecto político-económico de gobierno que el kirchnerismo despliega y en el cual se expresa el populismo como pacto.

Sin embargo, el análisis de la dimensión estructural de las relaciones de fuerzas, si bien provee claves ineludibles (de las cuales careceríamos o veríamos sub-valuadas desde un enfoque politicista), no agota la explicación del conflicto agrario. En este punto debemos asumir la dimensión política de las relaciones de fuerzas, viendo cómo juegan los componentes de sus distintas gradaciones en el desarrollo del conflicto.

6.4.2. La dimensión política de las relaciones de fuerzas y la gestación del antagonismo

El conflicto estalló con la sanción de la resolución 125 establecida por el Ministerio de Economía el 10 de marzo de $2008^{375}$. En un contexto de intensa variación de los precios internacionales, que en el caso de la soja presentaba un incremento del 118\% en sólo un año alcanzando los 566 dólares, esta resolución establecía en su artículo 1, una ecuación que implicaba la creación de un sistema de retenciones móviles para cereales y oleaginosas y, en los artículos 2 y 3 asentaba los nuevos valores de porcentajes que variaban según el precio internacional de las diversas mercancías. El nuevo esquema presentaba un fuerte aumento de los derechos de exportación para soja y girasol y una leve merma de los mismos para trigo y maíz. En principio, podemos mencionar que la propuesta inicial de retenciones móviles poseía la debilidad de no hacer diferenciaciones entre los distintos agentes (por ejemplo, en relación a su tamaño y ubicación geográfica) y además fijaba que, cuando los precios internacionales alcanzaran los 600 dólares, la alícuota aumentaría al punto de afectar el 95\% del valor

\footnotetext{
${ }^{375}$ El mismo había tenido como antecedente algunas protestas agrarias desarrolladas en 2006 y 2007 que no lograron un grado importante de adhesión ni trascendencia.
} 
que sobrepasara dicho monto, lo cual implicaba una anulación de los "mercados futuros” ${ }^{376}$, limitando esta vía de financiamiento al sector. La respuesta de las entidades agrarias no se hizo esperar y ya el 12 de marzo anunciaron un plan de lucha que incluía un paro con cese de comercialización.

Éste sería el inicio de un conflicto que fue articulando diversos agentes y actores, que dieron lugar a un proceso de encadenamiento de demandas, a la implementación de diversos repertorios de acción colectiva motivando la gestación de un antagonismo en base a la constitución de dos polos beligerantes con sus respectivas construcciones identitarias, alcanzando a poner en cuestión el orden vigente. El conflicto, comenzado como confrontación a una política impositiva, traspasaría la articulación de demandas a nivel gremial para alcanzar una dimensión específicamente política con fuertes efectos en el escenario de construcción de hegemonía, ya que, como señalan Godio y Robles, "el paro agropecuario se convirtió en un factor de reaglutinación política de la sociedad” (2008:148).

El conflicto se desplegó a través de distintos momentos de protesta y tregua presentando variaciones en las estrategias políticas, los discursos desplegados y en la magnitud y alcance de los repertorios de acción colectiva ${ }^{377}$. Sin pretender realizar una descripción cronológica del mismo, buscaremos seguir desentrañando los factores que hicieron de este conflicto un genuino antagonismo y su relación con las contradicciones centrales que lo subyacen.

En relación a las distintas gradaciones que Gramsci señala en la dimensión política de las relaciones de fuerzas, debemos observar que el conflicto ya desde sus inicios evidenció la tendencia a superar el grado económico-corporativo e incorporar crecientemente elementos propios del grado específicamente político, constituyendo una disputa por la hegemonía. Esto puede verse en tres factores centrales:

\footnotetext{
${ }^{376}$ Como señala Basualdo, "tradicionalmente el mercado de futuro tenía la función para el productor de asegurarse determinado ingreso por sus productos a partir de acordar su precio futuro en dicho mercado. Posteriormente, a esa función se le agrega otra que consiste en obtener ganancias financieras. Nuevamente, esta mutación (...) tiende a unificar los intereses de los terratenientes y las otras fracciones del capital agrario porque todas ellas operan, solas o asociadamente, en esos mercados (...) y tiende a unificarlos también en su oposición a la Resolución N¹25 porque la misma obstaculiza la realización de operaciones especulativas" (2011:153).

${ }^{377}$ Si bien iremos señalando los hitos más destacados del conflicto agrario, la exposición estará guiada por una lógica sistemática en base a las principales problemáticas teóricas que presenta y en vinculación a la propuesta gramsciana de análisis de relaciones de fuerzas. Algunas periodizaciones del conflicto pueden verse en Giarraca et al (2008) y Mengo y Pizarro (2010). También puede encontrarse un detallado seguimiento del conflicto día por día en Barsky y Dávila (2008).
} 
- El discurso proveniente del polo “campo” tendiente a la homogeneización, polarización y articulación de demandas más amplias.

- el repertorio de acción colectiva desplegado fue involucrando crecientes niveles de beligerancia.

- el rol de los medios masivos de comunicación como intelectual orgánico de lo que comienza a aparecer como un nuevo alineamiento de fuerzas portando un proyecto político-económico de gobierno que antagoniza con el oficialista.

En primer lugar, debemos mencionar la relevancia como actor de la denominada Mesa de Enlace ${ }^{378}$, que articuló a las cuatro entidades patronales agrarias de mayor relevancia: la Sociedad Rural Argentina (SRA), la Federación Agraria Argentina (FAA), las Confederaciones Rurales Argentinas (CRA) y la Confederación Intercooperativa Agropecuaria Limitada (CONINAGRO). Ésta se fue convirtiendo en el principal referente en la conducción de la protesta. Según Gras y Hernández (2009) estas entidades habían sufrido importantes transformaciones vinculadas a los cambios en el proceso productivo, y que se centraban en el desarrollo y ampliación de una amplia variedad de servicios para sus asociados ${ }^{379}$ (referidos a la prestación de información, capacitación, asistencia técnica y comercial) que complejizó la estructura interna de las entidades, fortaleciendo la presencia de los gerentes y profesionales en su dirección y generando una adscripción que se sustentaba en un vínculo muchas veces similar al usuario-empresa, más que en una búsqueda de representación corporativa o gremial; así el rol de las entidades se enfocaba en apoyar las transformaciones tecnológicas acaecidas en el agro. Si bien la Mesa de Enlace muestra una importante capacidad de dirección del conflicto, también debe rescatarse la importancia de otro actor particular: los “auto-convocados”. Como dicen Gras y Hernández,

"en ellos confluyen tanto productores que son miembros de alguna de las entidades gremiales (o
de sus organizaciones de base), como otros que no tienen pertenencia institucional alguna. En
términos de su posición en la estructura socio productiva, podemos decir que integran un arco
heterogéneo de productores en lo que refiere al tamaño de sus explotaciones (la mayoría de
nuestros entrevistados trabajan superficies entre 500 y 2500 hectáreas, si bien algunos pocos
operan explotaciones mayores); las actividades que realizan (si bien todos dedican parte de su
explotación al cultivo de soja y trigo, algunos combinan con la producción ganadera y en menor
medida, con la actividad tambera); o las formas de control de la tierra (casi todos combinan la
propiedad de la tierra con contratos accidentales para el cultivo de cereales, y en menor medida
arrendamiento). Por otra parte, se trata de productores que están a cargo de la gestión económica

${ }^{378}$ Esta Mesa es formalmente llamada como Comisión de Enlace de Entidades Agropecuarias.

${ }^{379}$ En este punto siguen a Lattuada (2003). 
y productiva de sus explotaciones, y que emplean a uno o dos trabajadores permanentes, contratando buena parte de las tareas productivas a empresas de maquinaria” (2009:15).

De este modo, aparece un actor heterogéneo que articula productores, contratistas, profesionales, rentistas, entre otros, que cumplieron un papel clave en los cortes de ruta, sometiendo a discusión en asamblea las directivas de la Mesa de Enlace. A su vez, los autores remarcan la importancia de los auto-convocados en su capacidad de movilizar no sólo a los productores sino también a los pobladores, dando la imagen de un "interior vivo". Esta dimensión es relevante para pensar el proceso de radicalización que se fue gestando a lo largo del conflicto en estrecha relación a la posibilidad de poder superar el carácter meramente gremial de las demandas articulando un espectro más amplio de reclamos que irían dando lugar a la constitución identitaria al calor del antagonismo.

Las primeras intervenciones públicas de los miembros de la Mesa de Enlace y otras entidades agrarias se orientaron a confrontar la medida de cambio de régimen y aumento de las retenciones, las cuales se constituyeron en la demanda central del conflicto. La medida era considerada por los dirigentes agropecuarios como una “confiscación a la producción agropecuaria, de neto corte fiscal”, al tiempo que se atacaba el principal argumento oficial, en tanto para el vicepresidente de la SRA, Hugo Biolcatti, "No tiene ningún sentido hablar de abaratar el precio de los alimentos cuando la soja no incide en absoluto en el precio final que paga el consumidor. Se exporta el 95\% de esta oleaginosa, por eso no veo lógica en esto” (Clarín, 12/3/2008).

Se inicia así una intensa disputa de sentidos que ponía a las retenciones en el corazón del debate político. Entendemos que la centralidad y la significación de la demanda contra las retenciones, percibidas como medidas confiscatorias, son factores claves que habilitaron la agudización del conflicto. Esto, a su vez, provee una pauta discursiva para comprender la profundidad que adquirió el conflicto, más allá de que lo que estuviera en juego, tanto en el mejor como en el peor de los casos, era ganar más de lo previsto en el momento de la siembra ${ }^{380}$.

Como señalan Gras y Hernández, las entidades agrarias debían saldar discursivamente la paradoja de que se trataba precisamente de uno de los sectores de la

\footnotetext{
${ }^{380}$ Margen que variaba, como dijimos, según el tamaño del productor en virtud del peso de la escala en la distribución de la ganancia al interior del circuito, entre otros factores.
} 
economía que mayor crecimiento había tenido desde 2002 y se hacía necesario argumentar de que, si bien era cierto que el productor tenía rentabilidad, las retenciones y, en general, la política del gobierno hacia el sector, la comprometía fuertemente, apelando a presentarse públicamente a través de la autodefinición como un sector “perjudicado”. En este camino, la significación de las retenciones adquiere un lugar clave:

\begin{abstract}
“Todas las organizaciones que componen la Mesa de Enlace han sostenido que las retenciones constituyen un mero mecanismo recaudatorio, que perjudica a los productores, al distorsionar los precios. En las asambleas, los autoconvocados profundizan esta caracterización al sostener que las retenciones tienen un carácter "expropiador", que no buscaría en las actuales circunstancias redistribuir ingresos hacia otros grupos sociales sino "destruir", "castigar”, "someter” a un sector que produce riqueza “genuina”, desde el “trabajo”” (Gras y Hernández, 2009:17).
\end{abstract}

En este camino, el discurso del polo "campo" fue avanzando hacia una creciente eliminación de las diferenciaciones a su interior, lo que permitió el abroquelamiento y la polarización y, a su vez, la irreductibilidad de las posiciones dotó de mayor vigor a la dinámica del antagonismo. Así, del lado del “campo”, la heterogeneidad de agentes y actores era limada por varios factores:

1) Por la unidad en torno a la demanda central, las retenciones, revestía para el polo “campo” una doble cualidad, por lado, permitía unificar disimulando las diferencias de escala, modo de inserción en el circuito productivo, capacidad diferencial de apropiación de renta y ganancia, etc. y, por otro lado, colocaba en la radicalización de la demanda (la exigencia de eliminación de las retenciones) el debate por el proyecto político-económico de gobierno ${ }^{381}$, en tanto su consecución era incompatible tanto con el desarrollo del modelo de acumulación en curso como con el modo de construcción de hegemonía característico de la Argentina post-convertibilidad. A su vez, siendo las retenciones un punto explicitado por distintos intelectuales orgánicos ligados al gobierno como "fuera de discusión” ${ }^{382}$, reforzaba la mutación de reclamo sectorial a demanda política y comenzaba a exhibir la posibilidad de una larga duración para el conflicto.

\footnotetext{
${ }^{381}$ Como señala el semiólogo Steimberg: "La diversidad del campo se conjuró mediante el carácter de extremado resumen de actitudes que tuvo ese discurso. (...) El borramiento de las diferencias se produjo por el carácter único de la demanda: las entidades consiguieron confundirse por la vía de la renuncia a la extensión del discurso y a la manifestación de sus particularidades en términos de su composición social” (Página 12, 3/4/08).

${ }^{382}$ Como constata la nota de Clarín (18/3/2008): “el jefe de Gabinete, Alberto Fernández replicó: "No vamos a revisar las retenciones. No es un tema que estemos discutiendo, para nada””.
} 
2) La articulación de la cadena avanzó, sin perder la centralidad de las retenciones, sobre otras demandas de agentes del sector (por ejemplo, en relación a la producción de carne y lácteos, entre otras) realizándolo con una lógica discursiva que apelaba a registros históricos del imaginario colectivo: la reedición de la disputa “pueblos del interior” vs Gobierno central fue cobrando presencia en los discursos de los miembros de la Mesa de Enlace y de los autoconvocados $^{383}$ actualizando el debate entre federalismo y centralismo que signó los años de guerra civil argentina entre federales y unitarios en el siglo XIX. Podemos ver en los comunicados de la Mesa de Enlace la apelación a un "país federal” (Comisión de Enlace, 26/5/2008) como demanda del polo “campo": "Nadie mejor que nuestro sector que vive y habita intensamente todo el territorio nacional para entender un verdadero federalismo, que ha sido causa impostergable del reclamo que llevamos adelante” (Comisión de Enlace, 6/6/2008). Asimismo, como señala Palma (2011), la dicotomía federalismo/no federalismo fue cobrando un lugar destacado en el discurso de De Angeli, principal vocero de los auto-convocados, realizando una particular lectura de la historia provincial que se "utiliza para legitimar la oposición a las retenciones móviles, presentando al conflicto como una consecuencia de la puja de poder entre el Gobierno Nacional y las Provincias. Así, se construye al concepto de federalismo en relación con la defensa de los derechos económicos de las provincias frente al poder central, que constituye sólo un aspecto de las reivindicaciones históricas del federalismo en la Argentina” (Palma, 2011:8) ${ }^{384}$.

Estos dos factores mencionados confluían habilitando el traspaso del grado económico-corporativo y económico general al grado específicamente político de las relaciones de fuerzas políticas, que constituye el ámbito primordial de la hegemonía. La disputa rápidamente traspasaba la lucha por la demanda en torno a las retenciones sino que comenzaba a expresar, en el discurso del polo “campo”, una disputa entre una Argentina agraria que precisaba de la liberación de trabas “distorsivas” para poder

\footnotetext{
383 Como señalan Giarraca et al (2008), los dirigentes agrarios lograron ampliar su base de apoyo apelando en su discurso al bienestar de los pueblos y ciudades del interior.

${ }^{384}$ En este sentido Palma cita que "al hacer referencia al panorama actual del sector agropecuario y a las consecuencias negativas que tendría la aplicación del proyecto de retenciones móviles, ADA señala: "No hay federalismo, están saqueando las provincias. Los gobernadores están alineados detrás de una política partidaria, no están representando al pueblo, porque nosotros somos parte del pueblo el sector agropecuario, de los pueblos del Interior. Entonces que paren” (A dos voces, 27 de abril, Canal TN)" (2011:8). ADA= Alfredo De Angeli.
} 
aflorar vs la Argentina estatista, donde Estado aparece ligado a las características de corrupción e ineficiencia, haciendo visible la dimensión hegemónica que fue cobrando el conflicto. Se genera un efecto a nivel ideológico que avanza hacia la restauración de distintos componentes de la idea de Estado mínimo puesta en crisis hacia 2001: la libertad de mercado como consustancial de la libertad del individuo, la acción del Estado como perturbación al mercado, la idea de que el mercado utiliza mejor los recursos que el gobierno y que el desarrollo nacional se alcanza, por ende, a través de más mercado libre.

Esta estrategia discursiva era amplificada por la polarización creciente, conllevando, a su vez, la invisibilización de otras voces ${ }^{385}$. Es en este trayecto que, como señalan Giarraca et al, “A medida que el conflicto se despliega, el significante “campo" comienza a integrar mayor cantidad de reclamos que abarcan, desde la suspensión de la resolución 125 que fija las retenciones móviles hasta un cambio de modelo productivo; desde la revalorización de las instituciones estatales (Congreso, Poder Judicial) hasta la desvalorización de la imagen presidencial” (2008:43).

A su vez, la lógica del antagonismo se fue radicalizando a través de la implementación de amplios repertorios de acción colectiva ${ }^{386}$. Y es en esta dimensión donde se produce uno de los factores que hacen de este conflicto un caso singular de alta relevancia: la acción colectiva proveniente de las entidades patronales apela a la apropiación del acervo de protesta desplegada por los actores de las clases subalternas en su lucha contra el neoliberalismo que tuviera su momento álgido en 2001. Como vimos en el capítulo 3, el "piquete” o corte de ruta se conformó en el componente clave de la protesta de los desocupados argentinos al punto de que su movimiento fuera nominado como “piquetero”. En 2008 fueron las entidades patronales quienes tradujeron al piquete y lo incorporaron al repertorio de acción de las clases dominantes:

\footnotetext{
${ }^{385}$ Por ejemplo, según Teubal y Palmisano (2010), a lo largo del conflicto no participaron en forma directa ni el sector campesino, ni las comunidades indígenas, ni una parte importante de la agricultura familiar, aunque muchos de estos últimos manifestaron críticas al gobierno por razones que no tenían necesariamente que ver con el problema de las retenciones. Estos actores y sus reclamos tendieron a ser invisibilizados por la polarización del conflicto y la apariencia de homogeneización del polo "campo" que ocultaba los rasgos heterogéneos del agro argentino.

${ }^{386}$ Como señala Tilly "El término teatral "repertorio" captura la combinación de elaboración de libretos históricos e improvisación que caracteriza generalmente a la acción colectiva” (2000:14). En este sentido analizaremos los elementos principales que constituyeron los repertorios de acción colectiva en el conflicto agrario, viendo la rearticulación de acciones de protesta que habían cobrado auge durante la crisis del modelo de la convertibilidad y cómo éstas son apropiadas y resignificadas en 2008 añadiendo, asimismo, otras acciones novedosas.
} 
el corte de ruta se convirtió en la principal medida apelada por el polo "campo" en todo el conflicto ${ }^{387}$. El corte de ruta estuvo, asimismo, acompañado por el paro de comercialización y el desabastecimiento generado por los mismos.

El segundo componente fundamental del repertorio de acción colectiva de las patronales agrarias fueron las asambleas. Así como en 2001 y 2002 emergió un amplio fenómeno de conformación de asambleas vecinales ante el desgaste de las formas de representación tradicional que parecían ser renovadas en nuevas formas de participación, debate y tomas de decisiones de modo más directo, en 2008 esta medida es apropiada para fortalecer el alcance de la estrategia de confrontación de la Mesa de Enlace. En los distintos pueblos y piquetes se gestaron asambleas, en las cuales los auto-convocados jugaron un rol relevante, tendiendo a transmitir, debatir y organizar el plan de lucha de las patronales agrarias, e incluso a promover medidas de acción directa más allá de las definiciones de la Mesa de Enlace misma.

Un tercer factor fueron los cacerolazos: el movimiento de "caceroleros", que expresaba un modo clave de protesta de los sectores medios contra las restricciones impuestas por el "corralito", se convirtió a lo largo del conflicto agrario en un modo de articulación y adhesión de sectores de los centros urbanos a las medidas desplegadas en las rutas por las patronales. A esta acción se añade la disputa del espacio público y las plazas, ligada al fenómeno de los cacerolazos articulados con la movilización y la búsqueda de legitimar la construcción identitaria en el antagonismo, en tanto cada uno de los polos reclamaba para sí la envestidura de “pueblo" frente al otro-poder que encarnaba la anti-comunidad. En este sentido, fueron notables los enfrentamientos por la ocupación de la Plaza de Mayo, debido a la gravitación simbólica que esta plaza tiene en la historia argentina. También debe notarse que en muchos pueblos del interior la movilización y ocupación del espacio público adquirió la forma de "tractorazo", dotando al repertorio de acción de una característica propia de los actores movilizados.

Un cuarto factor desarrollado en las fases más avanzada del conflicto, principalmente a partir de que el proyecto de las retenciones comenzó a ser tratado en el Parlamento, fue la presión directa y agresión sobre legisladores y funcionarios, mostrando el elevado grado de beligerancia que llegó a alcanzar el antagonismo, que

\footnotetext{
${ }^{387}$ Según Hora, "La importancia de los cortes de ruta para darle una base organizativa al reclamo agrario no podría exagerarse, y no sólo porque los piquetes volvieron políticamente productivos los tiempos muertos del ciclo agrícola" (2010:87).
} 
incluso implicó la reapropiación de otra acción de protesta acuñada en la lucha de las clases subalternas como el “escrache” ${ }^{388}$.

De este modo, vemos una paradójica reminiscencia al proceso más álgido de lucha de las clases subalternas y la reapropiación de su repertorio de acción por parte de las patronales agrarias. Esto nos permite dimensionar el primer punto de inflexión que encarna el preludio de nuestro período de estudio: el 2001, que marca de formas diversas la nueva etapa de la Argentina post-convertibilidad. Pero la crisis proveniente de las clases subalternas muestra su reverso en 2008: es el fortalecimiento de los agentes dominantes de los circuitos agroindustriales a través de los cuales estalla el antagonismo. En este punto es necesario rescatar algunos elementos centrales del discurso oficial con el fin de proveer las claves explicativas del antagonismo en sus dos polos constitutivos, para luego profundizar en el tercer factor que mencionamos como central en el desarrollo del polo “campo" ligado al rol de los medios masivos de comunicación.

Cristina Fernández mantuvo un discurso de corte fundacional, al igual que Néstor Kirchner, donde el 2003 aparece como un vértice histórico que marcaría el comienzo de una nueva Argentina: "hemos visto la transformación tan importante, que ha tenido la Argentina, desde el año 2003, a la fecha” (Fernández, 25/3/2008). En este primer discurso público que remite al conflicto agrario, dado en la Casa Rosada con el motivo de la firma de convenios entre AySA y distintos municipios, construye una contraposición que tendría efectos duraderos a lo largo del conflicto: recuerda la crisis de 2001 caracterizándola como "la tragedia de los argentinos” y habla de los "piquetes de la miseria” a los que contrasta con los “piquetes de la abundancia” para caracterizar la medida de fuerza de las entidades agrarias:

\footnotetext{
“Recuerdo esa Argentina de los años 2003, 2002, 2001, miles de argentinos en piquetes, cortando calles, rutas porque les faltaba trabajo, porque hacía años que habían perdido su trabajo o, tal vez, en el 2001, porque se habían apropiado de los depósitos de pequeños ahorristas de la clase media. Eran los piquetes, como digo yo, de la miseria y la tragedia de los argentinos.

Este último fin de semana largo nos tocó ver la contracara, lo que yo denomino los piquetes de la abundancia, los piquetes de los sectores de mayor rentabilidad.” (Fernández, 25/3/2008)
}

De este modo, da cuenta de la apropiación del piquete en el repertorio de acción de las entidades agrarias, leyéndolo de una manera que niega toda legitimidad al

\footnotetext{
${ }^{388}$ El escrache había sido la acción de protesta característica desplegadas por las asociaciones de hijos de desaparecidos de la última dictadura con el fin de reclamar el enjuiciamiento de los responsables del terrorismo de Estado.
} 
reclamo ${ }^{389}$ al punto de sostener que la Argentina "se ha transformado de aquella tragedia a esto que parece casi un paso de comedia” (Fernández, 25/3/2008). De este modo acelera una de las claves constitutivas del conflicto: la polarización; ya que la impugnación de la legitimidad del reclamo genera una negación sobre los actores en conflicto que obtura la vía del diálogo y la negociación. La estrategia discursiva se articula así a través de la confrontación directa y, a continuación, la Presidenta pasa a enumerar los beneficios que ha reportado el modelo post-convertibilidad a los agentes agrarios $^{390}$, haciendo énfasis en la política de tipo de cambio ${ }^{391}$, a lo que suma el desacople de los precios del combustible, obras en infraestructura, e incluso denuncia los bajos salarios que paga el sector y las condiciones de informalidad de los trabajadores rurales.

Aparece entonces otro factor constitutivo de la estrategia discursiva oficial: el acento en el carácter redistributivo de las retenciones,

\begin{abstract}
"las retenciones, no son medidas fiscales, son profundas medidas redistributivas del ingreso. (...) ¿qué es la distribución del ingreso? ¿Cómo se hace la distribución del ingreso si no es, precisamente, sobre aquellos sectores que tienen rentas extraordinarias sino de qué ejercicio me están hablando en materia de distribución del ingreso, a quién le vamos a pedir, a los países fronterizos, a quién, qué es la distribución del ingreso? Algo que siempre se declama, algo que siempre se dice pero que muy pocas veces se cumple, ¿por qué?, porque hay que tocar intereses que muchas veces son muy poderosos y que cuestan” (Fernández, 25/3/2008).
\end{abstract}

El discurso presidencial enfatiza que las retenciones aportan, junto a otros tributos como el IVA, al superávit fiscal que habilita la recomposición del Estado y que dio lugar, a través del desarrollo del proyecto kirchnerista, a la nueva etapa que camina la Argentina. Las retenciones están entonces enlazadas con la distribución del ingreso que involucra el prevalecimiento del bienestar colectivo por sobre los intereses sectoriales, y que conlleva en sí un conflicto: tocar intereses poderosos. En esta línea, oponerse a las retenciones aparece asimilado a oponerse a la realización de la promesa

\footnotetext{
${ }^{389}$ Uno de los pasajes indicativos de esta impugnación a la protesta agraria puede verse cuando la presidenta sostiene que: "Hay una rara conducta, muchas veces, es como que cuando hay pérdidas la sociedad debería absolverlas, es una suerte de socialización de las vacas flacas y cuando las vacas vienen gordas, las vaquitas para ellos y las penitas para los demás” (Fernández, 25/3/2008).

390 “... las condiciones macroeconómicas del modelo que tanto critican y que es instauró desde el 25 de mayo de 2003, es el que los ha tornado absolutamente competitivos y con una rentabilidad nunca vista." (Fernández, 25/3/2008).

${ }^{391}$ Señala que una de las causas de la rentabilidad del sector agropecuario se explica "por el tipo de cambio; sostener un tipo de cambio competitivo, como lo hace el Estado argentino a través de un sistema, no de regulación cambiaria, sino de administración cambiaria, es decir, absorbemos dólares cuando entra y se liquida toda la cosecha para que se mantenga el valor porque sino el dólar se cae, se hace con una política que está siendo sustentada por el Gobierno y que también forma parte de la utilización del superávit fiscal” (Fernández, 25/3/2008).
} 
de plenitud y al bienestar de la voluntad colectiva, implicando la priorización de la parte por sobre el todo, un todo en clave del pacto populista, es decir, del proceso de armonización de fracciones de clases como "partes". Esto puede observarse cuando afirma:

"nadie critica que puedan comprarse una 4 por 4 o que vivan bien y que tengan lo que tantísimos argentinos querrían tener; lo que no me parece bien es que además quieran hacerlo a costa de que otros argentinos no puedan acceder a las cuestiones más elementales” (Fernández, 25/3/2008).

En este primer discurso aparece otro factor que va a ser central, no sólo en el conflicto de 2008, sino en el discurso y las estrategias políticas que se irán desarrollando con posterioridad a dicho punto de inflexión: la polarización adquiere contenido concreto, así lo que se juega en cada conflicto va a ser "si queremos volver al país de unos poquitos o queremos volver a un país más justo, con mayor equidad, con mayor distribución” (Fernández, 25/3/2008, el subrayado es nuestro). Debe notarse la peculiaridad de que se habla de dos pasados (a través del verbo volver) y en esta articulación discursiva podemos recuperar uno de los ejes estratégicos del kirchnerismo como cultura política: la recuperación del imaginario del regreso a la Argentina peronista, que hace del "nosotros" kirchnerista una reformulación singular de la identidad peronista. Pero, como vimos en el capítulo 3, aparece otro componente igualmente fundante de la cultura política kirchnerista, vinculado a la delimitación del “ellos” identificado en torno a otro pasado distinto: a la Argentina neoliberal. Es en este punto donde se puede comprender la disputa entre esos dos pasados: es el pasado neoliberal que se cierne nuevamente sobre la realidad política nacional procurando su restauración, aquel pasado frente al cual se habían levantado las fuerzas populares de 2001 y que luego comenzó a ser parte de la creación de voluntad colectiva bajo el nuevo Príncipe en clave kirchnerista. Este pasado neoliberal vuelve ahora a cobrar consistencia concreta: se encarna en los adversarios del conflicto agrario. Frente a esa re-emergencia del pasado neoliberal, que busca afectar el rol regulador del Estado y que desafía el modelo de acumulación vigente (a pesar de ser uno de sus principales beneficiarios), es que el discurso presidencial eleva el pasado mítico que expresaría el momento histórico de referencia para la promesa de plenitud: el retorno a la Argentina peronista.

Y es en este camino que la líder del kirchnerismo a lo largo de sus discursos hará contraposición entre los intereses de la parte o sector y los intereses del pueblo o del conjunto de sectores: "Yo puedo entender los intereses del sector, pero quiero que sepan 
que soy Presidenta de todos los argentinos y que tengo que gobernar para todos los argentinos y para los intereses de todos los argentinos y para que los argentinos que vivimos aquí, en la Argentina, sigamos teniendo costos también argentinos en materia de alimentos, en materia de todo lo que hace a nuestra vida cotidiana.” (Fernández, 25/3/2008, el subrayado es nuestro). De este modo, se refuerza el rol del Estado como mediación y se enfrenta abiertamente a quienes pongan en cuestión dicha función estatal, defendiendo los mayores niveles de autonomía relativa alcanzados.

Señalamos, de este modo, un conjunto de factores fundamentales que marcan la estrategia discursiva oficial, cada uno de los cuales está a su vez ligado al discurso que el kirchnerismo ya había comenzado a construir bajo la presidencia de Néstor Kirchner, y que irían cobrando cada vez mayor fuerza con el recrudecimiento del conflicto:

a) la polarización en base la confrontación

b) el énfasis en la distribución del ingreso (que en Cristina Fernández posee aún mayor acento)

c) la recuperación del imaginario del regreso a la Argentina peronista, enfrentando el proyecto kirchnerista contra los intentos de retorno a la Argentina neoliberal.

Ya en su segundo discurso en referencia al conflicto, convocado por el kirchnerismo en Parque Norte el 27 de marzo con el fin de apoyar la resolución 125 y al gobierno nacional $^{392}$, Cristina Fernández realizó un primer intento de diferenciación al interior del polo "campo" contraponiendo los pequeños productores y los grandes pools y productores. En este camino, puso de relieve el conjunto de compensaciones orientadas en materia de política pública y de transferencia de recursos hacia los pequeños productores e interpeló directamente a la Federación Agraria a través de una mención al Grito de Alcorta, hablando de Netri, abogado de los pequeños productores asesinado "por un sicario, dicen, de la aristocracia del campo”. Así explicitó un intento

\footnotetext{
${ }^{392}$ Como señalan Mengo y Pizarro, "En el escenario, la Jefa de Estado tuvo como escoltas en el palco a la totalidad del Gabinete Nacional, como así también a numerosos gobernadores peronistas y dirigentes del oficialismo. También asistió el ex presidente Néstor Kirchner, quien ocupó uno de los lugares centrales. A un costado se ubicaron Hugo Moyano -líder de la CGT-, Luis D'Elía -dirigente social de barrios marginales-, el diputado Juan Carlos Dante Gullo y el dirigente piquetero Emilio Pérsico, quienes ocuparon un segundo plano luego del protagonismo que tuvieron por aquellos días, al controlar la Plaza de Mayo cuando la misma fue ocupada espontáneamente por los opositores al gobierno. La alocución partió con tono conciliador, aunque ratificando las retenciones al campo anunciadas por el Gobierno.” (2010:105)
} 
de aproximación: “este Gobierno popular siempre va a contemplar los intereses de los pequeños productores” (Fernández, 27/3/2008).

Debemos entonces preguntarnos por qué no dieron resultado las estrategias de fragmentación del rival. Un primer elemento explicativo se ubica en las lógicas de entrelazamiento que se fueron gestando en las transformaciones del proceso productivo al interior de los circuitos agroindustriales, que hicieron que ese agente al que se apelaba en el discurso no exista en tanto tal, sino que hubiera mutado. La preeminencia de la escala para el acceso a la producción tiende a convertir al antiguo pequeño productor en rentista, al tiempo que el viejo arrendatario de tierras poseedor de herramientas de trabajo, si tuvo la oportunidad de capitalizarse, se constituyó en contratista. Así, productores, rentistas y contratistas aparecen articulados en las nuevas lógicas productivas. Estos procesos fueron generando una transformación en las bases sociales de las entidades agrarias. Como señalan Godio y Robles:

\begin{abstract}
"El caso paradigmático es sin dudas Federación Agraria que sufrió la merma de asociados recordemos que sus bases históricamente han provenido en particular de las capas de la pequeña producción familiar, una de las más castigadas durante la década del '90 y donde se registró la mayor cantidad de salidas de la producción, según mostraron los datos censales de 2002 aludidos en la sección anterior. Pero también recordemos aquí la transformación en rentistas de muchos otros (...) Una situación similar encontramos en la Sociedad Rural Argentina. En este caso, vinculada a las transformaciones en la cúpula del sector, que desplazaron a muchos grandes propietarios de su rol de pivot central del nuevo modelo de los agronegocios” (2008:11)
\end{abstract}

Esto habla de cómo los cambios a nivel estructural se ligan con las relaciones de fuerzas políticas en su grado económico-corporativo, en tanto las transformaciones en los lugares (en términos de Poulantzas) impactan en los rasgos de los agentes y éstos en la representación corporativa de los intereses. Además las lógicas propias del circuito productivo fueron generando un entrelazamiento de intereses, que sumado al fuerte predominio patronal, fueron factores relevantes que intervinieron para sostener la unidad de acción frente a los intentos de fragmentación.

En segundo lugar, es necesario ver cómo la dinámica misma del conflicto tendiente a la polarización terminó cristalizando la indiferenciación: esta homogeneización parte, en un primer momento, del error del gobierno de no contemplar compensaciones y distinciones en la formulación inicial de la $125^{393}$, pero también de la

\footnotetext{
393 Incluso como señalan Giarraca et al (2008) al error de la estrategia oficial de no realizar diferenciaciones en la formulación de la 125, se sumó un error en el momento de enunciación de la medida: ésta se realiza cuando los dirigentes de las patronales agrarias están reunidos en el Senado con la
} 
productividad política del discurso del polo “campo” y la efectividad de la estrategia de la Mesa de Enlace al mantener unidas a las entidades patronales. Al mismo tiempo, la capacidad de integrar distintas dimensiones simbólicas, como la idea de un "interior vivo" que se visibilizaba en un resurgir de la histórica antinomia federalismo/centralismo, también jugó un papel importante.

A pesar de las transformaciones de los circuitos agroindustriales y la efectiva heterogeneidad que involucraba el polo “campo”, su homogeneización fue reforzada también por la estrategia discursiva del gobierno nacional, atravesada por la polarización y la búsqueda de cerrar fuerzas en torno de sí para librar la batalla política. Esto puede observarse en la construcción identitaria que iba moldeándose a partir de múltiples apelaciones al imaginario colectivo ligadas a la cultura política del polo oficial y que recorren de modo más difuso el enfrentamiento entre “pueblo vs oligarquía”, remitiendo al peronismo originario, cobrando forma más concreta en la oposición entre “gobierno nacional y popular vs dictadura/neoliberalismo”.

Ya en sus primeros discursos Cristina Fernández caracterizaba la protesta agraria como un ataque contra el gobierno y el pueblo, identificando a ambos en la construcción del "nosotros”. Se trataba, según la Presidenta, de "un lock out patronal, contra el Gobierno, en definitiva, contra el pueblo al quitarle los alimentos o al hacer que estos suban producto de la escasez" y convocaba al diálogo pidiendo el fin de la protesta: "Las puertas de la Casa de Gobierno están abiertas, pero por favor, levanten las medidas contra el pueblo” (Fernández, 27/3/2008). Asimismo, se preguntaba en torno a la naturaleza del conflicto vigente, planteando que el enfrentamiento trascendía los límites del reclamo gremial para instalarse en la disputa de proyecto de sociedad: "Y, entonces, ¿de qué naturaleza es el conflicto para algunos sectores? De una naturaleza política. Pero no política por partido, política por modelo de país” (Fernández, 27/3/2008).

Esta comprensión del carácter político del conflicto conlleva la polarización que está en el seno de la radicalización creciente que el mismo fue cobrando. El populismo como lógica hegemónica se alza así en toda su extensión y la estrategia discursiva oficial busca construir una identidad que conquiste un amplio conjunto de significantes en el delineamiento de la comunidad, al tiempo que busca definir al polo opositor como

oposición para discutir política agropecuaria, por lo que se tomó como una provocación y facilitó la respuesta rápida y unificada. 
la anti-comunidad asignándole un grupo de rasgos, que incluían su carácter oligárquico en tanto poderoso sector minoritario ${ }^{394}$, conteniendo prácticas golpistas y encarnando la resurrección del proyecto neoliberal. Cristina Fernández sostiene claramente en el discurso del 1 de abril, en el denominado “Acto por la convivencia y el diálogo” en Plaza de Mayo, una construcción de "nosotros” como pueblo y Nación argentina contrapuesta a un "ellos" definido como "el rostro del pasado que quiere volver" (Fernández, 1/4/2008). En este camino, compara directamente la protesta agraria de 2008 con el preludio del golpe de Estado de 1976:

\begin{abstract}
“tal vez muchos no lo recuerdan, pero un 24 de febrero de 1976 también hubo un lock out patronal, las mismas organizaciones que hoy se jactan de poder llevar adelante el desabastecimiento del pueblo llamaron también a un lock out patronal allá por febrero del 76. Un mes después, el golpe más terrible, la tragedia más terrible que hemos tenido los argentinos. Esta vez no han venido acompañados de tanques, esta vez han sido acompañados por algunos "generales" multimediáticos que además de apoyar el lock out al pueblo, han hecho lock out a la información, cambiando, tergiversando, mostrando una sola cara” (Fernández, 1/4/2008).
\end{abstract}

Frente a la anti-comunidad de carácter golpista, se construye un "nosotros" definido por el "apoyo al gobierno nacional y popular”, donde gobierno, pueblo y nación se funden en uno: "somos la plaza del reencuentro y la transformación de los argentinos” (Fernández, 1/4/2008). Esto implica una articulación singular de Estado, nación y pueblo, vinculada, a su vez, con la construcción del adversario.

Como señalaba O’Donnell (1978), la nación como referente de la acción estatal involucra un arco de solidaridades que une a un "nosotros" definido por la pertenencia a un territorio estatal, que se aloja por encima de los clivajes de clase otorgando un sentido homogeneizante. Así, la nación es articulada en el discurso presidencial con el pueblo que instituye una mediación entre el Estado y la sociedad, que ubicándose también por fuera de las clases sociales implica un “todos” más acotado, que deja por fuera un segmento de la nación: es aquí donde aparece la "oligarquía”. Esta figura permite presentar la acción estatal como reparadora de la entidad pueblo dañada o en riesgo de serlo, delimitando un adversario cuyo triunfo implicaría no sólo un perjuicio para el pueblo (por ejemplo, retroceso en la distribución del ingreso) sino que cierne una

\footnotetext{
${ }^{394}$ En el acto del 25 de mayo, realizado en la provincia de Salta con el fin de conmemorar el $198^{\circ}$ aniversario de la revolución, establecía claramente el enfrentamiento en términos de sector vs patria: "les pedimos para en serio rendir homenaje a los hombres de Mayo, es que, como ellos, aprendamos que antes que el sector, que antes que nuestra propia individualidad están los intereses del país y de la Patria. (...) la historia está de nuestra parte, porque la historia la construyen los pueblos” (Fernández, 25/5/2008). Así, frente al "ellos" sectorial se plantea una construcción identitaria que contiene el tándem gobierno-pueblopatria/nación.
} 
amenaza sobre el conjunto de la nación: el fin del camino de redención iniciado en 2003 y el retorno del pasado dictadura/neoliberalismo, rasgos identificados con el adversario.

En este camino, se señala al adversario atacando al gobierno nacional y popular y al pueblo mismo mediante el desabastecimiento, y se refuerza la similitud entre el 24 de marzo de 2008 y el de 1976. Así, la Presidenta llama “a hacer un ejercicio de memoria” y convoca a movilizar al "nosotros”. De este modo, la polarización y la confrontación se vinculan con la construcción de la voluntad colectiva y el ejercicio del Príncipe moderno de recuperar la memoria colectiva con el fin de suscitar la organización de lo disperso y templar ese "nosotros" en el enfrentamiento, que se ancla en la batalla entre democracia y dictadura que es representada en la actualidad como una contienda entre el proyecto de gobierno oficial y la re-emergencia del proyecto neoliberal: "No desaprovechemos la oportunidad, que no nos arrebaten el presente y el futuro, sepamos defender con inteligencia, con democracia y con tolerancia, sin hacer caso a las provocaciones, las conquistas sociales, políticas y económicas que hemos logrado en estos 5 años.” (Fernández, 1/4/2008) ${ }^{395}$. De esta manera refuerza un componente de la estrategia discursiva iniciada por Néstor Kirchner: la identificación del adversario con el tándem dictadura-neoliberalismo.

Son varios los discursos donde se remarca el carácter golpista y anti-democrático de la otredad. El 17 de junio, en el 53 aniversario del bombardeo a la Plaza de Mayo, la Presidenta evocó al conflicto entonces vigente hablando de los responsables civiles de los golpes de Estado ligados a los sectores que no pueden llegar a través del voto popular a implementar su proyecto de país y terminan recurriendo a la interrupción de los procesos democráticos para imponerlo ${ }^{396}$. El 18 de junio en Plaza de Mayo, en la convocatoria oficial denominada “Acto por la democracia”, Cristina Fernández señalaba el carácter que, en ese sentido, habría adquirido la protesta:

\footnotetext{
395 También se enfatiza la relación entre la democracia y el proyecto oficial: "la voluntad del pueblo siempre es inapelable, nos guste o no nos guste el resultado, y a eso me remito, argentinos y argentinas. (Aplausos) A este proyecto político de inclusión social, de redistribución del ingreso, de la vigencia irrestricta de los derechos humanos, por primera vez en este mi país, la Nación Argentina.” (Fernández, 1/4/2008).

396 “...las Fuerzas Armadas Argentinas (...) siempre han sido utilizadas como mascarón de proa en la historia reciente, para interrumpir procesos democráticos” (...) "la clave está en presentar las ideas de cada uno, los modelos de país de cada uno ante la ciudadanía, y cuando ésta elige y vota, si ese voto no nos ha sido favorable, a mejorar la propuesta y esperar el próximo turno electoral, esa es la clave” (Fernández, 17/6/2008).
} 
"Me di cuenta, entonces, que estaba ante otro escenario, ante otro cuestionamiento, ya no era retenciones sí o retenciones no, ya no eran intereses, se estaba socavando, se estaba interfiriendo en la misma construcción democrática (...) Tal vez con tanto golpe de Estado, con tanta interrupción institucional que hemos vivido, creemos que todo se arregla con intolerancia, con golpes, con bocinas, cacerolas o corte de ruta.” (Fernández 18/6/2008)

Si, por un lado, la remisión al "ellos” antagónico era realizada en términos de anti-comunidad, identificando con ésta al conjunto de la protesta agraria, dificultando así la diferenciación en su interior, por otro lado, el gobierno seguía intentando generar diferenciaciones con el fin de atraer la adhesión de los pequeños y medianos productores. Además de las citadas referencias del discurso oficial que buscaban deslindar a los pequeños productores, interpelando a la FAA en contraposición a la SRA, el gobierno comenzó a tomar, a medida que avanzaba el conflicto, un conjunto de acciones concretas para promover la fragmentación del polo opositor. En este camino, propuso distintas medidas compensatorias con el fin de diferenciar escalas de producción, promoviendo la creación de la Subsecretaría de Desarrollo Agropecuario y Agricultura Familiar, sumando acuerdos por la ampliación de las exportaciones de carne, entre otros ${ }^{397}$. Como señalan Godio y Robles (2008) la resolución 125 fue modificada el 18 de abril a través de las resoluciones $\mathrm{N}^{\mathrm{o}}$ 284/08 y 285/08, con el fin de reintegrar el aumento a pequeños productores que exportan menos de $500 \mathrm{tn}$; luego propusieron compensaciones por lejanía de los puertos y más adelante, el 29 de mayo, propone modificar la regla de alta tasa que se establecía cuando el precio superaba los 600 dólares y que, como dijimos, afectaba a los “mercados futuros”.

El momento más arriesgado en la articulación de confrontación y negociación fue cuando el gobierno nacional decidió enviar al Congreso el proyecto de retenciones móviles para buscar su legitimación institucional. En un primer momento, su tratamiento (y aprobación) en la Cámara de Diputados se efectuó ampliando las compensaciones $^{398}$ de modo de trascender la medida de retenciones conteniendo un mayor alcance como política agropecuaria. En este camino, el gobierno continuó desplegando un conjunto de acciones con el fin de fraccionar la cadena de demandas que se estaba constituyendo desde el polo antagónico.

\footnotetext{
${ }^{397}$ Ejemplos de esto pueden encontrarse en Giarraca et al (2008).

398 Según Basualdo: “El proyecto del Poder Ejecutivo para la ratificación en el Congreso Nacional fue modificado por la Cámara de Diputados, introduciéndole la denominada segmentación de las retenciones (una alícuota menor para los pequeños y medianos productores) y reconociendo una compensación por distancia (subsidio) para aquellos que producían a más de 400 km de la zona portuaria” (2008b:53).
} 
¿Por qué las estrategias de fragmentación no tuvieron éxito en esta instancia, cuando el gobierno comenzó a proponer un amplio espectro de compensaciones?

En este punto hay que tener en cuenta, por un lado, que una vez lanzado al ruedo el conflicto cobró su propio vigor, la polarización se tornó irreversible (en parte por la misma estrategia discursiva oficial) y las propias bases presionaban sobre sus dirigencias, e incluso adquirían distinto grados de autonomía respecto de ellas, factor que puede verse en el desempeño de los “autoconvocados”, que debatían las resoluciones de la Mesa de Enlace y definían las acciones a seguir. Y, por otro lado, parece indispensable aprehender un aspecto central en el desarrollo del antagonismo: el papel de los medios masivos de comunicación. Se evidencia en este conflicto un cambio de escenario que tendrá connotaciones duraderas para el nuevo período que se abre dentro de la Argentina post-convertibilidad: varios de los grandes grupo económicos de la comunicación, principalmente el grupo Clarín ${ }^{399}$, pasaron a alinearse explícitamente con las fuerzas opositoras emergentes.

Cómo señala Rzezak (2008) el papel de los medios de comunicación fue clave en el desarrollo del conflicto, generando una fuerte presión en contra de la propuesta del Gobierno, llevando tanto a fortalecer y unificar al polo “campo” como a debilitar y fragmentar al gobierno nacional:

\begin{abstract}
"En efecto, quizás en razón de la presencia de amplios terrenos en el Gran Buenos Aires por parte de los dueños de muchos de los principales conglomerados mediáticos, la mayoría de los grandes medios de comunicación, como los diarios Clarín, La Nación y Ámbito Financiero, así como los canales de aire y de cable (especialmente el canal de noticias Todo Noticias (TN) y la Radio 10), llevaron a cabo una fenomenal campaña política en contra del Gobierno. En ese contexto, se produjo una fuerte presión social que coadyuvó a generar un consenso social generalizado en favor de la derogación de la propuesta oficialista” (Rzezak, 2008:97)
\end{abstract}

Como señalamos en el primer capítulo, el rol de los intelectuales es dar cohesión a la fuerza a la cual se es orgánico, dotándola de conciencia de sus intereses, de fines y alentando su organización. También vimos que Gramsci observa que en determinadas circunstancias un grupo de intelectuales orgánicos, como los medios de comunicación, tienden a posicionarse "por encima" de los conflictos coyunturales cumpliendo un rol

\footnotetext{
${ }^{399}$ El Grupo Clarín es el principal multimedio de la Argentina concentrando cerca de 250 licencias de diversos medios como radio, televisión (Canal 13), canales de cable (como Todo Noticias, TyC Sports, Volver, Magazine, Canal Rural, Metro, entre otros), además de la emisora de cable (Cablevisión), portales digitales y empresas proveedoras de internet, numerosas empresas editoriales así como su tradicional diario Clarín y el diario La Razón, entre otras empresas. Este grupo había tenido una postura oficialista durante los primeros años del kirchnerismo y su paso a la oposición constituyó uno de los enfrentamientos claves en los años subsiguientes.
} 
estratégico de orientación para la clase en su conjunto. Sin embargo, en el conflicto agrario argentino, esta distancia se resquebrajó: grupos mediáticos que componían el “Estado Mayor intelectual” de la clase dominante en su conjunto dejaron de lado esta distancia para tomar una posición específica y convertirse en el intelectual orgánico de un alineamiento ${ }^{400}$ opositor que comenzó a cobrar forma con este conflicto singular, adquiriendo gradualmente rasgos propios. Así, un conjunto de los principales medios masivos de comunicación empezaron a actuar como intelectual orgánico, ya no de la clase dominante en su conjunto, sino de este nuevo aglomerado de fuerzas opositoras con el fin de conformarlo como fuerza alternativa con capacidad de disputar y vencer a su antagonista.

Los medios de comunicación son formadores destacados a nivel moral e intelectual en virtud de su capacidad de creación y difusión de concepciones de mundo que permean y construyen sentido común. Como señalan Ibáñez y Cabral (2008) los medios aplicaron un discurso tendiente a simplificar la complejidad del conflicto, condensando en algunos significantes una trama simbólica que remite al sentido común dominante. Esto puede verse, por ejemplo, en el tratamiento dado a las retenciones, que

\begin{abstract}
"es subsumido a una confrontación entre propiedad privada e intereses del Estado (a través de argumentos como "es como si el Estado se quedara con el $40 \%$ de su sueldo"), promoviendo la analogía falaz entre la rentabilidad del agroexportador, en relación al ingreso salarial de cualquier trabajador; remarca la legitimidad de la demanda de este particular "campo". Esta identificación por la semejanza entre un sujeto (cualquiera) y el "todos" podríamos ser o somos perjudicados por el gobierno, demuestra cómo se sigue sujetando el significante Estado con el color partidario del gobierno y a éste con la corrupción en la gestión de lo público bajo intereses privados -esta operación es reforzada constantemente encuadrando el conflicto presente en una temporalidad pasada los ’90” (Ibáñez y Cabral, 2008:5).
\end{abstract}

También era habitual una contraposición de la imagen de la Presidenta leída como soberbia y autoritaria frente a los dirigentes agrarios, como en el caso de De Angeli, que era caracterizado como un caudillo entrerriano "bueno”, pequeño productor de familia, creyente en la iglesia, presentado como la voz legitima de la protesta. Además, los autores también aportan claves para indagar cómo los grandes medios jugaron contra el gobierno en el tratamiento de los repertorios de acción colectiva de ambos contendientes:

\footnotetext{
“Apenas se iniciaba el conflicto, en aquel marzo del “cacerolazo espontáneo”, la cobertura mediática dividió las aguas: "Piqueteros” vs "vecinos” donde vecinos pareciera un significante que remite a quien se presenta de cara limpia, dentado, pelo luciente y cacerola en buen estado.

${ }^{400}$ Hablamos de un "alineamiento” ya que expresa una articulación de agentes y actores pero que aún no logra exhibir los rasgos unificados de una fuerza política estable.
} 
Así, aquel primer "cacerolazo" (o wok-azo) se vio confrontado por la marea de "piketeros" que bajaban hacia Plaza de Mayo para disputarles el espacio de la plaza. Nada más pedagógico que plantear la polarización entre el bien y el mal” (Ibáñez y Cabral, 2008:6)

El conjunto de factores señalados llevó a enfatizar un doble movimiento: por un lado, la centralidad de la politización del conflicto, superando el grado gremial de disputa para contener la simiente de lucha por un proyecto político-económico de gobierno alternativo, dando lugar a un proceso donde un conjunto de contradicciones se vuelven antagónicas, y en segundo lugar, se generó un profundo sacudimiento de las relaciones de fuerzas políticas, que puso fin al estadio hegemónico de la postconvertibilidad reabriendo un escenario de crisis, que en el conflicto agrario actuó bajo la lógica unificación/dispersión.

El primer movimiento, que ya fuimos describiendo, fue rápidamente explicitado por ambos polos del conflicto. Dentro del alineamiento oficial, la Presidenta puso de manifiesto, como mencionamos, la creciente politización que el conflicto iba adquiriendo, en tanto marcaba que lo que estaba en juego no era un interés sectorial, sino que "se está discutiendo la distribución del ingreso y un modelo de país" (Fernández, 27/3/2008). También fue visualizado del mismo modo por el polo agrario, en tanto los dirigentes de las patronales agrarias mencionaban explícitamente que había que poner en debate el modelo de país ${ }^{401}$. Si desde el gobierno nacional se buscaba identificar al polo "campo" con las figuras del neoliberalismo con el fin de reafirmar la construcción identitaria kirchnerista que desde su origen ubicaba en las figuras del neoliberalismo la construcción de su adversario, no es menos cierto que fueron las propias entidades agrarias las que pusieron en discusión la regulación estatal sobre el mercado, exigiendo la eliminación total de las retenciones, dando rasgos propios del neoliberalismo a su propio proyecto en pugna ${ }^{402}$. La politización del conflicto y su elevación a disputa por proyecto societario ponía en juego el devenir mismo del modelo de acumulación, ya que, como sostiene Basualdo, la confrontación

“indica la intención del agro pampeano de terciar en la disputa por la distribución del ingreso y, al mismo tiempo, subordinar a los asalariados y a la producción industrial a su propio proceso de acumulación de capital. En efecto, no se trata de una reacción sectorial ante un impuesto

\footnotetext{
${ }^{401}$ Ver por ejemplo el planteo de Buzzi, presidente de la FAA, citado por Godio y Robles (2008:149): "Esto no se trata de discutir cinco puntos más o menos de retenciones, sino que tiene que ver con un modelo de país distinto".

${ }^{402}$ De hecho trabajos como el de Godio y Robles (2008) sostienen que las exigencias planteadas por las asociaciones agropecuarias tenían 2 objetivos: 1) rechazar el modelo económico vigente 2) instalar un modelo alternativo de apertura económica que podría constituirse en el eje de reagrupación de la oposición.
} 
confiscatorio, ya que, como fue señalado, el nuevo régimen de retenciones le reconocía a los productores un incremento del 45 por ciento en su rentabilidad, sino de incrementar sus beneficios y ocupar el centro de la escena política y económica definiendo un patrón de acumulación de capital en donde tanto los asalariados como la producción industrial operen de allí en más en función de sus propios requerimientos de expansión” (2008b:47).

Esta dinámica expresa, a su vez, un caso de proceso concreto donde un conjunto de contradicciones se vuelven antagónicas. Por un lado, hay un cúmulo de tensiones vinculadas al desarrollo del modelo de acumulación: en primer lugar, la creciente autonomía relativa del Estado característica de la Argentina post-convertibilidad choca con los procesos de concentración económica que fueron agudizándose en los último 30 años y que no se revirtieron con la llegada del nuevo modelo (de hecho se profundizaron fuertemente durante los primeros años). Así el sistema de transferencia de recursos expone al gobierno nacional, en tanto conducción del Estado, frente a los agentes cuyos recursos afecta para distribuir hacia otras fracciones de clase. En segundo lugar, aparecen contradicciones que relacionan al modelo de acumulación con la especificidad de los circuitos agroindustriales. Esto se debe a la continuidad de la matriz productiva y se expresa, como señalan Godio y Robles (2008) en la contradicción entre garantizar precios bajos de alimentos, generar empleos y obtener divisas, frente a la búsqueda de optimizar ganancias, y es en este punto donde se ve en relieve la necesidad y la tensión en torno a la regulación estatal. Como señalan los autores: "Esta tensión entre la tentación del productor rural de orientar su actividad a la producción de bienes con altos precios en el mercado internacional, y la necesidad de producir alimentos a mucho menor precio para la población se ubica en el centro mismo del paro agropecuario” (Godio y Robles, 2008:170). En un sentido similar se expresan Giarraca et al cuando sostienen sobre los agronegocios que

"El modelo que impulsan estos sectores, además de romper la soberanía alimentaria de la Argentina, destruye puestos de trabajo y debilita a los pequeños y medianos productores ya que mientras la soja genera un puesto de trabajo cada 500 hectáreas, la economía familiar crea 35 puestos de trabajo cada 100 hectáreas, situación que se empalma con el hecho de que la soja demanda más de 500 hectáreas para que una unidad productiva sea viable y autosuficiente. Es en este contexto de debilitamiento de la situación de los trabajadores del campo y de la pequeña producción rural donde debe inscribirse el conflicto actual” (Giarraca et al 2008:40).

Esto nos lleva a un tercer elemento, central en todo análisis de clases: la contradicción capital/trabajo. La fuerte subsunción del trabajo al capital en el circuito productivo sojero condicionó el carácter subordinado de su participación en el conflicto y explica, en parte, la ausencia de reivindicaciones subalternas en el encadenamiento construido por el polo “campo”. En el polo “gobierno nacional”, las demandas 
subalternas fueron manifestadas en el discurso presidencial en el primer plano de justificación de la medida conflictiva: las retenciones eran presentadas como un mecanismo clave para la distribución del ingreso ${ }^{403}$. Sin embargo, la subordinación del polo trabajo se mantiene presente en virtud del proyecto político-económico del gobierno basado en el pacto populista: los intereses subalternos son articulados de forma hegemónica, concretamente con los intereses de los grupos industriales de la fracción productivo-exportadora del capital. Como señalaba la Presidenta durante el conflicto agrario: "el peronismo nunca planteó la lucha de clases, el peronismo nunca planteó la guerra entre los pobres y los ricos, para qué, no. Al contrario, somos los creadores de la articulación entre el capital y el trabajo” (Fernández, 27/3/2008).

En este punto es necesario observar cómo juega la sobredeterminación de la contradicción en el conflicto, según los componentes fundamentales que define Althusser (1988 [1962]):

a) el contexto mundial: evidenciando una tendencia orgánica al aumento del precio de los commodities, y una coyuntura internacional de aguda elevación de dichos precios en un corto plazo.

b) el pasado nacional: que aparece con peso en la recuperación de disputas históricas con gran gravitación en el imaginario colectivo como federalismo vs centralismo, peronismo vs anti-peronismo, dictadura vs democracia, entre otros.

c) factores del orden de la superestructura tales como: las transformaciones en el Estado, que implicaron cambios tanto en la política de tipo de cambio, que habilita ganancias y rentas extraordinarias a diversos agentes productivo-exportadores, como en el sistema tributario a través del régimen de retenciones que ocupó el centro de la escena; la batalla ideológica entre los patrones de cuño neoliberal que reemergen en la disputa, como el libre mercado vs la regulación estatal, en el marco de una ampliación de la autonomía relativa del Estado; los repertorios de acción colectiva de raigambre popular y su apropiación y resignificación por parte de las entidades patronales.

\footnotetext{
${ }^{403}$ Ya en su primer discurso vinculado al conflicto Cristina Fernández explicitaba: "la retención actúa como un efecto redistributivo” (Fernández, 25/3/2008).
} 
Son estos factores los que nos permiten pensar cuáles son las condiciones de articulación de las categorías de antagonismo y contradicción en el proceso histórico bajo estudio, y que permiten dotarnos de un caso concreto en que las contradicciones se vuelven antagónicas. Pensar la sobredeterminación de la contradicción nos convoca, a su vez, a sumergirnos en la propia lógica hegemónica del antagonismo, gestando el segundo movimiento que fue alterando las relaciones de fuerza en base a la dinámica unificación/dispersión que actuó al interior de cada una de las fuerzas en pugna. La beligerancia retórica fue reforzando la beligerancia en los repertorios de acciones, promoviendo la polarización creciente; como vimos, esto generó un primer momento de unificación hacia ambos lados del polo y de invisibilización de terceras partes.

Trascurrido ese primer momento, la efectividad política del polo “campo" en disimular la heterogeneidad interna de los agentes y actores movilizados en torno a la demanda unificadora contra las retenciones permitió articular otras demandas y ampliar el espectro de solidaridades. Así, a los agentes directamente vinculados a la medida se sumaron un abanico más amplio cuya inscripción fue territorial: los "pueblos del interior”, apelando a la antinomia histórica federalismo/centralismo. Luego, el rol de los medios masivos de comunicación fue clave en la ampliación del polo "campo", ya que pronto aparecieron en escena los partidos de oposición, y así comenzó a configurarse un alineamiento compuesto por actores y agentes dominantes que trascendería incluso al conflicto del campo y que, como señalaremos, sería una marca duradera para toda la fase posterior.

Del lado del Gobierno Nacional, el discurso polarizante desde un primer momento estableció una línea divisoria entre un "nosotros” compuesto por gobierno ligado a los significantes pueblo, nación/patria y democracia, frente al "ellos" caracterizado como oligárquico, golpista y neoliberal. Esta estrategia logró un primer aglutinamiento de fuerzas populares que buscó ser articulado en línea con su proyecto político-económico de gobierno con el núcleo industrial de la fracción productivoexportadora, apelando en este sentido al imaginario peronista clásico: trabajadores y “burguesía nacional” enfrentarían a la oligarquía en pos del desarrollo con distribución del ingreso.

Pero como señalan Giarraca et al, en esta dinámica de batalla simbólica y polarización "fueron los dirigentes de las entidades ruralistas -Eduardo Buzzi, Fernando 
Gioino, Mario Llambías y Luciano Miguens- quienes primero sacaron ventaja, pues desde el inicio se presentaron como representantes de "el campo". Esta postura les fue muy beneficiosa pues cuanto más abarcativo y laxo es un concepto, mayor es la posibilidad de incluir en su significado posiciones heterogéneas” (2008:42). En este camino, la gestación del momento álgido del conflicto estuvo signada por la dispersión de fuerzas oficialistas que cobró una visibilidad absoluta con el tratamiento de la 125 en el Congreso. Como señala Rzezak,

"Si observamos lo ocurrido con el Gobierno, podemos ver, en cambio, una fuerte desarticulación, ya sea entre los propios integrantes del Gobierno, como es el caso del vicepresidente Cobos y algunos gobernadores, como así también de muchos de los Diputados y Senadores oficialistas. En efecto, tanto Cobos, como ciertos miembros del Congreso pertenecientes al oficialismo votaron en contra del propio proyecto de la Presidenta” (2008:96).

Así, la capacidad de aglutinamiento del polo “campo”, con la comandancia de los medios masivos de comunicación y la importante capacidad de sostener un amplio repertorio de acción colectiva, le permitió a este contendiente ganar la batalla tanto en las calles (visible en su mayor capacidad de movilización y convocatoria) así como en el Congreso de la Nación mismo, a pesar de que inicialmente el oficialismo contaba con mayoría en ambas cámaras legislativas, generando que la mayor unidad del polo “campo” redundara en una mayor dispersión del polo "gobierno nacional” 404.

De este modo, el conflicto que estalló con la “resolución 125” marcó un punto de inflexión en diversas dimensiones. A nivel de las fracciones de clase, se produjo la particularidad que los agentes económicos y representaciones corporativas que salieron a enfrentar al gobierno constituían parte de la principal fracción beneficiaria del modelo, la fracción productivo-exportadora del capital. Este fenómeno tiene como sustrato estructural el conjunto de transformaciones de más largo plazo vinculadas a los circuitos productivos del agro, como la "revolución verde” y el proceso de agriculturización (devenido en creciente sojización), y el impacto que dichos procesos tuvieron sobre los

\footnotetext{
${ }^{404}$ Según Rzezak, "debemos tener en cuenta también la presión ejercida por las propias bases políticas de los diputados, senadores y gobernadores, tanto oficialistas, como opositores. Como se sabe, estos dirigentes responden desde sus puestos a quienes los eligieron. En ese contexto, no pueden independizarse del todo en sus medidas de sus bases sin perder el respaldo social de quienes los votaron y de quienes dependen, además, para ser reelectos en sus cargos. Precisamente, muchas de las provincias más afectadas por las retenciones, especialmente las regiones más alejadas de la fértil región pampeana, criticarán fuertemente el intento del Gobierno de aumentar las retenciones a la exportación agropecuaria. Presionados fuertemente por sus bases, y potenciados por la amplificación de las protestas por parte de los grandes medios de comunicación, muchos de los diputados y senadores del oficialismo, al igual que la mayoría de los congresistas de la oposición, y el propio Vicepresidente, quien probablemente pretendía cosechar el fuerte rechazo que generaba la medida en la población para acrecentar su imagen ante la opinión pública, decidieron votar en contra de la medida de su propio Gobierno.” (2008:97).
} 
agentes económicos. A nivel estructural analizamos un triple proceso de concentración que venía gestándose en el agro: concentración estructural de la tierra, del capital y de la organización y gestión del proceso productivo. En simultáneo, la creciente demanda de productos agrícolas explicada en parte por el creciente consumo de China y la mayor demanda mundial de agroalimentos y biocombustibles, impulsaron el incremento del precio de los principales cultivos, primordialmente de la soja, que con el tipo de cambio competitivo habilitaron ganancias y rentas extraordinarias.

La creciente concentración y el claro predominio empresarial en el proceso productivo fueron clave en el fortalecimiento de dichos agentes que salieron a disputar al Estado las retenciones: uno de los mecanismos fundamentales utilizados para limitar la inflación y transferir ingresos tanto hacia otras fracciones de clase. Es esta dinámica la que se encontró detrás del denominado “conflicto del campo” donde, a pesar de multiplicar su rentabilidad incluso con el nuevo esquema de retenciones, los agentes ligados al circuito sojero se lanzaron para disputar mayores márgenes de ganancias y rentas extraordinarias.

Es en este enfrentamiento donde comenzó a visualizarse la emergencia de un alineamiento que, organizado desde el interior de la clase dominante, se conformó como adversario del oficialismo. Cada vez de forma más clara comenzaron a aparecer articulados un espectro que abarca a agentes y corporaciones del agro, agentes de sectores medios, partidos opositores (con fuerte gravitación de derecha y centro-derecha política) y los principales medios de comunicación. Este alineamiento gestó una ofensiva que logró derribar en el Congreso la medida de retenciones móviles ${ }^{405}$, infringiéndole tanto la primera derrota como un desgranamiento a la fuerza oficialista $^{406}$. Se comenzó a conformar así un alineamiento que encarna las pretensiones de las clases dominantes de recuperar el paradigma neoliberal como proyecto de gobierno. El oficialismo parecía haber dilapidado el consenso hasta entonces alcanzado

\footnotetext{
${ }^{405}$ Y que también se mostraría triunfal en las elecciones legislativas de 2009, con la relevancia de derrotar en la provincia de Buenos Aires al mismísimo Néstor Kirchner en fórmula con el gobernador Daniel Scioli.

${ }^{406}$ En el mismo sentido se expresa Basualdo cuando señala que "el conflicto político a raíz del régimen de retenciones móviles se entabló entre un aparato estatal con una escasa capacidad de convocatoria y movilización social y un frente social conformado por diversas fracciones del agro pampeano, sectores medios, el oligopolio que controla los medios de comunicación y las fuerzas políticas opositoras. De esta manera, en una situación que se caracteriza por una creciente activación de la derecha política y una desmovilización popular, a lo largo de la confrontación el Gobierno perdió, primero la batalla por el «sentido común» en la sociedad, luego la disputa de la movilización social en las calles, y finalmente el litigio parlamentario" (2008b:48).
} 
en un conflicto que había ayudado a constituir y fortalecer a un adversario con claros ribetes de derecha, que reinstalaba debates con connotaciones culturales de cuño neoliberal, en torno la libertad de mercado, la apertura económica y la "libertad de ganancia” como valores.

De este modo, el conflicto agrario de 2008, el más prolongado de la historia argentina, instituyó un vértice tanto a nivel político como económico, cuyos rasgos constitutivos tendrán efectos duraderos tanto a nivel del modelo de acumulación como en materia de construcción de hegemonía.. En términos políticos se pasaría de la búsqueda de consensos, que habían sido desarrollados bajo la estrategia de “transversalidad” y luego de “concertación”, al enfrentamiento abierto con los adversarios. En términos económicos, si bien no se presentan quiebres fundamentales que permitan entrever un cambio a nivel del modelo de acumulación, sí se comenzarían a observar medidas fuertes que inciden en las relaciones de fuerza entre las clases sociales, buscando fortalecer la participación de agentes productivos industriales y de las clases subalternas en el alineamiento oficial, que empezaron a constituir un escenario propicio a la radicalización de los componentes heréticos del kirchnerismo. 


\section{Conclusiones}

\section{Neo-desarrollismo, populismo y sujetos.}

\section{Entre la profundización rupturista y la restauración neoliberal.}

El modelo de acumulación post-convertibilidad tuvo su origen en un contexto de principio de crisis orgánica que atravesó distintas dimensiones, expresando un genuino sacudimiento del bloque histórico que alcanzó su momento álgido en diciembre de 2001. Así, observamos la crisis a nivel ideológico-cultural, insinuada en la deslegitimación de algunos aspectos de la concepción del mundo neoliberal, principalmente en relación al rol del Estado, y de las prácticas desmovilizadoras e individualistas. En este sentido, comportó una crisis de la idea de Estado mínimo, alzando demandas de mayor presencia estatal y cambio de sus funciones, junto a la proliferación de distintas experiencias de participación popular y acción colectiva. Como crisis política, conllevó, por un lado, una crisis de "la" política, en su componente institucional de representación, observable en el desgaste del bipartidismo en tanto fórmula de gestión de la gobernabilidad post-dictadura, expresando un elemento clave que Gramsci (2003) identifica en los períodos de crisis orgánica: una situación de contraste manifiesto entre “representados y representantes”. Por otro lado, se afirmó una “crisis de autoridad”, ligada al impacto social producido por las reformas neoliberales que motivó una serie de reclamos que acarrearon un alto grado de movilización, expresando la articulación de una cadena demandas que no logran ser divididas y procesadas por el orden vigente, pasando de “democráticas” a "populares” (en sentido laclausiano). Este proceso, incluso llevó a crisis las dimensiones políticojurídicas que son propias del momento de la coerción, y que mostraron la incapacidad del gobierno en ejercicio de los aparatos del Estado para reprimir el conflicto creciente que derivó en la insurrección popular de diciembre. También expresó una crisis económica, debido a que el visible agotamiento del modelo de la convertibilidad, la caída en términos generales de la tasa de ganancia y la continuidad de la recesión expresaron las dificultades de los dominantes de hacer avanzar a la economía afectando la estructura, expresándose “por arriba” en una fractura de intereses entre distintas fracciones del capital que buscaban mejorar sus posiciones en base a dos propuestas 
diferentes de salida al modelo de los años 90. Además, el deterioro de los indicadores socio-económicos con incrementos incesantes en materia de desempleo, pobreza e indigencia, constituyó la base material que habilitó el creciente malestar de las clases subalternas, dando lugar a la proliferación de un amplio repertorio de acción colectiva.

En este contexto, se gestó el paso de clase dirigente a clase meramente dominante, que condicionó las construcciones con pretensiones hegemónicas posteriores y las estrategias de modificación del proceso de reproducción ampliada del capital. Es necesario reconocer el peso de este punto de origen y las incidencias concretas que trajo sobre nuestro período y problema de estudio, de modo de poder extraer las principales conclusiones tanto en materia de hegemonía como de acumulación, y responder así a las preguntas centrales asumidas.

Un momento clave en términos de la pregunta por el modelo de acumulación post-convertibilidad radica en su origen. El mismo se encuentra en la salida devaluacionista del modelo de la convertibilidad (1989-2001), el cual había encarnado la forma más acabada de profundización de la ofensiva del gran capital efectivizada con la instauración de un régimen de acumulación de carácter neoliberal ${ }^{407}$ a partir del golpe de Estado de 1976. Así, el modelo post-convertibilidad comenzó a configurarse a partir de seis políticas fundacionales, que constituyeron un punto de inflexión, quebrando las regularidades del modelo anterior y dando lugar a un conjunto de transformaciones perennes: 1) la devaluación, 2) la implementación de retenciones a las exportaciones, 3) la pesificación asimétrica de deudas y depósitos, 4) el "salvataje” al capital financiero, 5) el default, 6) el congelamiento y renegociación de tarifas. Estas políticas, que fueron en su mayoría perfiladas a partir de la Ley de Emergencia Pública del 6 de enero de 2002 y cuya piedra angular puede encontrarse en la política cambiaria, fueron dando origen a un nuevo modelo de acumulación que, presentando rupturas y continuidades respecto del modelo de los años 90, se vincularon a cambios particulares en las relaciones de fuerzas, definiendo un reparto diferencial de cargas y beneficios. Asimismo, notamos que la inversión pública volvió a constituir una intervención estatal significativa, y se desarrolló a través de la conformación de grandes planes de obra pública en materia de infraestructura (principalmente proyectos viales), energía,

\footnotetext{
${ }^{407}$ El mismo se basó en la apertura comercial (asimétrica), una creciente desregulación y liberalización económica, la valorización financiera, las privatizaciones, entre otras reformas estructurales, fundadas principalmente a partir de ingentes transferencias de recursos de trabajadores a capitalistas.
} 
vivienda y desarrollo urbano. De este modo, nos introdujimos en el momento superestructural de análisis del modelo de acumulación, partiendo del principio de autonomía relativa del Estado, para observar la acción estatal en sus múltiples incidencias tanto en las variables económicas como en las fracciones de clase.

Una primera conclusión que articula políticas, variables económicas y fracciones de clase es la centralidad del capital productivo-exportador. La devaluación generó un tipo de cambio internacionalmente competitivo que dio lugar a la dinamización de las exportaciones y, a través de su gravamen mediante retenciones, a la recomposición de las cuentas públicas. La recuperación económica conllevó un aumento de la producción manufacturera, impulsada por la dinámica exportadora e incluyendo un fenómeno incipiente de sustitución de importaciones producto de la protección generada por la modificación del tipo de cambio. Por otra parte, el efecto inflacionario ligado a la devaluación redujo sustancialmente el salario real, y junto con el congelamiento relativo de las tarifas de servicios, los altos precios de los commodities y el nuevo tipo de cambio, permitió a los agentes productivo-exportadores generar elevados márgenes de ganancia y recuperar niveles de actividad económica. Los gobiernos desarrollaron una política activa para mantener el tipo de cambio competitivo y alentar esta vía de expansión económica a partir del crecimiento de las exportaciones, generando un margen de protección que permitió también el desarrollo de las PyMEs. De este modo, la exportación se fue convirtiendo en una vía primordial de realización del capital, el contexto internacional favoreció esta inserción, y las acciones estatales se orientaron abiertamente a beneficiar la acumulación en este sentido y sostener las relaciones de fuerzas favorables a la fracción productivo-exportadora, dando origen a una nueva fase expansiva del ciclo económico.

Entendiendo que el proceso de reproducción ampliada del capital es al mismo tiempo un proceso de reproducción ampliada de las clases sociales, nos abocamos a analizar sus dos dimensiones: el lugar (Poulantzas) o posición (Gramsci) ocupado en la estructura, y los agentes que ocupan dicho lugar, su reproducción y sus características. En este camino, analizamos cómo se fueron gestando diversas condiciones que pusieron a la fracción productivo-exportadora del capital como principal beneficiaria de la Argentina post-convertibilidad al situarse en un lugar que comenzó a constituir un eje clave en el proceso de acumulación. Una fracción amplia compuesta por cuatro núcleos fundamentales constituidos por agentes de la industria automotriz (principalmente las 
terminales), las empresas de hidrocarburos, las mineras, un heterogéneo abanico de agentes vinculados a los circuitos agro-industriales, junto a empresas químicas y siderúrgicas. Son agentes caracterizados por fuertes dinámicas de concentración y creciente avance de la extranjerización económica, y, en líneas generales, una participación decreciente de los asalariados en la apropiación del valor creado. La concentración económica es visible al interior de cada núcleo, tanto en el liderazgo de las terminales automotrices; en el sector de hidrocarburos donde las primeras tres empresas extranjeras concentraban más del 60\% de la extracción de petróleo y el 75\% del gas; en el reducido grupo de mineras principalmente canadienses y europeas extrayendo los minerales en condiciones sumamente preferenciales; y en el triple proceso de concentración (de la tierra, el capital y la organización y gestión del proceso productivo) observable en los circuitos agro-industriales cuyas raíces se encuentran en las transformaciones técnicas y tecnológicas de largo plazo.

Se nos presenta una combinación de rupturas y continuidades: un nuevo énfasis en la producción de bienes, con un desempeño relevante de la industria manufacturera, pero que se enmarca en la matriz productiva heredada de las últimas décadas de neoliberalismo argentino. Es la persistencia de la reestructuración regresiva en la matriz productiva (Azpiazu y Schorr, 2010), que nos enfrenta con una Argentina que continúa siendo, en términos generales, exportadora de productos primarios y de manufacturas con escaso valor agregado, a lo que se suma la industria terminal automotriz, y algunos segmentos de la industria química y siderúrgica. Encontramos agentes cuyo lugar en el modelo se torna clave para la percepción de divisas, otorgando un aditamento al poder estructural de esta fracción. Esto se encuadra, a su vez, en el mantenimiento de una estructura productiva desequilibrada (Diamand, 1972) con un sector primario internacionalmente competitivo, al que se han añadido en las últimas décadas algunos núcleos industriales de grandes empresas de alta productividad orientadas, en general, al mercado externo, en los sectores previamente señalados, pero que coexisten con un tejido industrial de baja productividad, implicando que un tipo de cambio real alto genere ganancias y rentas extraordinarias para los circuitos principalmente ligados a la explotación y exportación de recursos naturales, en relación al resto de los agentes económicos.

Por otra parte, el fortalecimiento de los agentes productivo-exportadores ha tenido clara incidencia en el desarrollo y características del proceso inflacionario. Como 
señalamos, los precios ligados a los distintos agentes y fracciones evolucionan de forma disímil en una puja que expresa las diversas capacidades de apropiación de valor y, en este sentido, se vinculan a variaciones en las relaciones de fuerza. Los precios del petróleo, los minerales, los principales cultivos y los alimentos mostraron fuertes aumentos en el período de estudio. También debemos recordar que más de la mitad de las ventas al exterior correspondió a la suma de manufacturas de origen agropecuario y productos primarios que son, en general, bienes de consumo masivo de la población, lo cual repercute desfavorablemente en el nivel de inflación y, específicamente, en las condiciones de vida de las clases subalternas.

El dinamismo y concentración de estos agentes nos permiten pensar en una fracción productivo-exportadora del capital como núcleo dinámico del modelo postconvertibilidad, que tiende a presentar niveles de rentabilidad y ventas superiores al resto de las fracciones de clase, y cuyo lugar en la estructura se torna central en el funcionamiento del modelo de acumulación. La denominación productivo-exportadora de esta fracción no refiere a que sea únicamente exportadora, sino a que, en la configuración del modelo, el impulso que ha cobrado esta orientación al mercado externo ha permitido alcanzar un considerable superávit comercial que aunado al superávit fiscal, favorecido mediante retenciones a las exportaciones, configuran los dos pilares de estabilidad del modelo, aspecto que refuerza la afirmación en torno de la centralidad de esta fracción en el modelo post-convertibilidad.

En este camino, el modelo comenzó a cobrar rasgos productivos que implicaron una importante reactivación y crecimiento de la producción manufacturera y del empleo industrial, estableciendo una ruptura con el proceso de desindustrialización previo. En términos de las fracciones del capital, las PyMEs comenzaron a cumplir un rol dinámico en ese sentido. Esta fracción posee un conjunto de cualidades fundamentales para el análisis de la Argentina post-convertibilidad en dos dimensiones: su rol subordinado al interior de la clase dominante y su forma de relación con las clases subalternas. Si bien el modelo habilita una mejora general de los indicadores ligados a la fracción de PyMEs, con una rentabilidad que se triplica respecto de los años 90 en un contexto de precios relativos que le son favorables, asimismo su posición es crecientemente subordinada en tanto se amplía la brecha de ganancias respecto de las grandes empresas. Por otra parte, la creación de nuevas empresas de esta fracción y la destacada elasticidad empelo-producto que exhiben, han sido clave en el descenso de la desocupación, 
mostrando una tendencia al crecimiento del empleo que revierte aquella de creciente deterioro característica del modelo de la convertibilidad. Sin embargo, el tipo de empleo que generan es cualitativamente distinto comparado al de las grandes empresas; se trata de un empleo caracterizado por altas tasas de informalidad y bajos salarios, enmarcado en una débil evolución de la productividad laboral.

Se establece en este punto una contradicción nodal al interior de las clases dominantes que funciona como limitante de mediano o largo plazo para habilitar transformaciones estructurales que funcionen como base material de nuevos consensos en la construcción de hegemonía. Si, por un lado, encontramos PyMEs que son clave en la generación de empleo, pero de tipo precario y con bajos salarios, por otro lado, observamos un conjunto de grandes empresas que no se caracterizan por la generación masiva de empleo, pero sí por mayores niveles de formalidad y mejores salarios. Un factor a tener en cuenta es la creciente extranjerización de las grandes empresas. Esta puede percibirse en que, entre las 500 empresas más grandes, aquellas con más del $50 \%$ de participación extranjera pasaron de apropiarse el 35\% de las utilidades totales en 1993 alcanzando el 90\% en 2005. Además, la ENGE confirma y dimensiona el peso de la extranjerización económica: "Si bien prácticamente un tercio de las empresas son de capital de origen nacional, dicha relación no se mantiene cuando se analizan los agregados macroeconómicos. Para el año 2007, el 81,7 \% del valor bruto de producción del total del panel y el 83,8 \% del valor agregado del mismo, son generados por empresas con participación de capital extranjero” (INDEC, 2009:11).

Aquí reaparece un debate recurrente en la historia argentina: la pregunta por la burguesía nacional, que es también la pregunta por las potenciales alianzas entre fracciones de la clase dominante y las clases subalternas (o al menos la posibilidad estructural y los límites de complementación de intereses y de concesiones). Si bien dentro del gran capital existen algunas importantes empresas de capital local, su propia lógica transnacionalizada y el predominio general del capital extranjero cuestionan los discursos y proyectos que invocan la construcción de una alianza entre la burguesía nacional y los trabajadores como base de sustento del modelo. Como vimos, estos discursos intentan construir la imagen de un empresariado nacional comprometido con el desarrollo del mercado interno, la industrialización y la construcción de una alianza estratégica con los trabajadores. Sin embargo, las características mismas del capital productivo-exportador que encarna la fracción predominante de la post-convertibilidad 
parece quitar bases materiales sólidas a esta perspectiva: tanto su concentración y extranjerización, su lógica exportadora, y el hecho fundamental de que una de las claves de recomposición de la tasa de ganancia descanse en el bajo costo laboral, cuestionan la idea de una potencial alianza burguesía-trabajadores como fuera propuesta entre las décadas del 40 y 70. Esto se relaciona con que la orientación exportadora del gran capital productivo lejos de ver en el salario un factor fundamental (como consumo en el mercado interno) para la realización del capital, encuentra en él un costo que busca ser limitado para ganar rentabilidad; ya que una de las claves de la competitividad internacional y ganancias empresarias en la post-convertibilidad se halla en que, en un contexto de aumento de la productividad laboral, la limitada evolución del salario real generó una reducción del costo laboral: salarios que (aunque sean más altos que los provistos por la fracción de PyMEs), son bajos en relación al producto que generan, y también son bajos en términos de divisas.

Hay un corte aquí en términos de productividad: las grandes empresas proveen salarios mejores en pesos que no constriñen los altísimos niveles de rentabilidad empresaria de la Argentina post-convertibilidad, ya que la inversión y el reordenamiento del proceso productivo generaron un aumento de la productividad laboral que devino en plusvalía relativa, que no derivó en equivalentes aumentos de la participación asalariada sino en la apropiación privada de la misma. Ahora bien, estos salarios "relativamente altos” en pesos (en relación a los que otorgan las PyMEs) son salarios baratos en términos de divisas, base de competitividad internacional, de modo que no hay complementariedad de intereses subalternos (en términos de mejoras de condiciones de vida posible que sean mutuamente beneficiosas) ya que el salario sigue siendo un costo para empresas que realizan su capital en el mercado externo. Del otro lado del corte por productividad se encuentran las PyMEs. Ellas sí se encuentran orientadas primordialmente al mercado interno, ya sea como proveedoras de bienes intermedios pero también de bienes de consumo, y podrían verse beneficiadas de un mayor poder de compra de los agentes subalternos. Sin embargo, la baja productividad de estos agentes pone a los bajos salarios como condición de rentabilidad y subsistencia de esta fracción tan importante en términos de generación de puestos de trabajo (factor que explica también las magras condiciones cualitativas de estos empleos). Así, otra fracción que podría encarnar potencialmente a la burguesía nacional, ya que incluso se encuentra menos extranjerizada que las otras fracciones dominantes, se aleja de la pretensión 
invocada en los discursos. Nuevamente desaparece la complementariedad posible de intereses $^{408}$.

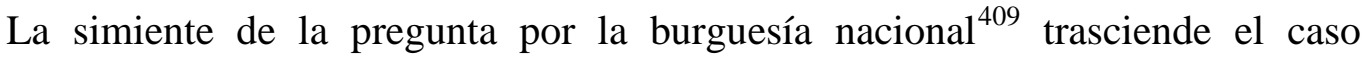
nacional, nos interroga por la constitución de sujetos dominantes y su capacidad (o no) de conducir procesos de desarrollos relativamente soberanos con articulación a las clases subalternas. A su vez el interrogante por la construcción de sujeto consustancial a la formación de una voluntad colectiva nos lleva a indagar en el otro polo del par dialéctico capital/trabajo, en las posiciones subalternas sin las cuales no hay sujetopueblo. En este camino, una pregunta emerge de la investigación concreta y se expande sobre toda una época: es la pregunta por la construcción de sujetos dirigentes del proceso histórico en contextos de fragmentación social.

Para dar cuenta del aspecto general de la pregunta debemos retornar primero al caso y ver el punto donde anudan las dimensiones de hegemonía y acumulación. Indagar complementariedades (existentes o potenciales) se vincula, por un lado, a la posibilidad de construcción de toda política hegemónica: ésta se define por su capacidad de rescindir intereses económico-corporativos inmediatos para garantizar los estratégicos otorgando concesiones, en un proceso que abarca la universalización de intereses y concepciones del mundo, en tanto la realización de la dirección de una fracción o bloque singular aparece como el desarrollo más pleno de todas las “energías” nacionales. Pero, por otro lado, hay una relevancia específica en nuestro caso y en nuestro período: la re-emergencia de proyectos políticos-económicos de gobierno basados en la gestación del pacto populista. Esta doble cualidad está directamente vinculada a lo que definimos como la doble lectura del populismo: el populismo como lógica hegemónica de articulación de demandas y construcción de sujetos en el antagonismo, y el populismo como pacto de conciliación de clase en su versión latinoamericana.

Ahora bien, previamente marcamos que los agentes dominantes, definidos por sus rasgos específicos y lugares ocupados en la estructura, mostraban deficiencias en la

\footnotetext{
408 Tampoco parece alcanzar la constitución de un núcleo de empresarios cercanos al oficialismo ni en la consolidación de ámbitos privilegiados de acumulación en donde los mismos están involucrados (Castellani, 2010) para suplantar a este sujeto clave, en el pasado, de la alianza policlasista.

${ }^{409}$ Recordamos que Poulantzas (1981) se refiere a la burguesía nacional como una fracción autóctona de la burguesía que, a partir de determinado tipo y grado de contradicciones con el capital imperialista extranjero, podría jugar un rol relativamente autónomo.
} 
generación de complementariedades con los agentes subalternos, pero entonces, ¿cómo es posible que fuera un proyecto basado en el pacto populista el que lograra constituir fuerza hegemónica?

Partimos del 2001 con un principio de crisis orgánica, donde la clase dirigente devino meramente dominante, lo cual se evidenció en la escalada represiva y la instauración del estado de sitio. Esta crisis orgánica no alcanzó su sentido pleno, en tanto no emergió una fuerza antagonista alternativa surgida de la subalternidad con capacidad de conformar una voluntad colectiva y fundar un nuevo bloque histórico. La heterogeneidad de las demandas y de sus portadores, logró encadenamientos suficientes como para alcanzar a la delimitación provisoria del adversario ligado en torno al significante vacío: “que se vayan todos” que alcanzó para golpear la hegemonía vigente pero mostró sus limitaciones para fundar un "nosotros”. Así, el carácter inconcluso de la crisis orgánica se vincula al carácter igualmente inconcluso del sujeto-pueblo en formación.

En este contexto emergió el gobierno de Duhalde presentándose como “presidente de transición” que convocaba a un gobierno de unidad para la "salvación nacional”. Sintetizamos su estrategia hegemónica en tres aspectos fundamentales. En primer lugar, en relación a la dimensión ideológico-cultural de la crisis, Duhalde, que había sido uno de los intelectuales orgánicos de la salida devaluacionista, se convirtió en el primer presidente post-convertibilidad en abrazar un discurso productivista con aspiraciones fundacionales proponiendo una nueva alianza de clase liderada por el capital productivo, que incluyera a los trabajadores, buscando diferenciarse del modelo anterior que en su discurso aparecía conducido por el capital financiero. Comienza a gestar una articulación duradera: caracteriza la necesidad del cambio definiendo el futuro como recuperación del imaginario peronista. En segundo lugar, respecto de la crisis política, su gobierno impulsó una estrategia dual basada en el par contención/coerción. El componente de contención se expresó en la masificación de los planes sociales con el fin de paliar el estallido de la desocupación, pobreza e indigencia que alcanzaron a récords históricos. El componente coercitivo se evidenció en una ofensiva contra los movimientos sociales basada en la represión y criminalización de la protesta social. En tercer lugar, en vinculación a la crisis económica, se sancionó la Ley de Emergencia $\mathrm{n}^{\circ} 25561$, la cual contuvo el núcleo de reformas en materia políticoeconómica que sentaron las bases de un nuevo modelo de acumulación. 
El gobierno de Duhalde dejó varias marcas duraderas tanto a nivel del modelo como de la construcción de hegemonía, imprimidas de un fuerte sesgo regresivo en tanto descargó los costos de transición sobre las clases subalternas. Además, logró materializar la fractura del "pueblo inconcluso", con el gradual abandono de las “cacerolas” del centro del escenario del conflicto social al tiempo que concentraba la represión sobre el movimiento piquetero. El repudio que generó su estrategia represiva, culminando con la Masacre del Puente Pueyrredón, hizo que debiera adelantar las elecciones.

Pero además, el 2002 duhaldista expresó el momento de máximo deterioro del tejido social, con los efectos del estallido inflacionario, mostrando un profundo efecto erosivo en materia de pobreza e indigencia así como en los índices de desocupación y subocupación. El modelo post-convertibilidad se inició, de este modo, con un carácter regresivo a través de las políticas que fundaron su propia matriz constitutiva. Durante el gobierno de Duhalde los componentes coercitivos y regresivos predominaron en tono con las nuevas relaciones de fuerzas entre las fracciones de clase y las políticas hacia las clases subalternas oscilaron entre la represión y la contención a través de planes sociales. Este escenario cambió a partir de 2003, con políticas activas desplegadas por el gobierno de Kirchner, quien procuró dar resolución a un conjunto de demandas planteadas por diversos actores corporativos y políticos de las clases subalternas durante la crisis de 2001. En este camino, se avanzó hacia cambios en la cuestionada Corte Suprema de Justicia, el descabezamiento de la cúpula militar, un profundo cambio en la política de Derechos Humanos, nuevas perspectivas de integración latinoamericana y su momento fundamental de rechazo al ALCA en $2005^{410}$, las políticas de ingresos orientadas a las clases subalternas, entre otras medidas progresivas. Estas políticas nos hablan del surgimiento de un proyecto político-económico de gobierno, que si bien sigue la línea establecida por Duhalde en términos del plantear el futuro como retorno a la Argentina peronista (ya que ambos pertenecen tanto a esa tradición como a ese mismo partido), por otra parte, el contenido y la lectura de la que parte, sugieren la conformación de un proyecto distinto. Como en el pasado, donde el ala derecha e

\footnotetext{
${ }^{410}$ En la IV Cumbre de Presidentes de las Américas, celebrada en Mar del Plata, el gobierno de Estados Unidos buscó hacer aprobar el Acuerdo de Libre Comercio para las Américas (ALCA), que venía impulsando desde varios años atrás con el fin de consolidar un espacio de explotación de recursos preferenciales para sus compañías transnacionales. Sin embargo, el mismo no alcanzó el consenso de los treinta y cuatro gobernantes, y la coordinación de varios gobiernos latinoamericanos, entre los que se destacaron el argentino y el venezolano, lograron derrotar este proyecto que amenazaba con concluir una genuina anexión de las economías latinoamericanas bajo el yugo del capital estadounidense.
} 
izquierda del movimiento peronista vivieron en confrontación, ahora también (sin llegar al grado de antagonismo y violencia que caracterizó aquel enfrentamiento en los años 70) aparece una diferenciación entre los componentes sistémicos y heréticos que componen todo proyecto basado en un pacto populista ${ }^{411}$.

Así llegamos al análisis de la hegemonía kirchnerista, siguiendo el trayecto que va desde su conformación como cultura política, al proyecto de gobierno, para imprimirse al fin como acción estatal. Observamos la concepción del mundo que modela la cultura política kirchnerista "planteando todas las cuestiones en torno a las cuales hierve la lucha” (Gramsci), ya que emergió de cara a los factores persistentes de la crisis de 2001; afrontó sus distintas dimensiones y se planteó a sí mismo como momento de clausura y superación. En este sentido, señalamos tres elementos fundamentales del kirchnerismo como cultura política: la construcción del neoliberalismo como adversario en el discurso; la recuperación del Estado como mediación ${ }^{412}$, con un rol destacado en el proceso de “armonización” de intereses; y la restitución de la promesa de articulación de la vida "interior” y "exterior" 413 del pueblo a partir de la recomposición de niveles de vida de las clases subalternas.

El kirchnerismo afrontó la crisis ideológico-cultural incorporando a su discurso una parte considerable de las demandas expresadas durante la crisis dándoles distintos grados de respuesta, en un doble movimiento que procuró comenzar a suturar también aspectos de la crisis política. De este modo, se comenzó a constituir una cadena que se singularizó en el líder, iniciando la construcción de una voluntad colectiva. Pero este proceso se realizó centralmente desde el Estado. En este camino, el gobierno enfrentó la crisis política buscando recomponer el vínculo entre “representados y representantes”, reformulando el desgastado bipartidismo en dos nuevos polos de centro-izquierda y centro-derecha, ocupando el kirchnerismo el primero. La estrategia de construcción de

\footnotetext{
${ }^{411}$ De este modo, podemos ver una doble dimensión implicada en las fuerzas políticas basadas en un pacto populista: por un lado, los componentes heréticos y sistémicos tienden a alojarse diferencialmente en distintos actores, más conservadores o progresivos, al interior de la fuerza, y, por otro lado, la tensión entre dichos componentes es co-extensiva a toda la fuerza en virtud de que es constitutiva del proyecto político-económico de gobierno.

${ }^{412}$ Mencionamos que hay mediaciones de distinto tipo, vinculado, por un lado a las transformaciones históricas del rol del Estado en que la incorporación de la subalternidad a la vida política y la inclusión elementos de la misma en la coalición gobernante, que implicaba una ampliación de la autonomía relativa, y su interlocución mediadora y articuladora con las corporaciones sindicales y patronales. En este sentido, el Estado como mediación implica la apariencia estar parándose (de modo siempre imposible) por fuera de la lucha de clases como un arbitraje que se sugiere imparcial sobre las partes en pugna, en búsqueda del "bien común”.

${ }^{413}$ Refieren, en los términos de Marcuse, a los órdenes de reproducción material y cultural de un pueblo.
} 
su fuerza contuvo dos tácticas articuladas, la de la transversalidad, teniendo un rol fundamental para la incorporación de demandas y parte de sus portadores a la nueva cadena equivalencial, y la concertación, que refirió a la alianza con sectores de otros partidos tradicionales, aprovechando ambas para la reconquista y aumento de la gravitación del Partido Justicialista.

El campo de antagonismo definió el trayecto de conformación identitaria de sujeto, en el que el kirchnerismo construyó a un amplio abanico de figuras vinculadas al neoliberalismo como adversario, responsable de la fractura de la promesa de plenitud que él mismo procuraba restaurar, desatando así su asociación con la impugnación generalizada del "que se vayan todos”. En este sentido, se propuso como lo "nuevo" que clausuraba a lo “viejo” y construía al Estado como instancia reparadora del pueblo dañado, comenzando a gestar a un “nosotros” nacional-popular heterogéneo en que el kirchnerismo reformulaba la identidad peronista.

El proyecto de gobierno comenzó a cobrar forma a partir de la recuperación y resignificación del peronismo como cultura política, ahora en clave kirchnerista. Emulando al peronismo clásico u originario, con su ampliación de la ciudadanía y la conquista de derechos sociales y políticos para las clases subalternas, procuró performar la promesa de plenitud, de articulación de la "vida interior" con la "vida exterior”, ya que, aunque sin romper las relaciones de explotación capitalista y de mercantilización de la vida, el peronismo kirchnerista buscó también transformar mediante reformas progresivas la "vida exterior" de las clases subalternas, al tiempo que las aspiró a dotarlas de una "vida interior” con las que se identifiquen masivamente: el kirchnerismo como cultura política, si bien lo hace en un contexto mundial y local profundamente distintos al de la emergencia del peronismo original.

Toda promesa de plenitud se encuentra ligada a un proyecto de gobierno, que consigna las tareas que permitirían transitar del momento de crisis a la sutura, en una particular lectura del pasado y una proyección del futuro. En este aspecto, Kirchner llamó a construir un "capitalismo nacional” que permita la movilidad social ascendente, volviendo a la senda del desarrollo con inclusión social, con un Estado que amplíe su autonomía relativa recuperando su capacidad mediadora, reguladora y mayores atributos en la gestión del excedente. En el discurso pueden recopilarse un conjunto de factores político-económicos que van dando forma al proyecto de gobierno, que incluye desde el 
perfil industrialista, la preocupación por el doble superávit, la integración latinoamericana hasta la política de DDHH. Continuó la propuesta de cambio de alianza entre el Estado y las fracciones de clase, manteniendo la centralidad de la burguesía nacional, aunque se la comenzó a ver como un actor que no estaba plenamente constituido sino que debía ser apuntalado; mientras, fue cobrando mayor jerarquía el lugar del trabajo.

Así fue cobrando forma concreta la doble lectura del populismo: a) como lógica política, se conforma un otro-poder, identificando a su adversario en torno al neoliberalismo, pero cuyo centro de acción parte, a su vez desde el Estado mismo, presentado como emanación de la voluntad popular para reparar al propio pueblo dañado, y b) como pacto populista, en una vasta estrategia de conciliación de clases a través de la ampliación de la autonomía relativa del Estado, gestando una nueva alianza estratégica tripartita entre el Estado, los trabajadores y agentes del capital productivo que pudieran encarnar el rol de la "burguesía nacional”, desplegando un sistema de transferencia de recursos para armonizar los compromisos inestables entre las fracciones de clase.

Es por esto que concluimos que el kirchnerismo expresa una construcción ambivalente: aparece como un proyecto de normalización política y económica, pero que cobra forma conflictivamente articulándose con un discurso que constituye sus propios antagonistas y abre juego a los componentes heréticos del peronismo. El kirchnerismo, sin procurar una transformación radical del orden (en sentido de clase), avanza a recomponer la promesa de plenitud, reconstituyendo las condiciones de empleo e ingresos de las clases subalternas en el marco del proyecto de "capitalismo serio o nacional”. Pero contiene asimismo un elemento herético que prolifera en tanto la dimensión del conflicto aparece presente en el modo en que son desplegadas las políticas, en la recuperación del espacio público como ámbito de disputa desde la acción estatal, en la reivindicación de la política como herramienta de cambio, y en el ser parte de los gobiernos que en América Latina comenzaron, con distintos grados de profundidad, a enfrentar el orden neoliberal. Así, la función del conflicto como productor de orden y la limitación de éste a un horizonte sistémico en el proyecto de capitalismo “serio", imprime una tensión perdurable entre estos dos componentes que marcan la cultura política de esta fuerza fundada en el pacto populista: el componente sistémico y el herético permanecen en un “tire y afloje”, articulándose e imponiéndose 
alternativamente. Son las tensiones propias de una fuerza que tiende a expresar una versión hegemónica del capitalismo argentino (como decía James) al mismo tiempo que representa "el hecho maldito del país burgués" (evocando a Cooke), cuyos componentes populares no pueden dejar de ser vistos como amenazantes por la clase dominante.

La progresividad de sus medidas varía en esta tensión, así como varía el alcance de las mismas. En materia de política de ingresos, identificamos un conjunto de acciones estatales tendientes a apuntalar los ingresos mínimos de las clases subalternas y aumentar los salarios reales de modo más significativo en los sectores más dinámicos de la economía. Entre éstas, destacamos cuatro mecanismos principales: a) aumento del salario mínimo, b) impulso a los acuerdos y convenios colectivos de trabajo, c) aumento y extensión de las jubilaciones mínimas y d) acuerdos de precios para limitar la inflación.

Estos mecanismos tuvieron impactos diversos. En primer lugar, mostraron un efecto positivo, mejorando todos los indicadores sociales desde el momento de su implementación con particular incidencia en la reducción de la pobreza y la indigencia, en un contexto de rápido descenso de la desocupación. Este efecto positivo se visualiza principalmente en el elevamiento de los “pisos” de ingresos, de las condiciones mínimas de vida. Sin embargo, el impacto de estas medidas sobre las clases subalternas ha constituido un efecto dispar en términos particulares, en tanto puede percibirse una creciente heterogeneización de las clases subalternas, evidenciada en el incremento de la fragmentación salarial correspondiente a los distintos tipos de categorías laborales. Por un lado, los trabajadores del sector privado, registrados y generalmente bajo convenio colectivo, consiguieron, hacia 2007, aumentos tendencialmente superiores al índice inflacionario mejorando sus condiciones de vida, mientras que los trabajadores informales y estatales obtuvieron, en distinta medida, ingresos reales por debajo de los percibidos en 2001. Esto, a su vez, se conjuga con un efecto limitado en lo general, ya que si bien los salarios reales comienzan a recuperarse desde 2003, la distribución funcional del ingreso y el salario real promedio quedaron en 2007 aún por debajo de los de 2001. Esto nos muestra políticas que si bien mejoran los “pisos” de ingresos, no logran mover el "techo" distributivo, determinado por la voluntad del capital de no ceder márgenes de ganancia. 
Es aquí donde podemos completar el cuadro en torno a la pregunta por la burguesía nacional y la complementariedad de intereses posible. Observamos una dinámica contradictoria establecida entre dos fracciones del capital: a) una fracción productiva-exportadora que ocupa un lugar central en el modelo, fuertemente extranjerizada, que no se destaca en su capacidad de generación de empleo mientras provee salarios relativamente elevados en pesos aunque bajos en divisas constituyendo una clave de su competitividad internacional y de la realización del capital en el mercado externo beneficiada por el tipo de cambio, y b) una fracción de PyMEs, con mayor nivel de capital local, orientada mayormente al mercado interno, que sí es relevante en términos de generación de puestos de trabajo pero que se caracteriza por altos niveles de informalidad laboral y bajos salarios. Esta relación contradictoria en términos de habilitación de complementariedades estructurales y alianzas hacia las clases subalternas tiene por base la disparidad y la creciente fragmentación de las clases subalternas. Y en este punto, los rasgos que pueden aparecer como contradictorios en el mediano o largo plazo para la construcción de hegemonía, pueden ser visto como una complementariedad compleja al interior de las clases dominantes: el dinamismo creciente de la fracción productiva exportadora habilita ingresos por sobre el índice de inflación a un segmento de los trabajadores que, junto con las políticas de empleo y de aumento de los “pisos” de ingresos de los sectores con mayor propensión marginal a consumir permiten la reactivación del consumo y del mercado interno, sin generar, sin embargo, un modelo basado principalmente en el mercado interno y el consumo popular sino un modelo cuyo eje central está constituido por una dinámica productivoexportadora. Esta dinámica contradictoria expresa la línea de tensión que articula el pacto populista en el marco del modelo post-convertibilidad. Una articulación disruptiva de sujetos fragmentarios: una burguesía fragmentada cuyas fracciones no alcanzan a constituir un sujeto del tipo burguesía nacional que es apelado en el discurso y un Estado que promueve la conciliación virtuosa con una clase trabajadora igual o mayormente fragmentada.

Asistimos así a la conformación de una voluntad colectiva de signo particular: el carácter nacional-popular del proyecto de gobierno implica una tensión generalizante en la nación que procura ampliar al pueblo a un espectro más amplio (traspasando la subalternidad de posiciones), a un populus, pero que apela, al mismo tiempo, a un sentido equiparador de las desigualdades que afectan al plebs y lo constituyen en tanto 
tal. De este modo, el pueblo como plebs convoca al Estado como mediación reparadora, pero limitada a la construcción de un pueblo como populus que incluya a los agentes dominantes (en tantos ciudadanos del populus en la nación), a la burguesía nacional como sujeto en formación ${ }^{414}$, con la nación como referente generalizante de la acción estatal. En este camino, vemos la unión del proyecto de gobierno y el modelo de acumulación, de las dimensiones estructurales y superestructurales que componen nuestro objeto de estudio. Pero para poder delimitarlas con mayor precisión debemos retornar al análisis específico del modelo.

Fuimos dando cuenta de los principales elementos involucrados en nuestra propuesta teórico-metodológica de abordaje del modelo de acumulación. El mismo aparece constituido por tres núcleos conceptuales; un componente superestructural: las políticas económicas; y dos componentes estructurales: las variables económicas y las fracciones de clases. Habiendo analizado los rasgos específicos de cada componente en su vinculación dinámica, reconstituyendo el momento de totalidad del modelo de acumulación, procuramos establecer un conjunto de regularidades que evidenciaban la configuración de un nuevo modelo, así como el orden de prelación, la jerarquía explicativa, que pone de manifiesto las características propias del modelo, explicitando un conjunto de rupturas y continuidades con el previo. Nos preguntamos ahora por su nomenclatura, ya que, siendo extendido el uso de modelo "post-convertibilidad", no podemos dejar de notar que esta designación remite al modelo anterior, refiriendo a la ruptura establecida a nivel del tipo de cambio, manifestando las dificultades que implica caracterizar el modelo inaugurado en 2002. ¿Cómo denominar entonces al modelo que se abre en la post-convertibilidad a partir de sus características propias?

El análisis de los distintos núcleos conceptuales del modelo y la dinámica de la relación social fundamental capital-trabajo en la Argentina post-convertibilidad nos permite dar respuesta a la caracterización y nominación del modelo de acumulación

\footnotetext{
${ }^{414}$ En el discurso del kirchnerismo encontramos la caracterización de que la burguesía no constituye un sujeto acabado para cumplir el rol de desarrollo nacional esperado en el proyecto político-económico, sino que debe ser apuntalado. Las distancias entre los distintos agentes concretos y el rol asignado dentro del pacto populista, generan que el sujeto dominante aparezca muchas veces como una apelación mítica del rol cumplido por la burguesía nacional (en los términos definidos por Basualdo, 2010) durante el peronismo clásico) más que como un sujeto pleno y pujante dentro del pacto y el proyecto que lo expresa. Esto se debe justamente a la base fragmentaria del capital productivo en Argentina que mencionamos, marcada por las distintas escalas, productividades, lógicas de acumulación, origen del capital, orientación de la producción, etc. entre aquellos que forman parte de la fracción productivo-exportadora y la de PyMEs.
} 
post-convertibilidad como modelo productivo-exportador. La relevancia de la política de tipo de cambio real competitivo y la excepcional coyuntura de precios de los commodities, el bajo salario en divisas en términos de costo laboral y competitividad internacional, el segmento de ganancia empresaria que se realiza en el mercado externo basado principalmente en la extracción y procesamiento de recursos naturales y la industria automotriz, la vitalidad de las exportaciones como componente de la demanda agregada en relación a la década previa, entre otras, constituyen factores dinámicos que habilitaron la consecución inédita de sucesivos superávits comerciales. Éstos, junto a la política de retenciones y el aumento de la recaudación tributaria en general, dieron lugar a superávits fiscales constituyendo los dos pilares de sustentabilidad del modelo, posibilitando el despliegue del complejo sistema de transferencia de recursos. Estos elementos, en relación a los factores de análisis que nos llevaron a definir la centralidad del capital productivo-exportador, nos proveen algunas pautas cardinales para concluir en esta nomenclatura del modelo.

En este punto, debemos retornar al análisis de las fracciones de clase que, habiendo alcanzado centralidad en los años 90, fueron desfavorecidas (relativamente) en sus relaciones de fuerzas al interior de la clase dominante, visualizando cómo la acción estatal tendió a conformar iniciativas compensatorias a través del sistema de transferencia para saldar la crisis interburguesa de 2001, explicitando también otro conjunto de cambios relevantes a nivel del modelo de acumulación así como varias continuidades que persisten en el mismo.

La devaluación y la política de tipo de cambio real competitivo que la siguió, establecieron cambios en los precios relativos: los bajos salarios ya mencionados, la caída de las tarifas y de la tasa de interés real. Como vimos, los precios expresan relaciones de fuerzas, y los mismos evolucionaron de forma dispar distribuyendo cargas y beneficios entre las distintas fracciones de clase. El fin de la convertibilidad perjudicó las posiciones relativas de la mayoría de las empresas de servicios con su núcleo destacado de privatizadas. En 2002 se establecieron las herramientas legales iniciando el congelamiento y renegociación de tarifas, y el gobierno de Duhalde desplegó una estrategia dual, por un lado, beneficiando a las empresas ubicadas en áreas no sensibles al consumo popular y, por otro, dilatando las negociaciones en todas las áreas sensibles para dejarlas al gobierno siguiente (Azpiazu y Schorr, 2003). Durante el gobierno de Kirchner se desplegó una estrategia heterogénea consistente en tres acciones estatales 
diferenciadas: renegociación, reestatización y creación empresarial. Esta estrategia persiguió tres objetivos: 1) desmantelar los procesos judiciales que muchas privatizadas llevaban adelante en el CIADI; 2) evitar un “tarifazo”, limitando la inflación y buscando mantener el nuevo esquema de precios relativos favorable a la producción de bienes transables; y 3) aumentar la influencia del Estado en determinadas áreas.

Las renegociaciones tendieron a presentar aumentos, dirigidos principalmente a los grandes consumidores, procurando evitar el impacto directo sobre los sectores más vulnerables de las clases subalternas y manteniendo un esquema de precios relativos favorables a la producción de bienes. Si bien en todos los casos el acuerdo implicó el retiro de las demandas del CIADI, a las privatizadas no se les exigieron las inversiones anteriormente incumplidas. Las reestatizaciones fueron realizadas por fuera de las figuras legales para empresas estatales formándose sociedades anónimas, consignadas bajo la Ley $\mathrm{n}^{\circ} 19.550$ que regula y tipifica las sociedades comerciales, con mayoría accionaria estatal. Esto sucedió, en nuestro período de estudio, con el Correo Argentino, Aysa, el espacio radioeléctrico, entre otras, y hubo reestatizaciones parciales como Aeropuertos y el Ferrocarril San Martín. Esta acción estatal parece una clara ruptura con el paradigma de la Argentina neoliberal, que había ido cobrando un perfil claramente privatizador, devastando las funciones estatales heredadas de regímenes de acumulación previos. La tercera variante fue la creación empresarial por parte del Estado. Éste fue el caso de Enarsa, creada como parte de la política energética del gobierno para incidir en esta área clave.

Los gobiernos de la post-convertibilidad, si bien asumieron una postura de mayor firmeza frente a las privatizadas, no desplegaron, hasta 2008, un plan integral de recuperación de servicios y recursos estratégicos. Aún así, las privatizadas ocupan una posición subordinada respecto de la década del 90, época en que presentaban las rentabilidades más elevadas de la estructura económica en su conjunto. En el modelo productivo-exportador, las empresas de servicios vuelven paulatinamente a estar sujetas a las prioridades del capital productivo y la acción estatal procura además establecer tarifas diferenciadas con el fin de preservar las condiciones de vida de las clases subalternas. Esto se observa también en que, en el modelo actual, las empresas de servicios públicos privatizadas (a diferencia de las privatizadas productivoexportadoras), en general, han perdido posiciones al interior de la cúpula empresarial. Estos cambios en relación a las privatizaciones, si bien no revierten enteramente el 
cuadro previo, establecen claras distinciones a nivel de la acción estatal y en el lugar ocupado por los agentes de la fracción de empresas de servicios públicos, marcando, al menos como tendencia, el fin de la panacea privatizadora y desreguladora, confluyendo a un el retorno gradual de mayores atribuciones en manos del Estado.

Asimismo, se ha desplegado una política de subsidios compensatorios que representan mecanismos de transferencia de recursos desplegados desde el Estado con el fin de recomponer el equilibrio de compromisos inestables al interior de la clase dominante. Esta acción complementa otras como la pesificación asimétrica de deudas y depósitos ${ }^{415}$, mecanismo establecido durante el gobierno de Duhalde para socializar las deudas del capital, un aspecto de continuidad respecto de las lógicas previas. Cuando el lobby empresarial logró forzar al gobierno a derogar el techo impuesto inicialmente en US\$100.000 para la pesificación de deudas, ésta se convirtió en un mecanismo de licuación masiva de las deudas del capital productivo y las privatizadas con la banca local.

Fue en este contexto, que el gobierno de Duhalde dispuso un plan de "salvataje” al capital financiero, dando lugar a transferencias de recursos destinadas a compensar a dicha fracción del capital por las consecuencias de la salida devaluacionista y la pesificación asimétrica, y que fueron cubiertas con emisión de nueva deuda pública.

Las políticas vinculadas a la deuda pública tuvieron un claro impacto en las relaciones de clase, en tanto una parte considerable de los bonos en default estaban en poder de los conglomerados financieros, que habían visto perjudicadas sus relaciones de fuerzas por la salida devaluacionista y pesificadora y que habían comenzado a ser compensados en 2002 a través del “salvataje”. La salida del default concretada con el canje de 2005 presentó una importante quita del 43.4\% sobre el total canjeado. Aparecieron en el canje componentes novedosos como las Unidades Ligadas al PIB, cupones que, en las condiciones de crecimiento económico reciente, produjeron ganancias que se multiplicaron año tras año. Otro elemento relevante es que más del $40 \%$ de la deuda se encontró pesificada e indexada a la inflación, aspecto que fue cobrando cada vez más relevancia. La indexación de deuda a la inflación debe ser entendida como una medida que garantiza al capital financiero no perder más posiciones

\footnotetext{
${ }^{415}$ Recordamos que esta política implicó que los bancos debieron devolver los depósitos en dólares a $\$ 1.40$ por cada US\$1, mientras que los deudores con la banca local vieron pesificadas sus deudas en dólares a \$1 por US\$1.
} 
respecto del capital productivo-exportador, principal beneficiario del ciclo inflacionario en tanto sus precios evolucionaron por encima del resto de las fracciones dominantes y subalternas. Aún con la importante quita del canje, quedó un calendario de pagos con exigentes desembolsos anuales. El canje eliminó del corto plazo el panorama de crisis de la deuda pero la continuidad del ciclo de endeudamiento en ausencia de una reforma tributaria profunda tiende a representar la cristalización de una nueva transferencia de recursos de asalariados a capitalistas en virtud de la regresividad de estructura tributaria.

Aún así, la fracción financiera del capital comienza a ocupar una función parcialmente distinta a la característica de los años 90. El descenso de la tasa de interés real y el hecho de que la rentabilidad bancaria no esté dada por los resultados de las tasas de interés sino por la simple tenencia de bonos y los servicios, implica (más aún con la caída de la convertibilidad de la moneda que operaba como seguro de cambio gratuito) un freno al proceso de "valorización financiera” y su circuito ligado al endeudamiento externo, derivación improductiva de recursos de grandes empresas al sistema financiero procurando aprovechar el diferencial positivo entre las tasas de interés internas y externas, posterior fuga de capitales y quiebra de las cuentas del Estado (que en los 90 se operaba en pos de estabilizar la balanza de pagos y mantener la convertibilidad). De este modo, el capital financiero dejó de performar este papel articulador a nivel del modelo de acumulación, si bien desde 2005 sus rentabilidades se recuperan y logran un importante incremento. Esta fracción sigue cumpliendo un rol importante en el proceso de endeudamiento público, pero los descensos de la relación deuda/PBI, deuda/exportaciones y deuda/reservas en un contexto de solidez de las cuentas públicas asentado en el doble superávit (fiscal y comercial) constituyen un panorama distinto, manejable al menos en el corto y mediano plazo.

Otro elemento que señalamos en materia de acción estatal referida al capital financiero es que una de las últimas medidas progresivas, dentro de nuestro período de estudio, fue la estatización de las AFJP, realizada por el gobierno de Cristina Fernández. De este modo, se retrajo una reforma estructural de corte neoliberal, recuperando recursos y capacidad decisión para el Estado. Aun así, debe notarse que esto no afectó decisivamente la rentabilidad bancaria, que, para la época de la reestatización del sistema jubilatorio, ya superaba el promedio de los años 90 . 
Asimismo, debemos notar que el capital financiero local ha proseguido un camino de creciente concentración pero, a diferencia de las otras fracciones del capital concentrado, exhibe una merma en su extranjerización, debido al avance de grupos de capital local en este sector. Por otra parte, es necesario observar la persistencia de limitaciones ligadas a la vigencia de la legislación financiera proveniente de la última dictadura y, también, la escasa articulación de la banca privada con la fracción de PyMEs, lo cual representa un problema para el modelo en sus propios términos, restando una complementariedad necesaria que hace que las inversiones tiendan a ser financiadas a través de la propia ganancia inmediata.

Por otra parte, una comprensión más completa del sistema de transferencias de recursos, requiere de una aproximación a la estructura impositiva para ver la distribución de las cargas aplicadas para obtener los fondos que permiten su existencia. En esta área la acción estatal no ha mostrado avances significativos. Llegando a 2007, el IVA, impuesto de naturaleza regresiva, explicó más del 31\% de la recaudación. Fue seguido por el Impuesto a las Ganancias, que hasta la reforma de 2007 afectaba a amplios sectores de trabajadores, por la demora en la actualización del mínimo no imponible. En cuarto lugar, luego de los ingresos en materia de Seguridad Social, aparecen las retenciones (principal insumo del tributo de Derechos al comercio exterior), que representaron cerca del 14\% de la recaudación. Este impuesto marca una novedad: por un lado, busca desdoblar los precios del mercado externo e interno procurando limitar la inflación (una variable con prelación y regularidad en nuestro período de estudio) que afecta principalmente a las clases subalternas; por otro lado, se grava a la fracción más dinámica del capital (productivo-exportador), para derivar recursos a otras fracciones de dominantes y subalternas a través de los distintos mecanismos directos e indirectos que fuimos identificando. Representa un intento de construir gobernabilidad a partir de la compensación de distintos intereses de clase. Por una parte, las retenciones, limitando el proceso inflacionario, acompañan a las medidas de apuntalamiento de salarios y jubilaciones. Por otra parte, las retenciones incrementan el superávit primario que será destinado en parte al capital financiero vía pago de deuda acompañando otras acciones, como las compensaciones a los bancos, o transfiriendo recursos a las privatizadas vía subsidios. También debemos señalar que las retenciones comenzaron a constituir un factor de creciente diferenciación al interior de la fracción productivo-exportadora, entre quienes aparecen afectados por ellas y quienes quedan 
exentos y muchas veces son beneficiarios de otras transferencias como subsidios industriales o beneficios impositivos.

Para el caso de los agentes de los circuitos agroindustriales, esta diferenciación no sólo se estableció en virtud de dicha acción estatal, sino que estaba ligada de modo singular con un conjunto de procesos estructurales y superestructurales que confluirían para gestar un nuevo antagonismo, reabriendo una crisis de hegemonía, que establece al año 2008 como punto de inflexión, también en términos de acumulación. Así, abordamos el "conflicto del campo" y el circuito productivo sojero para ver las dinámicas de hegemonía y acumulación en un caso concreto que sienta tendencias claves para comprender el período que se abre con posterioridad a nuestro recorte temporal.

Tomando herramientas del enfoque de análisis regional, abordamos las transformaciones productivas, los agentes y el lugar que ocupan en la producción. En este camino, dimos cuenta de los proceso de “revolución verde” y agriculturización, observando cómo los cambios técnicos conllevaron modificaciones en los procesos de trabajo. Además, analizamos cómo impactó en el circuito el cambio de modelo de acumulación, viendo el impacto favorable que las políticas fundacionales de la postconvertibilidad y el nuevo contexto mundial ejercieron sobre el mismo.

Situando a los agentes del circuito como parte de la fracción productivoexportadora del capital, dimos cuenta de distintos núcleos que van de los productores de insumos y maquinaria, pasando por las figuras de rentista, contratista y propietario, las empresas agropecuarias y los pools de siembra, los agentes del acopio y la producción industrial. Así indagamos la formación de precios y percibimos la presencia de un triple proceso de concentración: a) concentración estructural de la tierra, donde sólo el 4,2\% de las explotaciones agropecuarias (que poseen más de $2500 \mathrm{Ha}$ ) poseen el 62,8\% de las Ha totales, con la desaparición del 21\% de las explotaciones agropecuarias en el periodo inter-censal 1988-2002 y un incremento del 25\% de la superficie media de cada establecimiento; b) concentración del capital, presente tanto en el desdoblamiento creciente entre propietarios (devenidos en rentistas) y contratistas (propietarios de tierra o no), y en la industrialización concentrada en un 80\% por seis empresas; c) concentración de la organización y gestión del proceso productivo mediante la 
consolidación de grandes empresas agropecuarias-financieras y la expansión de los pools de siembra.

Luego abordamos el lugar del trabajo en el circuito. Dimos cuenta de la baja capacidad de generación de empleo, visible en que su elasticidad empleo-producto del 0,12 contrastaba con la de 0,54 de la economía argentina. En términos de condiciones laborales, vimos que el marco legislativo provee menores derechos a los trabajadores rurales los mayores niveles de informalidad y las remuneraciones más bajas del país, transfiriendo recursos a los agentes propietarios del circuito, evidenciando una fuerte subsunción del trabajo frente al férreo predominio de los agentes capitalistas.

La aplicación a un caso concreto del plan de análisis de fuerzas gramsciano nos llevó a completar su dimensión estructural para luego abordar la dimensión política en sus distintas gradaciones: del carácter económico de la disputa hasta el momento estrictamente político donde el conflicto se convierte en guerra de posiciones.

De este modo, dimos cuenta del lugar del circuito sojero y sus agentes en relación al doble superávit, el proceso inflacionario y el papel de las retenciones. En este punto reforzamos la hipótesis de la armonización de intereses en base a la gestación de sistema de transferencia de recursos con el fin de equilibrar los compromisos inestables entre las fracciones de clase. Así comenzamos a comprender la dinámica del conflicto: un Estado activo que gestiona el excedente transfiriendo recursos pero que, al hacerlo, queda expuesto frente a los agentes que afecta con sus políticas, al tiempo que los procesos de concentración del agro incrementan el poder de presión de sus agentes. El análisis de rentabilidades, que en 2007 del 72\% por encima del promedio de los años 90 e incluso con la aplicación del esquema de retenciones móviles habilitaba un incremento del 43\% respecto de la campaña anterior, nos permitió sostener que no fue la "crisis” de los agentes involucrados que los llevó a la protesta sino su fortalecimiento en el marco del cambio en las relaciones de fuerzas.

Entendemos que los principales factores que explican el sustrato estructural del conflicto agrario se encuentran en: a) la creciente capacidad de acumulación de dichos agentes, ligada al proceso de transformación productiva; b) la interrelación de los agentes en las dinámicas productivas del circuito, y c) el triple proceso de concentración 
señalado. Se gestó así un conflicto que tendió a poner en crisis la hegemonía postconvertibilidad basada en el proceso de armonización promovido por el Estado y que tiene centro en el proyecto de gobierno kirchnerista, en el cual se expresa el populismo como pacto.

En relación a la dimensión estrictamente política de las relaciones de fuerzas, fuimos dando cuenta del despliegue del antagonismo desatado a partir del establecimiento de la resolución 125 , que dio lugar a un proceso de encadenamiento de demandas, a la implementación de diversos repertorios de acción colectiva y a la constitución de dos polos beligerantes con sus respectivas construcciones identitarias, alcanzando a poner en cuestión el orden vigente.

El traspaso del mero reclamo económico a la disputa por la hegemonía puede verse en tres factores centrales:

1) El discurso proveniente del polo “campo" tendiente a la homogeneización, polarización y articulación de demandas más amplias.

2) El repertorio de acción colectiva desplegado fue involucrando crecientes niveles de beligerancia.

3) El rol de los medios masivos de comunicación como intelectual orgánico de lo que comenzaba a aparecer como un nuevo alineamiento de fuerzas portando un proyecto político-económico de gobierno que antagoniza con el oficialista.

Para dar cuenta del proceso de antagonismo fuimos delineando las demandas y sus portadores. Adentrándonos en el polo campo dimos cuenta del rol protagónico de la “mesa de enlace” y la relevancia de los “auto-convocados”. El discurso del polo “campo" fue avanzando hacia una creciente eliminación de las diferenciaciones a su interior, lo que permitió el abroquelamiento y la polarización y, a su vez, la irreductibilidad de las posiciones dotó de mayor vigor a la dinámica del antagonismo.

La heterogeneidad de agentes y actores era limada por varios factores. En primer lugar, por la unidad en torno a la demanda central: las retenciones, que revestía para el polo “campo” una doble cualidad, por lado permitía unificar disimulando las diferencias (de escala, modo de inserción en el circuito productivo, capacidad diferencial de apropiación de renta y ganancia, etc.) y, por otro lado, colocaba en la radicalización de 
la demanda, la exigencia de eliminación de las retenciones, el debate por el proyecto político-económico de gobierno, en tanto su consecución era incompatible tanto con el desarrollo del modelo de acumulación como con el modo de construcción de hegemonía vigentes. A su vez, siendo las retenciones un punto explicitado por el gobierno como “fuera de discusión”, reforzaba la mutación de reclamo sectorial a demanda política. En segundo lugar, por la articulación de la cadena, que avanzó, sin perder la centralidad de las retenciones, sobre otras demandas de agentes del sector (por ejemplo, en relación a la producción de carne y lácteos, entre otras) realizándolo con una lógica discursiva que apelaba a registros históricos del imaginario colectivo: la reedición de la disputa “pueblos del interior” vs Gobierno central actualizando el debate entre federalismo y centralismo, peronismo/antiperonismo, etc.

La lógica del antagonismo se fue radicalizando a través de la implementación de amplios repertorios de acción colectiva con la particularidad que las entidades patronales apelaron a la apropiación del acervo de protesta desplegada por los actores de las clases subalternas en 2001, como el piquete, las cacerolas, las asambleas y el "escrache”.

Por otra parte, dimos cuenta de la estrategia del gobierno de Cristina Fernández frente al conflicto, haciendo foco en el discurso presidencial. El mismo también fomentaba la polarización en tanto negaba toda legitimidad al reclamo y demarcaba a los agentes movilizados como antagonistas que procuraban restaurar la Argentina neoliberal, aún cuando eran principales beneficiarios de las políticas públicas. Frente a esa re-emergencia del pasado neoliberal, el discurso presidencial eleva el pasado mítico que referencia la promesa de plenitud: el retorno a la Argentina peronista. Asimismo, se refuerza en el discurso el rol del Estado como mediación, y su rol regulador, defendiendo los mayores niveles de autonomía relativa alcanzados.

Así se gesta la confrontación, promoviendo la homogeneización y polarización del conflicto, en base al desarrollo de dos apelaciones ligadas a la cultura política del polo oficial: el enfrentamiento "pueblo vs oligarquía”, remitiendo al peronismo originario, actualizado en la oposición entre "gobierno nacional y popular vs dictadura/neoliberalismo”, como ya hiciera Néstor Kirchner en su propia presidencia. El populismo como lógica hegemónica se alza así en toda su extensión, y la estrategia discursiva oficial busca construir una identidad que conquiste un amplio conjunto de 
significantes en el delineamiento de la comunidad al tiempo que busca definir al polo opositor como la anti-comunidad.

Asimismo, dimos cuenta de los fallidos intentos de segmentación que el oficialismo intentó realizar sobre el polo “campo”. Y, en este camino, abordamos el papel de principales medios masivos de comunicación y su alineamiento con las fuerzas opositoras, cumpliendo un rol de intelectual orgánico destacado, dando cohesión a la fuerza antagonista, dotándola de conciencia de intereses y fines, alentando su organización.

Así el antagonismo cobra forma a partir de un doble movimiento:

1) la centralidad de la politización del conflicto, superando el grado gremial de disputa para contener la simiente de lucha por un proyecto político-económico de gobierno alternativo, dando lugar a un proceso donde un conjunto de contradicciones se vuelven antagónicas. A partir del estudio de caso, notamos un cúmulo de contradicciones vinculadas al desarrollo del modelo de acumulación: a) la creciente autonomía relativa choca con los procesos de concentración económica, poniendo en el centro de la disputa al sistema de transferencias de recursos. b) La contradicción entre garantizar precios bajos de alimentos, generar empleos y obtener divisas, frente a la búsqueda de optimizar ganancias (Godio y Robles, 2008), y es en este punto donde se ve en relieve la necesidad y la tensión en torno a la regulación estatal. c) La contradicción capital/trabajo expresada en la fuerte subsunción del trabajo al capital en el circuito sojero que condicionó el carácter subordinado de su participación en el conflicto y explica, en parte, la ausencia de reivindicaciones subalternas en el encadenamiento del polo "campo", pero que tampoco lograron ser incorporadas de modo efectivo al encadenamiento oficial, en el marco del modelo productivo-exportador, que lo dificulta. Además, dimos cuentas de los distintos factores que constituyeron la sobredeterminación de la contradicción en el conflicto: tanto el contexto mundial con el aumento de precio de los commodities; el pasado nacional que aparece con peso en la recuperación de disputas históricas como unitarios vs federales, peronismo vs anti-peronismo, dictadura vs democracia, entre otros; y los factores del orden de la superestructura tales como: las transformaciones en el Estado, en el sistema tributario, la batalla ideológica librada, y los repertorios de acción colectiva. 
2) se generó un profundo sacudimiento de las relaciones de fuerzas políticas, que puso fin al estadio hegemónico reabriendo un escenario de crisis, que en el conflicto agrario actuó bajo la lógica unificación/dispersión. Unificación hacia ambos polos, invisibilizando terceras partes. Y la gestación de un nuevo alineamiento opositor que logró derribar en el Congreso la medida de retenciones móviles, infringiéndole tanto la primera derrota como un proceso de dispersión, dando lugar a un desgranamiento parcial de la fuerza oficialista.

Para ir culminando, podemos desplegar tres conclusiones finales: una sobre la dinámica política que deja instalada el antagonismo de 2008, otra sobre la relación modelo-régimen de acumulación y una última sobre la conformación de sujeto en relación a la articulación entre las dimensiones de hegemonía y acumulación atravesada por las bases de contradicción y antagonismo que se extraen de la tesis y parecen reforzarse con el punto de inflexión de 2008.

El antagonismo de 2008 dejó instalada la articulación de un alineamiento que, desde el interior de la clase dominante, se conformó como adversario del oficialismo. Cada vez de forma más clara comenzaron a aparecer articulados un espectro que abarca a agentes y corporaciones del agro, agentes de sectores medios, partidos opositores (con fuerte gravitación de derecha y centro-derecha política) y los principales medios de comunicación. La composición social predominantemente patronal y la recuperación de demandas en el discurso parecen estar indicando que se comenzó a conformar un alineamiento que encarna las pretensiones de las clases dominantes de recuperar el paradigma neoliberal como proyecto de gobierno. El oficialismo parecía haber dilapidado el consenso hasta entonces alcanzado en un conflicto que había ayudado a articular y fortalecer a un adversario con claros ribetes de derecha, que reinstalaba debates con connotaciones culturales de cuño neoliberal, en torno la libertad de mercado, la desregulación, la apertura económica y la “libertad de ganancia” como valores, reinstalando lecturas ligadas a la concepción de Estado mínimo.

Se instituyó así un vértice tanto a nivel político como económico. En términos políticos se pasaría de la búsqueda de consensos, que habían sido desarrollados bajo la táctica de la “transversalidad” y luego de la “concertación”, a un enfrentamiento más abierto con los adversarios. En términos económicos, si bien no se presentan quiebres fundamentales que permitan entrever un cambio a nivel del modelo de acumulación, sí 
se comenzarían a observar medidas fuertes que inciden en las relaciones de fuerza entre las clases sociales, buscando fortalecer la participación de agentes productivos industriales y de las clases subalternas en el alineamiento oficial, la cuales empezaron a constituir un escenario propicio a la radicalización de los componentes heréticos del kirchnerismo.

En el escenario político se observó la profundización de la confrontación en las calles y en las plazas tanto para dar cauce a las políticas públicas desde el oficialismo, como para enfrentarlas, desde el alineamiento conservador. El avance de la confrontación gobierno-oposición comienza a expresar de forma cada vez más clara distintos proyectos de gobierno y con sus respectivas alianzas de clases, planteando una doble tensión: una que podríamos denominar restrictiva, y otra expansiva.

La tensión restrictiva se refiere a que se gesta una polarización que tiende a consolidar una reformulación del bipartidismo, desgastado en 2001, en dos nuevos polos de centro-izquierda y centro-derecha, ocupando el oficialismo el primero y la oposición conservadora el segundo, que dificulta la emergencia y desarrollo de otras opciones alternativas basadas en las clases subalternas Ésta es la encrucijada en la que se encontraban, por ejemplo, frentes políticos como el Nuevo Encuentro o Proyecto Sur, fuerzas que contienen organizaciones diversas del campo del progresismo y la izquierda, y que debían construir sus estrategias frente a un escenario político caracterizado por la complejidad y la polarización, tendiendo el primero a generar crecientes acuerdos y articulaciones con el oficialismo; mientras que el segundo procuraba capitalizar el perfil anti-kirchnerista, acumulando referencia a través de los espacios provistos por los grupos económicos de la comunicación. Al mismo tiempo, ambas fuerzas buscaban desarrollar sus lazos con los movimientos sociales a través de las distintas organizaciones que contenían y planteaban la necesidad de gestar políticas profundas que habiliten un proceso de transformación social favorable a las clases subalternas.

La tensión expansiva, por su parte, implica la posibilidad desde el conjunto de organizaciones de las clases subalternas de promover mejoras, ya sea a través de políticas y leyes como de disputas sectoriales a partir del conflicto, aprovechando el espacio abierto por la crisis desatada al interior de la clase dominante. Esta crisis está caracterizada por el fin del momento hegemónico alcanzado hacia 2006-2007 y el nuevo 
desarrollo del enfrentamiento al interior de la burguesía, entre, por un lado, sus elementos dispuestos a aceptar algún grado de acuerdo y transferencias de recursos hacia las clases subalternas y, por otro, los grupos más conservadores del capital que en busca de proteger sus privilegios se vuelcan crecientemente hacia el alineamiento opositor. Este contexto genera un marco propicio para el desarrollo de otros núcleos de conflicto favorables a las clases subalternas, no necesariamente contenidos en la disputa entre el oficialismo y la oposición conservadora.

En relación a la vinculación modelo-régimen de acumulación, recordamos que en la definición conceptual del modelo señalamos que éste representa un momento dentro de un régimen del cual se separaba por su alcance espacio-temporal y el distinto nivel de abstracción y generalidad de análisis. En este sentido, podemos avanzar sobre el interrogante en torno a las rupturas y continuidades que se expresan en materia de acumulación y preguntarnos si el modelo productivo-exportador forma parte del régimen de acumulación neoliberal establecido a partir de la última dictadura o si expresa modificaciones suficientes como para suponer que establece el comienzo de un nuevo régimen de acumulación.

En primer lugar, observamos un perfil más productivo del modelo, que muestra una tendencia a la recuperación del tejido industrial, aunque lo haga de forma desestructurada sin lograr revertir la matriz productiva previa. Este énfasis en la producción de bienes tuvo un impacto positivo sobre el empleo, que fue apuntalado por acciones estatales, reduciendo significativamente la desocupación, yendo en contramano de lo sucedido en los años 90, que mostraba períodos de crecimiento con aumento del desempleo. En segundo lugar, la inversión pública vuelve a constituir una variable con regularidad y prelación para el análisis del modelo. Los recursos estatales se orientan a acondicionar el proceso productivo y se vuelcan en infraestructura recordando un talante desarrollista. En tercer lugar, se continúa fomentando la inversión externa pero se procura orientarla hacia la producción de bienes transables, en este camino observamos un descenso de las inversiones extranjeras en el sector financiero y en las empresas de servicios para alojarse en agentes del capital productivo-exportador. Un cuarto factor es que observamos desde 2003 políticas de ingresos favorables a las clases subalternas (en materia de salario mínimo, convenios colectivos, jubilaciones y acuerdos de precios) tras treinta años de políticas regresivas, que mejoran los niveles básicos de vida de las clases subalternas pero que, sin embargo, no logran revertir el 
cuadro de distribución del ingreso, estableciendo un techo en su participación en el valor socialmente creado. De este modo, parece visualizarse un cambio en la orientación de la intervención estatal cuya matriz ideológica se distancia de los cánones propios del paradigma neoliberal, en relación a la cultura política de la fuerza hegemónica.

De este modo, entendemos que en nuestro periodo de estudio se conformó un modelo productivo-exportador, con que procuró saldar la dimensión económica de la crisis de 2001 y en el que el Estado emergió como un actor fundamental en la movilización de recursos a través de diversos mecanismos de transferencia. Estos mecanismos, enlazados con los cambios en la correlación de fuerzas entre las distintas fracciones de clase, buscaron gestar un nuevo momento conciliatorio en la administración de la fase expansiva del ciclo económico. El perfil productivoexportador del modelo, las nuevas modalidades de intervención estatal, el conjunto de rupturas en materia de variables y políticas económicas, junto con otras como el impulso de la obra pública en infraestructura, parecen sugerir la gestación de un nuevo régimen de acumulación de carácter neo-desarrollista ${ }^{416}$, aunque el mismo continúa arrastrando una pesada herencia en su matriz productiva. El neo-desarrollismo, aparecería entonces caracterizado como un régimen de acumulación que sin pretender producir una ruptura explícita en todas las reformas neoliberales, sí exhibe cambios de acento y nuevos énfasis tanto en materia social como en políticas de producción, confiando en las posibilidades del capitalismo productivo y "nacional”, con altos incentivos a la inversión extranjera ${ }^{417}$, priorizando la integración regional. Este régimen evidencia una creciente intervención estatal, mostrando mayores niveles de autonomía relativa, tanto en el desarrollo de grandes planes de obra pública, la gestación de un sistema de transferencias de recursos con el fin de compensar los equilibrios inestables entre las fracciones de clase, al tiempo que se procura mejorar la vida de las clases subalternas a través de políticas de empleo y de ingresos aunque sin llegar a alterar sustancialmente la distribución funcional del ingreso. Neo-desarrollismo cuyo componente "neo" no remite sólo a “nuevo", sino también a la articulación de la permanencia de elementos sedimentados provenientes del régimen de acumulación neoliberal con otros novedosos que evocan un carácter cercano al desarrollismo, en el

\footnotetext{
${ }^{416}$ No se busca aquí justificar o definir exhaustivamente el régimen de acumulación neo-desarrollista, sino presentar algunos elementos que pudieran abonar esta idea y proyectar la continuidad del trabajo de investigación en el comienzo de dicha problematización.

${ }^{417}$ Rescatamos aquí algunos factores a través de los cuales caracterizamos al neo-desarrollismo en la declaración del Grupo de Trabajo sobre Economía Mundial de CLACSO (2009).
} 
sentido de procurar el dinamismo de algunos segmentos de la producción industrial con alta productividad e inversiones externas con el fin de insertarse en el mercado mundial, junto al mantenimiento de grados importantes de concentración económica, y el rol activo del Estado en el acondicionamiento del proceso de acumulación, por ejemplo, a través de los planes de inversión pública.

Sin embargo, podemos plantear algunos factores que evidencian tensiones presentes en el modelo productivo-exportador como primer experiencia del régimen neo-desarrollista, en su relación con el proyecto político-económico de gobierno y la constitución de sujeto. Mientras que el proyecto se funda en la idea de un "capitalismo nacional”, nos encontramos con una estructura económica que posee un alto grado de concentración y extranjerización, lo cual permite cuestionar la idea de burguesía nacional, presente tanto en los discursos de los gobiernos de la post-convertibilidad como en los de los grupos concentrados del capital productivo, para quienes esa burguesía podría establecer una alianza virtuosa con los trabajadores. La predominante extranjerización económica no implica la desaparición del capital local, sino su subordinación a las lógicas transnacionalizadas de acumulación y al liderazgo de empresas de envergadura global. Las empresas extranjeras no sólo han recompuesto sus ganancias sino que superan ampliamente las obtenidas en promedio durante el modelo anterior, y a pesar de ello es poco lo que dejan en el país ${ }^{418}$. Resulta difícil imaginar una burguesía nacional independiente, mercado-internista, “aliada” con la clase trabajadora, cuando sus intereses se encuentran fuertemente transnacionalizados e incluso su composición está claramente extranjerizada. Como ya señalamos, la orientación exportadora del gran capital productivo implica que el salario no es visualizado como un factor fundamental para la realización del capital (como consumo en el mercado interno), sino que aparece como un costo para la empresa, que busca limitar su evolución para ganar rentabilidad. Así, observamos que una de las claves de la competitividad y las ganancias empresariales en la post-convertibilidad se encuentra en el aumento de la productividad laboral no retribuido en salario, que, sobre todo al comienzo del período de estudio con la dispar evolución de precios y salarios, provocó una fuerte reducción del costo laboral. Además estos salarios resultan aún más bajos en

\footnotetext{
418 “Aún hacia 2004, en un contexto de apreciable recuperación de la economía y con una renta de la IED que resultó un 55\% superior al promedio observado en la década del 90, las ETs remitieron utilidades por un monto mayor al obtenido en dicho año, y fue sólo en 2005, y con una renta que superó en un $120 \%$ al promedio de los 90 a pesar de la pérdida de valor del peso, que las utilidades reinvertidas cambiaron su signo: las ETs dejaron en el país el 9\% de la renta obtenida” (Sacroisky, 2006: 41).
} 
términos de divisas y terminan constituyendo un factor de competitividad internacional en vinculación con la política cambiaria vigente.

Tampoco es posible hallar el rol de la burguesía nacional en los agentes de la fracción de PyMEs, ya que si bien está compuesta por empresas que son claves para la producción de empleo y tienen una mayor orientación al mercado interno, su baja productividad y escala de producción derivan en que su rentabilidad y condición de existencia tiendan a yacer en el incremento de las condiciones de explotación de la fuerza de trabajo, ofreciendo en promedio bajos salarios y altos índices de informalidad laboral. La persistencia de esta baja productividad y las restricciones relativas a la escala de producción son dos factores que disminuyen las complementariedades posibles con la clase trabajadora. Más aún, podríamos arriesgarnos a decir que las PyMEs terminan teniendo mayores complementariedades con el gran capital como lo tiene la lógica de tercerización, ya que muchas veces abastecen de insumos a las grandes empresas incorporándose a sus circuitos como proveedores del valor generado en condiciones de fuerte explotación laboral generando un trasvasamiento de valor hacia éstas, al tiempo que las grandes empresas las oxigenan al proveer salarios relativamente altos en pesos a un segmento de las clases subalternas que, en complementación a las políticas progresivas de ingresos desplegadas desde 2003 y la recuperación del empleo, permitieron la expansión del consumo y el mercado interno.

El inicio regresivo del modelo con la salida devaluacionista-inflacionaria en 2002 parece dejar establecido un conjunto de "reglas de juego" que modelan las relaciones de fuerzas entre las distintas fracciones de clase. En este complejo cuadro se gestó el modelo productivo-exportador sustentado en el doble superávit, comercial y fiscal, pero estos dos pilares de estabilidad del modelo se encuentran amenazados por distintos flancos. Por un lado, la ausencia de un proyecto de industrialización planificado no logró revertir la desarticulación productiva, y muchas de las industrias que se reactivaron a través del principal instrumento utilizado (el tipo de cambio) contienen un alto componente de insumos importados en su producción. Incluso en el contexto auspicioso analizado podemos observar cómo la balanza comercial de la industria, que habiendo roto inicialmente la tendencia de la década anterior al volverse superavitaria, comienza a deteriorarse con las nuevas dificultades que va a imprimir el advenimiento de una nueva crisis mundial, abriendo lugar a las tensiones propias de la necesidad de financiar con divisas los déficits sectoriales. A su vez, el superávit 
comercial se encuentra ligado al precio de los commodities que exporta Argentina, que son fijados en el mercado externo, mostrando una vía de vulnerabilidad externa. Asimismo, el superávit fiscal está vinculado al comercial a partir de la importancia de las retenciones, al tiempo que los recursos fiscales son fundamentales para la gestación del sistema de transferencia de recursos con los que el Estado construye hegemonía en la post-convertibilidad. De este modo, estos dos pilares son importantes tanto en términos de acumulación como de hegemonía, y su deterioro prolongado podría traer serios problemas en ambos sentidos.

Además, al constituirse el Estado en un actor fundamental cada vez más visible de la distribución diferencial de recursos a través del sistema de transferencias analizado, el mismo (y fundamentalmente la fuerza política que lo conduce) queda expuesto ante los agentes que grava y beneficia. A su vez, esta tensión parece cobrar mayor relevancia en cuanto los principales agentes económicos siguieron incrementando su poder estructural, debido al aumento de su margen de ganancia durante la post-convertibilidad y a la continuidad de los procesos de concentración.

Quedan establecidas un conjunto de tensiones a nivel del modelo de acumulación que, al mismo tiempo, no son ajenas a las tensiones que acarrea el propio proyecto de gobierno que inspira el componente de políticas, y la cultura política en la cual éste se enmarca. Este desagregado analítico que generamos, manteniendo la centralidad en la investigación del modelo y avanzando hacia los distintos factores que nos permiten pensar los principales rasgos de la construcción de hegemonía que asisten su conformación, nos da la clave para arribar a nuevas conclusiones, donde las categorías de contradicción y antagonismo siguen mostrando su potencia heurística.

En este punto, explicitamos una conclusión que refiere a que los componentes heréticos y normalizadores de la fuerza hegemónica, enmarcados en el proyecto de “capitalismo serio”, dieron lugar a una dinámica político-económica con dos motores. Un primer motor que anida en las superestructuras complejas: la construcción de consensos en la sociedad civil en base a las transferencias de recursos, donde el rol del trabajo vuelve a recuperar relevancia e incluso da lugar a una política de no-represión del conflicto social a nivel de la sociedad política. Por primera vez desde la instauración del neoliberalismo en Argentina vuelve a haber una política progresiva sostenida en el tiempo. El elemento herético del kirchnerismo encuentra vía de realización en el avance 
de reformas tales como las políticas sociales y de ingreso, la unidad latinoamericana que fue cobrando algunos ribetes antiimperialistas, el proceso de democratización y participación política que impulsa, la política de Derechos Humanos que es parte de una confrontación más general con el legado del tándem dictadura-neoliberalismo, entre otros. Es justamente esta conformación del adversario y los rasgos objetivos que el mismo fue cobrando en el conflicto, lo que caracteriza la reapertura generalizada del antagonismo y alienta a la proliferación de los componentes populares y transformadores dentro del kirchnerismo. Pero hay también un segundo motor, ligado a la dimensión económico-estructural que, si bien avanza rompiendo con algunos patrones característicos del neoliberalismo, lo hace más lentamente. Las persistencias en materia de matriz productiva con la inserción subordinada de argentina al mercado mundial como proveedor de recursos naturales y mano de obra barata, la explotación no sustentable de los recursos hidrocarburíferos y mineros, los problemas ligados a la explotación del recurso tierra con las lógicas que analizamos y, sobre todo, las serias limitaciones en materia de distribución funcional (agravadas por la escasa tasa de sindicalización), son parte de continuidades que retrasan el proceso de cambio a nivel estructural.

Esto tiene que ver con las contradicciones gestadas a nivel del modelo en términos de la reproducción ampliada de las clases sociales que el mismo implica. La existencia de una burguesía fragmentaria, con capitales rectores fuertemente concentrados y extranjerizados y capitales subordinados con problemas de escala y productividad, desconectados del sistema financiero, articulados en una complementariedad deficitaria. La contradicción capital/trabajo que se expresa diferenciadamente en su inserción en estas disímiles experiencias de explotación, desde los mejores salarios con mayor nivel de formalidad pero mayor extracción de plusvalía relativa en el gran capital, y la masificación del empleo pero con altos índices de informalidad y bajos salarios propios de las PyMEs. Aun así, el descenso global de la desocupación implica una base estructural que habilita el fortalecimiento del movimiento obrero. Esto, sumado a los factores que mencionamos dentro de la tensión expansiva del escenario político, da aire tanto a los componentes heréticos dentro del kirchnerismo como de las organizaciones populares en términos generales.

Otra contradicción característica de nuestro período, que vimos en el caso del circuito productivo sojero y que puede percibirse en forma más generalizada, es la que 
comienza a darse entre el aumento de la autonomía relativa del Estado y persistencia del carácter oligopólico de la estructura. Esto crea un sustrato estructural de tensiones vinculadas al esquema mismo de construcción de hegemonía, más aún en el marco de un proyecto que no se propone superar los límites de la sociedad capitalista. En este punto no podemos dejar de notar que los apoyos de los agentes dominantes al proyecto kirchnerista parecen estar fundados más en la multiplicación de las ganancias que presentan las empresas de la cúpula económica (que superan ampliamente las que obtenían en la década de los 90) que en una adhesión ferviente a un proceso de desarrollo nacional. Esta constituye una base estructural para la gestación de nuevos antagonismos. Distribuir implica afectar recursos, disciplinar agentes dominantes que después de varias décadas de neoliberalismo que incluyeron de forma constitutiva la proliferación de ámbitos privilegiados de acumulación, cada intento de restringir ganancias puede crear una coyuntura de enfrentamiento. Esto se liga, a su vez, con que ya está en escena una alternativa conservadora al proyecto y modelo en vigencia. Como vimos, un conjunto de agentes de la clase dominante comenzaron a capitanear un nuevo alineamiento que empezó a recuperar al neoliberalismo como proyecto de gobierno. Es así que arribamos a una nueva conclusión: parece que el punto donde se juntan las dinámicas de antagonismo y contradicción yace en el par profundización rupturista vs restauración neoliberal.

¿Por qué? Porque el alineamiento conservador cuenta con grupos sociales poderosos, incluyendo a los principales medios masivos de comunicación, con gran potencial de incidencia en la construcción de sentido, de articulación hegemónica de demandas, cumpliendo un rol destacado como intelectual orgánico. Este alineamiento ya mostró capacidad de movilización en las calles, recuperando y resignificando el repertorio de acción colectiva de 2001, capacidad de disputa electoral y capacidad de crear opinión e instalar agenda pública. Nada dice que los grupos dominantes que pasaron a la oposición puedan ser neutralizados en el corto plazo, lo cual da vida al polo de restauración neoliberal. Por otra parte, el polo de profundización remite al avance de mayores rupturas y queda establecido porque son precisamente las continuidades reminiscentes del régimen neoliberal lo que conforma el sustrato de la relación de fuerzas estructural favorable a los restauracionistas. Además, perdiendo aliados en las clases dominantes, el kirchnerismo se ve compelido a profundizar alianzas con las clases subalternas, alimentando su propio componente herético y habilitando 
transformaciones crecientes. Incluso el contexto latinoamericano empuja como sobredeterminación a la dinámica profundización/restauración, ya que Argentina se encuentra articulada en el bloque regional con los procesos revolucionarios de Venezuela, Bolivia y Ecuador, que, entre otros gobiernos populares, lideran un proceso de cambio continental anti-neoliberal, con crecientes rasgos antiimperialistas y que comienzan a plantear la necesidad de superación de la sociedad de clases en nuevas búsquedas con horizonte socialista. Los intentos desestabilizadores promovidos por EEUU y algunos grupos dominantes locales no hacen más que evidenciar el rol geopolítico de la alternativa restauracionista, con un visible signo de derecha que no hace demasiada distinción entre neo-desarrollistas y socialistas, al menos mientras estos forman parte del mismo bloque político a nivel continental.

Una pregunta final queda ligada a ¿qué es profundizar y qué implica? Lo que incluye plantearse hasta dónde profundizar no hará llevar a contradicción al propio pacto populista expresado en el proyecto oficial y dará lugar a que los rasgos de “revolución desde arriba” se conviertan en una tendencia a la “revolución desde abajo”.

La pregunta por la profundización está, en parte, ligada a la velocidad de los “dos motores”, a equiparar los cambios a nivel económico-estructural con la potencia de los cambios ideológico-culturales que proclaman a la política y a la participación popular mediante la militancia como vía de dirección de las sociedades. Pero nuevamente, distribuir recursos implica sacar de un lugar para poner en otro, y, como se vio claramente en el conflicto agrario, conlleva una disputa. El desarrollo del “capitalismo serio" incluye la necesidad de disciplinar al menos parcial y gradualmente a la burguesía, una burguesía concentrada y acostumbrada a no ser regulada ni menos disciplinada, con décadas y décadas de relaciones preferenciales con un Estado que le ha sabido garantizar la proliferación de diversos ámbitos privilegiados de acumulación, muchos de los cuales, como señala Castellani (2010), continuaron durante la postconvertibilidad. Cada acción disciplinadora corre el riesgo de que el agente disciplinado pase a formar parte de las filas del adversario, si esto ha sido limitado en parte se debe a la capacidad del modelo de continuar creciendo y por las monumentales tasas de ganancia que otorga. Problema aún mayor cuando se trata de agentes con gran poder estructural, con poder de decisión sobre las variables económicas, como la formación de precios, la inversión, el empleo, etc. Hay ahí una limitante del sistema de transferencia de recursos en base al populismo como pacto. Del otro lado, las clases subalternas 
precisan de crecientes resoluciones de demandas que se fueron acumulando en las décadas de oprobio neoliberal, lo cual requiere justamente de desconcentrar, disciplinar y hacer aceptar a la contra-parte contradictoria (el capital) que la hegemonía se construye en base a realizar concesiones y que luego de 30 años de transferir recursos de asalariados a capitalistas, se debe ejecutar el movimiento inverso: es el único modo de sustentar la promesa de plenitud. ¿Qué batallas librar para realizar la epopeya de la distribución del ingreso? Ésta parece una pregunta central para el devenir de la Argentina post-convertibilidad, que conlleva otra: ¿qué modificaciones realizar en el modelo de acumulación?

En términos de hegemonía las tensiones e inquietudes no son menores. Aparece la pregunta por la guerra de posiciones y por la construcción de poder. El Príncipe moderno en clave kirchnerista comienza a constituirse desde el Estado mismo: es un sujeto político nacido con una fuerte lógica estatalista. Un problema que lo atraviesa es que una fuerza de este tipo tiene posibilidad de crecer rápidamente en base a la potencia que habilitan los resortes y recursos estatales, pero que no garantizan la solidez de la construcción, sino todo lo contrario: a una fuerza de este carácter, la pérdida de la conducción del Estado puede infringirle un duro golpe, y un cambio de administración puede arrastrar a los intelectuales orgánicos menos afianzados a la fuerza que detente con posterioridad los recursos. Nuevamente, la contradicción capital/trabajo parece sugerir algo al respecto. Si las solidaridades dominantes dependen, al menos en este contexto histórico, de la tasa de ganancia y son por ello altamente inestables, las solidaridades del campo popular requieren de los avances en la articulación/resolución de demandas, pero su alcance y sustentación también se encuentran ligados al tipo de poder construido. Actualmente, casos como el de Venezuela muestran un ejemplo donde la política pública se encuentra explícitamente orientada a la construcción de sujeto, por ejemplo en la conformación de cooperativas, fábricas socialistas, o en el desarrollo de las “misiones”. No sólo se evidencia transferencia de recursos y sutura de demandas, sino que se hace de un modo en que dichas acciones estatales procuran generar organización, participación, y formación de sujeto-pueblo. Las lecciones dejadas por los intentos de golpes de Estado evidenciaron la capacidad que tiene la organización popular para defender un proyecto que considera propio. Es por eso que la conformación de sujeto-pueblo reclama de lógicas que no lo tengan de “cliente” o de mero asalariado, como sucede muchas veces con los planes sociales con 
contraprestación laboral en Argentina que terminan reducidos a cuadrillas de trabajo precario con salarios mínimos, con escasa capacidad de decisión sobre recursos, objetivos y organización del proceso de trabajo. Parece necesario para la formación de sujeto-pueblo que, por el contrario, los recursos destinados se apliquen directamente a favorecer la auto-organización de los sectores populares, como vía para sustentar solidaridades duraderas que permitan el sostenimiento del proyecto y su profundización. También es clave en este proceso el incremento del nivel de sindicalización y la conquista de la adhesión y participación del movimiento obrero organizado, por su peso y lugar estructural. Pero esto, a su vez, no puede dejar de estar en relación con el desempeño de los componentes "heréticos”, “plebeyos” de la propia fuerza en formación.

Nuevamente parece necesario volver sobre la construcción de sujeto. El Estado parece estar cumpliendo un rol clave en el acondicionamiento y apuntalamiento en la conformación de sujeto. En la tesis vimos este rol, por un lado, a través del análisis de la política económica, conformando un sistema de transferencia de recursos así como en las incidencias más generales que establece en el proceso de acumulación, y, por otro lado, a partir de la lógica del antagonismo, en la gestación de la voluntad colectiva a partir del príncipe-fuerza política y el desarrollo de la guerra de posiciones.

En relación a esto podemos extraer varias conclusiones que al mismo tiempo habiliten vías futuras para la prospección. En primer lugar, vemos un punto de tensión permanente, intrínseca a la construcción de la voluntad colectiva basada en el pacto populista, que comenzamos a delinear previamente: es una voluntad colectiva que busca limar la contradicción nodal de toda sociedad capitalista, la contradicción capital/trabajo, procurando constituir complementariedades y articulaciones que permitan sostener la conciliación en un proyecto societario que impulse un modelo de acumulación de modo expansivo al tiempo que aparezca realizando la promesa de plenitud de articulación de la vida “exterior” e “interior” del pueblo. Como vimos la construcción de hegemonía incluye un amplio abanico de fenómenos, de los cuales destacamos la articulación de una cadena equivalencial de demandas. La tensión que atraviesa aquí al modelo y a la construcción hegemónica pone en juego la articulación de demandas de portadores heterogéneos anclados estructuralmente en una relación de contradicción y, por ende, de tendencia al conflicto. Es aquí que recordamos que cuanto más amplia es la cadena más inestable se torna: la combinación de los elementos 
sistémicos y heréticos es igualmente inestable. No son novedad los enfrentamientos entre actores conservadores y actores transformadores en los sujetos políticos constituidos bajo la lógica populista del populismo como pacto. Como nuevo Príncipe que busca suscitar la voluntad colectiva, esta tensión es heredada por el sujeto-pueblo que procura constituir. Esto quiere decir que no sólo hay que ver la lógica polarizada de los escenario políticos contemporáneos entre fuerzas de cambio y fuerzas restauracionistas (o en algunos casos lisa y llanamente entre revolución y reacción), sino que también hay que ver al interior de los sujetos en formación. Todo sujeto tiene creación, componentes ex novo, que son irreductibles a la previa historia de demandas y portadores, pero dicho sujeto no es independiente de estas demandas y portadores, y la cultura política hegemónica marca el carácter del pueblo en formación. Así, un sujeto puede perecer no sólo por el daño que le causa el adversario en la guerra de posiciones sino que puede ser devorado desde su interior, por ejemplo, por la anulación de los elementos heréticos por parte de los sistémicos.

Pero también puede acontecer lo contrario. Un clima de polarización que nos enfrenta con un escenario caracterizado por el par profundización/restauración puede llevar a que la lógica del antagonismo de vida a los elementos heréticos y que estos terminen predominando sobre los sistémicos. Este es otro camino de ruptura del pacto populista pero a través de la resolución de la contradicción que dicho pacto guarda en su interior. Es aquí donde nos encontramos con la posibilidad de que una "revolución desde arriba" se vuelva una "revolución desde abajo", donde la radicalización de la profundización de los elementos heréticos culmine en la instauración de un horizonte de cambio societario de raíz: resolver la contradicción principal de la sociedad burguesa en el terreno del antagonismo. Casos como el de la izquierda peronista de los 70 y la emergencia del "socialismo nacional”, del chavismo venezolano con el "socialismo del siglo XXI", Bolivia con el "socialismo comunitario" o Ecuador con la revolución ciudadana y el "socialismo del buen vivir", son ejemplos de movimientos que originalmente no planteaban un horizonte de ruptura sistémica, pero que sin embargo, al calor del antagonismo comenzaron a percibir su necesidad. Entonces dentro del sujeto parido del pacto comienza a percibirse que para vencer sobre el par restauracionista, es necesario vencer en simultáneo, a través de un cambio de relaciones de fuerzas, a los componentes sistémicos de su propio interior. 
En el caso argentino, queda por ver cómo actuarán los limitantes estructurales analizados en este trabajo en contradicción con las políticas progresivas desarrolladas desde 2003 cuando un mayor mejoramiento de los ingresos y niveles de vida de las clases subalternas comience a poner en cuestión la ganancia empresaria. Cualquier proyecto que proponga transformar las condiciones de vida de las clases subalternas y avanzar hacia la resolución de las grandes cuestiones nacionales deberá plantearse las problemáticas en torno a la matriz productiva, los recursos naturales, la distribución del ingreso, las condiciones laborales, la concentración y extranjerización económica, la estructura impositiva, el lugar de las finanzas en relación a la producción y al desarrollo social, la estrategia de inserción en la economía mundial y regional, y los posibles sujetos y estrategias de poder en pos del cambio social. Así, todo avance sobre los factores estructurales reminiscentes del pasado neoliberal auguran la emergencia de nuevos antagonismos, donde el par profundización rupturista vs restauración neoliberal reactualizará de modo dinámico el escenario nacional de la lucha de clases, en estrecha relación con el proceso transformador que se despliega actualmente en América Latina. 


\section{Bibliografía}

Adorno, Theodor y Horkheimer Max. 1969. “Cultura y civilización”, en La sociedad. Lecciones de sociología. Proteo. Buenos Aires.

AIPE (Agencia Interamericana de Prensa Económica). 2005. “Llegó la hora de cerrar el FMI”, en Diario de América, http://www.diariodeamerica.com/front_nota_detalle.php?id_noticia=929

Alexander, Jeffrey. 1992. Las teorías sociológicas desde la Segunda Guerra Mundial. Análisis multidimensional. Editorial Gedisa. Barcelona.

Almond, Gabriel. A., y Verba, Sidney. 1989 [1963]. The Civic Culture. Political Attitudes and Democracy in Five Nations. Sage Publications. Newbury Park.

Althusser, Louis. 2003 [1970]. Ideología y aparatos ideológicos de Estado. Nueva Visión. Buenos Aires.

Althusser. Louis. 1988 [1962]. “Contradicción y sobredeterminación (Notas para una investigación)”, en La revolución teórica de Marx. Siglo XXI Editores. México D. F.

Amadeo, Máximo. 2003. “Industria siderúrgica”, Informe sectorial, noviembre, Capital Markets Argentina, Reaserch Departement.

Anderson, Perry. 1987 [1976]. Consideraciones sobre el marxismo occidental. Siglo XXI. México.

Arceo, Enrique. 2003. Argentina en la Periferia próspera. Renta internacional, dominación oligárquica y modo de acumulación. UNQ-FLACSO-IDEP. Buenos Aires.

Arceo, Nicolás y Rodríguez, Javier. 2008. “Inflación, retenciones y rentabilidad agrícola. Ganan como nunca” en Cash, Página 12, 16/3/08. Buenos Aires.

Arditi, Benjamín. 1995. "Rastreando lo político”, en Revista de Estudios Políticos, nº 87, enero-marzo, pp. 333-351. Madrid. 
Aronskind, Ricardo. 2001. ¿Más cerca o más lejos del desarrollo? Transformaciones económicas en los '90. Libros del Rojas. Buenos Aires.

Arrilaga, Hugo; Grand, Lucila, Locher, Valentina y Busso, Gabriela. 2007. “Cambios en la matriz productiva del sector agropecuario y dinámica poblacional en la región pampeana”. Ponencia presentada en el VIII Encuentro Nacional de la Red de Economías Regionales en el Marco del Plan Fénix - I Jornadas Nacionales de Investigadores de las Economías Regionales, 13 y 14 de septiembre.

Artese, Matías. 2009. “Criminalización de la protesta en Argentina. Una construcción de lo delictivo más allá de la esfera jurídica”, en América Latina Hoy, vol. 52, agosto, pp. 149-169. Universidad de Salamanca. España.

Arzadun, Daniel. 2008. El peronismo: Kirchner y la conquista del reino. Editorial Sudamericana-COPPALK. Argentina.

Astarita, Rolando. 2007. “Tendencias en la economía mundial y los cambios en Argentina” en ¿Coyuntura favorable o nuevo modelo?: Economía argentina. Anuario EDI n³. Ediciones Luxemburg. Buenos Aires.

Azpiazu, Daniel, Eduardo Basualdo y Matías Kulfas. 2005. "La industria siderúrgica en Argentina y Brasil durante las últimas décadas”. FETIA-CTA. Buenos Aires.

Azpiazu, Daniel y Eduardo Basualdo. 2004. "Las privatizaciones en la Argentina. Genesis, desarrollo y principales impactos estructurales”, en D. Azpiazu y E. Basualdo Las privatizaciones en la Argentina. Genesis, desarrollo y principales impactos estructurales, FLACSO, Facultad Latinoamericana de Ciencias Sociales. Sede Argentina.

Azpiazu, Daniel y Martín Schorr. 2003. Crónica de una sumisión anunciada. Las renegociaciones con las empresas privatizadas bajo la administración Duhalde. Siglo XXI Editores. Buenos Aires.

Azpiazu, Daniel y Martín Schorr. 2008. "Del "modelo de los noventa" a la posconvertibilidad. Reflexiones preliminares”, en Realidad económica, $\mathrm{n}^{\circ} 240$. Buenos Aires. 
Azpiazu, Daniel y Schorr, Martín. 2010. Hecho en Argentina Industria y economía, 1976-2007. Siglo XXI. Buenos Aires.

Azpiazu, Daniel, Basualdo, Eduardo y Khavisse, Miguel. 2004 (nueva edición). El Nuevo Poder Económico en la Argentina de los años 80. Legasa. Buenos Aires.

Azpiazu, Daniel, Pablo Manzanelli y Martín Schorr. 2011. “Concentración y extranjerización en economía argentina posconvertibilidad”. FLACSO. Buenos Aires.

Azpiazu, Daniel. 2005. Las privatizadas II. Ayer, hoy y mañana. Claves Para Todos, Capital Intelectual. Buenos Aires.

Bachelard, Gastón. 1984. La formación del espíritu científico. Siglo XXI. México.

Bandieri, Susana. 2005. “La posibilidad operativa de la construcción histórica regional o cómo contribuir a una historia nacional más complejizada”, en S. Fernández y G. Dalla Corte (comps.), Lugares para la historia. Espacio, historia regional e historia local en los estudios contemporáneos. UNR Editora. Rosario.

Barbetta, Pablo y Karina Bidaseca. 2004. "Reflexiones sobre el 19 y 20 de diciembre de 2001 “piquete y cacerola, la lucha es una sola”: ¿emergencia discursiva o nueva subjetividad?”, en Revista Argentina de Sociología, mayo-junio, año/vol. 2, n $\mathrm{n}^{0} 002$ pp.67-88. Consejo de Profesionales en Sociología. Buenos Aires.

Barsky, Osvaldo y Mabel Dávila. 2008. La rebelión del campo. Historia del conflicto agrario argentino. Sudamericana. Buenos Aires.

Basualdo, Eduardo. 2000. Concentración y centralización del capital en la Argentina durante la década de los noventa. Universidad Nacional de Quilmes. Bernal.

Basualdo, Eduardo. 2001. Sistema político y modelo de acumulación en la Argentina. Universidad Nacional de Quilmes-FLACSO-IDEP. Bernal.

Basualdo, Eduardo. 2003. "Las reformas estructurales y el Plan de Convertibilidad durante la década de los noventa. El auge y la crisis de la valorización financiera”, en Realidad Económica, n 200, IADE. Buenos Aires. 
Basualdo, Eduardo. 2007. “Concepto de patrón o régimen de acumulación y conformación estructural de la economía”, en Documento nª $^{\circ}$, Maestría en Economía Política Argentina, Área de Economía y Tecnología de la FLACSO, en www.flacso.org.ar/economía.

Basualdo, Eduardo. 2008. "La distribución del ingreso en la Argentina y sus condicionantes estructurales”, en Memoria Anual 2008, Centro de Estudios Legales y Sociales (CELS). Buenos Aires.

Basualdo, Eduardo. 2008b. "El agro pampeano: sustento económico y social del actual conflicto en la Argentina”, en Cuadernos del CENDES, año 25, n 68, tercera época, mayo-agosto. Venezuela.

Basualdo, Eduardo. 2010 [2006]. Estudios de historia económica argentina: desde mediados del siglo XX a la actualidad. Siglo XXI-FLACSO. Buenos Aires.

Basualdo, Eduardo. 2011. Sistema político y modelo de acumulación. Tres ensayos sobre la Argentina actual. Cara o Ceca. Buenos Aires.

Becerra, Luis y Méndez, Andrés. 2005. "Renegociación de la deuda: un éxito demasiado caro” en Economistas de Izquierda ${ }^{\circ} 1$. Buenos Aires.

Bembi, Mariela y Nemiña, Pablo. 2007. Neoliberalismo y desendeudamiento. La relación Argentina-FMI. Claves para todos, Capital Intelectual. Buenos Aires

Bergel, Martín y Bruno Fornillo, 2006. “Los siete puntos para un balance de la rebelión popular argentina del 2001”, en El Rodaballo, nº 16. Buenos Aires.

Berstein, Serge. 1998. "La cultura política”, en Jean-Pierre Rioux y Jean-Francois Sirinelli (ed.), Para una historia cultural. Taurus. México DF.

Bisang, Roberto. 2008. "La agricultura argentina: cambios recientes, desafíos futuros y conflictos latentes”, en $A R I, \mathrm{n}^{\circ} 111$. Real Instituto Elcano. España.

Blanco, Graciela. 2006. “Las explotaciones ganaderas en la Patagonia: sujetos sociales, articulación comercial y organización socio-espacial”, en S. Bandieri, G. Blanco y G. Varela, (dir.), Hecho en Patagonia. La historia en perspectiva regional. Edic. CehirUniversidad Nacional del Comahue (UNCo), pp. 155-190. Neuquén. 
Bonnefoy, Juan Cristóbal. 2006. “Indicadores de Desempeño en el Sector Público”. ILPES-CEPAL.

Bonnet, Alberto y Adrián Piva. 2010. “El estado kirchnerista. Un análisis de los cambios en la forma de estado a partir de la crisis de 2001”, en VI Jornadas de Sociología de la UNLP “Debates y perspectivas sobre la Argentina y América Latina en el marco del Bicentenario. Reflexiones desde las Ciencias Sociales”. 9 y 10 de diciembre. La Plata.

Bonnet, Alberto. 2002. "La crisis de la convertibilidad”, en Theomai (edición electrónica) Invierno, número especial, Red Internacional de Estudios sobre Sociedad, Naturaleza y Desarrollo. Universidad Nacional de Quilmes.

Bonnet, Alberto. 2008. La hegemonía menemista. Prometeo. Buenos Aires.

Boron, Atilio y Oscar Cuéllar. 1983. “Apuntes críticos sobre la concepción idealista de la hegemonía” en Revista Mexicana de Sociología, Año XLV. Vol. XLV n4 . Octubrediciembre pp.1143-1177. México. Versión online: http://www.gramsci.org.ar/12/AABoron_y_OCuellar_concepc_idealista_hegemon.htm

Boron, Atilio. 2001. “El nuevo orden imperial y cómo desmontarlo”, ponencia presentada en el Foro Social Mundial el día 27 de enero de 2001, en http://bibliotecavirtual.clacso.org.ar/ar/libros/seattle/boron.pdf.

Botana, Natalio. 2006. Poder y Hegemonía. El régimen político después de la crisis. Emecé. Buenos Aires.

Bourdieu, Pierre y Loïc Wacquant. 1995. Respuestas, por una antropología reflexiva. Grijalbo. México.

Bourdieu, Pierre, Jean-Claude Chamboredon, y Jean-Claude Passeron. 2008 [1973]. El oficio de sociólogo. Siglo Veintiuno editores. Buenos Aires.

Bourdieu, Pierre. 1990. “Algunas propiedades de los campos”, en Sociología y cultura, pp. 135-141. Grijalbo. México.

Bourdieu, Pierre. 1990b. "Espacio social y génesis de las 'clases"” en Sociología y Cultura, pp. 281-310. Grijalbo. México. 
Bourdieu, Pierre. 1997. "Espacio social y espacio simbólico” en Razones prácticas. Anagrama editorial. Barcelona.

Bourdieu, Pierre. 2008 [2000]. Las estructuras sociales de la economía, Buenos Aires, Manantial.

Bowles, Samuel y Edwards, Richard. 1985. Introducción a la economía: competencia, autoritarismo y cambio en las economías capitalistas. Alianza Universidad. Madrid.

Boyer, Robert. 1989. La teoría de la regulación Un análisis crítico. Ed. Área de Estudios e Investigaciones Laborales de la SECYT, CEIL/CONICET, CREDAL/CNRS, Humanitas. Buenos Aires.

Bresser Pereira, Luiz Carlos. 1991. "La Crisis de América Latina. ¿Consenso de Washington o Crisis Fiscal?”, en Pensamiento Iberoamericano, n¹9, pp.13-35. España.

Buci-Glucksmann, Christine. 1986. Gramsci y el Estado (Hacia una teoría materialista de la filosofía). Siglo XXI. México.

Campione, Daniel y Beatriz Rajland. 2006. “Piqueteros y trabajadores ocupados en la Argentina de 2001 en adelante: novedades y continuidades en su participación y organización en los conflictos”, en Caetano, Gerardo (comp), Sujetos sociales y nuevas formas de protesta en la historia reciente de América Latina. CLACSO. Buenos Aires.

Campione, Daniel. 2006. “Antonio Gramsci. Breves apuntes sobre su Vida y Pensamiento”. En línea: http://www.gramsci.org.ar/12/Campione_apuntes.htm

Campione, Daniel. 2007. Para leer a Gramsci. Ediciones del CCC. Centro Cultural de la Cooperación Floreal Gorini. Buenos Aires.

Castellani, Ana y Mariano Szkolnik. 2005. "Devaluacionistas y dolarizadores. La construcción social de las alternativas propuestas por los sectores dominantes ante la crisis de la Convertibilidad. Argentina 1999-2000”, en http://www.argiropolis.com.ar.

Castellani, Ana y Martín Schorr. 2004. “Argentina: convertibilidad, crisis de acumulación y disputas en el interior del bloque de poder económico” en Revista Cuadernos del CENDES n57, septiembre-diciembre. Caracas. 
Castellani, Ana. 2004 “Gestión económica liberal-corporativa y transformaciones en el interior de los grandes agentes económicos de la Argentina durante la última dictadura militar” en Pucciarelli, Alfredo, ed., Empresarios, tecnócratas y militares. La trama corporativa de la última dictadura. Siglo XXI. Buenos Aires.

Castellani, Ana. 2008. "Instituciones y desarrollo en América Latina: el caso del correo oficial de la República Argentina”, en The Center for Migration and Development Working Paper Series $n^{\circ} 08-05^{a}$. Princeton University.

Castellani, Ana. 2009. Estado, empresas y empresarios. La construcción de ámbitos privilegiados de acumulación entre 1966 y 1989. Prometeo. Buenos Aires.

Castellani, Ana. 2010. “Estado y grandes empresarios en la Argentina de la postconvertibilidad”, en Cuestiones de Sociología. Revista de Estudios Sociales, n5/6, FAHCE-UNLP. La Plata.

Castells, Manuel. 1985 [1973]. "La teoría marxista de las clases y la lucha de clases en América Latina”, en Zenteno Benítez, R. (coord.) Las clases sociales en América Latina, Instituto de Investigaciones Económicas, UNAM y Siglo XXI. México.

Castiñeira, Ramiro. 2008. “La Deuda Pública tras la manipulación del IPC”, en Argentina Macroeconomic Outlook, mayo, Econométrica S.A. Buenos Aires.

Castro Gomes, Angela. “O Populismo e as Ciencias Sociais no Brasil. Notas sobre a Trajetória de um Conceito”, en Tempo, Vol I, N² 2, Dezembro 1996; pp 31-58. Brasil.

CEDEX. 2007. “Encuesta a Pymes exportadoras”. Universidad de Palermo. Buenos Aires.

CENDA. 2007. "El gasto público en la post-convertibilidad: quiebres y continuidades”, en Notas de la economía Argentina, $\mathrm{n}^{\circ}$ 04, diciembre. Buenos Aires.

CENDA. 2007b. "La trayectoria de las ganancias después de la devaluación: la "caja negra” del crecimiento argentino", en Notas de la economía argentina, Informe Macroeconómico, n4. Buenos Aires. 
CENDA. 2007c. “Los principales cambios en la legislación laboral 2003-2007”, en El Trabajo en Argentina. Condiciones y perspectivas, $\mathrm{n}^{\circ} 13$, Informe trimestral, primavera. Buenos Aires.

CENDA. 2008. “Condiciones de trabajo y distribución del ingreso en el sector agropecuario”, en El trabajo en Argentina. Condiciones y perspectivas, Informe trimestral $n^{\circ} 15$. Buenos Aires.

CENDA. 2008b. "El complejo automotriz argentino: las terminales a la promoción y el desarrollo industrial al descenso” en Notas de la economía argentina, $\mathrm{n}^{\circ 5}$, agosto. Buenos Aires.

CENDA. 2008c. "Mercado de trabajo y estadísticas", en El Trabajo en Argentina. Condiciones y perspectivas, $\mathrm{n}^{\circ} 14$, Informe trimestral, otoño. Buenos Aires.

CENDA. 2008d. "La pobreza hoy: evolución mapa y perfil de quienes viven en situación de pobreza en la Argentina”, en El Trabajo en Argentina. Condiciones y perspectivas, $\mathrm{n}^{\circ} 14$, Informe trimestral, otoño. Buenos Aires.

CENDA. 2010. La anatomía del nuevo patrón de crecimiento y la encrucijada actual. La economía argentina en el período 2002-2010. Atuel. Argentina.

CEP. 2005. "Performance exportadora reciente de las pequeñas y medianas empresas”. En http://www.industria.gov.ar/cep/pancomexterior/estudios/2005/expo\%20pymes.pdf

CEP. 2005b. "Performance exportadora reciente de las pequeñas y medianas empresas", en Realidad Económica, n² 214, IADE. Buenos Aires.

CEP. 2008. "La industria Argentina: Balance 2003-2007. Los nuevos sectores dinámicos.”. En http://www.cep.gov.ar/industrial/2008/s57_indarg_2003_2007.pdf

Chomsky, Noam. 2007. "La imposición de libre mercado como misión imperial: de Reagan a Bush” [CLASE], en Curso virtual La Economía mundial y el imperialismo. Programa Latinoamericano de Educación a Distancia, Centro Cultural de la Cooperación, septiembre. Buenos Aires.

Ciani, Rubén. 2005. "Perspectivas regionales del mercado de soja. Situación en Argentina”, I Foro Regional de la Agroindustria, SAGPyA. Argentina. 
Cibils, Alan. 2006. “La política monetaria 2003-2006”, Serie Análisis de Coyuntura, nº 11, CIEPP. Argentina.

Cobe, Lorena. 2009. La salida de la convertibilidad. Los bancos y la pesificación. Colección Claves Para Todos (Nun coord.). Capital Intelectual. Buenos Aires.

Cooke, John William. 2010 [1971]. Peronismo y revolución. El peronismo y el golpe de estado informe a las bases. Biblioteca Popular. Buenos Aires.

Cortés, Rosalía y Adriana Marshall. 1999. “Estrategia económica, instituciones y negociación política en la reforma social de los '90”, en Desarrollo Económico, n 154. Buenos Aires.

Costa, Augusto, Axel Kicillof y Cecilia Nahón. 2004. "Las consecuencias económicas del Sr. Lavagna. Dilemas de un país devaluado”, en Realidad Económica, n 214, IADE. Buenos Aires.

Cotarelo, María Celia y Nicolás Iñigo Carrera. 2004. "Algunos rasgos de la rebelión en Argentina 1993-2001". PIMSA, Documentos y Comunicaciones. Buenos Aires.

Cremonte, Juan Pablo. 2007. “El estilo de actuación política de Néstor Kirchner”. En E. Rinesi, G. Nardacchione y G. Vommaro (eds.) Los lentes de Víctor Hugo. Transformaciones políticas y desafíos teóricos en la Argentina reciente. Prometeo Libros, Universidad de General Sarmiento. Buenos Aires.

Damill, Mario, Roberto Frenkel y Martín Rapetti. 2005. “La deuda argentina: historia, default y reestructuración” en CEDES, n²16, Buenos Aires.

De Jong, Gerardo. 1981. “El análisis regional: consideraciones metodológicas”, Boletín Geográfico, n8, Dpto. de Geografía, Universidad Nacional del Comahue.

De Jong, Gerardo. 1995. “Cambios estructurales en la fruticultura del Alto Valle. Un marco de referencia necesario”. En Realidad Económica n 136, IADE. Buenos Aires.

Diamand, Marcelo. 1972. "La estructura productiva desequilibrada argentina y el tipo de cambio”, en Desarrollo Económico, Vol. 12, n45. Buenos Aires. 
Diamand, Marcelo. 1973. Doctrinas Económicas, Desarrollo e Independencia. Paidós. Buenos Aires.

Díaz Ronner, Lucila. 2003. «La incorporación de nuevas tecnologías: el caso de la soja». En Documentos del CIEA, n²1. CIEA/IIHES/Fac. Cs. Econ./UBA. Buenos Aires.

Dussel, Enrique. 1985. La producción teórica de Marx. Un comentario a los GRUNDRISSE. Siglo XXI Editores. México.

Elias, Norbert. 1988 [1939]. “Sociogénesis de la oposición entre 'cultura' y civilización' en Alemania” en El proceso de la civilización. Investigaciones sociogenéticas y psicogenéticas. Fondo de Cultura Económica. México.

Engels, Friedrich. 2003 [1878]. La revolución de la ciencia de Eugenio Dühring ("AntiDühring"). Instituto del Marxismo-Leninismo \& Editorial Progreso, Moscú. Digitalizado en 2003 por Ediciones Bandera Roja, Marxists Internet Archive.

Esquenazi, Matías. 2009. "El espectro de la dolarización. Discutiendo las interpretaciones sobre la disputa interburguesa en el origen de la crisis de la convertibilidad”, en Alberto Bonnet y Adrián Piva, ed., Argentina en pedazos. Luchas sociales y conflictos interburgueses en la crisis de la convertibilidad, Peña Lillo. Buenos Aires.

Esteves, Ricardo. 2008. “Hegemonía K. Discurso y hegemonía en Argentina 20032005” en línea: http://rickyesteves.wordpress.com/2008/07/01/hegemonia-k-discurso-yhegemonia-en-argentina-2003-2005/

Etchemendy, Sebastián. 2001. “Construir coaliciones reformistas: la política de las compensaciones en el camino hacia la liberalización económica”, en Desarrollo Económico nº 160, Buenos Aires.

Fal, Juan, Pinazo, Germán y Lizuaín, Juan. 2009. “Notas sobre la post-convertibilidad: los límites a la mejora en las condiciones de vida de los sectores populares”, en Periferias, Revista de Ciencias Sociales n¹8. Ediciones FISyP. Buenos Aires.

Fanelli, José María. 2002. “Crecimiento, inestabilidad y crisis de la convertibilidad en Argentina”, en Revista de la CEPAL, $\mathrm{n}^{\circ}$ 77. Santiago de Chile. 
Féliz, Mariano y Pablo Pérez. 2004. “Conflicto de clase, salarios y productividad. Una mirada de largo plazo para la Argentina” en Robert Boyer, Julio César Neffa (coords.), La economía Argentina y su crisis (1976-2001): visiones institucionalistas y regulacionistas, CEIL-PIETTE CONICET, Miño y Dávila Editores. Buenos Aires.

Féliz, Mariano y Pablo Pérez. 2007. “¿Tiempos de cambio? Contradicciones y conflictos en la política económica de la posconvertibilidad”, en Boyer, Robert y Julio Neffa (comp.), Salidas de crisis y estrategias alternativas de desarrollo. La experiencia argentina, Institut CDC pour la Recherche, CEIL-PIETTE/CONICET, Miño y Dávila Editores. Buenos Aires.

FISyP. 2009. “Informe de coyuntura. Primer trimestre 2009”, Fundación de Investigaciones Sociales y Políticas, Buenos Aires, en http://www.fisyp.org.ar/WEBFISYP/INFCOY.doc.

Frenkel, Roberto y Rapetti, Martín. 2007. “Política Cambiaria y Monetaria después del Colapso de la Convertibilidad”, en Ensayos Económicos, n46, BCRA. Argentina.

Gálvez, Eduardo. 2011. “La construcción de una nueva hegemonía en Argentina durante la crisis de 2001-2002”. En Nuevo Mundo Mundos Nuevos, Cuestiones del tiempo presente. En línea: http://nuevomundo.revues.org/62157.

Gambina, Julio y colaboradores. 2006. “La política económica del gobierno argentino (2003/2006)”, en http://www.fisyp.org.ar/WEBFISYP/GTTNI.doc.

Gambina, Julio y Daniel Campione. 2003. Los años de Menem. Cirugía mayor. Centro Cultural de la Cooperación. Buenos Aires.

Gambina, Julio, Antonio Lizuaín y Sergio Papi. 2009. “Consideraciones sobre la cuestión minera en Argentina”, en Fundación de Investigaciones Sociales y Políticas. En http://www.fisyp.org.ar/modules/news/article.php?storyid=378.

Garay Reyna, Zenaida M. 2007. "Interpretaciones sobre la cultura política del peronismo en Argentina”, en Papeles Políticos, Vol. 12, N² 2, pp. 347-367. Bogotá.

Garbers, Ricardo. 2007. «El Contratista Rural Bonaerense. Perfil y Evolución». FACMA. 
http://www.facma.com.ar/Biblioteca\%20Articulos/A\%20El\%20Contratista\%20Rural\% 20Bonaerense\%20Garbers\%20R.pdf

García, Alfredo. 1998. “Cómo leer la Balanza de Pagos”, en Realidad Económica, n¹55, IADE. Buenos Aires.

García, Marcelo. 2004. “”Estilo K”: un gobierno a la medida de las petroleras”, en http://www.socialismo-o-barbarie.org/argentinazo/040418_marcelo_garcia_ ungobalamedidadelaspetroleras_parte1.htm

Giarracca, Norma, Miguel Teubal y Tomás Palmisano. 2008. "Paro agrario: crónica de un conflicto alargado”, en Realidad Económica n²37, $1^{\circ}$ de julio/15 de agosto. Buenos Aires.

Giuliano, Héctor. 2006. Problemática de la Deuda Pública Argentina. I- La Deuda bajo la Administración Kirchner. Grupo editor del encuentro. Buenos Aires.

Godio, Julio y Alberto J. Robles. 2008. El tiempo de CFK. Entre la movilización y la institucionalidad. El desafío de organizar los mercados. Corregidor. Buenos Aires.

Godio, Julio. 2006. El tiempo de Kirchner. El devenir de una revolución "desde arriba”. Ediciones Letra Grifa. Buenos Aires.

Golla, Jorge. 2006. “Dimensión de los Conglomerados Financieros: el Caso Argentino”, en Documento de Trabajo $\mathrm{n}^{\circ} 10$ del CEFIDAR. Buenos Aires.

Gómez, Pedro A. 2001. “Imaginarios sociales y análisis semiótico. Una aproximación a la construcción narrativa de la realidad”, en Cuadernos, febrero, nº17, pp. 195-209. Universidad de Jujuy, Facultad de Humanidades y Ciencias Regionales, Secretaría de Ciencia y Técnica y Estudios Regionales. San Salvador de Jujuy.

Gramsci, Antonio. 2003. Notas sobre Maquiavelo, sobre la política y sobre el Estado moderno. Nueva Visión. Buenos Aires.

Gramsci, Antonio. 2004. Los intelectuales y la organización de la cultura. Nueva Visión. Buenos Aires 
Gramsci, Antonio. 2008. El materialismo histórico y la filosofía de Benedetto Croce. Nueva Visión. Buenos Aires.

Graña, Juan M. y Damian Kennedy. 2007. “Salarios y productividad: especificidades de tamaño en la distribución del excedente”, I I Jornadas de Economía Política, 6 y 7 de diciembre. Los Polvorines.

Gras, Carla y Valeria Hernández. 2009. ““‘Son los piquetes de la abundancia” Actores y Estado en el conflicto agrario en Argentina”. Ponencia preparada para presentar en el Congreso 2009 de la Asociación de Estudios Latinoamericanos 11 al 14 de Junio. Rio de Janeiro, Brasil.

Grupo de Trabajo sobre Economía Mundial. 2009. "Declaración sobre la crisis mundial”, CLACSO, en http://www.eleconomista.cubaweb.cu/2009/nro365/clacso.html.

Guerrero Iraola, Jerónimo. 2011. “Apuntes sobre hegemonía. Disquisiciones acerca de la construcción de sentido del “kirchnerismo””, en Question, UNLP. La Plata.

Gutiérrez Rohán, Daniel. 2007. "Reflexiones sobre la construcción del objeto de estudio”, Cuaderno de trabajo, $\mathrm{n}^{\circ}$ 11, proyecto PAPIME: Innovación de métodos, estrategias y materiales didácticos para la enseñanza de la metodología para la investigación en ciencias sociales, responsable: Carlos Gallegos Elías, UNAM. México.

Heredia, Mariana. 2011. "La hechura de la política económica. Los economistas, la Convertibilidad y el modelo neoliberal”, en Pucciarelli, A. (coord.) Los años de Menem. La construcción del orden neoliberal. Siglo XXI. Buenos Aires.

Hora, Roy. 2010. “La crisis del campo del otoño de 2008”, en Desarrollo Económico vol. 50, n¹97, abril-junio. Buenos Aires.

Horkheimer, Max. 2000 [1937]. Teoría tradicional y teoría crítica. Colección Pensamiento contemporáneo. I.C.E. de la Universidad autónoma de Barcelona. Ediciones Paidós. Barcelona.

Ibáñez, Ileana y Ximena Cabral. 2008. “Entre apuntadores y guionistas: el papel de los medios en el conflicto campo/gobierno”, Boletín Onteaiken n 5, octubre. Córdoba. 
Ingaramo, Jorge. 2004. «La renta de las tierras pampeanas», Bolsa de Cereales de Buenos Aires. Argentina.

Ingaramo, Jorge. 2006. «Presión Impositiva sobre la Producción Agrícola Pampeana». Bolsa de Cereales de Buenos Aires. Argentina.

James, Daniel. 2006. Resistencia e integración. El peronismo y la clase trabajadora argentina, 1946-1976. Siglo Veintiuno Editores. Buenos Aires.

Jessop, Bob. 1982. “The capitalist State”, Oxford, Martin Robertson, cap. 1 traducido por Roy Hora y María Celia Labandeira, en Horacio Tarcus (comp.) Marx y Estado (II). Cuadernos de la Cátedra de Teoría Política, FAHCE-UNLP. La Plata.

Joensen, Lilian y Semino, Stella. 2004. «Argentina: estudio de caso sobre el impacto de la soja $R$ l» Grupo de Reflexión Rural. http://www.grain.org/research_files/Argentina\%20RRsoya\%20case\%20study.pdf

Katz, Claudio. 2005. “¿Quién gana con el canje?”, en Economistas de Izquierda nº 1. Buenos Aires.

Katz, Claudio. 2005b. “La deuda después del default”, en Periferias Revista de Ciencias Sociales, $\mathrm{n}^{0} 12$. FISyP Ediciones. Buenos Aires.

Katz, Claudio. 2008. "El agro-capitalismo de la soja”, en http://lahaine.org/katz/b2img/EL_AGRO-CAPITALISMO_DE_LA_SOJA.doc.

Kohan, Néstor. 2003. El Capital. Historia y método -Una introducción-. Universidad de Madres de Plaza de Mayo. Argentina.

Kohan, Néstor. 2006. “La gobernabilidad del capitalismo periférico y los desafíos de la izquierda revolucionaria. Crisis orgánica y revolución pasiva: el enemigo toma la iniciativa”. En Rebelión. En línea: http://www.rebelion.org/noticias/2006/10/40194.pdf

Kulfas, Matías. 2009. "Las pymes argentinas en el escenario post convertibilidad. Políticas públicas, situación y perspectivas”, CEPAL, Naciones Unidas. Santiago de Chile. 
Kulfas, Matías. 2011. Las PyMEs y el desarrollo. Desempeño presente y desafíos futuros. Colección Clave para Todos, Capital Intelectual. Buenos Aires.

Laclau, Ernesto y Mouffe, Chantal. 2004 [1987]. Hegemonía y estrategia socialista. FCE. Buenos Aires.

Laclau, Ernesto. 1978. “Hacia una teoría del populismo”, en E. Laclau, Política e ideología en la teoría marxista. Capitalismo, fascismo, populismo. Siglo Veintiuno. Madrid.

Laclau, Ernesto. 1990. Nuevas Reflexiones sobre la revolución de nuestro tiempo. Nueva Visión. Buenos Aires.

Laclau, Ernesto. 2005. La razón populista. FCE. Buenos Aires.

Laclau, Ernesto. 2006. “Ideología y posmarxismo”, en Filosofía política del currículum Anales de la educación común, Tercer siglo, año 2, número 4, agosto. Publicación de la Dirección General de Cultura y Educación de la Provincia de Buenos Aires, Pp. 20-35. Argentina.

Lakatos, Imre. 1978. La metodología de los Programas de Investigación. Editorial Alianza. Madrid.

Lattuada, Mario. 2003. “Transformaciones institucionales en las corporaciones empresarias agrarias de fines de siglo XX. El caso de Federación Agraria Argentina” en Bendini, M., Cavalcanti, S., Murmis, M. y Tsakoumagkos, P. (comps) El campo en la sociología actual: una perspectiva latinoamericana. Actores, lazos sociales y reestructuraciones. GESA, Editorial La Colmena. Buenos Aires.

Lenin, Vladimir Ilich. 1980 [1915]. En torno a la cuestión de la dialéctica. Colección V.I. Lenin, Marx Engels Marxismo. Ediciones en lenguas extranjeras. Pekin.

Llach, J, Harriague, M. y O’Connor, E. 2004. “La Generación de Empleo en las Cadenas Agroindustriales”. Fundación Producir Conservando. Buenos Aires.

Llovera, Guillermo. 2006. “Competitividad del acopio”. Foros MERCOSOJA, ACSOJA. Argentina. 
Lo Vuolo, Rubén y Fernando Seppi. 2008. “La falacia del desendeudamiento del sector público en la Argentina. Evolución de la deuda post-default y sus impactos fiscales”, en Documento de Trabajo, n60, Ciepp. Buenos Aires.

Lowy, Michael. 2001. "La significación metodológica de "socialismo o barbarie””, en Socialismo o Barbarie, año 2, n6. Buenos Aires.

Lozano, Claudio, Rameri, Ana y Tomás Raffo. 2006. “El debate de la distribución”. IEF-CTA. En http://www.institutocta.org.ar

Lozano, Claudio, Rameri, Ana y Tomás Raffo. 2007. “Análisis y propuesta frente al presupuesto 2007”. IEF-CTA. En http://www.institutocta.org.ar/spip.php?article263.

Lozano, Claudio, Rameri, Ana y Tomás Raffo. 2007b. “La cúpula empresaria argentina luego de la crisis: los cambios en el recorrido 1997-2005”, IEFCTA, Buenos Aires.

Lozano, Claudio, Roberto Larrosa, Rameri, Ana y Tomás Raffo. 2006. “Crecimiento y distribución del ingreso”, publicado el 03/05/2006 en http://www.Argenpress.com.ar.

Lozano, Claudio. 2008. “Una mirada sobre la coyuntura económico y social”, IEFCTA. En http://www.aterosario.org.ar/IMG/article_PDF/article_252.pdf.

Lucita, Eduardo. 2005. "El regreso a la "normalidad"”. En http://www.rebelion.org/noticia.php?id=14936.

Lucita, Eduardo. 2005b. “Nueva reestructuración de la deuda”, publicado el 28/5/2005, en http://www.ARGENPRESS.info.

Lukács, Georg, 1969 [1923]. “¿Qué es marxismo ortodoxo?” en Historia y conciencia de clase. Grijalbo. México.

Lukács, Georgy. 1973 [1920]. “Vieja y nueva Kultur” en Revolución socialista y antiparlamentarismo. Cuadernos de Pasado y Presente, n 41. Córdoba.

Mackinnon, María M. y Mario A. Petrone (comps.). 1999. Populismo y neopopulismo en América Latina: el problema de la Cenicienta. Eudeba. Buenos Aires.

Malamud, Andrés y De Luca, Miguel (coord.). 2011. La política en tiempos de los Kirchner. Eudeba. Buenos Aires. 
Mansilla, Diego. 2008. "Empresas de servicios públicos: argentinización, integración, provincialización”, en el Instituto Argentino para el Desarrollo Económico, IADE, http://www.iade.org.ar/modules/noticias/article.php?storyid=2618

Maquiavelo. 1995 [1513]. El Príncipe. Notas y comentarios de Napoleón Bonaparte. Ediciones O\&C. Barcelona.

Marcuse, Herbert, 1967 [1937]. “Acerca del carácter afirmativo de la cultura”, en Cultura y Sociedad. Sur. Buenos Aires.

Marcuse, Herbert. 1972 [1965]. "Notas para una nueva definición de la cultura”, en Ensayos sobre política y cultura. Ariel. Barcelona.

Marticorena, Clara. 2010. "Relaciones de laborales y condiciones de trabajo en la industria manufacturera (2003-2009)”, en VI Jornadas de Sociología de la UNLP "Debates y perspectivas sobre Argentina y América Latina en el marco del Bicentenario. Reflexiones desde las Ciencias Sociales”, 9 y 10 de diciembre. La Plata.

Marx, Karl y Friedrich Engels. 1960 [1948]. El Manifiesto Comunista. Colección MarxEngels-Lenin-Stalin. Ediciones Sociales. La Habana.

Marx, Karl y Friedrich Engels. 1985 [1846]. La Ideología Alemana. Ediciones Pueblos Unidos y Editorial Cartago. Buenos Aires.

Marx, Karl. 1845. Tesis sobre Feuerbach. En línea en Marxist.org, http://www.marxists.org/espanol/m-e/1840s/45-feuer.htm\#topp

Marx, Karl. 1859. Prólogo a la Contribución a la Crítica de la Economía Política. En línea en Marxist.org, http://www.marxists.org/espanol/m-e/1850s/criteconpol.htmç

Marx, Karl. 1865. Salario, precio y ganancia. En línea en Marxist.org, http://www.marxists.org/espanol/m-e/1860s/65-salar.htm

Marx, Karl. 1973 [1867]. El capital, Crítica de la economía política. Editorial Ciencias del Hombre. Buenos Aires.

Marx, Karl. 2000 [1852]. El dieciocho Brumario de Luis Bonaparte. Siglo Veintidós editora. Buenos Aires. 
Marx, Karl. 2002 [1868]. El Capital, Tomo I. Biblioteca de pensamiento socialista. Siglo XXI. Buenos Aires.

Marx, Karl. 2002b [1857-61]. Economic Works of Karl Marx 1857-61. Grundrisse der Kritik der Politischen Ökonomie. Outlines of the Critique of Political Economy. En Marxist.org: http://www.marxists.org/archive/marx/works/1857/grundrisse/

Marx, Karl. 2006 [1894]. El Capital. Tomo III, Libro Tercero, Siglo XXI, México.

Marx, Karl. 2007 [1885]. El Capital, Tomo II Biblioteca de pensamiento socialista. Siglo XXI. México D.F.

Matus, Carlos. 2007. “Los tres cinturones del gobierno”. Ediciones Universidad de la Matanza, CiGob, Fundación Altadir. Buenos Aires.

Mengo, Renee y Hugo Pizarro. 2010. "El discurso oficial en el conflicto entre el gobierno y el campo argentino”, en Educación y Humanidades vol.1, n 1, pp 88-120. Universidad de La Frontera. Temuco. Chile.

Mira, Pablo y Esteban Kiper. 2009. “Políticas de Ingresos desde 2003”, en Nota Técnica, $\mathrm{n}^{\circ} 19$, Empleo e Ingresos, Ministerio de Economía y Finanzas Públicas. Argentina.

Moreira, Carlos y Sebastián Barbosa. 2010. "El kirchnerismo en Argentina: origen, apogeo y crisis, su construcción de poder y su forma de gobernar”, en Sociedade e cultura, vol. 13, n², julio-diciembre. Universidade Federal de Goiás. Goianaia. Brasil.

Mouffe, Chantal. 2007. En torno a lo político. FCE. Buenos Aires.

Muñoz, María Antonia y Retamozo, Martín. 2008. “Hegemonía y Discurso en la Argentina contemporánea. Efectos políticos de los usos de 'pueblo' en la retórica de Néstor Kirchner”, en Revista Perfiles Latinoamericanos, № 31, pp. 121-149. México.

Murillo, Victoria. 1997. "La adaptación del sindicalismo argentino a las reformas de mercado en la primera presidencia de Menem”, en Desarrollo Económico, vol. 37, n 147, Octubre-Diciembre pp. 419-446. Buenos Aires. 
Novaro, Marcos. 1997. “El liberalismo política y la cultura política popular”, en Nueva Sociedad, No 149, Mayo-Junio 1997, pp. 114-129. Buenos Aires.

Novaro, Marcos. 2004. "Problemas de gobernabilidad en la última crisis argentina: entre la hegemonía y la fragmentación”, en Revista internacional de filosofía política, № 23, pp. 160-186. UNED-UAM. Madrid y México.

Nun, José. 1987. "Vaivenes de un régimen social de acumulación en decadencia”, en J. Nun y J.C. Portantiero, comps., Ensayos sobre la transición democrática en la Argentina, 83-116. Puntosur. Buenos Aires.

O’Donnell, Guillermo. 1977. “Estado y alianzas en la política argentina 1956-1976” en Desarrollo Económico, n64. Buenos Aires.

O'Donnell, Guillermo. 1978. “Apuntes para una teoría del Estado”, en Revista Mexicana de Sociología, Vol. 40, No. 4, Estado y Clases Sociales en América Latina (2) (Oct. Dic.), pp. 1157-1199. México D. F.

O’Donnell, Guillermo. 1978b. “Notas para el estudio de la burguesía local, con especial referencia a sus vinculaciones con el capital transnacional y el aparato estatal”, en Estudios Sociales $n^{\circ} 12$. Buenos Aires.

O’Donnell, Guillermo. 1982. El Estado burocrático-autoritario. Editorial de Belgrano. Buenos Aires.

Olin Wright, Erik. 1994. "Class and Politics", en Interrogating Inequality. Verso. Londres.

Ortiz, Ricardo y Martín Schorr. 2006. “Crisis del Estado y pujas interburguesas. La política de la hiperinflación”, en Pucciarelli A. coord. Los años de Alfonsín ¿El poder de la democracia o la democracia del poder? Siglo XXI. Buenos Aires.

Ortiz, Ricardo y Martín Schorr. 2006b. “La economía política del gobierno de Alfonsín: creciente subordinación al poder económico durante la 'década perdida'”, en Pucciarelli, Alfredo (coord.), Los años de Alfonsín. ¿El poder de la democracia o la democracia del poder? Siglo XXI. Buenos Aires. 
Ortiz, Ricardo y Martín Schorr. 2007. "La rearticulación del bloque de poder en la Argentina de la post-convertibilidad”, en Papeles de trabajo, Revista electrónica del Instituto de Altos Estudios Sociales de la Universidad Nacional de General San Martín. Año 1, no 2. Buenos Aires.

Palma, Alejandra G. 2011. "Las oposiciones léxicas en el discurso de Alfredo De Angeli: análisis de las funciones estratégicas y la construcción de destinatarios durante el conflicto agrario argentino del año 2008”. Ponencia presentada al V Coloquio de Investigadores en Estudios del Discurso, II Jornadas Internacionales de Discurso e Interdisciplina, 24, 25 y 26 de agosto. Universidad Nacional de Villa María. Argentina.

Peña, Milcíades. 2000 [1958]. Introducción al pensamiento de Marx (notas inéditas de un curso de 1958). Obras completas de Milcíades Peña I. Ediciones El cielo por asalto. Buenos Aires.

Pereyra, Carlos. 1977. “Los conceptos de inversión y sobredeterminación en Althusser”, en Revista Dialéctica, Año II, 3, pp. 55-68. México.

Pérez, Pablo Ernesto, Féliz, Mariano y Toledo, Fernando. 2006. “¿Asegurar el empleo o los ingresos? Una discusión para el caso argentino de las propuestas de ingreso ciudadano y empleador de última instancia”, en Macroeconomía, grupos vulnerables y mercado de trabajo. Desafíos para el diseño de políticas públicas, Asociación Trabajo y Sociedad / CEIL-PIETTE, pp. 289-318. Buenos Aires.

Piotte, Jean Marc. 1973. El pensamiento político de Antonio Gramsci. Cuadernos de Cultura Revolucionaria. Buenos Aires.

Piva, Adrián. 2007. "Modo de acumulación y hegemonía en Argentina” en ¿Coyuntura favorable o nuevo modelo?: Economía argentina. Anuario EDI $\mathrm{n}^{\circ} 3$. Ediciones Luxemburg. Buenos Aires.

Portantiero, Juan C. 1977. “Economía y política en la crisis argentina”, en Revista Mexicana de Sociología n². México D.F.

Portelli, Hugues. 1987. Gramsci y el bloque histórico. Editorial Siglo XXI. México. 
Poulantzas, Nicos. 1981 [1976]. Las clases sociales en el capitalismo actual. Siglo XXI Editores. México D.F.

Poulantzas, Nicos. 1985 [1973]. “Las clases sociales” en Zenteno Benítez, R. (coord.) Las clases sociales en América Latina, México, Instituto de Investigaciones Económicas, UNAM y Siglo XXI. México D.F.

Poulantzas, Nicos. 2001 [1968]. Poder político y clases sociales en el Estado capitalista. Siglo XXI. Buenos Aires.

Pucciarelli, Alfredo. 2004a. "La última dictadura militar y el origen del liberalismo corporativo argentino". Ansaldi, Waldo, coord, Calidoscopio latinoamericano. Imágenes históricas para un debate vigente. Ariel. Buenos Aires.

Pucciarelli, Alfredo. 2004b. “Introducción” en Pucciarelli (coord.) Empresarios, tecnócratas y militares. La trama corporativa de la última dictadura. Siglo XXI Editores. Buenos Aires.

Pulleiro, Adrián, Gambina, Alejandro, Allievi, Carolina, Ronconi, Micaela y Rodolfo Gómez. 2011. “La reconfiguración de la hegemonía cultural: significaciones en disputa en la esfera pública, los medios masivos de comunicación y el campo intelectual (20012007)”, en Gambina, J., Rajland, B. y Campione, D. (comps.) Hegemonía y proceso de acumulación capitalista en Latinoamérica hoy (2001-2007). El caso argentino. FISyP Ediciones y Rosa Luxemburg Stiftung. Buenos Aires.

Rajland, Beatriz. 2008. El pacto populista en la Argentina (1945-1955). Proyección teórico-política hacia la actualidad. Ediciones del CCC, Centro Cultural de la Cooperación Floreal Gorini. Buenos Aires.

Rapetti, Martín. 2005. “La Macroeconomía Argentina durante la Post-convertibilidad: evolución debates y perspectivas”, en Policy Papers n5, Observatorio Argentina, New School University. EEUU.

Rapoport, Mario. 2006. “La economía en la crisis de 2001. Causas y consecuencias”, en Cuadernos Argentina Reciente, ${ }^{\circ}$ 3. Buenos Aires. 
Reboratti, Carlos. 2003. "Desarrollo regional y territorios privatizados” en Acuña C. y Riella A., Territorio, sociedad y región. Perspectivas desde el Desarrollo Regional y Local. Rosgal. Montevideo.

Retamozo Benítez, Martín. 2009. "Lo político y la política: los sujetos políticos, conformación y disputa por el orden social”. Revista Mexicana de Ciencias Políticas y Sociales, vol. LI, núm. 206, mayo-agosto, pp. 69-9. Universidad Nacional Autónoma de México. México D. F.

Retamozo, Martín. 2011. "Movimientos sociales, política y hegemonía en Argentina”, en Polis, Revista de la Universidad Bolivariana, vol. 10, nº 28 pp243-279. Venezuela.

Rinesi, Eduardo y Vommaro, Gabriel. 2007. "Notas sobre la democracia, la representación y algunos problemas conexos”, en E. Rinesi, G. Nardacchione y G. Vommaro (eds.) Los lentes de Víctor Hugo. Transformaciones políticas y desafíos teóricos en la Argentina reciente. Prometeo Libros, Universidad de General Sarmiento. Buenos Aires.

Rodríguez, Javier y Nicolás Arceo. 2006. "Renta agraria y ganancias extraordinarias en Argentina, 1990-2003”, en Documentos de Trabajo, n4, CENDA. Buenos Aires.

Rodríguez, Javier. 2005. “Los complejos agroalimentarios y el empleo: una controversia teórica y empírica”, en Tendencias de la economía actual, Documento de Trabajo n³, CENDA, Buenos Aires.

Rofman, Alejandro. 1984. "Subsistemas espaciales y circuitos de acumulación regional”, en Revista interamericana de planificación, Vol. XVIII, n 70 . Buenos Aires.

Rofman, Alejandro. 1999. Las economías regionales a fines del siglo XX. Los circuitos de petróleo, el carbón y el azúcar. Ariel. Buenos Aires.

Rudnik, Isaac. 2012. "Por la reconstrucción de un discurso nacional y popular”. En González, H. y Rudnik, I. ¿Cómo juzgar al kirchnerismo? Dos miradas contrapuestas sobre la Argentina de la última década. ISEPCi, Nuestra América. Buenos Aires.

Rush, Alan. 2002. "Marxismo y posmarxismo. Polémica Laclau-Mouffe versus Geras. Primeras hipótesis y especulaciones”, en Herramienta. Debate y crítica marxista, $\mathrm{n}^{\circ} 18$, 
versión online: http://www.herramienta.com.ar/revista-herramienta-n-18/marxismo-yposmarxismo-polemica-laclau-mouffe-versus-geras-primeras-hipote-0

Rzezak, Hernán F. 2008. "El conflicto entre el gobierno y el campo en argentina. Lineamientos políticos, estrategias discursivas y discusiones teóricas a partir de un abordaje multidisciplinar", en Iberoforum Revista electrónica del Departamento de Ciencias Sociales y Políticas, añoo III, $n^{\circ}$ 6, julio-diciembre, pp. 82-106. Universidad Iberoamericana A.C. Ciudad de México.

Sacroisky, Ariana. 2006. "La Inversión Extranjera Directa en la post-Convertibilidad", en Documento de Trabajo, nº2, CEFIDAR. Buenos Aires.

Sánchez, Joan-Eugeni. 1991. Espacio, economía y sociedad. Siglo XXI de España Editores. Madrid.

Santarcángelo, Juan y Germán Pinazo. 2009. “La reindustrialización en la posconvetibilidad: una mirada desde el sector automotriz”, en Realidad Económica, n²47, IADE. Buenos Aires.

Sarlo, Beatriz. 2011. "Hegemonía cultural del kirchnerismo” en Diario La Nación, 4/3/11. Buenos Aires.

Schmitt, Carl. 1998 [1932]. El concepto de lo político. Alianza. Madrid.

Schorr, Martín y Andrés Wainer. 2005. “Argentina: muerte y resurrección? Notas sobre la relación entre economía y política en la transición del 'modelo de los noventa' al del 'dólar alto'” en Realidad Económica, n² 211, IADE. Buenos Aires.

Schorr, Martín. 2005. Modelo nacional industrial. Límites y posibilidades. Colección Claves para Todos. Capital intelectual. Buenos Aires.

Schvarzer, Jorge. 1996. "La política económica como política de poder”. En Quiroga, Hugo y César Tcach, ed., A veinte años del golpe. Con memoria democrática. Homo Sapiens Ediciones. Buenos Aires.

Schvarzer, José y Andrés Tavosnanska. 2007. “El complejo sojero argentino. Evolución y perspectivas”, en Documento de Trabajo $\mathrm{N}^{\circ} 10$. CESP, UBA, Buenos Aires. 
Seoane, José A. 2002. “Argentina: la configuración de las disputas sociales ante la crisis” en OSAL, Observatorio Social de América Latina, n 7. CLACSO. Buenos Aires.

Sevares, Julio. 2010. “Argentina: Los bancos te dan sorpresas”, en Olafinanciera, $\mathrm{n}^{\circ}$ 7, septiembre-diciembre, UNAM. México.

Sigal, Silvia y Eliseo Verón. 2004. Perón o muerte. Los fundamentos discursivos del fenómeno peronista. Eudeba. Buenos Aires.

Sirinelli, Jean-Francois. 1993. “El retorno de lo político”, en Historia Contemporánea 9 pp 25-35. Universidad del País Vasco. Bilbao.

Slipak, Daniela. 2006. “Más allá y más acá de las fronteras políticas: apuestas de reconstrucción del vínculo representativo en el discurso kirchnerista”. En línea: http://www.iigg.fsoc.uba.ar/Jovenes_investigadores/3JornadasJovenes/Templates/Eje\% 20representaciones/Slipak\%20Discursos.pdf>.

Svampa, Maristella y Sebastián Pereyra. 2004. Entre la ruta y el barrio. La experiencia de las organizaciones piqueteras. Segunda edición corregida y actualizada. Biblos. Buenos Aires.

Svampa, Maristella. 2006. “Las fronteras del gobierno de Kirchner”, en Crisis, $\mathrm{n}^{\circ} 0$. Buenos Aires.

Svampa, Maristella. 2010. “Movimientos Sociales, matrices socio-políticos y nuevos escenarios en América Latina” en Working Papers $\mathrm{n}^{0} 1$. OneWorld perspective. Universität Kassel. Alemania.

Tavosnanska, Andrés y Germán Herrera. 2009. “La industria argentina a comienzos del siglo XXI. Aportes para una revisión de la experiencia reciente.” En Müller, Alberto (coord.) Industria, desarrollo, historia. Ensayos en homenaje a Jorge Schvarzer. Facultad de Ciencias Económicas, UBA. Buenos Aires.

Teubal, Miguel y Tomás Palmisano. 2010. "El conflicto agrario en la Argentina (2008/2010): sojización vs. agricultura familiar de alimentos”. Ponencia presentada al VIII Congreso Latinoamericano de Sociología Rural. Porto de Galinhas, Brasil. 
Thwaites Rey, Mabel. 2003. "Presión de las compañías privatizadas. El fantasma de los juicios internacionales contra Argentina”, en Le Monde Diplomatique, Año V, n 49. Buenos Aires.

Tilly, Charles. 2000. “Acción colectiva”, en Apuntes de investigación, n 6, pp. 9-32. Buenos Aires.

Tolón, Gaspar. 2005. "El crecimiento del complejo agroalimentario”, en Datos \& Opinión de la coyuntura cooperativa, $\mathrm{n}^{\circ}$ 58, Instituto Movilizador de Fondos Cooperativos. Buenos Aires.

Torrado, Susana. 1992. Estructura social de la Argentina: 1945-1983. Ediciones de la flor. Buenos Aires.

Tse-tung, Mao. 1968 [1937]. Sobre la contradicción. Obras escogidas de Mao Tse-tung. Ediciones en lenguas extranjeras. Pekin.

Varesi, Gastón y Pinazo, Germán. 2011. “Acumulación, políticas y clases sociales en la Argentina post-convertibilidad”, en Gambina, Rajland y Campione (comps) Hegemonía y proceso de acumulación capitalista en Latinoamérica hoy (2001-2007). El caso argentino. FISyP (Fundación de Investigaciones Sociales y Políticas) y RLS (Rosa Luxemburg Stiftung, Alemania). Buenos Aires.

Varesi, Gastón. 2008. “La Argentina neoliberal. Acciones estatales y clase dominante: del modelo de la Convertibilidad al modelo Productivo-exportador" en Tortti C. comp. Trabajos finales licenciatura en sociología: 1985-2007. UNLP.

Varesi, Gastón. 2008b. “La actualidad de deuda argentina. Resolución del default, actores y políticas en el modelo post-convertibilidad, 2002-2007”, en Periferias Revista de Ciencias Sociales, n¹6. Ediciones FISyP. Buenos Aires.

Varesi, Gastón. 2009a. “Inflación, transferencias y distribución del ingreso en la Argentina post-convertibilidad. ¿Cómo se gestan y a quiénes benefician?”, en Sociohistórica, Cuadernos del CISH, n²6. Centro de Investigaciones Socio Históricas, UNLP. Edulp. La Plata. 
Varesi, Gastón. 2009b. “Empresas privatizadas y acciones estatales en el modelo postconvertibilidad, 2002-2007”. Ponencia presentada al XXVII Congreso ALAS, del 31 de agosto al 4 de septiembre. Buenos Aires.

Varesi, Gastón. 2009c. "La configuración del modelo post-convertibilidad: políticas y clases. Algunas claves para su caracterización, 2002-2007”, en Cuestiones de Sociología. Revista de estudios sociales, nº 5/6. FAHCE-UNLP. La Plata.

Varesi, Gastón. 2010a. “Inflación en la Argentina post-convertibilidad. Algunas claves para su explicación”, en Olafinanciera, n5, enero-abril 2010, Facultad de Economía e Instituto de Investigaciones Económicas, UNAM. México.

Varesi, Gastón. 2010b. "El circuito productivo sojero argentino en el modelo postconvertibilidad. Una aproximación desde el enfoque de análisis regional”, en Cuadernos del CENDES, nº74, UCV. Caracas.

Varesi, Gastón. 2010c. “La Argentina post-convertibilidad: modelo de acumulación”. en Problemas del Desarrollo, Revista Latinoamericana de Economía, vol. 41, núm. 161, abril-junio, IIEE, UNAM. México.

Varesi, Gastón. 2010d. "La Argentina post-convertibilidad en el contexto de la crisis mundial”, en J. Gambina (coord.) La crisis capitalista y sus alternativas. Una mirada desde América Latina y el Caribe. Colección Grupos de Trabajo CLACSO. Buenos Aires.

Varesi, Gastón. 2010e. "El gobierno de Néstor Kirchner: características y alcances de la recomposición hegemónica”, en Espacio Crítico, Revista colombiana de análisis y crítica social, n²12. Bogotá.

Varesi, Gastón. 2010f. “El kirchnerismo como cultura (política) afirmativa. Elementos culturales, políticos y económicos de la estrategia oficial, 2003-2007.” en Periferias, Revista de Ciencias Sociales nro.19, Buenos Aires.

Varesi, Gastón. 2011a. "Crisis mundial, políticas y lucha de clases. El neodesarrollismo en Argentina (2002-2010)", en Revista de Economía y Comercio Internacional $\mathrm{n}^{\circ} 1$, Grupo de Estudios Internacionales Contemporáneos, Editorial del GEIC. Córdoba. 
Varesi, Gastón. 2011b. “Argentina 2002-2011: neodesarrollismo y radicalización progresiva”, en Realidad Económica, n²64, IADES. Buenos Aires.

Varesi, Gastón. 2012a. La configuración del modelo post-convertibilidad: políticas económicas y fracciones de clase en Argentina, 2002-2007. Tesis de Maestría. Maestría en Ciencias Sociales. FAHCE-UNLP.

Varesi, Gastón. 2012b. “Modelo de acumulación, dinámica política y clases sociales en la Argentina post-convertibilidad, 2002-2010”, aceptado en La posconvertibilidad en debate, UNQUI. En prensa.

Varesi, Gastón Ángel. 2012c. “Crisis mundial, modelo de acumulación y lucha de clases en la Argentina actual”, en Estrada (coord.) La crisis capitalista mundial y América Latina. Lecturas de economía política, CLACSO, Colección Grupos de Trabajo. Buenos Aires.

Veltmeyer, Henry. 2006. "El proyecto post-marxista: aporte y crítica a Ernesto Laclau” en Revista THEOMAI, Estudios sobre Sociedad Naturaleza y Desarrollo, $\mathrm{n}^{\circ} 14$. Argentina.

Viguera, Aníbal. 1998. “Estado, empresarios y reformas económicas: en busca de una perspectiva analítica integradora”, en Perfiles Latinoamericanos junio, año/vol. 7, n¹2. FLACSO. México.

Villarreal, Juan. 1985. "Los hilos sociales del poder”, en Crisis de la dictadura Argentina. Siglo XXI. Buenos Aires.

Wainer, Andrés. 2010. “Clase dominante, hegemonía y modos de acumulación. La reconfiguración de las relaciones de fuerza en el interior de la burguesía durante la crisis y salida de la convertibilidad (1998-2003)". Tesis de Doctorado. Programa de Doctorado en Ciencias Sociales. Facultad Latinoamericana de Ciencias Sociales, sede Argentina.

Wainer, Andrés. 2011. “Más allá del consejo monetario: grandes empresas”, en Problemas del Desarrollo, vol. 42, nro 164, enero-marzo, UNAM. México.

Weber, Max. 1984. Economía y Sociedad. FCE. México. 
Weskamp, Alejandro. 2006. "La importancia de ser parte de los mercados para la efectiva comercialización de los granos - "todos los granos a los mercados”" Foros MERCOSOJA, ACSOJA. Argentina. 


\section{Fuentes citadas}

\subsection{Documentos públicos}

BCRA. 2005. “Índice del Tipo de Cambio Real Multilateral”, Resumen ejecutivo de mayo, Subgerencia General de Investigaciones Económicas. Argentina.

Comisión de Enlace. 26/5/2008. “Comunicado de prensa de la Comisión de Enlace”. En http://www.ruralarg.org.ar/newsite/interna.php?inc=inc_hojas/notas_detalle.php\&id=37 $\underline{78}$

Comisión de Enlace. 6/6/2008. “Comunicado de Prensa de la Comisión de Enlace”. En http://www.ruralarg.org.ar/newsite/interna.php?inc=inc_hojas/notas_detalle.php\&id=27 $\underline{44}$

Dirección de Mercados Agroalimentarios. 2006. «Matriz de indicadores para el diseño de políticas agroalimentarias» SAGPyA. En http://www.sagpya.mecon.gov.ar/new/00/programas/dma/indicadores/matriz_indicadores.pdf. Enero 2006.

INDEC. 2007. “Grandes Empresas en la Argentina. Años 2003-2005”, en base a ENGE. En http://www.indec.gov.ar/nuevaweb/cuadros/16/enge_01_07.pdf.

INDEC. 2009. “Grandes Empresas en la Argentina. Año 2007”, en base a ENGE. En http://www.indec.gov.ar/nuevaweb/cuadros/16/enge_02_09.pdf

INTA (Instituto Nacional de Tecnología Agropecuaria). Sin Año. “Pool de siembra”. En línea en http://anterior.inta.gov.ar/extension/finan/tool/pool.htm

Ministerio de Economía. 2006. Plan Nacional de Inversiones Públicas 2006-2008. Resumen Ejecutivo, elaborado por la Dirección Nacional de Inversión Pública. Argentina.

Ministerio de Economía. 2007. “Argentina Indicadores económicos”, mayo 2007. Argentina. En http://noticias.mecon.gob.ar/.

Ministerio de Economía. 2008. Plan Nacional de Inversiones Públicas 2008-2010, elaborado por la Dirección Nacional de Inversión Pública. Argentina. 
Ministerio de Economía. 2009. Plan Nacional de Inversiones Públicas 2009-2011, elaborado por la Dirección Nacional de Inversión Pública. Argentina.

Ministerio de Trabajo, empleo y seguridad social 2004. "Costos laborales en la Argentina 2003. Un análisis comparativo”, Serie de documentos de trabajo $\mathrm{n}^{\circ} 1$, Argentina.

SAGPyA. 2006. “Matriz de indicadores para el diseño de políticas agroalimentarias”.

Dirección de Mercados Agroalimentarios. Enero 2006. En http://www.sagpya.mecon.gov.ar/new/0-

0/programas/dma/indicadores/matriz_indicadores.pdf. Pág. 38.

Secretaría de Finanzas. 2007. “Estrategia y Programa Financiero 2008”, Ministerio de Economía. Argentina.

Subsecretaría de Comercio Internacional. 2010. “Informe sectorial. Sector Minería”. Ministerio de Relaciones Exteriores, Comercio Internacional y Culto. Argentina.

\subsection{Leyes, resoluciones y decretos (ordenados por fecha)}

Ley 22.248 Poder Ejecutivo Nacional (P.E.N.) Régimen Nacional del Trabajador Agrario. Publicada en el Boletín Oficial del 18/7/1980. Argentina.

Ley de Entidades Financieras n 21.526. Sancionada el 14/2/1977. Argentina.

Ley de Sociedades Comerciales $\mathrm{n}^{\circ}$ 19.550. Texto ordenado por el Anexo del Decreto $\mathrm{N}^{\circ}$ 841/84 B.O. 30/03/1984 con las modificaciones introducidas por normas posteriores al mismo. Argentina.

Ley de Reforma del Estado n 23.696. Sancionada el 17/8/1989. Argentina.

Ley de Emergencia Económica nº 23697. Sancionada el 1/9/1989. Argentina.

Ley de Convertibilidad n 23.928. Sancionada el 27/3/1991. Argentina.

Resolución 167/96. Soja tolerante a glifosato. Publicado en el Boletín Oficial: 7/3/1996. Argentina. 
Ley $n^{\circ}$ 25.250. Ley de Reforma Laboral. Promulgada el 11/5/2000. Argentina.

Ley de Emergencia Pública y Reforma del Régimen Cambiario ${ }^{\circ}$ 25.561, sancionada: 6/1/2002, promulgada parcialmente: 6/1/2002. Argentina.

Decreto 71/2002. Emergencia pública y reforma del régimen cambiario, Normas reglamentarias del régimen cambiario establecido por la Ley $N^{\circ}$ 25.561, 9/1/2002. Argentina.

Resolución 06/2002. Cronograma de vencimientos reprogramados de los depósitos existentes en el sistema bancario. Ministerio Economía. 9/1/2002. Buenos Aires.

Decreto 214/02, "Reordenamiento del sistema financiero”. 3/2/2002. Argentina.

Ley 25.820 Prórroga a la Ley de Emergencia Económica. Sancionada: 19/11/ 2003, promulgada: 2/12/2003. Argentina.

Ley $\mathrm{n}^{\circ}$ 25.877. Ordenamiento del Régimen Laboral. Boletín Oficial: 13/2/2004. Argentina.

Ley $\mathrm{n}^{\circ}$ 26.086. Concursos y Quiebras. Modificación de la Ley $\mathrm{N}^{\circ}$ 24.522. Sancionada el 22/3/2006. Promulgada el 10/4/2006. Argentina.

Ley $\mathrm{n}^{\circ}$ 26.088. Régimen Contrato de Trabajo. Fecha de publicación en el Boletín Oficial: 24/4/2006. Argentina.

Resolución 125/2008. Derechos de exportación. Fórmula de determinación aplicable a determinadas posiciones arancelarias correspondientes a cereales y oleaginosas. Ministerio de Economía y Producción. 10/3/2008. Buenos Aires.

Resolución 284/2008. Producción agrícola. Créase un régimen destinado a otorgar compensaciones a pequeños productores de soja o girasol de la cosecha 2007/2008. Ministerio de Economía y Producción. 18/4/2008. Buenos Aires.

Resolución 285/2008. Créase un régimen destinado a compensar para la cosecha 2007/2008, el transporte de granos oleaginosos (soja y girasol) producidos en las provincias extrapampeanas. 18/4/2008. Buenos Aires. 
Ley 26.417 Movilidad de las Prestaciones del Régimen Previsional Público. Modificación de la Ley $\mathrm{N}^{0}$ 24.241. Sancionada: Octubre 1 de 2008. Promulgada: 15/10/2008. Argentina

Ley 26.425 - Sistema Integrado Previsional Argentino - Régimen Previsional Público. Unificación. Sancionada: 20/11/2008. Promulgada: 4/12/2008. Argentina.

Ley 26.727. Régimen de Trabajo Agrario. Sancionada: Diciembre 21 de 2011 Promulgada: 27/12/2011. Argentina.

\subsection{Diarios y revistas}

Diario Clarín. 18/9/2006.

Diario Clarín. 26/12/2006.

Diario Clarín. 12/3/2008. “Jornada de protesta del campo por la suba en las retenciones" http://edant.clarin.com/diario/2008/03/12/um/m-01626800.htm

Diario Clarín. 18/3/2008. “Continúa el paro del campo y los productores aseguran que no buscan el desabastecimiento” http://edant.clarin.com/diario/2008/03/18/um/m$\underline{01631315 . h t m}$

Diario El Día. 18/1/2005.

Diario Página 12. 3/4/08. "La guerra de los discursos por el campo. Tres semiólogos analizan las expresiones de los productores rurales y del gobierno" http://www.pagina12.com.ar/diario/elpais/1-101765-2008-04-03.html

Infobae. 30/3/2003. “Duhalde se despide abriendo el corralón”. Online en http://www.infobae.com/contenidos/51064-0-0-Duhalde-se-despide-abriendo-elcorralon

iProfesional. 26/6/2011. "Por qué ricos y pobres se sienten clase media todos por igual". Online en http://economia.iprofesional.com/notas/118163-Por-qu-ricos-y-pobres-sesienten-clase-media-todos-por-igual- 
Revista Informe Industrial, nº 208. Editorial Melipal. Buenos Aires.

Revista Mercado, junio de 2008. Buenos Aires.

\subsection{Discursos (ordenados por fecha)}

Duhalde, Eduardo. 1/1/2002. "Palabras del Presidente de la Nación, Doctor Eduardo Duhalde, ante la Asamblea Legislativa”.

Duhalde, Eduardo. 2/1/2002. "Palabras del Presidente de la Nación, Doctor Eduardo Duhalde, ante amigos y militantes en Casa de Gobierno”.

Duhalde, Eduardo. 4/1/2002. "Palabras del Presidente de la Nación Eduardo Alberto Duhalde ante empresarios reunidos en la residencia de Olivos”.

Duhalde, Eduardo. 10/1/2002. "Discurso del Presidente Eduardo Duhalde al recibir a las Organizaciones No Gubernamentales en Olivos”.

Duhalde, Eduardo. 1/2/2002. "Palabras del Presidente Eduardo Duhalde ante en la residencia presidencial de Olivos”.

Kirchner, Néstor. 25/5/2003. “Discurso de Kirchner ante la Honorable Asamblea Legislativa el día de su asunción presidencial”.

Kirchner, Néstor. 25/5/2003b. “Ceremonia de juramento del Gabinete Nacional”.

Kirchner, Néstor. 5/6/2003. “Mensaje al país del Presidente Néstor Kirchner”. En Discursos del Presidente Néstor Kirchner 2003-2007 (Primera Parte). Cuadernos de la militancia n ${ }^{\circ}$ 2. Ediciones Punto Crítico. Buenos Aires.

Kirchner, Néstor. 10/7/2003. “149 Aniversario de la Bolsa de Comercio de Buenos Aires”.

Kirchner, Néstor. 11/12/2003. "Discurso del Presidente Néstor Kirchner en el $79^{\circ}$ Aniversario de la Cámara Argentina de Comercio”. En Discursos del Presidente Néstor Kirchner 2003-2007 (Primera Parte). Cuadernos de la militancia n 2. Ediciones Punto Crítico. Buenos Aires. 
Kirchner, Néstor. 11/3/2004. "Palabras del Presidente Néstor Kirchner en el Encuentro de la Militancia”. En Discursos del Presidente Néstor Kirchner 2003-2007 (Primera Parte). Cuadernos de la militancia n ${ }^{\circ}$ 2. Ediciones Punto Crítico. Buenos Aires.

Kirchner, Néstor. 24/03/2004. "Palabras del presidente de la nación, doctor Néstor Kirchner, en el acto de firma del convenio de la creación del museo de la memoria y para la promoción y defensa de los derechos humanos”.

Kirchner, Néstor. 1/3/2005. "Discurso del Presidente Néstor Kirchner ante la Asamblea Legislativa en la apertura de las $123^{\circ}$ Sesiones del Congreso". En Discursos del Presidente Néstor Kirchner 2003-2007 (Primera Parte). Cuadernos de la militancia n ${ }^{\circ}$ 2. Ediciones Punto Crítico. Buenos Aires.

Kirchner, Néstor. 4/11/2005. "Palabras del Presidente de la Nación, Néstor Kirchner, durante la Ceremonia de Inauguración de la IV Cumbre de las Américas, en el Auditorio del Hotel Provincial, en la Ciudad de Mar del Plata”. En Discursos del Presidente Néstor Kirchner 2003-2007 (Primera Parte). Cuadernos de la militancia ${ }^{\circ}$ 2. Ediciones Punto Crítico. Buenos Aires.

Kirchner, Néstor. 1/3/2006. "Mensaje del Presidente Néstor Kirchner ante la Asamblea Legislativa (124 ${ }^{\circ}$ períodos de sesiones)”. En Discursos del Presidente Néstor Kirchner 2003-2007 (Segunda Parte). Cuadernos de la militancia nº 3. Ediciones Punto Crítico. Buenos Aires.

Kirchner, Néstor. 1/3/2007. "Palabras del Presidente de la Nación, Doctor Néstor Kirchner, en el Acto de Apertura del $125^{\circ}$ Período Ordinario de Sesiones del Honorable Congreso de la Nación”. En Discursos del Presidente Néstor Kirchner 2003-2007 (Segunda Parte). Cuadernos de la militancia ${ }^{\circ}$ 3. Ediciones Punto Crítico. Buenos Aires.

Fernández, Cristina. 30/5/2007. “Cristina Fernández expuso en el Seminario sobre Modernización del Estado”.

Fernández, Cristina. 25/3/2008. “Discurso de Cristina Fernández en el acto de firma de convenios entre AySA y municipios bonaerenses”. 
Fernández, Cristina. 27/3/2008. "Palabras de la Presidenta de la Nación, Dra. Cristina Fernández de Kirchner durante el encuentro en Parque Norte”.

Fernández, Cristina. 1/4/2008. "Palabras de la Presidenta de la Nación, Dra. Cristina Fernández de Kirchner en el Acto por la convivencia y el diálogo, en la Plaza de Mayo”. Fernández, Cristina. 25/5/2008. “Palabras de la Señora Presidenta de la Nación, doctora Cristina Fernández de Kirchner, en el Acto de conmemoración del $198^{\circ}$ aniversario de la Revolución de Mayo, en la provincia de Salta”.

Fernández, Cristina. 17/6/2008. “Palabras de la Señora Presidenta de la Nación, Cristina Fernández de Kirchner, en conmemoración del $53^{\circ}$ aniversario del bombardeo a la Plaza de Mayo".

Fernández, Cristina. 18/6/2008. "Palabras de la Señora Presidenta de la Nación, Cristina Fernández de Kirchner, en el acto de Plaza de Mayo”. 